Timmo Krüger

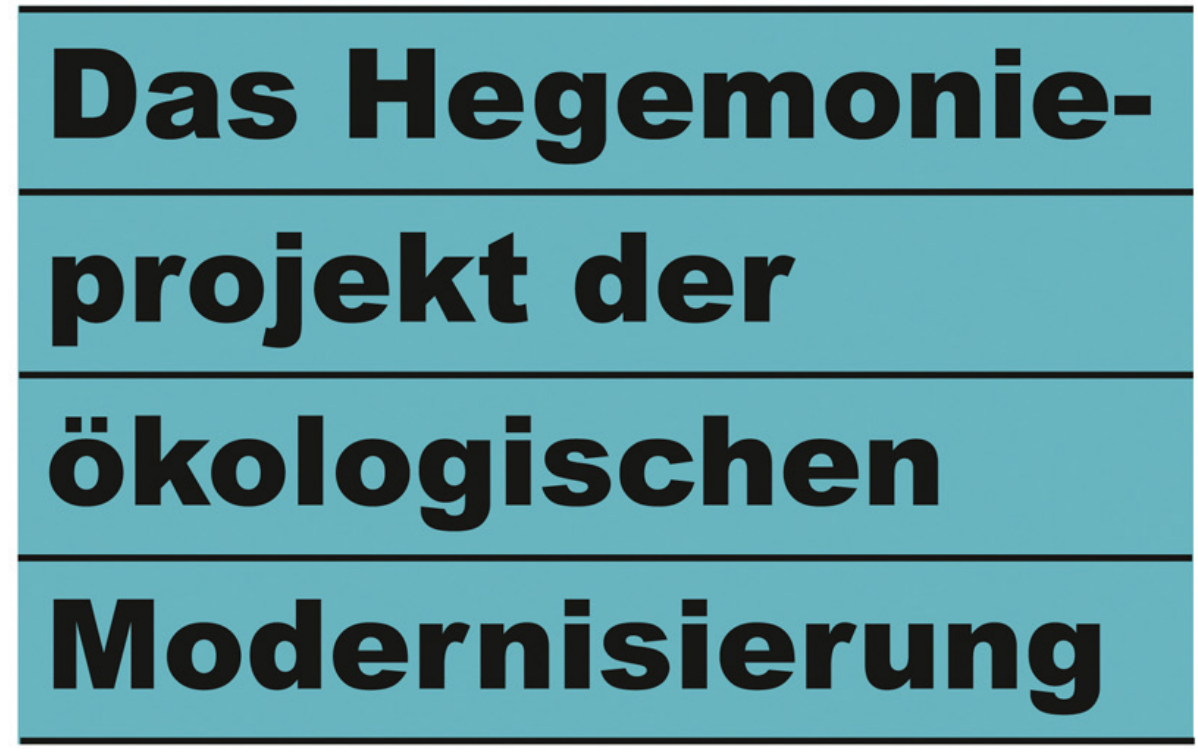

Die Konflikte um Carbon Capture and Storage (CCS) in der internationalen Klimapolitik

[transcript] Edition Politik 
Timmo Krüger

Das Hegemonieprojekt der ökologischen Modernisierung

Edition Politik | Band 28 
Timmo Krüger (Dr. rer. pol.), geb. 1982, ist Politik- und Kulturwissenschaftler. Seine Arbeitsschwerpunkte liegen in den Bereichen Diskurs- und Hegemonietheorie sowie ökologische Krise und Klimapolitik. 
Timmo KRÜGER

\section{Das Hegemonieprojekt}

der ökologischen Modernisierung

Die Konflikte um Carbon Capture and Storage (CCS)

in der internationalen Klimapolitik

[transcript] 
Die vorliegende Arbeit wurde unter dem Titel »Carbon Capture and Storage (CCS) und das Hegemonieprojekt der ökologischen Modernisierung. Eine Analyse (ent-)politisierender Prozesse in der internationalen Klimapolitik« als Dissertation an der Universität Kassel im Fachbereich Gesellschaftswissenschaften eingereicht. Die Disputation fand am 28.01.2015 statt.

\section{(9) $(1) \Theta$}

Dieses Werk ist lizenziert unter der Creative Commons Attribution-NonCommercial-NoDerivs 4.0 Lizenz (BY-NC-ND). Diese Lizenz erlaubt die private Nutzung, gestattet aber keine Bearbeitung und keine kommerzielle Nutzung. Weitere Informationen finden Sie unter https://creativecommons.org/licenses/by-nc-nd/4.o/deed.de/. Um Genehmigungen für Adaptionen, Übersetzungen, Derivate oder Wiederverwendung zu kommerziellen Zwecken einzuholen, wenden Sie sich bitte an rights@transcript-verlag.de

\section{(C) 2015 transcript Verlag, Bielefeld}

Die Verwertung der Texte und Bilder ist ohne Zustimmung des Verlages urheberrechtswidrig und strafbar. Das gilt auch für Vervielfältigungen, Übersetzungen, Mikroverfilmungen und für die Verarbeitung mit elektronischen Systemen.

\section{Bibliografische Information der Deutschen Nationalbibliothek}

Die Deutsche Nationalbibliothek verzeichnet diese Publikation in der Deutschen Nationalbibliografie; detaillierte bibliografische Daten sind im Internet über http://dnb.d-nb.de abrufbar.

Umschlaggestaltung: Kordula Röckenhaus, Bielefeld Korrektorat \& Satz: Timmo Krüger

Druck: Majuskel Medienproduktion GmbH, Wetzlar

Print-ISBN 978-3-8376-3233-0

PDF-ISBN 978-3-8394-3233-4

Gedruckt auf alterungsbeständigem Papier mit chlorfrei gebleichtem Zellstoff. Besuchen Sie uns im Internet: http://www.transcript-verlag.de Bitte fordern Sie unser Gesamtverzeichnis und andere Broschüren an unter: info@transcript-verlag.de 


\section{Inhalt}

Tabellenverzeichnis |7

Vorwort $\mid 9$

1. Einleitung | 13

1.1 Erkenntnisinteresse und Forschungsfragen | 14

1.2 Forschungsstand und Forschungslücke $\mid 23$

2. Theorie und Operationalisierung $\mid 31$

2.1 Diskurstheoretische Hegemonieanalyse | 31

2.2 Gesellschaftliche Naturverhältnisse | 43

2.3 Forschungsdesign, Aufbau und methodisches Vorgehen $\mid 64$

3. Das Projekt der ökologischen Modernisierung | 73

3.1 Die Ökologische Krisendiagnose $\mid 76$

3.2 Die Formierung des ökomodernen Diskurses $\mid 78$

3.3 Die Grundannahmen des ökomodernen Projekts $\mid 97$

3.4 Die Hegemoniestrategien des ökomodernen Projekts $\mid 99$

3.5 Das ökomoderne Hegemonieversprechen | 111

3.6 Die Hegemonialisierung des ökomodernen Projekts | 115

3.7 Die reflexive Reproduktion von Hegemonie | 123

\section{Das ökomoderne Projekt und CCS | 125}

\section{CCS in der internationalen Klimapolitik | 129}

5.1 Einführung in die internationale Klimapolitik | 130

5.2 Einführung in CCS-Technologien $\mid 161$

5.3 Die Politikberatung des IPCC zu CCS-Technologien | 179

5.4 Die CCS-CDM-Kontroverse in den Klimaverhandlungen | 215

5.5 Synthese: CCS-Konflikte in der Klimapolitik | 311

\section{CCS und das ökomoderne Hegemonieprojekt | 327}

6.1 Die Bedeutung des Scheiterns von CCS-Projekten | 328

6.2 Die Bedeutung des Erfolgs der CCS-Community | 329

6.3 Die (ent-)politisierenden Effekte der CCS-Konflikte | 333 
7. Resümee und Ausblick | 337

7.1 Zusammenfassung der Ergebnisse | 337

7.2 Ausblick | 346

Abkürzungs- und Begriffsverzeichnis | 355

Literatur | 363

Anhang | 385

A.1 Verzeichnis der analysierten Stellungnahmen 385

A.2 Liste der identifizierten Enthymeme | 387 


\section{Tabellenverzeichnis}

Tabelle 1 Übersicht über die Stellungnahmen der Länder | 219

Tabelle 2 Übersicht über die CCS-Aktivitäten der Länder | 220

Tabelle 3 Übersicht über die Stellungnahmen der Beobachterorganisationen | 220

Tabelle 4 Die umweltpolitischen Positionen der Beobachterorganisationen | 221

Tabelle 5 Positionen bezüglich CCS-Technologien im Allgemeinen | 224

Tabelle 6 Positionen bezüglich der Aufnahme von CCS in den CDM | 225

Tabelle 7 Das Argument der Bedeutung von CCS als Element des Portfolios | 227

Tabelle 8 Das Argument der hohen Kosten von CCS | 228

Tabelle 9 Das Argument des Zielkonflikts zwischen Erneuerbaren und CCS | 229

Tabelle 10 Das Argument der mangelnden Nachhaltigkeit | 230

Tabelle 11 Das Argument der Brückentechnologie | 231

Tabelle 12 Das Argument der ökologischen und gesundheitlichen Risiken | 232

Tabelle 13 Ökomoderne Basis-Artikulationen | 293

Tabelle 14 Technokratische Artikulationen | 297

Tabelle 15 Artikulationen des Primats der Betriebsökonomie | 299

Tabelle 16 Inkrementelle Artikulationen | 301

Tabelle 17 Artikulationen der reflexiven Naturbeherrschung | 303

Tabelle 18 Artikulationen des reflexiven Fortschritts | 305

Tabelle 19 Artikulationen des nachhaltige Wachstums | 307

Tabelle 20 Positionen zum ökomodernen Projekt | 309

Tabelle 21 Positionen zur Einbeziehung von CCS ins ökomoderne Projekt | 310

Tabelle 22 Verweise auf den IPCC und die IEA und in den Stellungnahmen | 312

Tabelle 23 Verweise auf Prognosen des IPCC | 313

Tabelle 24 Verzeichnis der Stellungnahmen der Länder | 385

Tabelle 25 Verzeichnis der Stellungnahmen der Beobachterorganisationen | 386 



\section{Vorwort}

„Der einzige Weg, der Natur beizustehen, liegt darin, ihr scheinbares Gegenteil zu entfesseln, das unabhängige Denken.“

(Horkheimer 1990: 123)

Eine Dissertation stellt eine Qualifizierungsarbeit dar, die bestimmten formalen und inhaltlichen Anforderungen genügen muss. Darüber hinaus ist sie das Ergebnis der individuellen Auseinandersetzung mit einem bestimmten Themengebiet. In der Entscheidung für einen Forschungsgegenstand, der einen über Jahre hinweg begleitet, spielen in vielen Fällen auch die eigene Sozialisation sowie persönliche und politisch-ethische Motive eine wichtige Rolle. Meine eigene Motivation möchte ich an dieser Stelle aus zwei Gründen offen legen: Erstens um die politische Dimension der Problemstellung dieser Arbeit und mein diesbezügliches normatives Anliegen deutlich zu machen. Zweitens um die Forderung nach Transparenz zu beherzigen, die sich aus der postpositivistischen Absage an die Möglichkeit eines ,objektiven“ Standpunkts ergibt (vgl. Kapitel 2.3.1).

Die inhaltliche Auseinandersetzung mit der Forderung nach Klimagerechtigkeit sowie die Organisation von Klimacamps und anderen Aktionen des Klima!Bewegungsnetzwerks (heute: Energiekämpfe in Bewegung, EkiB) prägten meine klimapolitische Sozialisation. Parallel zur Ausarbeitung meines Promotionsvorhabens engagierte ich mich unter anderem bei der Organisation des Lausitzer Klima- und Energiecamps 2011. Ein zentrales Anliegen des Camps war die Verhinderung eines geplanten CCS-Kohlekraftwerks (für die Definition von CCS vgl. die Erläuterung im Abkürzungsverzeichnis). Im Verlauf der intensiven Auseinandersetzung mit CCS-Technologien wurde mir immer wichtiger, nicht nur auf die gesundheitlichen und ökologischen Risiken der $\mathrm{CO}_{2}$-Speicherung hinzuweisen. Vielmehr fokussierte ich in der politischen Arbeit zunehmend auf die Bedeutung von CCS-Technologien für aktuelle Konflikte in der Energie- und Klimapolitik. 
CCS-Technologien stehen symptomatisch für die Suche nach einer Lösung des Klimaproblems ohne gesellschaftliche Strukturen - insbesondere die Abhängigkeit der Wirtschaft von fossilen Brennstoffen - ändern zu müssen. Die mit CCS-Technologien legitimierte Fortführung der fossilen Energieinfrastruktur soll für Wirtschaftswachstum, Profit- und Wohlstandsmaximierung sorgen.

Dieses Versprechen ist ein zentraler Grund, warum sich neben den Energiekonzernen auch viele Akteur_innen aus der Politik und der Wissenschaft für die Entwicklung und den Einsatz von CCS-Technologien aussprechen. Dabei wird meiner Meinung nach die Gefahr des carbon lock-ins unterschätzt: Die Fortführung der fossilen Energieinfrastruktur beeinträchtigt die Ausgangsbedingungen für Transformationsprozesse hin zu einer klimaneutralen Lebensweise. Dahinter steht die Annahme, dass die Ursachen des anthropogenen Klimawandels in den gesellschaftlichen Strukturen liegen und eine klimaneutrale Lebensweise nur durch einen radikalen Wandel der Produktions- und Konsummuster - insbesondere in den Ländern des globalen Nordens - zu erreichen ist.

In dem Zusammenhang ist mir die Verknüpfung der ökologischen mit der sozialen Frage sehr wichtig. Schließlich zeichnen sich die klimaschädlichen Strukturen durch eine hohe soziale Ungleichheit aus - sowohl zwischen verschiedenen Gruppen innerhalb einer Gesellschaft als auch zwischen den Ländern des globalen Nordens und des globalen Südens. Darüber hinaus wird immer deutlicher, dass die Folgen des Klimawandels soziale Ungleichheiten verschärfen. Deshalb gehe ich davon aus, dass unbegrenztes Wirtschaftswachstum und der dafür nötige Verbrauch begrenzter Ressourcen in einem grundlegenden Widerspruch zum Schutz der Natur und dem Kampf für soziale Gerechtigkeit stehen.

Aufgrund dieser Überzeugung ist eine zentrale Motivation dieser Arbeit, die Potenziale und Grenzen antagonistischer Forderungen auszuloten, die auf eine Infragestellung und Veränderung verstetigter sozialer Strukturen zielen. Statt weiter vergeblich auf die Entkopplung des Wirtschaftswachstums vom Ressourcenverbrauch bzw. der Treibhausgasemissionen zu hoffen, sollten wir die „Dialektik der Aufklärung" ernst nehmen und die Idee des unendlichen Wachstums als Mythos der Moderne entzaubern (vgl. die Ausführungen zum Umschlag von Aufklärung in Mythologie in Horkheimer/Adorno 2009: 9ff).

Neben der politisch-ethischen Verortung innerhalb eines bestimmten gesellschaftspolitischen Kontextes wurde die Umsetzung meines Promotionsvorhabens durch den direkten persönlichen Austausch und ein unterstützendes Umfeld geprägt. Den Einzelpersonen und Institutionen, die für die Fertigstellung dieser Arbeit wichtig waren, möchte ich danken. 
Ein Stipendium der Rosa-Luxemburg-Stiftung ermöglichte mir die Fokussierung auf die Promotion und die Fortsetzung meines politischen Engagements. Auch bei der Publikation wurde ich von der RLS mit einem Druckkostenzuschuss unterstützt. Vielen Dank für die Förderung!

Inhaltlich begleitet wurde ich von meinen beiden Betreuern Christoph Görg und Ulrich Bröckling, die mir im Verlauf des Schreibprozesses hilfreiche Impulse gaben. Vielen herzlichen Dank für die konstruktive Kritik!

Auch der Austausch mit Kolleg_innen, Freund_innen und Verwandten stellte eine wichtige Inspirationsquelle für die Entwicklung dieser Arbeit dar. Das Feedback der Personen, mit denen ich über meine Arbeit gesprochen habe und die verschiedene Teile meiner Arbeit redigiert haben, trug ungemein zur stilistischen Verbesserung des Textes und zur Schärfung der Argumentation bei. Mir haben mehr Menschen geholfen als ich hier aufzählen kann, aber einige Namen möchte ich dennoch nennen: Danke Alex L., Alex S., Annemarie, Dörte, Florian, Frank, Ingmar, Julia, Lena, Lisa, Maria, Nina, Renke und Susanne. Nicht nur, aber vor allem in den letzten Wochen war eure Hilfe sehr wichtig! Besonders intensive Diskussionen hatte ich mit Philip. Seine versierten Kommentare, seine Genauigkeit und seine Fähigkeit, implizite Strukturen des Textes offen zu legen, haben mir sehr geholfen. Danke dafür!

Meine Eltern, Gundolf und Meike, haben nicht nur durch ihre Bereitschaft, Teile der Arbeit Korrektur zu lesen, zum Gelingen dieser Arbeit beigetragen. Ihr stetes Interesse an meinem Leben und ihre bedingungslose Unterstützung bei allem was ich tue sind einmalig! Euch verdanke ich das nötige Vertrauen in mich und die Welt.

Abschließend möchte ich Wiebke danken, die mich während des gesamten Promotionsprozesses mit all seinen Höhen und Tiefen - von der Suche nach Betreuern bis zur endgültigen Fertigstellung - begleitet hat. Danke, dass du immer für mich da warst.

Berlin, im Dezember 2014 



\section{Einleitung}

Seit den 1970er Jahren wird in der politischen und wissenschaftlichen Öffentlichkeit das Verhältnis des Menschen zur Natur als krisenhaft begriffen (vgl. Becker/Jahn 2003: 92f; Brand 2010: 143; Görg 2003a: 9f). Auslöser dieser Problematisierung der gesellschaftlichen Naturverhältnisse ${ }^{1}$ waren Phänomene wie der anthropogene Klimawandel oder der Verlust der Biodiversität, die als nicht-intendierte Nebenfolgen hegemonialer Strukturen interpretiert wurden. Von einer ökologischen Krise zu sprechen impliziert deshalb die Annahme, dass die herkömmlichen gesellschaftlichen Institutionen nicht (mehr) angemessen auf ökologische Probleme reagieren können (vgl. Brand 2010: 143). Die mit dieser Politisierung ${ }^{2}$ verbundenen Auseinandersetzungen um die Bearbeitung der ökologischen Krise bilden den Untersuchungsgegenstand dieser Arbeit.

Im Folgenden führe ich in das Konfliktfeld der ökologischen Krise ein, stelle das Erkenntnisinteresse sowie die Forschungsfragen dieser Arbeit vor (1.1) und gebe einen Überblick über den Forschungsstand (1.2). Dabei fokussiere ich, wie in der gesamten Arbeit, auf die internationale Klimapolitik. Diese Schwerpunktsetzung ist der herausgehobenen Bedeutung geschuldet, die dem Klimawandel von vielen Akteur_innen beigemessen wird (vgl. Ihlen 2009: 246). Innerhalb dieser Schwerpunktsetzung wiederum gehe ich insbesondere auf die Konflikte um Carbon Capture and Storage (CCS) ${ }^{3}$ ein, die im Verlauf der Arbeit einer mikroanalytischen Untersuchung unterzogen werden.

1 Der Begriff der gesellschaftlichen Naturverhältnisse verweist darauf, dass Natur und Gesellschaft in einem konstitutiven Vermittlungsverhältnis stehen (vgl. Görg 2003a: 14f; für eine ausführliche Einführung in den Begriff vgl. Kapitel 2.2.3).

2 Das Politische wird hier als der Moment gefasst, in dem etwas ,als entscheidbar und entscheidungsbedürftig erkannt und mit einigem Erfolg propagiert wird“ (Greven 2010: 69). Zum Begriff des Politischen vgl. Kapitel 2.1.

3 Für die Erläuterung von CCS-Technologien vgl. Kapitel 5.2 oder die knappe Definition im Abkürzungs- und Begriffsverzeichnis. In dem Verzeichnis werden Abkürzungen und Begriffe erläutert, die für das Verständnis der Arbeit wichtig sind. 


\subsection{ERKENNTNISINTERESSE UND FORSCHUNGSFRAGEN}

Die These von der menschlichen Verursachung des Klimawandels hat sich sowohl in der öffentlichen Debatte als auch in den wissenschaftlichen und politischen Diskursarenen weitestgehend durchgesetzt. Trotz einer einflussreichen klimaskeptischen Lobby, die vor allem im angloamerikanischen Raum relativ aktiv und erfolgreich ist (vgl. Brunnengräber: 2013: 47; Klein 2014: 35), kann der anthropogene Klimawandel im Allgemeinen als gesellschaftlich anerkannte Tatsache bezeichnet werden (vgl. Weingart/Engels/Pansegrau 2008). Der Klimawandel wurde von einer naturgegebenen Gefahr in ein entscheidungsabhängiges Risiko transformiert und damit Gegenstand gesellschaftlicher Auseinandersetzungen (vgl. Engels/Weingart 1997: 92). Die Politik hat den anthropogenen Klimawandel zu einem wichtigen Aufgabengebiet deklariert - auf der Ebene der internationalen Politik geschieht dies in erster Linie im Rahmen der UN-Klimaverhandlungen.

Das Kyoto-Protokoll ist das bisher bedeutsamste Ergebnis dieser Klimaverhandlungen. Allerdings steigen die globalen Treibhausgasemissionen trotz Kyoto-Protokoll und anderer klimapolitischer Maßnahmen stetig an - zwischen dem Vergleichsjahr der Reduktionsziele des Kyoto-Protokolls (1990) und dem Auslaufen seiner ersten Verpflichtungsperiode (2012) um mehr als $60 \%$ (vgl. Informationsstelle Peru 2014: 5). Eine Ausnahme bildeten bislang lediglich kurze Phasen der wirtschaftlichen Rezession (vgl. IPCC 2014: 6). Von einer erfolgreichen Klimapolitik kann also keine Rede sein. Im Gegenteil steigt sogar der prozentuale Anstieg der Emissionen von Dekade zu Dekade (vgl. IPCC 2014: 6f). Das Scheitern der bisherigen Reaktionen auf die ökologische Krise ließe sich auch für andere Bereiche zeigen, beispielsweise für den fortschreitenden Verlust der Biodiversität. Diese ernüchternde Bilanz ist ein zentraler Ausgangspunkt dieser Arbeit.

Problemstellung: Die bisherigen gesellschaftlichen Reaktionen auf die ökologische Krise sind gescheitert. Hinter dieser Problematisierung steht die normative Orientierung, dass es von elementarer Bedeutung ist, die Ursachen der fortschreitenden ökologischen Krise zu beheben und ihre negativen Effekte abzuschwächen. Ich halte eine ambitionierte Klima- und Umweltpolitik für notwendig, um langfristig die Spielräume für eine emanzipatorische Politik zu erhöhen, die sich für ein ,gutes Zusammenleben' der Menschen untereinander und mit der Natur einsetzt. 
Die Einigung auf verbindliche und wirkungsvolle klimapolitische Maßnahmen wird durch den Umstand erschwert, dass der Klimawandel ein Querschnittsthema ist, das Grundstrukturen unserer Gesellschaft tangiert. Als Ursache für den anthropogenen Klimawandel wird in den naturwissenschaftlichen Studien der hohe globale Ausstoß von Treibhausgasen ausgemacht. Die darauf basierende Politikberatung - beispielsweise des Zwischenstaatlichen Ausschusses für Klimaänderungen (Intergovernmental Panel on Climate Change, IPCC) - fokussiert auf den Ausstoß von $\mathrm{CO}_{2}$, weil es zum einen den höchsten Anteil an den Treibhausgasen ausmacht und zum anderen in der Atmosphäre besonders langlebig ist (vgl. IPCC 2007: 2).

Aufgrund der Bedeutung des Kohlenstoffdioxids wiederum wird vor allem der Primärenergieverbrauch zum Problem und damit insgesamt die Produktions- und Konsummuster der Industriemoderne. Seit der industriellen Revolution ist das Wirtschaftswachstum an den proportionalen Anstieg des Primärenergieverbrauchs gekoppelt (vgl. Hannesson 2002). Primärenergie wurde seitdem und wird immer noch fast ausschließlich aus fossilen Brennstoffen gewonnen. Der stetig steigende Ausstoß von $\mathrm{CO}_{2}$ ist der weltweit durchgesetzten fossilen Wirtschaftsweise inhärent (vgl. Scheer 2000: 9ff). Insofern stellt der anthropogene Klimawandel eine Herausforderung an zentrale gesellschaftliche Strukturen dar, welche die Nutzung fossiler Brennstoffe, das Primat des Wirtschaftswachstums und die darauf basierende imperiale Lebensweise ${ }^{4}$ betreffen.

Die Schlussfolgerung der Umweltbewegungen lautete in den 1970er Jahren, dass es einer Transformation des gesamten Systems - unserer Wirtschaftsweise, unseres Lebensstils usw. - bedürfe. Diese radikale, d. h. an den Wurzeln ansetzende

4 Mit der imperialen Lebensweise ist der sogenannte, westliche“ Lebensstil (vor allem der Ober- und Mittelschicht) gemeint, der sich durch Wohlstand und ein hohes Konsumniveau auszeichnet. Diese Lebensweise besitzt eine hohe Attraktivität sowohl für Menschen im globalen Norden als auch im globalen Süden. In den Schwellenländern übernehmen die Ober- und Mittelschichten den ,westlichen' Lebensstil (soweit sie es sich finanziell leisten können) und verschärfen damit die mit der Lebensweise verbundenen massiven ökologischen Schäden (vgl. Brand/Wissen 2011: 23ff). „Die Lebensweise des globalen Nordens beinhaltet einen prinzipiell unbegrenzten Zugriff auf Ressourcen, Raum, Arbeitsvermögen und Senken. Sie setzt deshalb voraus, dass nicht alle Menschen in glei chem Maße hierauf zugreifen. Anderenfalls wären viele Ressourcen in kurzer Zeit verbraucht, und zwar auf eine Weise, die die Kapazität der Ökosysteme zur Absorption von Emissionen übersteigern würde. Ein exklusiver, durch Verträge oder offene Gewalt abgesicherter Zugang zu Ressourcen sowie eine Externalisierung der sozial-ökologischen Kosten, die bei ihrer Nutzung anfallen, ist die conditio sine qua non der Lebensweise des globalen Nordens.“ (Brand/Wissen 2011: 24; Hervorhebung im Original) 
Reaktion auf die ökologische Krise wird weiterhin in verschiedenen Variationen von unterschiedlichen Akteur_innen gefordert. Seit den 1990er Jahren gibt es im Niger-Delta Widerstand gegen die Ölförderung durch internationale Konzerne, die in Nigeria in besonders rücksichtsloser und zerstörerischer Form durchgeführt wird (vgl. Klein 2014: 305ff). In den Industrieländern wehren sich Bürgerinitiativen und Klimacamps mit Demonstrationen und Aktionen zivilen Ungehorsams gegen den Aufschluss neuer Tagebaue und streiten für Klimagerechtigkeit und eine demokratisch kontrollierte dezentrale Energiewende (vgl. Bedall 2014: 165ff; Dietz/Garrelts 2013). In Lateinamerika setzen sich Wissenschaftler_innen und indigen geprägte soziale Bewegungen für das Buen Vivir (das gute Zusammenleben) als Alternative zum konventionellen Entwicklungsmodell ein. Sie lehnen die (neo-)extraktivistische Politik der exportorientierten Ressourcenausbeutung ab, die neben dem Klima auch die Lebensgrundlage der Menschen in den Abbaugebieten und lokale Ökosysteme zerstört (vgl. Gudynas 2012). In China gibt es regelmäßig Proteste gegen schmutzige Fabriken und den Neubau von Kohlekraftwerken. Die an den Produktionsstandorten ansässige Bevölkerung ist nicht länger bereit, den bedingungslosen Industrialisierungskurs auf Kosten ihrer Gesundheit und der Natur mitzutragen (vgl. Klein 2014: 300, 350f). Im Oktober 2014 blockieren Bewohner_innen pazifischer Inseln in Australien den größten Kohlehafen, um Australiens Pläne zur Verdopplung der Kohleexporte und zur drastischen Steigerung der Gasgewinnung zu kritisieren. Sie fordern effektive Maßnahmen, um den Klimawandel abzuschwächen, von dessen Folgen - dem Anstieg des Meeresspiegels sowie der Zunahme von Fluten und Stürmen - sie existenziell bedroht sind (vgl. Oels 2014).

Trotz der genannten Proteste gibt es bislang keine breite, einflussreiche Bewegung für eine radikale Transformation der sozialen Ordnung hin zu einer klimaverträglichen Gesellschaft. Bis dato führte die Anerkennung der ökologischen Krise als gesellschaftliche Herausforderung nicht zu einer grundlegenden Veränderung unserer Wirtschafts- und Lebensweise. Dies ist zum einen auf Pfadabhängigkeiten zurückzuführen, die beispielsweise die Bedeutung der fossilen Brennstoffe für die Wirtschaft, die zentralisierte Energieinfrastruktur, die Abhängigkeit wohlfahrtsstaatlicher Programme von stetigem Wirtschaftswachstum, aber auch „mentale Infrastrukturen“ (Welzer 2011), d. h. den Status quo erhaltende soziale Identitäten, betreffen. Zum anderen hat sich eine Umweltpolitik etabliert, die nicht auf eine möglichst weitreichende Transformation gesellschaftlicher Strukturen, sondern auf die Anpassungsfähigkeiten der etablierten politischen, sozialen und ökonomischen Institutionen setzt. Die Überzeugung, dass die Institutionen und Strukturen der sogenannten ,westlichen' Moderne die ökologische Krise erfolgreich bearbeiten können, hat sich weitestgehend durchgesetzt und wurde zum umweltpolitischen Mainstream 
(zum Grad der Verbreitung und des Einflusses dieses Ansatzes der ökologischen Modernisierung vgl. Kapitel 3.6). Die ökologische Restrukturierung der bestehenden gesellschaftlichen Strukturen, die ökologische Modernisierung der Moderne, wurde damit zum Leitbild internationaler Umweltpolitik. Mit diesem Projekt der ökologischen Modernisierung ist tendenziell eine Entpolitisierung der ökologischen Krise verbunden (zum Hegemonieprojekt der ökologischen Modernisierung vgl. Kapitel 3): Das Verhältnis des Menschen zur Natur und die gesellschaftlichen Strukturen werden im ökomodernen Ansatz nicht grundsätzlich hinterfragt. Stattdessen wird nach Lösungen gesucht, die sich möglichst unkompliziert innerhalb der gegebenen Rahmenbedingungen implementieren lassen. Der Fokus liegt dabei auf marktkonformen Anreizstrukturen, Effizienzsteigerungen und der Entwicklung neuer Technologien.

Erkenntnisinteresse: Meine Analyse des Konfliktfeldes der ökologischen Krise folgt dem Interesse, die Prozesse der Öffnung und Schließung des Terrains des Politischen zu verstehen und zielt darauf, die hegemoniale Strukturierung der gesellschaftlichen Naturverhältnisse offenzulegen. Im Fokus stehen damit die reund entpolitisierenden Prozesse in den Auseinandersetzungen um die Bearbeitung der ökologischen Krise: Inwieweit werden etablierte soziale Praktiken und Strukturen grundsätzlich hinterfragt und darüber hinaus als veränderbar und veränderungswürdig angesehen? Diesem Erkenntnisinteresse liegt die theoretische Annahme zugrunde, dass sich die soziale Ordnung - und damit auch die Bearbeitung der ökologischen Krise - durch Kämpfe um Hegemonie entwickelt, in denen bestimmte Deutungs- und Handlungsmuster gegenüber anderen privilegiert werden (vgl. Kapitel 2.1). Des Weiteren beruht es auf der Überzeugung, dass es einer umfassenden Transformation gesellschaftlicher Strukturen bedarf, um die ökologische Krise adäquat bearbeiten zu können (vgl. Vorwort). ${ }^{5}$

5 Der Fokus auf strukturverändernde Forderungen und Maßnahmen in diesem konkreten Fall impliziert aber weder eine prinzipielle Gleichsetzung von antagonistischer Politik mit Emanzipation noch ihre grundsätzliche Präferierung gegenüber reformorientierter Politik. Schließlich können auch kleinschrittige Reformprozesse zur Politisierung hegemonialer Strukturen beitragen und damit emanzipatorische Prozesse ermöglichen. Unabhängig davon ist nicht jede antagonistische Praxis begrüßenswert und nicht alle Politisierungsprozesse sind emanzipatorisch (vgl. Methmann 2011: 77f). Insofern sollen hier reformorientierte nicht gegen systemkritische Ansätze ausgespielt werden, zumal diese Unterscheidung nur analytischer Natur sein kann und in der konkreten Praxis alle möglichen Zwischenstufen mit fließenden Übergängen zu finden sind. 
Wie bereits angedeutet, halten sich die Erfolge des ökomodernen Projekts bislang in Grenzen. Die globalen Treibhausgasemissionen steigen stetig an. Der Preis für $\mathrm{CO}_{2}-$ Äquivalente in den Kohlenstoffmärkten ist auf einem so geringen Niveau, dass er keine Anreize für Emissionseinsparungen bietet. Im Zuge der Wirtschaftskrisen seit 2007 (Banken-, Finanz-, Euro- und Schuldenkrisen), verlor die ökologische Krise an politischer Brisanz. Die Bereitschaft, umweltpolitische Maßnahmen zu beschließen, zu finanzieren und umzusetzen, ist gesunken, da in vielen Politikarenen die Bearbeitung der Wirtschaftskrise oberste Priorität besitzt und umweltschützende Instrumente dabei keine wesentliche Rolle spielen (vgl. Brunnengräber/Haas 2014; Haas/Sander 2013: 28; Klein 2014: 110). Der Post-Kyoto-Prozess, in dem um ein internationales Klimaabkommen im Anschluss an das Kyoto-Protokoll gerungen wird, ist seit dem Scheitern des Klimagipfels 2009 in Kopenhagen ins Stocken geraten. ${ }^{6}$ Das Vertrauen in die Gestaltungsfähigkeit der Politik im Allgemeinen und in die UN-Klimaverhandlungen im Besonderen, die ökologische Krise durch umweltpolitische Maßnahmen bearbeiten zu können, ist aktuell auf einem sehr geringen Niveau. Vor diesem Hintergrund setzen die Anhänger_innen des ökomodernen Ansatzes verstärkt auf Technofixes ${ }^{7}$ (vgl. Methmann 2011: 161ff). Dabei spielen CCSTechnologien eine besondere Rolle, da sie auf dem Status quo der fossilen und zentralisierten Energieinfrastruktur basieren.

Im aktuellen Sachstandsbericht des IPCC nimmt die Diskussion von CCS-Technologien einen größeren Raum ein als in früheren Sachstandsberichten (vgl. Petersen 2014). Im Beitrag der Arbeitsgruppe III (Mitigation of Climate Change) zum 2014er IPCC-Bericht wird in verschiedenen Kapiteln auf die Potenziale von CCSTechnologien sowie auf mögliche Risiken und Hindernisse auf dem Weg zu ihrem

6 Verschiedene Beobachter_innen der Verhandlungsprozesse gehen zwar davon aus, dass auf der nächsten Klimakonferenz, die 2015 in Paris stattfindet, ein Abkommen verabschiedet wird (vgl. Germanwatch 2014). Allerdings sind die daran geknüpften Erwartungen nicht mit den Erwartungen vergleichbar, die im Vorfeld der Kopenhagener Konferenz artikuliert wurden. Im bisherigen Verhandlungsprozess haben sich die Staaten darauf geeinigt, dass jedes Land seine eigenen Reduktionsziele selbst festlegt. Weiterhin soll ein „verbindlicher Rahmen gesetzt werden, der Vergleichbarkeit, gegenseitige Anerkennung und regelmäßige Überprüfung sicherstellt“ (Germanwatch 2014: 6). Die von den einzelnen Ländern bisher vorgeschlagenen Reduktionsziele sind sehr moderat, so dass sie „nicht ausreichen werden, um das Zwei-Grad-Limit zur Vermeidung eines in großem Maße gefährlichen Klimawandels einzuhalten“ (Germanwatch 2014: 6).

7 Unter Technofixes werden technologische Lösungsansätze verstanden, mit denen die Hoffnung verbunden ist, Symptome komplexer Probleme bekämpfen zu können, ohne gesellschaftliche Strukturen ändern zu müssen. 
großflächigen Einsatz hingewiesen. Auch in der Zusammenfassung für politische Entscheidungsträger_innen gibt es einen eigenen Abschnitt zu CCS-Technologien, der mit folgender Einschätzung beginnt:

„Carbon dioxide capture and storage (CCS) technologies could reduce the lifecycle GHG emissions of fossil fuel power plants (medium evidence, medium agreement).“ (IPCC 2014: 22; Hervorhebung T. K.)

In der Beurteilung des Forschungsstandes (,medium evidence, medium agreement") deutet sich bereits das Konfliktpotenzial an, das CCS-Technologien bergen. Obgleich der IPCC im 2014er Bericht konstatiert, dass es noch keine kommerzielle Anwendung von CCS-Technologien bei fossilen Großkraftwerken gebe (vgl. IPCC 2014: 22), geht er verstärkt auf die Kombination von Bioenergiekraftwerken und CCS-Technologien ein (vgl. Petersen 2014). Dabei ist dieser Anwendungsbereich noch weniger ausgereift, wie sich auch in der diesbezüglichen Einschätzung des Forschungsstandes zeigt:

"Combining bioenergy with CCS (BECCS) offers the prospect of energy supply with largescale net negative emissions which plays an important role in many low-stabilization scenarios, while it entails challenges and risks (limited evidence, medium agreement)." (IPCC 2014: 22; Hervorhebung T. K.)

Der IPCC betont, dass in den meisten Szenarien (in den von ihm zusammengetragenen Studien) CCS-Technologien für Bioenergiekraftwerke (BECCS) für die Erreichung des Zwei-Grad-Ziels ${ }^{8}$ eine entscheidende Rolle spielen (vgl. IPCC 2014: 13,

8 Das Zwei-Grad-Ziel besteht darin, die globale Erwärmung auf weniger als zwei Grad gegenüber dem Niveau vor Beginn der Industrialisierung zu begrenzen. Das Ziel ist eine politische Setzung, die sich auf wissenschaftliche Szenarien über wahrscheinliche Folgen des Klimawandels beruft. Entscheidend für die Festlegung auf zwei Grad Erwärmung ist die Annahme, dass mit der Überschreitung der Zwei-Grad-Grenze sogenannte Kippunkte erreicht würden. Klimaexpert_innen gehen davon aus, dass die Erwärmung des Klimas ab einem gewissen Level sich selbst verstärkende irreversible Rückkopplungseffekte auslöst. Häufig genannte Beispiele sind das Abschmelzen des Westantarktischen Eisschildes und das Auftauen von Permafrostböden. Weder der Eintritt dieser Kipppunkte noch ihre Folgen sind tatsächlich vorhersehbar. Deshalb wird an dem Zwei-Grad-Ziel kritisiert, dass es eine Berechenbarkeit und Beherrschbarkeit des Klimawandels suggeriert, die mit naturwissenschaftlichen Aussagen nicht begründet werden kann. Ein weiterer Kritikpunkt ist, dass mit dem Zwei-Grad-Ziel die Zerstörung der Lebensgrundlage vieler Menschen in einigen Inselstaaten, Küstenregionen sowie Wald- und Trockengebieten in Kauf genommen wird. 
15, 19, 22). Die Hoffnung auf noch nicht ausgereifte Technologien wie CCS und BECCS muss im Zusammenhang mit den stetig steigenden Treibhausgasemissionen gesehen werden. Die mangelnden Erfolge bisheriger Klimapolitik erhöhen - in der ökomodernen Logik - den Erfolgsdruck in Bezug auf die Suche nach der sogenannten silver bullet, der einen entscheidenden Wunderwaffe gegen den Klimawandel oder nach dem geeigneten Portfolio technologischer Optionen ${ }^{9}$.

Auch wenn der Zeitpunkt für eine mögliche großflächige Anwendung von CCSTechnologien nicht feststeht, hat bereits die Hoffnung auf CCS großen Einfluss auf die Auseinandersetzungen um die Klima- und Energiepolitik sowohl auf internationaler als auch auf nationaler und regionaler Ebene vieler Länder (für den gesamten Absatz vgl. Markusson/Shackley 2012: 36; Markusson/Shackley/Evar 2012a: 5f; Meadowcroft/Langhelle 2009a: 267ff). Die besondere Bedeutung von CCS-Technologien, die sie von anderen Klimaschutzmaßnahmen unterscheiden, besteht in ihrer Kompatibilität mit der fossilen Energieinfrastruktur (vgl. IPCC 2005: 12). Darin liegt die spezifische Attraktivität von CCS-Technologien, denn fossile Brennstoffe sind ein zentraler Wachstumstreiber und elementare Basis des etablierten Entwicklungs- und Wohlstandsmodells. CCS-Technologien versprechen damit, durch die fortgesetzte Nutzung fossiler Brennstoffe weiteres Wirtschaftswachstum zu schaffen, ohne die Treibhausgaskonzentration in der Atmosphäre in großem Ausmaß zu erhöhen. Insbesondere Energiekonzerne und Regierungen aus Ländern mit fossilen Reserven investieren in CCS-Technologien. Diese CCS-befürwortende Koalition ${ }^{10}$ setzt auf CCS-Technologien, um ihre bewährten Muster der betriebswirtschaftlichen Profitmaximierung bzw. der volkswirtschaftlichen Wohlstandsmaximierung fortführen zu können. Die Titulierung von fossilen Kraftwerken als ,CCS-Ready ${ }^{11}$ ist ein wichtiges Argument für die Rechtfertigung von Kraftwerksneubauten, die im Zuge der Auseinandersetzungen um den anthropogenen Klimawandel zunehmend unter Legitimationsdruck geraten.

9 Zum Begriff des Portfolios technologischer Optionen vgl. Kapitel 5.3.4.

10 Für einen Überblick über die Akteur_innen und Argumente der CCS-befürwortenden und der CCS-kritischen Koalition vgl. Kapitel 5.2.

11 Der Begriff ,CCS-Ready` soll anzeigen, dass ein Kraftwerksneubau auf die nachträgliche Installation von CCS-Technologien ausgelegt ist. Es besteht allerdings Unklarheit darüber, welche Kriterien ein Kraftwerk erfüllen muss, um als CCS-Ready zu gelten. De facto bedeutet CCS-Ready in vielen Fällen vor allem die Bereitstellung einer Fläche, die für eine mögliche Abscheidung von $\mathrm{CO}_{2}$ benötigt werden würde. Darüber hinaus spielt die Nähe zu möglichen Speicherorten bzw. zu möglichen Transportwegen eine Rolle. 
Die damit verbundene Fortführung der fossilen Energieinfrastruktur wird dagegen von der CCS-kritischen Koalition beklagt. Aus ihrer Sicht verhindert die Hoffnung auf CCS-Technologien den dringend notwendigen strukturellen Wandel weg von fossilen Brennstoffen. Umgekehrt geht die CCS-befürwortende Koaliton davon aus, dass die Investitionen in CCS-Technologien auf der realistischen Einschätzung basieren, dass strukturverändernde Vorschläge politisch nicht durchsetzbar und ökonomisch nicht rentabel wären. Die kurz- bis mittelfristige Kontinuität des fossilen Zeitalters sei eine Tatsache, die man - unabhängig von ihrer Bewertung - als unvermeidliche Rahmenbedingung zu akzeptieren habe.

Angesichts vermeintlicher Sachzwänge und Pfadabhängigkeiten gilt die Entwicklung und Anwendung von CCS-Technologien in der Argumentation der CCSbefürwortenden Koaltion als unersetzliche Brückentechnologie. Sie halten positive Klimaschutzeffekte durch einen großflächigen Einsatz von CCS-Technologien für realistischer als eine Veränderung von Produktions- und Konsummustern. Zur Begründung verweisen sie auf infrastrukturelle und auf technische Pfadabhängigkeiten, auf den Widerstand der einflussreichen Energiekonzerne gegen klimapolitische Vorgaben, auf die fehlende Bereitschaft der Bevölkerung zum Konsumverzicht sowie auf die geringen Erträge langwieriger politischer Aushandlungsprozesse. In Bezug auf erneuerbare Energien vertreten CCS-Befürworter_innen oftmals die Position, dass diese noch zu teuer seien und noch nicht die nötige Reife besäßen, um den globalen Energiebedarf decken zu können (vgl. Meadowcroft/Langhelle 2009a: 279; Tabelle 11 in Kapitel 5.4.2). Daraus ziehen sie die Schlussfolgerung, dass CCS als Brückentechnologie fungieren sollte, bis es durch die Entwicklung alternativer technologischer Optionen, insbesondere erneuerbarer Energien, überflüssig werde.

Die Implementierung von CCS als ,Brückentechnologie‘ birgt allerdings aus Sicht der CCS-kritischen Koalition ein doppeltes Risiko: Erstens ist die Speicherung von $\mathrm{CO}_{2}$ in geologischen Formationen mit ökologischen und gesundheitlichen Risiken verbunden (vgl. Kapitel 5.2). Zweitens sind technologische Entwicklungen nur eingeschränkt plan- und vorhersehbar. Dies betrifft sowohl den Einsatz von CCS selber als auch dessen Funktion als Brückentechnologie. Es ist unklar, ob, und wenn ja, ab wann ein großflächiger Einsatz von CCS-Technologien möglich ist. In den Prognosen über technische Entwicklungen und die zukünftige Energieinfrastruktur werden politische und soziale Einflussfaktoren, die bei der Gestaltung des Energiesystems eine besonders wichtige Rolle spielen, in der Regel unterschätzt (vgl. Hansson 2012: 75ff). Dies ist ein entscheidender Unsicherheitsfaktor bezüglich der Vorstellung, eine bestimmte Technologie könne eine Brücke in eine Energieinfrastruktur bilden, in der sie selber keine Rolle mehr spielt. 
So machen hohe Investitionssummen, der Aufbau einer eigenen Infrastruktur sowie die Schaffung juristischer und finanzieller Rahmenbedingungen den bewussten Rückbau einer Technologie - in diesem Fall CCS - sehr unwahrscheinlich (vgl. Meadowcroft/Langhelle 2009a: 279). Somit droht die Gefahr eines sogenannten carbon lock-ins. Der Lock-in-Effekt würde darin bestehen, dass der Ausbau der fossilen Energieinfrastruktur die Ausgangsbedingungen für spätere Transformationsprozesse weiter verschlechtert. Angesichts dieses doppelten Risikos interpretieren die Naturwissenschaftler Daniel Spreng, Gregg Marland und Alvin M. Weinberg die Entwicklung und den Einsatz von CCS-Technologien als ,Faustschen Pakt':

„CSS appears to be a classic Faustian Bargain. But, as in Faust's initial bargain, it need not mean that our soul is left to the devil. It should mean that we accept the challenge of continual striving and vigilance, striving for more durable answers to global climate change and vigilance in assuring that stored carbon is not subsequently released to the climate system." (Spreng/Marland/Weinberg 2007: 854)

Diese Zuspitzung - sowohl der spezifischen Attraktivität als auch des doppelten Risikos von CCS-Technologien - verdeutlicht, wie kontrovers die Auseinandersetzungen um CCS geführt werden. Nichtsdestotrotz ist das Interesse ganz unterschiedlicher Akteur_innen aus Wirtschaft, Politik und Wissenschaft an CCS-Technologien ungebrochen. ${ }^{12}$

Die Auseinandersetzungen um CCS-Technologien sind damit ein prädestinierter Untersuchungsgegenstand für die Analyse der re- und entpolitisierenden Prozesse im Konfliktfeld der ökologischen Krise. CCS-Technologien können als eine Klimaschutzmaßnahme beschrieben werden, die auf eine nicht-intendierte Nebenfolge der Industriemoderne mit einem risikoreichen Technofix reagiert. Als solches scheinen CCS-Technologien eine Voraussetzung und zugleich ein Ergebnis der Stabilität hegemonialer Strukturen zu sein. Gerade deshalb ist die Entwicklung von CCS-Technologien besonders starker Kritik ausgesetzt und steht unter erhöhtem Legitimationsdruck. In den CCS-Konflikten spitzt sich die Frage zu, inwieweit es zur adäquaten Bearbeitung der ökologischen Krise einer Änderung gesellschaftlicher Strukturen bedarf.

12 In Deutschland spielen CCS-Technologien zwar seit der Verabschiedung des CCSGesetzes eine eher marginale Rolle. Diese Entwicklung spiegelt allerdings nicht die Prozesse in anderen Ländern und auf internationaler Ebene wider. Insbesondere die Anwendung in China und Indien halten viele Akteur_innen für wahrscheinlich (vgl. Román 2011: 393; im Internet: www.germanwatch.org/klima/ccsdeu09.pdf, www.brandenburg. nabu.de/naturschutz/energie/12504.html, www.ufz.de/index.php?de=18404, letzter Zugriff am 02.12.2014). 
Insofern gehe ich davon aus, dass sich an den Auseinandersetzungen um CCSTechnologien paradigmatisch zentrale Konflikte analysieren lassen, in denen um die weitere Entwicklung des ökomodernen Projekts bzw. insgesamt um die gesellschaftliche Bearbeitung der ökologischen Krise gerungen wird.

Um die Dynamiken in diesen Kämpfen um Hegemonie in den Blick zu bekommen, halte ich die genaue Untersuchung einzelner Konfliktfelder für wichtig. Eine solche Rückbindung an konkretes empirisches Material schärft den Blick für die Prozesse der Stabilisierung und Verflüssigung sozialer Praktiken, die Risse und Brüche hegemonialer Diskurse sowie die permanente Reproduktionsleistung hegemonialer Projekte. Umgekehrt gewinnt die Analyse der CCS-Konflikte durch ihre Einbettung in den breiteren gesellschaftlichen Kontext an Tiefe. Nur so können die in diesen Konflikten wirksamen Deutungs- und Handlungsmuster als Hegemoniepraktiken dekonstruiert werden, die eine bestimmte Strukturierung der gesellschaftlichen Naturverhältnisse (re-)produzieren. Deshalb oszilliere ich zwischen der mikroanalytischen Untersuchung konkreter CCS-Konflikte und der abstrakteren Verdichtung im Hinblick auf die (Re-)Organisation gesellschaftlicher Naturverhältnisse. Auf diese beiden Ebenen beziehen sich meine Forschungsfragen:

\section{Forschungsfragen:}

1) Wie und bis zu welchem Grad konnte das ökomoderne Projekt hegemonial werden und die gesellschaftlichen Reaktionen auf die ökologische Krise bestimmen?

2) Welche Bedeutung haben die Konflikte um CCS-Technologien in den Auseinandersetzungen um die weitere Entwicklung des ökomodernen Projekts?

3) Welche Auswirkungen haben die Konflikte um CCS-Technologien auf die Auseinandersetzungen um die Bearbeitung der ökologischen Krise?

Entsprechend meines Erkenntnisinteresses fokussiere ich bei der Beantwortung der Forschungsfragen stets auf die Herausarbeitung re- und entpolitisierender Prozesse.

\subsection{FORSCHUNGSSTAND UND FORSCHUNGSLÜCKE}

Mit dem Fokus auf die re- und entpolitisierenden Effekte reagiere ich auf eine Forschungslücke in der (sozial-)wissenschaftlichen Beschäftigung mit CCS-Technologien. Diese Lücke in der CCS-Forschung besteht bezüglich der Verknüpfung der Untersuchung konkreter Konflikte mit einer Analyse des breiteren gesellschaftlichen Kontextes. Um diese Verknüpfung leisten zu können, schließe ich an verschiedene theoretische Ansätze und empirische Studien an, in denen die hegemonialen 
Kämpfe um die gesellschaftlichen Reaktionen auf die ökologische Krise ebenfalls im Mittelpunkt des Erkenntnisinteresses stehen. Bevor ich einen kurzen Überblick über diese Ansätze gebe, diskutiere ich im Folgenden zunächst den Stand der sozialwissenschaftlichen Forschung zu CCS und arbeite heraus, worin genau die Forschungslücke besteht.

Die Anfänge der technischen Entwicklung von CCS wurden fast ausschließlich von ingenieur- und naturwissenschaftlichen Studien begleitet. Erst in den letzten Jahren mehrten sich sozialwissenschaftliche Arbeiten, die sich vor allem mit Fragen der Kosten, der Wahrnehmungen und Meinungen von Stakeholdern sowie der öffentlichen Akzeptanz von CCS-Technologien beschäftigen (vgl. Markusson/Shackley/Evar 2012a: 2f). Unter diesen sind es in erster Linie wirtschaftswissenschaftliche Ansätze der Modellierung von (zukünftigen) Energiesystemen und daraus abgeleitete Kostenprognosen, die Einfluss auf die wissenschaftlichen und politischen Auseinandersetzungen um CCS-Technologien haben. Politikwissenschaftliche Ansätze und allgemein Ansätze, die mit qualitativen Methoden arbeiten, erhalten dagegen weitaus weniger Aufmerksamkeit (vgl. Markusson/Shackley/Evar 2012a: 11).

In groß angelegten CCS-Forschungsprogrammen werden Sozialwissenschaftler_innen oftmals allein mit der Analyse der öffentlichen Akzeptanz von CCS-Technologien beauftragt. Insgesamt nahm die Akzeptanzforschung mit der wachsenden politischen Bedeutung von CCS-Technologien ab Mitte der 2000er Jahre deutlich zu. Dabei dominiert ein instrumentaler Rückgriff auf sozialwissenschaftliche Ansätze mit der Intention, durch verbesserte Kommunikationsstrategien eine Akzeptanz von CCS-Technologien in der Öffentlichkeit herzustellen.

„Industry has huge incentives to reverse this lack of social acceptance, especially since several disposal projects have already been halted by social protests. It also has the economic and intellectual capacity to do so, by employing methods of scientific authority. These methods have emanated from attempts to persuade ENGOs and social scientists to conduct research into public perceptions of CCS, and into how to influence public opinion, present information, and initiate education campaigns concerning climate change and its technological solutions. In this context, social science is reduced to uncritically supporting and propagating facts already produced by industry or by CCS proponents in academia.“(Galis/Hansson 2012: 349)

Tatsächlich zielt die Mehrzahl der (sozial-)wissenschaftlichen CCS-Studien, teils explizit und teils implizit, auf die Überwindung möglicher Hindernisse, die einer Einführung von CCS-Technologien entgegen stehen könnten (vgl. Bäckstrand/Meadowcroft/Oppenheimer 2011: 277; Ishii/Langhelle 2011: 358; Markusson/Shackley/Evar 2012a: 12; Meadowcroft/Langhelle 2009b: 16). Eine kritische Reflexion dieser instrumentalen CCS-Forschung findet sich in Galis/Hansson 2012, Hansson 2012 und Hansson/Bryngelsson 2009. 
Neben diesen Analysen, Prognosen und Empfehlungen zur Durchsetzung und Verbreitung von CCS-Technologien wurden allerdings auch sozialwissenschaftliche Studien publiziert, die eine etwas weiter gefasste Perspektive einnehmen und das wechselseitige Verhältnis von sozialem Wandel und Technologieentwicklung beleuchten. Einen Überblick über den Stand der diesbezüglichen Forschung geben die Sammelbände „Caching the Carbon“ (Meadowcroft/Langhelle 2009c) und „The Social Dynamics of Carbon Capture and Storage“ (Markusson/Shackley/Evar 2012b) sowie eine Sonderausgabe der Zeitschrift Global Environmental Change aus dem Jahr 2011.

In „Caching the Carbon“ werden die CCS-Politiken sieben verschiedener OECD-Länder (USA, Australien, Kanada, Norwegen, Deutschland, Großbritannien, Niederlande) und der EU analysiert. An diese Fallstudien schließt ein Aufsatz an, der die empirischen Ergebnisse zusammenfasst und zueinander ins Verhältnis setzt. Der Sammelband endet mit einem Text, der über die Reflexion der gewonnenen Erkenntnisse einen Ausblick auf mögliche Entwicklungspfade von CCS-Technologien gibt.

Das „Special Issue on The Politics and Policy of Carbon Capture and Storage“ der Zeitschrift Global Environmental Change fokussiert ebenfalls auf den Vergleich der Politikprozesse in verschiedenen Ländern und analysiert zusätzlich allgemeine Rahmenbedingungen für CCS-Projekte auf internationaler Ebene. In den Artikeln stehen die Kontroversen und Konflikte um CCS-Technologien im Fokus. Konkret wird die Wahrnehmung und Akzeptanz von CCS-Technologien untersucht, die Darstellung von CCS in den Medien erforscht, die rechtliche Rahmensetzung und die politische Regulierung von CCS-Technologien beleuchtet (vgl. Bäckstrand/Meadowcroft/Oppenheimer 2011: 275f).

In dem Sammelband „The Social Dynamics of Carbon Capture and Storage“ werden CCS-Deutungsmuster verschiedener Akteur_innen herausgearbeitet, die Darstellungen von CCS in wissenschaftlichen Studien analysiert, die unterschiedlichen CCS-Positionen von Umwelt-NGOs aufgezeigt, Personennetzwerke der CCSCommunity beschrieben, Governance-Analysen durchgeführt sowie die Bedeutung bestimmter Akteur_innen und spezifischer Wissensformen für Innovationsprozesse untersucht.

Insgesamt ist die sozialwissenschaftliche CCS-Forschung durch einen stark Empirie-geleiteten Zugang kennzeichnet, in dem nur hin und wieder einzelne theoretische Konzepte zur Erklärung hinzugezogen werden (vgl. beispielsweise Meadowcroft/Langhelle 2009b: 16). Viele Studien verzichten gänzlich auf theoretische Ansätze, andere greifen auf einzelne theoretische Begriffe zurück. So werden die CCSspezifischen Akteurskonstellationen unter anderem mit Konzepten der story lines, 
discourse coalitions und advocacy coalitions herausgearbeitet (vgl. Markusson/ Shackley/Evar 2012a: 7; Meadowcroft/Langhelle 2009b: 16f; Pollak/Phillips/ Vajjhala 2011). Die CCS-Community wird als eine epistemic community beschrieben (vgl. Stephens/Liu 2012; Stephens et al. 2011). Weiterhin wird das empirische Material aus den Perspektiven der technology innovation (vgl. Stephens 2009), der sociology of expectations (vgl. Hansson 2012) und des issue-attention cycle (vgl. Shackley/Evar 2012) beleuchtet.

Eine über die Anwendung einzelner theoretischer Begriffe oder Konzepte hinausgehende Verknüpfung von CCS-Forschung mit gesellschaftstheoretischen Analysen stellt weiterhin eine Forschungslücke dar (vgl. Bäckstrand/Meadowcroft/Oppenheimer 2011: 278). Insofern verstehen Heleen de Coninck und Karin Bäckstrand ihren Aufsatz „An International Relations perspective on the global politics of carbon dioxide capture and storage" (2011) als Einstieg in eine stärker theoriegeleitete CCS-Forschung (vgl. Bäckstrand/de Coninck 2011: 368f). In ihrem Artikel prüfen sie drei Theorien - Realismus, liberaler Institutionalismus und Konstruktivismus auf ihre Erklärungskraft bezüglich der Entstehung, der Organisationsweise und des Einflusses internationaler CCS-Organisationen.

Ähnlich explorativ gehen Nils Markusson, Simon Shackley und Benjamin Evar (2012c) in der Zusammenfassung ihres Sammelbandes vor. Dabei ordnen sie die Auseinandersetzungen um CCS-Technologien in die Ansätze des Technokratismus, der ökologischen Modernisierung, der Risikogesellschaft und des Öko-Sozialismus ein. Die Konzepte stellen für sie nicht nur Analysemodelle, sondern in erster Linie mögliche Governance-Modelle dar (vgl. Markusson/Shackley/Evar 2012c: 267). Dementsprechend arbeiten sie in ihrer jeweiligen Kritik an den Ansätzen heraus, inwieweit sie sich zur politischen Governance von CCS-Technologien eignen und an welchen Punkten sie nicht zur Überwindung der Hindernisse, die der Entwicklung und Anwendung von CCS-Technologien entgegen stehen, beitragen können (vgl. Markusson/Shackley/ Evar 2012c: 258, 262, 264f, 266f).

Diese doppelte Verwendung theoretischer Ansätze als Analysemodell zur Erklärung gesellschaftlicher Prozesse und zugleich als analytisches Hilfsmittel für aktive Politikformulierung ist symptomatisch für die starke Anwendungsorientierung, die nahezu die gesamte (sozialwissenschaftliche) CCS-Forschung charakterisiert. Markusson, Shackley und Evar, die den mangelnden Einfluss qualitativer und politikwissenschaftlicher CCS-Studien beklagen (vgl. Markusson/Shackley/Evar 2012a: 11), wollen mit ihrem Sammelband demonstrieren, dass die Sozialwissenschaften - wie andere Disziplinen auch - politikrelevantes Wissen generieren können: 
„It was important in planning this book to show how social science can contribute in a practical way to decision-making for governance and beyond. We have therefore sought to include and develop insights of relevance to CCS practioners, policymakers, project managers and others.“ (Markusson/Shackley/Evar 2012c: 268)

Als normative Grundlage und Orientierung für die Generierung anwendungsorientierter Erkenntnisse gilt dabei oftmals eine mehr oder weniger explizite Vorstellung von ,nachhaltiger Entwicklung' (vgl. beispielsweise Meadowcroft/Langhelle 2009b: 17). Aus dieser Perspektive sollen die Potenziale und Probleme der Integration von CCS-Technologien in ein Portfolio technologischer Klimaschutzoptionen ausgelotet werden.

„From such a perspective, CCS has serious potential as an emission reduction pathway. But its contribution must be judged in relation to the wider challenge of developing a carbon neu tral energy system, as well as the requirement of sustainable development. Costs and risks must be considered as well as promised benefits. And experiences with other emergent technologies, and lessons from other regulatory domains, may help decision makers structure societal engagement with CCS in ways that maximize the benefits and reduce the costs and risks. In other words, if CCS is to be done, let us try to get it as right as possible. "(Meadowcroft/Langhelle 2009b: 18; Hervorhebung T. K.)

Wie das Zitat von James Meadowcroft und Oluf Langhelle deutlich macht, wird dabei die Entwicklung und zukünftige Implementierung von CCS-Technologien oftmals als gegeben vorausgesetzt. Zur Debatte steht lediglich, in welcher Form und in welchem Umfang CCS-Technologien Anwendung finden sollen. Im Gegensatz zur weiter oben erwähnten rein instrumentalen CCS-Forschung werden Risiken und mögliche nicht-intendierte Nebenfolgen von CCS-Technologien in diesem Forschungsstrang durchaus ernst genommen, um deren negative Konsequenzen möglichst gering zu halten. Diese für die CCS-Thematik typische (sozial-)wissenschaftliche Herangehensweise kann als konstruktiv-kritische Intervention in den Politikbetrieb beschrieben werden. Dabei unterscheiden sich die CCS-Studien durchaus inwieweit sie direkte Handlungsempfehlungen für politische Entscheidungsprozesse formulieren oder eher allgemeinere Einschätzungen entwickeln. Ein prototypisches Beispiel für eine direkte Ableitung politikrelevanten Wissens stellen die Schlussfolgerungen im Aufsatz von Atsushi Ishii und Oluf Langhelle dar, in denen sie ihren analytischen Ansatz und ihre empirischen Ergebnisse in Bezug auf die Möglichkeit zur Generierung politischer Handlungsanweisungen reflektieren:

„If we view the framework [of an integrated carbon capture and storage policy; T. K.] as a diagnostic tool intended to provide policy recommendations for enhancing the level of integration of CCS policies, we see that it works as intended. Japan should focus more on vertical 
issues such as insurance, longterm liability, public acceptance, and climate policy, and on horizontal issues such as energy policy, to address fragmentation and evaluate trade-offs and synergies and to solve the contradiction between RD\&D and the LDPD licensing system. Norway must take biodiversity issues more seriously and address other climate technologies, most notably new renewable energy technologies." (Ishii/Langhelle 2011: 366)

Meiner Arbeit liegt im Gegensatz zur Mehrzahl der (sozial-)wissenschaftlichen CCS-Forschung keine Anwendungsorientierung in diesem Sinne zugrunde. Stattdessen unterziehe ich die Auseinandersetzungen um CCS-Technologien einer dekonstruktiven Analyse. Damit produziere ich kein positives handlungsleitendes Wissen, das direkten Einfluss auf die Art und Weise der Entwicklung und Anwendung von CCS-Technologien nehmen soll (,to get it as right as possible“). Vielmehr ziele ich auf die Offenlegung von Kämpfen um Hegemonie, in denen verschiedene Akteur_innen um die Entwicklung, Relevanz und Akzeptanz von CCS-Technologien ringen. Eine solche Analyse dient nicht der konstruktiven Intervention in die Politik, sondern stellt eine dekonstruktive Intervention in den Raum des Politischen dar (vgl. die Unterscheidung von der Politik/dem Sozialen und dem Politischen in Kapitel 2.1.1). Mein Erkenntnisinteresse dreht sich damit nicht um die Frage, ob und wie CCS-Technologien entwickelt und angewendet werden sollten, sondern wie es dazu kam, dass sie in einer bestimmten Art und Weise entwickelt und angewendet werden bzw. in bestimmten Fällen nicht zum Einsatz kommen. Dabei fokussiere ich insbesondere auf die damit verbundenen Effekte auf die allgemeinen Konflikte um die Bearbeitung der ökologischen Krise. Dementsprechend schwingt permanent die Frage mit, welche Alternativen einmal möglich waren oder noch möglich sind und durch welche Hegemoniestrategien sie unmöglich gemacht bzw. marginalisiert wurden oder werden.

An den Auseinandersetzungen um CCS-Technologien interessiert mich also, inwiefern sich in ihnen bestimmte Konflikte um die weitere Entwicklung der Organisation gesellschaftlicher Naturverhältnisse zuspitzen. Diese Frage nach der Bedeutung von CCS-Technologien für Prozesse der (Ent-)Politisierung der ökologischen Krise stellt eine Forschungslücke dar. Diese Forschungslücke besteht auf zwei Ebenen. Zum einen fehlt es bislang an Arbeiten, die einen Zusammenhang herstellen zwischen den Auseinandersetzungen um CCS-Technologien und der sozialen Verfasstheit und Strukturiertheit gesellschaftlicher Naturverhältnisse. Zum anderen stellt der Fokus dieser Arbeit auf die re- und entpolitisierenden Prozesse eine Erweiterung der bisherigen CCS-Forschung dar. Mit diesem spezifischen Erkenntnisinteresse rücken Kontingenz und Konflikthaftigkeit der CCS-Governance ins Zentrum der Aufmerksamkeit. 
Damit schließe ich an verschiedene theoretische Ansätze und empirische Studien an, in denen die hegemonialen Kämpfe um die gesellschaftlichen Reaktionen auf die ökologische Krise ebenfalls im Mittelpunkt des Erkenntnisinteresses stehen. Da wären zunächst einmal Arbeiten zu nennen, in denen die Entwicklung des ökomodernen Projekts diskursanalytisch dekonstruiert wird (beispielsweise Dingler 2003 und Hajer 1995). Diese Analysen zielen auf die Herausarbeitung von story lines, Diskurskoalitionen und -strategien. Im Fokus stehen dabei die Kontinuitäten und Brüche in den dominanten umweltpolitischen Deutungsmustern. Insbesondere Johannes Dingler (2003) analysiert darüber hinaus, wie gegenhegemoniale Positionen artikuliert werden. Insgesamt bieten diese Studien einen guten Überblick über die Entwicklung des ökomodernen Diskurses. Dabei sind für meine eigene Arbeit die empirischen Analysen besonders hilfreich, in denen die Bedeutung verschiedener Ereignisse und Akteur_innen für die Durchsetzung und Verbreitung des ökomodernen Diskurses herausgearbeitet wird und aufzeigt wird, inwiefern mit seiner zunehmenden Dominanz alternative Deutungs- und Handlungsmuster marginalisiert werden.

Neben diesen diskursanalytischen Studien greife ich auf regulationstheoretische Arbeiten zurück, die einen stärkeren Fokus auf die Auseinandersetzungen um die Ausgestaltung politischer und ökonomischer Institutionen legen (beispielsweise Brand 2010; Brand/Görg 2003 und Görg 2003a). In diesen Texten werden die Konflikte um die Bearbeitung der ökologischen Krise im Zusammenhang eines gesamtgesellschaftlichen Wandlungsprozesses - dem Übergang vom Fordismus zum Postfordismus - analysiert. Dementsprechend fokussieren diese Studien auf das Verhältnis von Freihandelsregimen und Umweltregimen. Dabei zeigen sie, dass diese keine klar getrennten Politikarenen darstellen, sondern eng verwoben sind und die Zielsetzung des Freihandels die Ausgestaltung der Umweltregime in großem Maße prägt (vgl. Görg 2003a: 298f). Damit wird die Inwertsetzung von Natur als zentrales Paradigma herausgearbeitet, das die strukturellen Rahmenbedingungen vorgibt, innerhalb derer um die (Re-)Organisation der gesellschaftlichen Naturverhältnisse gerungen wird (vgl. Görg 2003a: 297). Da in den genannten regulationstheoretischen Studien das Konzept der gesellschaftlichen Naturverhältnisse entwickelt und angewendet wird, zeichnen sie sich durch eine analytisch geschärfte Perspektive auf die gesellschaftliche Organisation des Verhältnisses zur Natur aus, an die ich anknüpfe.

In Bezug auf das Feld der internationalen Klimapolitik beziehe ich mich in erster Linie auf Arbeiten, die wahlweise der Multi-Level-Governance-Forschung oder der Internationalen Politischen Ökonomie zugerechnet werden können (beispielsweise Brunnengräber 2009 und Brunnengräber/Dietz/Hirschl/Walk/Weber 2008: 
57ff). Im Zentrum dieser Analysen steht der Einfluss und die Rolle bestimmter Akteur_innen und Institutionen in den Auseinandersetzungen um die internationale Klimapolitik. Dabei verweisen sie auf Interdependenzen zwischen Politikarenen, die auf verschiedenen räumlichen Maßstabsebenen angesiedelt sind. Insgesamt zielen die Studien auf eine kritische Analyse der Genese und Funktionsweise des internationalen Klimaregimes sowie dessen Blindstellen. Für meine eigene Arbeit haben sich zwei Thesen aus diesem Forschungsfeld als besonders zentral erwiesen: Erstens die Beobachtung, dass mit der Deutung der ökologischen Krise als eine globale Krise ausgeblendet wird, dass die Verursachung ebenso wie die Betroffenheit von ökologischen Problemen sozial wie regional sehr unterschiedlich verteilt sind (vgl. Brunnengräber et al. 2008: 57ff). Zweitens die in den genannten Studien herausgearbeitete Trennung zwischen der Input-Seite der Energie-Produktion und der Output-Seite der Emissionen. Mit den marktbasierten Instrumenten des Kyoto-Protokolls erfolgt keine direkte Regulierung der Nutzung fossiler Brennstoffe, sondern nur der daraus entstehenden Emissionen (vgl. Brunnengräber et al. 2008: 188ff). Dies hat weitreichende Folgen für die Effekte des internationalen Klimaregimes und bringt Pfadabhängigkeiten mit sich, auf die ich an verschiedenen Stellen eingehen werde.

Auf diese drei Forschungsstränge greife ich im Verlauf meiner Arbeit immer wieder zurück. Ihre empirischen Ergebnisse und theoretischen Verdichtungen integriere ich in meine eigene Argumentation, der die Forschungsperspektive der diskurstheoretischen Hegemonieanalyse zugrunde liegt. 


\section{Theorie und Operationalisierung}

Meine Forschungsperspektive basiert auf der diskurstheoretischen Hegemonieanalyse und dem Konzept der gesellschaftlichen Naturverhältnisse. Die mit diesen Ansätzen einhergehenden Grundannahmen und Begriffe werde ich in den Kapiteln 2.1 (diskurstheoretische Hegemonieanalyse) und 2.2 (gesellschaftliche Naturverhältnisse) offen legen. In einem weiteren Kapitel (2.3) stelle ich das Forschungsdesign, den Aufbau und das methodische Vorgehen dieser Arbeit vor.

\subsection{Diskurstheoretische Hegemonieanalyse}

Die Begriffe und Konzepte der diskurstheoretischen Hegemonieanalyse ${ }^{1}$ prägen die Forschungsperspektive dieser Arbeit. Dabei orientiere ich mich an den Ausarbeitungen von Ernesto Laclau und Chantal Mouffe in „Hegemony and Socialist Strategy" (Laclau/Mouffe 2001) sowie den theoretischen Weiterentwicklungen durch Laclau und anderen Autor_innen (vgl. beispielsweise Laclau 1990a; Nonhoff 2006; Reckwitz 2006; Wullweber 2010). Die Autor_innen definieren die verwendeten Begriffe durchaus verschieden und teilweise unterscheiden sich auch ihre theoretischen Annahmen. Insofern soll hier nicht suggeriert werden, dass es die eine homogene diskurstheoretische Hegemonieanalyse gäbe. Um meine eigene Forschungsperspektive möglichst transparent $\mathrm{zu}$ machen, werden in den folgenden Ausführungen die Grundannahmen meines theoretischen Zugangs offengelegt und die verwendeten Arbeitsbegriffe definiert (2.1.1 bis einschließlich 2.1.4). Anschließend gehe ich auf die Schwierigkeit der Operationalisierung von Hegemonialisierungs- und Politisierungsprozessen ein. Mit der Unterscheidung fünf verschiedener Phasen - als Bandbreite möglicher empirischer Ergebnisse - soll eine differenzierte Einschätzung der beobachteten Kämpfe um Hegemonie erleichtert werden (2.1.5).

1 Für die Ansätze dieser Forschungsperspektive werden unter anderem auch die Bezeichnungen postmarxistische oder poststrukturalistische Diskurstheorie verwendet. 


\subsubsection{Das Primat des Politischen: Das Soziale und das Politische}

Um die virulenten Auseinandersetzungen im Konfliktfeld der ökologischen Krise adäquat analysieren zu können, habe ich mich für eine Forschungsperspektive entschieden, welche die Prozesse der permanenten (Re-)Produktion von Hegemonie in den Mittelpunkt rückt und auf die Brüche, Ambivalenzen und Widersprüche innerhalb von Diskursen fokussiert.

„Insgesamt hilft die Diskurs- und Hegemonietheorie dabei, den Blick für die Ambivalenzen und Heterogenitäten zu schärfen, die innerhalb sozialer Wirklichkeiten bestehen. Im Fokus der Analyse steht also weniger die vermeintliche Homogenität von Diskursen, sondern eher deren permanente Unabschließbarkeit und Veränderlichkeit.“ (Glasze/Mattissek 2009: 154)

Postfundamentalistische Ansätze, zu denen die diskurstheoretische Hegemonieanalyse zählt, basieren auf der Annahme, dass moderne Gesellschaften durch unabschließbare Auseinandersetzungen um die Fundierung der sozialen Ordnung geprägt sind. Diese Annahme reflektiert „ein empirisch nachvollziehbar gewandeltes Bewusstseins- und Praxisverhältnis der Menschen in der Moderne, durch das ihnen ihre gesamte gesellschaftliche Lebenswelt latent kontingent und damit entscheidbar geworden ist" (Greven 2010: 68). Damit soll nicht behauptet werden, dass alle gesellschaftlichen Phänomene permanent neu verhandelt werden. Eine solche Situation, in der Bedeutungszuschreibungen gar nicht institutionalisiert sind und keinerlei Fixierung anzutreffen ist, wäre ein Zustand jenseits von Gesellschaft (vgl. Laclau 2005: 133). Der Großteil der alltäglichen sozialen Beziehungen und Praktiken wird routiniert vollzogen, ohne problematisiert zu werden (vgl. Berger/ Luckmann 2004: 26f). Dennoch sind moderne Gesellschaften konstitutiv durch die "Gleichursprünglichkeit von Konflikt und Kontingenz" (Marchart 2013: 204) geprägt. Die Absage an die Möglichkeit einer Letztbegründung von Gesellschaft impliziert den Konflikt um die Ordnung des Sozialen. Stets besteht die Möglichkeit, dass etwas „als entscheidbar und entscheidungsbedürftig erkannt und mit einigem Erfolg propagiert wird“" (Greven 2010: 69). Gesellschaft muss also permanent neu gegründet und begründet werden (vgl. Marchart 2013: 204).

Diesem konfliktorientierten Gesellschaftsbegriff liegt ein theoretisch begründetes Primat des Politischen zugrunde. Damit ist gemeint, dass das Soziale $-\mathrm{d}$. h. verstetigte soziale Identitäten, Beziehungen, Handlungen und Strukturen - immer einen politischen Ursprung hat. Die gesellschaftliche Ordnung entwickelt sich durch Kämpfe um Hegemonie, in denen bestimmte Deutungs- und Handlungsmuster gegenüber anderen privilegiert werden. Diese Privilegierung wird im Zuge der Routinisierung entpolitisiert. Alternativen werden marginalisiert und geraten in 
Vergessenheit. Da dieser Prozess der Verstetigung sozialer Praktiken nie vollkommen gelingt, kann es keine eindeutige, sondern nur eine graduelle Unterscheidung des Sozialen vom Politischen geben. ${ }^{2}$ Das Politische wird hier als der Moment gefasst, in dem die Kontingenz der Gesellschaftsordnung deutlich und die Entscheidung zwischen Alternativen als das Ergebnis von Machtbeziehungen erkennbar wird (vgl. Laclau 1990a: 33ff; Reckwitz 2006: 346). Durch die Bewusstmachung des kontingenten Ursprungs des Sozialen können auch Alternativen wieder an Bedeutung gewinnen und bestimmte Deutungs- und Handlungsmuster in den politischen Bereich der Auseinandersetzungen um Hegemonie geholt werden. Von einem Primat des Politischen auszugehen meint demnach, Politik nicht als einen gesellschaftlichen Teilbereich neben anderen anzusehen, sondern vom politischen Ursprung des Sozialen insgesamt auszugehen (vgl. Wullweber 2010: 85ff).

\subsubsection{Das Ringen um Hegemonie: Subjektpositionen und Diskurse}

Die soziale Ordnung basiert damit auf einem permanenten Ringen um Hegemonie. Hegemonie wird dabei ,als eine dominante Lesart der Welt und die mit dieser Lesart verbundenen vorherrschenden Praktiken und Subjektivierungen“ (Nonhoff 2010: 41) verstanden. In der hier vertretenen diskurstheoretischen Perspektive sind es nicht bestimmte Subjekte oder soziale Kräfte, die hegemonial werden, sondern bestimmte Diskurse - d. h. Deutungs- und Handlungsmuster (soziale Praktiken) sowie die damit verbundenen sozialen Identitäten (Subjektpositionen) (vgl. Bedall 2014: 48ff). Diese Kämpfe können nur temporär und prekär ruhig gestellt werden, indem bestimmte Diskurse eine partielle Hegemonie erlangen. Dabei sind die Diskurse, in denen Praktiken sowie Vorstellungen vom Gemeinwohl und von idealen Gesellschaftsordnungen (re-)produziert werden, immer partikulare Diskurse. Sie entstehen und gelten stets in einem bestimmten historischen, regional- und gruppenspezifischen Kontext. Gesellschaft kann somit als ,eine Agglomeration von ,Diskursen“" (Reckwitz 2006: 341) beschrieben werden.

Ein Diskurs ist ein System von Unterscheidungen, die ,eine ,Ordnung der Dinge' produzieren, in deren Zusammenhang den Dingen erst bestimmte Bedeutungen zugeschrieben wird und bestimmtes Handeln möglich ist" (Reckwitz 2006: 341). Diskurse werden durch soziale Praxis (re-)produziert. Dabei wird jede soziale Praxis als artikulatorisch und damit als Teil von Diskursen verstanden, da in ihrem Vollzug Deutungs- und Handlungsmuster (re-)produziert werden (vgl. Laclau/ Mouffe 2001: 113). Als Akte der Bedeutungsgenerierung produzieren und verbrei-

2 In den Debatten über die, politische Differenz' wird zwischen, der Politik' (hier: ,das Soziale‘) und ,dem Politischen“ unterschieden (vgl. Bedorf/Röttgers 2010; Marchart 2010). 
ten solche Artikulationen Diskurse. Gleichzeitig ermöglichen und beschränken Diskurse bestimmte soziale Praktiken (vgl. Laclau/Mouffe 2001: 113f). Diskurse bestehen somit aus miteinander zusammenhängenden Artikulationen, die in den Ansätzen der Diskurstheorie die kleinste Analyseeinheit darstellen. Dabei kann nicht davon ausgegangen werden, dass im empirischen Material ,objektive“ Artikulationen unabhängig von der Perspektive des Beobachters/der Beobachterin identifiziert werden könnten. Eine Artikulation liegt nicht einfach vor, sondern ist immer das Ergebnis von Interpretationsarbeit. Somit kann man den als typisch interpretierten Bedeutungsgehalt einzelner oder verschiedener konkreter sozialer Praktiken als Artikulation fassen. Artikulationen, die Vorstellungen vom Gemeinwohl bzw. von der idealen Gesellschaftsordnung beinhalten, stellen politische Artikulationen dar und werden in dieser Arbeit als Forderungen bezeichnet (vgl. Bedall 2014: 41f; Nonhoff 2006: 138). Mit den Forderungen sind Partikularinteressen verknüpft, die auf die Subjektpositionen verweisen, aus denen heraus die Forderungen artikuliert werden.

Als Subjektpositionen gelten im Diskurs (re-)produzierte Identitätsangebote, die von Subjekten ausgefüllt werden, die damit zu Diskursträger_innen werden (vgl. Reckwitz 2006: 341, 346f; Wullweber 2010: 63). Durch die aktive Einnahme einer Subjektposition verbreiten, stabilisieren und entwickeln Diskursträger_innen einen Diskurs. Sie prägen und (re-)produzieren einen Diskurs und schreiben dabei ihre Partikularinteressen, ihre spezifischen Forderungen in den Diskurs ein. Insofern kann man auch mit einer diskurstheoretischen Perspektive unterschiedliche Wirkmächtigkeiten von Subjekten und sozialen Kräften analysieren (vgl. Bedall 2014: 48ff). Die Wirkmächtigkeit bemisst sich in der Fähigkeit, Diskurse zu prägen und zu verbreiten. ${ }^{3}$ Dazu bedarf es in der Regel die - bewusste oder unbewusste - Bildung von Diskurskoalitionen (vgl. Hajer 1995: 65).

3 In Bezug auf die Frage nach dem Verhältnis von Struktur und Subjekt wird hier weder die Struktur noch das Subjekt als vorrangig gefasst (vgl. Wullweber 2010: 76). Die Handlungen der Subjekte werden durch die Diskurse zugleich begrenzt und ermöglicht. Gleichzeitig formen die Subjekte mit ihrer Praxis die Diskurse. Dahinter steht die Annahme, dass eine komplette Schließung der Struktur nicht möglich ist. Aufgrund des Fehlens einer genauen Handlungsvorschrift wird das Subjekt zur Entscheidung gezwungen (vgl. Wullweber 2010: 77f). Die Situation der Unentschiedenheit ist allerdings eine strukturierte Unentschiedenheit. „Eine Entscheidung wird vielmehr immer innerhalb eines bestimmten strategisch-selektiven Kontextes [...] getroffen und kann von diesem nicht getrennt werden. Kontexte schränken daher sowohl die strukturelle Unentschiedenheit, [sic!] als auch die zu einem historischen Zeitpunkt möglichen Inhalte ein“ (Wullweber 2010: 79). In dislozierten Situationen, in denen sich die Brüche und Risse einer hegemonialen Struk tur zeigen, erhöht sich die Handlungsfähigkeit von Subjekten (vgl. Bedall 2014: 50). 


\subsubsection{Die Universalisierung: Hegemonieprojekt und Diskursorganisation}

Insofern bestimmte Forderungen von Diskursträger_innen über einen gewissen Zeitraum miteinander verknüpft und wiederholt artikuliert werden, kann man von einem Hegemonieprojekt sprechen (vgl. Wullweber 2010: 105f). ${ }^{4}$ Hegemonieprojekte versuchen Diskurse zu universalisieren, d. h. sie als alternativlos zu präsentieren (vgl. Reckwitz 2006: 343). Sie ringen darum, bestimmte Deutungsund Handlungsmuster in gesellschaftlichen Auseinandersetzungen durchzusetzen, sie zu institutionalisieren (vgl. Wullweber 2010: 108ff). Für diesen Prozess der Durchsetzung von sozialen Praktiken und Subjektpositionen verwende ich sowohl den Begriff der Hegemonialisierung als auch den der Universalisierung.

Verschiedene Hegemonieprojekte konkurrieren um die Fundierung der sozialen Ordnung. Ein Projekt hat dann Hegemonie erreicht, wenn die in ihm enthaltenen Partikularinteressen als Allgemeininteresse der Gesellschaft erfolgreich postuliert und als gesellschaftlicher Konsens ${ }^{5}$ durchgesetzt wurden (vgl. Wullweber 2010: 83). In einem solchen Fall wird ein Hegemonieprojekt, das Hegemonie anstrebt, zu einem hegemonialen Projekt, das Hegemonie erlangt hat. Die Durchsetzung eines bestimmten Konsenses basiert dabei immer auf der erzwungenen Ausgrenzung von Alternativen (vgl. Laclau 1990a: 31; Wullweber 2010: 83).

„Eine hegemoniale gesellschaftliche Struktur beinhaltet folglich immer auch die Unterdrückung von Menschen (genauer: Subjektpositionen), die sich nicht mit dem vorherrschenden Konsens, sondern mit alternativen Bedeutungen identifizieren. Die Hegemonietheorie hebt hervor, dass der Grad der Zustimmung und ebenso der Grad der Undenkbarmachung von Alternativen die Stabilität einer Hegemonie bestimmen. Hierdurch wird verdeutlicht, dass ein gesellschaftlicher Konsens regelmäßig auf Gewaltanwendung gründet, deren Spuren, durch zur Gewohnheit gewordene Wiederholungen, verwischt sind.“(Wullweber 2010: 83)

4 Es kann nicht davon ausgegangen werden, dass sich konkrete Einzelpersonen oder Gruppen in ihrer Selbstwahrnehmung als Diskursträger_innen eines Hegemonieprojekts verstehen - wobei dies in Einzelfällen auch zutreffen mag. Stattdessen ist die Identifizierung eines Hegemonieprojekts das Ergebnis von Interpretationsarbeit. Durch die Analyse können Zusammenhänge zwischen singulären Artikulationen, d. h. hegemoniale Strukturen und Strategien zur Durchsetzung von Hegemonieprojekten rekonstruiert werden.

5 Konsens meint in hegemonietheoretischen Ansätzen in Anschluss an Antionio Gramsci immer einen aktiv hergestellten Konsens, der das Ergebnis von von Kämpfen um Hegemonie ist. Insofern sind in einem Konsens stets bestimmte Partikularinteressen privilegiert eingeschrieben (vgl. Wullweber 2010: 83). 
Hegemonie wird zwar nur in seltenen Fällen durch direkten Zwang durchgesetzt und abgesichert. Allerdings geht die (Re-)Produktion eines bestimmten Konsenses stets mit dem Ausschluss von Alternativen einher und hat damit repressive Effekte. Dabei werden die ausschließenden Dimensionen eines hegemonialen Projekts in der Tendenz umso weniger als Zwang und Repression wahrgenommen, je gefestigter seine Hegemonie ist (vgl. Scherrer 2007: 72f). Aufgrund der Verstetigung sozialer Praktiken und der Marginalisierung von Alternativen, die in Vergessenheit geraten, wird ein hegemonialer Diskurs tendenziell unhinterfragt reproduziert (vgl. Laclau 1990a: 33ff).

Die sozialen Praktiken, die ein Hegemonieprojekt verbreiten und stabilisieren, fasse ich als Hegemoniestrategien (vgl. Wullweber 2010: 141). Der Begriff der Strategie wird hier diskurstheoretisch verwendet und bezieht sich somit nicht allein auf ein intentionales Vorgehen einzelner Akteur_innen, sondern im umfassenden Sinn auf die Muster der Anordnung diskursiver Elemente im Zeitverlauf (vgl. Nonhoff 2007: 184f). Der Einsatz von Hegemoniestrategien zielt darauf, Zustimmung zu den jeweiligen Hegemonieprojekten - und damit Konsens - zu erzeugen (vgl. Candeias 2007: 19; Scherrer 2007: 72). Ein zentraler Mechanismus ist dabei die Schaffung von attraktiven Subjektpositionen (vgl. Reckwitz 2006: 343).

Die Schaffung von attraktiven Subjektpositionen setzt an dem Bedürfnis von Subjekten nach Identifikation an, an der „Hoffnung, in dem bestehenden Bedeutungsuniversum aufzugehen“ (Wullweber 2010: 78). ${ }^{6}$ Für diese, auch als ,fantasmatisch“ (vgl. beispielsweise Bedall 2014: 55f; 59ff) bezeichnete Dimension von Diskursen verwende ich den Begriff des Hegemonieversprechens. Diskurse beinhalten stets ein imaginäres Versprechen auf einen glückselig machenden Zustand, der herbeigeführt oder vor seiner Zerstörung bewahrt werden soll. Das Hegemonieversprechen suggeriert, dass die Universalisierung des Diskurses zu ,gesellschaftlicher Harmonie und Vollkommenheit“" (Bedall 2014: 42) führe bzw. diese erhalte. So werden Diskurse und ihre Subjektpositionen attraktiv und erstrebenswert. Hegemonieversprechen beinhalten eine jeweils spezifische Vorstellung von Gemeinwohl und der idealen Gesellschaftsordnung, die als allgemeingültig artikuliert wird (vgl. Wullweber 2010: 108ff).

6 Bei der Fassung des Verhältnisses von Diskurs und Subjekt greifen viele Autor_innen der diskurstheoretischen Hegemonieanalyse auf den Subjektbegriff von Jacques Lacan zurück (vgl. beispielsweise Wullweber 2010: 77f). Mit dem Subjektverständnis von Lacan geht die Annahme einher, dass die Versuche der Integration des Subjekts in das Bedeutungsuniversum letztlich zum Scheitern verurteilt sind. Der Prozess der Identifikation ist somit stets prekär (vgl. Wullweber 2010: 78f). 
In vielen Arbeiten zur diskurstheoretischen Hegemonieanalyse wird davon ausgegangen, dass die Herausbildung eines, leeren Signifikanten` als Symbol der spezifischen Vorstellung von Gemeinwohl ein entscheidender Schritt zur Hegemonialisierung eines Diskurses sei (vgl. beispielsweise Bedall 2014: 45ff; Laclau 1996; Nonhoff 2006: 124ff; Nonhoff 2007: 180; Wullweber 2010: 139f, 150f). Auch wenn der Begriff des leeren Signifikanten in meiner Arbeit keine ganz so prominente Rolle spielt, werde ich an verschiedenen Stellen auf ihn zurückgreifen. Ich verwende den Begriff des leeren Signifikanten für die Bezeichnung der Kernforderung eines Hegemonieprojekts, die gleichzeitig das imaginierte Gemeinwohl repräsentiert. Ein leerer Signifikant hat damit eine Doppelfunktion: Er bezeichnet eine spezifische Forderung, gleichzeitig repräsentiert er aber auch den Diskurs insgesamt (vgl. Glasze/Mattissek 2009: 165f).

„Leere Signifikanten repräsentieren gewissermaßen den kleinsten gemeinsamen Nenner verschiedener Elemente und verknüpfen diese damit in einen diskursiven Zusammenhang. Je größer die Menge der Elemente innerhalb eines solchen Zusammenhangs, desto kleiner wird deren gemeinsamer Nenner und desto unspezifischer muss auch der leere Signifikant werden - daher die Bezeichnung leerer Signifikant.“ (Glasze/Mattissek 2009: 165; Hervorhebung im Original)

Um die Repräsentationsfunktion ausfüllen zu können, muss der Signifikant tendenziell entleert werden und damit gleichzeitig unterbestimmt und überdeterminiert bleiben. Ein leerer Signifikant ist unterbestimmt, weil er nicht eindeutig auf nur einen Signifikaten verweist. Er ist gleichzeitig überdeterminiert, hat Bedeutungsüberschüsse, weil er verschiedene Artikulationen repräsentiert (vgl. Reckwitz 2006: 343).

Die erfolgreiche Universalisierung eines Diskurses durch ein hegemonial gewordenes Projekt beinhaltet, dass die mit dem Diskurs verbundenen Praktiken und Subjektpositionen gesellschaftlich institutionalisiert und dominant sind. In einem solchen Fall kann man von einer (hegemonialen) Diskursorganisation sprechen. Eine Diskursorganisation stellt eine verstetigte ,und infolgedessen über einen gewissen Zeithorizont und innerhalb eines bestimmten sozio-politischen Raums stabilisierte soziale Verfasstheit und Strukturiertheit von Gesellschaft“" (Wullweber 2010: 113) dar. ${ }^{7}$

7 Dabei sei noch einmal betont, dass Akteur_innen zwar ihre Interessen privilegiert in ein Hegemonieprojekt einschreiben und es damit prägen und forcieren können, es aber nie die konkreten Personen oder Gruppen sind, die hegemonial sind bzw. werden, sondern die Diskurse, die Bedeutung generieren, Subjektpositionen vorgeben und auf eine bestimmte Gesellschaftsorganisation zielen (vgl. Wullweber 2010: 111). 
Die Identifikation von Diskursen und Diskursorganisationen ist - wie bereits in Bezug auf die Hegemonieprojekte angemerkt - eine analytische Rekonstruktionsleistung. Insofern hängt die Erfassung von Zusammenhängen zwischen Ereignissen und Praktiken sowie ihre Interpretation als Diskursorganisation von der Beobachtungsperspektive ab. Dabei ist es durchaus sinnvoll, von verschiedenen, sich teilweise überlagernden Diskursorganisationen auszugehen (vgl. Laclau/Mouffe 2001: 139).

Dementsprechend lassen sich Diskursorganisationen mit unterschiedlicher Reichweite ausmachen. Sie können erstens „hinsichtlich des adressierten Personenkreises, das heißt hinsichtlich des Kreises von Individuen und Gruppen, um dessen kollektives Begehren es geht" (Nonhoff 2006: 139) unterschieden werden. Zweitens kann unterschieden werden, ob sie sich auf das Gemeinwohl per se oder auf ein spezifisches Gemeinwohl beziehen. Damit ist gemeint, dass Diskurse beispielsweise innerhalb bestimmter Gesellschaftsbereiche (wie dem politischen System) oder bestimmter Sachgebiete (wie der Umweltpolitik) hegemonial sein können (vgl. Nonhoff 2006: 139). Diese sozio-politischen Räume - für die ich im Folgenden auch den Begriff der (Diskurs-)Arena verwende - werden ebenfalls in hegemonialen Kämpfen ${ }^{8}$ ausgehandelt und (re-)produziert. ${ }^{9}$

Mit der Verstetigung der permanenten Kämpfe um Hegemonie entwickeln sich Diskursorganisationen. In ihnen bilden sich gesellschaftliche Kräfteverhältnisse ab, die eine gewisse Festigkeit erlangt haben (vgl. Wullweber 2010: 115).

„Diese Kräfteverhältnisse wirken dadurch, dass sie in die soziale Struktur, in die Institutionen und täglichen Praktiken der Subjekte dieser Gesellschaft eingeschrieben wurden, strukturierend auf die Möglichkeiten der Artikulation neuer Relationen und damit auch auf die Gestaltung des Wahrheitshorizonts einer Gesellschaft ein. Eine spezifische Diskursorganisation ist also nicht nur Ausdruck der historischen Kräfteverhältnisse einer Gesellschaft, sondern wirkt retroaktiv und performativ auf die Konstituierung dieser Gesellschaft ein." (Wullweber 2010: 115; Hervorhebung im Original)

8 Korrekt wäre die Bezeichnung ,Kämpfe um Hegemonie‘. Schließlich sind die Kämpfe selber nicht hegemonial. Mit dem Begriff sind Praktiken gemeint, die auf die Universalisierung von Diskursen zielen. Aus stilistischen Gründen verwende ich in dieser Arbeit aber an manchen Stellen auch den Ausdruck der , hegemonialen Kämpfe‘.

9 In der Debatte um die ,Politics of Scale“ gibt es dafür den Begriff der ,skalaren Strategie‘. Skalare Strategien zielen darauf ab, über die Produktion und Veränderung räumlich-institutioneller Arenen Machtverhältnisse zu festigen, zu verschieben oder zu bekämpfen (vgl. Wissen/Röttger/Heeg 2008). Insofern sind sie Hegemoniestrategien, die sich auf die räumliche Dimension von Diskursorganisationen beziehen. 
Trotz der strategisch-selektiven Strukturierung der Gesellschaft, die bestimmte Artikulationen privilegiert und andere benachteiligt, ist die Stabilität einer Diskursorganisation konstitutiv prekär. Eine Diskursorganisation muss durch die permanente (Re-)Produktion des eigenen und der Marginalisierung der sie bedrohenden alternativen Diskurse aufrecht erhalten werden (vgl. Laclau 1990a: 31ff; Wullweber 2010: 113f). Eine ,vollständige hegemoniale Strukturierung ist nicht möglich“ (Wullweber 2010: 115), da Diskursorganisationen stets Risse und Brüche enthalten, die durch Dislokationen virulent werden können und Ansatzpunkte für gegenhegemoniale Projekte bieten - worauf ich im nächsten Abschnitt genauer eingehen werde.

\subsubsection{Die Prekarität von Hegemonie: Dislokationen und Antagonismen}

In vielen Texten zum Ansatz der diskurstheoretischen Hegemonieanalyse wird der Begriff der Äquivalenzkette synonym zu dem des Diskurses verwendet (vgl. beispielsweise Wullweber 2010: 59, 102). Mit dieser Formulierung soll ausgedrückt werden, dass die Elemente eines Diskurses als zusammengehörig - d. h. als äquivalent zueinander - artikuliert werden. Damit verbunden ist die Annahme, dass jede Universalisierung auf der Abgrenzung gegenüber einem verworfenen Außen basiert, ,im Verhältnis zu dem sich die Vielzahl einander überschneidender Differenzen zu einer übergreifenden Identität vereinheitlichen lässt" (Reckwitz 2006: 344). Die Elemente eines Hegemonieprojekts werden also nicht durch ein geteiltes positives Merkmal geeint, sondern durch die geteilte Opposition zum verworfenen Außen (vgl. Laclau 2007: 32), das als Hindernis bzw. Bedrohung für die Erreichung bzw. Erhaltung der idealen Ordnung gilt. „Universalisierungen sind paradoxerweise auf ein Anderes jenseits der Universalität angewiesen, gegen das sie ankämpfen.“ (Reckwitz 2006: 345)

Damit wird ein Antagonismus instituiert, der die Grenze markiert zwischen den , legitimen'Artikulationen innerhalb des Diskurses und den Artikulationen, die als Bedrohung für das Gemeinwohl gelten. Der Antagonismus kann dabei weder als Auseinandersetzung zwischen ,objektiv“ existierenden Gruppen noch als quasilogischer Widerspruch, welcher der gesellschaftlichen Struktur inhärent ist, gedacht werden (vgl. Laclau 1990a: 17). Als Antagonismus gilt dagegen der „Prozess der Grenzziehung, der den Diskurs in einen Bereich des ,Eigenen“ und einen des ,Anderen" unterteilt" (Glasze/Mattissek 2009: 166f). Der Antagonismus hat zugleich stabilisierende und destabilisierende Effekte. Zunächst einmal ist er die Grundlage für die Konstitution von Subjektpositionen und, legitimen`Artikulationen. Gleichzeitig unterminiert die Existenz eines verworfenen Außen den Universalitätsanspruch eines Hegemonieprojekts (vgl. Laclau 1990a: 39ff; Reckwitz 2006: 345). 
„Der hegemoniale Diskurs beansprucht Allgemeingültigkeit und Alternativenlosigkeit und demonstriert durch das sinnhafte Präsenthalten eines Außens, das sich nicht in die universale Ordnung fügt, seine eigene Kontingenz und Partikularität.“ (Reckwitz 2006: 345)

Hegemonieprojekte können also eine partielle Stabilität und Dominanz erreichen, diese bleibt aber konstitutiv prekär. Aufgrund der konstitutiven Prekarität von Hegemonie gibt es immer wieder Situationen ,die so neu sind, dass sie nicht aus der bestehenden sozialen Wirklichkeit heraus bearbeitet werden können“" (Glasze/ Mattissek 2009: 161). In diesen Situationen wird das Soziale disloziert. Der Dislokation von Identitäten, Hegemonieprojekten und Diskursorganisationen liegt die Überdeterminierung, die alle Versuche der Bedeutungsfixierung gemeinsam haben, zugrunde (vgl. Laclau/Mouffe 2001: 97f, 142; Laclau 1990a: 40).

Die Bedeutungsfixierung ist niemals total und niemals vollkommen stabil. Da Diskurse aus miteinander verwobenen partikularen Artikulationen bestehen, überlagern sich in Diskursen immer unterschiedliche Begründungsmuster und Sinnkonstruktionen. Insofern beinhalten - auch stark hegemonialisierte - Diskurse hybride und teilweise auch in sich widersprüchliche Momente. Deshalb kommt es immer wieder zu Dislokationen, d. h. zu Situationen in denen die Überdeterminierung aufbricht und hybride sowie widersprüchliche Momente der hegemonialen Diskursorganisation sichtbar werden (vgl. Glasze/Mattissek 2009: 157). Diese dislozierenden Effekte werden in dieser Arbeit als Brüche und Risse bezeichnet. Durch die Risse und Brüche, die den Universalitätsanspruch konterkarieren, wird die Kontingenz eines hegemonialen Diskurses deutlich. „Das, was ist, wird mit dem konfrontiert, was sein könnte: dem radikal Anderen [dem verworfenen Außen; T. K.]“ (Bedall 2014: 57; Hervorhebungen im Original). Damit stehen Dislokationen für den Moment des Politischen, in dem die Kontingenz des Sozialen und die Entscheidung zwischen Alternativen als das Ergebnis von Machtbeziehungen erkennbar wird (vgl. Laclau 1990a: 33ff; Reckwitz 2006: 346).

Joscha Wullweber benennt zwei mögliche Ursachen für Dislokationen. Zum einen hat die Unfähigkeit einer Diskursorganisation, bestimmte Ereignisse hegemonial $\mathrm{zu}$ integrieren, dislozierende Effekte. Zum anderen können Risse und Brüche virulent werden, wenn kritische Forderungen auf Dauer von einer Diskursorganisation ignoriert werden (vgl. Wullweber 2010: 140). Ein dislozierter Diskurs kann sich ganz verschieden entwickeln. Die Entwicklung hängt unter anderem von der Stärke der Dislokation, der Homogenität des hegemonialen Projekts und der Verbreitung von gegenhegemonialen Projekten ab.

Dabei stellt die Manifestation eines Antagonismus nur eine mögliche diskursive Antwort auf Dislokationen dar (vgl. Glasze/Mattissek 2009: 166). Die Manifestation eines Antagonismus bedeutet die (Re-)Politisierung eines vormals als 
universal und alternativlos geltenden Diskurses durch die vermehrte positive Bezugnahme auf das verworfene Außen. Damit wird ein latenter Antagonismus sichtbar und zum Ausgangspunkt virulenter Kämpfe um Hegemonie. Jede verworfene Position (-ierung) kann der Ort eines neuen manifesten Antagonismus werden (vgl. Laclau/Mouffe 2001: 131). Dem verworfenen Außen ist also stets die Möglichkeit der Politisierung inhärent, insbesondere wenn Hegemonieprojekte auf die Schließung von Diskurshorizonten ${ }^{10}$ drängen. Das verworfene Außen kann Quelle der Faszination und Attraktivität werden und von gegenhegemonialen Projekten positiv angeeignet werden (vgl. Reckwitz 2006: 345). Als gegenhegemoniale Projekte bezeichne ich solche Hegemonieprojekte, die sich auf das vom hegemonialen Diskurs verworfene Außen positiv beziehen und durch antagonistische Artikulationen auf eine (Re-)Politisierung verstetigter sozialer Strukturen zielen.

\subsubsection{Stabilitätsstufen der Hegemonie}

Mit meinen Forschungsfragen (vgl. Kapitel 1.1) ziele ich auf die Einschätzung der Stabilität von Hegemonie und (den Möglichkeiten) der (Re-)Politisierung gesellschaftlicher Naturverhältnisse. Eine derartige Beurteilung birgt einige Herausforderungen. Zum einen ist es schwierig, das Theorem der Hegemonie so zu operationalisieren, dass der Blick für Nuancen nicht verloren geht. Zum anderen erschwert die Annahme, dass Hegemonie durch komplexe Wechselspiele von Zwang und Konsens hergestellt wird, eine empirische Untersuchung von Hegemonie (vgl. Scherrer 2007: 82). Dennoch erscheint es mir sinnvoll, von unterschiedlich starker Stabilität hegemonialer Diskursorganisationen auszugehen und das empirische Material im Hinblick auf derartige graduellen Unterschiede möglichst differenziert zu betrachten. Ansonsten bestünde die Gefahr, homogene stabile Strukturen vorauszusetzen und damit den Blick für Ambivalenzen, Widersprüche sowie hybride Konstellationen im Material zu vernachlässigen. Damit würden weder die permanente Reproduktionsleistung dominanter Hegemonieprojekte noch die Prozesse der (Re-)Politisierung, an denen ein Aufbrechen des Diskurshorizonts zu beobachten ist, ausreichend gewürdigt werden.

Im Folgenden entfalte ich eine Bandbreite möglicher empirischer Ergebnisse meiner Analyse der (Stabilität der) Diskursorganisation im Bereich der gesellschaftlichen Naturverhältnisse. Diese Heuristik der Einteilung in fünf mögliche Stabilitätsstufen habe ich entwickelt, um eine differenzierte Einschätzung vornehmen zu können. Die dargestellten Phasen der Kämpfe um Hegemonie sind nicht als lineare Entwicklung zu interpretieren, in der eine Stufe zwangsläufig auf die andere folgt.

10 Laclau bezeichnet diese Prozesse als „discourse of closure“ (Laclau 1990b: 92). 
Ich gehe vielmehr davon aus, dass sprunghafte Wechsel zwischen den fünf verschiedenen Stufen möglich sind.

- Einfache Reproduktion der Hegemonie: Die Kritik an der hegemonialen Diskursorganisation ist marginalisiert. Gegenhegemoniale Projekte haben kaum Einfluss. Der hegemoniale Diskurs ist sehr stabil und wird nahezu umfassend reproduziert. Die damit verbundene Entpolitisierung bedeutet eine Schließung des Diskurshorizonts.

- Reflexive ${ }^{11}$ Reproduktion der Hegemonie: Der reflexiven Reproduktion geht eine Dislokation voraus, die vom hegemonialen Diskurs nicht ohne weiteres bearbeitet werden kann. In der Folge verliert das bislang dominante Hegemonieprojekt an Deutungshoheit gegenüber einem neuen Hegemonieprojekt (oder mehreren Hegemonieprojekten), das allerdings um die gleichen Kernforderungen kreist. Die etablierte Vorstellung vom Gemeinwohl wird nicht verworfen, sondern bildet ebenfalls die Kernforderung des aufstrebenden Hegemonieprojekts. Allerdings wird die Kernforderung in reflektierter Form - d. h. unter Berücksichtigung der Anforderungen, die sich aus der Dislokation ergeben - reproduziert. Dies bedeutet eine leichte kurzfristige Öffnung des Diskurshorizonts. Langfristig ist damit aber unter Umständen eine Schließung des Diskurshorizonts verbunden, wenn der hegemoniale Diskurs in reflektierter Form auf Dauer noch stabiler ist. Die Stabilität würde in dem Fall auf der geschaffenen Möglichkeit beruhen, auf bestimmte Dislokationen reagieren zu können.

- Politisierung: Kritische Forderungen werden auf Dauer von der Diskursorganisation ignoriert und gewinnen an Einfluss, wodurch die Brüche und Risse des hegemonialen Diskurses verstärkt werden. In der Folge werden gegenhegemoniale Projekte, die auf das verworfene Außen Bezug nehmen, wirkmächtiger und bilden ein Gegengewicht zum hegemonialen Projekt. Die Partikularität des hegemonialen Diskurses wird manifest und Antagonismen werden virulent. Das etablierte Hegemonieprojekt behält weiterhin seine dominante Position, aber alternative Praktiken und Subjektpositionen gewinnen an Einfluss. Dies beinhaltet eine Öffnung des Diskurshorizonts.

11 In Anlehnung an Christoph Görg und Alejandro Pelfini (vgl. Kapitel 2.2.3) wird hier mit reflexiver Reproduktion das Management nicht-intendierter Nebenfolgen gefasst. Davon grenzen Görg bzw. Pelfini die zweite Reflexion bzw. Reflexivität ab. Zweite Reflexion bzw. Reflexivität gehen über die einfache Reflexion nicht-intendierter Nebenfolgen hinaus, indem sie ,auf die Selbstkritik von Konstruktionsprozessen und auf ihre gesellschaftliche Veränderbarkeit“ (Görg 2003a: 49) zielen. 
- Hegemoniekrise ${ }^{12}$ : Der hegemoniale Diskurs verliert seine alternativlose Position. Es gibt eine offene Auseinandersetzung unterschiedlicher Hegemonieprojekte, die verschiedene Kernforderungen artikulieren. Die etablierten Subjektpositionen verlieren an Attraktivität und Diskursträger_innen des hegemonialen Diskurses brechen weg (vgl. Laclau/Mouffe 2001: 136). Dies bedeutet eine starke Öffnung des Diskurshorizonts.

- Neue Diskursorganisation: Im Anschluss an eine Hegemoniekrise entwickelt sich eine neue Diskursorganisation, die auf einer anderen Kernforderung basiert und andere Subjektpositionen produziert. Damit wird der durch die Hegemoniekrise stark geöffnete Diskurshorizont wieder partiell geschlossen.

\subsection{Gesellschaftliche NaturVerhältnisse}

In diesem Kapitel lege ich meine theoretische Perspektive auf die ökologische $\mathrm{Krise}^{13}$ dar. Dazu nähere ich mich allgemein der Frage, welchen Beitrag konstruktivistische Ansätze zur Analyse der ökologischen Krise leisten können (2.2.1). Anschließend konkretisiere ich diese Frage in Bezug auf den von mir gewählten Ansatz der diskurstheoretischen Hegemonieanalyse. Dabei argumentiere ich, dass es angesichts der Herausforderungen durch die ökologische Krise eines spezifischen Analyseinstrumentariums und eines elaborierten Begriffs von Natur bedarf (2.2.2). Um dem gerecht $\mathrm{zu}$ werden, integriere ich das Konzept der gesellschaftlichen Naturverhältnisse in meine Forschungsperspektive. Dazu führe ich in die Annahmen und Begrifflichkeiten des Konzepts ein (2.2.3). Abschließend zeige ich, inwiefern das Konzept der gesellschaftlichen Naturverhältnisse mit dem Ansatz der diskurstheoretischen Hegemonieanalyse kompatibel ist und warum diese Kombination für die Beantwortung meiner Forschungsfragen fruchtbar ist (2.2.4).

12 Diese Situation bezeichnen Laclau und Mouffe in Anlehnung an Gramsci als ,organic crisis‘ (vgl. Laclau/Mouffe 2001: 131). Das gramscianische Konzept der organischen Krise ist allerdings nur zum Teil in die Diskurstheorie integrierbar. Um die bei Laclau und Mouffe bereits angelegte Abgrenzung gegenüber Gramsci (vgl. Laclau/Mouffe 2001: 137f) deutlich zu machen, schlage ich die Verwendung des Begriffs der Hegemoniekrise vor.

13 Korrekter wäre, von einer ,sozial-ökologischen Krise‘ oder von einer ,Krise gesellschaftlicher Naturverhältnisse‘ zu sprechen (vgl. Becker/Jahn 2003: 94). Um die Anschlussfähigkeit an verschiedene wissenschaftliche und politische Debatten zu erhöhen, verwende ich jedoch den gängigeren Begriff der ökologischen Krise. 


\subsubsection{Das Verhältnis von Natur und Gesellschaft}

Mit der diskurstheoretischen Hegemonieanalyse liegt meiner Arbeit eine konstruktivistische Forschungsperspektive zugrunde. Gerade weil konstruktivistische Ansätze oftmals der Kritik ausgesetzt sind, dass sie wenig zur Analyse der ökologischen Krise beitragen könnten, werde ich eingehend die konstruktivistische Perspektive auf das Verhältnis von Natur und Gesellschaft darlegen. In erkenntnistheoretischer Hinsicht wird konstruktivistischen Ansätzen vorgeworfen, dass sie eine Autonomie des Sozialen annehmen, mit der die Abhängigkeit der Gesellschaft von Natur unterschlagen würde. Auf normativer Ebene wird kritisiert, dass sie aus der Einsicht in die gesellschaftliche Konstruktion der Wirklichkeit eine Aufforderung zur beliebigen Umgestaltung von Natur ableiten würden (vgl. beispielsweise Görg 2003b: 120). Ob und inwieweit diese Kritik auf welche Spielarten des Konstruktivismus zutrifft, soll hier nicht diskutiert werden. Stattdessen zielt die Argumentation auf die Offenlegung der eigenen Grundannahmen, um zum einen Missverständnisse vermeiden und zum anderen die Potenziale einer konstruktivistischen Perspektive aufzeigen zu können. Dazu greife ich primär auf Bernhard Gills Aufsatz „Paradoxe Natur. Zur Vieldeutigkeit der Unterscheidung von Natur und Gesellschaft“ (Gill 1998) zurück.

Gills Ausgangspunkt ist die Feststellung, dass konstruktivistische Analysen der ökologischen Krise nicht zur Beschreibung dessen, was als Natur und Gesellschaft objektiv vorliegt, beitragen (Beobachtung erster Ordnung), sondern gesellschaftliche Konstruktionen von Natur und Gesellschaft untersuchen (Beobachtung zweiter Ordnung). Dahinter steht die Annahme des sogenannten Thomas-Theorems ${ }^{14}$, dass diese gesellschaftlichen Konstruktionen eine Wirklichkeit erzeugen, weil sie die Deutungs- und Handlungsmuster der Akteur_innen prägen (vgl. Gill 2003: 17). Die konstruktivistische Perspektive zielt also auf die Analyse der in der Gesellschaft getroffenen Unterscheidungen von Natur und Gesellschaft und die daran geknüpften sozialen Praktiken.

Wie Gill differenziert ausführt, wird in verschiedensten sozialen Praktiken (alltäglicher, wissenschaftlicher, juristischer Art usw.) zwischen ,Natur' und ,Gesellschaft' auf jeweils ganz unterschiedliche Arten und Weisen (vgl. Gill 1998) unterschieden. Diese Unterscheidungen anhand von verschiedenen Leitsemantiken variieren je nach Kontext und Subjektposition. In Abgrenzung zur Akteur-NetzwerkTheorie ${ }^{15}$ konstatiert Gill, dass diese Unterscheidungen weder erst in der Moderne vollzogen werden noch absolute Unterscheidungen sind, folglich schon immer

14 „If men define situations as real, they are real in their consequences.“ (Thomas 1928: 572) 
durchlässig waren. Gill arbeitet heraus, dass das Verhältnis von Natur und Gesellschaft in den seltensten Fällen als Dichotomie betrachtet wird. Darüber hinaus betont er, dass Unterscheiden nicht mit dem Ausschluss von Übergängen und Zwischenbereichen oder gar der Negation von Wechselbeziehungen gleichzusetzen sei (vgl. Gill 1998: 224). Um nun aber diese gesellschaftlichen Unterscheidungen in den Blick zu bekommen, bedarf es analytischer Begriffe von Natur und Gesellschaft. Deshalb plädiert Gill dafür - hier steht er erneut im Gegensatz zur AkteurNetzwerk-Theorie - nicht nur aus normativen ${ }^{16}$, sondern auch aus analytischen Erwägungen heraus in sozialwissenschaftlichen Arbeiten nicht auf die Unterscheidung von Natur und Gesellschaft zu verzichten (vgl. Gill 1998: 223, 246f).

In diesem Sinne gehe ich im Folgenden auf die zwei Unterscheidungen ein, die für Gesellschaften der, westlichen ' Moderne ${ }^{17}$ besonders relevant sind: die Unterscheidung zwischen innerer und äußerer Natur sowie die Unterscheidung zwischen erster und zweiter Natur bzw. zwischen Natur und Gesellschaft. Die analytischen Differenzierungen in Bezug auf die Konstruktionen von Natur und Gesellschaft ermöglichen die Beobachtung von Verschiebungen in den Natur- und Gesellschaftskonstruktionen. Diese in der Gesellschaft vorgenommenen Verschiebungen und ihre legitimatorischen und normativen Dimensionen stehen letztlich im Fokus konstruktivistischer Analysen. Die folgenden Abschnitte bereiten somit die Beantwortung der Ausgangsfrage des Kapitels vor, was es bedeutet, die ökologische Krise aus konstruktivistischer Perspektive in den Blick zu nehmen.

\section{Die Unterscheidung zwischen innerer und äußerer Natur}

Eine für Gesellschaften wichtige Unterscheidung ist die zwischen , uns ' - den Mitgliedern der Kommunikationsgemeinschaft - und ,den Anderen'. Diese Unterscheidung wurde und wird in unterschiedlichen Raum-Zeit-Kontexten ganz verschieden getroffen. In der ,westlichen“ Moderne wird in dem Zusammenhang gemeinhin

15 Die Akteur-Netzwerk-Theorie geht auf Bruno Latour zurück. Latour vertritt die These, dass die Unterscheidung zwischen Natur und Gesellschaft erst in der Moderne getroffen wird und plädiert für die Überwindung des Dualismus (vgl. Latour 2001).

16 Als normative Begründung verweist Gill auf die Notwendigkeit der Unterscheidung zwischen Natur und Gesellschaft für die Konstitution eines verantwortungsbewussten Subjekts, an das die Frage nach der sozial-ökologischen Gestaltung von Lebensweisen adressiert werden kann (vgl. Gill 1998: 237ff).

17 Der in dieser Arbeit vorherrschende Fokus auf Prozesse in Ländern des globalen Nordens spiegelt die Machtverhältnisse in der internationalen Politik wider. $\mathrm{Zu}$ der mit diesem Fokus einhergehenden Gefahr der analytischen Verdopplung von Hegemonie vgl. die Reflexionen zu Beginn des dritten Kapitels. 
zwischen einer inneren Natur des Menschen (worunter beispielsweise seine organische Konstitution, aber auch sein Bewusstsein sowie unbewusst ablaufende psychische Prozesse gefasst werden) und einer ihn umgebenden äußeren Natur (z. B. Pflanzen, Tiere, leblose Dinge) unterschieden (vgl. Gill 1998: 225ff). Diese Unterscheidung ist keineswegs absolut. Oftmals wird auch die Gemeinsamkeit des ,Natürlichen' bzw. des ,Organischen' betont. Weiterhin sind die exakten Kriterien der Unterscheidung nicht unumstritten. Als Unterscheidungskriterien werden bestimmte Attribute angeführt, die nur der inneren Natur des Menschen zugesprochen werden, wie beispielsweise Reflexionsvermögen, Vernunft, freier Wille oder Seele. Dennoch kann man - innerhalb eines bestimmten Raum-Zeit-Kontextes wohlgemerkt - phänomenologisch eine mehr oder weniger klare Unterscheidung beobachten.

Helmuth Plessner sieht als Bedingung der Möglichkeit, zwischen der inneren und der äußeren Natur unterscheiden zu können, eine dem Menschen eigene spezifische Vollzugsmodalität (für den gesamten Absatz vgl. Plessner 1975: 288ff). Den Vollzug seiner Grenze zum Umfeld sieht Plessner durch die exzentrische Positionalität des Menschen charakterisiert. Damit ist gemeint, dass zwar der physischpsychische Körper des Menschen wie der des Tieres ist. Das Tier ist durch eine zentrische Positionalität gekennzeichnet, da seine Beziehung zur Außenwelt über sein Zentralorgan verläuft, in dem die äußeren Reize verarbeitet werden. Auch der Mensch verarbeitet die äußeren Reize über sein Zentralorgan, ist allerdings im Gegensatz zum Tier dazu in der Lage, seine Organisationsform zu reflektieren. Sein Zentrum kann in Distanz zu sich stehen und sich beobachten. Die menschliche Positionalität ist damit, ohne die Zentrierung durchbrechen zu können, exzentrisch. Vom Blickpunkt außerhalb des Körpers erkennt sich der Mensch als Mensch, d. h. er erkennt seine exzentrische Positionalität (vgl. Plessner 1975: 343).

Plessners Aussage, dass der Mensch ein geschichtsbedingtes und geschichtsbedingendes Wesen ist, relativieren seine eigenen anthropologischen Annahmen, die nicht unabhängig von historischen Konstellationen $\mathrm{zu}$ denken sind (vgl. Plessner 1981: 182). Der homo absconditus (vgl. Plessner 1983), der verborgene Mensch, ist gezwungen, sich stets neu zu erfinden, sein Leben auf eine bestimmte Art und Weise zu führen (vgl. Plessner 1975: 309f). Dazu gehören elementar die gesellschaftlichen Aushandlungen über die Grenzziehungen zwischen ,uns ' und ,den Anderen“. Diese Grenzziehungen werden stets neu artikuliert und können nur partiell und temporär durch Hegemoniepraktiken fixiert werden. ${ }^{18}$

18 Ein besonders prominentes Beispiel für den umkämpften Charakter der Unterscheidung zwischen der inneren und der äußeren Natur ist die Artikulation des universellen Anspruchs der Menschenrechte. Zur Begründung des Gleichheitspostulats wird ,die Natur 
Die Unterscheidung zwischen erster und zweiter Natur bzw. zwischen Natur und Gesellschaft

Eine weitere wichtige Unterscheidung ist die zwischen erster Natur und zweiter Natur. Dabei gilt die erste Natur als ursprünglich, die zweite Natur als vom Menschen hergestellt. In Bezug auf die innere Natur des Menschen präzisiert Gill erste Natur als „,prähistorische bzw. angeborene Menschennatur“ und zweite Natur als „Habitus, Traditionen, Sozialstruktur“ (Gill 1998: 233). In Bezug auf die äußere Natur bezeichnet Gill die erste Natur als ,unberührte Natur“ und die zweite Natur als „,domestizierte Natur, technische Artefakte“ (vgl. Gill 1998: 233). In den Gesellschaften wird auf unterschiedliche Weise zwischen erster und zweiter Natur unterschieden. Dabei wird erste Natur oftmals rein negativ - als das Andere des vom Menschen geschaffenen Bereichs der Gesellschaft - gedeutet. Umgekehrt gilt Gesellschaft als das Andere der unberührten Natur. Die konkrete inhaltliche Füllung dieser Unterscheidung ist von Mehrdeutigkeiten gekennzeichnet und bedarf der stetigen (Re-)Konstruktion. Die diesbezüglichen gesellschaftlichen Aushandlungen verlaufen anhand verschiedener Begriffspaare wie Natur-Kultur, Natur-Zivilisation, Natur-Technik usw. (vgl. Schiemann 2004: 72ff). In diesen Aushandlungsprozessen werden bestimmte Deutungs- und Handlungsmuster gesellschaftlich verankert und institutionalisiert - wenn auch nur partiell und vorübergehend.

Die Übergangsbereiche und die Schwierigkeiten der Unterscheidung stehen in wissenschaftlichen Arbeiten im Fokus (vgl. Schiemann 2004: 61). Aus sozialwissenschaftlicher Perspektive erfolgt der Übergang von erster zu zweiter Natur durch komplexe Prozesse menschlichen Handelns. Insofern wird nicht von einer absoluten Grenze zwischen erster und zweiter Natur, sondern von fließenden Übergängen ausgegangen. Die Prozesse der Umwandlung werden gemeinhin als gesellschaftliche Prozesse bezeichnet. Das Ergebnis dieser Umwandlungsprozesse, die zweite Natur, bildet die Gesellschaft. Somit stellt die Umwandlung von erster in zweite Natur eine Bedingung für Gesellschaft dar.

des Menschen“ mit ,Vernunft‘ gleichgesetzt, die wiederum der außermenschlichen Natur abgesprochen wird. Dieses Begründungsmuster war stets prekär und ist es bis heute geblieben. So wird auch Tieren, Pflanzen oder Dingen Vernunft zugesprochen, woraus teilweise die Forderung nach einer Ausweitung der Menschenrechte abgeleitet wird. Umgekehrt kommt es immer wieder zur Artikulation vermeintlich ,natürlicher Unterschiede“ zwischen Menschen. Im Recht spielen insbesondere Unterscheidungen bezüglich der Vernunftfähigkeit eine Rolle. Die Menschenrechte werden dabei mit Verweis auf die Potenzialität allen Menschen zugestanden - auch wenn diese noch nicht oder nicht mehr ,vernünftig' sein können. Allerdings gibt es im Zivil- und Strafrecht sehr wohl Abstufungen der Geschäfts- und Schuldfähigkeit, beispielsweise bei Kindern (vgl. Gill 1998: 227). 
Ulrich Brand und Christoph Görg präzisieren diese Annahme in Bezug auf die äußere Natur. Sie argumentieren, dass Gesellschaft notwendigerweise auf einen Stoffwechsel mit der Natur angewiesen ist, da in gesellschaftlichen Prozessen immer materiell-stoffliche Elemente der äußeren Natur eingehen (vgl. Brand/Görg 2003: 17). Auf dieser basalen Ebene der physikalisch-chemischen Umwandlung von Stoffen findet also immer Naturaneignung - die Umwandlung von erster in zweite Natur - statt.

In Bezug auf die innere Natur des Menschen betonen Peter L. Berger und Thomas Luckmann, dass der Mensch notwendigerweise sich selbst schaffen muss (für den gesamten Absatz vgl. Berger/Luckmann 2004: 49ff). Sie greifen dabei auf Aussagen der philosophischen Anthropologie zurück. Mit Verweis auf die Arbeiten von Arnold Gehlen und Helmuth Plessner gehen sie davon aus, dass der Mensch aufgrund seiner ,Instinktarmut' der Formung durch gesellschaftliche Institutionen bedarf. Die ,Weltoffenheit des Menschen' muss durch die Schaffung von Habitualisierungen und Institutionen ausgeglichen werden. Diese Umwandlung der ersten in zweite Natur ist dabei notwendigerweise immer eine gesellschaftliche Produktion. Nicht nur die Psyche, sondern auch der physische Organismus des Menschen entwickelt sich nach der Geburt weiter, während er schon im Austausch mit seiner Umwelt steht. Diese Umwelt wiederum ist das Ergebnis permanenter gesellschaftlicher (Re-)Produktion. Die gesellschaftliche Produktion der menschlichen Welt basiert auf der intersubjektiven Schaffung von gemeinsamen Deutungs- und Handlungsmustern, von Institutionen. Berger und Luckmann denken also die Beziehung zwischen dem Menschen und der Gesellschaft als ein Wechselverhältnis. Menschen als Kollektivgebilde schaffen die gesellschaftliche Welt und werden gleichzeitig von dieser geschaffen (vgl. Berger/Luckmann 2004: 65).

Die Annahme der Produktion von Subjekten durch die Gesellschaft verweist auf den ,objektiven' Charakter der zweiten Natur. Die intersubjektive Schaffung von Institutionen ist ein Prozess der Vergegenständlichung, der Objektivation. Institutionen treten dem Individuum als objektive Faktizität gegenüber. ${ }^{19}$ Insofern wird eine institutionalisierte Welt (zweite Natur) als objektive Wirklichkeit erlebt. Damit geht ein Kontrollcharakter von Institutionen einher, wie Berger und Luckmann deutlich machen:

19 Somit ist es sinnvoll, nicht nur von einer physischen, sondern auch von einer sozialen Materialität zu sprechen. Materialität in diesem Sinne würde sowohl die innere als auch die äußere erste und zweite Natur umfassen. Die Prozesse der Verstetigung und Verflüssigung von zweiter Natur würden allerdings nicht in den Bereich der Materialität fallen. Dies kann nur eine analytische Unterscheidung bleiben, denn empirische Phänomene weisen immer sowohl einen fluiden als auch einen verstetigten Anteil auf. 
„Durch die bloße Tatsache ihres Vorhandenseins halten Institutionen menschliches Verhalten unter Kontrolle. Sie stellen Verhaltensmuster auf, welche es in eine Richtung lenken, ohne ,Rücksicht' auf die Richtungen, die theoretisch möglich wären. Dieser Kontrollcharakter ist der Institutionalisierung als solcher eigen. Er hat Priorität vor und ist unabhängig von irgend welchen Zwangsmaßnahmen, die eigens zur Stütze einer Institution eingesetzt werden oder worden sind.“ (Berger/Luckmann 2004: 58f)

Diese Annahmen über Institutionen und Prozesse der Objektivation entsprechen der in Kapitel 2.1 eingeführten Vorstellung von Hegemonie, die als aktiv hergestellter Konsens alternative Diskurse marginalisiert. Institutionen haben aufgrund ihrer Faktizität (ihrer hegemonialen Position) Macht über das Individuum. Darüber hinaus werden sie gesellschaftlich legitimiert (durch Hegemoniepraktiken universalisiert) und mit Kontrollmechanismen ausgestattet (vgl. Berger/Luckmann 2004: 64f). Gerade deshalb betonen Berger und Luckmann, dass wir uns immer wieder ins Bewusstsein rufen müssen, ,daß die Gegenständlichkeit der institutionalen Welt, so dicht sie sich auch dem Einzelnen darstellen mag, von Menschen gemachte, konstruierte Objektivität ist“" (Berger/Luckmann 2004: 64). Diese Auffassung von Hegemonie bildet die Voraussetzung für intendierte dekonstruktive Prozesse der Verflüssigung von gesellschaftlicher Objektivität. Es gilt also, den gesamten Kreislauf der permanenten Umwandlung von erster in zweite Natur in den Blick zu nehmen: „Gesellschaft ist ein menschliches Produkt. Gesellschaft ist eine objektive Wirklichkeit. Der Mensch ist ein gesellschaftliches Produkt." (Berger/Luckmann 2004: 65; Hervorhebung im Original)

Verschiebungen zwischen innerer und äußerer sowie zwischen erster und zweiter Natur

Im Zusammenhang mit dem objektiven Charakter der zweiten (inneren und äußeren) Natur steht die Frage nach (der Einschätzung) ihrer Beeinflussbarkeit. Auch in Bezug auf die erste (innere und äußere) Natur wird die intentionale Beeinflussbarkeit je nach Kontext und Subjektposition unterschiedlich eingeschätzt. Die Grenze zwischen dem Gegebenen und dem Beeinflussbaren wird stets neu gezogen, sie ist nicht statisch, sondern wird in jeder Handlungssituation neu hergestellt (vgl. Gill 1998: 233).

„Ob eine zunächst gegebene stoffliche Struktur, ursprünglich oder bereits hergestellt, ob ein zunächst gegebenes (institutionelles) Verhaltensmuster, instinktiver oder doch eher konventioneller Art, als unabänderlich hingenommen oder als beeinflußbar angesehen wird, das hängt vom Handlungswillen und vom Handlungsvermögen des relevanten Akteurs ab.“ (Gill 1998: 233f) 
Somit entsteht ein - von den als gegeben angesehenen festen Strukturen (erster und zweiter Natur) nicht klar getrennter, sondern durchlässiger - Bereich von beeinflussbaren Stoffqualitäten und Handlungsweisen. In Bezug auf ihre (zugeschriebene und tatsächliche) Beeinflussbarkeit weisen innere und äußere Natur ähnliche Eigenschaften auf. Ihre diesbezügliche Ähnlichkeit trägt zur Verwischung der Unterscheidung von innerer und äußerer Natur bei. Darüber hinaus besteht zwischen technischen Artefakten und Sozialstrukturen ein wechselseitiges Stützungsverhältnis, das die analytische Unterscheidung zusätzlich erschwert (vgl. Gill 1998: 233f). So kommt es zur Vermischung von gesellschaftlichen Traditionen und stofflicher Natur. Alltagssprachlich wird mit dem Adjektiv ,natürlich“ „schlicht auf Gegebenes und daher vermeintlich nicht Begründungspflichtiges [verwiesen; T. K.], gleichgültig ob es sich um ursprüngliche stoffliche Strukturen oder hergestellte stoffliche Strukturen oder um gesellschaftliche Strukturen handelt" (Gill 1998: 233; Hervorhebungen im Original).

Neben dieser Vermischung von innerer und äußerer Natur finden auch Verschiebungen zwischen erster und zweiter Natur sowie zwischen nicht beeinflussbaren und beeinflussbaren Bereichen statt - und zwar sowohl in faktischer als auch in definitorischer Hinsicht. In faktischer Hinsicht kommt es grundsätzlich durch die Umwandlung von erster in zweite Natur zu Verschiebungen. Darüber hinaus unterliegen sowohl erste als auch zweite Natur durch ihren permanenten Einbezug in Handlungssituationen einer stetigen, wenn auch oft minimalen, Veränderung. Die permanente (Re-)Produktion von Natur in sozialen Praktiken impliziert zwangsläufig Wandlungsprozesse. In definitorischer Hinsicht werden Verschiebungen von dem Bereich der als nicht beeinflussbar geltenden Natur in den Bereich der als beeinflussbar geltenden Phänomene vorgenommen und vice versa. Die Verschiebung von stofflichen oder sozialen Strukturen und Verhaltensweisen in den Bereich der nicht beeinflussbaren Natur fasst Gill als Naturalisierung. Da Naturalisierungen immer auch Handlungen oder Unterlassungen sowie unerwünschte Handlungsfolgen rechtfertigen - durch den Verweis auf deren Alternativlosigkeit bzw. auf die Ohnmacht von Akteur_innen - verwendet er auch den Begriff der , legitimatorischen Diskurse‘ (vgl. Gill 1998: 234f). Ich würde in dem Zusammenhang nicht von Diskursen, die ich auf einer höheren Abstraktionsebene ansiedele, sondern von legitimierenden Effekten sprechen. Die umgekehrte Verschiebung von Phänomenen in den Bereich des Beeinflussbaren bezeichne ich als De-Naturalisierung. Die damit verbundenen Verweise auf mögliche Alternativen bzw. auf die Wirkmächtigkeit von Akteur_innen stellen immer auch Handlungen oder Unterlassungen in Frage, insbesondere bei unerwünschten Handlungsfolgen. Insofern könnte man bei denaturalisierenden sozialen Praktiken von delegitimierenden Effekten sprechen. 
Neben dieser legitimatorischen Dimension beinhalten Unterscheidungen zwischen nicht beeinflussbarer Natur auf der einen und dem beeinflussbaren Bereich auf der anderen Seite auch eine normative Dimension. Die normative Dimension gibt eine Antwort auf die Frage, ob Ursprüngliches oder Hergestelltes verändert werden darf bzw. verändert werden soll. So gehen Praktiken des Naturschutzes, des Denkmalschutzes oder der Traditionspflege von der Veränderbarkeit bestimmter als schützenswert betrachteter - Phänomene aus, weshalb sie aktiv versuchen, Wandlungsprozesse zu unterbinden. Umgekehrt können soziale Praktiken darauf zielen, die Veränderung bestimmter Phänomene, die als schädlich, hässlich oder negativ gelten, anzustreben (vgl. Gill 1998: 235).

Die konstruktivistische Perspektive auf die gesellschaftlichen Unterscheidungen zwischen Natur und Gesellschaft

Um auf die Ausgangsfrage zurückzukommen, was es bedeutet, die ökologische Krise aus konstruktivistischer Perspektive in den Blick zu nehmen, fasse ich die bisherigen Ausführungen kurz zusammen. Sozialen Handlungen liegen ganz verschiedene Unterscheidungen zugrunde: zwischen innerer und äußerer Natur, zwischen erster und zweiter Natur (bzw. Gesellschaft) sowie zwischen beeinflussbaren und nicht beeinflussbaren Phänomenen. Diese Unterscheidungen haben immer eine legitimatorische und eine normative Dimension. Die Art und Weise wie zwischen Natur und Gesellschaft unterschieden wird und welche (de-)legitimierenden Effekte und normativen Forderungen damit verknüpft sind, ist entscheidend für Gesellschaftsordnungen im Allgemeinen und die gesellschaftlichen Reaktionen auf die ökologische Krise im Besonderen. Der Beitrag einer konstruktivistischen Perspektive für die Analyse der ökologischen Krise besteht dementsprechend darin, die in der Gesellschaft getroffenen Unterscheidungen in Bezug auf ihre Implikationen und Konsequenzen zu analysieren.

\subsubsection{Die ökologische Krise aus diskurstheoretischer Perspektive}

Nachdem ich allgemein in die konstruktivistische Perspektive auf die ökologische Krise eingeführt habe, stelle ich im Folgenden den Ansatzpunkt der diskurstheoretischen Hegemonieanalyse dar - vor allem im Hinblick auf die legitimatorischen und normativen Dimensionen der Unterscheidungen von Natur und Gesellschaft. Die Grundannahme einer kontingenten Gesellschaft, deren Ordnung permanent durch die Hegemoniepraktiken miteinander konkurrierender Hegemonieprojekte (re-)produziert wird, bestimmt den Blick der diskurstheoretischen Hegemonieanalyse auf Natur und Gesellschaft. 
In der hier vertretenen Forschungsperspektive wird davon ausgegangen, dass das Verhältnis zwischen Natur und Gesellschaft in gesellschaftlichen Auseinandersetzungen hergestellt wird und somit hegemonial strukturiert ist. Damit ist weder gemeint, dass es Natur außerhalb sozialer Praktiken nicht gäbe, noch, dass soziale Praktiken Natur beliebig formen könnten. Die Annahme ist schlicht, dass es verschiedene Möglichkeiten der Gestaltung des Verhältnisses von Natur und Gesellschaft gibt und dass die jeweils dominante Art und Weise der Naturaneignung ein Ergebnis gesellschaftlicher Auseinandersetzungen ist. In Bezug auf die legitimatorische Dimension der Unterscheidung zwischen Natur und Gesellschaft nimmt die diskurstheoretische Hegemonieanalyse damit tendenziell eine denaturalisierende Perspektive ein. Wie alle konstruktivistischen Theorien eignet sie sich zur Dekonstruktion vermeintlich unberührter oder angeborener (erster) Natur als gesellschaftlich produzierte (zweite) Natur. Im Fokus der dekonstruktivistischen Forschungsarbeit stehen die gesellschaftlichen Prozesse der Vergegenständlichung und der Naturalisierung. Diese werden als konfliktbehaftete Aushandlungsprozesse verstanden. Gesellschaften und ihr Verhältnis zur Natur erscheinen damit als prinzipiell veränderbar und ihre historische Gestalt durch bestimmte Diskurse geschaffen. Insofern hat diese Perspektive tendenziell delegitimierende Effekte in Bezug auf die Unterscheidung von Natur und Gesellschaft. ${ }^{20}$

20 Allerdings ist mit dieser theoretischen Perspektive auch eine Skepsis gegenüber den Handlungsspielräumen (im Sinne einer intendierten Veränderung gesellschaftlicher Strukturen) von Akteur_innen verbunden. Die Annahme einer kontingenten Gesellschaftsordnung, die durch Diskurse strukturiert wird, hat ein komplexes Verständnis von Subjekt und Struktur zur Folge. Subjekte (re-)produzieren die Strukturierung durch Diskurse, indem sie ihre partikularen Interessen in Diskurse einschreiben, bestimmte Hegemonieprojekte vorantreiben usw. Umgekehrt ermöglichen und beschränken Diskurse bestimmte soziale Praktiken (vgl. Laclau/Mouffe 2001: 113f). Akteur_innen werden also von Diskursen geprägt und nehmen Subjektpositionen ein. Diese führen sie allerdings nicht mechanisch, sondern aktiv aus, wodurch wiederum Veränderungen der Diskurse ausgelöst werden. Gerade aufgrund der Prekarität der Strukturierung, der Risse und Brüche der Diskurse sowie der Hybridität der Konsense, ergeben sich Gestaltungsspielräume für Subjekte (vgl. Bedall 2014: 50). Diese Gestaltungsspielräume wiederum können nicht unabhängig von ihrem strategisch-selektiven Kontext betrachtet werden (vgl. Wullweber 2010: 79). Die Gesellschaft als kontingent zu verstehen meint somit, weder von einer Zufälligkeit (was einer Abwesenheit von Struktur gleich käme) noch von einer Notwendigkeit (im Sinne einer kompletten Determinierung) sozialen Handelns auszugehen (vgl. Wullweber 2010: 63). 
Was die normative Dimension der Unterscheidung von Natur und Gesellschaft betrifft, so geht die diskurstheoretische Hegemonieanalyse davon aus, dass die Prozesse der Verstetigung und Verflüssigung der zweiten Natur notwendigerweise konflikthaft und machtgeprägt sind. Eine wie auch immer geartete konfliktlose und in keinerlei Hinsicht exkludierende Organisationsweise von Gesellschaft ist aus diskurstheoretischer Perspektive nicht denkbar. Der dekonstruktivistische Ansatz zielt also darauf, die Genese der aktuellen Diskursorganisationen und die in ihr eingeschriebenen partikularen Interessen herauszuarbeiten. Auf dem Prüfstand steht die historisch geronnene Organisation von Gesellschaft, die als kontingent, d. h. als eine Möglichkeit neben anderen, reflektiert wird. Darauf können normative Vorstellungen von Verflüssigung, von (Re-)Politisierung und gegenhegemonialen Projekten aufbauen. Die konkreten normativen Orientierungen können allerdings nicht aus der Diskurstheorie abgeleitet werden, sondern gelten als politische Entscheidungen.

Die Stärke der diskurstheoretischen Hegemonieanalyse für die Betrachtung sozial-ökologischer Phänomene liegt m. E. darin, dass sie die gesellschaftlichen Konstruktionen von Natur und Gesellschaft und damit die Auseinandersetzungen um die Verschiebungen zwischen Natur und Gesellschaft in den Blick nimmt. Dies ist zentral für die Analyse der ökologischen Krise, die erst mit der Durchsetzung einer denaturalisierenden Perspektive auf ökologische Probleme zu einer Krise mit delegitimierenden Effekten wurde. Schließlich liegt der Grund für die Politisierung der gesellschaftlichen Naturverhältnisse als ökologische Krise in der Etablierung einer dreifachen Problematisierung: Erstens wird davon ausgegangen, dass die aktuellen Umweltprobleme gesellschaftlich relevant sind. Zweitens beinhaltet die Krisendiagnose die Annahme, dass ökologische Probleme zunehmend gesellschaftlich verursacht werden. Daraus folgt drittens, dass die herkömmlichen Institutionen und Strukturen in ihrer jetzigen Form nicht angemessen auf die ökologischen Probleme reagieren können (vgl. Brand 2010: 143). Das Festhalten am business as usual wird damit delegitimiert. In Bezug auf den Klimawandel zeigt sich die dreifache Problematisierung wie folgt: Erstens wird davon ausgegangen, dass der Klimawandel eine ernst zunehmende Bedrohung darstellt, die gesellschaftlich bearbeitet werden muss. Zweitens gilt der Klimawandel als anthropogen verursacht. Drittens wird daraus geschlussfolgert, dass der Klimawandel von den bestehenden Strukturen nicht reibungslos bearbeitet werden kann. Diese dreifache Problematisierung und die damit verknüpfte offene Frage nach der ,richtigen“ Reaktion auf die ökologische Krise zieht politische Aushandlungsprozesse nach sich. Für die Analyse dieser konflikthaften Aushandlungsprozesse eignet sich die diskurstheoretische Hegemonieanalyse. Allerdings hat die diskurstheoretische Hegemonieanalyse als allgemeine Gesellschaftstheorie kein spezifisches Konzept für die Bearbeitung sozial- 
ökologischer Forschungsfragen. Ein derartiges Konzept wäre aber hilfreich, um den Besonderheiten der äußeren Natur als Untersuchungsgegenstand gerecht zu werden.

Angesichts der drängenden Beschäftigung mit der ökologischen Krise ist es zentral, die Relevanz der äußeren Natur für gesellschaftliche Prozesse anzuerkennen. In der Tendenz fokussieren die Sozialwissenschaften auf die Prozesse der (Re-)Konstruktion der inneren Natur, weshalb sie lange Zeit nicht adäquat auf die gesellschaftlichen Herausforderungen durch die ökologische Krise reagierten (zur Kritik vgl. Brand/Görg 2003: 16f; Görg 2003a: 9ff; Jahn/Wehling 1998: 75ff). Insofern plädiere ich dafür, der ökologischen Krise als Untersuchungsgegenstand einen besonderen Stellenwert einzuräumen und die äußere Natur, auch was das Analyseinstrumentarium betrifft, nicht außer Acht zu lassen. In dieser Hinsicht hat es bereits verschiedene Versuche gegeben, an die es anzuknüpfen gilt (vgl. Jahn/Wehling 1998: 78ff). Die Ignoranz gegenüber ökologischen Themen steht - insbesondere in modernisierungstheoretischen Ansätzen - teilweise im Zusammenhang mit einem Optimismus bezüglich der Gestaltung der äußeren Natur nach menschlichen Wunschvorstellungen (vgl. Brand/Görg 2003: 17). Dabei geht die Aufmerksamkeit für das Scheitern von Konstruktionsprozessen verloren. Gerade die ökologische Krise zeigt jedoch, wie wichtig es ist, destabilisierende Momente und nichtintendierte Folgen von Konstruktionsprozessen in die Analyse mit einzubeziehen. Dafür braucht es theoretische Begriffe, mit denen die Momente der Widerständigkeit und Unverfügbarkeit der Natur sowie deren Auswirkungen auf die Auseinandersetzungen um die Fundierung der Gesellschaftsordnung in den Blick geraten (vgl. Gill 1998: 246; Jahn/Wehling 1998: 77). Um den genannten Herausforderungen begegnen zu können, welche die sozialwissenschaftliche Beschäftigung mit der ökologischen Krise mit sich bringt, werde ich im Folgenden das Konzept der gesellschaftlichen Naturverhältnisse in meine Forschungsperspektive integrieren.

\subsubsection{Das Konzept der gesellschaftlichen Naturverhältnisse}

Bei der Darstellung des Konzepts der gesellschaftlichen Naturverhältnisse orientiere ich mich an Görgs Ausarbeitungen. Görgs Ansatz eignet sich m. E. besonders gut zur Integration in die Forschungsperspektive der diskurstheoretischen Hegemonieanalyse, da er auf die historische Genese gesellschaftlicher Phänomene fokussiert. Damit stehen Gestaltungsspielräume, strukturelle Zwänge, Macht- und Herrschaftsverhältnisse sowie konflikthafte Aushandlungsprozesse im Mittelpunkt des Erkenntnisinteresses. ${ }^{21}$

21 Alternativ wäre eine Orientierung an den ähnlich gelagerten Arbeiten des Instituts für sozial-ökologische Forschung mögliche gewesen. Allerdings fokussieren diese auf vitale 
Görg erarbeitet das Konzept der gesellschaftlichen Naturverhältnisse im Rückgriff auf die klassische Kritische Theorie. Dabei bezieht er sich insbesondere auf die „Dialektik der Aufklärung“ (Horkheimer/Adorno 2009) und auf verschiedene andere Schriften von Theodor W. Adorno. Das Konzept der gesellschaftlichen Naturverhältnisse bildet den zentralen Ansatzpunkt seiner „kritischen Theorie der ökologischen Krise“ (Görg 2003a). Seine Überlegungen zu den Vermittlungsverhältnissen von Individuum, Gesellschaft und Natur zielen letztlich ,auf die Kritik eines dominanten Paradigmas von Naturbeherrschung, das zwar mit der Erosion des Berechenbarkeitsglaubens heute seinen Gehalt gewandelt hat, aber in veränderter Form und strukturell verankert in gesellschaftlichen Herrschaftsverhältnissen (insbesondere in geschlechtsspezifischen, aber auch in ökonomischpolitischen) nach wie vor als Grenze von Gestaltungsfähigkeit auftritt“" (Görg 2003a: 21f).

Ausgangspunkt des Konzepts der gesellschaftlichen Naturverhältnisse ist die notwendige Verschränkung von Individuum, Gesellschaft und Natur. In der klar abgrenzbaren Reinform sind die Begriffe ,Individuum', ,Gesellschaft‘ und ,Natur' als analytische Konstrukte zu verstehen. Tatsächlich stehen Individuum, Gesellschaft und Natur in unhintergehbaren Vermittlungsverhältnissen (vgl. Görg 2003a: 34ff). Die Art und Weise ihrer Gestaltung hat unterschiedliche Grade an Freiheit bzw. Herrschaft zur Folge. Freiheit fasst Görg dabei als Reflexionsvermögen über die Vermittlungsverhältnisse. Herrschaft bedeutet im Umkehrschluss die Einschränkung dieser Reflexion durch dominante Deutungs- und Handlungsschemata bzw. die Unterbindung von Reflexion durch die Leugnung von Abhängigkeit.

Grundbedürfnisse des Menschen und basale gesellschaftliche Naturverhältnisse, die ,sowohl für die individuelle als auch für die gesellschaftliche Reproduktion und Entwicklungsfähigkeit unverzichtbar sind“ (Becker/Hummel/Jahn 2011: 78). Auf diesen basalen gesellschaftlichen Naturverhältnissen basiert ihre normative Orientierung der Regulierung der Naturverhältnisse, so „dass alle Menschen ihre Grundbedürfnisse befriedigen können“ (Becker/Hummel/Jahn 2011: 79). Diese Schwerpunktsetzung mag sinnvoll sein, um transdisziplinäre und angewandte Forschung zu ermöglichen (vgl. Becker/Hummel/ Jahn 2011: 78ff). Aus einer diskurstheoretischen Perspektive stellt der Ansatz aber eine verkürzte Reflexion der Kontingenz des Vermittlungszusammenhangs von Mensch, Gesellschaft und Natur dar. Diesbezüglich betont auch Görg, dass es keine Trennung zwischen ,notwendiger' bzw. ,natürlicher' auf der einen und ,dekadenter' bzw. ,künstlicher Naturaneignung auf der anderen Seite geben kann. Stattdessen gilt es, in Bezug auf das Verhältnis zur Natur scheinbare Sachzwänge und Notwendigkeiten als historische Ergebnisse hegemonialer Aushandlungsprozesse zu erkennen und Potenziale gesellschaftlicher Freiheit auszuloten (vgl. Görg 2003a: 42f; Görg 2003b: 119f). 
„In der Konstellation dieser drei Momente [Naturbeherrschung, soziale Herrschaft und Herrschaft im Subjekt; T. K.] kann also ein Grundmodell von Herrschaft in der Erlangung und Durchsetzung von Selbstständigkeit gesehen werden, sofern diese durch die Verleugnung von Abhängigkeit erkauft wird.“ (Görg 2003a: 36f, Hervorhebungen im Original)

Dieses Verständnis von Herrschaft und Freiheit wird in der folgenden Diskussion des Konzepts der gesellschaftlichen Naturverhältnisse aufgegriffen werden. Im Sinne einer Einführung in das Konzept stelle ich zunächst die Grundannahmen und zentralen Begriffen dar. Abschließend fasse ich die Aspekte zusammen, die für die Integration des Konzepts in die Forschungsperspektive der diskurstheoretischen Hegemonieanalyse besonders relevant sind.

\section{Die Nichtidentität der Natur}

Ausgangspunkt des Konzepts der gesellschaftlichen Naturverhältnisse ist die Annahme, dass sich die ökologische Krise von anderen gesellschaftlichen Herausforderungen unterscheidet, weil die Natur besondere Eigenschaften besitzt (für den gesamten Absatz vgl. Görg 2003a: 41; Görg 2003b: 123). Es bedarf eines elaborierten Begriffs von Natur, um ihren Eigensinn in den Blick zu bekommen, der sich insbesondere beim Scheitern gesellschaftlicher Konstruktionsprozesse - in der ökologischen Krise - zeigt. Diese Besonderheit bezeichnet Görg als Nichtidentität der Natur. Die Akzeptanz der Nichtidentität der Natur bedeutet die Anerkennung der Natur als Anderes, d. h. der Einsicht, dass Natur im Menschen und in der Gesellschaft ist, ohne mit ihr identisch zu sein. Natur wird somit als eine dem Menschen fremde (äußere wie innere) Bedingung seiner Existenz gefasst. Der Begriff der Nichtidentität steht für die Reflexion darüber, dass Natur in allen sozialen Prozessen involviert ist und dieses Implikat immer auch Momente der Unverfügbarkeit und Widerständigkeit behält.

\section{Naturaneignung}

Natur ist in allen sozialen Praktiken involviert, ,weil in den gesellschaftlichen Prozess immer materiell-stoffliche Elemente eingehen und dieser damit auf den Stoffwechsel mit der Natur angewiesen ist" (Brand/Görg 2003: 17). Auf dieser basalen Ebene kann die Gesellschaft ,aus den Abhängigkeiten im Verhältnis zur Natur grundsätzlich nicht entkommen“ (Brand/Görg 2003: 17). Insofern gibt es immer eine gesellschaftliche Gestaltung des Verhältnisses von Mensch und Natur, die beispielsweise die Art und Weise der physikalisch-chemischen Umwandlung von Stoffen sowie deren Verteilung und Konsumtion betreffen. Diese Gestaltung bezeichnet Görg als Naturaneignung (für den gesamten Absatz vgl. Görg 2003a: 42f; Görg 2003b: 119f). Auch wenn Naturaneignung eine gesellschaftliche Notwendigkeit ist, 
so unterliegt ihre konkrete Form doch immer spezifischen Deutungen und Praktiken, die gesellschaftlich konstruiert werden. Fasst man also die je spezifische Form der Naturaneignung als gesellschaftliches Produkt, geraten zwangsläufig Gestaltungsspielräume in den Blick. Es kann dabei keine Trennung zwischen , notwendiger' bzw. ,natürlicher' auf der einen und ,dekadenter' bzw. ,künstlicher' Naturaneignung auf der anderen Seite geben, denn dies würde eine Naturalisierung des gesellschaftlichen Verhältnisses zur Natur bedeuten. Stattdessen gilt es, in Bezug auf das Verhältnis zur Natur scheinbare Sachzwänge und Notwendigkeiten als historische Ergebnisse gesellschaftlicher Aushandlungen zu erkennen und Potenziale gesellschaftlicher Freiheit auszuloten.

\section{Die falsche Alternative}

In den Auseinandersetzungen um die Gestaltung der Naturaneignung herrscht laut Görg eine ,falsche Alternative“ vor (für den gesamten Absatz vgl. Görg 2003a: 41ff). Mit der falschen Alternative sind die Forderungen nach Unterordnung unter eine vermeintliche Ordnung der Natur bzw. nach Unterwerfung der Natur gemeint. In beiden Fällen wird eine bestimmte Deutung des Mensch-Natur-Verhältnisses festgeschrieben und die Kontingenz der Vermittlung geleugnet. Im ersten Fall werden Naturgesetze proklamiert, welche die Ausgestaltung der Gesellschaft bestimmen sollen. Damit werden Notwendigkeiten geschaffen und die prinzipielle Gestaltbarkeit gesellschaftlicher Naturverhältnisse negiert. Diese Naturalisierung leugnet das Vermittlungsverhältnis von Natur und Gesellschaft und schreibt einen bestimmten Zustand gesellschaftlicher Naturverhältnisse fest. Damit wird die historische Genese der gesellschaftlichen Naturverhältnisse unterschlagen und die Reflexion über ihre Gestaltung eingeschränkt. Im zweiten Fall wird die Nichtidentität der Natur als Existenzbedingung für Gesellschaft geleugnet. Infolgedessen wird eine Kontrolle, eine Unterwerfung der Natur angestrebt. Diesen Pol der falschen Alternative arbeitet Görg genauer heraus, weil die Naturbeherrschung nicht nur die ökologische Krise verursacht hat, sondern auch bei den gesellschaftlichen Auseinandersetzungen um ihre Bearbeitung das dominante Paradigma darstellt (vgl. Görg 2003a: 21f).

\section{Naturbeherrschung}

Naturbeherrschung stellt eine spezifische Form der Naturaneignung dar. In Bezug auf das bereits genannte Kriterium für Herrschaft - die Leugnung der Eigenständigkeit eines Anderen als die Bedingung der eigenen (vermeintlichen) Unabhängigkeit - zeichnet sich Naturbeherrschung durch die Subsumtion der Natur unter die gesellschaftlichen Funktionslogiken und der damit einhergehenden Negation der Natur als etwas Selbstständiges aus (vgl. Görg 2003a: 43ff). 
Görg unterscheidet dabei Naturbeherrschung als „begriffliche Konstitution“ und Naturbeherrschung als „technisch-praktische Verfügung über Natur“ (Görg 2003a: 43). Naturbeherrschung als begriffliche Konstitution löst das Verhältnis zwischen Natur und Gesellschaft entweder in Richtung Natur oder in Richtung Gesellschaft auf. Im ersten Fall wird die gesellschaftliche Vermittlung von Natur und die gesellschaftliche Konstruktionsleistung, die allen Naturbegriffen zugrunde liegt, geleugnet. Durch das „,begrifflich-identifizierende Denken“ (Görg 2003c: 46), d. h. durch die Subsumtion von Natur unter ,gesellschaftliche Klassifikationsschemata“ wird eine „Ordnung der Natur“ (Görg 2003a: 43) konstituiert, die der Mensch zu kontrollieren, die er zu unterwerfen hat. In dieser begrifflichen Konstruktion von Natur, die sich selber als direkten, als objektiven Zugriff auf Natur versteht, wird die konkrete Mannigfaltigkeit des natürlichen Geschehens dequalifiziert (vgl. Görg 2003a: 43; Görg 2003c: 46), wodurch Natur ,,zur beliebigen Projektionsfolie gesellschaftlicher Zwecksetzungen degradiert“ (Görg 2003b: 127) wird. Im zweiten Fall wird von der vollkommenen Kontingenz der gesellschaftlichen Konstruktionen ausgegangen und damit die uneingeschränkte Unabhängigkeit von jeglichem Naturmoment oder Substrat der Natur postuliert. Damit werden die Momente der Unverfügbarkeit und der Widerständigkeit, die Natur als nichtidentisches Andere auszeichnen, ignoriert (vgl. Görg 2003a: 43).

Naturbeherrschung als technisch-praktisches Verhältnis bedeutet eine Naturaneignung, die sich ausschließlich an Maßgaben gesellschaftlicher Strukturmerkmale orientiert. Dabei wird der Natur kein Eigenwert beigemessen. Dies führt letztlich zu Naturausbeutung, die gezügelte bis schrankenlose Formen annehmen kann. Die Entscheidung über die Quantität der Naturausbeutung richtet sich dabei rein nach den (historisch institutionalisierten) gesellschaftlichen Funktionslogiken (vgl. Görg 2003a: 43f). Das Wissen um die langfristige Abhängigkeit von einer bestimmten Naturressource kann durchaus zu gezügelter Ausbeutung führen. Der Beweggrund liegt dann allerdings in der Vermeidung zukünftiger Engpässe - ohne dass der Natur Geltung ein Eigensinn zugestanden würde.

\section{Die zweite Reflexion und Selbstkritik als gesellschaftliche Freiheit}

Laut Görg führt Naturbeherrschung nicht zu gesellschaftlicher Freiheit. Nicht die „Verfügbarkeit materiell-stofflicher Ressourcen, sondern die Nicht-Festgelegtheit: Sich keinen Alternativen beugen zu müssen“ (Görg 2003a: 43) sieht Görg als Maßstab für gesellschaftliche Freiheit. Freiheit besteht für ihn in der Unabhängigkeit von Zwängen. Freiheit kann demnach nur über die Reflexion gesellschaftlicher Naturverhältnisse - unabhängig von der starren Alternative zwischen Unterordnung unter die Natur und Beherrschung der Natur - erreicht werden. Insofern ist festzu - 
halten, dass das naturbeherrschende Denken und Handeln nicht nur die Bedingungen der menschlichen Existenz zerstört, sondern gleichzeitig die gesellschaftlichen Möglichkeiten zur Reflexion und Selbstverwirklichung nicht ausschöpfen kann, da es die Vermittlung zwischen Natur und Gesellschaft leugnet (vgl. Görg 2003a: 41). Gestaltungsspielräume können ausschließlich dann wachsen, wenn die gesellschaftliche Konstruktion der scheinbaren Sachzwänge und Notwendigkeiten aufgedeckt und als Ergebnis von institutionalisierten Machtbeziehungen gesehen wird (vgl. Görg 2003a: 43).

Mit dem von Adorno übernommenen Begriff der ,zweiten Reflexion“ wendet sich Görg gegen die - weiter oben als begriffliche Konstitution der Naturbeherrschung beschriebene - Auflösung des Vermittlungsverhältnisses von Natur und Gesellschaft in die eine oder die andere Richtung (für den gesamten Absatz vgl. Görg 2003a: 47ff; Görg 2003b: 123). Die zweite Reflexion baut auf der ersten - der Reflexion darüber, dass wir die Natur an sich nicht wahrnehmen können, sondern Natur immer konstruierte Natur ist - auf, geht aber über diese hinaus. Zweite Reflexion bedeutet insofern, Natur nicht nur als Ergebnis gesellschaftlicher Konstruktionsprozesse zu betrachten, sondern ihren Eigensinn in Rechnung zu stellen. Das impliziert zu reflektieren, dass Natur nicht in ihrer Konstruktion aufgeht. Mit dem Begriff der zweiten Reflexion weist Görg darauf hin, dass Natur stets mehr ist als wir wahrnehmen können. Nicht nur, aber auch gerade in Momenten des Scheiterns der Naturaneignung ist eine Erfahrung von der Widerständigkeit eines Objekts möglich. Die Erfahrung der Nichtidentität der Natur ist somit der Ausgangspunkt für eine zweite - weil über das Objekt vermittelte Reflexion.

Die Erinnerung der Natur im Menschen und in der Gesellschaft stellt für Görg die Voraussetzung für Selbstkritik im radikalen Sinne dar. Der erste Schritt der ,Wiedergutmachung am Nichtidentischen“ besteht in der Anerkennung der Natur als Anderes und der Einsicht, dass Natur im Menschen und in der Gesellschaft ist, ohne mit ihr zusammenzufallen (vgl. Görg 2003a: 52). Insofern ist die Annahme einer Differenz von Mensch und Natur konstitutiv für die Reflexion ihrer Vermittlung. Görg lehnt die Interpretation des Verhältnisses von Mensch und Natur als Dualismus ab, welche die Leugnung der Natur im Menschen impliziert und damit auf Kontrollierbarkeit, auf Naturbeherrschung zielt (vgl. Görg 2003a: 41). Gleichzeitig positioniert er sich gegen die Aufhebung der Differenz zwischen Mensch und Natur (was die Forderung nach einer Unterordnung unter eine scheinbar natürliche Ordnung zur Folge hätte). Dementsprechend enthält Görgs Ansatz kein ontologisches Primat der Natur, wie dies in biozentristischen Ansätzen der Fall ist. Insofern zielt 
die zweite Reflexion ,auf die Selbstkritik von Konstruktionsprozessen und auf ihre gesellschaftliche Veränderbarkeit" (Görg 2003a: 49). ${ }^{22}$

\section{Die unreduzierte Erfahrung als normativer Fluchtpunkt}

Diese doppelte Ablehnung - des Dualismus und der Aufhebung der Differenz liegt auch Görgs Konzept der unreduzierten Erfahrung zugrunde. Inhaltlich greift Görg dabei auf Adornos Perspektive der, Versöhnung mit der Natur' zurück (vgl. Görg 2003a: 60). ${ }^{23}$ Für die unreduzierte Erfahrung ist das Bewusstsein, dass man in der Aneignung der Natur dieser auch verhaftet bleibt, genauso wie die ,kulturelle Besonderung des Menschen von der Natur" (Görg 2003a: 52) konstitutiv. Eine theoretische Perspektive kann nicht von der immer wieder in der Gesellschaft vorgenommenen Unterscheidung von Natur und Gesellschaft absehen. Die gesellschaftlichen Konstruktionen von Gesellschaft basieren auf der Abgrenzung von Natur und vice versa: Gesellschaft wird als das Andere der Natur und Natur als das Andere der Gesellschaft angesehen. Diese Unterscheidungen und die sich daraus ergebenden Konsequenzen müssen analysiert werden, denn nur so kann die Krise gesellschaftlicher Naturverhältnisse erfasst werden. Deshalb kann der Weg aus dieser Krise nicht darin liegen, die Differenzierungen zwischen Natur und Gesellschaft zu überspielen (vgl. Görg 2003a: 52f). ${ }^{24}$

22 Ähnlich argumentiert Pelfini mit dem Begriff der Reflexivität, den er von Reflexion abgrenzt. Reflexivität fasst er als Reflexion der Reflexion im Sinne einer Selbstkonfrontation der Moderne mit ihren Basisprinzipien (vgl. Pelfini 2005: 92; Pelfini 2006: 153). Reflexivität geht über die einfache Reflexion nicht-intendierter Nebenfolgen der Industriemoderne hinaus, indem sie ,eine Bereitschaft zur Selbstkritik und zum vorsichtigen Umgang mit den Folgen menschlichen Handelns“ (Pelfini 2006: 154) signalisiert. Pelfini spitzt sein Konzept von Reflexivität zu, indem er es als politisches Projekt begreift, das die etablierte Deutung des Verhältnisses von Natur und Gesellschaft in Frage stellt. „Sie besteht aus dem Bewusstsein, dass eine absolute Beherrschung der Natur unmöglich ist.“ (Pelfini 2006: 160)

23 Görg plädiert allerdings dafür, anstatt wie Adorno von ,Versöhnung mit der Natur', von einer unreglementierten oder unreduzierten Erfahrung zu sprechen. Gegenüber dem Begriff der Versöhnung hat er Vorbehalte, weil dieser an die Idee einer unabhängig vom Menschen existierenden unberührten Natur erinnert. Dies sei missverständlich, da die gesamte Argumentation von einer immer schon vergesellschafteten Natur ausgehe (vgl. Görg 2003a: 60).

24 Ähnlich argumentiert Gill, wie ich in Kapitel 2.2.1 ausführe (vgl. Gill 1998: 223, 246f). 
Der normative Fluchtpunkt besteht bei Görg deshalb darin, Natur als Anderes wahrzunehmen statt gesellschaftlichen Kategorien und Funktionslogiken unterzuordnen. Natur soll etwas Fremdes bleiben, mit Eigenheiten, auf die der Mensch weder direkten Zugriff hat noch anstrebt (vgl. Görg 2003a: 52f). Die Respektierung der Natur als Fremdes beinhaltet nicht die Unterordnung des Menschen unter die Natur. Mit der Forderung nach einer unreduzierten Erfahrung ist vielmehr ein „Eingedenken“ des „Ich als Natur“ (Görg 2003a: 54) gemeint. Dies bedeutet nicht ein Verhältnis zur Natur jenseits von gesellschaftlicher Konstruktion von Natur. Da ein derart direktes Verhältnis zur Natur nicht möglich ist, wird die „,bewusste Projektion“ (Görg 2003a: 40) zum Ideal. Damit ,zielt diese Utopie auf die gleichzeitige Freisetzung von Reflexionsfähigkeit und mimetischer Gegenstandserfahrung“" (Görg 2003a: 40).

Die Forderung nach unreduzierter Reflexion bezieht sich auf zwei Ebenen: Zum einen soll die Nichtidentität von Natur reflektiert werden und damit dem Umstand Rechnung getragen werden, dass Natur nicht in begrifflichen Vermessungen aufgeht, sondern sich immer auch der begrifflichen Identifikation entzieht (vgl. Schäfer 2004: 84). Zum anderen soll dem mimetischen Moment, der bildhaften (als Ergänzung der zeichenhaft-begrifflichen) Annäherung an eine „,rätselhaft bleibende Welt“ (Schäfer 2004: 59) Raum gewährt werden. Damit kann Adorno, auf den Görg hier zurückgreift, aber keine vermeintlich ursprüngliche Einheit von Mimesis und Rationalität meinen. Kritisiert wird nicht die begriffliche Rationalität - der Anspruch des (begrifflichen) Begreifens der Natur - per se, sondern ihr totalitärer Charakter. Kritisiert wird die Verabsolutierung des identifizierenden Umgangs mit Natur, der von den singulären qualitativen Eigenschaften des begrifflich erfassten Gegenstands absieht (vgl. Schäfer 2004: 64ff). Stattdessen soll das scheinbar absolut getrennte Natur und Gesellschaft, Mimesis und Rationalität, Subjekt und Objekt - ,in seinem wechselseitigen Bezug“" (Schäfer 2004: 84) erkannt werden.

„Eine solche Dialektik von Bild und Zeichen hebt deren Trennung nicht auf, aber sie könnte eine Perspektive erlauben, in der dieser wechselseitigen Vorausgesetztheit Gerechtigkeit widerfahren könnte - jenseits von Herrschaft.“ (Schäfer 2004: 84)

\section{Der Begriff der gesellschaftlichen Naturverhältnisse}

Abschließend fasse ich nun die Aspekte zusammen, die für die Integration des Konzepts in die Forschungsperspektive der diskurstheoretischen Hegemonieanalyse besonders relevant sind. Der Begriff der gesellschaftlichen Naturverhältnisse verweist darauf, dass Natur gesellschaftlich konstruiert ist - und zwar sowohl begrifflich als auch stofflich. Entgegen dualistischen Konzepten wird hier Natur nicht als unab- 
hängig von Gesellschaft gedacht. Natur ist nicht das „was quasi übrig bliebe, wenn alle gesellschaftlichen Vermittlungen abgezogen würden“ (Görg 2003b: 122). Von gesellschaftlichen Naturverhältnissen zu sprechen, bedeutet also davon auszugehen, dass es ,keine unberührte Natur [gibt; T. K.] (nicht nur nicht mehr, sondern es hat sie eigentlich noch nie gegeben), denn Natur ist immer in Relation zu einer historisch bestimmten gesellschaftlichen Situation zu interpretieren, jenseits dessen die Rede von Natur keinen Gehalt hat" (Görg 2003c: 40).

Gleichzeitig wird mit dem Begriff der gesellschaftlichen Naturverhältnisse angezeigt, dass es keine Autonomie des Sozialen gibt. Gesellschaft wird dagegen als grundlegend mit Natur vermittelt begriffen. Damit steht der Begriff gegen Tendenzen der Ausblendung von Natur und für die Anerkennung von Natur als Existenzbedingung für Gesellschaft (vgl. Görg 2003a: 14f, 27; Görg 2003b: 119).

„Was Gesellschaft ist und wie sie sich entwickelt, wird wesentlich dadurch bestimmt, wie Natur ganz konkret vergesellschaftet wird, d. h. wie sie sprachlich-kulturell (als kulturspezifische Naturvorstellungen oder als wissenschaftliche Naturbegriffe) und materiell-praktisch (z. B. als Ressource in der Ökonomie) in den gesellschaftlichen Prozess involviert ist.“ (Görg 2003c: 40)

Das Konzept der gesellschaftlichen Naturverhältnisse impliziert einerseits eine Kritik an dualistischen Vorstellungen von Natur und Gesellschaft. Andererseits betont Görg, dass Natur und Gesellschaft nicht identisch sind (vgl. Görg 2003a: 27) wobei er Natur und Gesellschaft auch nicht als ,,säuberlich getrennte Gegenstandsbereiche“ (Görg 2003b: 121) versteht. Erst die Annahme einer Differenz von Mensch und Natur rückt ihr Verhältnis ins Zentrum der Aufmerksamkeit. Nicht nur auf der erkenntnistheoretischen, sondern auch auf der normativen Ebene lehnt Görg eine Aufhebung der Differenz zwischen Mensch und Natur ab und steht damit gegen naturalistische Vorstellungen von Gesellschaft, die Forderungen nach einer Unterordnung unter eine scheinbar natürliche Ordnung nach sich ziehen (vgl. Görg 2003a: 41, 54). Zentral ist für ihn das Vermittlungsverhältnis von Mensch, Natur und Gesellschaft (vgl. Görg 2003a: 49).

„Natur ist zu verstehen als eine Konstruktion und gleichzeitig als das, was, obwohl in und durch Gesellschaften reproduziert, als das Andere von Gesellschaft, Kultur oder Technik diesen in konkreten Situationen oder Konstellationen entgegengesetzt ist. [...] Natur ist grundsätzlich nur im Verhältnis zu dem zu bestimmen, von dem es zugleich unterschieden, dem es tendenziell auch entgegengesetzt ist.“(Görg 2003b: 121; Hervorhebungen im Original)

Mit diesem Fokus auf die Vermittlungsverhältnisse geht eine spezifische Auseinandersetzung mit der ökologischen Krise einher. Mit dem Konzept der gesellschaftlichen Naturverhältnisse verbindet Görg den Anspruch, ,die Ökologieproblematik 
ganz eng an die konkrete Verfasstheit der Gesellschaft und insbesondere an deren Herrschaftsverhältnisse“ (Görg 2003c: 41) zu koppeln. Erkenntnistheoretisch bedeutet dies, in Herrschaftsverhältnissen die Ursache für eine Fehlentwicklung in den Naturverhältnissen auszumachen. Normativ folgt daraus, „dass erst über eine Kritik der herrschaftlichen Verfasstheit von Gesellschaften eine Alternative zur krisenhaften Vergesellschaftung der Natur zu gewinnen ist"“ (Görg 2003c: 41).

\subsubsection{Naturverhältnisse in der diskurstheoretischen Hegemonieanalyse}

Wenn sich die ökologische Krise - wie Görg argumentiert - strukturell von anderen gesellschaftlichen Herausforderungen unterscheidet, bedarf es eines spezifischen Konzepts, mit dem das Verhältnis des Menschen zur Natur adäquat untersucht werden kann. Da Görg die Analyse der ökologischen Krise sehr eng an die Analyse der allgemeinen sozialen Ordnung koppelt, kann das Konzept der gesellschaftlichen Naturverhältnisse m. E. nur im Rahmen einer allgemeinen Gesellschaftstheorie sinnvoll angewendet werden. Um diesen beiden Herausforderungen gerecht zu werden, integriere ich in meiner Arbeit das Konzept der gesellschaftlichen Naturverhältnisse in die diskurstheoretische Hegemonieanalyse.

Diese Kombination bildet das theoretische Werkzeug für die Verfolgung meines Erkenntnisinteresses: die Analyse der re- und entpolitisierenden Prozesse im Konfliktfeld der ökologische Krise. Sowohl die diskurstheoretische Hegemonieanalyse als auch das Konzept der gesellschaftlichen Naturverhältnisse gehen von einem Primat des Politischen aus (zum Primat des Politischen vgl. Kapitel 2.1). Die Ursachen und die Bearbeitung der ökologischen Krise werden mit einer solchen Perspektive als Folge hegemonialer Kämpfe um die Ausgestaltung der Naturaneignung betrachtet. Gleichzeitig gerät damit die ökologische Krise als (möglicher) Auslöser (re-)politisierender Prozesse in den Blick.

Im Mittelpunkt der theoretischen Auseinandersetzung mit der ökologischen Krise stehen dann die Fragen nach Verstetigung und Verflüssigung bestimmter Formen der Naturaneignung und deren Konsequenzen für die Diskursorganisation gesellschaftlicher Naturverhältnisse. Mit einer solchen Perspektive können Gestaltungsspielräume dadurch erhöht werden, dass die gesellschaftlichen Konstruktionen scheinbarer Sachzwänge, natürlicher Ordnungen oder eines vermeintlich objektiven Gemeinwohls aufgedeckt und als Ergebnis von institutionalisierten Machtbeziehungen gesehen werden (vgl. Görg 2003a: 43).

Was die normativen Implikationen anbelangt, so geht die diskurstheoretische Hegemonieanalyse allerdings - im Gegensatz zu Görgs Fluchtpunkt der unreduzierten Erfahrung - nicht über den Verweis auf eine mögliche (Re-)Politisierung der ge- 
sellschaftlichen Naturverhältnisse hinaus. Eine Gesellschaft bzw. gesellschaftliche Naturverhältnisse jenseits von Machtbeziehungen und Hegemoniepraktiken ist mit ihr nicht denkbar. Deshalb können aus der diskurstheoretischen Hegemonieanalyse keine konkreten normativen Zielvorstellungen abgeleitet werden. Diese gelten als politische (Wert-)Entscheidungen, für die keine objektive Geltung beansprucht werden kann.

\subsection{Forschungsdesign, Aufbau Und methodisches Vorgehen}

In diesem Kapitel erläutere ich die Argumentationsstruktur der Arbeit und mein methodisches Vorgehen. Dazu reflektiere ich zunächst allgemein die Implikationen, die sich aus einer konstruktivistischen Perspektive für den Forschungsprozess ergeben (2.3.1). Anschließend stelle ich den Aufbau des empirischen Teils dieser Arbeit vor und gehe dabei insbesondere auf das Verhältnis der verschiedenen Ebenen des von mir analysierten Untersuchungsgegenstands ein (2.3.2). Abschließend stelle ich die Interpretationsmethode dar, mit der die konkrete Feinanalyse einzelner Dokumente durchgeführt wurde (2.3.3).

\subsubsection{Implikationen einer konstruktivistischen Forschungsperspektive}

Im Anschluss an Reflexionen über Spezifika einer konstruktivistischen, poststrukturalistischen oder postpositivistischen Methodologie (vgl. Bedall 2014: 199ff; Glynos/Howarth 2007; Keller 2008: 268ff; Wullweber 2010: 44ff) gehe ich davon aus, dass dem Aufbau und dem methodischen Vorgehen einer Arbeit (alltags-)theoretische Grundannahmen, forschungspragmatische Entscheidungen sowie normative Setzungen zugrunde liegen. Die konstruktivistische Perspektive auf Wissenschaft verwirft das Beharren auf der Möglichkeit einer objektiven Erklärung und zielt stattdessen auf eine plausible Erklärung eines Problems. Die Plausibilität einer Erklärung kann dabei durch ein methodisches Vorgehen erhöht werden, das transparent, konsistent sowie offen und angemessen gegenüber dem zu erklärenden Problem ist.

Die Forderungen nach Offenlegung und Reflexion der eigenen Positionierung und des methodischen Vorgehens ergibt sich aus der Absage an einen vermeintlich objektiven Standpunkt. Transparenz und Nachvollziehbarkeit erhöhen die Möglichkeit der Reflexion blinder Flecken - sowohl für die Leser_innen als auch für den Forschenden selber. Insofern gilt es, über die allgemeine Darstellung der politischnormativen Selbstverortung (vgl. Vorwort und Einleitung) und der theoretischen 
Grundannahmen (vgl. Kapitel 2.1 und 2.2) hinaus, die konkreten Entscheidungen im Forschungsprozess zu reflektieren, offen zu legen und zu begründen.

Eine weitere Bedingung für die Erzeugung von Plausibilität ist Konsistenz. Die zugrunde gelegten Annahmen und das methodische Vorgehen sollten in sich wie auch im Verhältnis zueinander widerspruchsfrei sein. Weiterhin ist entscheidend, dass sich die Erklärungen schlüssig aus dem Forschungsprozess ergeben und auf die Forschungsfragen antworten.

Damit ist bereits das nächste Plausibilitätskriterium angesprochen: die Angemessenheit gegenüber dem zu erklärenden Problem. Weder Theorie noch Methodik sollten Selbstzweck sein. Beide können allerdings sinnvolle Werkzeuge für die Generierung plausibler Erklärungen sein. Im Sinne einer datenbasierten Theorie (vgl. Strauss 1998: 31) bzw. einer problemgeleiteten Forschung bedarf es einer Offenheit und Anpassungsfähigkeit der verwendeten Theorien, Konzepte und Methoden gegenüber dem Untersuchungsgegenstand (vgl. Bedall 2014: 204).

Die Problemstellung bildet somit das Zentrum und den Ausgangspunkt des Forschungsprozesses. Jede Forschung beginnt mit einer Irritation, ,mit einem (theoretischen oder empirischen) Gegenstand, der unsere Aufmerksamkeit erregt" (Wullweber 2010: 46). Einer Irritation ist kein objektives Problem inhärent, sondern eine Irritation gibt den Anlass für die Formulierung einer Problemstellung. Bereits diese Problematisierung basiert auf dem Erkenntnisinteresse sowie der politisch-normativen Positionierung und den persönlichen Erfahrungen des Forschenden. Mit diesen Vorannahmen fließen erste implizite oder explizite Hypothesen in die Definition des Untersuchungsgegenstands und die Formulierung der Forschungsfragen ein.

Im weiteren Forschungsprozess folgen induktive, deduktive und verifizierende Arbeitsschritte. In der Regel bilden diese keine separaten Arbeitsphasen, die in sequentieller Reihenfolge abgearbeitet werden können. Tatsächlich changieren die meisten empirisch arbeitenden Sozialwissenschaftler_innen kontinuierlich zwischen der induktiven Hypothesenbildung, der deduktiven Ableitung von Implikationen aus den Hypothesen und der verifizierenden Hypothesenüberprüfung am Material (vgl. Strauss 1998: 37). Die Generierung von Erkenntnis erfolgt somit in einem zirkulären Prozess, der als Retroduktion bezeichnet wird (vgl. Glynos/Howarth 2007: 18ff). Die retroduktive Zirkel-Bewegung sollte bewusst forciert werden, um vorschnelle Schlüsse zu vermeiden sowie die normativen und theoretischen Setzungen und das methodische Vorgehen reflektieren und gegebenenfalls adaptieren oder verwerfen zu können. Dieser Prozess wird aus forschungspragmatischen Gründen mit der Formulierung einer (vorläufigen) Erklärung beendet, auch wenn der hier verfolgte Ansatz davon ausgeht, ,dass niemals eine ultimative und damit objektive, 
sondern immer nur eine plausible Erklärung gefunden werden kann und der Erkenntnisprozess niemals zu einem Ende führt“ (Wullweber 2010: 47).

\subsubsection{Die retroduktive Erklärung}

Die retroduktive Zirkel-Bewegung wiederholt sich in meiner Arbeit bei der Analyse der verschiedenen Ebenen des Untersuchungsgegenstandes. Ich oszilliere zwischen der Analyse von Artikulationen (als kleinste von mir untersuchte analytische Einheiten), ihren jeweiligen (akteurs-)spezifischen Kontexten und dem ökomodernen Hegemonieprojekt (als größte von mir untersuchte analytische Einheit).

In Kapitel 3 nehme ich die Organisation gesellschaftlicher Naturverhältnisse in den Blick und untersuche die Auseinandersetzungen um die Bearbeitung der ökologischen Krise seit Ende der 1960er Jahre. Über die Interpretation von Schlüsseldokumenten und wissenschaftlichen Studien analysiere ich die Formierung, Durchsetzung und (Grenzen der) Dominanz des ökomodernen Hegemonieprojekts in der internationalen Umweltpolitik. Die Auswahl und die Interpretation der Daten folgen dabei dem Erkenntnisinteresse an den Prozessen der Öffnung und Schließung des Terrains des Politischen (vgl. Kapitel 1.1) und zielen auf die Offenlegung der hegemonialen Strukturierung der Organisation gesellschaftlicher Naturverhältnisse. Dabei arbeite ich bestimmte Hegemoniestrategien heraus, über die Zustimmung zum ökomodernen Projekt erzeugt wird und antagonistische Artikulationen marginalisiert werden. Gleichzeitig beleuchte ich Brüche und Risse, die auf die Prekarität der Dominanz des ökomodernen Hegemonieprojekts verweisen.

Ausgehend von den Hegemoniestrategien und den Brüchen und Rissen werden in Kapitel 4 Fragen formuliert, die mit der mikroanalytischen Untersuchung ${ }^{25}$ der CCS-Konflikte in der internationalen Klimapolitik beantwortet werden sollen. Darüber hinaus begründe ich in dem Kapitel, warum die CCS-Konflikte eine besondere Rolle in den hegemonialen Kämpfen um die Bearbeitung der ökologischen Krise spielen. Meine Vermutung ist, dass sich an den Auseinandersetzungen um CCS-Technologien paradigmatisch zentrale Konflikte um die weitere Entwicklung des ökomodernen Projekts bzw. der Frage nach der (Ent-)Politisierung gesellschaftlicher Naturverhältnisse analysieren lassen.

25 Ich bezeichne diesen Teil meiner Arbeit als mikroanalytische Untersuchung, weil ich bei der Analyse der CCS-Konflikte auf mikroanalytische Methoden zurückgreife (vgl. die Ausführungen zur Feinanalyse einzelner Dokumente in Kapitel 2.3.3). Der Gegenstand der Untersuchung ist allerdings nicht auf der Mikroebene angesiedelt. 
Die Betrachtung der CCS-Konflikte in Kapitel 5 beginnt mit einer Einführung in das UN-Klimaregime als zentrale Arena internationalen Klimapolitik. Darauf folgt eine Annäherung an das Konfliktfeld der CCS-Technologien. Nach dieser Erarbeitung des Kontextes analysiere ich eine konkrete Auseinandersetzung: die Kontroverse um die Zulassung von CCS-Technologien als CDM-Projekte (kurz: CCS-CDM-Kontroverse).

In einem eigenen Unterkapitel widme ich mich dabei zunächst der besonderen Rolle des IPCC in der CCS-CDM-Kontroverse. Die Analyse der Politikberatung durch den IPCC beginnt mit einer Analyse allgemeiner Kontextfaktoren wie die Arbeitsweise und seine Funktion innerhalb des UN-Klimaregimes. Darauf aufbauend untersuche ich die konkrete Politikberatung, die sich in der Erstellung eines Sonderberichts zu CCS manifestiert. Dabei nehme ich sowohl die Auswahl der Autor_innen als auch die Argumentationslinie des Berichts in den Blick. Darüber hinaus binde ich die Ergebnisse an Kapitel 3 zurück und frage nach dem Verhältnis der Politikberatung des IPCC zum ökomodernen Hegemonieprojekt.

Im Anschluss an die Analyse der Politikberatung durch den IPCC stehen die politischen Aushandlungsprozesse der CCS-CDM-Kontroverse im Fokus. Ich beginne mit einem Überblick über den Verlauf der Verhandlungen sowie über die am Aushandlungsprozess beteiligten Akteur_innen und ihre Positionen. Dieser Überblick basiert auf einer Analyse der schriftlichen Dokumente der Verhandlungen (Stellungnahmen und Protokolle). Aufgrund der formalisierten und transparenten Arbeitsweise der UN-Gremien sind diese Dokumente leicht zugänglich und geben den offiziellen Verhandlungsprozess präzise wieder. Allerdings geben sie keine Hinweise auf inoffizielle Absprachen und Aushandlungen, weshalb ich die Analyse der Dokumente mit Informationen, Einschätzungen und Interpretationen aus wissenschaftlichen Studien, Publikationen von Beobachterorganisationen ${ }^{26}$ und zwei eigens durchgeführten Expert_inneninterviews ${ }^{27}$ ergänze.

26 Neben den Regierungsdelegationen nehmen an den UN-Klimaverhandlungen viele Akteur_innen mit einem Beobachter_innenstatus teil. Diese werden als ,Beobachterorganisationen' bezeichnet (vgl. Kapitel 5.1.1).

27 Meine Interviewpartner_innen waren Heleen de Coninck und Manfred Treber. Heleen de Coninck war bei der Erstellung des IPCC-Sonderberichts zu CCS eine der Coordinating Lead Authors (vgl. Kapitel 5.3.2). Darüber hinaus beobachtete sie als wissenschaftliche Beobachterin die CCS-CDM-Kontroverse. Manfred Treber nahm im Auftrag der Beobachterorganisation Germanwatch an den UN-Klimaverhandlungen zu CCS teil. An den Stellen, an denen ich auf Informationen aus den Interviews zurückgreife, markiere ich das mit einer Fußnote. 
Anschließend greife ich einzelne Akteur_innen heraus, die in der Debatte eine besonders wichtige Rolle spielten und analysiere ihre spezifische Bedeutung und Argumentationslinie in den Verhandlungen. Dafür stelle ich zunächst relevante Kontextfaktoren dar. ${ }^{28}$ Für die Interpretation der Argumentationslinien greife ich auf die von ihnen eingereichten schriftlichen Stellungnahmen zurück und arbeite die darin enthaltenen Artikulationen heraus. Diese Interpretation konkreter Artikulationen auf der Ebene von Einzeldokumenten geschieht vor dem Hintergrund der akteurspezifischen Kontextfaktoren und der in Kapitel 3 diskutierten Entwicklungen in den Auseinandersetzungen um die ökologische Krise.

Auf die akteursbezogene Betrachtung folgt eine Einschätzung der gesamten Kontroverse um CCS-Technologien in den UN-Klimaverhandlungen, die ich mit den Fragen nach den Brüchen, Rissen und Strategien des ökomodernen Hegemonieprojekts ins Verhältnis setze. Erst die Einbettung in die breitere Analyse des gesellschaftlichen Kontextes ermöglicht die Dekonstruktion von Artikulationen als Hegemoniepraktiken, die eine bestimmte Strukturierung der gesellschaftlichen Naturverhältnisse (re-)produzieren (vgl. Wullweber 2010: 50).

Um diese Einbettung weiter zu forcieren, stelle ich zusätzlich in einem weiteren Abschnitt die Verknüpfungen zwischen den verschiedenen Analyseschritten in den einzelnen Unterkapiteln her. Der konkrete Verhandlungsablauf und die darin vertretenen Positionen werden dadurch in Beziehung gesetzt zu den CCS-Konflikten in anderen Arenen, zu den akteursspezifischen Kontextfaktoren und zu der besonderen Rolle des IPCC im UN-Klimaregime.

In Kapitel 6 gehe ich explizit der Frage nach, welche Rückschlüsse aus der Analyse der CCS-Konflikte für die Einschätzung der Stabilität und der (möglichen) weiteren Entwicklung des ökomodernen Hegemonieprojekts gezogen werden können. Damit komme ich am Ende der Zirkel-Bewegung wieder zur größten Analyseeinheit zurück. Angereichert durch die Erkenntnisse aus der mikroanalytischen Untersuchung der CCS-Konflikte wird noch einmal der Status quo der hegemonialen Kämpfe in der internationalen Umweltpolitik ins Zentrum der Analyse gerückt.

Die Arbeit schließt mit Kapitel 7, in dem die empirischen Ergebnisse im Hinblick auf die Forschungsfragen zusammengefasst werden.

28 Bei Staaten sind dies beispielsweise ihre Energie- und Klimapolitik sowie ihre CCSAktivitäten. Bei Beobachterorganisationen gehe ich unter anderem auf ihre allgemeinen umweltpolitischen Positionierungen und ihre bisherigen Beiträge in den UNKlimaverhandlungen ein. 


\subsubsection{Das methodische Vorgehen bei der Feinanalyse}

Als Feinanalyse bezeichne ich die Arbeitsschritte dieser Arbeit, in denen einzelne Dokumente unter Rückgriff auf methodisches Werkzeug interpretiert werden. Dies betrifft die Interpretation des IPCC-Berichts zu CCS-Technologien und der schriftlichen Stellungnahmen der CCS-CDM-Kontroverse. Die Herausarbeitung der konkreten Artikulationen in den Dokumenten basiert auf einem methodischen Vorgehen, das vorschnelle Schlüsse vermeiden und die Offenheit gegenüber dem Material absichern soll. Dazu bedarf es eines methodischen Vorgehens, das einerseits rigide genug ist, um die sorgfältige Auseinandersetzung mit dem Material $\mathrm{zu}$ fördern und andererseits flexibel genug, um die für die Forschungsfragen relevanten Aspekte in ihrer Komplexität erfassen zu können. Darüber hinaus muss das methodische Vorgehen adäquat gegenüber dem Untersuchungsgegenstand, dem Erkenntnisinteresse und den Forschungsfragen sein.

Meinen Forschungsfragen entsprechend (vgl. Kapitel 1.1) interessiert mich an den Dokumenten weder ihre Fallstruktur noch die Intention der Autor_innen, sondern ihr Beitrag $\mathrm{zu}$ den Auseinandersetzungen um die Universalisierung bestimmter Deutungs- und Handlungsmuster. Um diese Hegemoniepraktiken in den Dokumenten offenlegen zu können, greife ich auf ein Interpretationselement des narrativ-analytischen Auswertungsverfahrens von Martha Feldman et al. zurück: das Enthymem. ${ }^{29}$ Die rhetorische Figur des Enthymems ist ein ,unvollständiger bzw. ,nachlässiger‘ Syllogismus (vgl. Feldman/Sköldberg/Brown/Debra 2004: 152). Syllogismen wiederum bilden den Kern der aristotelischen Logik und bestehen aus einer ersten Prämisse (z. B. „Alle Menschen sind sterblich.“), einer zweiten Prämisse (z. B. „Alle Griechen sind Menschen.“) und einer Schlussfolgerung (z. B. „Alle Griechen sind sterblich."). Wie Syllogismen bestehen auch Enthymeme prinzipiell aus diesem Dreischritt.

Im Gegensatz zu einem Syllogismus handelt es sich bei einem Enthymem allerdings nicht unbedingt um einen korrekt logischen Schluss, sondern die Schlussfolgerungen können auch auf Plausibilitätsargumenten oder Wahrscheinlichkeitsaussagen beruhen (vgl. Feldman et al. 2004: 152). Eine weitere Besonderheit des Enthymems besteht darin, dass nicht immer alle drei Elemente in expliziter Form vorliegen. Sehr häufig wird die erste Prämisse nicht expliziert, es können aber auch die zweite Prämisse oder die Schlussfolgerung implizit bleiben. Feldman et al. geben zwei mögliche Gründe für implizite Aussagen an. Sie werden entweder als selbstverständliche Tatsachen vorausgesetzt oder aber für besonders kontrovers

29 Den Anstoß zur Operationalisierung der diskurstheoretischen Hegemonieanalyse mit Hilfe der Narrativ-Analyse von Feldman et al. gab mir Philip Bedall (2013). 
gehalten. Im ersten Fall erscheint dem/der Sprecher_in eine explizite Erwähnung unnötig, da die betreffenden Wissensbestände als unzweifelhafte, geteilte Basis gelten oder derart internalisiert sind, dass sie gar nicht bewusst gedacht werden. Im zweiten Fall will der/die Sprecher_in Widerspruch vermeiden (vgl. Feldman et al. 2004: 152). In beiden Fällen handelt es sich um die (Re-)Produktion von Konsens.

Dies verweist auf das entscheidende Charakteristikum des Enthymems: die KoProduktion der Aussagen durch Autor_in bzw. Sprecher_in und Leser_in bzw. Publikum (für den gesamten Absatz vgl. Bitzer 1959: 408; Smerecnik, Karl R./ Renegar, Valerie R. 2010: 157). Mit Hilfe ihres Alltagsverstandes und ihres Vorwissens füllt das Publikum die Lücken der impliziten Elemente und komplettiert damit das Enthymem. Enthymeme sind deshalb Kernbestandteil von Argumentationen, die auf die Überzeugung des Publikums zielen. Durch die Vervollständigung mit Hilfe des Alltagswissens laden ,erfolgreiche“ Enthymeme nicht zur weiteren Reflexion ein, sondern erzeugen im Gegenteil eine unmittelbare Plausibilität. Der Einsatz von Enthymemen als rhetorische Figur - um Zustimmung zu erzeugen muss dabei keinesfalls bewusst erfolgen. In den meisten Fällen werden sie tatsächlich unbewusst eingesetzt.

Mit der Interpretation von Enthymemen werden unausgesprochene hegemoniale Diskurse bzw. Hegemoniestrategien offengelegt, in denen Konsens für partikulare Vorstellungen vom Gemeinwohl, von einer idealen Gesellschaft, hergestellt wird. Das macht die Interpretation von Enthymemen besonders interessant für eine Forschungsperspektive, die auf die Analyse von Auseinandersetzungen um Hegemonie und die darin agierenden (ent-)politisierenden Praktiken zielt. Schließlich basiert Hegemonie in erster Linie auf der Durchsetzung eines Konsenses, in dem die eigenen Partikularinteressen privilegiert eingeschrieben sind (vgl. Kapitel 2.1).

Die von mir durchgeführte Feinanalyse der Dokumente zielt also auf die Herausarbeitung der in ihnen enthaltenen Enthymemen. Die Enthymeme liegen nicht offensichtlich im Text vor, sondern die Erfassung konkreter Textpassagen als Elemente von Enthymemen - als erste Prämisse, zweite Prämisse oder Schlussfolgerung - ist das Ergebnis von Interpretationsarbeit. Die Identifizierung von Textpassagen als Enthymeme orientiert sich an zwei Aspekten. Erstens basieren Enthymeme stets auf impliziten oder expliziten Oppositionen, d. h. auf dem Ausschluss verworfener alternativer Deutungen. Oppositionen sind somit Hinweise (,Marker') auf Enthymeme (vgl. Feldman et al. 2004: 151, 155). Zweitens geben das Erkenntnisinteresse und die Forschungsfragen einen thematischen Rahmen vor, innerhalb dessen nach relevanten Enthymemen gesucht wird (vgl. Feldman et al. 2004: 154). Auf diese Art und Weise können die für die Fragestellung relevanten impliziten oder expliziten Artikulationen im Untersuchungsmaterial identifiziert 
und in Form von Enthymemen rekonstruiert werden. Die Interpretation von impliziten Aussagen geschieht dabei stets vor dem Hintergrund der (akteursspezifischen) Kontextbedingungen und der Argumentationslinie, die das jeweilige Dokument als Ganzes durchzieht.

Diese im Anhang präsentierten Enthymeme bilden die Grundlage für die Nachzeichnung der Argumentationslinien verschiedener Akteur_innen. Bei der Darstellung der Argumentationslinien (vgl. Kapitel 5.3.3 und 5.4.3) verzichte ich aus Gründen der besseren Lesbarkeit darauf, die Enthymeme in ihrer formalisierten Struktur darzustellen. Stattdessen formuliere ich die in ihnen enthaltenen Prämissen und Schlussfolgerungen in einem Fließtext als Argumente der Akteur_innen aus. Zur besseren Nachvollziehbarkeit verweise ich aber auf die Enthymeme, die den Ausformulierungen in den jeweiligen Absätzen zugrunde liegen.

Abschließend demonstriere ich an zwei Beispielen, wie die aufgelisteten Enthymeme im Anhang zu lesen sind. Zur Darstellung der Enthymeme sei vorausgeschickt, dass die im Bericht implizit gebliebenen Aussagen in Großbuchstaben geschrieben sind und die Seitenzahlen die Textstellen des Dokuments anzeigen, auf die sich die Interpretation bezieht. Im Beispiel interpretiere ich folgende Passage aus der zweiten schriftlichen Stellungnahme der brasilianischen Regierung zur CCS-CDM-Kontroverse:

„Developed countries, which shall lead the process of combating climate change, should be the first to use CCS in geological formation on large scale in their territories in order to acquire knowledge about the risks related to leakage, monitoring and liability before exporting premature experiences to developing countries.“(UNFCCC 2008: 3)

Bei dieser dichten Textstelle arbeitete ich zwei Enthymeme heraus: BRA 2-3 und BRA 2-4. Der Name der Enthymeme setzt sich aus der Abkürzung des Akteurs/der Akteurin (BRA steht für die brasilianische Regierung), der Benennung der Stellungnahme (2 steht für die zweite brasilianische Stellungnahme) und des Enthymems (3 bzw. 4 steht für das dritte bzw. vierte Enthymem, das in dieser Stellungnahme identifiziert wurde). 


\section{Enthymem BRA 2-3 (Seite 3)}

Erste Prämisse: DIE FÜHRUNG IN DER BEKÄMPFUNG DES KLIMAWANDELS ZU ÜBERNEHMEN BEDEUTET, FÜR DIE ENTWICKLUNG DES PORTFOLIOS TECHNOLOGISCHER OPTIONEN VERANTWORTLICH ZU SEIN.

Zweite Prämisse: Die Industrieländer sollten die Führung in der Bekämpfung des Klimawandels übernehmen.

Schlussfolgerung: DIE INDUSTRIELÄNDER SIND FÜR DIE ENTWICKLUNG DES PORTFOLIOS TECHNOLOGISCHER OPTIONEN VERANTWORTLICH.

Beim Enthymem BRA 2-3 steht die zweite Prämisse explizit im Text. Sowohl die erste Prämisse als auch die Schlussfolgerung bleiben in der Stellungnahme allerdings implizit (weshalb sie in Großbuchstaben geschrieben sind), können aber vor dem Hintergrund des Kontextes erschlossen werden.

\section{Enthymem BRA 2-4 (Seite 3)}

Erste Prämisse: NOCH UNREIFE TECHNOLOGIEN DES PORTFOLIOS SOLLTEN ZUNÄCHST NUR IN DEN INDUSTRIELÄNDERN SELBER ZUM EINSATZ KOMMEN, BEVOR SIE IN ENTWICKLUNGSLÄNDER EXPORTIERT WERDEN.

Zweite Prämisse: CCS ist noch eine unreife Technologie.

Schlussfolgerung: CCS sollte zunächst nur in den den Industrieländern selber zum Einsatz kommen, bevor es in Entwicklungsländer exportiert wird.

Beim Enthymem BRA 2-4 bleibt allein die erste Prämisse implizit, die zweite Prämisse und die Schlussfolgerung liegen dagegen in expliziter Form vor. 


\title{
3. Das Projekt der ökologischen Modernisierung
}

\author{
"We have the means to limit climate change. The \\ solutions are many and allow for continued \\ economic and human development.“ \\ (Rajendra Pachauri) ${ }^{1}$
}

Seit den 1970er Jahren gibt es Debatten über die ökologische Krise und Auseinandersetzungen um ihre Bearbeitung. Dabei hat sich eine Kluft zwischen dramatisierenden Problemanalysen und inkrementellen Lösungsansätzen aufgetan. Vor diesem Hintergrund formuliert beispielsweise Ulrich Brand in einem Aufsatz die These, dass es zwar eine große Einigkeit über die Notwendigkeit einer radikalen Transformation der gesellschaftlichen Naturverhältnisse gebe, tatsächliche politische Veränderungen aber ausblieben und stattdessen Passivität vorherrsche, da es an akzeptierten Alternativen und sozialen (Gegen-)Kräften mangele (vgl. Brand 2009: 104, 116). Diese Einschätzung verweist auf die Schwierigkeiten der Artikulation einer antagonistischen sozial-ökologischen Politik. In diesem Kapitel ${ }^{2}$ möchte ich allerdings sowohl historisch als auch analytisch einen Schritt zurück gehen und prüfen, welche Vorstellungen bezüglich der Bearbeitung der ökologischen Krise von welchen Akteur_innen wie verhandelt werden, auf was für eine zukünftige Gesellschaftsordnung sie zielen und wo die Gründe für die vermeintliche Passivität zu suchen sind. ${ }^{3}$

1 Das Zitat des damaligen Vorsitzenden des IPCC entstammt der Pressemitteilung des IPCC vom 02.11.2014 anlässlich der Vorstellung des fünften Sachstandsberichts (vgl. im Internet: www.ipcc.ch/pdf/ar5/prpc_syr/11022014_syr_copenhagen.pdf, letzter Zugriff am 26.02.2015).

2 Einzelne Abschnitte dieses Kapitels wurden - in einer früheren Fassung - bereits veröffentlicht in Krüger 2013 und Krüger 2014.

3 Tatsächlich ist es so, dass diese beiden hier gegenüber gestellten Erklärungsversuche letztlich als komplementär zu verstehen sind, worauf ich weiter unten in These fünf (vgl. Kapitel 3.6) eingehen werde. Der Mangel an akzeptierten Alternativen und sozialen 
Dabei gehe ich nicht von einer großen Einigkeit über die Notwendigkeit einer radikalen Transformation der gesellschaftlichen Naturverhältnisse aus. Stattdessen vermute ich virulente Kämpfe um Hegemonie, in denen unterschiedliche Vorstellungen vom Gemeinwohl und von der idealen Gesellschaftsordnung miteinander konkurrieren. In diesen Auseinandersetzungen um die Bearbeitung der ökologischen Krise ist das Hegemonieprojekt der ökologischen Modernisierung besonders einflussreich. Die Hegemoniepraktiken des ökomodernen Projekts wirken einer weitreichenden Transformation gesellschaftlicher Naturverhältnisse bislang relativ erfolgreich entgegen. Dementsprechend stehen die Formierung und die Hegemoniepraktiken des ökomodernen Projekts im Zentrum dieses Kapitels, in dem ich die Beantwortung der ersten Forschungsfrage dieser Arbeit anstrebe (vgl. Kapitel 1.1).

1) Wie und bis zu welchem Grad konnte das ökomoderne Projekt hegemonial werden und die gesellschaftlichen Reaktionen auf die ökologische Krise bestimmen?

Um diese Frage beantworten zu können, arbeite ich über die Interpretation von Schlüsseldokumenten und wissenschaftlichen Studien die Charakteristika und die (Grenzen der) Dominanz des ökomodernen Hegemonieprojekts in der internationalen Umweltpolitik heraus. Diese Analyse geht über eine historische Nacherzählung oder eine Aneinanderreihung von Forschungsergebnissen hinaus. Die Auswahl und die Interpretation der Daten folgt dem Erkenntnisinteresse an den Prozessen der Öffnung und Schließung des Terrains des Politischen (vgl. Kapitel 1.1) und zielt auf die Offenlegung der hegemonialen Strukturierung der gesellschaftlichen Naturverhältnisse. Grundsätzlich beinhaltet die Problematisierung gesellschaftlicher Naturverhältnisse als ökologische Krise - ein Deutungsmuster, das sich seit den 1970er Jahren zunehmend durchgesetzt hat - ein stark politisierendes Moment. Allerdings sind mit dem partiellen Erfolg ökomoderner Hegemoniestrategien entpolitisierende Effekte verbunden. Über die Analyse der re- und entpolitisierenden Prozesse wird im Folgenden das Konfliktfeld der ökologischen Krise skizziert und nach Erklärungsansätzen für die beobachtete Kluft zwischen dramatisierenden Problemanalysen und inkrementellen Lösungsansätzen gesucht.

(Gegen-)Kräften steht in einem engen Zusammenhang mit der aktiven Reproduktionsleistung durch ein ökomodernes Hegemonieprojekt, das eine spezifische Bearbeitung der ökologischen Krise vorantreibt. Auch Ulrich Brand, auf den hier verwiesen wird, arbeitet in verschiedenen Texten die Mechanismen der aktiven Reproduktion hegemonialer Praktiken heraus. Insofern dient die Gegenüberstellung lediglich dazu, den Fokus dieses Kapitels zu verdeutlichen. 
Im ersten Abschnitt wird die ökologische Krisendiagnose und die daran geknüpfte Gesellschaftskritik als Ausgangspunkt des ökomodernen Diskurses beleuchtet (3.1). Anschließend folgt ein Überblick über die wichtigsten Ereignisse und Entwicklungsschritte in der Formierung des ökomodernen Diskurses (3.2). Auf diesen empirisch dichten Beschreibungen bauen die abstrakteren Analysen auf, in denen ich die Grundannahmen (3.3), die Hegemoniestrategien (3.4) und das Hegemonieversprechen (3.5) des ökomodernen Projekts herausarbeite. Weiterhin formuliere ich sechs Thesen zur Frage der (Grenzen der) Dominanz des ökomodernen Projekts (3.6). Abschließend diskutiere ich die Bedeutung des ökomodernen Projekts für die Stabilität der hegemonialen Bearbeitung der ökologischen Krise (3.7).

\section{Die Gefahr der analytischen Verdopplung von Hegemonie}

Prinzipiell zielt meine Analyse auf die internationale Politik und damit auf international bzw. transnational agierende Akteur_innen sowie die Strukturen, in denen die Akteur_innen eingebettet sind. Dabei sind auch bestimmte regionale oder nationalstaatliche Entwicklungen von Interesse, insoweit sie auf die Ebene der internationalen Politik Auswirkungen haben. So nahm die Formierung des ökomodernen Diskurses in den Ländern des globalen Nordens ihren Anfang und setzte sich über den Einfluss dieser Länder auch in der internationalen Umweltpolitik mehr und mehr durch. Insofern spiegelt ein Fokus auf die Akteur_innen und Prozesse aus diesen Ländern die Machtverhältnisse in der internationalen Politik wider. Wenn im Folgenden unspezifisch von bestimmten Prozessen, Akteur_innen und Gruppen die Rede ist (wie zum Beispiel von ,den Umweltbewegungen'), dann bezieht sich das primär auf (west-)europäische, nordamerikanische und japanische Phänomene. Damit soll nicht geleugnet werden, dass es in anderen Regionen der Welt auch aktive Umweltbewegungen gab und gibt (vgl. Radkau 2011: 188ff). An der Entwicklung des ökomodernen Projekts hatten diese jedoch einen weitaus geringeren Anteil und sind deshalb in Bezug auf meine Forschungsfragen weniger relevant. Auch wenn in dieser Arbeit bestimmte Prozesse herausgegriffen und verallgemeinert werden, gehe ich - um bei dem Beispiel zu bleiben - nicht von einer homogenen globalen Umweltbewegung aus. Tatsächlich lassen sich viele Unterschiede zwischen den regional verankerten Umweltbewegungen finden (vgl. Radkau 2011: 175ff), auf die ich aber nicht näher eingehen werde.

Im Fokus dieses Kapitels liegen all jene Phänomene, die einflussreich waren in Bezug auf die Entwicklung und Durchsetzung des ökomodernen Diskurses in den Arenen der internationalen Umweltpolitik. Aus dem Blick geraten damit tendenziell historische Ereignisse mit geringer Resonanz, weniger einflussreiche Praktiken und Akteur_innen sowie regional verschiedene Entwicklungsprozesse. Dies birgt die Gefahr der analytischen Verdopplung von Hegemonie. Die Gefahr besteht darin, dass mit dem Erkenntnisinteresse an der Durchsetzung von Hegemonie die marginalisierten Ereignisse und Akteur_innen auch in der 
Analyse nicht wahrgenommen werden und damit eine erneute Marginalisierung erfahren. Deshalb bedarf es der besonderen Aufmerksamkeit der Leser_innen gegenüber den Verweisen auf und den Exkursen über marginalisierte Positionen in dieser Arbeit.

Das Erkenntnisinteresse an hegemonialen Ereignissen, Akteur_innen und Praktiken birgt allerdings nicht nur die Gefahr der analytischen Verdopplung von Hegemonie, sondern auch das Potenzial für eine emanzipatorisch gewendete Aneignung der Genese hegemonialer Strukturen. Die Bedingung für eine solche Dekonstruktionsleistung ist, dass die Kontingenz von Hegemonie betont wird. Mit einem solchen Blick für historisch möglich gewesene und prinzipiell denkbare Alternativen bleibt der politische Ursprung des Sozialen präsent - und damit die Möglichkeit der Überführung des Sozialen in den politischen Bereich der Ausei nandersetzungen um Hegemonie (vgl. Wullweber 2010: 315f).

\subsection{Die ÖKologische Krisendiagnose}

Bis in die 1970er Jahre wurde Umweltverschmutzung im Grunde als ein Problem wahrgenommen, dem man durch technologische End-of-pipe-Lösungen ${ }^{4}$ beikommen könne. Die Organisation der gesellschaftlichen Naturverhältnisse zeichnete sich durch ein klares Primat der industriellen Produktion aus, dem additive Umweltschutzmaßnahmen wie Partikelfilter oder Entschwefelungsanlagen nachgeschaltet waren (vgl. Hajer 1995: 25). Der Umgang mit Natur war durch den Glauben an eine fortschreitende Rationalisierung und an die Möglichkeit der Kontrolle von Natur durch Technologien geprägt (vgl. Becker/Jahn 2006: 66). Diese hegemoniale Diskursorganisation der gesellschaftlichen Naturverhältnisse, die ich als Modernisierung mit nachgeschaltetem Umweltschutz bezeichne, geriet mit der Diagnose einer ökologischen Krise ins Wanken. Phänomene wie der saure Regen, das Ozonloch, der anthropogene Klimawandel oder der Verlust der Biodiversität und der natürlichen Ressourcen wurden als Symptome einer ökologischen Krise identifiziert. Aufgrund dieser Erkenntnisse und Deutungen wurde in der politischen und wissenschaftlichen Öffentlichkeit ab den 1970er Jahren die Organisation der gesellschaftlichen Naturverhältnisse problematisiert. Angesichts der wahrgenommenen Zunahme der gesellschaftlichen Verursachung ökologischer Probleme wird das Verhältnis des Menschen zur Natur in ökologischen Debatten seitdem als krisenhaft begriffen (vgl. Brand 2010: 143; Görg 2003a: 9f).

4 Als End-of-pipe-Technologien werden Umweltschutzmaßnahmen bezeichnet, die den Produktionsprozess selber unangetastet lassen und die Umweltschäden durch nachgeschaltete Filter oder ähnliche Maßnahmen verringern. 
Mit der ökologischen Krisendiagnose geht eine Politisierung der gesellschaftlichen Naturverhältnisse einher (vgl. Becker/Jahn 2006: 66). Diese Politisierung stellt keine ,natürliche' Folge einer Steigerung ,objektiv' beobachtbarer Zivilisationsrisiken dar (vgl. Prittwitz 1993: 39). Stattdessen liegt ihr Grund in der Verbreitung der Deutung, dass die herkömmlichen gesellschaftlichen Strukturen nicht (mehr) angemessen auf ökologische Probleme reagieren können (vgl. Brand 2010: 143).

Die Umweltbewegungen, die sich Ende der 1960er Jahre zunächst in den USA und (West-)Europa formierten (vgl. Radkau 2011: 137), ${ }^{5}$ forderten einen grundsätzlich neuen Umgang mit der Ökologieproblematik und kritisierten die reine Symptombehandlung. Sie stellten das Selbstverständnis der ,westlichen“ Gesellschaften radikal infrage, insbesondere das zugrunde liegende Entwicklungsmodell der Moderne. Die Umweltbewegungen sahen die Ursachen der ökologischen Krise im Wachstumsprimat der Industriemoderne und den damit einhergehenden Produktions- und Konsummustern (vgl. Görg 2003a: 134f).

In den 1970er Jahren wurden ökologische Probleme somit nicht als isolierte Probleme betrachtet, sondern als Symptom einer generellen „Krise der Modernität“ (Görg 2003a: 135). Mit dem Verweis auf Ursachen, die in den gesellschaftlichen Strukturen begründet sind, kamen auch die sozialen Konsequenzen der ökologischen Krise stärker in den Blick und zogen Forderungen nach einem grundsätzlichen gesellschaftlichen Wandel nach sich. Abgelehnt wurden dagegen technokratische Antworten auf die Ökologieproblematik (vgl. Hajer 1995: 88f).

In dieser Phase brach das radikalere Spektrum der Umweltbewegungen mit der ihnen vom hegemonialen Diskurs zugewiesenen Subjektposition, welche die politischen Mittel der Lobbyarbeit und der Vertretung einer Interessengemeinschaft vorsah. Stattdessen etablierten sie einen eigenen Politikstil, der in einen alternativen Lebensstil eingebettet war und auf die Beeinflussung der Öffentlichkeit durch Massendemonstrationen, autonome Zeitungen und Radiosender setzte (vgl. Hajer 1995: 90). Die Veränderung des Aktionsrepertoires geht auf die engen Verbindungen - nicht nur, aber auch aufgrund personeller Kontinuitäten $-\mathrm{zu}$ den

5 Umweltbewegungen im weiteren Sinne hat es zwar schon mehrfach in der Geschichte gegeben, allerdings setzte spätestens mit Beginn der 1970er Jahre eine neue Phase ein. Eine Besonderheit war, dass nicht mehr ,die Sorge um die Natur als solche, sondern die Sorge um den Menschen“ (Radkau 2011: 193) im Mittelpunkt stand. Spezifisch für die 70er Jahre war darüber hinaus die Revitalisierung der Bewegungen und die Virulenz der politischen Auseinandersetzungen. Es scheint schwer, den einen hinreichenden Grund für diese Zäsur anzugeben (vgl. Radkau 2011: 161f), wobei der Zusammenhang mit den Protesten der Studierenden und der damit entstehenden Subkultur ab den 1960er Jahren sicherlich nicht zu unterschätzen ist (vgl. Radkau 2011: 156). 
Protesten der Studierenden und der damit entstehenden Subkultur ab den 1960er Jahren zurück (vgl. Radkau 2011: 156). In ihren antagonistischen Praktiken fokussierten die Umweltbewegungen auf den Widerstand gegen die Kernkraft (vgl. Hajer 1995: 91). Im Kampf gegen die Nutzung der Atomenergie spitzte sich ihre Skepsis gegenüber der Beherrschbarkeit von Natur zu.

Insgesamt ist festzuhalten, dass die antagonistischen Forderungen der Umweltbewegungen, die auf eine Neuaushandlung der Organisation gesellschaftlicher Naturverhältnisse zielten, wesentliche Impulse für eine Auseinandersetzung mit der ökologischen Krise in der breiten Öffentlichkeit gaben (vgl. Brand 2009: 105).

\subsection{Die Formierung des ÖKomodernen DiskURSES}

Im Verlauf der 1980er Jahre erlangten ökologische Fragen gesamtgesellschaftliche Relevanz und wurden vor allem in der Wissenschaft, aber auch von Entscheidungsträger_innen in Politik und Wirtschaft diskutiert (vgl. Huber 1993: 51; Huber 2011a: 279). Diese Entwicklung verschiedener Diskursstränge in den unterschiedlichen gesellschaftlichen Bereichen hatte Einfluss auf die Genese eines ökomodernen Diskurses, dessen Formierung ich im Folgenden rekonstruiere.

\subsubsection{Die Formierung des ökomodernen Diskurses im Club of Rome}

Eine herausragende Rolle für die gesellschaftlichen Auseinandersetzungen mit der ökologischen Krise spielte der 1972 erschienene Bericht über die Grenzen des Wachstums (vgl. Brand 2010: 143; Hajer 1995: 83f). Die Studie „The Limits to Growth" wurde vom Club of Rome, einem 1968 gegründeten Thinktank, in Auftrag gegeben und wird deshalb auch als Club-of-Rome-Bericht bezeichnet. Maarten Hajer sieht den Grund für den Erfolg des Berichts in der theoretischen Fundierung durch die Kybernetik. Die Kybernetik ist eine Wissenschaftsperspektive, die sich mit der Steuerung und Regelung biologischer, technischer und sozialer Systeme beschäftigt. Laut Hajer war sie in den 1970er Jahren bei Entscheidungsträger_innen sehr beliebt, die in ihr die Möglichkeit sahen, trotz wachsender Komplexität sozialer Verhältnisse rationale und wissenschaftlich fundierte Entscheidungen fällen zu können (vgl. Hajer 1995: 81). Umgekehrt verstanden die Autor_innen des Clubof-Rome-Berichts die Entwicklung ihres Weltmodells als eine Reaktion auf die mangelhafte Versorgung der ,entscheidenden Stellen' mit wissenschaftlichen Analysen und Prognosen (vgl. Meadows et al. 1972: 109). Der Bericht bot somit eine ideale Grundlage für Weißbücher (vgl. Hajer 1995: 82). 
Mit dem Erfolg des Berichts wurde die Deutung der Ökologieproblematik als globale Krise für breite gesellschaftliche Kreise plausibel. Konstitutiv für diese bis heute dominante Deutung ist, dass die sozial und lokal sehr unterschiedlichen Verursachungen und Betroffenheiten von ökologischen Problemen ausgeblendet werden (vgl. Brunnengräber et al. 2008: 57ff). Mit all ihren problematischen Aspekten hat sich diese Fassung der ökologischen Krise durchgesetzt - besonders ersichtlich am Beispiel der internationalen Klimapolitik, die auf eine Begrenzung der Treibhausgaskonzentration in der Atmosphäre zielt - und stellt einen wichtigen Schritt in der Entwicklung des ökomodernen Diskurses dar.

Die Antwort auf die ökologische Krise wird vom Club of Rome in der verstärkten Anwendung von wissenschaftlicher Betriebsführung gesehen. Bleibt dies in The Limits to Growth noch etwas vage, so werden in weiteren Berichten des Club of Rome unter anderem folgende Lösungsvorschläge behandelt: verstärkte internationale politische Zusammenarbeit, Erstellung eines WeltressourcenManagement-Plans, Liberalisierung des Handels sowie Kooperation multinationaler Konzerne im Hinblick auf die Industrialisierung und Entwicklung der Landwirtschaft im globalen Süden (vgl. Hajer 1995: 83). In The Limits to Growth wird zunächst - ohne konkrete Umsetzungsvorschläge - auf abstrakter Ebene die rationale Steuerung relevanter Regelkreise propagiert, um ein möglichst stabiles System, einen Gleichgewichtszustand herzustellen. Damit soll das exponentielle Wachstum von Bevölkerungszahl und Kapital, das nach Meinung der Autor_innen zum katastrophalen Zusammenbruch führen würde, verhindert werden (vgl. Meadows et al. 1972: 129). Die Wissenschaftler_innen vertrauen dabei auf die rationale Anwendung kybernetischer Erkenntnisse durch, entscheidende Stellen“ und nicht auf politische Auseinandersetzungen. Insofern hoffen sie darauf, „daß vielleicht auch die Forschung bald bessere Daten liefern kann“ (Meadows et al. 1972: 108) und lehnen Denkmodelle ab, ,die eine Mischung unvollständiger Information und Intuition darstellen und denen meistens politische Entscheidungen zugrunde liegen" (Meadows et al. 1972: 109; Hervorhebung T. K.). Hier wird bereits ein technokratischer Einschlag deutlich, der eine Konstante im ökomodernen Diskurs bleiben wird.

Der Bericht war ein Katalysator für die Entstehung einer Diskurskoalition, welche die Bedrohlichkeit der ökologischen Krise anerkannte, ohne daraus eine Modernisierungskritik abzuleiten. Stattdessen wurde die Lösung in verbesserter Organisation, Wirtschaftlichkeit und wissenschaftlichem Fortschritt gesehen - sprich: in fortschreitender Rationalisierung unter kybernetischem Vorzeichen (vgl. Hajer 1995: 83f). In dem Zusammenhang verweist Hajer auf Gemeinsamkeiten zwischen den Vorschlägen der Expert_innen und dem radikalen Teil der Umweltbewegungen. Seiner Meinung nach deuteten beide Gruppen die Ökologieproblematik als eine 
Frage des Überlebens und sahen in den wissenschaftlichen Strömungen der Kybernetik und der Ökologie Lösungspotenziale (vgl. Hajer 1995: 86). Dagegen trauten beide Gruppen den klassischen staatlichen Maßnahmen nicht zu, die strukturellen Probleme lösen zu können. Damit trugen sie dazu bei, die Legitimation der eher traditionellen Konzepte und Praktiken konventioneller Umweltpolitik - wie zum Beispiel Umweltauflagen zur Vermeidung von Schadstoffen - zu untergraben (vgl. Hajer 1995: 86f). Allerdings unterschieden sich die Gruppen in Bezug auf ihre Positionen zu den gegebenen Machtverhältnissen und zur Rolle von Eliten. Für die Koalition der technokratischen Expert_innen, für deren Entstehung laut Hajer der Club-of-Rome-Bericht Auslöser war, lag die Forderung nach Vernetzung und Zusammenarbeit der Eliten auf der Hand. Dagegen formulierte die aus den sozialen Bewegungen kommende Koalition, die Hajer eher durch die Publikationen „Small is Beautiful“ (Ernst Friedrich Schumacher, 1973) und „Blueprint for Survival“ (Edward Goldsmith und Robert Allen, 1972) geprägt sieht, radikale Kritik an sozialen Verhältnissen (vgl. Hajer 1995: 86).

\subsubsection{Die Formierung des ökomodernen Diskurses in der Wissenschaft}

Die große Bedeutung des Club-of-Rome-Berichts ist bereits ein erster Hinweis darauf, dass die Entwicklung des ökomodernen Diskurses besonders innerhalb der Wissenschaft vorangetrieben wurde. Dabei waren die Übergänge von politischem Programm und wissenschaftlicher Theorie immer fließend. Gerade in der Anfangsphase spielte die politische Dimension auch bei den wissenschaftlichen Publikationen eine wichtige Rolle (vgl. Mol/Jänicke 2009: 18; Spaargaren/Mol 2009: 72f). Martin Jänicke beansprucht für sich, den konkreten Wortlaut der ,ökologischen Modernisierung' in einer Debatte des Berliner Abgeordnetenhauses vom 22. Januar 1982 eingeführt zu haben (vgl. Jänicke 1993: 18). An diesem Ereignis wird die besondere Verquickung der politischen und wissenschaftlichen Motivation deutlich, die auch mit der Doppelfunktion einzelner Protagonist_innen einher ging. Wissenschaftliche und politische Dimensionen des ökomodernen Konzepts verband dabei die Annahme, dass Wirtschaftswachstum und Umweltschutz nicht im Widerspruch zueinander stehen müssen (vgl. Huber 2011a: 279).

Bereits in den 1970er Jahren gab es - prominent vertreten durch Martin Jänicke und Joseph Huber - Beiträge, die sich der wissenschaftlichen Erarbeitung eines Konzepts der ökologischen Modernisierung widmeten (vgl. Hajer 1997: 108; Huber 1993: 55). Auch wenn der Terminus der ,ökologische Modernisierung' seine Ursprünge in der deutschsprachigen Wissenschaft hat, fällt im internationalen Vergleich eine strukturelle Ähnlichkeit mit anderen Neukonzeptionalisierungen der 
Umweltprobleme zur damaligen Zeit auf (vgl. Hajer 1997: 108). Zunächst wurden verschiedene Einzelaspekte des Ansatzes entwickelt, die nach und nach auf der Basis des modernisierungstheoretischen Paradigmas zusammengefügt wurden (vgl. Huber 2011a: 279). Was die theoretische Weiterentwicklung des Ansatzes betrifft, spielten neben Huber auch niederländische sowie englische und skandinavische Autor_innen eine wichtige Rolle (vgl. Mol/Jänicke 2009). Bereits in den 1990er Jahren erlangte das Konzept der ökologischen Modernisierung eine internationale Breitenwirkung (vgl. Jänicke 2001: 2).

In relativ kurzer Zeit entwickelte sich in der Wissenschaft ein ökomoderner Diskursstrang, der mit vielen Basisannahmen der ökologischen Kritik, wie sie von den Umweltbewegungen vertreten wurde, brach. Diese Einschätzung gibt Huber selber in einem Sammelband von 1993 wieder:

„Ein Fachkompendium wie dieses unter der Überschrift, Umweltpolitik als Modernisierungsprozess “ wäre noch bis Mitte der 80er Jahre als Widerspruch in sich aufgefaßt worden. Denn unter Modernisierung verstand man im Kern Industrialisierung und Wirtschaftswachstum, und diese galten als Hauptursache der Umweltprobleme.“ (Huber 1993: 51)

Er hält fest, dass ,ökologisches Wirtschaftswachstum‘ als Beitrag zur Lösung der Umweltprobleme bis Mitte der 1980er Jahre in keiner Weise konsensfähig war. Dagegen konstatiert er für den Beginn der 90er Jahre, dass ,,bereits große Minderheiten, wenn nicht schon die Mehrheit, eine solche Vorstellung für einlösbar hält" (Huber 1993: 51). Dieser Stimmungswandel kann jedoch nicht allein auf wissenschaftliche Publikationen zurückgeführt werden. Es bedurfte zusätzlich einflussreicher Akteur_innen in anderen Bereichen, die sich die ökologische Modernisierung auf die Fahnen schrieben.

\subsubsection{Die Formierung des ökomodernen Diskurses in der Politik}

Katalytische Wirkung für die Beschäftigung mit der Ökologieproblematik auf der Ebene internationaler Politik hatte, neben dem 1972 erschienenen Club-of-RomeBericht zu den Grenzen des Wachstums, die im gleichen Jahr stattfindende Weltumweltkonferenz in Stockholm. Auf der United Nations Conference on the Human Environment wurde eine Deklaration mit Prinzipien für zukünftige Umwelt- und Entwicklungspolitik, sowie ein Aktionsplan mit empfohlenen Maßnahmen beschlossen. Darüber hinaus wurde das Umweltprogramm der Vereinten Nationen gegründet (United Nations Environment Programme, UNEP), das im Verlauf der politischen Auseinandersetzungen um die ökologische Krise wichtige Akzente setzte (vgl. Dingler 2003: 214f). 
Ein weiteres zentrales Ereignis für die Etablierung einer ökomodernen Umweltpolitik war die Ölkrise im Jahr 1973, die den Warnungen vor der Erschöpfung natürlicher Ressourcen zu Aufmerksamkeit verhalf. Gleichzeitig führte die durch die Ölkrise ausgelöste weltweite wirtschaftliche Rezession zum Erstarken eines einflussreichen ökonomischen Diskurses der Standortpolitik, der wirtschaftlichen Aufschwung durch die Sicherung von Wettbewerbsvorteilen versprach (vgl. Brand 2008: 225). Die weit verbreiteten Ängste vor Inflation und Massenarbeitslosigkeit hatten Einfluss auf die ökologischen Debatten, in denen die Kritik am Wirtschaftswachstum zunächst stark polarisierend wirkte und ab den 1980er Jahren nach und nach zur Randposition wurde (vgl. Hajer 1995: 94f).

Für die durch die Ölkrise verschärften Auseinandersetzungen um die ökologische Krise geht Hajer davon aus, dass insbesondere auf der Ebene inter- und transnationaler Politik die verschiedenen Diskursstränge zu einem kohärenten politischen Konzept der ökologischen Modernisierung geformt und als Grundlage von Politikformulierung etabliert wurden. Entscheidende Institutionen in diesem Prozess waren unter anderem die Organisation für wirtschaftliche Zusammenarbeit und Entwicklung (OECD), das Umweltprogramm der Vereinten Nationen (UNEP), die Kommission der Vereinten Nationen für Nachhaltige Entwicklung (CSD), der von den Vereinten Nationen eingerichtete Sachverständigenrat der Weltkommission für Umwelt und Entwicklung (WCED) sowie gemäßigte Nichtregierungsorganisationen (NGOs) wie die Internationale Union für die Bewahrung der Natur und natürlicher Ressourcen (IUCN) und der World Wide Fund For Nature (WWF) (vgl. Hajer 1995: 101).

Steven Bernstein betont in dem Zusammenhang den starken Einfluss der OECD, der für den ökonomischen Bereich große Kompetenzen zugesprochen wurden. Diesen Einfluss nutzte sie, um den immer wichtiger werdenden ökologischen Debatten eine neue Richtung zu geben, so dass sie in die wachstumsorientierten ökonomischen Konzepte integriert werden konnten (vgl. Bernstein 2000: 495). Ihr Plädoyer für die Aufhebung des Gegensatzes von Umweltschutz und Wirtschaftswachstum hatte große Wirkung auf Multiplikator_innen und Entscheidungsträger_innen. Die International Conference on Environment and Economics der OECD aus dem Jahre 1984 bezeichnet Bernstein dabei als „key event“ (Bernstein 2000: 495). Als Fazit der Konferenz galt die These, dass sich ökologische und ökonomische Ziele - bei kluger Steuerung - nicht widersprechen, sondern gegenseitig positiv beeinflussen. Beide Zielformulierungen würden technologische Innovationen fördern, von denen die Erreichung der Ziele abhänge (vgl. Hajer 1995: 99). Der Einfluss dieser Konferenz im Besonderen und der OECD im Allgemeinen zeigt sich in der Übernahme einiger Grundannahmen und Schlussfolgerungen durch die 
WCED. Für diese Verbindung spricht auch die Personalie Jim MacNeill, der bis 1984 für die OECD als Environment Director arbeitete und damit für die Organisation der besagten Konferenz verantwortlich war. Anschließend hatte er als außerordentliches Mitglied großen Einfluss auf den Bericht der WCED (vgl. Bernstein 2000: 496f).

Huber betont - im Gegensatz zu Bernstein - die Bedeutung sozialdemokratischer Politiker_innen wie Gro Harlem Brundtland und Volker Hauff, durch die seiner Meinung nach ,wesentliche Elemente einer Strategie ökologischer Modernisierung Eingang in den Brundtland-Report (Weltkommission für Umwelt und Entwicklung 1987) und damit in das Leitbild der nachhaltigen Entwicklung gefunden haben“" (Huber 2011b: 143).

Dieser 1987 erschienene Bericht der WCED, „Our Common Future“ (oftmals als Brundtland-Bericht bezeichnet, benannt nach der damaligen Vorsitzenden der Kommission Gro Harlem Brundtland), wird von vielen Autor_innen als paradigmatischer Text des ökomodernen Diskurses hervorgehoben, der die konzeptionelle Grundlage für die Umweltpolitik der 1990er Jahre legte (vgl. Bäckstrand/Lövbrand 2006: 52f; Brand 2010: 143; Hajer 1995: 8f, 26; Hajer 1997: 108). Im Zentrum von Our Common Future steht die Idee eines dauerhaften menschlichen Fortschritts, der durch die ökologische Krise in Gefahr gerate, aber durch nachhaltige Entwicklung (,Sustainable Development ${ }^{6}$ ) aufrecht erhalten werden könne (vgl. Dingler 2003: 313). Nachhaltige Entwicklung wird somit als rationale Intervention zur Stabilisierung des Fortschritts gefasst, um die Befriedigung menschlicher Bedürfnisse, sowohl der jetzigen als auch der zukünftigen Generationen, zu sichern.

Damit steht Sustainable Development in der Tradition der Entwicklungstheorien der ersten Nachkriegsjahrzehnte, die auf die Universalisierung des ,westlichen“ Zivilisationsmodells der Moderne zielen. Das Paradigma der Entwicklungstheorie zeigt sich auch in der im Bericht vertretenen Annahme, dass Armut ein wesentlicher Grund für die ökologische Krise sei (vgl. Weltkommission für Umwelt und Entwicklung 1987: 3). ${ }^{7}$ Im Bericht wird davon ausgegangen, dass Armut zu unkontrollierter und ineffizienter Ressourcennutzung und damit $\mathrm{zu}$ Umweltzerstörung

6 In der World Conservation Strategy, die 1980 vom UN-Umweltprogramm und dem WWF publiziert wurde, tauchte der Begriff ,Sustainable Development' zum ersten Mal in einem internationalen Dokument auf (vgl. Dingler 2003: 215). Bekanntheit erlangte er aber vor allem mit dem Erfolg des Brundtland-Berichts.

7 Daneben werden zwar auch manche Formen des Wirtschaftens in den Industriegesellschaften als Ursachen für Umweltprobleme genannt, insgesamt wird diesen aber weniger Aufmerksamkeit geschenkt als der Verursachung von Umweltzerstörung durch Armut (vgl. Dingler 2003: 225). 
führe (vgl. Weltkommission für Umwelt und Entwicklung 1987: 7f, 10). Sustainable Development basiert auf dem klassischen Entwicklungsbegriff, der um eine Nachhaltigkeitskomponente ergänzt wird. Diese Vorstellung von nachhaltiger Entwicklung soll durch das konzeptionelle Dreieck, bestehend aus ökologischen, ökonomischen und sozialen Kriterien, realisiert werden (vgl. Dingler 2003: 222f, 311). Das Kernanliegen des Brundtland-Berichts ist dabei die Versöhnung von Umweltschutz und Wirtschaftswachstum.

„In unserem Bericht, der den Titel ,Unsere gemeinsame Zukunft" trägt, prognostizieren wir daher auch kein Umsichgreifen des ökologischen Zerfalls in einer von wachsender Not und Armut sowie zunehmender Umweltverschmutzung und immer knapper werdenden Ressourcen gekennzeichneten Welt. Wir sehen vielmehr sehr wohl Chancen für eine neue Ära des wirtschaftlichen Wachstums; eine Ära, die aufbauen muß auf der Bewahrung alter und der Nutzung neuer, in unserer Umwelt vorhandener Ressourcen." (Weltkommission für Umwelt und Entwicklung 1987: 1f; Hervorhebung T. K.)

Es sind vor allem zwei Argumente, die plausibel machen sollen, warum Umweltschutz und Wirtschaftswachstum nicht nur keinen Widerspruch darstellen, sondern sich sogar gegenseitig bedingen. Das erste Argument ist, dass Wirtschaftswachstum notwendig sei, um Armut und damit Umweltzerstörung überwinden zu können (vgl. Weltkommission für Umwelt und Entwicklung 1987: 7f, 10). Das zweite Argument besteht in der Reformulierung der Grenzen des Wachstums. Werden im Club-ofRome-Bericht noch absolute Grenzen, die in der Natur begründet sind, angenommen, so geht der Brundtland-Bericht von relativen Grenzen aus, die sich aus den verwendeten Technologien und der Gesellschaftsorganisation ergeben. Diese relativen Grenzen, so die These, könnten durch neue wissenschaftliche Erkenntnisse, technologischen Fortschritt und adäquates Management immer weiter ausgedehnt werden (vgl. Weltkommission für Umwelt und Entwicklung 1987: 10). Das Plädoyer zielt dann nicht auf die Anerkennung der Grenzen des Wachstums, sondern vielmehr auf die Realisierung eines Wachstums der Grenzen (vgl. Dingler 2003: 224ff).

Mit dem Konzept der Sustainable Development brachte der Brundtland-Bericht einflussreiche Institutionen wie die Weltbank und den Internationalen Währungsfonds (IWF) dazu, ihre ablehnende Haltung gegenüber ökologischen Debatten aufzugeben (vgl. Hajer 1995: 12). Auch innerhalb der Welthandelsorganisation (World Trade Organisation, WTO) ermöglichte die programmatische Verschiebung von den Grenzen des Wachstums zum Wachstum der Grenzen und zur Sustainable Development die Thematisierung ökologischer Probleme (vgl. Eglin 1995: 770), allerdings ohne dass grundsätzliche Konsequenzen daraus gezogen oder die konkreten sozialökologischen Folgen der Freihandelspolitik analysiert worden wären (vgl. Santarius et al. 2003: 58). Darüber hinaus beeinflusste der Brundtland-Bericht die Strategien 
wichtiger Umweltorganisationen des globalen Nordens, die sich positiv auf ihn beriefen, um Einfluss auf politische und wirtschaftliche Entscheidungsträger_innen nehmen zu können (vgl. Mol/Sparrgaren/Sonnenfeld 2009: 5). Von den radikaleren Teilen der Umweltbewegungen wurde das Konzept der Sustainable Development allerdings kritisiert, da sie darin vor allem eine Strategie der Aufrechterhaltung des Wachstumsgedankens (,to sustain development") sahen, welche die tatsächlichen Ursachen der ökologischen Krise nicht benennen würde (vgl. Hajer 1995: 12).

Im Anschluss an den Brundtland-Bericht war die Konferenz der Vereinten Nationen über Umwelt und Entwicklung 1992 in Rio de Janeiro (im Folgenden: Rio-Konferenz) ein weiteres wichtiges Ereignis in der Herausbildung und Verbreitung des ökomodernen Diskurses. Mit der Konferenz wurde das Konzept der nachhaltigen Entwicklung im internationalen politischen System verankert. Stärker als im Brundtland-Bericht rückten in Rio die industrialisierten Länder als Hauptverursacher der ökologischen Krise in den Mittelpunkt (vgl. Dingler 2003: 234). Die Ursachen der ökologischen Krise wurden in einer mangelnden Effizienz und einer mangelnden Modernisierung bestimmter Produktionsmuster gesehen, aber nicht im Wirtschaftswachstum selbst. Als Lösungen wurden Effizienzsteigerungen, neue Technologien und ein wissenschaftliches Ressourcenmanagement vorgeschlagen (vgl. Dingler 2003: 233ff). Auf der Rio-Konferenz wurde die Konvention über biologische Diversität, die Klimarahmenkonvention, ein Dokument über Prinzipien des Waldmanagements, die Rio-Erklärung über Umwelt und Entwicklung und die Agenda 21 verabschiedet. Gerade durch die Agenda 21, die viele Prozesse auf kommunaler Ebene anstieß (vgl. Brand 2008: 229), trug die RioKonferenz zur Verbreitung des Konzepts der nachhaltigen Entwicklung bei, das zur Leitlinie öffentlichen Handelns wurde (vgl. Dingler 2003: 240).

20 Jahre nach der Rio-Konferenz fand 2012 ebenfalls in Rio de Janeiro erneut eine internationale Umweltkonferenz statt. Diese Konferenz der Vereinten Nationen über nachhaltige Entwicklung wird in Anspielung an die erste Rio-Konferenz auch als Rio+20 bezeichnet. Im Vorfeld von Rio+20 publizierte die 2008 vom UNUmweltprogramm gegründete Green Economy Initiative (GEI) den Bericht „Towards a Green Economy: Pathways to Sustainable Development and Poverty Eradication". Aufgrund der Positionierung verschiedener Akteur_innen stand Green Economy als zentraler Diskussionsrahmen bereits im Vorfeld der Rio+20-Konferenz fest. Neben dem UN-Umweltprogramm kamen die Initiativen von der Grünen Partei (v. a. in Deutschland) und der Heinrich-Böll-Stiftung, von Teilen der Gewerkschaften und der Sozialdemokratie, von der Europäischen Kommission (EU-Kommission) und der OECD, von innovativen Unternehmen und ökologisch orientierten Investmentfonds, von Gremien wie dem Wissenschaftlichen Beirat der 
deutschen Bundesregierung Globale Umweltveränderungen und Thinktanks wie der New Economics Foundation sowie der mit ihr verbundenen Green New Deal Group in Großbritannien (vgl. Wissen 2012: 28).

Das Konzept einer Green Economy, wie es unter anderem im GEI/UNEPBericht ausgearbeitet und auf der Konferenz diskutiert wurde, gilt als Weiterentwicklung von Sustainable Development. Der Hauptunterschied liegt - trotz Betonung der Kontinuität zur Konferenz von 1992 und zum Ansatz der Sustainable Development - in der Schwerpunktverlagerung innerhalb des sogenannten Nachhaltigkeitsdreiecks. Der stärkere Fokus auf ökonomische Prozesse im Vergleich zu sozialen und ökologischen Aspekten der Nachhaltigkeit (vgl. UNEP 2011: v) zeigt sich bereits im Begriff der Green Economy. Diese Schwerpunktsetzung wird mit der großen Wirksamkeit der ökonomischen Instrumente nachhaltiger Entwicklung begründet. Dahinter steckt die Annahme, dass der beste Schutz der Natur in ihrer Inwertsetzung liege (vgl. UNEP 2011: 6ff).

In dem GEI/UNEP-Bericht wird die Green Economy als Königsweg zur Armutsbekämpfung und $\mathrm{zu}$ einer ,nachhaltigen Entwicklung' präsentiert (vgl. UNEP 2011: 38). Green Economy gilt als Schlüssel, um das Gemeinwohl in seinen vielen Facetten verwirklichen zu können (vgl. UNEP 2011: 2). Im Kern des Konzepts steht die Idee eines nachhaltigen Wachstums, mit dem neben den ökonomischen auch soziale und ökologische Ziele erreicht werden. Wirtschaftswachstum soll in einer Green Economy über Investitionen erfolgen, die den Ausstoß von Treibhausgasen reduzieren, Energie- und Ressourceneffektivität vorantreiben und damit die Biodiversität sowie die ,Ökosystemdienstleistungen“ (ecosystem services $^{8}$ ) erhalten (vgl. UNEP 2011: 2). Das Verhältnis zur Natur ist in dem Konzept durch eine radikal ökonomische Sicht gekennzeichnet, in der Natur ein wirtschaftlicher Wert zugemessen wird (vgl. UNEP 2011: 5). Die Inwertsetzung von Natur gilt dabei zum einen als ideales Mittel für Umweltschutz und zum anderen als Zweck von Umweltschutz.

„The development path should maintain, enhance and, where necessary, rebuild natural capital as a critical economic asset and as a source of public benefits, especially for poor people whose livelihoods and security depend on nature.“(UNEP 2011: 2)

Die Bedeutung der Rio+20-Konferenz für die Auseinandersetzungen um die ökologische Krise sind ambivalent einzuschätzen. Mit der Green Economy wurde zwar ein neuer Begriff geprägt, der eine entscheidende Verschiebung innerhalb des ökomodernen Diskurses bedeutet und auf den sich viele Akteur_innen berufen. Die

8 Mit dem Begriff der ecosystem services werden die, Dienstleistungen“ der Natur bzw. der Nutzen, den Menschen aus ökologischen Systemen ziehen, bezeichnet. 
konkreten Ergebnisse der Konferenz werden allerdings - anders als bei der RioKonferenz des Jahres 1992 - vermutlich kaum Einfluss auf zukünftige umweltpolitische Aushandlungsprozesse haben. Die Delegierten einigten sich auf die Abschlusserklärung The Future We Want, in der viele Ziele formuliert, aber weder konkrete Umsetzungsstrategien noch verbindliche Vereinbarungen enthalten sind, weshalb sie von NGOs stark kritisiert wurde (vgl. Hmaidan 2012).

Die dargestellten Entwicklungen auf der Ebene internationaler Umweltpolitik stehen in einem engen, wechselseitigen Verhältnis zu den umweltpolitischen Dynamiken in verschiedenen Nationalstaaten. Besonders früh hat sich das japanische Wirtschaftsministerium mit ökomodernen Ideen beschäftigt, allerdings ohne Verwendung des Begriffs und ohne auf die erst später einsetzenden wissenschaftlichen Debatten zurückgreifen zu können. Bereits 1974 entwickelte das Ministerium ein Konzept der wissensintensiven und ressourcensparenden Wirtschaft (vgl. MITI 1974; Mol/Jänicke 2009: 17). Im gleichen Jahr lancierte es auch das Sunshine Project zur Förderung der Erforschung erneuerbarer Energien (vgl. im Internet: www.meti.go.jp/english/aboutmeti/data/ahistory2009.html, letzter Zugriff am 02.12.2014).

Für die Entwicklung in Deutschland beschreibt Jänicke, dass der sich entwickelnde ökomoderne Diskurs ab den 1980er Jahren die umweltpolitischen Debatten der Sozialdemokratie und der Gewerkschaften stark beeinflusste (vgl. Jänicke 1993: 18; Jänicke 2001: 2). Mit dem Bündnis 90/Die Grünen nahm sich später eine weitere Partei des Konzepts an, so dass die rot-grüne Bundesregierung in der Koalitionsvereinbarung von 1998 explizit ein Programm der ökologischen Modernisierung formulierte (vgl. Jänicke 2001: 2).

Auch in anderen Industrieländern setzte sich der ökomoderne Diskurs durch, in der Regel ohne dass die Nationalstaaten durch zwischenstaatliche Abkommen oder Verträge dazu verpflichtet gewesen wären. Grundsätzlich waren Regierungen bestrebt, der Kritik von Seiten der Umweltbewegungen und der Wissenschaft eigene umweltpolitische Impulse entgegen zu setzen. Dabei führten vor allem Effekte der Nachahmung, der Durchsetzung von neuen Normen und die Orientierung an internationalen Organisationen dazu, dass es eine Diskursverschiebung hin zu ökomodernen Deutungsmustern und Praktiken gab (vgl. Busch/Jörgens/Tews 2005). Huber hebt in dem Zusammenhang die Bedeutung des weit verbreiteten Glaubens an Lösungen durch technologische Entwicklungen hervor:

„Im Hinblick auf die Erreichbarkeit der Ziele ökologischer Nachhaltigkeit, speziell auch in der Klimapolitik, ist ökologische Modernisierung durch technologisch-industrielle Innovation zum regierungsoffiziellen Credo in den fortgeschrittenen Industriestaaten geworden." (Huber 2011a: 288) 
Insgesamt gab es ab Mitte der 1980er Jahre einen Trend, in dem die grundlegenden ökomodernen Ideen und damit spezifische Problemdefinitionen und Lösungsstrategien sowohl in verschiedenen Industrienationen als auch in internationalen Organisationen wie der UN, der OECD und der Europäischen Union an Einfluss gewannen (vgl. Hajer 1995: 26). Allerdings standen die Länder des globalen Südens dem plötzlichen Interesse der Industrienationen an ökologischen Themen zunächst skeptisch gegenüber. Sie vermuteten darin den Versuch, von den Fragen nach Entwicklung und Umverteilung abzulenken (vgl. Hajer 1995: 79).

\subsubsection{Die Formierung des ökomodernen Diskurses in der Wirtschaft}

Die überwiegende Zahl der Unternehmen und Wirtschaftsverbände hat sich bislang kaum mit der ökologischen Krise beschäftigt und steht Umweltschutzmaßnahmen passiv bis abwehrend gegenüber (vgl. Pulver 2011: 583, 585). Die wenigen Unternehmen und Verbände allerdings, die sich aktiv in die Auseinandersetzungen um die ökologische Krise eingebracht haben, sind dabei relativ einflussreich gewesen. So gehen bestimmte Entwicklungen des ökomodernen Diskurses - wie die Zurückdrängung dirigistischer und die Bevorzugung marktorientierter Instrumente - unter anderem auf die Lobbyarbeit einzelner Unternehmen oder Verbände, insbesondere aus dem Finanz- und Energiesektor, zurück (vgl. Ihlen 2009: 246; Kolk/Levy 2001: 501; Meckling 2011; Rest 2011: 114).

Spätestens in der zweiten Hälfte der 1990er Jahre wurde es für die Lobby der Energiekonzerne und der energieintensiven Branchen immer schwieriger, die ökologische Krise glaubhaft zu leugnen. Dennoch investier(t)en weiterhin einzelne Konzerne aus diesem Bereich viel Geld in die Verbreitung klimaskeptischer Positionen (vgl. Brunnengräber 2013; im Internet: www.greenpeace.org/kochindustries, letzter Zugriff am 02.12.2014). Andere Konzerne wiederum verlegten sich auf subtilere Formen der Verhinderung oder zumindest Verzögerung von politischen Vorgaben. Beispielsweise im Rahmen der Global Climate Coalition (GCC) wiesen Unternehmen vermehrt auf die generelle Ungewissheit wissenschaftlicher Prognosen hin und zogen bestimmte unliebsame wissenschaftliche Erkenntnisse in Zweifel - unter anderem durch eigens in Auftrag gegebene Studien. Weiterhin betonten sie die negativen Folgen, die eine umweltpolitische Regulierung ihrer Meinung nach für die Wirtschaft hätte (vgl. Fauset 2008: 15). Gleichzeitig wuchs die Zahl derjenigen Unternehmen, die ihre Fundamentalopposition aufgaben. Diese Unternehmen versprachen sich von der Ablehnung jeglicher Veränderung ihres Geschäftsmodells nur noch wenig Erfolg. 
Deshalb gingen einzelne Unternehmen und Verbände mehr und mehr dazu über, die Art und Weise der umweltpolitischen Regulierung - beispielsweise hin zu marktkonformen Lösungen - zu beeinflussen (vgl. Ihlen 2009: 246). Die Ausarbeitung und Festschreibung der flexiblen Mechanismen ${ }^{9}$ des Kyoto-Protokolls ging unter anderem auf einen Wandel der Lobby-Strategie - von der reinen Abwehrhaltung hin zur Befürwortung einer bestimmten politischen Bearbeitung - eines Teils der großen Konzerne zurück (vgl. Meckling 2011). So setzte sich der World Business Council for Sustainable Development (WBCSD), eine Lobbyorganisation in der über 100 Konzerne Mitglied sind, bei den UN-Klimaverhandlungen für flexibilisierende Mechanismen ein (vgl. Najam 2013: 37).

Weiterhin initiierte beispielsweise der Erdölkonzern BP vor den Verhandlungen in Kyoto die Bildung einer Koalition aus Wirtschaftsverbänden und Umwelt-NGOs, um marktorientierte Instrumente durchzusetzen (vgl. Kolk/Levy 2001: 501). Im gleichen Zeitraum begann BP verstärkt in Solarenergie zu investieren und übernahm 1999 die Fotovoltaikfirma Solarex. Im Juli 2000 präsentierte BP, was ursprünglich für British Petroleum stand, ein neues, grünes Markensymbol mit dem Slogan BP - Beyond Petroleum (vgl. Kolk/Levy 2001: 505). Tatsächlich sind die Investitionen von BP in erneuerbare Energien nach wie vor marginal. Über $90 \%$ der Gesamtinvestitionen fließen weiterhin in fossilen Brennstoffe.

In Bezug auf die BP-Kampagne Helios Power aus dem Jahre 2007 zeigen Karl Smerecnik und Valerie Renegar, wie die verwendete Rhetorik bestimmte Umweltschutz-Aktivitäten in den Mittelpunkt rückt und andere gar nicht benennt und damit der Aufmerksamkeit entzieht (vgl. Smerecnik/Renegar 2010: 153). Dabei arbeitet BP vor allem mit dem Inkrementalismus - der Vorstellung, mit kleinen Schritten in die richtige Richtung zu einer Lösung komplexer sozialer Probleme zu kommen. Eine inkrementelle Vorgehensweise vermeidet Umbrüche. Stattdessen sollen die bestehenden Strukturen so lange wie möglich ausgebaut und optimiert werden. Über die inkrementelle Strategie - die schon im zentralen Slogan der Kampagne, A little better gas station, deutlich wird - kann BP versichern, zur Lösung ökologischer Probleme beizutragen, ohne weitreichende Schritte in diese Richtung unternehmen zu müssen. Vor allem wird über den Inkrementalismus die aktuelle Nutzung fossiler Brennstoffe legitimiert, so lange es in naher Zukunft a little better passiert, sprich mit etwas saubereren Technologien (vgl. Smerecnik/Renegar 2010: 162). Als

9 Im Kyoto-Protokoll sind drei marktbasierte Mechanismen festgelegt, deren Zweck es ist, die Einhaltung der Obergrenzen für die Annex-B-Staaten möglichst kostengünstig zu gestalten: der Emissionsrechtehandel, der Mechanismus für umweltverträgliche Entwicklung (Clean Development Mechanism, CDM) und die Gemeinsame Umsetzung (Joint Implementation, JI) (für eine ausführliche Erläuterung vgl. Kapitel 5.1.2). 
positive Norm zum Umgang mit ökologischen Problemen wird in der Kampagne der Markt bzw. Marktmechanismen, die Produktion von Gütern durch ,grüne Unternehmen“ und die Konsumtion der Güter durch ,kritische Konsument_innen“ propagiert. Ausgeblendet werden dagegen Lösungsvorschläge oder Aktivitäten, die im Widerspruch zum Streben nach Wirtschaftswachstum stehen könnten (vgl. Smerecnik/Renegar 2010: 166). Die in der Kampagne pointiert artikulierte Hoffnung auf inkrementelle Verbesserungen - innerhalb der gegebenen strukturellen Rahmenbedingungen - ist ein wichtiges Element des ökomodernen Diskurses.

Mittlerweile verzichtet BP wieder darauf, sich als möglichst ökologisch zu präsentieren. Die Propagierung der ökologischen Modernisierung des Unternehmens ging auf die Initiative des damaligen Vorstandsvorsitzenden John Browne zurück. Seit dessen Rücktritt im Jahre 2007 sind die ökomodernen Ambitionen wieder in den Hintergrund getreten. Die Aktivitäten im Bereich der erneuerbaren Energien wurden zurückgefahren, gleichzeitig investiert BP in den besonders schädlichen Abbau von Ölsand in Kanada (vgl. im Internet: www.theguardian.com/business/ 2010/may/17/tar-sands-extraction-friends-earth, www.greenpeace.org.uk/files/tarsands/ tar-sands.html, letzter Zugriff am 02.12.2014). Auch die anderen großen Energiekonzerne haben ihre Investitionen in erneuerbare Energien in den letzten Jahren zurückgefahren und stattdessen verstärkt in die Förderung unkonventioneller Öl- und Gasquellen ${ }^{10}$ investiert (vgl. Klein 2014: 111f).

Wie das Beispiel BP zeigt, thematisieren einzelne multinationale Konzerne zumindest phasenweise ökologische Probleme - insbesondere den Klimawandel - und propagieren damit eine unternehmerische Gesellschaftsverantwortung (corporate social responsibility, CSR). Øyvind Ihlen sieht in der Betonung der gesellschaftlichen Verantwortung von Unternehmen eine Strategie zur Vermeidung eines Legitimations-Defizits (vgl. Ihlen 2009: 257). Allerdings gibt es bislang keine Anzeichen dafür, dass CSR zur Voraussetzung ökonomischen Erfolgs wird. ,There is plenty of evidence to show that the market does not necessarily punish corporations that do not engage in CSR." (Ihlen 2009: 258) Unabhängig davon ist zu beachten, dass mit einer Strategie der gesellschaftlichen Verantwortung nicht immer eine tatsächliche Vermeidung von Umweltschäden einhergeht. Ihlen betont, dass der Formulierung einer sozial-ökologischen Verantwortung durch Unternehmen nur selten wirksame Maßnahmen folgen (Ihlen 2009: 246).

10 Aufgrund knapper werdender Ressourcen kommt es vermehrt zur Förderung unkonventioneller Öl- und Gasquellen (z. B. Ölförderungen in der Tiefsee und Teersandabbau). 
,[...] corporate environmental reports rarely recognize problems with environmental performance or discuss fundamental problems such as whether certain industries and the lifestyles they support ,inherently produce more harms than benefits.““ (Ihlen 2009: 247)

Das Zitat verdeutlicht ein zentrales Element des ökomodernen Diskurses: Lösungsansätze, die auf strukturelle Veränderungen zielen, finden kaum Beachtung. Trotz der mageren Ergebnisse artikulieren sich einzelne multinationale Konzerne als Teil der Problemlösung und als wichtige Akteurinnen bei der Verhinderung eines extremen Klimawandels (vgl. Ihlen 2009: 255). Dabei begreifen sie ökologische Probleme auch als ökonomische Chance. Aufgrund des sogenannten first mover advantage versprechen sich bestimmte Firmen durch die Übernahme einer Pionierrolle Wettbewerbsvorteile und damit entsprechende Gewinnchancen (vgl. Ihlen 2009: 256).

Dies trifft insbesondere für Unternehmen aus den Bereichen der erneuerbaren Energien, der Energie- und Rohstoffeffizienz, der Kraft-Wärme-Kopplung, der nachhaltigen Mobilität und der Kreislaufwirtschaft zu, die auch als „Unternehmen aus dem Nachhaltigkeitssektor“ (Brunnengräber 2009: 190) bzw. als „grüne Industrien“ (Oberthür/Ott 2000: 111) bezeichnet werden. Im Rahmen eigener Wirtschaftsverbände wie dem European Business Council for Sustainable Energy (e5) setzen sie sich für striktere Regulierungen ein, da sie sich davon ein Wachstum ihrer Absatzmärkte erhoffen (vgl. Brunnengräber 2009: 190). Primär zielt ihre Lobbyarbeit auf die Förderung der von ihnen bereits entwickelten und noch zu entwickelnden Technologien. Durch ihre geringen Marktanteile, gerade im Vergleich zu Erdöl- und Erdgasunternehmen, ist ihr Einfluss zwar begrenzt, aber aufgrund ihrer relativ hohen Zahl an Beschäftigten und ihrer Exportorientierung auch nicht ganz unerheblich (vgl. Rest 2011: 103ff).

Diese ,grünen Industrien` stehen paradigmatisch für die ökomoderne Hoffnung auf innovative Technologien als Lösung der ökologischen Krise. Daneben spielen sie als Wachstumsbranche in Bezug auf das ökomoderne Argument der Vereinbarkeit von Umweltschutz und Wirtschaftswachstum eine wichtige Rolle, insbesondere durch die Schaffung von sogenannten green jobs. Insgesamt stellen die neuen ,Grünen Kapitalfraktionen“ eher ein Versprechen als eine reale gesellschaftliche Kraft dar. Dies zeigt sich aktuell in den Reaktionen auf die ökonomischen Krisen. Sowohl die staatlichen Förderungen als auch die Gesamtinvestitionen in erneuerbare Energien waren innerhalb der Europäischen Union in den letzten Jahren rückläufig (vgl. Haas/Sander 2013: 28). 


\subsubsection{Die Neoliberalisierung des ökomodernen Diskurses}

Innerhalb des ökomodernen Diskurses gab und gibt es verschiedene Perspektiven auf die Rolle des Staates. Prinzipiell ist die Umsetzung ökomoderner Politik sowohl durch staatliche Investitionen und/oder Regulierung als auch durch marktkonforme Anreizstrukturen denkbar. Lange Zeit hielten sich die Befürworter_innen und Gegner_innen eines stark regulierend eingreifenden Staates die Waage. So konstatiert Huber in einem Aufsatz aus dem Jahr 1993 einen „Streit zwischen den Befürwortern eines eher staatsdirigistischen Weges und eines eher marktwirtschaftlichen Weges der ökologischen Modernisierung“ (Huber 1993: 64). Wurde im Brundtland-Bericht (1987) noch verstärkt auf staatliche Regulierungen der Ökonomie gesetzt, so dominierte bereits bei der Rio-Konferenz (1992) die Betonung marktorientierter Lösungsvorschläge (vgl. Dingler 2003: 238). Im Laufe der 1990er Jahren hat sich vorerst der marktwirtschaftliche Weg durchgesetzt. Die Hinwendung $\mathrm{zu}$ freiwilligen Verpflichtungen der Wirtschaftsunternehmen sowie zu marktbasierten Instrumenten lässt sich sowohl in den Industriestaaten als auch auf internationaler Ebene ausmachen (vgl. Bernstein 2000; Busch/Jörgens/Tews 2006: 124; Görg 2003a; Kaufmann/Müller 2009: 158; Oels 2010). Liberalisierung, Privatisierung und Marktanreize werden zu zentralen Bearbeitungsstrategien im ökomodernen Diskurs. Insbesondere in Bezug auf die internationale Klimapolitik zeigt sich eine starke Orientierung auf Marktmechanismen (vgl. Kapitel 5.1.2 und 5.1.3). Die Neoliberalisierung der Umweltpolitik ist kein Einzelphänomen, sondern steht im Zusammenhang mit der Durchsetzung neoliberaler Ansätze im Bereich der Ökonomie und den dadurch ausgelösten Verschiebungen in der Agglomeration hegemonialer Diskurse ${ }^{11}$. So kam es ab den 1970er Jahren in nahezu allen Politikbereichen zur Durchsetzung neoliberaler Praktiken (vgl. Bedall 2014: 118ff).

Allerdings ist durchaus denkbar, dass es im Zuge der aktuellen Auseinandersetzungen um die adäquaten Reaktionen auf Wirtschaftskrisen (Banken-, Finanz-, Euro- und Schuldenkrisen) zu einer Zurückdrängung neoliberaler Diskurse kommt. Schließlich konnten die Deutungsmuster, in denen neoliberale Praktiken als (Teil-) Ursache für die ökonomischen Krisen gesehen werden, zunehmend an Bedeutung gewinnen, auch wenn sie sich in Bezug auf die konkreten Bearbeitungsstrategien nur in Ausnahmefällen durchsetzen konnten. Ein solcher Wandel hätte weitreichen-

11 Mit dem Begriff der ,Agglomeration hegemonialer' Diskurse bezeichne ich die hegemoniale Strukturiertheit des Sozialen über verschiedene Diskursarenen hinweg, die sich aus dem Zusammenspiel verschiedener, sich teilweise überlagernden Diskursorganisationen ergibt (vgl. Kapitel 2.1.3). Mit der Begriffswahl lehne ich mich an die in Kapitel 2.1.2 eingeführte Definition von ,Gesellschaft‘ als eine ,Agglomeration von Diskursen“ an. 
de Folgen für die Agglomeration hegemonialer Diskurse und würde sicherlich auch zu Veränderungen in der Organisation gesellschaftlicher Naturverhältnisse führen (vgl. Bedall 2014: 144ff). Dabei muss es keineswegs zu einer Abkehr vom ökomodernen Projekt kommen. Schließlich können sich die ökomodernen Deutungsund Handlungsmuster durchaus in unterschiedlichen Ausformungen jenseits des Neoliberalismus manifestieren. Das ökomoderne Projekt könnte somit auch wieder einen „eher staatsdirigistischen Weg[es]“(Huber 1993: 64) einschlagen.

Eine solche Entwicklung könnte insbesondere vom Energiesektor ausgehen, der stärker als andere Bereiche der Umweltpolitik durch staatliche Eingriffe geprägt ist. Die staatlichen Investitionen in die Infrastruktur (beispielsweise in Strom- und Gasnetze) und/oder die Vorgaben für deren Betrieb prägen die aktuell vorherrschende Form der zentralisierten Energieinfrastruktur. Insofern hängt die Ausgestaltung etablierter oder umgekehrt die Durchsetzung neuer Energieinfrastrukturen maßgeblich von staatlicher Politik ab. Staaten greifen nicht nur, aber auch über direkte und indirekte Subventionen für bestimmte Energieformen in den Energiesektor ein (vgl. Meadowcroft/Langhelle 2009a: 278). Die politische Steuerung der Energieinfrastruktur soll Planungssicherheit für staatliches und unternehmerisches Handeln herstellen. Darüber hinaus sind es geostrategische Überlegungen (insbesondere in Bezug auf die Abhängigkeit von Energieimporten), die prägend für die Energiepolitik sind (vgl. Langhelle/Meadowcroft 2009: 257ff). Insgesamt sind die Verflechtungen zwischen Staaten und ihrer Energiewirtschaft sehr eng. Dies zeigt sich in staatlichen Energieunternehmen, staatlichen Anteilen an Konzernen oder in der Abhängigkeit von Steuereinnahmen aus dem Energiesektor (vgl. Kapitel 5.5.3).

Vor diesem Hintergrund ist es nicht verwunderlich, dass es innerhalb der Energiepolitik Anzeichen für eine Zurückdrängung neoliberaler Ansätze gibt. Beispielsweise gibt es eine Tendenz zur Rekommunalisierung der Energieversorgung (vgl. Klein 2014: 96ff). Allerdings lässt sich zum jetzigen Zeitpunkt nur schwer einschätzen, inwieweit dies auf einen allgemeinen Trend in der Umweltpolitik hinweist - zumal es auch Phänomene gibt, die für eine Kontinuität marktliberaler Umweltpolitik sprechen, insbesondere auf internationaler Ebene. So werden in den PostKyoto-Verhandlungen die Marktmechanismen der internationalen Klimapolitik nicht in Frage gestellt und die mit dem Kyoto-Protokoll geschaffenen Kohlenstoffmärkte wachsen stetig (vgl. Kapitel 5.1.2 und 5.1.3). Insgesamt ist davon auszugehen, dass sich die Frage nach der Stabilisierung oder Rücknahme neoliberaler Umweltpolitik maßgeblich an den Diskursverschiebungen oder -konsolidierungen im Bereich der Wirtschaftspolitik entscheidet. Der Ausgang aktueller Auseinandersetzungen über diverse Freihandelsabkommen (CETA, TiSA, TTIP usw.) könnte ein Gradmesser für die Einschätzung der diesbezüglichen Kräfteverhältnisse sein. 


\subsubsection{Der Wandel der Umweltbewegungen}

Die Formierung des ökomodernen Diskurses steht in engem Zusammenhang mit der Entwicklung der Umweltbewegungen. Die Umweltbewegungen stießen Ende der 1960er, Anfang der 70er Jahre einen gesellschaftlichen Wandel an und etablierten die ökologische Krise als relevante gesellschaftliche Herausforderung. Die breite Auseinandersetzung mit der ökologischen Krise in verschiedenen Gesellschaftsbereichen wirkte wiederum auf die Umweltbewegungen zurück. So durchliefen Teile der Umweltbewegungen in den 1980er Jahren einen Wandel zu Gegenexpert_innen. Mit dieser Professionalisierung ging ein Strategiewechsel einher, der vor allem zu einem stärkeren Interesse an der Beeinflussung konkreter politischer Entscheidungen führte. ${ }^{12}$ Mit dem Strategiewechsel war eine Verschiebung der Problemdefinition von einer sozial-ökologischen zu einer rein ökologischen verbunden und damit auch ein Wandel der Lösungsvorschläge. Zur Lösung sozial-ökologischer Probleme bedarf es notwendig einer Transformation gesellschaftlicher Strukturen, wohingegen für rein ökologische Probleme im Einzelfall (vorwiegend technische) Lösungen gefunden werden können, ohne dass die Ursachen in den Strukturen der Gesellschaft gesucht und bekämpft werden müssen. Diskurstheoretisch kann man diesen Wandel innerhalb der Umweltbewegungen als einen Wechsel von popularen ${ }^{13}$ zu separierten Forderungen ${ }^{14}$ bezeichnen (vgl. Laclau 2005: 74; Laclau/ Mouffe 2001: 137).

12 Dabei kann nicht einfach ein Automatismus angenommen werden - im Sinne eines kausalen Zusammenhangs zwischen der Professionalisierung einer Bewegung und der Abkehr von radikaler Systemkritik. Stattdessen müssen die konkreten Prozesse in den Blick genommen werden, um die Hinwendung zu gemäßigteren Positionen erklären zu können.

13 Ich übernehme hier Martin Nonhoffs Übersetzung des englischen Begriffs ,popular‘. Nonhoff begründet den Verzicht auf die gängige Bezeichnung ,populär‘ in der Übersetzung eines Artikels von Laclau (2007b). Die mit populär verknüpften Konnotationen bekannt, volksnah oder volkstümlich hält er für unpassend. Dagegen schätzt er an ,popular die Anlehnung an die deutsche Übersetzung von Gramscis ,popolare‘. Damit möchte er zum einen die Bezugnahme Laclaus auf Gramsci hervorheben und zum anderen den Bedeutungskern des Begriffs als volksbezogen deutlich machen (vgl. Laclau 2007: 36f).

14 Laclau verwendet die Begriffe „democratic demands“ und „popular demands“ (Laclau 2005: 125ff). Wullweber übernimmt diese Wortwahl und unterscheidet zwischen „demokratischen“ und „populären Forderungen“ (Wullweber 2010: 91). Durch die Gegenüberstellung mit dem Adjektiv, demokratisch“ erhält der Begriff des Populismus m. E. eine pejorative Konnotation, gegen die Laclau mit seiner Gesamtargumentation entgegen tritt. Deshalb bevorzuge ich die Bezeichnung der separierten Forderung. 
Eine separierte Forderung zeichnet sich durch ihren partikularen Inhalt aus. Sie stellt eine isolierte Forderung dar, die nicht Teil einer Äquivalenzkette ist. Eine populare Forderung ist dagegen durch die Betonung der Gemeinsamkeit mit anderen Forderungen charakterisiert. Ihr partikularer Inhalt verliert demnach an Bedeutung. Die Gemeinsamkeit popularer Forderungen besteht in der Kritik an der hegemonialen Diskursorganisation, d. h. in der Kritik an Ursachen, die als ,im System liegend' verstanden werden (vgl. Laclau 2005: 74; Wullweber 2010: 91).

Dieser Wechsel von popularen $\mathrm{zu}$ separierten Forderungen der Umweltbewegungen verlief komplementär zu einem Wandel der Subjektpositionierung: Die Rolle des/der Gegenexpert_in wurde zum attraktiven Identitätsangebot und die fachliche Qualifikation zu einem wichtigen Element des Selbstverständnisses (vgl. Brand 2008: 240; Brand/Eder/Poferl 1997: 192ff; Hajer 1995: 93f). Die Selbst- und Fremdzuschreibung von Attributen wie realistisch, seriös und professionell wurde durch diese Subjektposition ermöglicht und hatte sie gleichzeitig zur Voraussetzung. Dagegen musste der Eindruck eines romantischen Träumers/einer romantischen Träumerin vermieden werden, um als Gegenexpert_in Gewicht zu haben (vgl. Hajer 1995: 102). War für die Umweltbewegungen in den 1960er und 70er Jahren die Entgegnung von ökonomischen Kosten-Kalkulationen oder wissenschaftlichen Risiko-Kalkulationen mit moralischen Argumenten ein gangbarer Weg, so wurde dies in den 80er Jahren seltener, da dies nicht mit der Subjektposition des/der Expert_in kompatibel war. Die politische Arbeit zielte nicht mehr primär auf Massenmobilisierung, sondern auf die Beeinflussung von Entscheidungsträger_innen in Politik und Wirtschaft. Durch diesen Strategiewechsel bedurfte es einer neuen Sprache, durch die man sich der Möglichkeit der moralischen Argumentation beraubte (vgl. Hajer 1995: 103). Im Zusammenhang mit den Einschränkungen durch den Wandel der Subjektposition und einer daran gekoppelten neuen Sprache benennt Hajer noch ein besonders interessantes Phänomen: Sobald es einen gesellschaftlichen Konsens über die Notwendigkeit gab, auf die ökologische Krise reagieren zu müssen, wurde es für radikale Gruppen zunehmend schwerer, Deutungshoheit über die Problemdefinition und die daraus folgenden adäquaten Lösungen zu erlangen (vgl. Hajer 1995: 102f). Diese Beobachtung werde ich in Kapitel 3.4.3 aufgreifen.

Hajer nennt verschiedene Gründe - wobei nicht immer eindeutig zwischen Ursache und Wirkung unterschieden werden kann - für den Wandel der Umweltbewegungen. Er sieht in der ökonomischen Rezession in den 1970er Jahren einen äußeren Zwang, auf weit verbreitete Ängste vor Inflation und Massenarbeitslosigkeit reagieren zu müssen. Weiterhin konstatiert er einen Zusammenhang des Wandels der Subjektpositionierung mit dem Wechsel der Themen, welche die ökologischen Debatten dominierten - weg von der Kernkraft hin zu neuen Themen wie 
saurem Regen oder dem Verschwinden der Ozon-Schicht, die sich weniger für antagonistische Forderungen eigneten. Darüber hinaus kam es zur Professionalisierung der Umweltbewegungen, NGO-Eliten bildeten sich heraus. Der Erfolg des ökomodernen Diskurses - der in Wissenschaft, Thinktanks und internationalen Organisationen wie der OECD und dem UNEP Einzug hielt - war ein weiterer Grund, auf eine antagonistische Position zu verzichten und stattdessen über interne Kritik Erfolge anzustreben (vgl. Hajer 1995: 94f).

Neben den genannten Gründen wirkte sich auch eine Entwicklung in ökonomischen Diskursen auf die ökologischen Aushandlungsprozesse aus. Spätestens seit dem Zusammenbruch der Sowjetunion 1989/90 blieben Artikulationen, die sich um die Forderung nach einer alternativen Wirtschaftsordnung jenseits marktwirtschaftlicher Prinzipien (beispielsweise Öko-Sozialismus) gruppieren, aus (vgl. Kaufmann/Müller 2009: 157). Damit ging auch eine prinzipielle Absage an eine Politik der langfristigen volkswirtschaftlichen Planung einher, weil die damit verbunden politischen Eingriffe in das Wirtschaftssystem als diskreditiert galten (vgl. Klein 2014: 124f). Insgesamt lässt sich festhalten, dass es parallel zur schrittweisen Durchsetzung des ökomodernen Diskurses zu einer Marginalisierung antagonistischer Positionen kam.

Allerdings sieht beispielsweise Achim Brunnengräber Anzeichen für einen neuen Bewegungszyklus, der den Zyklus der NGOisierung, der durch die Professionalisierung der Umweltbewegungen gekennzeichnet war, ablösen könnte (vgl. Brunnengräber 2012). Die Proteste während des G8-Gipfels 2007 in Heiligendamm und die Klimacamps als neue Protestform stellen seiner Meinung nach erste Kristallisationspunkte des neuen Zyklus dar. Der neue Bewegungszyklus zeichnet sich für Brunnengräber durch eine Re-Polarisierung politischer Auseinandersetzungen aus. Mit der Bildung transnationaler Bewegungsnetzwerke entwickeln sich neue Strategien der Politisierung, die durch einen Anti-Institutionalismus geprägt sind. Dennoch wird weiterhin auf die Politik offizieller Institutionen - beispielsweise im Rahmen der UN-Klimaverhandlungen - im Sinne einer kritischen Begleitung Bezug genommen (vgl. Brunnengräber 2012: 45f). Dass in diesen hybriden Netzwerken neben den basisorientierten Gruppen auch NGOs agieren, ist sicherlich zum Teil auf deren Enttäuschung von der 15. Vertragsstaatenkonferenz der Klimarahmenkonvention $\left(\mathrm{COP}^{15} 15\right)$ in Kopenhagen zurückzuführen. Mit dem Verlust des Vertrauens in die UN-Klimaverhandlungen geht tendenziell eine Hinwendung zu

15 Wenn im Folgenden die Abkürzung COP verwendet wird, dann ist damit stets die Vertragsstaatenkonferenz der Klimarahmenkonvention gemeint. Es gibt im Rahmen der UN zwar auch Konferenzen zu anderen Politikfeldern, die ebenfalls mit COP abgekürzt werden. Diese anderen COPs werden in dieser Arbeit allerdings nicht erwähnt. 
radikaleren Positionen und protestorientierter Arbeit sowie eine verstärkte Zusammenarbeit mit Bewegungsaktivist_innen einher. Symptomatisch für diese Entwicklung steht die Stellungnahme von Wael Hmaidan im Plenum der 2012 in Rio de Janeiro stattgefundenen Konferenz der Vereinten Nationen über nachhaltige Entwicklung. Darin wehrt sich der Vorsitzende des Climate Action Network (CAN) gegen die Vereinnahmung der NGOs durch die Regierungsvertreter_innen.

„You cannot have a document titled 'the future we want' without any mention of planetary boundaries, tipping points, or the Earth's carrying capacity. The text as it stands is completely out of touch with reality. Just to be clear, NGOs here in Rio in no way endorse this document. Already more than 1.000 organisations and individuals have signed in only one day a petition called ,The Future We Don't Want' that completely refuses the current text. It does not in any way reflect our aspiration, and therefore we demand that the words ,in full participation with civil society“ are removed from the first paragraph." (Hmaidan 2012)

Als Vertreter des größten Zusammenschlusses von NGOs forderte er, dass in dem Verhandlungstext der Teilsatz gestrichen wird, in dem die Beteiligung, der Zivilgesellschaft' an den Verhandlungen betont wird. Damit macht er deutlich, dass auch die großen und gemäßigteren NGOs nicht mehr gewillt sind, den mageren Ergebnissen internationaler Klimapolitik durch ihre konstruktive Teilnahme an den Verhandlungen Legitimität zu verleihen. Noch ist nicht abzusehen, welche gesellschaftliche Wirkung diese (Re-)Polarisierung im zivilgesellschaftlichen Raum entfalten kann. Brunnengräber konstatiert, dass es den Bewegungen bislang an attraktiven Gegenentwürfen und einem klaren Programm fehle. Unabhängig davon gebe es sicherlich das Potenzial spezifischer Korrekturen bestehender ungleicher Verhältnisse (vgl. Brunnengräber 2012: 49). Damit sich in diesem neuen Bewegungszyklus ein gegenhegemoniales Projekt entwickeln kann, bedürfte es klaren antagonistischen Positionen mit einem eigenen Anspruch auf die Repräsentation des Gemeinwohls.

\subsection{Die Grundannahmen des ÖKomodernen Projekts}

Der ökomoderne Diskurs stellt eine spezifische Reaktion auf die ökologische Krisendiagnose und die daran geknüpfte Gesellschaftskritik dar. Verschiedene soziale Kräfte tragen als ökomoderne Diskursträgerinnen zu seiner (Re-)Produktion und Verbreitung bei. Ihre Hegemoniepraktiken zielen darauf, den ökomodernen Diskurs zu universalisieren: ihn als alternativlos zu präsentieren. In diesem Sinne verstehe ich ökologische Modernisierung als Hegemonieprojekt, das darum kämpft, ökomoderne Deutungs- und Handlungssysteme zu institutionalisieren. 
Die in den Kapiteln 3.1 und 3.2 durchgeführte Interpretation von Schlüsseldokumenten des ökomodernen Diskurses und Studien über ökologische Modernisierung bildet die Grundlage für die Identifikation von Grundannahmen und Hegemoniestrategien (vgl. Kapitel 3.4), die das Gerüst des ökomodernen Hegemonieprojekts darstellen. Mit Grundannahmen bezeichne ich implizite Annahmen, welche die unhinterfragten Deutungsmuster eines Diskurses abstecken. Folgende drei Grundannahmen kennzeichnen das ökomoderne Projekt:

1) Die erste ökomoderne Grundannahme bildet die Vorstellung, ökologische Probleme isoliert betrachten und lösen zu können. War die Deutung der ökologischen Krise in den 1970er Jahren noch häufig mit einer prinzipiellen Gesellschaftskritik verknüpft (vgl. Görg 2003a: 134f), so bleibt diese im ökomodernen Diskurs weitgehend aus. Gesellschaftspolitische Ziele, die über die Beseitigung der isoliert betrachteten ökologischen Probleme hinaus gehen, werden nicht formuliert. Es dominiert somit eine technokratische Vorstellung von Politik, die weder hegemoniale Strukturen noch die damit einhergehenden sozialen Kräfteverhältnisse hinterfragt (vgl. Hajer 1995: 25; Kaufmann/Müller 2009: 157).

2) Damit einher geht ein Wandel von revolutionären zu reformerischen Lösungsansätzen. Es werden Lösungen gesucht, die möglichst unkompliziert innerhalb der gegebenen Rahmenbedingungen umgesetzt werden können (vgl. Jänicke 1993: 19). Der Inkrementalismus, d. h. die Überzeugung, mit kleinen, vorwiegend technologischen Schritten innerhalb der institutionalisierten Strukturen in die richtige Richtung zur Lösung der ökologischen Probleme zu kommen, stellt die zweite Grundannahme des ökomodernen Diskurses dar (vgl. Hajer 1997: 113).

3) Das Primat der Betriebsökonomie bildet seine dritte Grundannahme. Als realistisch und umsetzbar gelten allein die Reaktionen auf die ökologische Krise, die mit dem Primat der Betriebsökonomie kompatibel sind, indem sie helfen (wenn schon nicht gegenwärtige, dann zumindest zukünftige) betriebswirtschaftliche Kosten zu vermeiden oder als Wachstumsmotor dienen können. Im ökomodernen Diskurs steht außer Frage, dass das Hauptkriterium zur Bewertung verschiedener Umweltschutzoptionen in ihrem kostensenkenden Beitrag zur Erreichung konkreter Umweltschutzziele besteht (vgl. Brunnengräber et al. 2008: 193f; Dingler 2003: 234; Huber 1993: 54; Jänicke 1988: 23; Oels 2010: 171; UNEP 2011: 2). Alternative denkbare Kriterien wie soziale Aspekte (die z. B. Fragen der Gerechtigkeit betreffen), über die gesellschaftlichen Funktionslogiken hinausgehende ökologische Aspekte (die der Natur einen Eigenwert beimessen) oder demokratische Aspekte (die z. B. auf die Mitbestimmung in Fragen der Energieproduktion und -distribution zielen) spielen dagegen nur eine untergeordnete Rolle. 


\subsection{Die Hegemoniestrategien des ökomodernen Projekts}

Durch die Interpretation von Schlüsseldokumenten des ökomodernen Diskurses und Studien über ökologische Modernisierung konnte ich drei ökomoderne Hegemoniestrategien identifizieren: reflexive Naturbeherrschung, reflexiver Fortschritt durch wissenschaftlich-technische Rationalität und nachhaltiges Wachstum. Über die Hegemoniestrategien wird Zustimmung zum ökomodernen Projekt erzeugt und ein ökomoderner Konsens hergestellt. Dies geschieht unter anderem durch die strategisch-selektive Aneignung kritischer Forderungen. Die Darstellung der ökomodernen Hegemoniestrategien erfolgt jeweils in vier Schritten. Zunächst zeige ich, wie die Hegemoniestrategie auf die ökologische Krise reagiert und wie dabei kritische Artikulationen in einen Diskurs der ökologischen Modernisierung integriert werden. Anschließend arbeite ich heraus, inwiefern mit der Hegemoniestrategie eine Veränderung gegenüber der bis in die 1970er Jahre hegemonialen Diskursorganisation der Modernisierung mit nachgeschaltetem Umweltschutz verbunden ist. Nach der Betrachtung dieser Öffnung des Diskurshorizonts nehme ich die mit der Strategie verknüpfte Schließung in den Blick, indem ich festhalte, welche Artikulationen dabei marginalisiert werden. Abschließend analysiere ich, an welchen Stellen Risse und Brüche auftauchen und antagonistische Praktiken ansetzen (könnten).

\subsubsection{Reflexive Naturbeherrschung}

Bis in die 1970er Jahre war das Credo, dass wissenschaftlich-technische Naturbeherrschung (zum Begriff der Naturbeherrschung vgl. Kapitel 2.2.3) zwangsläufig $\mathrm{zu}$ gesellschaftlichem Fortschritt führe, eine unangefochtene „Grundüberzeugung der Moderne“ (Becker/Jahn 2006: 66). Allerdings hat diese Grundüberzeugung durch die ökologische Krisendiagnose Risse erhalten. Mit der Deutung, dass ökologische Probleme zunehmend gesellschaftlich verursacht sind, wurde die Idee einer absoluten Kontrollierbarkeit der Natur weitestgehend aufgegeben (vgl. Brand/Görg 2003: 18f). In den 1980er Jahren wurde mit der aufkommenden Diskussion um sogenannte zivilisatorische Risiken und um nicht-intendierte Nebenfolgen der Moderne (vgl. Beck 1986: 48ff), die Fähigkeit von Wissenschaft und Technik, die Abhängigkeit der Gesellschaft von Natur zu minimieren, in Zweifel gezogen. Auch der Fähigkeit von Ökonomie, Politik und Kultur, die Naturbeherrschung immer besser kontrollieren zu können, wird zunehmend misstraut. Seitdem ist weder eine Ignoranz gegenüber ökologischen Problemen noch ein ungebrochener Glaube an die vollständige Beherrschbarkeit der Natur konsensfähig (vgl. Görg 2003a: 140). 
Im Verlauf der Auseinandersetzungen um die Bearbeitung der ökologischen Krise kam es zu wesentlichen Verschiebungen und es kristallisierte sich eine modifizierte Naturbeherrschung als ökomoderner Konsens heraus (vgl. Görg 2003a: 139f). Die modifizierte Naturbeherrschung stellt keine Rückkehr zur einfachen Modernisierung dar. Stattdessen mündete die Kritik an der absoluten Naturbeherrschung in einer reflexiven ${ }^{16}$ Variante derselben. Die Reaktion des ökomodernen Diskurses auf das Scheitern der Versuche einer absoluten Naturbeherrschung kann man damit als ökomoderne Hegemoniestrategie der reflexiven Naturbeherrschung (kurz: reflexive Naturbeherrschung) beschreiben. Ich sehe in dieser konkreten ökomodernen Hegemoniestrategie eine inhaltliche Füllung eines allgemeinen HegemoniestrategieTypus, den ich als Strategie der Reflexion nicht-intendierter Nebenfolgen ${ }^{17}$ fasse.

Mit der ökomodernen Strategie der reflexiven Naturbeherrschung wird die Kritik an der Naturbeherrschung in den ökomodernen Diskurs integriert, ohne dass die Naturbeherrschung als vorherrschendes Prinzip der Naturaneignung grundsätzlich in Frage gestellt wird. Mit der reflexiven Naturbeherrschung geht keine prinzipielle Reflexion der Abhängigkeit von Natur bzw. der Nichtidentität der Natur als Quelle von Unsicherheit einher (vgl. Görg 2003a: 188). Stattdessen stellt die reflexive Naturbeherrschung den Versuch dar, die nicht-intendierten Nebenfolgen der Naturbeherrschung berechenbar zu machen. Dabei wird die (Re-)Produktion der gesellschaftlichen Naturverhältnisse weiterhin durch die Subsumtion der Natur unter die gesellschaftlichen Funktionslogiken bestimmt, die wiederum - vor dem Hintergrund des dominanten ökonomischen Diskurses des globalen Konkurrenzkampfes - in erster Linie auf die Verbesserung der Wettbewerbsfähigkeit zielen (vgl. Görg 2003a: 140). Im ökomodernen Diskurs wird von einem Sachzwang zur „Erzielung eines ökologisch-ökonomischen Doppelnutzens“ (Jänicke 1988: 23) ausgegangen. Die Reaktionen auf die ökologische Krise werden auf das Ziel der Wettbewerbsfähigkeit ausgerichtet und als Wachstumsmotor begriffen (vgl. Görg 2003a: 214) - unter bewusster Inkaufnahme von Risiken, die aufgrund vermeint-

16 In Anlehnung an Görg und Pelfini wird hier mit reflexiver Naturbeherrschung das Management nicht-intendierter Nebenfolgen der Naturbeherrschung bezeichnet (vgl. Kapitel 2.2.3). Davon grenzen Görg bzw. Pelfini die zweite Reflexion bzw. Reflexivität ab. Zweite Reflexion bzw. Reflexivität gehen über die einfache Reflexion nicht-intendierter Nebenfolgen der Naturbeherrschung hinaus, indem sie die Nichtidentität der Natur in Rechnung stellen.

17 In Bezug auf den ökomodernen Diskurs findet sich dieser Typus ebenfalls bei der ökomodernen Strategie des reflexiven Fortschritts durch wissenschaftlich-technische Rationalität (vgl. Kapitel 3.4.2). Inwieweit sich auch in anderen Diskursen Strategien der Reflexion nicht-intendierter Nebenfolgen finden lassen, muss an dieser Stelle noch offen bleiben. 
licher Sachzwänge nicht verhindert, sondern allenfalls gemanagt werden können. Insofern bleibt beispielsweise die Extraktion von fossilen Brennstoffen eine zentrale Bedingung der weiterhin fossilistischen Weltwirtschaft, obwohl sich die damit verknüpften Konflikte zuspitzen (vgl. Brand/Görg 2003: 46). In dem Zusammenhang sind die Debatten über Peak Oil und die Zunahme geopolitischer Konflikte um die Ausbeutung und Verteilung von Rohstoffen zu sehen (vgl. Brand 2009: 107). Des Weiteren zeigt sich die Inkaufnahme von Risiken am Anstieg der globalen Treibhausgasemissionen, der Zunahme von Ölkatastrophen sowie an den steigenden ökonomischen, gesundheitlichen und ökologischen Kosten bei der Ausschöpfung von schwer zugänglichen Energiereserven durch Fracking, Tiefseebohrungen und Ölsandabbau. Damit zielt das ökomoderne Projekt auf eine kontrollierte und gemanagte Naturbeherrschung (vgl. Dingler 2003: 307).

Dennoch hat die Forderung nach reflexiver Naturbeherrschung eine Veränderung der Diskursorganisation gesellschaftlicher Naturverhältnisse zur Folge. Die Idee einer absoluten Kontrollierbarkeit der Natur wurde weitestgehend aufgegeben (vgl. Brand/Görg 2003: 18f). Damit gehen veränderte Deutungs- und Handlungsmuster einher, die auf die nicht-intendierten Nebenfolgen reagieren. Die Risikoabschätzung, als rationale Bearbeitung des Problems der Entscheidungsfindung unter Ungewissheit, spielt dabei eine wichtige Rolle (vgl. Görg 2003a: 140, 188).

Ausgeschlossen bleibt aber weiterhin grundsätzliche Kritik an der Naturbeherrschung. Sie läuft mangels Aufmerksamkeit ins Leere. Im ökomodernen Diskurs dominiert nicht ein offensiver Umgang - im Sinne der Artikulation eines antagonistischen Verhältnisses - mit ihr, sondern eine prinzipielle Kritik der Naturbeherrschung als Ursache sozialer und ökologischer Probleme wird dethematisiert.

Diese Dethematisierung ist möglich, so lange es keine wirkungsmächtigen gegenhegemonialen Projekte gibt. Wenn die marginalisierte Kritik an dem Prinzip der Naturbeherrschung einflussreicher artikuliert werden würde, gerieten die Momente der Widerständigkeit und Unverfügbarkeit der Natur stärker in den Fokus. Ereignisse, in denen das Management der nicht-intendierten Nebenfolgen scheitert, können Risse im ökomodernen Diskurs vertiefen, an denen (re-)politisierende Artikulationen ansetzen (können). So hatte die Nuklearkatastrophe in Fukushima in ganz verschiedenen Gesellschaften (re-)politisierende Effekte. Die tatsächlichen Änderungen in der Energiepolitik fielen allerdings sehr unterschiedlich aus. An diesem Beispiel wird ein Bruch im ökomodernen Diskurs besonders deutlich. Auf der einen Seite wird davon ausgegangen, dass absolute Naturbeherrschung nicht möglich ist. Auf der anderen Seite wird im ökomodernen Diskurs an der Vorstellung einer immer rationaleren Naturbeherrschung festgehalten. Durch den Mechanismus der Risikoabschätzung soll die bewusste Inkaufnahme nicht-intendierter Neben- 
folgen gemanagt werden. Dabei übt der vermeintliche Sachzwang der Wettbewerbsfähigkeit einen Druck auf die Verschiebung der Grenzen reflexiver Naturbeherrschung aus. So wurden nach der Nuklearkatastrophe in Fukushima weltweit viele Kernkraftwerke einer Sicherheitsprüfung unterzogen, um die Risiken eines Atomunfalls abschätzen zu können. Dabei wurden oftmals erhebliche Sicherheitsmängel festgestellt. Tatsächlich abgeschaltet wurden allerdings nur sehr wenige Kraftwerke (nur in Deutschland und Japan wurden laufende Atomkraftwerke mit sofortiger Wirkung abgeschaltet). Die Sorge um eine Gefährdung des Wirtschaftswachstums wog in den meisten Fällen schwerer als die Sicherheitsbedenken. Diese Inkaufnahme möglicher nicht-intendierter Nebenfolgen - die in diesem Fall bis hin zum Atomunfall reichen können - ist ein Beispiel für die einseitige Subsumtion der Natur unter die (historisch institutionalisierten) gesellschaftlichen Funktionslogiken.

\subsubsection{Reflexiver Fortschritt}

Der Fortschrittsbegriff der, westlichen“ Moderne bezieht sich auf die Annahme einer zunehmenden Rationalität in allen Gesellschaftsbereichen. Der Glaube an den Fortschritt beruht auf der Vorstellung, dass Wissen und Techniken - durch die Anwendung von Vernunft - kumuliert werden können, die schrittweise zur Befreiung des Menschen von äußeren Zwängen beitragen (vgl. Dingler 2003: 44ff). Für die Industriemoderne geht Ulrich Beck von einem technologiepolitischen Fortschrittskonsens aus, der ,sein Fundament in der allseits geteilten Friedensformel ,technischer Fortschritt gleich sozialer Fortschritt"“ (Beck 1986: 326; Hervorhebung im Original) hatte. Diese „Ineinssetzung von technischem mit sozialem Fortschritt“ (Beck 1986: 326) war laut Beck die Bedingung für die diskursive Trennung des technischen Fortschritts von seinen negativen sozialen und ökologischen Effekten. Die negativen Effekte wurden thematisiert, ohne das grundsätzliche Vertrauen in den Fortschritt - als Prinzip der systematischen Erzeugung technologischer Innovationen - in Frage zu stellen (vgl. Beck 1986: 326f). Beck geht davon aus, dass der Fortschrittsglaube erst mit dem Anwachsen der Risiken in den 1970er und 80er Jahren prekär wurde (vgl. Beck 1986: 324, 327). Allerdings betont er, dass der Verlust des Fortschrittsvertrauens nichts an dem Vollzug des technischen Wandels geändert habe. Beck konstatiert die auf den ersten Blick paradox anmutende Situation, dass es vermehrt Kritik am technischen Fortschritt gebe, das Prinzip des technischen Fortschritts aber selber unangetastet bleibe und die Kritik nahezu wirkungslos sei - zumal sie zumeist ex post, ,wie ein Nachruf auf längst getroffene Entscheidungen“ (Beck 1986: 329; Hervorhebung im Original) artikuliert werde. 
Ich teile zwar nicht Becks Annahme eines objektiven Anwachsens von Risiken, aufgrund dessen der Fortschrittsglaube brüchig geworden sei. ${ }^{18}$ Allerdings stimme ich seiner Einschätzung zu, dass der Fortschrittsoptimismus ab den 1970er Jahren prekär wurde, ohne dass dies in einer grundsätzlichen Kritik am Fortschrittsglauben mündete (vgl. Halfmann 1998: 7f).

Das Festhalten am brüchig gewordenen Fortschrittsglauben lässt sich mit den Dynamiken in den Auseinandersetzungen um die Risiken des technologischen Fortschritts erklären. Die Umweltbewegungen waren durchaus nicht durch eine homogene Fortschritts- und Technikskepsis geprägt. Somit wurde sowohl in der Öffentlichkeit als auch intern in den Umweltbewegungen um die ,richtigen“ Problemdefinitionen und -lösungen gerungen. Dabei hat die Fraktion, die „,modernisierende Perspektiven“ (Huber 2011b: 179) vertritt, relativ früh Deutungshoheit erlangt. In dieser Fraktion finden sich laut Hajer sowohl die technokratischen Expert_innen (worunter Hajer beispielsweise die Autor_innen des Club-of-Rome-Berichts zählt) als auch Teile der Umweltbewegungen wieder. Gemeinsamer Kern dieser Fraktion ist die Deutung der ökologischen Krise als eine Frage des Überlebens und der Suche nach Lösungen durch die wissenschaftlichen Strömungen der Kybernetik und der Ökologie (vgl. Hajer 1995: 86). In den modernisierenden Perspektiven dieser Fraktion zielt die Bearbeitung von Risiken primär auf Sicherheit - und nicht wie die Technikkritik der Kritischen Theorie auf die Freiheit und Autonomie des Individuums. Dementsprechend steht für sie die Angst vor Sicherheitseinbußen durch die Abhängigkeit von der Natur einer Infragestellung des totalitären Anspruchs der wissenschaftlich-technischen Rationalität entgegen. Aufgrund des großen Einflusses der modernisierenden Perspektiven liegt der Schwerpunkt in den Auseinandersetzungen um die nicht-intendierten Nebenfolgen (Risiken) des technischen Fortschritts primär auf der Frage der richtigen Ausgestaltung und nicht auf

18 Beck geht von einem strukturell bedingten immanenten Prozess der Modernisierung aus. Dagegen interpretiere ich die zunehmende Bedeutung des Deutungsmusters, dass der technologische Wandel zu einem Anwachsen von Risiken führt, als Ergebnis hegemonialer Auseinandersetzungen. Diese müssen nicht zwangsläufig mit Veränderungen in der physischen Materialität (als verstetigte gesellschaftliche Naturverhältnisse) korrelieren und können deshalb auch nicht allein auf diese zurückgeführt werden. Darüber hinaus bezweifle ich die Annahme einer unweigerlichen Entwicklung der Modernisierung hin zu einer ,reflexiven Modernisierung'. Die Behauptung einer logischen Abfolge oder immanenten Struktur sozialen Wandels ist weder theoretisch noch empirisch haltbar. Stattdessen gehe ich davon aus, dass die gesellschaftliche Entwicklung in Kämpfen um Hegemonie entschieden wird, in denen verschiedene soziale Kräfte um die Durchsetzung von Deutungs- und Handlungsmustern ringen. 
der grundsätzlichen Kritik des wissenschaftlich-technischen Paradigmas (vgl. Huber 2011b: 153). Die Reaktion des ökomodernen Diskurses auf fortschritts- und technikskeptische Artikulationen besteht somit in der ökomodernen Hegemoniestrategie des reflexiven Fortschritts durch wissenschaftlich-technische Rationalität (kurz: reflexiver Fortschritt). Diese Strategie kann - analog zur reflexiven Naturbeherrschung - dem Typus der Hegemoniestrategie der Reflexion nichtintendierter Nebenfolgen zugeordnet werden.

Mit dem bereits erwähnten Wechsel der Problemdefinition von einer sozialökologischen zu einer rein ökologischen in den 1980er Jahren geht ein Fokus auf die Suche nach technologischen Lösungen für isolierte Probleme einher (vgl. Becker/Jahn 2006: 54; Hajer 1995: 93).

„Effizienzsteigerung als Rationalisierung der Technik, technologische Innovationen als gesellschaftliche Anwendung rationaler Wissenschaftserkenntnis und Umweltmanagement als Rationalisierung des Umgangs mit der Natur stellen Mittel der Moderne dar, durch die auch im Rahmen einer nachhaltigen Entwicklung die gesellschaftliche Organisation sowie das gesellschaftliche Naturverhältnis auf der Grundlage der Vernunft restrukturiert werden sollen. Dabei wird implizit davon ausgegangen, dass sich ökologische Probleme weitgehend durch Wissenschaft, Technik oder Management - also letztlich durch Anwendungen der Rationalität - lösen lassen.“ (Dingler 2003: 301)

Was die „technologische Flucht nach vorn“ (Jänicke 1993: 18) vorantreibt, sind zum einen die Versuche der Steigerung des Sicherheitsempfindens durch das Management nicht-intendierter Nebenfolgen und zum anderen das ökonomische Ziel, Umwelttechnologien zum Exportschlager zu machen (vgl. Görg 2003a: 137f).

Die Forderung nach reflexivem Fortschritt hat eine spezifische Veränderung der Diskursorganisation gesellschaftlicher Naturverhältnisse bewirkt. So hat die Thematisierung von Risiken, die mit technologischen Innovationen verbunden sind, stark zugenommen. Dabei wird in der Perfektionierung der technologischen Entwicklung ein gangbarer Weg zur Erlangung von Sicherheit gesehen. Sowohl risikobewusste Praktiken wie Technikfolgenabschätzung, Technikakzeptanz-Forschung und Risikokommunikation als auch risikovermeidende Praktiken wie der Einsatz sogenannter sanfter Technologien oder der Fokus auf Effizienzsteigerung haben dadurch an Bedeutung gewonnen.

Damit ist eine Verlagerung der Aufmerksamkeit von den strukturellen Ursachen auf die Symptome der ökologischen Krise verbunden, von denen man annimmt, dass sie technisch gelöst werden können. Prinzipieller Kritik an dem Glauben an Fortschritt durch wissenschaftlich-technische Rationalität wird nicht offensiv - im Sinne der Konstruktion eines antagonistischen Verhältnisses - begegnet, sondern sie wird dethematisiert. 
Analog zur reflexiven Naturbeherrschung ist auch hier meine Vermutung, dass es zu (re-)politisierenden Prozessen kommen könnte, wenn sich Grenzen der Bearbeitung der ökologischen Krise durch Technologien zeigen. Darüber hinaus bilden Technologie-inhärente Risiken einen potenziellen Konfliktherd. Insbesondere wenn es zu sicherheitsgefährdenden Unfällen durch den Einsatz von (Umweltschutz-) Technologien kommt, würde die fortschritts- und technikskeptische Kritik wieder mehr Aufmerksamkeit erfahren. Für derartige antagonistische Artikulationen gibt es desto mehr Ansatzpunkte, je weniger erfolgreich die ökomoderne Doppelstrategie der gleichzeitigen Verfolgung ökologischer und ökonomischer Ziele ist.

Bei dem ökologischen Ziel der drastischen Reduktion von Treibhausgasemissionen bleibt die Wirkung der risikovermeidenden Praktiken - Energieeffizienz und der Einsatz sanfter Technologien - angesichts der Rebound-Effekte ${ }^{19}$ begrenzt. In Bezug auf das ökonomische Ziel kann man konstatieren, dass sich in bestimmten Industrieländern ein spezifisches Segment ,Grüner Kapitalfraktionen' herausgebildet hat, deren Profit auf der ökomodernen Bearbeitung der ökologischen Krise basiert (vgl. Kaufmann/Müller 2009: 160). Auch wenn sie einen wachsenden Sektor darstellen, bilden die Umwelttechnologien (noch) kein alternatives Geschäftsmodell für einen Großteil der Unternehmen (vgl. Bundesministerium für Umwelt, Naturschutz und Reaktorsicherheit 2009: 2). Speziell die Energiekonzerne beharren auf ihrer Kernkompetenz - der zentralisierten Energieproduktion auf Basis fossiler Brennstoffe (vgl. Hirsch 2011: 19; Rest 2011: 103ff). Angesichts der Versprechen einer Green Economy halten sich also vor allem die ökologischen, aber auch die ökonomischen Erfolge des ökomodernen Projekts in Grenzen.

19 Rebound-Effekte bezeichnen das Phänomen, dass Produktivitätssteigerungen zu einer Mehrnachfrage führen und dadurch die erwarteten absoluten Reduktionen des Ressourcenverbrauchs nicht in Gänze oder gar nicht eintreten. Tilman Santarius unterscheidet finanzielle, materielle, psychologische und Cross-Factor-Rebound-Effekte (vgl. Santarius 2012). So führt die Steigerung der Energieeffizienz zu einem Einkommensgewinn und damit zu neuem Verbrauch bei den Konsument_innen beziehungsweise zu neuen Investitionen bei Produzent_innen. Materielle Rebound-Effekte liegen vor, wenn die Herstellung und der Konsum von effizienteren Technologien mit einem erhöhten Energieaufwand einhergehen. Die psychologischen Rebound-Effekte erklären, wie es beim Wechsel zu energieeffizienten Technologien zu einer Steigerung der symbolischen Bedeutung dieser Güter und Dienstleistungen und damit zu einem Mehrverbrauch kommen kann. CrossFactor-Rebound-Effekte sind dafür verantwortlich, dass eine Steigerung der Arbeits- und Kapitalproduktivität eine Mehrnachfrage nach Energie nach sich ziehen kann, etwa durch energieverbrauchende Mechanisierung und Automatisierung oder wenn die Anwendung energieeffizienterer Technologien zugleich mit Zeitersparnissen einhergeht. 
Diese Diskrepanz kann zu einem Bruch innerhalb des ökomodernen Diskurses führen. In jedem Fall ist mit der ökomodernen Hegemoniestrategie des reflexiven Fortschritts durch wissenschaftlich-technische Rationalität ein gewisser Erfolgsdruck und ein technologischer Suchprozess - nach der silver bullet oder nach dem geeigneten Portfolio technologischer Lösungen - verbunden. Technologie nimmt im ökomodernen Diskurs die Funktion einer Deus ex machina ein, einer (Er-)Lösung, die unabhängig vom Ausgang gesellschaftlicher Auseinandersetzungen - und damit trotz wirtschaftlicher Pfadabhängigkeiten, trotz fehlender Bereitschaft zum Konsumverzicht, trotz schlechter Regierungsführung usw. - die ökologische Krise bearbeiten kann (vgl. de Lucia 2013: 123; Methmann 2011: 161ff).

\subsubsection{Nachhaltiges Wachstum}

Ab Ende der 1960er Jahre gab es eine öffentliche Debatte über die Grenzen des Wachstums (vgl. Huber 1993: 52). Die Kritik an der Wachstumsfixierung kam zunächst vor allem von Seiten des radikaleren Spektrums der Umweltbewegungen. Wichtiger Katalysator für die Ausweitung und Intensivierung der Debatte war der 1972 erschienene Club-of-Rome-Bericht The Limits to Growth, auf den ich bereits in Kapitel 3.2.1 eingegangen bin. Der Erfolg des Berichts trug zu den vermehrten Auseinandersetzungen mit der Wachstumsfrage in verschiedenen Gesellschaftsbereichen bei und machte die These, dass sich weiteres Wirtschaftswachstum und Umweltschutz widersprechen, für breite Kreise plausibel.

Auch Akteur_innen, die maßgeblich an der Entwicklung des Konzepts der ökologischen Modernisierung beteiligt waren, hatten lange Zeit Zweifel, ob Wirtschaftswachstum tatsächlich eine langfristige Option sein könne. So konstatierte Jänicke noch im Jahre 1993, dass "am Ende auch die Wachstumsfrage, zumindest aber die Rolle des Staates als Wachstumsmotor nicht zu umgehen sein wird" (Jänicke 1993: 19). Im Laufe der Entwicklung des ökomodernen Diskurses verlor die Wachstumskritik allerdings mehr und mehr an Bedeutung, da man - entgegen des historischen Arguments der Korrelation von Wirtschaftswachstum und Ressourcenverbrauch bzw. Treibhausgasemissionen - davon ausging, dass Wachstum und Ökologie nicht zwangsläufig Gegensätze zu sein bräuchten. Schließlich könne man sie so weit miteinander in Einklang bringen, wie es gelänge, die Steigerung der Ressourcen- und Senkenproduktivität, ähnlich der Arbeitsproduktivität, zu einer Wohlstandsquelle zu machen (vgl. Huber 2011a: 279). Die Qualitätssteigerung von Produkten wird in der ökomodernen Perspektive als Möglichkeit gesehen, eine Steigerung der Wertschöpfung bei sinkendem Stoffumsatz zu erzielen. 
Die Debatte um das Verhältnis von Ökologie und Wirtschaftswachstum wurde vor allem durch die Kritik aus den Umweltbewegungen, in der das Primat des Wachstums wiederkehrend in Frage gestellt wurde, aufrecht erhalten. Auch in der Wissenschaft wurde die Kontroverse stetig weitergeführt und mündete in der Ausarbeitung verschiedener Konzepte wie organisches, selektives, entkoppeltes oder qualitatives Wachstum, die dem Fokus auf quantitativem Wachstum entgegengesetzt wurden (vgl. Dingler 2003: 258ff; Huber 1993: 55f). Als eine Art Kompromissformel - Huber spricht von einer „Brücke, über die Parteigänger von Ökologie und Ökonomie einander näher kommen konnten" (Huber 1993: 56) - ermöglichte die Idee eines nachhaltigen Wachstums ein Festhalten am Wachstumsziel, ohne die Ökologieproblematik als irrelevant abzutun. Dabei gilt umgekehrt die Natur insofern als schützenswert, als ihre Zerstörung Kosten verursacht, die dem Wirtschaftswachstum schaden (vgl. Kaufmann/Müller 2009: 42).

„Ökologie wird in dieser Perspektive zu Ergebnis ebenso wie Bedingung rentabler Ökonomie, der Konflikt von Ökologie und Ökonomie im Prinzip aufhebbar.“ (Huber 1993: 54)

Der ökomoderne Diskurs greift die Kritik am Wirtschaftswachstum auf und integriert sie in den ökomodernen Diskurs. Die ökomoderne Hegemoniestrategie des nachhaltigen Wachstums (kurz: nachhaltiges Wachstum) basiert auf dem Typus der Hegemoniestrategie der Äquivalenzierung. Strategien der Äquivalenzierung zeichnen sich dadurch aus, dass sie kritische Artikulationen - in dem Fall die Forderung nach einem Ende des (Strebens nach) Wirtschaftswachstum(s) - nicht kategorisch ablehnen, sondern eine Vereinbarkeit zwischen den Artikulationen und dem Hegemonieprojekt herstellen (für den gesamten Absatz vgl. Wullweber 2010: 146f). So wird die Kritik des Wirtschaftswachstums als Forderung nach nachhaltigem Wachstum in die ökomoderne Äquivalenzkette integriert. Durch diese Integration einer potenziell antagonistischen Artikulation erfolgt eine Modifikation derselben. Die Grundprinzipien des konventionellen Entwicklungsmodells werden in dem Konzept des nachhaltigen Wachstums nicht in Frage gestellt. Weiterhin wird die Kritik an den - fossilistischen und zentralisierten - Strukturen des Wirtschaftens gekappt (vgl. Hajer 1997: 113). Dies bedeutet eine strategisch-selektive Aneignung der Wachstumskritik, die an das hegemoniale Setting angepasst wird. Der potenziell antagonistischen Artikulation wird so ihr bedrohlicher Charakter genommen.

Strategien der Äquivalenzierung machen aus ehemaligen Gegensätzen „einfache Differenzen, die nur einer entsprechenden Mediation bedürfen“ (Wullweber 2010: 147). Der vormals artikulierte Gegensatz zwischen Umweltschutz und Wirtschaftswachstum wird zur Synthese des nachhaltigen Wachstums, indem man annimmt, dass die beiden Ziele nicht kollidieren, sondern miteinander in Einklang gebracht werden können (vgl. Huber 1993: 54; Huber 2011a: 279). Der ökomoderne 
Diskurs geht sogar so weit, den von Kritiker_innen postulierten Gegensatz in sein Gegenteil zu verkehren und Wirtschaftswachstum als Bedingung für effizienten Umweltschutz sowie umgekehrt Umweltschutz als Wachstumsmotor zu begreifen (vgl. Pelfini 2006: 156). So wird beispielsweise in Artikel 3 der Klimarahmenkonvention betont, dass Staaten zusammenarbeiten sollen, ,um ein tragfähiges und offenes internationales Wirtschaftssystem zu fördern, das zu nachhaltigem Wirtschaftswachstum und nachhaltiger Entwicklung in allen Vertragsparteien, insbesondere denjenigen, die Entwicklungsländer sind, führt und sie damit in die Lage versetzt, die Probleme der Klimaänderungen besser zu bewältigen“ (UNFCCC 1992: 6). ${ }^{20}$

Allerdings hat die Äquivalenzierung einer Artikulation immer auch eine Veränderung des hegemonialen Diskurses zur Folge (vgl. Wullweber 2010: 146f). Hier bedeutet es die Akzeptanz der Ökologieproblematik und die Überzeugung, dass eine gänzlich unveränderte Fortschreibung der Wirtschaftsweise nicht zu verantworten ist (vgl. Hajer 1995: 3, 25). In Bezug auf die internationale Klimapolitik zeigt sich dies etwa in der Anerkennung von Obergrenzen für Treibhausgasemissionen. ${ }^{21}$ Die gestiegene Bedeutung von Umweltschutz lässt sich auch daran erkennen, dass sich mittlerweile sehr viele Akteur_innen, teilweise auch ehemalige Klimaskeptiker_innen, zu einem in die hegemonialen Strukturen eingebetteten sprich: marktförmigen und nicht wachstumshemmenden - Klimaschutz bekennen.

Damit wird das ökomoderne Projekt gestärkt, da nun vermeintlich , alle an einem Strang ziehen' - inklusive ehemaliger Klimaskeptiker_innen auf der einen und Wachstumskritiker_innen auf der anderen Seite. Diese Suggestion einer universellen Interessenlage diskreditiert alternative Artikulationen, die jenseits des ökomodernen Konsenses angesiedelt sind, als destruktive Beiträge. Schließlich gehe es nicht mehr um die Frage der richtigen Reaktion auf die ökologische Krise, - denn die sei ja mit dem Konzept der Sustainable Development gefunden - sondern zur Debatte stünde allein die Art und Weise ihrer Ausgestaltung.

20 Ganz ähnlich hieß es bereits 1992 in Grundsatz 12 der Rio-Erklärung über Umwelt und Entwicklung: „Die Staaten sollten gemeinsam daran arbeiten, ein stützendes und offenes Weltwirtschaftssystem zu fördern, das in allen Ländern zu Wirtschaftswachstum und nachhaltiger Entwicklung führt und es gestattet, besser gegen die Probleme der Umweltverschlechterung vorzugehen.“ (Konferenz der Vereinten Nationen über Umwelt und Entwicklung 1992: 2)

21 Allerdings stellen diese im Kyoto-Protokoll festgeschriebenen Obergrenzen für die Annex-B-Staaten nur minimale Veränderungen gegenüber dem business as usual dar. Aufgrund der flexibilisierenden Mechanismen führten sie auch nicht immer zu absoluten Reduktionen der Treibhausgasemissionen in den Industriestaaten (vgl. Kapitel 5.1). 
In diesem Zusammenhang muss Hajers bereits erwähnte Feststellung gesehen werden, dass es für radikale Gruppen zunehmend schwerer wurde, Deutungshoheit über die Problemdefinition und die daraus folgenden adäquaten Lösungen $\mathrm{zu}$ erlangen, sobald es einen gesellschaftlichen Konsens über die Notwendigkeit gab, auf die ökologische Krise reagieren zu müssen (vgl. Hajer 1995: 102f). Auch KarlWerner Brand, Klaus Eder und Angelika Poferl argumentieren, dass sich die Mobilisierungsarbeit für Umweltgruppen dadurch erschwert habe, dass sich die Auseinandersetzungen nicht mehr um die Frage drehe, ob, sondern wie auf ökologische Probleme reagiert werden soll. Die Lösungsvorschläge der Umweltgruppen konkurrieren dann mit Konzepten anderer Akteur_innen (vgl. Brand/Eder/Poferl 1997: 192, 201). Mit dem gestiegenen gesamtgesellschaftlichen Interesse an ökologischen Themen schwenkten die Umweltbewegungen auch strategisch um. Sie wählten tendenziell nicht mehr so häufig den Weg der scharfen Abgrenzung eigener Positionen, sondern entschieden sich öfter für den Dialog mit Entscheidungsträger_innen in Politik und Wirtschaft (vgl. Brand/Eder/Poferl 1997: 197ff).

Trotz der breiten Zustimmung zum Konzept des nachhaltigen Wachstums bleibt die Mediation zwischen Wirtschaftswachstum und Umweltschutz weiterhin latent brüchig. ${ }^{22}$ Die absolute Entkopplung von Wirtschaftswachstum und Ressourcenverbrauch bzw. Treibhausgasemissionen ist bislang eine theoretische Vorstellung ohne historische Belege (vgl. Hannesson 2002; Kaufmann/Müller 2009: 166f; Scheer 2000: 9ff; York/Rosa 2013: 292). Wenn auch in der nahen Zukunft empirische Nachweise für die Möglichkeit der Synthese von Wirtschaftswachstum und Umweltschutz ausbleiben, kann dies zu einem Aufbrechen von Rissen im ökomodernen Diskurs führen, worauf ich am Beispiel der Klimapolitik näher eingehe.

Die Schwierigkeit der Synthese besteht in der Abhängigkeit der Wirtschaft von fossilen Brennstoffen. Seit der industriellen Revolution steigt der Primärenergieverbrauch proportional zum Anstieg des Wirtschaftswachstums (vgl. Hannesson 2002). Da Primärenergie seitdem fast ausschließlich aus fossilen Brennstoffen gewonnen wird, ist der stetig steigende Ausstoß von $\mathrm{CO}_{2}$ der weltweit durchgesetzten fossilen Wirtschaftsweise inhärent (vgl. Scheer 2000: 9ff). Diese Schwierigkeit erfährt ihre hegemoniale Bearbeitung durch die Trennung in die Input-Seite der EnergieProduktion mit fossilen Brennstoffen und die Output-Seite der daraus entstehenden Emissionen, die sich in der internationalen Klimapolitik durchgesetzt hat (vgl. Brunnengräber et al. 2008: 188ff). So erfolgt keine direkte Regulierung der Nutzung fossiler Brennstoffe, sondern nur der daraus entstehenden Emissionen. Über die Einführung von handelbaren Emissionsrechten wird den ökologischen Kosten

22 Hier zeigt sich Wullwebers Feststellung, dass Strategien der Äquivalenzierung auf Simplifizierungen beruhen und deshalb nie vollständig gelingen (vgl. Wullweber 2010: 147). 
des Klimawandels ein monetärer Wert zugeordnet. Die alleinige Fokussierung auf die Emissionen ohne Berücksichtigung der Energieinfrastruktur trägt allerdings einen evidenten Widerspruch in sich, da gerade die Abhängigkeit der Wirtschaft von fossilen Brennstoffen die Umstellung auf eine klimaneutrale Lebensweise so schwierig macht. Dieser Widerspruch wird bisher durch die Möglichkeit des Zukaufs von zertifizierten Emissionsreduzierungen im Rahmen des Kyoto-Protokolls abgemildert (vgl. Kapitel 5.1.2). Die Realisierung von Reduktionsverpflichtungen wird den Industrienationen ermöglicht, ohne dass sie einen konsequenten Strukturwandel zur Unabhängigkeit von fossilen Brennstoffen einleiten müssen. Dabei ist offensichtlich, dass die ökologischen Erfolge des Kyoto-Protokolls bislang hinter den Erwartungen zurück bleiben. Der globale Ausstoß von Treibhausgasemissionen steigt weiterhin. Auch von einer absoluten Entkopplung von Wirtschaftswachstum und Treibhausgasemissionen kann bislang keine Rede sein. Ein Rückgang der globalen Treibhausgasemissionen ist nur in Zeiten krisenbedingter Wachstumseinbußen zu beobachten (vgl. IPCC 2014: 6f). Der mangelnde ökologische Erfolg des Kyoto-Protokolls und die fehlenden empirischen Nachweise für die Möglichkeit der Synthese von Wirtschaftswachstum und Umweltschutz produzieren Risse im ökomodernen Diskurs, die Ansatzpunkte für antagonistische Artikulationen darstellen.

\section{Zur Unterscheidung der verschränkten ökomodernen Hegemoniestrategien}

Die ökomodernen Hegemoniestrategien stehen untereinander in einem engen Zusammenhang, was ihre Unterscheidung erschwert. Deshalb werde ich im Folgenden darlegen, warum und wie ich die drei Hegemoniestrategien voneinander unterscheide. Die Subsumtion der Natur unter die gesellschaftlichen Funktionslogiken bildet den Kern der Hegemoniestrategie der reflexiven Naturbeherrschung. Dabei orientiert sich die naturbeherrschende Naturaneignung - aufgrund der Dominanz ökonomischer Diskurse - an den Vorgaben der Standortpolitik. Dementsprechend sollen die Reaktionen auf die ökologische Krise nicht nur die nicht-intendierten Nebenfolgen der Naturbeherrschung berechenbar machen, sondern gleichzeitig als Wachstumsmotor fungieren. Diese spezifische Ausrichtung der Naturbeherrschung ist mit einer weiteren ökomodernen Hegemoniestrategie verknüpft: Im Sinne eines nachhaltigen Wachstums sollen die beiden Ziele des Umweltschutzes und des Wirtschaftswachstums in Einklang gebracht werden. In Bezug auf die präferierten Maßnahmen zur Erreichung des ökologisch-ökonomischen Doppelnutzens zeigt sich die Verschränkung der ökomodernen Hegemonistrategien vollends: Der angestrebte reflexive Fortschritt durch wissenschaftlich-technische Rationalität - der die dritte ökomoderne Hegemoniestrategie darstellt - nimmt als wichtige Produktivkraft eine Schlüsselrolle für die Verwirklichung von reflexiver Naturbeherrschung und nachhaltigem Wachstum ein. Mit Hilfe von Risikoabschätzung und -management sollen die nicht-intendierten Nebenfolgen der Naturbeherr- 
schung vermieden bzw. kontrolliert werden. Technologische Innovationen sollen darüber hinaus ein nachhaltiges Wirtschaftswachstum generieren, das als Königsweg zum Erhalt einer intakten Umwelt gilt. Dese Verwobenheit erschwert die Differenzierung zwischen den ökomodernen Hegemoniestrategien. Dies trifft insbesondere auf die Hegemoniestrategien der reflexiven Naturbeherrschung und des reflexiven Fortschritts zu, die beide auf die Auseinandersetzungen um zivilisatorische Risiken reagieren. Ich habe mich dennoch für ihre Unterscheidung entschieden, weil sie in dieser Dreiteilung ihre heuristische Funktion - die differenzierte Analyse ökomoderner Praktiken im Untersuchungsmaterial - besonders gut erfüllen. Im Sinne einer empirischen Sättigung haben sich die Hegemoniestrategien - in Kombination mit den ökomodernen Grundannahmen - als sinnvolle analytische Kategorien herausgestellt, mit denen im Untersuchungsmaterial ökomoderne Artikulationen identifiziert und von alternativen Artikulationen bzw. Diskursen abgegrenzt werden können.

Mit der Hegemoniestrategie der reflexiven Naturbeherrschung sollen im Folgenden Artikulationen der Subsumtion von Natur unter die gesellschaftlichen Funktionslogiken erfasst werden. Hierbei spielen die Praktiken zur Steigerung der Kontrolle und der Berechenbarkeit von Natur eine entscheidende Rolle. Artikulationen, die auf eine stetige Rationalisierung aller gesellschaftlichen Lebensbereiche und eine Perfektionierung der technologischen Entwicklung zielen, ordne ich der Hegemoniestrategie des reflexiven Fortschritts durch wissenschaftlich-technischen Rationalität zu. Die Artikulationen, in denen die Synthese von Wirtschaftswachstum und Umweltschutz postuliert oder vorausgesetzt werden, interpretiere ich als (Re-)Produktion der Hegemoniestrategie des nachhaltigen Wachstums.

\subsection{DAS ÖKOMODERNE HEgEMONIEVERSPRECHEN}

Im ökomodernen Diskurs wird davon ausgegangen, dass die etablierten politischen, ökonomischen und sozialen Institutionen die ökologische Krise erfolgreich bearbeiten können (vgl. Hajer 1995: 25). Die Hoffnung auf Lösungspotenziale durch innovative Technologien ermöglicht es dem ökomodernen Projekt, die Bedrohlichkeit der ökologischen Krise anzuerkennen und gleichzeitig die als Sachzwang präsentierten Vorgaben der Standortpolitik zu erfüllen. Damit wird die gesellschaftliche Suche nach möglichen Reaktionen auf die ökologische Krise eingeschränkt. Als ,realistisch“ gelten nur noch Vorschläge, die sich in den Rahmen bestehender gesellschaftlicher Strukturen einbetten lassen, "weil der Wandel des Industrialismus eher die nötige Akzeptanz findet als seine Abschaffung" (Jänicke 1993: 19). Das ökomoderne Hegemonieversprechen bezieht sich somit gleichzeitig auf 
1) die Bewältigung der ökologischen Krise und

2) die Stabilisierung gesellschaftlicher Strukturen.

Wie in der Darstellung der Hegemoniestrategien deutlich wurde, greift das ökomoderne Projekt durchaus Forderungen der Umweltbewegungen auf, ohne jedoch davon eine allgemeine Systemkritik abzuleiten oder die ökologische Krise als Symptom einer „Krise der Modernität“ (Görg 2003a: 135) zu interpretieren. Stattdessen wird im ökomodernen Diskurs davon ausgegangen, dass ökologische Probleme durch eine Reform der Institutionen der, westlichen“ Moderne, durch eine ökologische Modernisierung der Moderne, erfolgreich bearbeitet werden können. Huber, selber Protagonist der ökologischen Modernisierungstheorie, fasst diesen Wandel von den modernisierungskritischen Artikulationen zur Integration ökologischer Forderungen in die Institutionen der Moderne - folgendermaßen zusammen:

„Von der ehedem prononcierten Modernisierungskritik bleibt die heute weitgehend unkontroverse Feststellung, dass Wachstum und Entwicklung wie zuvor nicht weitergehen können und sie also anders, eben in ökologisch angepasster und auch unter sozialen und kulturellen Aspekten neuerlich readaptierten Weise weitergehen müssen.“ (Huber 2011b: 144)

Für Arthur Mol, der ebenfalls wichtige Impulse für die Entwicklung der ökologischen Modernisierungstheorie lieferte, steht außer Frage, dass es keine Alternativen zur forcierten Modernisierung gibt, um die ökologische Krise in den Griff zu bekommen: ,the only possible way out of the ecological crisis is by going further into the process of modernization“" (zitiert in York/Rosa 2013: 283; Hervorhebungen im Original). Der ökomoderne Diskurs stellt eine spezifische Weiterentwicklung des modernisierungstheoretischen Paradigmas dar und baut auf folgenden Axiomen der Modernisierungstheorie auf:

1) Das Verhältnis zwischen Mensch und Natur wird im modernisierungstheoretischen Paradigma als anthropozentrisch begriffen (vgl. Huber 2011a: 283 und 2011b: 179). Dies hat in erster Linie die Konsequenz, den Menschen als ausschließlichen Bezugspunkt von ethischen Pflichten und Wertzuschreibungen zu setzen (vgl. Kirchhoff 2011: 39). So dient im ökomodernen Diskurs der Umweltschutz der nachhaltigen Stabilisierung der menschlichen Gesellschaft. Der Natur wird kein Eigenwert beigemessen (vgl. Dingler 2003: 306). Die anthropozentrische Perspektive des ökomodernen Diskurses wurde bereits mit der Definition von Sustainable Development im Brundtland-Bericht, auf die immer wieder zurückgegriffen wird, festgeschrieben (vgl. Weltkommission für Umwelt und Entwicklung 1987: 46). Dort bleiben die menschlichen Bedürfnisse der gegenwärtigen und zukünftigen Generationen alleiniger normativer Bezugspunkt. Deshalb erhält die Natur im ökomodernen Diskurs ihren Wert erst durch die 
Nutzung durch den Menschen. Dies zeigt sich paradigmatisch an dem Begriff der ,Ökosystemdienstleistungen', der in der Umweltforschung und der Umweltpolitik eine zunehmend wichtige Rolle spielt (vgl. These 6 in Kapitel 3.6).

2) Im modernisierungstheoretischen Paradigma wird das universelle Interesse und Ziel des menschlichen Daseins bzw. der Gesellschaft in der permanenten Entwicklung gesehen. Dabei wird Entwicklung als quantitatives Wachstum von Wohlstand, vom Besitz materieller Güter, definiert und primär anhand des Wirtschaftswachstums gemessen (vgl. Gudynas 2012: 7; Huber 2011a: 280ff und 2011b: 143ff). Im ökomodernen Diskurs wird eine nachhaltige Entwicklung angestrebt, in welcher der Gegensatz von Wirtschaftswachstum und Umweltschutz aufgehoben werden soll.

3) Das Ziel der Entwicklung wird im modernisierungstheoretischen Paradigma über eine einseitige Anwendung des begrifflichen, identifizierenden Denkens angestrebt, die Natur objektiviert, erfasst und für menschliche Zwecke verfügbar macht (vgl. Schäfer 2004: 58ff). ${ }^{23}$ Diese begriffliche Abstraktion manifestiert sich in zweckrationalem Denken und Handeln, tritt idealerweise als Expert_innenwissen (der Wissenschaft) zu Tage und materialisiert sich in technologischem Fortschritt (vgl. Huber 2011b: 179ff). Diese Form der Rationalität zeichnet sich durch ihren instrumentalen Zugriff auf die innere Natur des Menschen und die ihn umgebende äußere Natur aus (vgl. Horkheimer 1990). So wird Natur im ökomodernen Diskurs in erster Linie als Ressource wahrgenommen. Die Bearbeitung der ökologischen Krise zielt damit auf die Sicherung einer langfristigen Nutzung der sogenannten ,Ökosystemdienstleistungen“. Dabei gilt (bestimmtes) wissenschaftliches und technisches Wissen als lösungskompetentes Wissen, während andere Formen des Wissens vom ökomodernen Diskurs ausgeschlossen werden (vgl. Dingler 2003: 303, 306).

Die Universalisierung des modernisierungstheoretischen Paradigmas im ökomodernen Diskurs zeigt sich in der Überzeugung, dass eine Bearbeitung der ökologischen Krise nur durch weitere Modernisierungsprozesse möglich sei.

„Vor einem solchen Hintergrund ist es müßig, nach fundamentalen Entwicklungsalternativen zu suchen. Außerhalb des industriegesellschaftlichen Entwicklungskorridors gibt es für die moderne Gesellschaft keine reellen Optionen. Modernisierung und industrielle Entwicklung gehen weiter, aber sie können und sollen in veränderter, sozialökologisch restrukturierter Weise weitergehen.“ (Huber 2011b: 145)

23 Den Gegensatz zum begrifflichen Denken bildet bei Adorno und Horkheimer die Mimesis, die sich anpassende und nachahmende Annäherung an eine rätselhaft bleibende Welt (vgl. Schäfer 2004: 58ff). 
Damit sind wir beim fantasmatischen Kern des ökomodernen Hegemonieversprechens: die fortschreitende gesellschaftliche Entwicklung. Das ökomoderne Hegemonieversprechen bezieht sich auf den Erhalt eines glückselig machenden Zustandes, der vor seiner Zerstörung bewahrt werden soll. Die etablierten gesellschaftlichen Strukturen sollen als Garanten für die fortschreitende Entwicklung grundsätzlich bestehen bleiben. Um das Bestehende bewahren zu können, muss es allerdings auf die Herausforderungen der ökologischen Krise reagieren. Die gesellschaftlichen Strukturen sollen ökologisch restrukturiert werden, um den erstrebenswerten Zustand aufrecht erhalten zu können. Auf diese Restrukturierung beziehen sich auch die ökomodernen Kernforderungen Sustainable Development und Green Economy, die zumindest phasenweise die Rolle des leeren Signifikanten im ökomodernen Projekt einnehmen konnten (für die Diskussion der Kämpfe um die konkrete Ausgestaltung der ökomodernen Kernforderung vgl. These 6 in Kapitel 3.6).

Der Erhalt des glückselig machenden Zustandes gilt im ökomodernen Diskurs allerdings als akut bedroht. Das Gemeinwohl der fortschreitenden Entwicklung sei durch ,falsche' Reaktionen auf die ökologische Krise gefährdet. Auf der einen Seite würden die konventionellen nicht-reflexiven Modernisierungsdiskurse die Basis der fortschreitenden Entwicklung - die Möglichkeit der Nutzung natürlicher Ressourcen - aufs Spiel setzen, weil sie die Bedrohlichkeit der ökologischen Krise nicht anerkennen. Auf der anderen Seite gehe die Gefahr von radikalen ökologischen Diskursen aus, die das gesellschaftliche Ziel der fortschreitenden Entwicklung in Frage stellen. Im ersten Fall drohe ein Rückschritt durch selbstverschuldete ökologische Katastrophen, im zweiten Fall durch intendierte rückwärtsgewandte Transformationsprozesse. Gegen diese beiden, falschen' Reaktionen auf die ökologische Krise soll das Projekt einer ökologischen Modernisierung durchgesetzt werden, um eine dauerhafte fortschreitende Entwicklung zu garantieren.

Das verworfene Außen des ökomodernen Diskurses ist damit ,Ideologie‘. Ideologie wird hier im alltäglichen pejorativen Sprachgebrauch verwendet und meint die Verfolgung , unrealistischer' und ,interessengeleiteter' Lösungen. Die nicht-reflexiven Modernisierungsdiskurse gelten aus ökomoderner Perspektive als unrealistisch, weil sie ignorant gegenüber den wissenschaftlich bewiesenen Gefahren seien, die von der ökologischen Krise ausgehen. Die Propagierung eines business-as-usual wird dabei auf die Verfolgung von Interessen einer umweltschädigenden Wirtschafts- und Lebensweise zurückgeführt, die keine Rücksicht auf das Gemeinwohl nehme. Die radikalen ökologischen Diskurse gelten aus ökomoderner Perspektive ebenfalls als unrealistisch, weil ein Systemwechsel nicht möglich sei; zumindest nicht in der Geschwindigkeit, die nötig wäre, um auf diesem Weg die ökologische Krise erfolgreich bearbeiten zu können. Die Propagierung einer radikalen Transfor- 
mation gesellschaftlicher Strukturen wird dabei auf die Verfolgung partikularer politischer Interessen zurückgeführt, denen Priorität eingeräumt werde gegenüber der Bewahrung des durch die ökologische Krise bedrohten Gemeinwohls.

Mit dieser Frontstellungen gegenüber den als ,ideologisch“ verworfenen alternativen Diskursen, gibt das ökomoderne Hegemonieversprechen Antworten auf die identitätsstiftenden Fragen: Wer sind wir? Was ist unser Ziel bzw. worin besteht das Gemeinwohl? Wie erreichen wir unser Ziel bzw. das Gemeinwohl? Wir haben es hier also mit Identitätsangeboten zu tun, die im ökomodernen Diskurs (re-)produziert werden. In der Aneignung dieser Subjektpositionen durch Akteur_innen werden soziale Identitäten und damit Diskursträger_innen geschaffen. Diese wiederum bilden die Basis für die Zustimmung zum ökomodernen Diskurs und somit für die Stabilität des ökomodernen Projekts.

\subsection{Die Hegemonialisierung des ökomodernen Projekts}

Nach der Analyse der Formierung des ökomodernen Projekts ist es nun möglich, die Frage nach dem Grad und der Art und Weise der Durchsetzung eines ökomodernen Konsenses zu beantworten (vgl. die erste Forschungsfrage in Kapitel 1.1). In sechs Thesen diskutiere ich im Folgenden den Status quo der Verbreitung und des Einflusses des ökomodernen Diskurses.

\section{1) Das ökomoderne Hegemonieprojekt setzt sich über die Herstellung eines} passiven Konsenses durch.

Den Akteur_innen, welche die Entwicklung des ökomodernen Diskurses stark prägen - Wissenschaftler_innen, Entscheidungsträger_innen in Politik und Wirtschaft, Institutionen der Politikberatung - ist gemeinsam, dass sie zwar einflussreich sind, aber nicht unbedingt auf Massenmobilisierung zielen (vgl. Beck 2010: 254f). Damit korreliert, dass die Hegemoniepraktiken des ökomodernen Projekts einen passiven Konsens erzeugen. Das bedeutet, dass einflussreiche gesellschaftliche Kräfte das ökomoderne Projekt zwar ohne aktive Zustimmung großer Teile der Bevölkerung etablieren, dabei jedoch auch nicht auf großen Widerstand treffen.

Ein passiver Konsens kann Bestand haben, wenn eine gewisse Gleichgültigkeit herrscht, beispielsweise weil das Thema in der breiten Masse der Bevölkerung nicht wahrgenommen oder ihm keine besondere Bedeutung beigemessen wird (vgl. Wullweber 2010: 152f). In Bezug auf die Ökologieproblematik und speziell den Klimawandel wäre auch denkbar, dass es zwar ein generelles Interesse gibt, aber aufgrund der Komplexität ökologischer Debatten, die stark wissenschaftlich geprägt sind, den 
Entscheidungen und Positionen einer als kompetent eingeschätzten Elite passive Zustimmung gewährt wird. Man kann jedoch davon ausgehen, dass ein aktiver Konsens, in dem das Hegemonieprojekt von einer Mehrheit als wünschenswert angesehen werden würde, stabiler wäre als ein passiver. Insofern ist für die Einschätzung der weiteren Entwicklung des ökomodernen Projekts eine wichtige Frage, ob es ökomoderne Diskursträger_innen gibt, die das Potenzial haben, einen aktiven Konsens herzustellen. Grüne Parteien wären dafür prädestiniert. Schließlich streben Parteien danach, für bestimmte Forderungen, mit denen sie identifiziert werden, einen aktiven Konsens herzustellen (vgl. Lemke 2005: 130).

Nach wie vor gelten Grüne Parteien in Bezug auf ökologische Themen kompetenter und glaubwürdiger als andere Parteien, wohingegen sie mit anderen Themen weitaus weniger in Verbindung gebracht werden. Deshalb liegt es nahe, dass Grüne Parteien immer wieder Aspekte der Ökologieproblematik auf die Agenda setzen und die Erlangung des Gemeinwohls an die adäquate Bearbeitung der ökologischen Krise koppeln. Die Grünen Parteien sind historisch eng mit den Umweltbewegungen verknüpft. Ihr Aufstieg ist ein Ergebnis der Professionalisierung der Umweltbewegungen. Insofern verwundert es nicht, dass der mit der Professionalisierung der Umweltbewegungen verbundene Wandel von popularen zu separierten Forderungen (vgl. Kapitel 3.2.6) auch die Grünen Parteien prägt. Antagonistische Positionen werden zwar noch von Einzelpersonen vertreten, die Deutungshoheit haben allerdings Positionen erlangt, die dem ökomodernen Diskurs entlehnt sind. Dies macht die Grünen Parteien zu wichtigen Diskursträgerinnen des ökomodernen Diskurses, die potenziell in der Lage sind, das ökomoderne Projekt zu forcieren und die aktive Zustimmung von breiteren Teilen der Gesellschaft zu erzeugen.

Dass die Grünen Parteien tatsächlich an einem aktiven Konsens für das ökomoderne Projekt arbeiten, zeigte sich insbesondere im Europawahlkampf des Jahres 2009. Die Europäischen Grünen einigten sich im Vorfeld darauf, den Green New Deal ,ins Zentrum ihres programmatischen Angebots zu rücken“ (Bütikofer 2011: 29). Mit der offensiven Propagierung des Green New Deals war die Hoffnung verbunden, über die konkrete Wähler_innenmobilisierung hinaus, „eine neue, hegemonie-fähige Antwort auf die offenkundige, dreifache Krisensituation zu geben“ (Bütikofer 2011: 29). Offensichtlich gab es die explizite Strategie, die Entwicklung des aufstrebenden ökomodernen Hegemonieprojekts voranzutreiben. Im Sinne einer aktiven Subjektpositionierung bot sich die Möglichkeit, eigene Forderungen in das Projekt einzuschreiben. Von der Verknüpfung der europäischen Grünen Parteien mit dem ökomodernen Projekt versprach man sich Einfluss und Wähler_innenstimmen - für den Fall, dass es zur erfolgreichen Etablierung eines aktiven Konsenses kommen würde. Dann wäre der Erfolg des ökomodernen Projekts mit den Grünen 
Parteien als wichtige Protagonistinnen verbunden. Von dieser Erwartung zeugt folgendes Zitat von Reinhard Bütikofer, damaliger Spitzenkandidat von Bündnis 90/Die Grünen und seitdem Mitglied des Europäischen Parlaments:

„Der Green New Deal ist eine Transformationsstrategie, deren Aktualität unvermindert gilt. Aber er ist so etwas wie eine verheißungsvolle, sogar Sieg versprechende Revolution, die ihr revolutionäres Subjekt noch sucht.“ (Bütikofer 2011: 30)

Die Hoffnung, dass der Green New Deal eine Idee ist, „die die Massen ergreifen könnte“ (Bütikofer 2011: 32), hat Bütikofer allerdings mittlerweile aufgegeben, da er das Konzept für ,zu wenig emotionalisierbar und nicht besonders massentauglich“ (Bütikofer 2011: 32) hält. Die Europäischen Grünen halten zwar weiterhin am Green New Deal fest (vgl. im Internet: www.europeangreens.eu/greennewdeal, letzter Zugriff am 02.12.2014), gleichzeitig sind sie aber auf der Suche nach einer „großen Erzählung“ (Bütikofer 2011: 32), um das Konzept attraktiver zu machen. Dabei beziehen sie sich auch auf den Begriff der Green Economy, der die aktuellen Auseinandersetzungen um die ökologische Krise prägt (vgl. beispielsweise im Internet: www.europeangreens.eu/themes/green-economy, www.gruene-berlin.de/wahl2011/berlin-stadt-der-green-economy, letzter Zugriff am 02.12.2014). Insgesamt bleibt abzuwarten, inwieweit die Grünen Parteien das ökomoderne Projekt weiter forcieren und vor allem, wie erfolgreich sie damit sein werden. Prinzipiell denkbar wäre auch eine Rückkehr der Grünen Parteien zu einer antagonistischen Strategie, in der wieder populare Forderungen ins Zentrum gerückt werden würden.

2) Seit den 1980er Jahren dominiert das ökomoderne Hegemonieprojekt zunehmend die umweltpolitischen Aushandlungsprozesse in der internationalen Politik und in den Industrienationen.

Der ökomoderne Diskurs setzte sich ab den 1980er Jahren zunehmend bei den verschiedenen an umweltpolitischen Aushandlungsprozessen beteiligten Akteur_ innen durch. Spätestens seit den 90er Jahren fungiert das Konzept der ökologischen Modernisierung als Leitprinzip für innovative Politikformulierung im Umweltbereich - sowohl auf internationaler Ebene als auch auf der nationalstaatlichen bzw. regionalen Ebene vieler Industrieländer (vgl. Busch/Jörgens/Tews 2005; Hajer 1995: 26, 30, 100; Huber 2011a: 288). In diesen Arenen dominiert das ökomoderne Hegemonieprojekt die umweltpolitischen Aushandlungsprozesse. Von einer Dominanz des ökomodernen Projekts zu sprechen meint, dass es die Deutungsmuster vorgibt, innerhalb dessen um die richtige Antwort auf die ökologische Krise gerungen wird. Alternative Ansätze bleiben außen vor bzw. finden bei den Entscheidungsträger_innen kein Gehör. 
3) Die Dominanz des ökomodernen Projekts beschränkt sich primär auf den Bereich der Umweltpolitik.

Das ökomoderne Projekt dominiert die Umweltpolitik, die ihre Wirkung zum einen in eigenständigen Bereichen in konventionellen politischen Institutionen entfaltet, zum anderen aber auch über ergänzende Maßnahmenkonzepte, die den Kernbereich einer Institution flankieren (vgl. Jacob/Volkery 2006: 239, 258f). Über den Bereich der institutionalisierten Umweltpolitik hinaus entwickelte der ökomoderne Diskurs bislang keine gesamtgesellschaftliche Integrationskraft im Sinne einer Metaerzählung oder einer Selbstbeschreibung der Gesellschaft. Insofern ist die Wirkung des ökomodernen Projekts allein schon deshalb begrenzt, weil umweltpolitische Maßnahmen - egal ob von staatlicher oder unternehmerischer Seite - weiterhin dem Primat ökonomischer Diskurse und damit der Profitorientierung und der Standortpolitik unterliegen. Umweltschutzziele werden dem Kampf um Vorteile im internationalen Wettbewerb untergeordnet (vgl. Görg 2003a: 214; Ihlen 2009: 246, 258).

Dies erklärt bis zu einem gewissen Grad die Lücke zwischen dem Anspruch der ökologischen Modernisierung, weit mehr als ein dem Modernisierungsprozess nachgeschalteter Umweltschutz zu sein, und der Wirklichkeit, die darüber kaum hinaus kommt. Dieses Phänomen kann aber nicht allein auf den geringen Einfluss der ökologischen gegenüber anders gelagerten Diskursen erklärt werden. Die Diskrepanz zwischen Anspruch und Wirklichkeit des ökomodernen Projekts ist auch in seinen spezifischen Strategien begründet, wie in These vier näher ausgeführt wird.

\section{4) Ökomoderne Strategien enden aus diskursinhärenten Gründen dort, wo zentrale} Institutionen moderner Gesellschaften zur Disposition stehen.

Der ökomoderne Diskurs wird gerade deshalb von bestimmten gesellschaftlichen Kräften getragen, weil er den Status quo gesellschaftlicher Strukturen nicht in Frage stellt. Die Akteur_innen, die das ökomoderne Hegemonieprojekt maßgeblich vorantreiben, drängen nicht auf die Verschiebung gesellschaftlicher Kräfteverhältnisse. Deshalb enden ökomoderne Strategien dort, wo zentrale Institutionen ,westlicher ${ }^{6}$ Gesellschaften zur Disposition stehen (vgl. Brand 2010: 142; Görg 2003a: 140; Hajer 1995: 25; Hajer 1997: 108f, 113). Dies stellt vor dem Hintergrund der fossilistischen Wirtschaft eine starke Begrenzung dar, welche die bis dato eher geringen ökologischen Erfolge des ökomodernen Projekts erklärt. 
5) Die Hegemoniestrategien des ökomodernen Projekts verhinderten die Herausbildung wirkungsmächtiger gegenhegemonialer Projekte.

Die verschiedenen Elemente des ökomodernen Hegemonieprojekts eint der Ausschluss gesellschaftskritischer sozial-ökologischer Perspektiven, die sowohl in Bezug auf ihre Ursachen als auch in Bezug auf ihre Wirkungen die gesellschaftliche Vermitteltheit von ökologischen Krisenphänomenen in den Mittelpunkt stellen (vgl. Hajer 1995: 93f). In derartigen sozial-ökologischen Perspektiven ist die ökologische Krise ein Ergebnis gesellschaftlicher Organisationsprinzipien und ihre Bearbeitung kann somit auch nur über eine Änderung der gesellschaftlichen Strukturen - ihrer Deutungs- und Handlungsmuster samt ihrer verstetigten Materialisierung in Institutionen - erfolgen. ${ }^{24}$ Als verkürzt erscheint aus sozial-ökologischer Perspektive dagegen der Versuch, gesellschaftliche Probleme mit technologischen Lösungen beheben zu wollen (vgl. Hajer 1995: 88f). Diese Form der Gesellschaftskritik, wie sie in den 1970er Jahren von Umweltbewegungen artikuliert wurde, ist mit der Etablierung des ökomodernen Diskurses marginalisiert worden (vgl. Görg 2003a: 135). Dies trifft noch stärker auf ganz andere Perspektiven, wie zum Beispiel biozentristische Weltsichten, zu.

Dem ökomodernen Projekt ist es gelungen, kritische Forderungen in den ökomodernen Diskurs zu integrieren, ohne deren systemkritische Stoßrichtungen zu übernehmen. Mit dieser strategisch-selektiven Aneignung gewann das ökomoderne Projekt die Zustimmung vieler Umwelt-NGOs und anderer Akteur_innen aus dem Bereich der Umweltpolitik. Selbst viele (ehemalige) Protagonist_innen der Umweltbewegungen (re-)artikulierten ihre Forderungen innerhalb des ökomodernen Diskurses, um sich Gehör und Einfluss zu verschaffen. Damit gerieten antagonistische Artikulationen in eine stark marginalisierte Position.

Aufgrund der Dominanz des ökomodernen Diskurses sind, sowohl auf internationaler Ebene als auch auf der Ebene nationalstaatlicher Politik der Industrieländer, keine Forderungen einflussreich, die auf eine Umweltpolitik jenseits ökomoderner Strategien zielen. Die Attraktivität des ökomodernen Projekts - das Einfluss und Gestaltungsmöglichkeiten verspricht - verhinderte die Herausbildung wirkungsmächtiger gegenhegemonialer Projekte, die in der Lage wären, strukturverändernde Maßnahmen durchzusetzen und/oder gesellschaftliche Kräfteverhältnisse zu verschieben.

24 Eine sozial-ökologische Perspektive ist damit automatisch eine Nord-Süd-Perspektive, die regionale Unterschiede in Bezug auf Verursachung und Betroffenheit in den Blick nimmt. 
6) Die Durchsetzung der ökologischen Modernisierung als hegemoniale Diskursorganisation gesellschaftlicher Naturverhältnisse ist (noch) nicht abgeschlossen.

Die Institutionalisierung eines Diskurses bedeutet die temporäre Fixierung der durch ihn ermöglichten sozialen Ordnung, Subjektpositionen, Deutungs- und Handlungsmuster. Diese Kämpfe um die Fixierung der Elemente des ökomodernen Diskurses sind weiterhin virulent. In dem Zusammenhang sind die Verschiebungen in Bezug auf die ökomoderne Kernforderung - nachhaltige Entwicklung - zu sehen.

Seit Mitte der 1980er Jahre wird die konkrete Ausgestaltung der ökomodernen Kernforderung in den Auseinandersetzungen um das Konzept der Sustainable Development verhandelt. Wichtige Ereignisse in den Debatten über Sustainable Development waren die International Conference on Environment and Economics der OECD im Jahre 1984, der 1987 erschienene Brundtland-Bericht Our Common Future und die Konferenz der Vereinten Nationen über Umwelt und Entwicklung im Jahre 1992 (vgl. Kapitel 3.2.3). Die Idee der Versöhnung von Umweltschutz und Wirtschaftswachstum verhalf dem ökomodernen Diskurs zur Anschlussfähigkeit in verschiedenen Arenen. Die Forderung nach Sustainable Development wurde von einflussreichen Institutionen wie der OECD, der Weltbank und dem IWF übernommen, die bis dato ökologischen Themen sehr skeptisch gegenüber standen. Mit der Kernforderung nach Sustainable Development vermochte das ökomoderne Projekt einen partiellen Konsens herzustellen. Diese Möglichkeit der Universalisierung die sich darin zeigt, dass ganz verschiedene Akteur_innen Sustainable Development als unerlässlich zur Realisierung des Gemeinwohls erachten - liegt in der Entleerung des Begriffs begründet. Über die Kopplung an Grundannahmen und Hegemoniestrategien wurde die Forderung nach Sustainable Development in die hegemoniale gesellschaftliche Strukturen eingepasst. ${ }^{25}$ Innerhalb des dadurch fixierten Rahmens lässt die Forderung aber viel Raum, in den Akteur_innen ihre Partikularinteressen einschreiben können. Die Definition im Brundtland-Bericht, auf die immer wieder verwiesen wird, bezieht sich ganz allgemein auf menschliche Bedürfnisse:

„Dauerhafte Entwicklung ist Entwicklung, die die Bedürfnisse der Gegenwart befriedigt, ohne zu riskieren, daß künftige Generationen ihre eigenen Bedürfnisse nicht befriedigen können.“ (Weltkommission für Umwelt und Entwicklung 1987: 46)

Dementsprechend wurde Sustainable Development zum inflationär verwendeten Label, zu einem leeren Signifikanten. Laut Joachim Radkau diente es als „Kompromissformel, um die ,Umweltlobby des Nordens und die Entwicklungslobby des

25 Das Konzept zielte damit auf eine Transformation der hegemonialen Diskursorganisation in den gesellschaftlichen Naturverhältnissen (der Modernisierung mit nachgeschaltetem Umweltschutz; vgl. Kapitel 3.1). 
Südens“ auf einen Nenner zu bringen“ und auch „,bei Nord-Süd-Differenzen innerhalb der EU erwies sich sustainable development im Jahre von Rio als patente ,Versöhnungsformel““ (Radkau 2011: 552; Hervorhebung im Original). Durch die Kombination von umwelt- und entwicklungspolitischen Aspekten ermöglichte Sustainable Development somit die Herstellung eines Konsenses in der internationalen Politik (vgl. Bernstein 2000: 494). Brand spricht von einem ,container

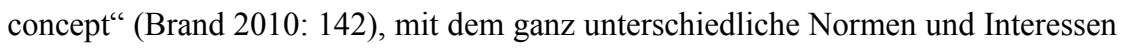
verknüpft wurden - auch die Inwertsetzung von Natur. Insofern schreibt Brand, „that the policy knowledge of sustainable development is not opposed to the valorization paradigm, but is an integral, however partly contradictory, part of it" (Brand 2010: 144; Hervorhebung T. K.).

Brand deutet in diesem Zitat an, dass sich die Forderung nach Sustainable Development nicht zur Gänze in die Agglomeration hegemonialer Diskurse einfügt. Der partielle Widerspruch liegt meiner Meinung nach in der gleichwertigen Bedeutung der ökonomischen - denen eben kein Primat zugesprochen wird - neben den sozialen und ökologischen Kriterien des Nachhaltigkeitsdreiecks. Zwar rückte die noch im Brundtland-Bericht prominent enthaltene Forderung nach intragenerationeller - und nicht nur intergenerationeller - Gerechtigkeit bei der Rio-Konferenz bereits in den Hintergrund (vgl. Dingler 2003: 234, 255). Dennoch bleibt die soziale Säule des Nachhaltigkeitsdreiecks aufgrund der Begriffsgeschichte von Entwicklung stets präsent und lenkt die Aufmerksamkeit auf die Chancen benachteiligter Menschen und Länder sowie auf die Frage nach globaler Gerechtigkeit.

Dies ist ein großer Unterschied zur Forderung nach einer Green Economy, die sich seit ein paar Jahren zur umkämpften Formel zur Erzeugung eines ökomodernen Konsenses entwickelte (vgl. UNEP 2011: 1). Spätestens mit der Rio+20-Konferenz löste die Green Economy die Sustainable Development als leeren Signifikant der ökomodernen Kernforderung ab. Damit findet eine diskursive Verschiebung statt. Sustainable Development stand für die gleichwertige Gewichtung der sozialen, ökologischen und ökonomischen Aspekte. Dagegen wird in der Forderung nach einer Green Economy dem ökonomischen Bereich eine übergeordnete Bedeutung zugewiesen. Die Engführung auf den Bereich der Wirtschaft wird von den Protagonist_innen des Konzepts der Green Economy als strategisch notwendige Entscheidung dargestellt, die nichts an der inhaltlichen Ausrichtung ändern würde.

"The concept of a ,green economy“ does not replace sustainable development, but there is now a growing recognition that achieving sustainability rests almost entirely on getting the economy right. [...] Sustainability is still a vital long-term goal, but we must work on greening the economy to get us there." (UNEP 2011: 2; Hervorhebung im Original) 
Sustainable Development bekommt den Status eines langfristigen Ziels, die konkreten Maßnahmen sollen allerdings aus dem Konzept der Green Economy abgeleitet werden. Dabei wird die soziale Säule des Nachhaltigkeitsdreiecks auf die Bekämpfung von Armut reduziert. Die Frage nach Gerechtigkeit wird ausgeklammert. Insgesamt haben soziale Kriterien eine geringe Bedeutung, was auf der Rio+20Konferenz auch von Delegierten aus dem globalen Süden kritisiert wurde (vgl. Poppe et al. 2013: 5).

In Bezug auf die ökologische Säule des Nachhaltigkeitsdreiecks gilt im Konzept der Green Economy die Inwertsetzung von Natur als Königsweg zur Erhaltung einer intakten Umwelt. Die Kommodifizierung von Natur, die auch mit der Forderung nach einer Sustainable Development durchaus kompatibel war (vgl. Brand 2010: 144), wird in dem Ansatz der Green Economy offensiv als erfolgversprechendste Umweltschutzstrategie propagiert (vgl. UNEP 2011: 6ff).

„Thus a green economy transition not only recognizes and demonstrates the value of natural capital - as a provider of human well-being, as a supplier of sustenance for poor households, as a source of new and decent jobs - but it also invests in and builds up this natural capital for sustainable economic progress.“ (UNEP 2011: 7)

Wie in dem Zitat deutlich wird, gilt nicht Natur an sich als schützenswert, sondern nur insofern sie als Naturkapital Wirtschaftswachstum befördert und als ,ecosystem services" (Ökosystemdienstleistungen) menschliche Bedürfnisse befriedigt. Umgekehrt wird in der mangelnden Integration von Natur in das ökonomische System die Hauptursache der ökologischen Krise gesehen (vgl. UNEP 2011: 6). Dementsprechend gelten im Ansatz der Green Economy klassische ökonomische Strategien, wie die Internalisierung externer Kosten, als effizienteste Mittel, um sowohl ökonomische als auch ökologische und soziale Ziele zu erreichen. Green Economy wird als ,neuer Wachstumsmotor` angepriesen (vgl. UNEP 2011: 2). Mit ,grünen Investitionen“ sollen Wachstumsraten und globaler Wohlstand generiert werden (vgl. UNEP 2011: 5). Angesichts des starken Fokus auf ökonomische Strategien, die auf den Erhalt und den Wiederaufbau von ,Naturkapital' als wichtige ökonomische Ressource zielen (z. B. UNEP 2011: 13), und auf klassische ökonomische Ziele wie Wachstum und Wohlstand fügt sich das Konzept der Green Economy noch stärker als Sustainable Development in die Agglomeration hegemonialer Diskurse ein.

Mit der Etablierung von Green Economy als leeren Signifikant für die ökomoderne Kernforderung verliert das ökomoderne Projekt vermutlich noch einmal mehr von seinem ohnehin stark eingeschränkten Potenzial zur Transformation gesellschaftlicher Verhältnisse. Allerdings würde mit der Forderung nach einer Green Economy sehr explizit ein - wenn auch nicht radikaler oder struktureller - Wandel der Weltwirtschaft zum Ziel des ökomodernen Projekts erklärt. Damit würde eine 
Fortsetzung des business as usual einen Widerspruch innerhalb des ökomodernen Diskurses bedeuten. Bei ausbleibenden ökologischen Erfolgen könnte ein solcher Widerspruch langfristig zu dislozierenden Effekten führen.

\subsection{Die Reflexive Reproduktion von Hegemonie}

Im Folgenden fasse ich die Ergebnisse des dritten Kapitels zusammen im Hinblick auf die Frage, welche re- bzw. entpolitisierenden Effekte mit der partiellen Durchsetzung eines ökomodernen Konsenses verbunden sind.

Die Diskursorganisation der gesellschaftlichen Naturverhältnisse in den Industrieländern war bis zu Beginn der 1970er Jahre relativ stabil. Für diese Phase der einfachen Reproduktion (für die Definition der verschiedenen Stabilitätsstufen vgl. Kapitel 2.1.5) kann man aufgrund der Dominanz des hegemonialen Diskurses der Modernisierung mit nachgeschaltetem Umweltschutz einen relativ eingeschränkten Diskurshorizont und damit eine stark verstetigte Organisation gesellschaftlicher $\mathrm{Na}$ turverhältnisse konstatieren (vgl. Kapitel 3.1).

Mit dem Erstarken der Umweltbewegungen und der Diagnose einer ökologischen Krise, die sich in verschiedenen gesellschaftlichen Bereichen durchsetzte, kam es zu einer Phase der Politisierung, in der sich gegenhegemoniale Projekte für einen ganz anderen Umgang mit Natur einsetzten. Mit der damit verbundenen Öffnung des Diskurshorizonts verlor das Hegemonieprojekt der Modernisierung mit nachgeschaltetem Umweltschutz seine Vormachtstellung (vgl. Kapitel 3.1).

In dieser dislozierten Situation entwickelte sich ab den 1970er Jahren der Diskurs der ökologischen Modernisierung, der in den 1980er Jahren stark an Einfluss gewann (für den gesamten Absatz vgl. Kapitel 3.2, 3.3, 3.4, 3.5, 3.6). Seit den 1990er Jahren dominiert der ökomoderne Diskurs die umweltpolitische Arena sowohl auf internationaler Ebene als auch auf der nationalstaatlichen bzw. regionalen Ebene vieler Industrieländer. Das ökomoderne Hegemonieprojekt steht für eine Phase, die ich als reflexive Reproduktion fasse. Diese zeichnet sich dadurch aus, dass bislang dominante Hegemonieprojekte an Deutungshoheit gegenüber neuen Hegemonieprojekten verlieren, die um die gleichen Kernforderungen kreisen. Die etablierten Vorstellungen vom Gemeinwohl werden also nicht verworfen, sondern sind ebenfalls die Kernforderungen der aufstrebenden Hegemonieprojekte. Konkret bedeutet dies, dass in Bezug auf die Diskursorganisation gesellschaftlicher Naturverhältnisse das Hegemonieprojekt der Modernisierung mit nachgeschaltetem Umweltschutz seit den 1970er Jahren gegenüber dem der ökologischen Modernisierung an Deutungshoheit verloren hat. Dabei steht Entwicklung in reflektierter Form 
weiterhin im Zentrum der Vorstellungen vom Gemeinwohl. Allerdings kommt es zu Modifikationen. Die konkrete Ausformung dessen, was nachhaltige Entwicklung bedeutet und ob es unter dem Label von Sustainable Development oder Green Economy propagiert wird, ist noch umkämpft.

Im Vergleich zu der Stabilität des Hegemonieprojekts der Modernisierung mit nachgeschaltetem Umweltschutz bis in die 1970er Jahre kann man also von einer leichten Öffnung des Diskurshorizonts sprechen. Allerdings ist noch unklar, ob diese Öffnung nur kurzfristiger Natur war. Langfristig könnte damit unter Umständen eine Schließung des Diskurshorizonts verbunden sein, wenn der hegemoniale Diskurs in reflektierter Form auf Dauer noch stabiler ist. Die Stabilität würde in dem Fall auf der geschaffenen Möglichkeit beruhen, kritische Positionen in das ökomoderne Projekt zu integrieren. Durch die breite Akzeptanz der Ökologieproblematik vermittelt der ökomoderne Diskurs den Eindruck, dass nun , alle an einem Strang ziehen' müssen. Diese Suggestion einer universellen Interessenlage diskreditiert antagonistische Artikulationen als destruktive Beiträge (vgl. Kapitel 3.4.3).

Insgesamt ist mit der Entwicklung des ökomodernen Projekts seit der ökologischen Krisendiagnose in den 1970er Jahren ein Prozess der Schließung des Diskurshorizonts und der Entpolitisierung verbunden. Antagonistische Artikulationen, die aus einer gesellschaftskritischen sozial-ökologischen Problemdefinition heraus strukturverändernde Lösungen der ökologischen Krise vorschlagen, wurden marginalisiert (vgl. Kapitel 3.6). Das Ausbleiben einer antagonistischen Kraft kann als Erfolg der Hegemoniepraktiken des ökomodernen Projekts gewertet werden. Schließlich beruht Hegemonie immer auf der Undenkbarmachung von Alternativen. Gleichzeitig ist Hegemonie immer prekär und diese Alternativen können niemals vollständig ausgelöscht werden (vgl. Wullweber 2010: 112).

An verschiedenen Stellen habe ich angedeutet, dass es innerhalb des ökomodernen Diskurses durchaus Brüche und Risse gibt (vgl. Kapitel 3.4, 3.6). Es ist eine offene Frage, ob es dem ökomodernen Projekt gelingt, seine Institutionalisierung als hegemoniale Diskursorganisation gesellschaftlicher Naturverhältnisse weiter voran zu treiben, ohne dass die inhärenten Risse und Brüche virulent werden. Insofern ist noch nicht absehbar, ob die ökologische Krise in einer langfristigen Öffnung des Diskurshorizonts mündet bzw. ob es in naher Zukunft zu einer Re-Politisierung gesellschaftlicher Naturverhältnisse kommt. 


\section{Das ökomoderne Projekt und CCS}

In diesem Kapitel wird die Verbindung zwischen der Analyse des ökomodernen Hegemonieprojekts (Kapitel 3) und der mikroanalytischen Untersuchung der CCSKonflikte (Kapitel 5) hergestellt. Die Auswahl des Untersuchungsgegenstands beruht auf der Annahme, dass sich an den Auseinandersetzungen um CCS paradigmatisch zentrale Konflikte um die weitere Entwicklung des ökomodernen Projekts bzw. der Bearbeitung der ökologischen Krise analysieren lassen.

2) Welche Bedeutung haben die Konflikte um CCS-Technologien in den Auseinandersetzungen um die weitere Entwicklung des ökomodernen Projekts?

3) Welche Auswirkungen haben die Konflikte um CCS-Technologien auf die Auseinandersetzungen um die Bearbeitung der ökologischen Krise?

Die in Kapitel 1.1 formulierten Forschungsfragen beziehen sich auf die re- und entpolitisierenden Prozesse im Konfliktfeld der ökologischen Krise: Inwieweit werden CCS-Technologien als relevante Klimaschutztechnologien in das ökomoderne Projekt integriert? Nehmen CCS-Technologien eine wichtige Rolle im ökomodernen Projekt ein, weil mit ihnen bestimmte Risse und Brüche des ökomodernen Diskurses gekittet werden sollen? Oder tragen die Konflikte um CCS dazu bei, dass bestimmte Risse und Brüche des ökomodernen Diskurses zum Ausgangspunkt (re-)politisierender Prozesse - innerhalb und/oder außerhalb des ökomodernen Diskurses - werden? Diese Fragen können in Bezug auf die in Kapitel 3 herausgearbeiteten ökomodernen Hegemoniestrategien präzisiert werden:

Die Bedeutung von CCS in Bezug auf die Strategie der reflexiven Naturbeherrschung CCS-Technologien stehen paradigmatisch für Klimaschutzmaßnahmen, die mit der Aufrechterhaltung bestimmter Produktions- und Konsummuster kompatibel sind, welche auf der Bereitstellung von Energie durch fossile Brennstoffe basieren. Damit wird mit CCS-Technologien eine spezifische Naturbeherrschung (re-)produziert, in der die Subsumtion von Natur unter die Funktionslogik der fossilen 
Energieinfrastruktur ein zentrales Element darstellt. Gleichzeitig stellen CCSProjekte als Klimaschutzmaßnahme eine Reaktion auf die nicht-intendierten Nebenfolgen dieser spezifischen Naturbeherrschung dar. Dabei wird wiederum die Möglichkeit der Kontrolle der Technologie-inhärenten Risiken und damit die Berechenbarkeit von Natur vorausgesetzt. Insofern lässt sich an den Konflikten um CCS analysieren, wie die Frage der (Erwünschtheit und Möglichkeit der) Naturbeherrschung aktuell verhandelt wird. Die Auseinandersetzungen um CCS-Technologien könnten in einer Ausweitung der bewussten Inkaufnahme möglicher nicht-intendierter Nebenfolgen (gesundheitlicher und ökologischer Risiken) münden, um den Klimawandel, der selber eine nicht-intendierte Nebenfolge darstellt, abzuschwächen. Die reflexive Dimension der Naturbeherrschung würde dabei insofern begrenzt, als dass die weitere Ausschöpfung der fossilen Brennstoffe nicht zur Debatte stehen, sondern gerade den Kern der CCS-Technologien ausmachen würde. Denkbar wäre aber auch, dass durch die Versuche einer solchen Ausweitung der bewussten Inkaufnahme möglicher nicht-intendierter Nebenfolgen die tendenziell wenig beachtete Kritik am Prinzip der Naturbeherrschung wieder mehr Aufmerksamkeit erfahren könnte. Eine derartige Entwicklung würde sicherlich durch ein konkretes Scheitern des Managements nicht-intendierter Nebenfolgen verstärkt werden - beispielsweise durch das Austreten größerer Mengen von $\mathrm{CO}_{2}$ bei CCS-Projekten oder durch eine erhöhte Sensibilität gegenüber den sozialen, ökologischen und gesundheitlichen Folgen des Kohleabbaus. Meine diesbezügliche Frage lautet also, inwieweit die Grenzen der reflexiven Naturbeherrschung in den Auseinandersetzungen um CCSTechnologien verschoben werden? Führt die Thematisierung von Risiken, die mit den CCS-Technologien verbunden sind, zu einer (Re-)Politisierung des Prinzips der Naturbeherrschung innerhalb und/oder außerhalb des ökomodernen Diskurses? Oder werden CCS-Technologien als ökomoderne Klimaschutzmaßnahme artikuliert, die zu einer reflexiven Naturbeherrschung beiträgt?

\section{Die Bedeutung von CCS in Bezug auf die Strategie des reflexiven Fortschritts}

CCS-Technologien sind unter den jetzigen Bedingungen weit davon entfernt, betriebswirtschaftlich rentabel zu sein (vgl. Kapitel 5.2.1). Deshalb setzt die CCSCommunity (vgl. die Ausführungen zur CCS-Community in Kapitel 5.3.2) auf Anreize durch die Politik und fordert öffentliche Investitionen in Forschung und Entwicklung, gesicherte Marktpreise für $\mathrm{CO}_{2}$-Äquivalente und die Aufnahme von CCS-Technologien in den CDM (vgl. de Coninck/Bakker 2005; Tjernshaugen 2008). Je höher der Subventionsbedarf allerdings ausfällt, desto größer wird die Diskrepanz zur ökomodernen Vorgabe der „Erzielung eines ökologischökonomischen Doppelnutzens“ (Jänicke 1988: 23). Meine diesbezüglichen 
Forschungsfragen lauten deshalb, ob, inwiefern und von welchen Akteur_innen der Subventionsbedarf von CCS-Technologien als Riss innerhalb des ökomodernen Diskurses oder als Bruch mit diesem artikuliert wird?

Neben der Kosteneffizienz stellt der Beitrag zur Steigerung des Sicherheitsempfindens einen relevanten Faktor für die Bewertung von Umwelttechnologien dar. Dabei spielen sowohl risikobewusste Praktiken wie Technikfolgenabschätzung, Technikakzeptanz-Forschung und Risikokommunikation als auch risikovermeidende Praktiken wie der Einsatz sogenannter sanfter Technologien oder der Fokus auf Effizienzsteigerung eine wichtige Rolle. Um CCS-Technologien mit den gestiegenen Anforderungen in Bezug auf das Sicherheitsempfinden in Einklang zu bringen, wird innerhalb der CCS-Community stark gerungen (vgl. Stephens/ Hansson/Liu/de Coninck/Vajjhala 2011: 386f). Bereits in der jetzigen Entwicklungsphase, in der nur vereinzelt Demonstrationsprojekte installiert werden, gibt es Widerstände von Bürgerinitiativen, die sich gegen den Einsatz einer ,Risikotechnologie" in ihrer Umgebung richten (vgl. Kapitel 5.2.1). Darauf wird mit einer großen Anzahl von Studien zur Akzeptanzforschung reagiert, die selber auf die Beschaffung von Akzeptanz für CCS-Technologien angelegt sind und/oder die Basis für derartige Kampagnen vorbereiten (vgl. Hansson 2012: 82ff; Meadowcroft/ Langhelle 2009b: 16). Diese Studien und Kampagnen zielen darauf ab, die CCSTechnologien durch die Gegenüberstellung mit zwei ,Horrorszenarien' konsensfähig zu machen - den Gefahren eines ungebremsten Klimawandels auf der einen und den hohen Kosten einer Verhinderung desselben bei Verzicht auf CCS auf der anderen Seite (vgl. Alphen et al. 2007: 4378; Hansson 2012: 84, 87). Im Vergleich zu diesen beiden Szenarien wird der großflächige Einsatz von CCS-Technologien als das kleinere Übel propagiert. Inwieweit ein derartiges Akzeptanz-Management erfolgreich sein wird, ist allerdings noch nicht abzusehen. sofern lautet eine weitere Frage, inwieweit CCS-Technologien trotz der ihnen inhärenten Sicherheitsrisiken von den Protagonist_innen des ökomodernen Projekts als wichtige Klimaschutzmaßnahme angesehen werden? Sollte dies prinzipiell der Fall sein, stellen sich daran anschließend drei weitere Fragen:

1) Könnten CCS-Technologien die Hoffnungen auf einen Deus ex Machina, auf eine (Er-)Lösung, die unabhängig von langwierigen politischen Auseinandersetzungen die ökologische Krise bearbeiten kann, erfüllen?

2) Inwiefern führt die Integration von CCS-Technologien in das ökomoderne Projekt zur weiteren Schließung des Diskurshorizonts, indem der reflexive Anteil die Bedeutung von risikobewussten und vor allem von risikovermeidenden Praktiken - zurückgedrängt wird? 
3) Inwieweit wird diese Schließung des Diskurshorizonts in der Folge als Riss innerhalb des ökomodernen Diskurses artikuliert und/oder als Ansatzpunkt für antagonistische Artikulationen außerhalb des ökomodernen Diskurses genutzt?

Es ist aber auch denkbar, dass CCS-Technologien im ökomodernen Projekt keine relevante Rolle spielen, weil risikovermeidende Klimaschutzmaßnahmen stärker gefördert werden. In diesem Fall wäre danach zu fragen, ob es dabei zu einer Öffnung des ökomodernen Diskurshorizonts kommt und damit zu (re-)politisierenden Prozessen in Bezug auf die ökomoderne Strategie des reflexiven Fortschritts?

\section{Die Bedeutung von CCS in Bezug auf die Strategie des nachhaltigen Wachstums}

CCS-Technologien stellen ein mögliches Vehikel für die strategisch-selektive Integration der Wachstumskritik dar (zur Strategie der Äquivalenzierung vgl. Kapitel 3.4.3), weil sie Wirtschaftswachstum - auf der Basis fossiler Energie - bei gleichzeitiger Reduktion der Treibhausgasemissionen versprechen. Wenn CCS-Technologien wirkmächtig sind (im Sinne von: als wichtige Klimaschutzmaßnahme gelten), könnte dies zur weiteren Schließung des Diskurshorizonts führen. Sie könnten als Indiz für die Möglichkeit der Entkopplung des Wirtschaftswachstums vom Anstieg der Treibhausgaskonzentration in der Atmosphäre (allerdings nicht von der Produktion von Treibhausgasen ${ }^{1}$ und auch nicht vom Ressourcenverbrauch) gelten. Wenn CCS-Technologien bedeutungslos sind (im Sinne von: nicht als relevante Klimaschutzmaßnahme gelten), könnten umgekehrt Risse und Brüche, die mit der Abhängigkeit des Wirtschaftswachstums von fossilen Brennstoffen verbunden sind, virulent werden. Die Bedeutung von CCS-Technologien in den klimapolitischen Aushandlungsprozessen interessiert mich hier in Bezug auf die Entkopplungsthese: Werden CCS-Technologien als Indiz für die Möglichkeit der Entkopplung des Wirtschaftswachstums vom weiteren Anstieg der Treibhausgaskonzentration in der Atmosphäre artikuliert? Und/Oder wird umgekehrt die Kritik an CCS-Technologien mit einer Kritik am Konzept des nachhaltigen Wachstums gekoppelt? Wird die Kritik, dass CCS-Technologien keine relevante Klimaschutzmaßnahme seien, als Beleg für die Unvereinbarkeit von Umweltschutz mit fossilen Brennstoffen und/oder Wirtschaftswachstum angeführt? Wird diese Kritik innerhalb oder außerhalb des ökomodernen Diskurses artikuliert?

1 Bei CCS-Projekten wird die Produktion von Treibhausgasen nicht reduziert, sondern allein der Anteil, der in die Atmosphäre gelangt. Dennoch wird oftmals vereinfachend auch in dieser Arbeit - ausgedrückt, dass mit CCS-Technologien die Treibhausgasemissionen reduziert werden. 


\title{
5. CCS in der internationalen Klimapolitik
}

\author{
"With CCS it is entirely possible for fossil fuels \\ to continue to be used on a large scale." \\ (Rajendra Pachauri) ${ }^{1}$
}

Diesem Kapitel liegt die Annahme zugrunde, dass die Konflikte um CCS-Technologien eine besondere Rolle in den hegemonialen Kämpfen um die Bearbeitung der ökologischen Krise spielen. Wie in Kapitel 4 näher ausgeführt, gehe ich davon aus, dass sich an den Auseinandersetzungen um CCS-Technologien paradigmatisch zentrale Konflikte um die weitere Entwicklung des ökomodernen Projekts und damit auch um die (Ent-)Politisierung gesellschaftlicher Naturverhältnisse analysieren lassen. Diesem Erkenntnisinteresse werde ich im Folgenden auf der Ebene der internationalen Klimapolitik nachgehen. Die internationale Klimapolitik wird in erster Linie durch die UN-Klimaverhandlungen bestimmt. Klimapolitische Absprachen und Verträge jenseits des UN-Regimes spielen kaum eine Rolle (vgl. Brunnengräber et al. 2008: 97). Allerdings nimmt die Kritik an der Fokussierung auf die UNKlimaverhandlungen, spätestens seit dem gescheiterten Klimagipfel 2009 in Kopenhagen, zu. Insofern ist es durchaus denkbar, dass andere Arenen an Bedeutung gewinnen. Für die jüngste Vergangenheit und die Gegenwart stellt das UNKlimaregime jedoch nach wie vor die zentrale Politikarena der internationalen Klimapolitik dar. Dementsprechend setze ich dort mit meiner Analyse der Auseinandersetzungen um CCS-Technologien an.

Seit Mitte der 2000er Jahre stehen CCS-Technologien regelmäßig auf der Tagesordnung der UN-Klimaverhandlungen. Konkret wird über die nachträgliche Aufnahme von CCS ins Kyoto-Protokoll diskutiert. Auf dem Klimagipfel 2010 in Cancún kamen diese Aushandlungen zu einem vorläufigen Ende. Dort wurde unter

1 Das Zitat des damaligen Vorsitzenden des IPCC entstammt der Pressekonferenz des IPCC vom 02.11.2014 anlässlich der Vorstellung des fünften Sachstandsberichts (vgl. im Internet: www.theguardian.com/environment/2014/nov/02/rapid-carbon-emission-cuts-severeimpact-climate-change-ipcc-report, letzter Zugriff am 26.02.2015). 
Vorbehalt beschlossen, CCS-Projekte als mögliche Maßnahme im Sinne des Clean Development Mechanism (CDM) gelten zu lassen. Diese Entscheidung wurde 2011 auf der COP 17 in Durban endgültig bestätigt. Wenn ich im Folgenden CCS-CDMKontroverse schreibe, dann ist stets diese CCS-Kontroverse in den UN-Klimaverhandlungen gemeint.

Die Auseinandersetzungen um die Aufnahme von CCS ins Kyoto-Protokoll bilden den primären Untersuchungsgegenstand in diesem Kapitel. Allerdings ziele ich nicht auf eine isolierte Betrachtung der CCS-CDM-Kontroverse. Stattdessen interessiert mich die Bedeutung der Kontroverse für die hegemonialen Kämpfe um die Bearbeitung der ökologischen Krise. Um die politischen Dynamiken bezüglich der Organisation der gesellschaftlichen Naturverhältnisse zu erfassen, halte ich die Analyse konkreter Prozesse für eminent wichtig. Dabei ist entscheidend, die Auseinandersetzung mit dem empirischen Material nicht vorschnell durch die Einordnung in theoretische Hypothesen und Begriffe abzukürzen. Gleichzeitig ist die Einbettung der mikroanalytischen Untersuchung in eine breitere Analyse des gesellschaftlichen Kontextes sehr wichtig, um die Bedeutung der konkreten Konflikte für Kämpfe um die (Re-)Strukturierung der gesellschaftlichen Naturverhältnisse erfassen zu können. Deshalb oszilliere ich in diesem Kapitel zwischen genauen Interpretationen des empirischen Materials, abstrakteren theoretischen Verdichtungen und Vergleichen zwischen verschiedenen Politikarenen.

Im Folgenden gebe ich einen Überblick über das UN-Klimaregime (5.1) und führe in die CCS-Konflikte ein (5.2). Da der IPCC einen großen Einfluss auf die UN-Klimaverhandlungen hat, untersuche ich dessen Politikberatung zu CCS-Technologien in einem eigenen Kapitel (5.3). Darauf folgt eine Analyse der CCS-CDMKontroverse und der darin aktiven Akteur_innen (5.4). Abschließend werden die Ergebnisse dieser vier Unterkapitel in einer Synthese zusammengeführt (5.5).

\subsection{EINFÜHRUNG IN DIE INTERNATIONALE KLIMAPOLITIK}

Das UN-Klimaregime geht auf die Verabschiedung der Klimarahmenkonvention zurück. Dieses Umweltabkommen aus dem Jahr 1992 ist bis heute ein prägendes Element der internationalen Klimapolitik. Deshalb erläutere ich in einem ersten Schritt die Ziele und die Arbeitsweise der Klimarahmenkonvention, auf deren Basis die UN-Klimaverhandlungen durchgeführt werden. Dabei gehe ich auch auf die an diesen Verhandlungen beteiligten Akteursgruppen ein (5.1.1). Anschließend fokussiere ich auf das daraus entstandene Kyoto-Protokoll als bislang wichtigstes Ergebnis des UN-Klimaregimes. Dazu erläutere ich die flexiblen Mechanismen des 
Kyoto-Protokolls und gebe einen Überblick über die an ihnen geübte Kritik (5.1.2). Darauf aufbauend arbeite ich die Dominanz des ökomodernen Diskurses im UNKlimaregime heraus (5.1.3). Abschließend stelle ich antagonistische Artikulationen dar, die eine alternative internationale Klimapolitik einfordern (5.1.4)

\subsubsection{Das UN-Klimaregime}

Die internationale Klimapolitik wird primär im Rahmen des UN-Klimaregimes, auf den seit 1995 jährlich stattfindenden Konferenzen der Mitgliedsstaaten der Klimarahmenkonvention, verhandelt. Diese als Klimagipfel bezeichneten Konferenzen wurden am 9. Mai 1992 ins Leben gerufen, als das Rahmenübereinkommen der Vereinten Nationen über Klimaänderungen (United Nations Framework Convention on Climate Change, UNFCCC) verabschiedet wurde. Die Anfänge der Klimapolitik im Rahmen der UN gehen auf eine Hochphase internationaler Umweltschutzbemühungen zurück. In dieser Anfangsphase setzten viele, vor allem auch die an den Verhandlungen beteiligten zivilgesellschaftlichen Akteur_innen, große Hoffnungen in die Klimarahmenkonvention, die im März 1994 in Kraft trat (vgl. Oberthür/Ott 2000: 63). Mittlerweile sind 195 Staaten plus die EU als supranationale Organisation der Klimarahmenkonvention beigetreten (vgl. im Internet: www.unfccc.int/ essential_background/convention/status_of_ratification/items/2631.php, letzter Zugriff am 02.12.2014).

Die Klimarahmenkonvention legte zentrale Elemente des UN-Klimaregimes fest, die bis heute gelten. Sie schuf nicht nur Institutionen und gab ein Verfahren für die Verhandlungen über Klimaschutz-Abkommen vor, sondern definierte auch Grundsätze und ein Ziel der internationalen Klimapolitik (vgl. Oberthür/Ott 2000: 63). So ist laut Artikel 2 das Ziel der Klimarahmenkonvention „die Stabilisierung der Treibhausgaskonzentrationen in der Atmosphäre auf einem Niveau zu erreichen, auf dem eine gefährliche anthropogene Störung des Klimasystems verhindert wird“ (UNFCCC 1992: 5). Eine der wichtigsten Grundsätze findet sich in Artikel 3. Dort ist das Prinzip der gemeinsamen, aber unterschiedlichen Verantwortlichkeiten festgelegt, das bis heute die Unterschiede zwischen den Verpflichtungen der Annex-BStaaten und denjenigen der Nicht-Annex-B-Staaten legitimiert (vgl. UNFCCC 1992: 5). 
Mit dem Begriff der Annex-B-Staaten sind die Industrie- und Transformationsländer ${ }^{2}$ gemeint, die in der Anlage B des Kyoto-Protokolls aufgelistet sind. Diese Länder haben sich für die Periode 2008-2012, die sogenannte erste Verpflichtungsperiode des Kyoto-Protokolls, zur Einhaltung von Emissionsobergrenzen verpflichtet. Diese Auflistung von Staaten ist, abgesehen von wenigen Ländern die im Kyoto-Protokoll dazu gekommen sind, mit der Auflistung in Anlage I der Klimarahmenkonvention identisch. Deshalb werden die Bezeichnungen Annex-I-Staaten und Annex-B-Staaten oftmals synonym verwendet. ${ }^{3}$ Mit Nicht-Annex-B-Staaten sind dagegen die Länder des globalen Südens gemeint. Sie sind nicht im Annex B zum Kyoto-Protokoll aufgelistet, weil sie sich nicht zur Einhaltung von Emissionsobergrenzen verpflichtet haben. Diese Unterscheidung zwischen den Annex-B- und den Nicht-Annex-B-Staaten ist die bedeutsamste Umsetzung des Prinzips der gemeinsamen, aber unterschiedlichen Verantwortlichkeiten.

Alle Länder - sowohl die Annex-B- als auch die Nicht-Annex-B-Staaten - sind Mitgliedsstaaten der Klimarahmenkonvention und nehmen somit am obersten Entscheidungsgremium, der Vertragsstaatenkonferenz der Klimarahmenkonvention (Conference of the Parties, COP), teil. Auf den COPs werden alle wichtigen Entscheidungen gefällt, beispielsweise über die Einsetzung von Nebenorganen ${ }^{4}$, über Änderungen des Vertrages und insbesondere über die Instrumente zur Erreichung des Endziels der Konvention (vgl. Oberthür/Ott 2000: 69). Änderungen des Übereinkommens und seiner Anlagen sollen laut Artikel 15 der Klimarahmenkonvention möglichst im Konsens entschieden werden, können im Zweifelsfall aber auch mit einer Dreiviertelmehrheit beschlossen werden (vgl. UNFCCC 1992: 20). Allerdings beinhaltet die Klimarahmenkonvention nur vage Vorgaben und Berichtspflichten. Konkrete Reduktionsziele sind dort nicht enthalten (vgl. Oberthür/Ott 2000: 64f). Insofern war abzusehen, dass sich das UN-Klimaregime durch rechtlich

2 Sowohl in der Klimarahmenkonvention als auch im Kyoto-Protokoll werden Transformationsländer als „Länder, die sich im Übergang zur Marktwirtschaft befinden“ (vgl. UNFCCC 1992: 25; UNFCCC 1997: 31) definiert.

3 In meiner Arbeit verwende ich durchgängig die Bezeichnung der Annex-B-Staaten, auch wenn ich Quellen wiedergebe, in denen von Annex-I-Staaten die Rede ist.

4 In der Klimarahmenkonvention sind zwei ständige Nebenorgane eingesetzt: das Nebenorgan für wissenschaftliche und technologische Beratung (Subsidiary Body for Scientific and Technological Advice, SBSTA) und das Nebenorgan für die Durchführung des Übereinkommens (Subsidiary Body for Implementation, SBI). Diese Organe arbeiten unter der Aufsicht der COP und alle Vertragsparteien können in ihnen mitarbeiten. Ein weitere wichtige Institution ist das Klimasekretariat, das seit 1996 seinen Sitz in Bonn hat und der Rahmenkonvention und ihren Organen administrative Unterstützung leistet. 
verbindliche Beschlussprotokolle weiterentwickeln würde. Da keine Bestimmungen zur Annahme eines Protokolls festgelegt wurden, gilt für diesen Fall die Konsenspflicht - schließlich wird mit einem Protokoll ein neues Abkommen geschaffen und nicht das bestehende Übereinkommen geändert (vgl. Oberthür/Ott 2000: 71f).

Gleich bei der ersten COP, die 1995 in Berlin stattfand, stand die Ausarbeitung eines solchen Protokolls im Zentrum. Das Konsensprinzip erschwerte diesen Prozess, der 1997 zur Verabschiedung des Kyoto-Protokolls führte, erheblich. Die Regierungsdelegationen verfolgten aufgrund verschiedener Interessenlagen und Machtkonstellationen sehr unterschiedliche Verhandlungsstrategien. Dabei haben sich diverse Gruppierungen herausgebildet, die ich kurz vorstelle.

Die EU vertritt in den UN-Klimaverhandlungen ihre Mitgliedsländer, die neben den USA maßgeblich für den Ausstoß von Treibhausgasen seit der industriellen Revolution verantwortlich sind (für den gesamten Absatz vgl. Brunnengräber 2009: 154ff, 158ff; Oberthür/Ott 2000: 40ff). Neben dieser historischen ökologischen Schuld trug der Druck von einflussreichen Umwelt-NGOs und das in einigen Mitgliedsländern ausgeprägte Umweltbewusstsein der Bevölkerung zur Einnahme einer Vorreiterrolle der EU bei. Darüber hinaus sprechen aufgrund der hohen Importabhängigkeit bei fossilen Brennstoffen auch ökonomische Interessen der EU für eine Forcierung der Energiewende durch Klimaschutzmaßnahmen. Deshalb galt sie lange als treibende Kraft in den Verhandlungen. Dieser Vorreiterrolle wird die EU aber spätestens seit den verschiedenen Wirtschaftskrisen immer weniger gerecht. So konnten sich die Mitgliedsstaaten der EU in letzter Zeit nur noch auf gemäßigte Klimaschutzziele einigen (vgl. Kapitel 5.4.3.3).

Als sogenannte ,Bremserkoalition“ gilt die Gruppe der Industrieländer die nicht zur EU gehören und als JUSSCANNZ bezeichnet werden (für den gesamten Absatz vgl. Brunnengräber 2009: 151ff, 161f; Oberthür/Ott 2000: 44ff). JUSSCANNZ steht für die Abkürzung der Namen der ersten Mitgliedsstaaten: Japan, USA, Schweiz, Kanada, Australien, Norwegen und Neuseeland. 1998 stieg die Schweiz aus dem Verhandlungsverbund aus, dafür kamen Russland und die Ukraine hinzu. Seitdem spricht man von der Umbrella Group. In dieser Koalition sind Länder mit unterschiedlichen Verhandlungsvoraussetzungen und umweltpolitischen Positionen versammelt, allerdings teilen sie eine verhältnismäßig hohe Abhängigkeit von der Produktion und/oder vom Verbrauch fossiler Brennstoffe (für Norwegen vgl. Kapitel 5.4.3.1). In den Kyoto-Verhandlungen, in denen vor allem die USA die Position der Gruppe bestimmte, einte sie ihre Ablehnung verbindlicher Reduktionsverpflichtungen. Die harte Verhandlungsführung der JUSSCANNZ führte dazu, dass ihren Mitgliedern im Kyoto-Protokoll vergleichsweise moderate Emissionsobergrenzen zugewiesen wurden. 
Die Transformationsländer in Mittel- und Osteuropa nehmen ebenfalls keine progressive Position in den internationalen Klimaverhandlungen ein (für den gesamten Absatz vgl. Brunnengräber 2009: 167f; Oberthür/Ott 2000: 49ff). Bei den Kyoto-Verhandlungen befanden sie sich in einer vorteilhaften Verhandlungsposition. Ihre Emissionen sanken rapide durch den Zusammenbruch der Sowjetunion und dem damit einhergehenden Rückbau der energieintensiven Industrien. Da sie trotz sinkender Emissionen eine Stabilisierung ihrer Treibhausgasemissionen auf dem Niveau von 1990 aushandelten, konnten sie in der ersten Verpflichtungsperiode große Teile ihrer Emissionsberechtigungen (zum Begriff der Emissionsberechtigungen vgl. Kapitel 5.1.2) verkaufen bzw. verfügen immer noch über ungenutzte Rechte. Diese sogenannte Hot Air war einer der Gründe, warum es zu einem Preisverfall der Emissionsberechtigungen kam.

Wie die Länder des globalen Nordens, so weisen auch die Länder des globalen Südens große Unterschiede bezüglich ihrer Ausgangsbedingungen und Verhandlungspositionen auf (für den gesamten Absatz vgl. Brunnengräber 2009: 156ff, 162ff; Oberthür/Ott 2000: 52ff). Grundsätzlich werden die Länder des globalen Südens in internationalen Verhandlungen durch die G77 vertreten. Allerdings gibt es in Bezug auf die Klimapolitik mitunter große Differenzen zwischen den Ländern der G77. China steht exemplarisch für die Schwellenländer, deren Pro-KopfAusstoß an Treibhausgasemissionen stetig steigt. Gerade wenn neben dem ProKopf-Ausstoß auch die absoluten Emissionszahlen betrachtet werden, ist die Klimapolitik der Schwellenländer zunehmend wichtig für die Möglichkeiten der Abschwächung des Klimawandels und für die Suche nach Kompromissen in den UNKlimaverhandlungen. Der Großteil der Länder des globalen Südens trägt jedoch kaum zum anthropogenen Klimawandel bei. Was die G77 dennoch als Zusammenschluss der Länder des globalen Südens eint, ist zum einen die tendenziell große Betroffenheit von den Folgen des Klimawandels und zum anderen der Fokus auf Gerechtigkeitsfragen. Die G77 setzt sich dafür ein, dass die wirtschaftliche und gesellschaftliche Entwicklung der Länder des globalen Südens nicht durch die Bewältigung eines Problems geschwächt wird, für das primär die Industrieländer verantwortlich sind.

Die von der Organisation erdölexportierender Länder (Organization of the Petroleum Exporting Countries, OPEC) vertretenen Staaten sind durch eine extrem hohe Abhängigkeit von fossilen Brennstoffen geprägt. Aufgrund ihres Interesses an der Fortführung des Exports von Erdöl und Erdgas stehen sie jeglichen Klimaschutzmaßnahmen skeptisch gegenüber, obwohl Prognosen davon ausgehen, dass sie selber stark von den Folgen des Klimawandels betroffen sein werden (vgl. Brunnengräber 2009: 167). 
Die Allianz der kleinen Inselstaaten (AOSIS) ist ein Zusammenschluss von über 40 tiefliegenden Ländern und Inselstaaten des globalen Südens, die durch die Folgen des Klimawandels - dem Anstieg des Meeresspiegels sowie der Zunahme von Fluten und Stürmen - akut in ihrer Existenz gefährdet sind (für den gesamten Absatz vgl. Brunnengräber 2009: 168f). Aufgrund ihrer bedrohlichen Situation fordern sie strikte Reduktionsziele, was ihnen den Ruf des ökologischen Gewissens der UN-Klimaverhandlungen einbrachte. Im Gegensatz zu vielen anderen Ländern des globalen Südens sehen sie auch die Notwendigkeit eines stärkeren Klimaschutzengagements der Nicht-Annex-B-Staaten. Die AOSIS-Länder verfügen kaum über eigene Mittel für Klimaanpassungsmaßnahmen, weshalb sie sich für Transferleistungen einsetzen.

Neben den Regierungsdelegationen nehmen viele Akteur_innen mit einem Beobachter_innenstatus an den COPs teil. Diese werden im Rahmen der UNKlimaverhandlungen als Beobachterorganisationen (,observer organizations') bezeichnet. Diese Organisationen versuchen die Entscheidungen unter anderem durch öffentliche Stellungnahmen und Gespräche mit Delegierten zu beeinflussen. Allerdings haben sie kein Recht auf Mitsprache und können von den Verhandlungen ausgeschlossen werden (vgl. Brunnengräber/Dietz/Hirschl/Walk/Weber 2008: 89). Zu den Beobachterorganisationen zählen verschiedene UN-Organisationen wie das UN-Umweltprogramm (UNEP), das Entwicklungsprogramm der Vereinten Nationen (United Nations Development Programme, UNDP) und der IPCC, internationale Organisationen wie die Globale Umweltfazilität (Global Environment Facility, GEF), die Weltorganisation für Meteorologie (World Meteorological Organization, WMO), die OECD und die IEA (vgl. Brunnengräber et al. 2008: 104). Weiterhin spielen vor allem NGOs eine immer größere Rolle in den Verhandlungen (vgl. Oberthür/Ott 2000: 58f). Als NGOs wird eine weite Bandbreite an zivilgesellschaftlichen Gruppen zugelassen, welche sich dadurch auszeichnen, dass sie nicht profitorientiert sind. Dabei gelten Lobbyverbände der Wirtschaft ebenfalls als NGOs, obgleich ihre Mitgliedsunternehmen sehr wohl profitorientiert sind. Solche Organisationen bezeichnet man in Abgrenzung zu anderen NGOs auch als Business and Industry NGOs (BINGOs). Die BINGOs sowie die Umwelt- und Entwicklungs-NGOs stellen die größten Gruppierungen innerhalb der Beobachterorganisationen dar. Eine weitaus kleinere Fraktion besteht aus kommunalen Organen, die bei den Verhandlungen durch den Internationalen Rat für Lokale Umweltinitiativen (ICLEI) vertreten werden (vgl. Oberthür/Ott 2000: 59).

Das Climate Action Network (CAN) bildet den größten Zusammenschluss von Umwelt- und Entwicklungs-NGOs bei den Klimaverhandlungen. CAN wurde 1989 im Vorfeld der Rio-Konferenz gegründet und mittlerweile sind mehr als 900 NGOs 
Mitglied (vgl. www.climatenetwork.org, letzter Zugriff am 20.11.2014). Die Mitglieder übernehmen verschiedene Funktionen, viele betreiben direkte Lobbyarbeit, andere wiederum bieten wissenschaftliche oder technische Beratung an (vgl. Oberthür/Ott 2000: 59f). Dabei hat sich die Arbeit der NGOs im Verlauf der Jahre gewandelt. In den Anfängen des UN-Klimaregimes zielten ihre Handlungen primär auf die Erzeugung eines öffentlichen Bewusstseins hinsichtlich der Problemlage und der Notwendigkeit weitreichender Lösungen. So forderten sie die ProKopf-Angleichung der Emissionen, mehr Gerechtigkeit in den Nord-SüdBeziehungen und eine andere, das Klima schützende Wirtschaftsweise. Mittlerweile übernehmen viele NGOs zunehmend Beratungs-, Monitoring- und Kontrollfunktionen bezüglich der Umsetzung des Kyoto-Protokolls, welches ein großer Teil von ihnen als alternativlose Verhandlungsgrundlage akzeptiert. Insofern können NGOs auch als Legitimationsressource bezeichnet werden, da sie die Akzeptanz der internationalen Beschlüsse erhöhen und deren lokale Implementierung erleichtern (vgl. Brunnengräber et al. 2008: 97f).

Im Zuge der Schwierigkeiten bei der Umsetzung des Kyoto-Protokolls, die nicht nur auf Umsetzungsfehler zurückzuführen sind, sondern auch strukturelle Probleme offenbaren, treten soziale Bewegungen und Organisationen, die den marktwirtschaftlichen Instrumenten eher kritisch bis ablehnend gegenüber stehen, wieder stärker in Erscheinung (vgl. Brunnengräber et al. 2008: 105; Kapitel 5.1.4).

Wie bei den NGOs wuchs auch die Zahl der BINGOs bei den UN-Klimaverhandlungen stetig an. Dies ist darauf zurückzuführen, dass einfachen Unternehmen der Zugang zu Foren und den Hauptverhandlungen verschlossen bleibt, BINGOs hingegen an den Sitzungen aktiv teilnehmen dürfen. Insofern stellt die Gründung einer BINGO für Unternehmen eine Möglichkeit dar, sich neue Einflussmöglichkeiten und Legitimität zu verschaffen (vgl. Vormedal 2008: 38). Während der COPs organisieren BINGOs sogenannte side-events, die gleichzeitig dem inhaltlichen Austausch sowie der Netzwerkbildung und -pflege dienen. Daneben finden Treffen mit dem Personal des UNFCCC-Sekretariats sowie den Delegationen der Regierungen statt. Die BINGOs verteilen Positionspapiere, reichen offizielle Stellungnahmen ein und unterstützen Delegierte bei der Verfassung von Rechtstexten (vgl. Vormedal 2008: 50). So ist beispielsweise die International Emissions Trading Association (IETA) mit vielen Delegierten eng vernetzt und regelmäßig in die Formulierung von Rechtstexten involviert (vgl. Vormedal 2008: 50f). In den transnationalen BINGOs dominieren Unternehmen aus dem globalen Norden, Unternehmen aus dem globalen Süden haben weitaus weniger Einfluss. 
Was ihre Ausrichtung in Bezug auf die internationale Klimapolitik betrifft, vertreten die BINGOs durchaus unterschiedliche Positionen (vgl. Vomedal 2008: 39). In verschiedenen Publikationen wird tendenziell zwischen einer ,grauen' und einer ,grünen“ Industrie unterschieden. Dabei werden die BINGOs der fossilen Energieunternehmen und der energieintensiven Branchen als ,grau' bezeichnet. Deren Interessen werden beispielsweise durch die IEA und die Internationale AtomenergieOrganisation (International Atomic Energy Agency, IAEA) vertreten. Ein besonders einflussreicher, grauer' Akteur ist lange Zeit das 1989 gegründete Netzwerk Global Climate Coalition (GCC) gewesen, das gegen alle klimapolitischen Regulierungen opponierte, die zu Wettbewerbsnachteilen für seine Mitglieder geführt hätten (vgl. Brunnengräber 2009: 187f; Oberthür/Ott 2000: 60; Vormedal 2008: 39). In der zweiten Hälfte der 1990er Jahre verließen allerdings einige der Kernmitglieder beispielsweise BP, Shell und General Motors - die GCC. 2002 wurde die GCC offiziell aufgelöst. Der, graue‘ Flügel wird nun unter anderem vom Australian Industry Greenhouse Network (AIGH) und dem Australian Aluminum Council (AAC) vertreten (vgl. Vormedal 2008: 39f).

Als ,grüne Industrien“ werden dagegen Unternehmen aus den Bereichen der erneuerbaren Energien, der Energie- und Rohstoffeffizienz, der Kraft-WärmeKopplung, der nachhaltigen Mobilität und der Kreislaufwirtschaft bezeichnet. Im Rahmen eigener Wirtschaftsverbände wie dem European Business Council for Sustainable Energy (e5) setzen sie sich für striktere Regulierungen ein, da sie sich davon ein Wachstum ihrer Absatzmärkte erhoffen (vgl. Brunnengräber 2009: 190f; Brunnengräber et al. 2008: 107; Vormedal 2008: 42f). Zu den ,grünen“ BINGOs werden in der Regel auch bestimmte Akteur_innen aus dem Finanzsektor gezählt, die sich für die Entwicklung der flexiblen Mechanismen des Kyoto-Protokolls einsetzen. Tatsächlich besteht ihr ureigenes Interesse in der Festigung von Emissionshandelssystemen, da diese einen boomenden Markt bedeuten, von dem sie hoffen, dass sein Volumen in den nächsten Jahren rapide ansteigt. Insofern treten einige Akteur_innen des Finanzkapitals für die Ausweitung des Kyoto-Kohlenstoffmarkts ein, unabhängig von seinen Effekten auf den Ausstoß von Treibhausgasen oder der Transformation des Energiesystems (vgl. Kaufmann/Müller 2009: 160; Lohmann 2009: 723; Rest 2011: 87, 114; Vormedal 2008: 42f).

Die meisten BINGOs sind auf dem Kontinuum zwischen diesen beiden Gruppen anzusiedeln und werden je nach dem tendenziell eher zum, grauen‘ (z. B. World Coal Association, Internationale Handelskammer) oder eher zum ,grünen“ (z. B. World Business Council on Sustainable Development, International Emissions Trading Association) Flügel gezählt. In diesem Spektrum befinden sich auch viele Unternehmen, die zu Beginn der UN-Klimaverhandlungen noch 
eindeutig zur ,grauen Industrie‘ zählten und Teil der GCC waren. Einige dieser Unternehmen gaben ihre Fundamentalopposition auf, da sie sich von der Ablehnung jeglicher Veränderung ihres Geschäftsmodells nur noch wenig Erfolgsaussichten versprachen. Stattdessen gingen einzelne Unternehmen und Verbände mehr und mehr dazu über, die Art und Weise der umweltpolitischen Regulierung - beispielsweise hin zu marktkonformen Lösungen - zu beeinflussen. Dabei versuchen sie Kosten und Risiken für die jeweils von ihnen vertretenen Wirtschaftszweige zu vermeiden und fokussieren auf Lösungsansätze, die ihnen im besten Fall Chancen und Wettbewerbsvorteile bieten (vgl. Brunnengräber et al. 2008: 107; Ihlen 2009: 246; Vormedal 2008: 40ff; Kapitel 3.2.4).

\subsubsection{Das Kyoto-Protokoll}

Das bisher folgenreichste Ergebnis der Klimarahmenkonvention ist das KyotoProtokoll, das im Jahre 1997 auf der dritten Vertragsstaatenkonferenz, der COP 3, beschlossen wurde. ${ }^{5}$ Es konnte allerdings erst 2005 in Kraft treten, nachdem die vereinbarte Mindestbeteiligungshürde erreicht wurde, laut der mindestens 55 Länder, die mehr als 55 \% der Treibhausgas-Emissionen des Jahres 1990 verursachten, das Abkommen ratifiziert hatten. ${ }^{6}$ Seitdem finden zeitgleich mit den COPs auch die Tagung der Mitgliedsstaaten des Kyoto-Protokolls statt (Conference of the Parties serving as the Meeting of the Parties to the Protocol, CMP).

Die CMP ist das oberste Leitungsorgan des Protokolls und hat vielfältige administrative und legislative Funktionen. Entsprechend der Bedeutung der COP für die UNFCCC ist die CMP vor allem dafür zuständig, die wirksame Durchführung des Protokolls zu überprüfen und darauf hinwirkende Beschlüsse zu fassen (vgl. Oberthür/Ott 2000: 309f). Im Kyoto-Protokoll wurde beschlossen, die Geschäftsordnung der COP sinngemäß auf das Protokoll anzuwenden. Somit sind beispielsweise Verhandlungen über eine zweite Verpflichtungsperiode der Konsenspflicht unterworfen - die erste Verpflichtungsperiode galt von 2008 bis 2012 (vgl. Oberthür/Ott 2000: 314). Allein bei Änderungen des Protokolls selber ist eine Entscheidung theoretisch mit einer Dreiviertelmehrheit möglich, allerdings soll auch dort eine Konsensentscheidung angestrebt werden. Ausgenommen von dieser Rege-

5 Einzelne Abschnitte dieses Kapitels wurden - in einer früheren Fassung - bereits veröffentlicht in Krüger 2012 und Krüger 2014.

6 Da die USA, die mit 36,2 \% den höchsten Anteil an den Treibhausgasemissionen des Jahres 1990 hatten (vgl. Oberthür/Ott 2000: 41), das Kyoto-Protokoll nicht ratifizierten war es schwierig, die Hürde von mehr als $55 \%$ der Treibhausgasemissionen zu überwinden. Letztlich gab die späte Ratifizierung Russlands den Ausschlag. 
lung ist allerdings die Anlage B, in der die Emissionsobergrenzen aufgelistet sind. Diese können nur mit Zustimmung der betreffenden Länder geändert werden (vgl. Oberthür/Ott 2000: 326f; UNFCCC 1997: 25).

Mit dem Kyoto-Protokoll verpflichteten sich die Industrieländer dazu, bis zum Jahre 2012 ihre Emissionen um durchschnittlich 5,2 \% gegenüber dem Basisjahr $1990 \mathrm{zu}$ verringern. Diese Reduktionsziele beziehen sich allein auf die Treibhausgasemissionen, die im eigenen Land entstehen. Es gibt also keine Obergrenze für Treibhausgase, die bei der Produktion von Gütern in Nicht-Annex-B-Staaten emittiert werden - auch wenn diese Güter in den Industrieländern konsumiert werden. Die Treibhausgasemissionen, die bei grenzüberschreitenden Transporten anfallen, werden keinem Land zugeordnet und unterliegen damit ebenfalls keiner Begrenzung. Diese beiden Emissionstypen werden im Kyoto-Protokoll nicht erfasst, obwohl sie einen stetig steigenden Anteil an den gesamten Emissionen ausmachen (vgl. Klein 2014: 79f).

„Consequently, increased consumption in the Annex B countries has caused an increase in global emissions contrary to the territorial emission statistics reported to the UNFCCC." (Peters/Minx/Weber/Edenhofer 2011: 8907)

Diese Externalisierung von Emissionen ist einer der Gründe für das auf den ersten Blick paradoxe erscheinende Ergebnis der ersten Verpflichtungsperiode des KyotoProtokolls. Einerseits wurde das formale Ziel erreicht (gemessen an den Emissionsbilanzen der Annex-B-Staaten), andererseits hat das Kyoto-Protokoll seinen Zweck nicht erfüllt (gemessen an den jährlich steigenden globalen Treibhausgasemissionen): Das in der Klimarahmenkonvention formulierte Ziel der Stabilisierung der Treibhausgasemissionen in der Atmosphäre wurde bislang verfehlt. Neben der bereits erwähnten Externalisierung bestimmter Emissionstypen kann das ernüchternde Ergebnis darauf zurückgeführt werden, dass mit den USA das Land mit den höchsten Emissionen ${ }^{7}$ (im Zeitraum der ersten Verpflichtungsperiode) dem Protokoll nie beigetreten ist. Ein zusätzlicher Grund für die mangelnden Erfolge liegt in weiteren Externalisierungsmöglichkeiten, die mit dem Kyoto-Protokoll geschaffen wurden: die sogenannten flexiblen Mechanismen.

Neben den quantifizierten Emissionsobergrenzen sind im Kyoto-Protokoll drei Mechanismen festgelegt, deren Zweck es ist, die Einhaltung der Obergrenzen für die Annex-B-Staaten möglichst kostengünstig zu gestalten: der Emissionsrechtehandel, der Mechanismus für umweltverträgliche Entwicklung (Clean Development

7 Dies trifft auf den Zeitraum der ersten Verpflichtungsperiode zu. Mittlerweile hat China die USA abgelöst und ist das Land mit den meisten absoluten Emissionen (allerdings nicht mit den höchsten Pro-Kopf-Emissionen). 
Mechanism, CDM) und die Gemeinsame Umsetzung (Joint Implementation, JI). Die Grundidee dieser flexiblen Mechanismen entstammt der klassischen Wirtschaftstheorie: Maßnahmen zur Reduzierung von Treibhausgasen sollen bevorzugt dort durchgeführt werden, wo es betriebswirtschaftlich am kostengünstigsten oder sogar gewinnbringend ist. Dahinter steht die Annahme, dass die Kosten von Emissionsreduktionen in den verschiedenen Ländern aufgrund der Unterschiede in der Energieeffizienz stark variieren (vgl. Oberthür/Ott 2000: 203).

Die flexiblen Mechanismen, die alltagssprachlich oftmals schlicht als Emissionshandel bezeichnet werden, bestehen aus zwei Grundprinzipien: Cap-andTrade (bezieht sich auf den Emissionsrechtehandel) und Offsetting (bezieht sich auf auf den CDM und die JI). Das Cap-and-Trade-Regime wird auf verschiedenen Ebenen umgesetzt. Zunächst einmal gibt es auf internationaler Ebene einen Handel mit Emissionsberechtigungen zwischen den Annex-B-Staaten. Die im Kyoto-Protokoll festgelegten Emissionsobergrenzen bilden dabei die Deckelung der Emissionen, den Cap. Aus diesen Obergrenzen leiten sich Emissionsbudgets der Länder ab. Die Anzahl der Emissionsberechtigungen bemisst sich am Ausstoß des Jahres 1990 plus/minus die in Anlage B festgelegte Emissionsreduzierung, -stabilisierung oder -erhöhung. Für diese Berechnungen werden die sechs wichtigsten Treibhausgase $\left(\mathrm{CO}_{2}, \mathrm{CH}_{4}, \mathrm{~N}_{2} \mathrm{O}, \mathrm{H}-\mathrm{FKW}, \mathrm{FKW}\right.$ und $\left.\mathrm{SF}_{6}\right)$ in Tonnen $\mathrm{CO}_{2}$ - ̈̈quivalente umgerechnet (durch die Multiplikation der jeweiligen Emissionsmenge eines Treibhausgases mit seinem vom IPCC festgelegten Treibhausgaspotenzial). Der Emissionsrechtehandel (Trade) soll die Erreichung der Reduktionsziel flexibilisieren und damit kostengünstiger gestalten. Der Handel ermöglicht den Ländern, Emissionsberechtigungen von anderen Annex-B-Staaten, die über das geforderte Maß hinaus $\mathrm{CO}_{2}$-Äquivalente einsparen, zu erwerben. Diese erworbenen Emissionsberechtigungen zählen wie die Emissionseinsparungen im eigenen Land für die Einhaltung der Emissionsobergrenzen. Im Kyoto-Protokoll findet sich zwar die Formulierung, dass jeglicher Handel „ergänzend“ (UNFCCC 1997: 10) zu den im eigenen Land ergriffenen Klimaschutzmaßnahmen erfolgen muss. Allerdings konnten sich die Vorschläge, im Kyoto-Protokoll festzuschreiben, dass die Industrieländer mindestens $50 \%$ ihrer Emissionsreduktionen im eigenen Land durchführen müssen oder dass es eine quantitative Obergrenze für den Emissionsrechtehandel gibt, nicht durchsetzen (vgl. Brunnengräber et al. 2008: 111). Neben diesem Handel auf internationaler Ebene gibt es verschiedene Plattformen zum Emissionsrechtehandel auf regionaler Ebene. Mit dem EU-Emissionshandel (European Union Emissions Trading System, EU ETS) wurde bereits zum 1. Januar 2005 der erste grenzüberschreitende und bis heute weltweit größte Emissionsrechtehandel eingeführt. Im EU ETS verteilen die Regierungen EU-Emissionsberechtigungen (European Unit Amounts, EUAs) an etwa 
11.000 Produktionsstandorte ausgewählter Industriezweige, die für ca. $40 \%$ der Treibhausgasemissionen der EU verantwortlich sind. Im Verlauf der verschiedenen Phasen des EU ETS soll die Anzahl der herausgegebenen Emissionsberechtigungen stetig reduziert werden. Diese Reduktionen bilden den Cap, der den Klimaschutzeffekt sichern soll. Wie die Länder, so können auch die Unternehmen mit den Emissionsberechtigungen Handel betreiben. Über die Linking Directive sind die Emissionsberechtigungen des EU ETS kompatibel mit den Emissionsberechtigungen des Kyoto-Protokolls. Dies ermöglicht den Unternehmen am internationalen Emissionsrechtehandel und an den Offset-Mechanismen CDM und JI teilzunehmen.

Offsets sind Investitionen in emissionsreduzierende Maßnahmen in anderen Ländern, mit denen die eigenen Treibhausgasemissionen kompensiert werden sollen. Im Kyoto-Protokoll sind die beiden projektbasierten Instrumente CDM und JI verankert. Ihre flexibilisierende Wirkung besteht darin, dass Staaten bzw. Unternehmen durch emissionsmindernde Maßnahmen in einem anderen Land ihre Reduktionsziele erreichen können, ohne selber weniger Treibhausgase emittieren zu müssen. Das wichtigste Kriterium besteht dabei in der ,Zusätzlichkeit‘ des Projekts. Damit ist gemeint, dass nur Maßnahmen angerechnet werden dürfen, die ohne CDM und JI nicht umgesetzt worden wären.

Mit dem CDM wird es Annex-B-Staaten ermöglicht, ihre Emissionsobergrenzen durch Offset-Projekte in Nicht-Annex-B-Staaten einzuhalten. Mit dem CDM soll eine ,nachhaltige Entwicklung' in den Zielländern des globalen Südens gefördert werden. Auf der anderen Seite werden dem beteiligten Annex-B-Staat sogenannte zertifizierte Emissionsverminderungen (Certified Emissions Reductions, CERs) gutgeschrieben. Die Summe der zugeteilten CERs ergibt sich aus einer fiktiven Rechnung. Die Emissionen dieser Projekte werden verrechnet mit dem kalkulierten Wert, den die Herstellung der gleichen Menge des spezifischen Produkts (z. B. Energie) unter Verwendung der Standard-Technologie des Ziellandes erzeugt hätte. Die CERs werden nicht von dem Emissionsbudget einer anderen Vertragspartei abgezogen, da die Nicht-Annex-B-Staaten keine Emissionsobergrenzen haben. Dadurch steigt die absolute Menge der Emissionsberechtigungen. Dies widerspricht insofern dem Ziel des Cap, als dass CDM-Projekte in den Zielländern nicht immer zu absoluten Emissionsreduktionen beitragen (vgl. Gilbertson/Reyes 2009: 54).

Um das Kriterium der Umweltverträglichkeit zu erfüllen, werden nur bestimmte Typen von Projekten als CDM anerkannt, beispielsweise Staudammprojekte, Methangas-Abscheidung bei industrieller Viehhaltung, Aufforstung, erneuerbare Energien etc. Mit der Ausnahme von Kernkraftprojekten, die nicht angerechnet werden können, soll der CDM ,Technologie-neutral' sein. Deshalb sind auch Projekte zugelassen, die auf fossilen Brennstoffen basieren. Es können sogar Kohle- 
kraftwerke als CDM-Projekte angerechnet werden, so lange sie effizienter sind als der Durchschnitt der Kraftwerke in den Zielländern (vgl. Carbon Market Watch 2011: 2). Im Kyoto-Protokoll ist festgehalten, dass die Annex-B-Staaten einen Teil ihrer Reduktionsverpflichtungen durch den Erwerb von CERs im Rahmen des CDM erfüllen können (vgl. UNFCCC 1997: 17). Eine quantitative Obergrenze ist nicht festgelegt (vgl. Oberthür/Ott 2000: 222).

Ein weiterer Offsetting-Mechanismus ist die Gemeinsame Umsetzung. Prinzipiell funktioniert die JI ähnlich wie der CDM, nur dass sowohl die Investition als auch die Umsetzung von Annex-B-Staaten durchgeführt wird. Das Konzept der JI erlaubt somit den Industrie- und Transformationsländern, Emissionsreduktionen aus Projekten in anderen Annex-B-Staaten auf ihre eigenen Minderungspflichten anzurechnen. Die JI ermöglicht also einen Transfer von Reduktionszertifikaten (Emission Reduction Units, ERUs) von einem Annex-B-Staat zu einem anderen. Die Gesamtmenge der allen Annex-B-Staaten zustehenden Emissionen wird durch die JI nicht erhöht.

Übersicht über die verschiedenen Arten von Emissionsberechtigungen (vgl. Oberthür/Ott 2000: 250):

- Die im Kyoto-Protokoll als „zugeteilte Menge“ (UNFCCC 1997) bezeichneten Emissionsberechtigungen bilden die Emissionsbudgets der Annex-B-Staaten.

- Im EU-Emissionshandel werden an die Produktionsstandorte EU-Emissionsberechtigungen (European Unit Amounts, EUAs) verteilt.

- Emissionsreduktionseinheiten (Emission Reduction Units, ERUs) werden aus Projekten der Gemeinsamen Umsetzung gewonnen.

- Zertifizierte Emissionsreduktionen (Certified Emissions Reductions, CERs) werden über den Mechanismus für umweltverträgliche Entwicklung erworben.

Die verschiedenen Emissionsberechtigungen stehen alle für jeweils eine Tonne $\mathrm{CO}_{2}$-Äquivalente und können gehandelt werden, d. h. sie sind funktional identisch. Aus Gründen der besseren Lesbarkeit verwende ich im Folgenden in den meisten Fällen den übergeordneten Begriff der Emissionsberechtigungen.

Die Entscheidung gegen starre Obergrenzen von Treibhausgasemissionen und für eine marktkonforme Anreizstruktur im Kyoto-Protokoll kam relativ kurzfristig und vor allem auf Druck der USA sowie der JUSSCANNZ-Länder zustande. Weiterhin setzte sich eine Koalition aus Wirtschaftsverbänden und einigen Umwelt-NGOs für marktorientierte Instrumente ein (vgl. Kolk/Levy 2001: 501; Meckling 2011). Zunächst zeigten sich die meisten europäischen Länder sowie ein Großteil der NGOs 
skeptisch. Die Länder des globalen Südens waren explizit dagegen. Sie argumentierten, dass aufgrund der ungleichen Machtverhältnisse die Projekte eher den Interessen der Investorländer entsprechen würden und den nationalen Entwicklungszielen der Zielländer möglicherweise sogar zuwiderlaufen könnten und dass sich der Schwerpunkt der Klimaschutzanstrengungen von den Industrieländern hin zu den Ländern des globalen Südens verlagern könnte (vgl. Oberthür/Ott 2000: 204ff). Trotz der Skepsis vieler Delegationen fanden die flexiblen Mechanismen schlussendlich, nach zähen Verhandlungen, Einzug ins Kyoto-Protokoll. Die Länder des globalen Südens beharrten in der entscheidenden Abstimmung aus zwei Gründen nicht auf ihrer Ablehnung. Erstens erhofften sie sich vom CDM Finanz- und Technologie-Transfers. Diese Hoffnung bezog sich zum einen auf die Funktionsweise des Mechanismus selber. Zum anderen galt sie der Gebühr, mit der die CDMProjekte versehen wurden und deren Einnahmen den AOSIS-Staaten und anderen vom Klimawandel besonders stark betroffenen Ländern zugute kommen soll (vgl. Oberthür/Ott 2000: 217). Zweitens spielte wohl auch die Tatsache eine Rolle, dass die Länder des globalen Südens sich in der letzten Pause vor der Abstimmung mit anderen Tagesordnungspunkten beschäftigten (vgl. Oberthür/Ott 2000: 248) und insgesamt die letzten Kompromisse unter den Bedingungen zunehmender Erschöpfung der Delegierten zustande kamen (vgl. Oberthür/Ott 2000: 128ff). In dem Zusammenhang ist erwähnenswert, dass es starke Unterschiede in Bezug auf die Größe der Delegationen gibt. In der Regel sind die Länder des globalen Südens mit kleineren Verhandlungsteams vertreten. Die US-Delegation war dagegen in Kyoto so gut vorbereitet, dass sich ihre Chefunterhändler_innen im Rotationsverfahren jeweils nach wenigen Stunden ablösen konnten (vgl. Oberthür/Ott 2000: 131). Die Verhandlungen dauerten so lange, dass nicht alle Delegierten bis zum Schluss blieben und am Ende sogar die Dolmetscher_innen ihre Arbeit einstellten und nur noch auf Englisch weiterverhandelt werden konnte (vgl. Oberthür/Ott 2000: 131).

Nachdem die flexiblen Mechanismen Eingang ins Kyoto-Protokoll gefunden hatten, war zunächst unklar, in welchem Maße sie angewendet werden würden und welche Auswirkungen sie auf die internationale Klimapolitik haben würden. Seit In-Kraft-Treten des Protokolls zeichnet sich aber zunehmend ab, dass viele Befürchtungen der Kritiker_innen eingetreten sind. So tragen die Offset-Regime sicherlich dazu bei, dass in manchen Annex-B-Staaten der Fokus auf Reduktionsmaßnahmen in anderen Ländern gelenkt wird. Darüber hinaus werden CDMProjekte vor allem in wirtschaftlich starken Schwellenländern durchgeführt. Investitionen in sogenannte Entwicklungsländer bleiben die Ausnahme und treiben somit dort auch keine nachhaltige Entwicklung voran. Über $90 \%$ der CERs wurden bislang durch Projekte in China, Indien, Süd-Korea und Brasilien generiert (vgl. im 
Internet: cdm.unfecc.int/Statistics/Public/CDMinsights/index.html, letzter Zugriff am 02.12.2014). Dies weist darauf hin, dass der CDM nicht zu einer nachhaltigen Transformation von Energiesystemen oder zur Reduzierung der weltweiten Energiearmut durch den Ausbau dezentraler erneuerbarer Energien in Entwicklungsländern beiträgt (vgl. Brunnengräber et al. 2008: 118).

Die flexiblen Mechanismen im Allgemeinen und die CDM-Projekte im Besonderen wurden bereits in mehreren sozialwissenschaftlichen Studien einer ausführlichen Kritik unterzogen. Deshalb begnüge ich mich hier mit einer knappen Auflistung der wichtigsten Kritikpunkte. Dabei lasse ich vermeintliche Umsetzungsfehler ${ }^{8}$ außen vor und konzentriere mich auf die grundsätzliche Kritik an den strukturell bedingten Schwierigkeiten und negativen Konsequenzen, die mit den flexiblen Mechanismen unvermeidlich einhergehen:

- Klimaschutz-Anstrengungen, die eine Unterschreitung der festgelegten Obergrenze an Emissionsberechtigungen bewirken würden, können im System der flexiblen Mechanismen nicht belohnt werden und werden deshalb auch gar nicht erst angestrebt. Sobald ein Land seine Reduktionsziele des KyotoProtokolls erreicht hat, gibt es keinen Anreiz zur weiteren Reduktion der Treibhausgasemissionen. Dies ist ein wesentlicher Unterschied zu anderen möglichen Klimaschutzinstrumenten - beispielsweise einer $\mathrm{CO}_{2}$-Steuer.

- Die Festlegung auf das Zwei-Grad-Ziel ${ }^{9}$ sowie die Quantifizierung und Aufteilung von Treibhausgasen in Emissionsbudgets, die noch emittiert werden dür-

8 In Bezug auf den EU-Emissionshandel wurden beispielsweise zu viele Emissionsberechtigungen ausgegeben und diese darüber hinaus zumeist kostenlos verteilt. Diese Überallokation führte zu Tiefstpreisen für $\mathrm{CO}_{2}$-Äquivalente. Darüber hinaus fuhren die Energiekonzerne sogenannte windfall-profits ein, da sie den Strompreis erhöhten, obwohl sie die Emissionsberechtigungen kostenlos zugeteilt bekamen und ihnen somit gar keine höheren Kosten entstanden waren (vgl. Brunnengräber et al. 2008: 118f). Diese Fehler in der Zuteilung von Emissionsberechtigungen sind bis heute nicht endgültig behoben. So überstieg beispielsweise die Zahl der Emissionsberechtigungen, welche die deutsche Industrie noch im Jahr 2013 zugeteilt bekam, ihre tatsächlichen Emissionen. Die Industrie (zu der die Energieanlagen nicht gezählt werden, da sie einen eigenen Bereich bilden) wurde also „überausgestattet“ (vgl. im Internet: dehst.de/SharedDocs/Downloads/DE/Publikationen/ VET-Bericht_2013.pdf?_blob=publicationFile: 64, letzter Zugriff am 02.12.2014).

9 Das Zwei-Grad-Ziel (vgl. Fußnote 8 auf Seite 19) wurde in den UN-Klimaverhandlungen mehrfach verkündet und auf der COP 16 in Cancún offiziell anerkannt. Dennoch liegt es nicht den Berechnungen des Kyoto-Protokolls zugrunde. Die darin angestrebten Emissionsreduzierungen sind weitaus weniger ambitioniert. 
fen, suggeriert eine Steuerbarkeit des Klimaproblems, die mit naturwissenschaftlichen Aussagen nicht begründet werden kann. Ausgeblendet werden Nebeneffekte und sich selbst verstärkende Prozesse, die nicht vorherzusehen sind (vgl. Weingart/Engels/Pansegrau 2008: 13).

- Der Ausstoß von Treibhausgasen wird kommodifiziert und in erster Linie als Produkt des Finanzmarkts behandelt. Die Folge ist, dass die Auswahl von Klimaschutzmaßnahmen vorrangig auf Profitmaximierung zielt und der Klimaeffekt zweitrangig ist (vgl. Lohmann 2010: 139). Darüber hinaus ist eine Spekulationsblase nicht auszuschließen. Wie Tamra Gilbertson und Oscar Reyes darlegen, sind Kohlenstoffmärkte dafür sogar besonders prädestiniert (vgl. Gilbertson/Reyes 2009: 51, 91). Sie sehen Ähnlichkeiten zum Handel mit Derivaten. In beiden Fällen ist der Wert der Finanzmarktprodukte schwer einschätzbar. Die Händler_innen wissen nicht, was sich an konkreten Maßnahmen hinter dem Finanzmarktprodukt verbirgt. Zudem werden durch die Anwendung von Techniken, die vom Handel mit Derivaten und von Hedgefonds bekannt sind, immer komplexere carbon products entwickelt.

- Die Anrechnung von Emissionsberechtigungen aus CDM- und JI-Projekten basiert auf einer fiktiven Rechnung. Aufgrund der Komplexität gesellschaftlicher Prozesse ist die Zukunft jedoch in diesem Fall nicht derart berechenbar. Die CDM- und JI-Projekte bedeuten stets eine zusätzliche Produktion von Gütern, sofern das Kriterium der Zusätzlichkeit zutrifft. Darüber hinaus werden die durch die Projekte generierten Gewinne in weitere wirtschaftliche Unternehmungen reinvestiert, deren Nachhaltigkeit nicht nachgewiesen werden muss. Insgesamt wird die Produktion und Konsumtion von Gütern befördert, wodurch de facto mehr Treibhausgase emittiert werden (vgl. Gilbertson/Reyes 2009: 54).

- Das Kriterium der Zusätzlichkeit ist kaum überprüfbar. Viele Studien gehen davon aus, dass bis zu 50 \% der CDM-Projekte dem Kriterium der Zusätzlichkeit nicht entsprechen (vgl. beispielsweise Carbon Market Watch 2011; Lohmann 2006: 145; Lohmann 2009: 732; Öko-Institut 2007: 40ff).

- Insgesamt ist die Berechnung der projektbezogenen Emissionssenkungen (bei CDM und JI) sehr komplex und birgt viele Möglichkeiten für die beteiligten Akteur_innen, die Anzahl der Reduktionseinheiten in die Höhe zu treiben. Dabei können Verlagerungen von emissionsintensiven Tätigkeiten an andere Standorte genauso wenig wie geheime Absprachen zwischen den Projektpartner_innen - in denen die erreichten Emissionssenkungen zum beiderseitigen Vorteil hochgerechnet werden - nicht ausgeschlossen werden (vgl. Lohmann 2010: 146; Oberthür/Ott 2000: 204). 
- CDM-Projekte bieten paradoxe Anreize. Um möglichst viele CERs verkaufen zu können, ist es beispielsweise vorteilhaft, wenn das Referenzszenario möglichst emissionsintensiv ist. Ein Staat, dessen Volkswirtschaft an CDM-Projekten verdient, ist deshalb unter Umständen motiviert, auf strengere Umweltvorschriften zu verzichten, da diese das Referenzszenario zu Ungunsten der Einnahmen aus CDM-Projekten verändern würden (vgl. Lohmann 2010: 145).

- Scharfe Kritik gibt es an CDM-Projekten, die über die Vermeidung bzw. Vernichtung von teilhalogenierten Kohlenwasserstoffen (HFCs) und Lachgas $\left(\mathrm{N}_{2} \mathrm{O}\right)$ in China, Indien und Brasilien große Mengen an CERs zugewiesen bekommen. Diese Projekttypen generierten bis zum Ende der ersten Verpflichtungsperiode des Kyoto-Protokolls etwa ein Drittel aller vergebenen CERs (vgl. Gilbertson/ Reyes 2009: 55; im Internet: cdm.unfccc.int/Statistics/Public/CDMinsights/ index.html, www.cdmpipeline.org letzter Zugriff am 02.12.2014). Die Maßnahmen zur Vernichtung der extrem klimaschädlichen Gase sind dem eigentlichen Produktionsprozess nachgeschaltete End-of-pipe-Technologien und tragen nicht zu einer wirklich nachhaltigen Entwicklung bei. Allerdings haben diese Gase ein extrem hohes Treibhausgaspotenzial, wodurch es möglich ist, schnell und kostengünstig viele CERs zu generieren. Paradoxerweise ist dies ein Anreiz, zunächst möglichst viele klimaschädliche Gase zu produzieren, um diese dann im Rahmen eines CDM-Projekts profitabel vernichten zu können. Im Fall der Projekte zur Vermeidung bzw. Vernichtung von teilhalogenierten Kohlenwasserstoffen und Lachgas wird über den CDM teilweise mehr Geld als mit dem Verkauf des eigentlichen Produkts erzielt (vgl. Brunnengräber et al. 2008: 117; Gilbertson/Reyes 2009: 55). Insofern muss man annehmen, dass in Einzelfällen ohne die Finanzierung im Rahmen des CDM die klimaschädlichen Treibhausgase gar nicht erst produziert würden bzw. worden wären. Mittlerweile hat zumindest die EU eine Sperre für den Handel von CERs aus HFC-Projekten ausgesprochen, die seit April 2013 für den EU-Emissionshandel gilt (siehe www. carbonmarketwatch.org/newsletter-20-july-2012, letzter Zugriff am 02.12.2014).

- Die Kosten der Validierung und Registrierung als CDM-Projekt sind so hoch, dass dies nur für Projekte mit Einsparungen ab ca. 50.000 Tonnen $\mathrm{CO}_{2}$-Äquivalenten wirtschaftlich ist. Deshalb dominieren Großprojekte und nicht dezentrale Anlagen. Dies geht nach Meinung vieler Beobachter_innen insgesamt zum Nachteil möglicher Nachhaltigkeitseffekte, die eher durch eine Vielzahl von Kleinprojekten bewirkt werden könnten (vgl. Lohmann 2006: 163f).

- Soziale und ökologische Kriterien werden im Rahmen der flexiblen Mechanismen nicht hinreichend beachtet (vgl. Lohmann 2010: 147ff). Ein typisches Beispiel dafür ist der Anbau von Eukalyptus-Plantagen als Monokulturen, wie er in 
Brasilien durchgeführt wird. Die schnell wachsenden Eukalyptus-Plantagen werden aufgrund ihrer Funktion als $\mathrm{CO}_{2}$-Senke gefördert. Allerdings wird für ihren Anbau zuvor Regenwald gerodet und damit der Lebensraum vieler Menschen und Tiere zerstört. Die in diesen Gebieten ansässige Bevölkerung, für die der Regenwald wichtige Funktionen erfüllt, wird mehrfach geschädigt. Die Menschen verlieren ihr Land und ihre Arbeitsplätze. Darüber hinaus führt der enorme Wasserbedarf von Eukalyptus zum Absinken des Grundwasserspiegels. Hinzu kommt eine Veränderung des lokalen Klimas, die zu längeren Dürrezeiten führt (vgl. Gilbertson/Reyes 2009: 80ff; Lohmann 2006: 302ff).

- Der eigentliche Vorteil der flexiblen Mechanismen, die Kosteneffizienz, zielt lediglich auf den Aspekt der betriebswirtschaftlichen, nicht jedoch der volkswirtschaftlichen Effizienz (vgl. Brunnengräber et al. 2008: 115f). Dies hat zur Folge, dass Projekte allein nach ihren kurzfristigen Emissionsreduktionen bewertet werden. Es gibt keine Fokussierung auf Maßnahmen, die zur Unabhängigkeit von fossilen Brennstoffen führen. Im Gegenteil: die Flexibilisierung durch die Kyoto-Mechanismen verstetigt geradezu den Verbrauch fossiler Brennstoffe in den Industrienationen (vgl. Lohmann 2010: 134, 142).

- Aber auch bei den CDM-Projekten, die in den Nicht-Annex-B-Staaten durchgeführt werden, steht die Überwindung fossiler Energieinfrastrukturen nicht zwangsläufig im Zentrum. Bis Juni 2013 wurde etwa nur ein Drittel der zertifizierten Emissionsreduktionen für die Förderung erneuerbarer Energien vergeben. Dabei machen Wasserkraft- ${ }^{10}$ und Windkraftprojekte den Hauptanteil aus, daneben gibt es einige Bioenergieprojekte und kaum Solarkraftprojekte (vgl. im Internet: cdm.unfccc.int/Statistics/Public/CDMinsights/index.html, letzter Zugriff am 02.12.2014). Tatsächlich fördern viele CDM-Projekte indirekt die fossile Wirtschaft - beispielsweise dadurch, dass für die Verbrennung von Methan Emissionsberechtigungen ausgegeben werden und damit der Kohleabbau, bei dem das Methan entsteht, profitabel wird (vgl. Lohmann 2010: 142). Darüber hinaus wird mit dem CDM auch direkt der Neubau von fossilen Kraftwerken in Nicht-Annex-B-Staaten gefördert. In China wurden beispielsweise alle 24 neuen Gaskraftwerke, die zwischen 2005 und 2010 gebaut wurden, als CDMProjekte unterstützt (vgl. Gilbertson/Reyes 2009: 56). Bis November 2013 wurden auch sechs Kohlekraftwerke als CDM-Projekte registriert und über 40 weitere befinden sich im Registrierungsprozess (vgl. Carbon Market Watch 2013).

10 Dabei darf nicht vergessen werden, dass auch überdimensionierte Wasserkraftprojekte soziale und ökologische Probleme verursachen: Menschen werden zwangsumgesiedelt und ganze Täler geflutet. Der Eingriff in die Lebensweise von (v. a. in indigenen Gemeinschaften lebenden) Menschen und das lokale Ökosystem ist enorm. 
- Der Anspruch des Kyoto-Protokolls, ein globales Klimaschutzregime zu installieren, nimmt den Handlungsdruck von allen Akteur_innen. So ist es ein gängiges Argument gegen alternative oder zusätzliche Maßnahmen, dass es mit dem Kyoto-Protokoll bereits festgeschriebene Emissionsobergrenzen und Klimaschutzinstrumente gebe. Darüber hinausgehende Forderungen an die Wirtschaft werden mit der Begründung abgelehnt, dass sie dem Wettbewerbsprinzip, auf dem die flexiblen Mechanismen basieren, widersprechen würden (vgl. Lohmann 2010: 138f).

Insgesamt ist zu bilanzieren, dass die flexiblen Mechanismen einer konsequenten Reduktion der Treibhausgasemissionen entgegenwirken und in Bezug auf andere soziale oder ökologische Aspekte kontraproduktive Effekte haben. Selbst Befürworter_innen des Cap-and-Trade-Prinzips sprechen sich für weitreichende Änderungen aus und üben starke Kritik am Offsetting, insbesondere am CDM (vgl. Ekardt 2011: 480).

Im Moment deutet allerdings vieles darauf hin, dass die flexiblen Mechanismen in ihrer jetzigen Form auch in Zukunft die internationale Klimapolitik prägen werden - obwohl die erste Verpflichtungsperiode des Kyoto-Protokolls ausgelaufen ist. So ist die dritte Phase des EU-Emissionshandels, die bis 2020 gilt und die flexiblen Mechanismen enthält, bereits beschlossen. Die EU strebt damit bis 2020 gegenüber dem Basisjahr 1990 eine Reduktion der Treibhausgasemissionen um $20 \%$ an bzw. $30 \%$ wenn es ein internationales Klimaschutzabkommen gibt, in dem sich andere Annex-B-Staaten zu vergleichbaren Anstrengungen verpflichten. Die EU-Pläne sehen vor, dass etwa $50 \%$ der Reduktionen durch CDM- und JI-Projekte erreicht werden können (vgl. CDM Watch 2010: 6). Insofern ändert sich für den größten Emissionsrechtehandel nichts - außer, dass die EU ihre damit angestrebten Reduktionsziele (die Auswirkungen auf die Anzahl der ausgegebenen und zum Teil versteigerten Emissionsberechtigungen haben) selbstständig wählt und nicht als Teil eines völkerrechtlich verbindlichen Abkommens.

Was die UN-Klimaverhandlungen betrifft, so wurde 2011 auf der COP 17 in Durban eine zweite Verpflichtungsperiode des Kyoto-Protokolls beschlossen und 2012 in Doha konkretisiert. Allerdings gehen in dieser zweiten Periode bislang weitaus weniger Länder, die zudem nur für knapp über zehn Prozent der aktuellen globalen Treibhausgasemissionen verantwortlich sind, Reduktionsverpflichtungen ein (vgl. im Internet: www.unfccc.int/files/meetings/durban_nov_2011/decisions/ application/pdf/awgkp_outcome.pdf, letzter Zugriff am 02.12.2014). Dennoch wird für die COP 21, die 2015 in Paris stattfindet, die Verabschiedung eines Post-KyotoAbkommens angestrebt. Diesbezüglich wird auch über die Rolle und die Ausgestaltung von Marktmechanismen verhandelt (vgl. im Internet: www.carbonmarketwatch. 
org/reap-what-you-sow-participation-in-a-global-carbon-market-should-be-limitedto-countries-with-ambitions-climate-targets, letzter Zugriff am 02.12.2014). Da in einem möglichen Abkommen vermutlich nur sehr moderate Reduktionsziele verabschiedet werden (vgl. Germanwatch 2014: 6), lässt sich dessen Bedeutung für den internationalen Kohlenstoffmarkt nur schwer absehen.

Unabhängig davon wird in den Statistiken der UNFCCC ein stetiger Anstieg der durch den CDM generierten CERs bis zum Jahr 2020 prognostiziert (vgl. im Internet: cdm.unfccc.int/Statistics/Public/CDMinsights/index.html, letzter Zugriff am 02.12.2014). Dies hat verschiedene Gründe: Neben der EU werden auch diverse andere Länder die flexiblen Mechanismen voraussichtlich weiter nutzen, um freiwillige Reduktionsziele einzuhalten. Weiterhin investieren Finanzinstitute, Banken und Entwicklungsfinanzierungsinstitute in die projektbasierten Mechanismen. Insgesamt gibt es einen wachsenden Markt für freiwillige Kompensationen von Treibhausgasemissionen, an dem neben Regierungen auch Unternehmen und Einzelpersonen investieren. Insofern kann davon ausgegangen werden, dass die flexiblen Mechanismen auch künftig in der internationalen Klimapolitik eine wichtige Rolle spielen werden - zumindest so lange der Widerstand gegen sie marginalisiert bleibt.

\subsubsection{Das ökomoderne Projekt in der internationalen Klimapolitik}

Innerhalb der sozialwissenschaftlichen Literatur wird von einer starken Dominanz des ökomodernen Diskurses in der internationalen Klimapolitik ausgegangen allerdings werden für die Annahmen und Strategien, die ich als ökomodern bezeichne, unterschiedliche Begriffe verwendet. So konstatiert beispielsweise Angela Oels, dass seit Mitte der 1990er Jahre der Klimawandel vom ,fortgeschrittenen liberalen Regieren' vereinnahmt wurde und damit als primär ökonomisches Problem betrachtet wird, ,für das kosteneffiziente, marktförmige und auf technologischem Fortschritt beruhende Lösungen gefunden werden müssen“ (Oels 2010: 171). Achim Brunnengräber, Kristina Dietz, Bernd Hirschl, Heike Walk und Melanie Weber sprechen von dem Deutungsmuster einer spezifischen sozial-ökonomischen Rationalität, in der die betriebswirtschaftlichen Kosten in den Vordergrund gerückt werden. Die Folge sei ein ,Monetarisierungszwang“. Damit ist gemeint, dass die Umwelt in monetären Größen bewertet werden muss, um die Natur in gängige ökonomische Modelle zu integrieren (vgl. Brunnengräber et al. 2008: 193f). Im Zuge dessen verringert sich der politische Handlungsspielraum, da alternative Deutungsund Handlungsmuster marginalisiert werden - insbesondere solche, die an der Vereinbarkeit von effizientem Klimaschutz und dem Status quo der Produktionsund Konsummuster zweifeln (vgl. Bäckstrand/Lövbrand 2006: 60; Oels 2010: 179). 
Im Folgenden arbeite ich heraus, inwiefern das Kyoto-Protokoll, als bisher folgenreichstes Instrument der internationalen Klimapolitik, auf den ökomodernen Grundannahmen (vgl. Kapitel 3.3) - der technokratischen Vorstellung von Politik, dem Inkrementalismus und dem Primat der Betriebsökonomie - und den damit verknüpften ökomodernen Strategien (vgl. Kapitel 3.4) - der reflexiven Naturbeherrschung, des reflexiven Fortschritts durch wissenschaftlich-technische Rationalität und dem nachhaltigen Wachstum - basiert.

In der Zielformulierung der Klimarahmenkonvention, die auch für das Kyoto-Protokoll gilt, wird der Zweck der Klimapolitik auf die Stabilisierung der Treibhausgaskonzentration in der Atmosphäre reduziert. In dieser technokratischen Perspektive wird das Problem der Treibhausgasemissionen isoliert betrachtet. Dementsprechend werden systemkritische Artikulationen ausgeklammert. Durch den Fokus auf die Emissionen und der technologischen Instrumente zu ihrer Bekämpfung geraten ethische Fragen, Gerechtigkeitsfragen sowie Fragen nach den Lebensbedingungen zukünftiger Generationen in den Hintergrund (vgl. Brunnengräber et al. 2008: 193f).

In der Berechnung der Emissionen, die den Ländern zugewiesen werden, zeigt sich die ökomoderne Strategie der reflexiven Naturbeherrschung. Die Festlegung auf das Zwei-Grad-Ziel und die im Kyoto-Protokoll durchgeführte Quantifizierung und Aufteilung von Treibhausgasen in Emissionsbudgets, die noch emittiert werden dürfen, zielt auf ein Management der nicht-intendierten Nebenfolgen der Naturbeherrschung. Dabei sind diese Berechnungen zum einen das Ergebnis machtpolitischer Aushandlungen zwischen den Ländern und zum anderen folgen sie dem Fokus auf marktbasierte Lösungen, die eine Komplexitätsreduktion benötigen. Um handelbare Güter schaffen zu können, muss von den spezifischen Eigenschaften verschiedener Treibhausgase (wann, wo und wofür sie entstehen) und den verschiedenen Klimaschutz-Maßnahmen abstrahiert werden. Ausgeblendet werden naturwissenschaftliche Aussagen über nicht vorhersehbare Nebeneffekte und sich selbst verstärkende Prozesse. Stattdessen wird davon ausgegangen, dass es eine klar definierte Grenze an Treibhausgasemissionen gebe, bis zu der das Ziel der Rahmenkonvention, „eine gefährliche anthropogene Störung des Klimasystems“ (UNFCCC 1992: 5) zu verhindern, erreicht würde. Das abstrakte System aus Verteilung und Handel mit quantifizierbaren Reduktionen von $\mathrm{CO}_{2}$-Äquivalenten ist ein in sich logisches, aber empiriefernes Produkt der Wirtschaftstheorie. Gerade die Quantifizierung suggeriert eine Beherrschbarkeit der ökologischen Krise (vgl. Weingart/ Engels/Pansegrau 2008: 13), weshalb man von einer Fortsetzung des Prinzips der Naturbeherrschung (wenngleich in reflexiver Variante) sprechen kann. Momente der Unverfügbarkeit bzw. Widerständigkeit der Natur haben darin keinen Platz. 
Die Einhaltung der Obergrenzen für den Ausstoß von Treibhausgasen werden über den Handel mit Emissionsberechtigungen und über die Kompensation von nicht erbrachten eigenen Emissionsreduktionen durch emissionsreduzierende Maßnahmen in anderen Ländern - ,flexibilisiert' (vgl. Kapitel 5.1.2). Diese ,Flexibilisierung ' wird durch die Trennung in die Input-Seite der Energie-Produktion mit fossilen Brennstoffen und die Output-Seite der daraus entstehenden Emissionen ermöglicht (vgl. Brunnengräber et al. 2008: 188ff; Kapitel 3.4.3). So erfolgt keine direkte Regulierung der Nutzung fossiler Brennstoffe, sondern nur der daraus entstehenden Emissionen. Über die Einführung von handelbaren Emissionsberechtigungen wird den ökologischen Kosten des Klimawandels ein monetärer Wert zugeordnet. Diese Inwertsetzung der schädlichen Treibhausgase ist eine wichtige Grundlage für ökomoderne Instrumente, da die Inwertsetzung ,erst die Debatten über technologische Lösungen wie Effizienzstrategien, Sequestrierung [Abscheidung und Speicherung von $\mathrm{CO}_{2}$; T. K.] und Senken ebenso wie die marktwirtschaftlichen Instrumente“ (Brunnengräber 2009: 104) ermöglichte. Die flexiblen Mechanismen haben den Zweck, die Einhaltung der Emissionsobergrenzen für die beteiligten Regierungen möglichst kostengünstig zu gestalten. Damit wird der kostensenkende Beitrag zur Erfüllung der Reduktionsziele zum Hauptkriterium für die Bewertung verschiedener Klimaschutzoptionen. Durch die flexiblen Mechanismen werden die Reduktionsverpflichtungen des Kyoto-Protokolls mit dem ökomodernen Primat der Betriebsökonomie kompatibel.

Die ökomoderne Strategie des nachhaltigen Wachstums zeigt sich in der Anlage der flexiblen Mechanismen. Gerade die ,Flexibilisierung' der Reduktionsverpflichtungen entspringt dem Ziel, über das Marktprinzip einen Wettbewerb um ressourcenschonende Produktionsweisen anzuregen und dabei das Wirtschaftswachstum nicht zu gefährden, sondern im besten Fall sogar anzukurbeln. Dies ist insofern nicht verwunderlich, als bereits in der Klimarahmenkonvention der hohe Stellenwert des Wirtschaftswachstums in den Artikeln 2 und 3 festgelegt ist:

„Das Endziel dieses Übereinkommens und aller damit zusammenhängenden Rechtsinstrumente, welche die Konferenz der Vertragsparteien beschließt, ist es, in Übereinstimmung mit den einschlägigen Bestimmungen des Übereinkommens die Stabilisierung der Treibhausgaskonzentrationen in der Atmosphäre auf einem Niveau zu erreichen, auf dem eine gefährliche anthropogene Störung des Klimasystems verhindert wird. Ein solches Niveau sollte innerhalb eines Zeitraums erreicht werden, der ausreicht, damit sich die Ökosysteme auf natürliche Weise den Klimaänderungen anpassen können, die Nahrungsmittelerzeugung nicht bedroht wird und die wirtschaftliche Entwicklung auf nachhaltige Weise fortgeführt werden kann. 
[...] Die Vertragsparteien haben das Recht, eine nachhaltige Entwicklung zu fördern, und sollten dies tun. Politiken und Maßnahmen zum Schutz des Klimasystems vor vom Menschen verursachten Veränderungen sollen den speziellen Verhältnissen jeder Vertragspartei angepaßt sein und in die nationalen Entwicklungsprogramme eingebunden werden, wobei zu berücksichtigen ist, daß wirtschaftliche Entwicklung eine wesentliche Voraussetzung für die Annahme von Maßnahmen zur Bekämpfung der Klimaänderungen ist. Die Vertragsparteien sollen zusammenarbeiten, um ein tragfähiges und offenes internationales Wirtschaftssystem zu fördern, das zu nachhaltigem Wirtschaftswachstum und nachhaltiger Entwicklung in allen Vertragsparteien, insbesondere denjenigen, die Entwicklungsländer sind, führt und sie damit in die Lage versetzt, die Probleme der Klimaänderungen besser zu bewältigen. Maßnahmen zur Bekämpfung der Klimaänderungen, einschließlich einseitiger Maßnahmen, sollen weder ein Mittel willkürlicher oder ungerechtfertigter Diskriminierung noch eine verschleierte Beschränkung des internationalen Handels sein." (UNFCCC 1992: 5f; Hervorhebungen T. K.) ${ }^{11}$

Der marktförmige Klimaschutz der flexiblen Mechanismen basiert darauf, dass aus dem Ausstoß von Treibhausgasen ein handelbares Gut wird. Die Folge dieser Kommodifizierung ist, dass die Auswahl zwischen verschiedenen Klimaschutzmaßnahmen vorrangig anhand des Kriteriums der Profitmaximierung erfolgt (vgl. Lohmann 2010: 139). Aufgrund der Anreizstruktur, die sich aus dem Marktwert von Emissionsberechtigungen ergibt, soll das dadurch in Gang gesetzte Wirtschaftswachstum einen nachhaltigen Charakter haben.

Hier setzt die ökomoderne Strategie des reflexiven Fortschritts durch wissenschaftlich-technische Rationalität ein. Die angestrebten Innovationen nehmen als wichtige Produktivkraft eine Schlüsselrolle für die Verwirklichung von reflexiver Naturbeherrschung und nachhaltigem Wachstum ein. So wird in den Schlüsseldokumenten der internationalen Klimapolitik (Rio-Erklärung über Umwelt und Entwicklung, Klimarahmenkonvention, The Future We Want) dem wissenschaftlichen Fortschritt, den technologischen Innovationen (die beispielsweise eine Steigerung der Energieeffizienz oder eine solare bzw. eine besonders effiziente Form der Energiegewinnung ermöglichen sollen) und dem Technologie-Transfer in Länder des

11 Ganz ähnlich hieß es bereits 1992 in Grundsatz 12 der Rio-Konferenz: „Die Staaten sollten gemeinsam daran arbeiten, ein stützendes und offenes Weltwirtschaftssystem zu fördern, das in allen Ländern zu Wirtschaftswachstum und nachhaltiger Entwicklung führt und es gestattet, besser gegen die Probleme der Umweltverschlechterung vorzugehen. Umweltbezogene handelspolitische Maßnahmen sollten weder ein Mittel willkürlicher oder ungerechtfertigter Diskriminierung noch eine verdeckte Beschränkung des internationalen Handels darstellen." (Konferenz der Vereinten Nationen über Umwelt und Entwicklung 1992: 2) 
globalen Südens eine wichtige Bedeutung beigemessen. Auf diese Aspekte wird in den Dokumenten an mehreren Stellen eingegangen, hier sei stellvertretend der Grundsatz 9 der Rio-Erklärung über Umwelt und Entwicklung zitiert:

„Die Staaten sollten zusammenarbeiten, um den Ausbau der eigenen Kapazitäten für eine nachhaltige Entwicklung zu stärken, indem sie das wissenschaftliche Verständnis durch den Austausch wissenschaftlicher und technologischer Kenntnisse vertiefen und die Entwicklung, Anpassung, Verbreitung und Weitergabe von Technologien fördern." (Konferenz der Vereinten Nationen über Umwelt und Entwicklung 1992: 2)

Auch in Bezug auf die Mechanismen des Kyoto-Protokolls lässt sich der Fokus auf technologische Klimaschutzmaßnahmen konstatieren. Die Förderung von Technologietransfer ist eine wichtige Begründung für die projektbasierten Mechanismen. Insgesamt zielen die Mechanismen auf die Schaffung einer Wettbewerbssituation für die Entwicklung und Verbreitung von Klimaschutztechnologien.

Die flexiblen Mechanismen entsprechen damit der ökomodernen Grundannahme des Inkrementalismus. Sie geben Anreize für kleine Schritte innerhalb des Status quo der Energieinfrastruktur sowie der allgemeinen Produktions- und Konsummuster. Die flexiblen Mechanismen ermöglichen es den Annex-B-Staaten, ihre Reduktionsverpflichtungen einzuhalten, ohne einen konsequenten Strukturwandel einleiten zu müssen (vgl. Kapitel 5.1.2). Diese fehlenden Transformationseigenschaften der flexiblen Mechanismen kann man sowohl als das Ergebnis als auch als weitere Festigung der Pfadabhängigkeiten der fossilen Energieversorgungssysteme interpretieren (vgl. Brunnengräber et al. 2008: 115 und 202).

Obwohl die globalen Treibhausgasemissionen weiterhin ansteigen, ist die Kritik am Prinzip der flexiblen Mechanismen auf internationaler Ebene marginalisiert. Kritisiert werden allein sogenannte Umsetzungsfehler, aber nicht der eingeschlagene Weg der Inwertsetzung von Natur durch Marktmechanismen. Selbst Akteur_innen wie die Länder des globalen Südens, die EU oder viele NGOs, die den flexiblen Mechanismen noch bis 1997 skeptisch bis ablehnend gegenüber standen, widmeten sich in der Folge den Detailfragen ihrer Ausgestaltung. Ein Teil der NGOs verfolgte diese Strategie aus pragmatisch-strategischen Gründen, da sie sich von einer Fundamentalopposition keinen politischen Gewinn versprachen. Das Argument lautete, dass die flexiblen Mechanismen, wenn sie schon nicht verhindert werden konnten, wenigstens möglichst sinnvoll umgesetzt werden sollten. Somit gibt es seit der Einigung auf das Kyoto-Protokoll keine Kritik von einflussreichen Akteur_innen am Primat von Marktmechanismen in der internationalen Klimapolitik (vgl. Brunnengräber 2009: 183; Brunnengräber et al. 2008: 97; Lohmann 2006: 50, 53). 


\subsubsection{Antagonistische Artikulationen in der internationalen Klimapolitik}

Gerade im Hinblick auf die internationale Klimapolitik wird deutlich, dass es in der Umweltpolitik keine einflussreiche oppositionelle Kraft jenseits des ökomodernen Diskurses gibt. ${ }^{12}$ Fragen der Gerechtigkeit, der sozial-ökologischen Transformation der Gesellschaft, der Änderung wirtschaftlicher Strukturen und der imperialen Lebensweise sind bei den UN-Klimaverhandlungen marginalisiert (vgl. Kaufmann/ Müller 2009: 185). Viele der an den COPs teilnehmenden NGOs stellen die Prinzipien der ökologischen Modernisierung - die mit den flexiblen Mechanismen des Kyoto-Protokolls konkret den Verhandlungsrahmen vorgeben - nicht mehr grundsätzlich in Frage, sondern versuchen, durch interne Kritik Verschiebungen zu erreichen (vgl. Brunnengräber 2009: 183; Brunnengräber et al. 2008: 97). Diese eher moderate Position vertritt auch das Climate Action Network (CAN), der größte Zusammenschluss von NGOs bei den Klimagipfeln.

Ein Teil der NGOs war mit dieser Ausrichtung von CAN nicht mehr zufrieden und gründete 2007 während der COP 13 in Bali das Netzwerk Climate Justice Now! (CJN!). CJN! versucht, mit der Forderung nach Klimagerechtigkeit eine antagonistische Position ins Spiel zu bringen (vgl. Kaufmann/Müller 2009: 190). Das Konzept der Umweltgerechtigkeit bzw. Environmental Justice wurde in den 1990er Jahren von indigenen Gruppen in den USA entwickelt. Zentrale Forderungen sind unter anderem die Anerkennung der historischen ökologischen Schuld des globalen Nordens und dadurch abgeleitete Ausgleichszahlungen an den globalen Süden. Weiterhin sollen fossile Brennstoffe im Boden belassen werden und die Kontrolle über die natürlichen Ressourcen an die dort ansässigen Menschen und lokal organisierten Kollektive zurückgegeben werden (Ernährungs-, Energie- und Ressourcensouveränität), wobei die Rechte der indigenen Bevölkerungen geachtet werden sollen. Abgelehnt werden marktbasierte und ,falsche ' Lösungen (als falsche Lösungen werden beispielsweise risikoreiche Technologien wie Atomkraft und CCS bezeichnet). Ehrgeizige Klimaschutzziele sollen dagegen durch eine Änderung der Lebensund Produktionsweisen erreicht werden (vgl. Bedall/Austen 2010).

Vor allem im Vorfeld der COP 15 in Kopenhagen (2009) wurde das Konzept der Klimagerechtigkeit zunehmend diskutiert und von verschiedenen Akteur_innen aufgegriffen. Einerseits bildete Klimagerechtigkeit die zentrale Forderung von CJN! und des eigens zur Mobilisierung von Aktionen massenhaften zivilen Ungehorsams gegründeten Netzwerks Climate Justice Action (CJA). Das Ziel dieser Gruppen lag in der Formierung einer Klimagerechtigkeitsbewegung, die Alternativen zur ökolo-

12 Einzelne Abschnitte dieses Kapitels wurden - in einer früheren Fassung - bereits veröffentlicht in Krüger 2014. 
gischen Modernisierung aufzeigen und möglichst erkämpfen sollte. Andererseits berief sich gleichzeitig eine Vielzahl von Akteur_innen auf Klimagerechtigkeit, die keine antagonistische Strategie verfolgten - wie zum Beispiel gemäßigte NGOs oder Ex-UN-Generalsekretär Kofi Annan. Insofern ist Klimagerechtigkeit ein umkämpfter Begriff, den verschiedene Akteur_innen auf ganz unterschiedliche Weise definieren (vgl. Bedall/Austen 2010; Kaufmann/Müller 2009: 195).

Im Anschluss an die COP 15 rutschten die Mobilisierungserfolge für antagonistische Forderungen in der Klimapolitik wieder nahezu auf das Niveau von vor den Klimaverhandlungen in Kopenhagen. Eine Ausnahme bildete der gut besuchte alternative Klimagipfel 2010 in Cochabamba. Als Reaktion auf die gescheiterte UN-Klimakonferenz in Kopenhagen lud der bolivianische Präsident Evo Morales am Internationalen Tag der Mutter Erde zu einer „Weltkonferenz der Völker über den Klimawandel und die Rechte der Mutter Erde“ ein. An den Verhandlungen und Diskussionsrunden nahmen mehr als 30.000 Teilnehmer_innen aus über 140 Ländern teil - unter ihnen Regierungsvertreter_innen aus 47 Ländern. Die dort verabschiedete „Erklärung der Weltkonferenz über den Klimawandel und die Rechte der Mutter Erde" wurde auch in die offiziellen UN-Klimaverhandlungen getragen. Die bolivianische Regierung hängte sie ihrer offiziellen Stellungnahme vom 26. April 2010 an die Ad Hoc Working Group on Long-term Cooperative Action an (vgl. UNFCCC 2010a). Bolivien fordert in diesem Vorschlag für einen Verhandlungstext die Anerkennung der, Mutter Erde“ als lebendiges System, mit dem wir auf untrennbare Weise verbunden sind und in einer gegenseitig abhängigen, komplementären und spirituellen Beziehung stehen. Die Anerkennung und Verteidigung der Rechte der Mutter Erde wird in dem Text als Voraussetzung beschrieben, um ein harmonisches Verhältnis zwischen Natur und Menschheit herstellen sowie die Prinzipien der Menschenrechte und Menschenwürde verwirklichen zu können (vgl. UNFCCC 2010a: 15f). Die Weltkonferenz der Völker ist ein wichtiger Bezugspunkt für viele zivilgesellschaftliche Akteur_innen. Insbesondere in den verschiedenen Gruppen, die sich der Klimabewegung zugehörig fühlen, hat die Erklärung der Weltkonferenz einen großen Stellenwert. Auf die offiziellen Verhandlungen hatte der Vorschlag Boliviens allerdings keine relevanten Auswirkungen.

Insofern gibt es immer noch keine oppositionelle Kraft, die in der Lage wäre, ein tatsächliches Gegengewicht zum ökomodernen Projekt zu bilden und relevanten Einfluss auf politische Entscheidungen hätte. Allerdings werden antagonistische Forderungen zunehmend artikuliert, vor allem von Aktivist_innen aus dem globalisierungskritischen Spektrum (beispielsweise auf Klimacamps), von radikaleren NGOs (insbesondere aus dem globalen Süden), von indigenen Gruppen und aus kirchlichen Kreisen (vgl. EKD 2009; WCC 2010). 


\section{Antagonistische Artikulationen aus kirchlichen Kreisen}

Kirchliche Gruppen treten, im Vergleich zu NGOs und Aktivist_innen aus dem globalisierungskritischen Spektrum, weniger offensiv an die Öffentlichkeit und ziehen auch nicht mit Aktionen zivilen Ungehorsams Aufmerksamkeit auf sich. Dennoch möchte ich in diesem kurzen Exkurs aus zwei Gründen auf die Kritik der kirchlichen Gruppen eingehen. Erstens sind die klimapolitischen Aktivitäten kirchlicher Akteur_innen bislang wenig erforscht (vgl. Glaab, Katharina/Fuchs, Doris: 2014). Zweitens ist davon auszugehen, dass die antagonistischen Artikulationen aus kirchlichen Kreisen, trotz mangelndem Medienecho, relativ viele Menschen erreichen, allein schon aufgrund der großen Anzahl an Kirchenmitgliedern.

Als exemplarisches Beispiel für die antagonistischen Artikulationen aus dem kirchlichen Spektrum stelle ich das 2009 erschienene Memorandum der Evangelischen Kirche in Deutschland vor: „Turning to life: Sustainable Development in the Context of Climate Change“. Es schließt direkt an die radikale Kritik aus den 1970er Jahren an und verortet sich explizit in einer Reihe mit dem EKD-Memorandum „,Der Entwicklungsdienst der Kirche: Ein Beitrag für Frieden und Gerechtigkeit in der Welt" aus dem Jahre 1973 (vgl. EKD 2009: 8). Die Basis für die Kritik am Status quo der Bearbeitung ökologischer Probleme bildet der Auftrag zur Bewahrung der Schöpfung (vgl. EKD 2009: 71ff). Einer anthropozentristisch und instrumentalistisch verkürzten Weltsicht wird „the right to live for all and the intrinsic value of God's creation“ (EKD 2009: 78) entgegengesetzt. Aus dieser theologisch begründeten Position heraus wird der Fokus auf Wirtschaftswachstum und die ressourcenintensive Lebensweise der industrialisierten Gesellschaften kritisiert (vgl. EKD 2009: 72). Als Mittel zur Minderung des Klimawandels und zur Bekämpfung von Armut wird Gerechtigkeit eingefordert - ,justice for our neighbours, especially our disadvantaged neighbours, justice for all of God's creation, and justice for future generations“ (EKD 2009: 99). Das Modell einer ,nachhaltigen und gerechten Entwicklung' (vgl. EKD 2009: 78) wird insofern explizit als antagonistische Position vertreten, als dass ein starker Bruch mit den gesellschaftlichen Strukturen gefordert wird: „Such a shift to a sustainable form of production and living requires a form of repentance known in the Bible as metanoia: a radical and all-encompassing turnabout" (EKD 2009: 72; Hervorhebung im Original).

Diese Positionen werden von Kirchen auch auf internationaler Ebene vertreten. Der Ökumenische Rat der Kirchen (World Council of Churches, WCC) hat dabei eine wichtige Rolle inne. Er ist der größte Zusammenschluss christlicher Kirchen und Gemeinschaften aus über 110 Ländern. Seit 1992 gibt es die WCC Working Group on Climate Change und damit einhergehend einen Fokus auf den Klimawandel. Die Auseinandersetzung mit dem Konzept der ökologischen Gerechtigkeit geht aber bis zur Diskussion der sustainable communities in den 1970er Jahren zurück (vgl. WCC 2010: 3). Die vom WCC vertretene Position fußt auf einer Kritik des ,westlichen“ Entwicklungsmodells, des Wirtschaftswachstums, der 
imperialen Lebensweise und der Inwertsetzung von Natur (vgl. WCC 2010: 4, 13).

In Bezug auf die Diskussion von Lösungsstrategien hat die Frage nach Gerechtigkeit - und zwar nicht nur zwischen Generationen, sondern auch zwischen den Mächtigen und den Marginalisierten sowie zwischen der Menschheit und anderen Lebewesen - einen zentralen Stellenwert (vgl. WCC 2010: 3f, 12f). Mit dem Fokus auf Gerechtigkeitsfragen wird auf die historische ökologische Schuld der Industrienationen verwiesen und die Nord-Süd-Debatte auf die Agenda gesetzt (vgl. WCC 2010: 3, 14ff). Ausgehend von einer sozial-ökologischen Problemdefinition ist für den Ökumenischen Rat der Kirchen eine adäquate Bearbeitung der ökologischen Krise nur im Rahmen einer radikalen Transformation gesellschaftlicher Naturverhältnisse denkbar:

„The central committee of the WCC recognizes the need for a drastic transformation at all levels in life and society in order to end the ecological indebtedness and restoring right relationships between peoples and between people and the earth. This warrants a re-ordering of economic paradigms from consumerist, exploitive models to models that are respectful of localized economies, indigenous cultures and spiritualities, the earth's reproductive limits, as well as the right of other life forms to blossom. And this begins with the recognition of ecological debt. "(WCC 2010: 15)

Diese Programmatik verfolgt der Ökumenische Rat der Kirchen in verschiedenen Aktivitäten, die von der theoretischen und spirituellen Auseinandersetzung über Bildungsarbeit bis hin zur politischen Interessenvertretung reichen (vgl. WCC 2010: 4ff). Was die Versuche der Einflussnahme auf politische Entscheidungen betrifft, gibt es einen Fokus auf die UNKlimaverhandlungen. Dabei organisiert der Ökumenische Rat der Kirchen nicht nur Veranstaltungen im Rahmenprogramm der Alternativgipfel, sondern nimmt auch aktiv an den Verhandlungen teil. So waren Delegierte des WCC auf den Verhandlungen, die zur Ratifizierung der Klimarahmenkonvention führten, und anschließend auf allen COPs vertreten (vgl. WCC 2010: 5f).

In diesem Konfliktfeld positionieren sich verschiedene Akteur_innen der Wissenschaft und der Zivilgesellschaft mit Forderungen nach grundsätzlichen Alternativen zum wachstumsbasierten Entwicklungsmodell, die unter den Labels Postwachstum, Degrowth, Décroissance oder Buen Vivir verhandelt werden. Die Forderung nach Buen Vivir, dem guten Zusammenleben zwischen Menschen und mit der Natur, hat dabei eine besondere Stellung, da es im Kontext antikolonialer Bewegungen in Lateinamerika entwickelt wurde. Die antikoloniale Stoßrichtung macht Buen Vivir zu einem attraktiven Bezugspunkt für die Suche nach Alternativen zum wachstumsbasierten Entwicklungsmodell, das gemeinhin als ,westlich`verstanden wird. 
So repräsentiert Buen Vivir in der Erklärung der Weltkonferenz über den Klimawandel und die Rechte der Mutter Erde das alternative Gemeinwohl, das dem ,kapitalistischen System' und dem ,patriarchalischen Zivilisationsmodell' entgegengesetzt wird. In Lateinamerika beschäftigen sich einige Wissenschaftler_innen mit Buen Vivir (für einen Überblick vgl. Altmann 2013). Unter ihnen befindet sich Eduardo Gudynas, der Buen Vivir explizit als Kernforderung, als leeren Signifikanten eines gegenhegemonialen Projekts, vorschlägt. In Anlehnung an die Auseinandersetzungen um die Verankerung von Buen Vivir als Staatsziel in den Verfassungen von Bolivien und Ecuador ${ }^{13}$ sieht Gudynas in der Forderung nach dem guten $\mathrm{Zu}$ sammenleben das Potenzial zur Bündelung antagonistischer Kräfte.

In Europa sind es vor allem politische Stiftungen und soziale Bewegungen, die sich mit dem Konzept des Buen Vivir auseinander setzen (vgl. Altmann 2013). Die Beschäftigung mit Buen Vivir zielt dabei durchaus darauf, die Erfahrungen aus den Andenländern auch für den Suchprozess nach alternativen Gesellschaftsordnungen in Europa fruchtbar zu machen. Buen Vivir wird als Kernforderung eines gegenhegemonialen Projekts verstanden, welches politische Kämpfe miteinander verbindet, um auf verschiedenen politischen Ebenen und in verschiedenen Regionen die sozialen Kräfteverhältnisse und die Vorstellungen vom Gemeinwohl verändern zu können.

Im Zentrum von Buen Vivir steht die Ablehnung des hegemonialen Entwicklungsmodells (vgl. Gudynas 2012: 5, 19, 31). Damit erscheint das verworfene Außen des ökomodernen Diskurses hier nicht als ,Ideologie“ (im alltäglichen pejorativen Sinne) und ,Rückschritt' (zum verworfenen Außen des ökomodernen Diskurses vgl. Kapitel 3.5), sondern wird mit dem Konzept des Buen Vivir positiv angeeignet und damit zum Ausgangspunkt von Politisierungsprozessen. Dabei werden antagonistische Positionen zu den bereits genannten modernisierungstheoretischen Axiomen (vgl. Kapitel 3.5) vertreten. So wird „die anthropozentrische Grundlage des herrschenden Verständnisses von Entwicklung“ (Gudynas 2012: 8) in Frage gestellt. Stattdessen sprechen die Protagonist_innen des Buen Vivir der Natur den Status eines Rechtssubjekts mit spezifischen Rechten zu (vgl. Gudynas 2012: 8).

Kritisiert wird „die Rationalität des herrschenden Entwicklungsmodells, seine Betonung von wirtschaftlichen Aspekten und Fragen des Marktes, seine klare Ausrichtung auf Konsum sowie der Mythos eines kontinuierlichen Fortschritts“

13 Im Zuge der Verabschiedung neuer Verfassungen wurde das Prinzip des Buen Vivir 2008 in Ecuador und 2009 in Bolivien als Verfassungsziel verankert. Dabei wurde in Bolivien den Menschen das Recht auf eine intakte Umwelt zugesprochen. In Ecuador wurde darüber hinaus die Natur selber als Rechtssubjekt mit eigenen Rechten ausgestattet (vgl. Gudynas 2012: 8ff). 
(Gudynas 2012: 7). Der Ansatz des Buen Vivir widerspricht der ökonomistischen Vorstellung von Entwicklung, in der die Lebensqualität mit dem Besitz materieller Güter gleichgesetzt wird. Es wird darauf verwiesen, dass mit einem solchen vermeintlichen Fortschritt oftmals negative soziale und ökologische Konsequenzen einhergehen, die zu einem ,schlechten Leben' führen würden (vgl. Gudynas 2012: 7, 26). Dies ist eine Absage an das hegemoniale Entwicklungsmodell und der Proklamierung von (Wirtschafts-)Wachstum als universelles Gemeinwohl. Entwicklung ist für Gudynas ,ein in der Krise befindliches Konzept, das Ausdruck der Moderne ist und klare koloniale Implikationen aufweist" (Gudynas 2012: 7).

Weiterhin stellt Buen Vivir ein Gegenentwurf zum Primat der Zweckrationalität dar. Es wird kritisiert, dass technokratisches Expert_innenwissen privilegiert werde - insbesondere wenn es um (politische und andere) Entscheidungsprozesse geht. Mit dem Ansatz des guten Zusammenlebens wird gefordert, die Vielfalt verschiedener Wissensformen einzubeziehen (vgl. Gudynas 2012: 22f, 25). Dies bedeute auch eine stärkere Gewichtung emotionaler Aspekte sowie die Anerkennung von ganz anderen, beispielsweise spirituellen, Perspektiven (vgl. Gudynas 2012: 8, 23).

Gudynas betont, dass es nicht das eine und auch nicht das indigene Konzept des Buen Vivir gebe, sondern dass zum einen zwischen den regional unterschiedlich tradierten indigenen Fassungen des Konzepts Differenzen bestehen und dass zum anderen bestimmte Strömungen mit, westlicher' Tradition - wie die Tiefenökologie als biozentrische Umweltbewegung, der radikale Feminismus oder der Postkolonialismus - mit in die aktuelle Erneuerung des Konzepts einfließen würden (vgl. Gudynas 2012: 6, 14).

Gudynas sieht in dem Konzept des Buen Vivir einen geeigneten Ausgangspunkt für die Suche nach Alternativen zum hegemonialen Entwicklungsmodell (vgl. Gudynas 2012: 5, 19, 31). Dies kann meiner Meinung nach auf die Auseinandersetzungen um die Reaktionen auf die ökologische Krise zugespitzt werden. Buen Vivir könnte als ein Repräsentant des Gemeinwohls fungieren, unter dem verschiedene antagonistische Forderungen zu einem gegenhegemonialen Projekt verknüpft werden. Die unterschiedlichen Akteur_innen, die als Diskursträger_innen eines derartigen gegenhegemonialen Konzepts in Frage kommen, könnten dabei ihre jeweiligen Besonderheiten beibehalten. Was einen gegenhegemonialen Diskurs des Buen Vivir einen würde, wäre in erster Linie nicht eine positive Gemeinsamkeit, sondern die geteilte Ablehnung des hegemonialen Entwicklungsmodells (vgl. Gudynas 2012: 18f) bzw. (bezogen auf das Konfliktfeld der ökologischen Krise) dem Paradigma der ökologischen Modernisierung. ${ }^{14}$

14 Vgl. die Ausführungen zur Universalisierung von Diskursen durch die Abgrenzung gegenüber einem verworfenen Außen in Kapitel 2.1.4. 
Ein derartiges gegenhegemoniales Projekt könnte allerdings nur Erfolg haben, wenn es Ausdruck dynamischer Politisierungsprozesse und Akteurskonstellationen ist, die eine Verschiebung sozialer Kräfteverhältnisse ermöglichen. Der Etablierung von Buen Vivir als Staatsziel ging in Bolivien und Ecuador ein Erstarken sozialer vor allem indigener - Bewegungen voraus, die sich mit ihren Protesten gegen neokoloniale und neoliberale Institutionen und Politiken wendeten. Aus ihren verschiedenen partikularen Forderungen entwickelte sich im Rahmen von Allianzen zwischen verschiedenen sozialen Kräften eine populare Kritik an der bestehenden Ordnung insgesamt (vgl. Radhuber/Schilling-Vacaflor 2012: 13ff; zum Begriff der popularen Forderung vgl. Kapitel 3.2.6). Die sozialen Bewegungen waren erfolgreich, weil es ihnen gelang, Politisierungsprozesse einzuleiten, die „zur Herausbildung eines neuen Alltagsverstandes sowie einer eigenen politischen Agenda führten“" (Radhuber/Schilling-Vacaflor 2012: 14). Die Folge waren Regierungswechsel - 2006 kam in Bolivien Evo Morales und 2007 in Ecuador Rafael Correa an die Macht - und eine bis heute anhaltende politische Dynamik, die sich unter anderem auf die Klima- und Energiepolitik der beiden Länder auswirkt.

Dabei endete der Kampf für eine Alternative zum Entwicklungsmodell, für eine Politik des guten Zusammenlebens, nicht mit der Wahl der verfassungsgebenden Versammlung oder der Besetzung von Regierungsposten durch den Bewegungen nahe stehenden Personen. Die Umsetzung der neuen Verfassungsziele gestaltet sich als äußerst schwierig, wie das Festhalten am (neo-)extraktivistischen Entwicklungsmodell, das Scheitern der Yasuní-ITT-Initiative oder die Ignoranz der Regierungen gegenüber der Kritik lokaler Gemeinden an Megaprojekten - am Bau von Schnellstraßen und Wasserkraftwerken sowie an Bergbau-, Erdgas- und Erdölaktivitäten zeigen (vgl. Dietz 2013; Radhuber/Schilling-Vacaflor 2012: 18ff). Die Herausforderungen und Rückschläge bei der Realisierung der angestrebten Veränderungen „gehen auf festgefahrene und daher schwer veränderbare institutionelle Strukturen, auf Widersprüche zwischen verschiedenen Politikbereichen und -zielen, auf politische Kräfteverhältnisse im Land und auf die Einbettung Boliviens [und Ecuadors; T. K.] in internationale Strukturen zurück." (Radhuber/Schilling-Vacaflor 2012: 13)

Trotz der ambivalenten Ergebnisse der sogenannten progressiven Regierungen wird der politischen Entwicklung in Lateinamerika international viel Aufmerksamkeit entgegengebracht. Die Artikulation von Alternativen zum hegemonialen Entwicklungsmodell bietet das Potenzial für transnationale Politisierungseffekte wenngleich offensichtlich ist, dass es in anderen Regionen der Welt zur Entfaltung dieses Potenzials anderer Politisierungsprozesse und anderer Diskursträger_innen bedarf. Inwieweit sich das gute Zusammenleben - wie von Gudynas vorgeschlagen - über diese Unterschiede hinweg zu einer gemeinsamen Kernforderung eines 
gegenhegemonialen Projekts eignet, kann nicht theoretisch beantwortet werden, sondern wird sich in den konkreten Auseinandersetzungen um die Bearbeitung der ökologischen Krise zeigen.

Auf einem anderen Blatt steht die Frage nach der Erwünschtheit einer solchen Entwicklung. Die Universalisierung von Buen Vivir zu einer überregionalen Kernforderung eines gegenhegemonialen Projekts würde unweigerlich mit internen Hegemonialisierungsprozessen einhergehen, in deren Folge bestimmte partikulare Forderungen an Bedeutung gewinnen und andere Forderungen wiederum an Bedeutung verlieren würden. Deshalb steht Philipp Altmann den Versuchen der Öffnung des Begriffs des Buen Vivir skeptisch gegenüber. Er befürchtet eine Schwächung der indigenen Bewegungen. Schließlich seien ursprünglich konkrete Forderungen der Indigenen mit dem Buen Vivir verknüpft gewesen, die in einer universalisierten Version des Begriffs verloren gehen würden (vgl. Altmann 2013: 108f).

\subsection{EINFÜHRUNG IN CCS-TECHNOLOGIEN}

Nachdem ich mit der Einführung in die internationale Klimapolitik (5.1) die Diskursarena meiner mikroanalytischen Untersuchung dargestellt habe, folgt nun mit der Einführung in die CCS-Technologien die Vorstellung des Konfliktgegenstands. Neben der Funktionsweise von CCS-Technologien gehe auf den Stand der Technik ein und gebe einen Überblick über die Aktivitäten der Akteur_innen, die maßgeblich an der Entwicklung von CCS-Technologien beteiligt sind (5.2.1). Anschließend stelle ich knapp die Positionen vor, die sich in den politischen Auseinandersetzungen um CCS-Technologien gegenüberstehen (5.2.2). Die Ausführungen in diesen beiden Abschnitten basieren auf empirischen Ergebnissen der CCSForschung (zum Stand der CCS-Forschung vgl. Kapitel 1.2). Bevor die genannten Aspekte behandelt werden können, ist eine kurze Begriffsklärung und die Nennung einiger Grundlagen unerlässlich. Carbon Capture and Storage (CCS) steht für

1) die Abscheidung von $\mathrm{CO}_{2}$ bei fossilen Kraftwerken oder anderen Industriestandorten mit hohen $\mathrm{CO}_{2}$-Emissionen,

2) den Transport des Kohlenstoffdioxids in Pipelines oder Schiffen zu geeigneten Speicherstätten,

3 ) in denen das $\mathrm{CO}_{2}$ endgelagert werden soll und

4) dessen Verbleib in den Speicherstätten über eine sehr lange Zeitspanne mit Monitoring-Technologien überwacht werden muss. 
Insofern handelt es sich bei CCS nicht um eine konkrete Technologie, sondern um eine Kombination verschiedener Technologien. CCS-Technologien werden wegen ihres erhofften Klimaschutz-Potenzials entwickelt und angewendet. Mit Hilfe von CCS sollen ca. 85-95 \% ${ }^{15}$ des entstehenden Kohlenstoffdioxids einzelner Verbrennungsanlagen abgeschieden und anschließend in unterirdischen Speicherstätten oder in Tiefseegebieten eingelagert werden (für den gesamten Absatz vgl. Berger 2010: 146; IPCC 2005: 4, 27). Im Gegensatz zu anderen Klimaschutzstrategien wie erneuerbare Energien oder effizienzsteigernde Maßnahmen stellen sie weder zusätzliche Energie bereit noch sparen sie Energie ein. Im Gegenteil, die Anwendung von CCS-Technologien führt aufgrund des erhöhten Energiebedarfs von 10-40 \% zu einem Wirkungsgradverlust, der wiederum die anfallenden Emissionen erhöht. Zieht man also die CCS-bedingten Emissionen (die bei der notwendigen zusätzlichen Förderung von Brennstoffen, bei der Abscheidung, beim Transport, bei der Verpressung usw. anfallen) mit ein, liegen die Reduktionen des in die Atmosphäre emittierten Kohlenstoffdioxids - eine sichere Speicherung vorausgesetzt - bei maximal 67-90 \%. Der Ressourceneinsatz erhöht sich dabei um bis zu $40 \%$ pro erzeugte Kilowattstunde und damit auch die sozialen und ökologischen Probleme, die bei der Gewinnung von Brennstoffen zusätzlich zu den Emissionen auftreten.

CCS-Technologien werden seit den 1970er Jahren erforscht, allerdings kam es erst in den 1990er Jahren, mit der zunehmenden politischen Bedeutung des Klimawandels, zu einem gesteigerten Interesse. Ab den 2000er Jahren wurde die Erforschung und Entwicklung von CCS-Technologien noch einmal intensiviert (vgl. Evar/Armeni/Scott 2012: 19ff; Meadowcroft/Langhelle 2009b: 4ff). Dennoch befinden sich CCS-Technologien weiterhin in der Entwicklungsphase. Von den Akteur_innen, die an der Weiterentwicklung von CCS-Technologien arbeiten und/oder diese finanzieren, wird ein großflächiger Einsatz für den Zeitraum 2020 bis 2030 anvisiert (vgl. Evar/Armeni/Scott 2012: 18). Inwieweit dies realistisch ist (für eine kritische Einschätzung vgl. Berger 2010: 147) und ob CCS-Technologien überhaupt im großen Stil eingesetzt werden, ist aus verschiedenen Gründen noch unklar. Die Reife der verschiedenen technologischen Komponenten spielt dabei eine Rolle neben anderen Aspekten wie der Frage der Kosten von CCS-Technologien, den zukünftigen ökonomischen Anreizen zur $\mathrm{CO}_{2}$-Vermeidung, dem Preis fossiler Brennstoffe, dem weiteren Ausbau erneuerbarer Energien und der Akzeptanz von CCS an möglichen Einsatzorten. All diese Rahmenbedingungen liegen nicht objektiv vor, sondern werden von den Akteur_innen unterschiedlich eingeschätzt.

15 Bei Kohlekraftwerden werden die angestrebten Abscheidungsquoten bis jetzt allerdings nur unter atypischen Experiment-Bedingungen erreicht (vgl. Berger 2010: 146). 


\subsubsection{Die Entwicklung von CCS-Technologien}

Die Entwicklung der technologischen Komponenten für die verschiedenen Teilschritte der Abscheidung, des Transports und der Speicherung ist unterschiedlich weit voran geschritten. In Bezug auf den Vorgang der Abscheidung des Kohlenstoffdioxids werden drei verschiedene Verfahren erprobt: vor, während oder nach der Verbrennung. Mit Hilfe der Pre-Combustion-Methode wird durch eine Kohlevergasung, unter hohem Druck und einer Erhitzung auf $650-2000^{\circ} \mathrm{C}$, das $\mathrm{CO}_{2}$ vorab aus der Kohle gelöst. Bei der Oxyfuel-Methode wird Kohle oder Gas nicht mit normaler Luft, sondern mit reinem Sauerstoff verbrannt. Im Idealfall bleibt nach der Verbrennung ein Gemisch aus $\mathrm{CO}_{2}$ und Wasserdampf zurück. Mit der Post-Combustion-Methode wird $\mathrm{CO}_{2}$ nachträglich aus dem Abgasstrom abgeschieden. Dazu muss das Kohlendioxid chemisch aus dem Rauchgas gewaschen werden. Alle drei Methoden sind sehr energieaufwändig und noch nicht ausgereift - vor allem in Bezug auf die Anwendung bei Kohlekraftwerken (vgl. Berger 2010: 146). Am weitesten entwickelt ist die Post-Combustion-Methode, die für die meisten der EU-finanzierten Demonstrationsanlagen vorgesehen ist. Ein weiterer Vorteil dieser Methode ist, dass bestehende Kraftwerke relativ einfach mit der notwendigen Technik nachgerüstet werden können (vgl. Evar/Armeni/Scott 2012: 22).

Was den Transport des $\mathrm{CO}_{2}$-Gasstroms betrifft, kann auf bereits existierende Techniken (Pipelines oder Tankschiffe) zurückgegriffen werden. Bei diesem Teilabschnitt sind die Herausforderungen eines großtechnischen Einsatzes vergleichsweise gering. Allerdings ist der Transport mit hohen Kosten und hohem Ressourcenverbrauch verbunden (vgl. Umweltbundesamt 2009: 2).

Die Methoden zur dauerhaften leckagefreien geologischen Speicherung (d. h. ohne dass $\mathrm{CO}_{2}$ entweicht) stellen dagegen weitestgehend neue Techniken dar. Hier sieht beispielsweise das Umweltbundesamt, ,die meisten Unsicherheiten und potenziellen Umweltwirkungen“ (Umweltbundesamt 2009: 2). Als mögliche $\mathrm{CO}_{2}$-Lager gelten zum einen geologische Formationen wie (erschöpfte) Erdöl- und Erdgaslagerstätten, salzhaltige tiefe Aquifere ${ }^{16}$ oder Kohleflöze. Aber auch eine Lagerung in der Tiefsee wird untersucht. Generell wird die letzte Option von den meisten Forscher_innen jedoch sehr skeptisch bewertet, weil die Auswirkungen auf die Ökosysteme im Ozean besonders schwer zu prognostizieren seien (vgl. IPCC 2005: 8, 38). Kurzfristig scheinen, aufgrund der größten Erfahrungen in diesem Bereich, vor allem erschöpfte Erdöl- und Erdgaslagerstätten interessant zu sein. Als Enhanced Oil Recovery (EOR) bzw. Enhanced Gas Recovery (EGR) wird bereits

16 Saline Aquifere sind poröse Sandsteinformationen, die mit mineral- und salzhaltigem Wasser gefüllt sind. 
seit den 1970er Jahren $\mathrm{CO}_{2}$ in fast erschöpfte Erdöl- bzw. Erdgaslagerstätten injiziert (vgl. IPCC 2005: 31, 60). Durch dieses Verfahren erhöht sich der Druck in den Lagerstätten und die Fördermenge steigt. Diese Projekte zielten bislang allerdings allein auf die Erhöhung der Fördermengen und trafen deshalb keine Vorkehrungen für den Verbleib des Kohlenstoffdioxids in den Lagerstätten. An diesem Punkt besteht also noch Entwicklungsbedarf. Da die EOR- und EGR-Projekte kein Monitoring betreiben, lassen sich aus ihnen auch keine empirisch fundierten Prognosen bezüglich der Möglichkeit einer leckagefreien $\mathrm{CO}_{2}$-Speicherung ableiten (vgl. Evar/Armeni/Scott 2012: 21; Umweltbundesamt 2009: 2). Wenn CCS in der Größenordnung angestrebt wird, die für einen relevanten Klimaschutzeffekt nötig ist, wird man langfristig vor allem auf die Endlagerung in salinen Aquiferen setzen müssen. Von den verschiedenen Möglichkeiten der Endlagerung besitzt die Lagerung in tiefen Sedimentschichten - genauer: in deren mit Salzwasser gefüllten Poren - das größte Speicherpotenzial (vgl. Evar/Armeni/Scott 2012: 23; Meadowcroft/Langhelle 2009b: 3). Bei dieser Speichertechnik ist entscheidend, dass ab ca. $800 \mathrm{~m}$ Tiefe der Druck so groß wird, dass das $\mathrm{CO}_{2}$ im überkritischen $\mathrm{Zu}$ stand bleibt und eine ähnlich große Dichte wie das Salzwasser hat, wodurch es dieses aus den Poren verdrängen kann. Damit ist aber gleichzeitig ein hohes Risiko verbunden, da nicht vorhergesehen werden kann, wo das verdrängte Salzwasser verbleibt und die Gefahr besteht, dass es ins Grundwasser gelangt. Damit ein erneutes Zutagetreten des Kohlenstoffdioxids vermieden werden kann, müssen die salinen Aquifere durch eine natürlich vorhandene undurchlässige Deckschicht (beispielsweise aus Ton oder Salzstein) abgedeckt sein (vgl. Evar/Armeni/Scott 2012: 23). Neben Erdöl- und Erdgaslagerstätten sowie salinen Aquiferen kommen theoretisch noch andere Speicherorte in Betracht, wie zum Beispiel Kohleflöze - allerdings gelten diese als anfälliger für Leckagen (vgl. Evar/Armeni/Scott 2012: 23).

Für die Überwachung und Kontrolle des gespeicherten Kohlenstoffdioxids gibt es noch keine einsatzfähige Technologie, da eine Beobachtung von der Erdoberfläche aus (beispielsweise mit seismischen Methoden) nicht ausreicht. Die Überwachung auf Leckagen und die Messung der $\mathrm{CO}_{2}$-Austrittsmenge sollte direkt am Speicher ansetzen und auch die nähere Umgebung (Gesteinsschichten, Formationswasser) umfassen (vgl. Umweltbundesamt 2009: 3).

Die gesamte CCS-Kette wird im großindustriellen Maßstab bislang in vier Projekten erprobt. Bei dem weltweit ersten CCS-Projekt verpresst der norwegische Energiekonzern Statoil seit $1996 \mathrm{CO}_{2}$ offshore in einem salinen Aquifer in der norwegischen Nordsee. Bei diesem Projekt namens Sleipner entsteht das $\mathrm{CO}_{2}$ bei der Aufbereitung von gefördertem Erdgas. Ein ähnliches Verfahren wendet Statoil seit 2008 auch beim Snøhvit-Feld in der Barentssee an. Im In-Salah-Projekt (Algerien) 
wird ebenfalls bei gefördertem Erdgas, das für die Bedürfnisse des Marktes aufbereitet (purifiziert) werden muss, $\mathrm{CO}_{2}$ abgeschieden. Seit 2004 wird dort das $\mathrm{CO}_{2}$ onshore in salinen Aquiferen endgelagert. Im Weyburn-Midale-Projekt (Kanada) wird seit 2000 onshore $\mathrm{CO}_{2}$, das in einer Kohlevergasungsanlage entsteht, in eine Erdöllagerstätte gepumpt (EOR). Es ist kein Zufall, dass drei der vier Projekte an Erdgasaufbereitungsanlagen angegliedert sind. Dort ist die Abscheidung des Kohlenstoffdioxids vergleichsweise günstig (vgl. Evar/Armeni/Scott 2012: 21). Die Ausnahme bildet hier das Weyburn-Midale-Projekt, das allerdings durch die Anwendung als EOR mit den erhöhten Öl-Fördermengen eine zusätzliche Einnahmequelle besitzt.

Was die allgemeinen Kosten von CCS-Technologien betrifft, so variieren die Prognosen extrem. Generell sind solche Prognosen sehr unsicher, da zukünftige Entwicklungen (des Preises von Rohstoffen, der Weiterentwicklung von Technologien, der Energieinfrastruktur usw.) kaum einschätzbar sind (vgl. Evar/Armeni/ Scott 2012: 24f). In vielen Studien werden Diskontinuitäten ausgeklammert, um überhaupt Berechnungen anstellen zu können (vgl. Hansson/Bryngelsson 2009). Dies führte in der Vergangenheit dazu, dass die Prognosen bezüglich der Kosten von CCS-Technologien in verschiedenen Zukunftsszenarien zu optimistisch ausfielen und bereits nach kurzer Zeit nicht mehr mit den höher veranschlagten Kosten in neueren Studien vergleichbar waren (vgl. Hansson 2012; Hansson/Bryngelsson 2009; Shackley/Evar 2012: 159f). Insgesamt ist davon auszugehen, dass CCSTechnologien hohe Investitionssummen benötigen. In den meisten Fällen werden sie, neben der angestrebten Vermeidung von $\mathrm{CO}_{2}$-Emissionen, keinen betriebswirtschaftlichen Nutzen haben. Im Gegenteil, CCS-Technologien senken die Effizienz durch den zusätzlich benötigten Energieaufwand. Auf EOR-, EGR- und ECBM-Projekte, die mit der zusätzlichen Förderung fossiler Brennstoffe zumindest einen Teil ihrer Kosten kompensieren, trifft dies in abgeschwächter Form zu. Bei sehr hohen Öl- oder Gas-Preisen können diese gegebenenfalls auch rentabel sein (vgl. IPCC 2005: 10f). Prinzipiell gilt aber, dass CCS-Technologien sich nur durch hohe finanzielle Anreize zur Vermeidung von Emissionen lohnen können.

Deshalb werden CCS-Projekte derzeit auch in der Regel zu einem großen Anteil mit staatlichen Geldern finanziert (vgl. Evar/Armeni/Scott 2012: 25; Stephens/Liu 2012: 139ff). Die Länder mit dem größten bisherigen finanziellen CCS-Engagement sind (in alphabetischer Reihenfolge): Australien, Frankreich, Großbritannien, Kanada, Japan, Norwegen, Niederlande, die USA und mit etwas Abstand folgen Deutschland sowie Spanien (für die Aussagen zu den öffentlichen Investitionen vgl. Stephens/Liu 2012: 140ff; Tjernshaugen 2008: 8). Weiterhin finanziert die EU viele Projekte. Norwegen ist - gemessen am Anteil der Fördergelder an ihrem Brutto- 
sozialprodukt - das Land mit den höchsten Subventionen zur Erforschung und Entwicklung von CCS-Technologien. In absoluten Zahlen liegen die USA weit vorne. Im Folgenden gebe ich einen Überblick über das CCS-Engagement dieser Länder.

\section{Australien}

In der australischen Klimapolitik spielten CCS-Technologien schon zu einem relativ frühen Zeitpunkt eine wichtige Rolle, insbesondere im Hinblick auf den Erhalt der eigenen fossilen Energieinfrastruktur und der langfristigen Absicherung des Kohle- und Erdgasexports. In Australien ist der Einfluss von klimaskeptischen Argumenen der Industrie relativ hoch. Dies hat zur Folge, dass die australische Klimapolitik stark auf technologische Lösungen fokussiert, da andere Klimaschutzstrategien schwerer durchsetzbar wären. Bislang wurden weniger erneuerbare Energien, sondern primär CCS-Technologien favorisiert (vgl. Sinclair/ Gunningham 2009: 54ff). Vor allem die australischen Regierungen (sowohl die der Labor Party als auch die der Liberal Party), verschiedene Bundesstaaten und die Industrie unterstützten die Entwicklung von CCS-Technologien (vgl. Sinclair/Gunningham 2009: 50). Die Grüne Partei (The Greens) und Australische Umwelt-NGOs positionieren sich dagegen tendenziell kritisch bis ambivalent. Allerdings unterstützen auch einige Umwelt-NGOs, wie beispielsweise WWF Australia, die Entwicklung und Anwendung von CCS-Technologien (vgl. Sinclair/Gunningham 2009: 67f). Die CCS-Forschung ist in Australien sehr elaboriert. Das wichtigste Forschungsinstitut ist das Cooperative Research Centre for Greenhouse Gas Technology (CO2CRC), dessen Expert_innen auch für den IPCC, das Carbon Sequestration Leadership Forum (CSLF) und das IEA Greenhouse Gas Research and Development Program (IEA GHG) arbeiten. Das CO2CRC ist ein entscheidender Akteur bei der Entwicklung von CCS-Technologien und wird sowohl durch staatliche Mittel als auch durch Gelder von Rohstoffkonzernen finanziert (vgl. Sinclair/Gunningham 2009: 65f). In Australien gibt es diverse CCS-Demonstrationsprojekte, die in verschiedenen Implementierungsphasen stehen. Beim Otway-Projekt wird seit $2008 \mathrm{CO}_{2}$, das bei der Aufbereitung von gefördertem Erdgas entsteht, in eine Erdgaslagerstätte verpresst (vgl. Sinclair/Gunningham 2009: 69).

\section{Deutschland}

In Deutschland wird ein relativ großer Anteil des elektrischen Stroms in Kohlekraftwerken produziert. Mit dem beschlossenen Atomausstieg und dem Ziel der Verringerung der Importabhängigkeit erhielt die Verstromung der heimischen Kohle zusätzlich neuen Auftrieb, was zu hohen $\mathrm{CO}_{2}$-Emissionen im Energiesektor führte (vgl. Praetorius/Stechow 2009: 125f). Da es gleichzeitig im Vergleich zu anderen Ländern relativ ehrgeizige Emis sionsreduktionsziele gibt, werden CCS-Technologien von großen Teilen der Politik und der Industrie als wichtige Brückentechnologie erachtet (vgl. Praetorius/Stechow 2009). Deshalb gibt es verschiedene Forschungsprogramme, die mit staatlichen Geldern unterstützt werden. 
Darüber hinaus ist seit 2008 die Pilotanlage Schwarze Pumpe in Betrieb, in der das OxyfuelVerfahren zur Abscheidung des Kohlenstoffdioxids eines Kohlekraftwerks getestet wird. Die vier großen Energiekonzerne (EnBW, E.ON, RWE und Vattenfall) investieren in CCSTechnologien. Allerdings gehört Deutschland keineswegs zu den CCS-Vorreiter-Staaten. Die Unterstützung von CCS-Technologien nahm erst ab Anfang/Mitte der 2000er Jahre zu (vgl. Praetorius/Stechow 2009: 125ff). Die Frage der Sicherheit der $\mathrm{CO}_{2}$-Endlagerung wird in Deutschland kontrovers diskutiert (vgl. Praetorius/Stechow 2009: 126). Die Parteien Die Linke und Bündnis 90/Die Grünen sowie die Ökoforschungsinstitute und moderaten NGOs stehen den CCS-Technologien skeptisch bis ablehnend gegenüber. Etwas radikalere NGOs, lokale Bürgerinitiativen und Klimaaktivist_innen lehnen den Einsatz von CCS-Technologien prinzipiell ab. Neben den mit CCS verbundenen Risiken kritisieren sie die Verlängerung der Kohleverstromung in Grundlastkraftwerken, die im Widerspruch zu einer flexiblen Energieinfrastruktur stehe, in der die erneuerbaren Energien dominieren (vgl. Praetorius/ Stechow 2009: 141ff). Der Protest von NGOs, Bürgerinitiativen und des Lausitzer Klimaund Energiecamps 2011 trug dazu bei, dass die Pläne für ein CCS-Demonstrationsprojekt beim Neubau des Kohlekraftwerks Jänschwalde aufgegeben wurden. Darüber hinaus führte der Widerstand zur Änderung des CCS-Gesetzes. Bundesländern wurden Vetorechte gegen die Anwendung von CCS-Technologien eingeräumt (vgl. Shackley/Evar 2012: 161f).

EU

Die CCS-Aktivitäten der EU beschreibe ich ausführlich in Kapitel 5.4.3.3, weshalb ich hier nur kurz auf sie eingehe. Die EU treibt die Entwicklung und Anwendung von CCSTechnologien - insbesondere in der Anwendung bei Kohlekraftwerken - durch verschiedene Maßnahmen voran. Sie fördert Forschungsprogramme und hat eine Richtlinie zur Auswahl, zum Genehmigungsverfahren und zum Betrieb von $\mathrm{CO}_{2}$-Speichern verabschiedet. Diese Richtlinie wurde allerdings noch nicht von allen Mitgliedsländern in die nationale Gesetzgebung überführt. Darüber hinaus strebt die EU die Finanzierung von zwölf Demonstrationsprojekten mit insgesamt zwölf Milliarden Euro an (vgl. Claes/Frisvold 2009: $211 \mathrm{ff}$; de Coninck 2008: 929; Langhelle/Meadowcraft 2009: 244, 257).

\section{Frankreich}

Die französische Regierung betrachtet CCS als wichtige Klimaschutztechnologie und finanziert Forschungs- und Entwicklungsprogramme (vgl. Ha-Duong/Nadaï/Campos 2009: 633). Ihr CCS-Engagement bezieht sich in erster Linie auf die Anwendung von CCSTechnologien in der energieintensiven Industrie, beispielsweise in der Stahlproduktion. Dementsprechend ist auch ein CCS-Demonstrationsprojekt in der Stahlindustrie geplant (vgl. im Internet: www.globalccsinstitute.com/project/low-impact-steel-project-formerlyulcos-blast-furnace, letzter Zugriff am 02.12.2014). 


\section{Großbritannien}

Lange Zeit gehörte Großbritannien nicht zu den Ländern, welche die Entwicklung von CCS-Technologien vorantrieben. Dies ist unter anderem darauf zurückzuführen, dass die Regierung lange zögerte, bis sie eine finanzielle Förderung bereitstellte, da sie zunächst nicht in den Wettbewerb privater Energieunternehmen eingreifen wollte. Jedoch setzte sich die Regierung Großbritanniens in juristischen Belangen und in Bezug auf die Integration in den EU-Emissionsrechtehandel für CCS-Technologien ein (vgl. Tjernshaugen 2008: 17f). Darüber hinaus beteiligte sie sich schließlich doch an der Finanzierung von mehreren Demonstrationsprojekten, die allerdings bislang noch nicht in Betrieb gegangen sind (vgl. Scrase/Watson 2009: 176f, 181). In Großbritannien setzt man, wie in Deutschland, in erster Linie auf den Einsatz von CCS-Technologien bei Kohlekraftwerken, da die eigenen Kohlereserven zur Erhöhung der Energiesicherheit und zur Senkung der Importabhängigkeit gefördert werden sollen (vgl. Scrase/Watson 2009: 158ff). Die Umwelt-NGOs in Großbritannien vertreten unterschiedliche Positionen. Wirtschaftsnahe Organisationen wie der WWF UK unterstützen CCS als Brückentechnologie, andere wiederum, beispielsweise Greenpeace UK, kritisieren CCS-Technologien und fordern stattdessen mehr Investitionen in erneuerbare Energien. Daneben gibt es eine relativ starke Klimabewegung, die mit ihrem Widerstand - unter anderem im Rahmen des Camps for Climate Action 2008 - gegen ein als ,CCS-Ready، geplantes Kohlekraftwerk in Kingsnorth dazu beitrug, dass der Neubau vorerst gestoppt wurde (vgl. Scrase/Watson 2009: 174, 178).

\section{Kanada}

In Kanada standen CCS-Technologien schon relativ früh auf der politischen Agenda. Ein Grund ist die intensive Förderung fossiler Brennstoffe für den Eigenbedarf und den Export. In Kanada gibt es sowohl viel Kohlebergbau als auch Erdöl- und Erdgasförderung. Mit den Ölsanden gehört Kanada zu den Ländern mit den größten Ölvorkommen. Da Kanada gleichzeitig Emissionsreduktionsziele anstrebt - diese aber aufgrund der steigenden Förderung fossiler Brennstoffe bislang nicht einhält ${ }^{17}$ - werden CCS-Technologien von vielen politischen Akteur_innen und den Energiekonzernen als Klimaschutzstrategie favorisiert (vgl. Jaccard/Sharp 2009: 75ff). Deshalb werden viele öffentliche Mittel für die Entwicklung von CCS-Technologien bereitgestellt. Mit dem Weyburn-Midale-Projekt startete bereits im Jahr 2000 das erste kanadische Demonstrationsprojekt im großindustriellen Maßstab und weitere sollen folgen (vgl. Jaccard/Sharp 2009: 88ff). Umwelt-NGOs und Umwelt-Aktivist_innen kritisierten in Kanada zunächst einhellig CCS-Technologien als Verstetigung der fossilen Energieproduktion. Ab Mitte der 2000er Jahre schwenkten allerdings einige Akteur_innen aus diesem Bereich auf eine moderatere Position um und fordern nun die Einbettung von

17 Um Strafzahlungen zu vermeiden ist Kanada deshalb 2011, vor Ende des Ablaufs der ersten Verpflichtungsperiode, aus dem Kyoto-Protokoll ausgestiegen. 
CCS-Technologien in eine umfassende Klimapolitik, in der Energieeffizienz und erneuerbare Energien die Eckpfeiler bilden. Eine Ausnahme bildet die große NGO Greenpeace Canada, die ihre prinzipielle Ablehnung von CCS-Technologien aufrecht erhält (vgl. Jaccard/Sharp 2009: 90f).

\section{Japan}

Japan gehört zu den wenigen Ländern, in denen bereits seit den späten 1980er Jahren an CCS-Technologien geforscht wird. Das japanische Ministerium für Wirtschaft, Handel und Industrie setzt sich für die Entwicklung von CCS-Technologien ein. Zwei Aspekte machen die Anwendung von CCS-Technologien in Japan attraktiv: die große Zahl potenzieller Speicherstätten und die seit den 1990er Jahren zunehmende Kohleverstromung (vgl. Ishii/Langhelle 2011: 362). Neben der möglichen Anwendung im eigenen Land, werden CCS-Technologien in Japan aufgrund ihres Potenzials als zukünftige Exportschlager gefördert. Dabei zielt die Kommerzialisierung von CCS-Technologien in erster Linie auf die Generierung von Emissionsberechtigungen im Rahmen des CDM. Um bei den CCSTechnologien zu den führenden Nationen zu gehören, unterstützt die japanische Regierung die Erforschung und Entwicklung von CCS-Technologien durch private Unternehmen. Bereits seit 2000 gibt es ein Projekt zur Erforschung der Speicherpotenziale in salinen Aquiferen (Nagaoka). 2008 mündeten die verschiedenen japanischen CCS-Engagements in der Gründung von Japan CCS (JCCS). Shareholder sind verschiedene Firmen, die bereits mit fossilen Brennstoffen ihr Geld verdienen oder zur energieintensiven Industrie gehören (z. B. Stahl, Chemie oder Zement). JCCS erprobt CCS-Technologien seit 2008 in zwei Demonstrationsprojekten. Beim Projekt NEDO wird das $\mathrm{CO}_{2}$ eines Kohlekraftwerks in eine offshore Erdgaslagerstätte zum Zwecke des Enhanced Gas Recovery (EGR) gepumpt. Im Projekt METI wird nach Gebieten (saline Aquifere) gesucht, die sich als Speicherstätten eignen (vgl. im Internet: www.globalccsinstitute.com/insights/authors/kristinastefanova/2011/10/ 03/ccs-and-global-ccs-institute-japan-looking-forw, www.xdos.co.jp/CCSJp.pdf, www.japan ccs.com, letzter Zugriff am 02.12.2014).

\section{Norwegen}

In Kapitel 5.4.3.1 gehe ich ausführlich auf die norwegischen CCS-Aktivitäten ein, deshalb erfolgt hier nur ein kurzer Überblick. Wie bereits erwähnt, befinden sich in Norwegen zwei der bislang vier weltweit operierenden CCS-Projekte im großindustriellen Maßstab: Sleipner und Snøhvit. Vor allem aufgrund der norwegischen $\mathrm{CO}_{2}$-Steuer ist Norwegen bereits in den 1990er Jahren Vorreiter in der Erforschung und Entwicklung von CCSTechnologien gewesen (vgl. Langhelle/Meadowcroft 2009: 246). In Norwegen gibt es eine breite Zustimmung zu CCS-Technologien, die als Kompromissformel für das Dilemma der norwegischen Klimapolitik fungieren: dem Anspruch, den Klimaschutz voran zu treiben, ohne auf die Förderung und den Export fossiler Brennstoffe verzichten zu wollen (vgl. 
Tjernshaugen/Langhelle 2009: 111). Deshalb wird in Norwegen sehr viel Geld in die Entwicklung von CCS-Technologien investiert. Gemessen am Anteil der Förderung am Bruttosozialprodukt ist Norwegen das Land mit den höchsten CCS-Subventionen (vgl. Tjernshaugen 2008: 8; Tjernshaugen/Langhelle 2009: 113).

\section{Niederlande}

Die Niederlande gehörte zwar nicht zu den CCS-Vorreiterstaaten, allerdings stieg die Bedeutung der CCS-Technologien im letzten Jahrzehnt rasant an. Insbesondere für das Rotterdamer Hafengebiet gibt es ambitionierte CCS-Pläne (vgl. Vergragt 2009: 189ff). Zu dieser Entwicklung trugen die CCS-Forschungsprogramme bei, die Ende der 1990er und Anfang der 2000er Jahre starteten. Ab Mitte der 2000er Jahre finanzierte die niederländische Regierung bereits kleinere CCS-Demonstrationsprojekte. Des Weiteren lief in den Niederlanden 2004 das Projekt K12B an, in dem offshore Enhanced Gas Recovery betrieben wird. Allerdings ist dies insofern kein klassisches CCS-Projekt, als dass der Hauptfokus auf der Erhöhung der Erdgasförderung und nicht auf der permanenten Speicherung des verpressten Kohlenstoffdioxids liegt (vgl. Vergragt 2009: 192). CCS-Technologien werden in den Niederlanden vor allem hinsichtlich der Anwendung bei Kohlekraftwerken diskutiert. Die CCS-Technologien spielen bei den Plänen der Energiekonzerne, neue Kohlekraftwerke zu bauen, eine wichtige Rolle (vgl. Vergragt 2009: 195ff). Allerdings gibt es auch öffentlichen Gegenwind gegen neue Kohlekraftwerke. In dem Zusammenhang positionieren sich Greenpeace Netherlands und andere niederländische Umweltgruppen gegen CCS-Technologien. Andere NGOs wiederum begrüßen CCS als Beitrag zum Klimaschutz (vgl. Vergragt 2009: 201ff). Aufgrund von Protesten wurde 2010 das CCS-Projekt Barendrecht aufgegeben und die niederländische Regierung entschied, dass CCS-Technologien von nun an nur noch offshore angewendet werden sollen (vgl. Shackley/Evar 2012: 162).

\section{Spanien}

Die spanische Regierung gründete 2006 CUIDEN, ein Institut zur Erforschung und Entwicklung von CCS-Technologien, das auch konkrete Demonstrationsprojekte durchführt. Das bislang größte Projekt Compostilla lief allerdings 2013 aus und wird nicht, wie ursprünglich geplant, weitergeführt. Stattdessen starteten kleinere Forschungsprojekte wie die Abscheidung und Speicherung von $\mathrm{CO}_{2}$ in Hontomín (vgl. Global CCS Institute 2014: 151; im Internet: www.ciuden.es/index.php/en/tecnologias/proyectos, www.ciuden.es/index. php/en, letzter Zugriff am 02.12.2014).

\section{USA}

Die USA gehören zu den wenigen Ländern, in denen schon in den frühen 1990er Jahren die Erforschung von CCS-Technologien finanziert wurde. Insgesamt wurden in den USA bislang mehr Geld in CCS-Technologien investiert und mehr Demonstrationsprojekte gefördert 
als in jedem anderen Land. Laut Global CCS Institute gibt es in den USA 19 CCS-Demonstrationsprojekte (vgl. im Internet: www.globalccsinstitute.com/projects/large-scale-ccsprojects, letzter Zugriff am 02.12.2014). Dies zeugt von der zentralen Rolle von CCS-Technologien im technologieorientierten Ansatz, den die US-Klimapolitik mit der australischen Klimapolitik gemein hat (vgl. Langhelle/Meadowcroft 2009: 237; Stephens 2009: 22). Die US-Regierung finanziert u. a. die CCS-Forschung des National Energy Technology Laboratory (NETL), das Carbon Sequestration Regional Partnership Program und verschiedene Demonstrationsprojekte (vgl. Stephens 2009: $31 \mathrm{ff}$ ). Neben den staatlichen Institutionen treiben vor allem Energiekonzerne - die Öl- und Gas-Unternehmen noch stärker als die Kohleindustrie - die Erforschung und Entwicklung von CCS-Technologien voran (vgl. Stephens 2009: 36f). Was die Umwelt-NGOs betrifft, so haben viele keine eindeutige Position, manche sehen CCS kritisch, andere wiederum unterstützen die Entwicklung und Anwendung von CCS-Technologien. Insgesamt überwiegt dabei die Anerkennung von CCS als wichtige Klimaschutztechnologie (vgl. Stephens 2009: 37f). Allerdings regt sich mittlerweile lokaler Widerstand gegen den Einsatz von CCS-Technologien (vgl. Shackley/Evar 2012: 162). Die wissenschaftliche Community in den USA steht den CCS-Technologien im Allgemeinen positiv gegenüber und arbeitet teilweise in Partnerschaft mit der Industrie (vgl. Stephens 2009: 38f). Die USA war an der Gründung von zwei internationalen Initiativen zur Förderung von CCS-Technologien beteiligt: beim Carbon Sequestration Leadership Forum (CSLF) und bei der Asia-Pacific Partnership on Clean Development and Climate (APP) (vgl. Stephens 2009: 42).

Der Überblick über das Engagement der Länder, die sich bislang am aktivsten in die Erforschung und Entwicklung von CCS-Technologien einbringen, zeigt, dass es durchaus unterschiedliche Ausgangsbedingungen und unterschiedliche Zielvorstellungen sind, die den CCS-Aktivitäten zugrunde liegen. Da CCS-Technologien sehr kapitalintensiv sind, beteiligen sich vor allem Industrieländer an ihrer Entwicklung. Es gibt auch Länder des globalen Südens, in denen CCS-Technologien erforscht werden (für das Beispiel Brasilien vgl. Kapitel 5.4.3.2), allerdings in geringerem Maße. Weiterhin ist offensichtlich, dass das Engagement der Länder für CCS-Technologien mit der Förderung fossiler Brennstoffe bzw. mit den Reserven fossiler Brennstoffe positiv korreliert (vgl. Tjernshaugen 2008: 17).

Analog dazu sind es auf Seiten der privaten Akteur_innen vor allem Energiekonzerne, die an der Erforschung und Entwicklung von CCS-Technologien arbeiten, um ihr Geschäftsmodell auf zukünftige Klimaschutzregularien und/oder einen steigenden Preis der Tonne $\mathrm{CO}_{2}$-Äquivalente in Kohlenstoffmärkten vorzubereiten. Da die Vorläufer von CCS-Technologien im EGR und EOR liegen, sind die Unternehmen der Öl- und Gasindustrie stärker als die der Kohleindustrie in CCS- 
Aktivitäten involviert (vgl. Stephens 2009: 36f; Vormedal 2008: 51f). An einem von der International Petroleum Industry Energy Conservation Association (IPIECA) organisierten runden Tisch zu CCS-Geschäftsmodellen nahmen beispielsweise folgende Unternehmen und Verbände teil: Alstom, Anglo Coal, API, BP, Chevron, Concawe, ConocoPhillips, EURELECTRIC, ExxonMobil, Gassnova, General Electric, Hess, Hydro, IEA, Jupiter Oxygen, Marathon Oil, Nexen, OGP, Petrobrás, Petrotrin, Rio Tinto, RWE, Santos, Sask Power, Shell, Siemens, Statoil, Suncor, Total und Vattenfall (vgl. Kheshgi et al. 2009: 4486). Neben diesen Unternehmen und Verbänden der Energiebranche gibt es eine Reihe von Organisationen, die sich besonders stark für CCS-Technologien einsetzen und teilweise auch zweckgebunden zur Unterstützung von CCS-Technologien initiiert wurden. Von diesen stelle ich einige kurz vor:

\section{Bellona Foundation}

Die Bellona Foundation ist vermutlich die Umwelt-NGO, die sich am stärksten für CCSTechnologien einsetzt und zwar sowohl in ihrem Ursprungsland Norwegen als auch auf internationaler Ebene. Sie gehört zu den frühesten und stärksten Befürworter_innen von CCS aus dem zivilgesellschaftlichen Bereich (vgl. Meadowcroft/Langhelle 2009b: 13). Da Bellona CCS als besonders vielversprechende Klimaschutztechnologie begreift, betreibt sie auf verschiedenen Ebenen Lobbyarbeit. Im Rahmen der UN-Klimaverhandlungen organisierte sie beispielsweise diverse side-events zu den verschiedenen Aspekten der CCSTechnologien (vgl. Treber o. J.). Die Bellona Foundation verfolgt einen sehr technologieaffinen Ansatz. Durch ihre optimistische Hoffnung auf technologische Innovationen steht sie, anders als andere NGOs, in einem positiven Verhältnis zur Industrie. Bellona sucht den Dialog mit den Unternehmen und Wirtschaftsverbänden aus dem Bereich der Energiewirtschaft und den energieintensiven Industrien, von denen sie auch finanziell unterstützt wird (vgl. de Coninck 2008: 932; Tjernshaugen/Langhelle 2009: 107ff).

\section{Carbon Sequestration Leadership Forum (CSLF)}

2003 gründeten die USA mit dem CSLF eine zwischenstaatliche Organisation, um die Entwicklung von CCS-Technologien im globalen Maßstab voran zu treiben. Um technische, ökonomische und umweltbezogene Hürden zu überwinden, soll das CSLF die Kooperation zwischen Regierungen und der Industrie fördern. Es dient in erster Linie als Plattform für Wissenstransfer und propagiert die Förderung von CCS-Technologien durch staatliche Institutionen. Beim Auftakttreffen des CSLF waren etwa 500 Vertreter_innen aus den Bereichen Politik, Wirtschaft und Forschung anwesend. Neben der Abhängigkeit von fossilen Brennstoffen und dem damit verbundenen Interesse an CCS-Technologien war die geopolitische Allianz mit den USA ein Kriterium, um eingeladen zu werden. Aktuelle Mitglieder sind 
Australien, Brasilien, China, Deutschland, EU, Frankreich, Griechenland, Großbritannien, Indien, Italien, Japan, Kanada, Mexiko, Niederlande, Neuseeland, Norwegen, Polen, Russland, Saudi-Arabien, Südafrika, Südkorea, die USA und die Vereinigten Arabischen Emirate (vgl. de Coninck/Bäckstrand 2011: 371f; Stephens/Hansson/Liu/de Coninck/Vajjhala 2011: 388; im Internet: www.cslforum.org, letzter Zugriff am 02.12.2014).

\section{Global CCS Institute (GCCSI)}

Das GCCSI wurde 2009 von der australischen Regierung gegründet, die auch die finanzielle Grundausstattung des Instituts bereitstellt - bis 2013 mit 100 Millionen Australischen Dollar pro Jahr und seitdem in geringerem Maße. Zusätzlich zahlen die ca. 370 Mitglieder (Stand Oktober 2013) Mitgliedsbeiträge. Damit gehört das GCCSI zu den ressourcenstärksten internationalen Organisationen, die zu CCS-Technologien arbeiten. $\mathrm{Zu}$ den Mitgliedern aus über 40 Ländern zählen Regierungen, multinationale Konzerne, kleine Unternehmen, NGOs, Forschungsinstitute und Universitäten. Das Ziel des GCCSI ist die Förderung der weltweiten Entwicklung und Anwendung von CCS-Technologien. Um dieses Ziel zu erreichen, trägt das GCCSI zum Wissenstransfer bei, berät seine Mitglieder, betreibt Lobbyarbeit und versucht, die öffentliche Akzeptanz von CCS-Technologien zu erhöhen (vgl. de Coninck/Bäckstrand 2011: 372; im Internet: www.globalccsinstitute.com, letzter Zugriff am 02.12.2014).

\section{International Energy Agency Greenhouse Gas R\&D Programme (IEA GHG)}

Die Internationale Energieagentur (International Energy Agency, IEA) bietet eine Plattform für die Kooperation der OECD-Länder in Energiefragen. Dabei liegt ihr Schwerpunkt auf der Energieversorgung mit fossilen Brennstoffen (vgl. Brunnengräber et al. 2008: 104). Das Greenhouse Gas R\&D Programme der IEA (IEA GHG) wurde 1991 gegründet und zielt auf die Entwicklung von Technologien zur Reduktion von Treibhausgasen, die bei der Nutzung fossiler Brennstoffe anfallen. Dabei hat sich CCS zunehmend zum Schwerpunkt des Programms entwickelt. Das IEA GHG gehört damit zu den wenigen internationalen Institutionen, die sich bereits zu einem so frühen Zeitpunkt mit CCS beschäftigten und hat sich zu einer der wichtigsten Informationsquellen in Bezug auf die ökonomischen und rechtlichen Rahmenbedingungen von CCS-Technologien entwickelt. Das IEA GHG gibt regelmäßig Studien heraus, organisiert jährlich eine Summer School und veranstaltet etwa halbjährlich gut besuchte CCS-Konferenzen. Auf diese Weise gab das IEA GHG viele Impulse für die CCS-Forschung. Das Forschungsprogramm wird von 19 Ländern, der EU-Kommission, der OPEC und 21 multinationalen Konzernen, darunter vor allem Energiekonzerne, gefördert und ist Mitglied im GCCSI (vgl. De Conninck/Bäckstrand 2011: 369, 371; de Coninck/ Bakker 2005: 15; Meadowcroft/Langhelle 2009b: 5; im Internet: www.ieaghg.org, www. globalccsinstitute.com, letzter Zugriff am 02.12.2014). 


\section{International Emissions Trading Association (IETA)}

Da ich in Kapitel 5.4.3.4 die CCS-Aktivitäten der International Emissions Trading Association (IETA) ausführlich beschreibe, gebe ich hier nur einen knappen Überblick. Die IETA ist ein Verband für Unternehmen, die am Kyoto-Kohlenstoffmarkt agieren (für den gesamten Absatz vgl. Vormedal 2008: 40ff). Darunter fallen beispielsweise Finanzmarktakteur_innen, die sich auf den Handel mit Emissionsberechtigungen spezialisiert haben, Agenturen, die für die Akkreditierung von Offset-Projekten zuständig sind oder Unternehmen, die viele Emissionen verursachen und deshalb auf die Zuteilung und/oder den Handel mit Emissionsberechtigungen angewiesen sind. Insofern spielt die IETA bei den UN-Klimaverhandlungen eine wichtige Rolle. Dort setzte sie sich aktiv für die Aufnahme von CCSTechnologien in den CDM ein. In ihrer Lobbyarbeit kann die IETA auf das spezifische Wissen ihrer Mitglieder zurückgreifen - in diesem Fall auf die Expertise der Unternehmen, die an der Entwicklung von CCS-Technologien beteiligt sind. Damit ist es der IETA möglich, sehr direkt und konkret die Positionen einzelner Regierungsdelegationen zu beeinflussen.

\section{International Petroleum Industry Energy Conservation Association (IPIECA)}

Die International Petroleum Industry Energy Conservation Association (IPIECA) ist ein Wirtschaftsverband, der die Interessen der Öl- und Gasindustrie in den UN-Gremien vertritt. Da die Vorläufer der CCS-Technologien aus dem Öl- und Gasbereich stammen, ist in der IPIECA viel technisches Wissen versammelt, das sie in Form von Lobbyarbeit und konkreten Lösungsvorschlägen in die CCS-CDM-Kontroverse tragen konnte (vgl. Vormedal 2008: 59; im Internet: www.ipieca.org/about-us, letzter Zugriff am 02.12.2014).

Auf diese CCS-Akteur_innen wird im Verlauf der Arbeit immer wieder verwiesen werden. Sie bilden den Kern einer CCS-befürwortenden Koalition, die sich für CCS-Technologien einsetzt. Neben dieser CCS-befürwortenden Koalition gibt es auch kritische Stimmen von lokalen Bürgerinitiativen, NGOs und Klimaaktivist_innen. Diese CCS-kritische Koalition ist im Vergleich zu den CCS-affinen Regierungen, Energiekonzernen und Wirtschaftsverbänden mit weitaus weniger Ressourcen und Macht ausgestattet. Ihre Bedenken und Argumente haben aber durchaus Einfluss auf die öffentliche Meinung und auf CCS-spezifische politische Entscheidungen (vgl. Shackley/Evar 2012: 160ff). Die Positionen dieser beiden Koalitionen werden im nächsten Kapitel (5.2.2) behandelt.

Den Begriff der CCS-befürwortenden Koalition verwende ich im Folgenden für die Bezeichnung der Akteur_innen, die sich für CCS-Technologien im Allgemeinen einsetzen. Auf der anderen Seite steht die CCS-kritische Koalition, die sich gegen den Einsatz von CCS-Technologien positioniert. Dabei muss differenziert werden, dass sich in dem hier untersuchten konkreten Fall der UN-Klimaverhandlungen bei- 
spielsweise die brasilianische Regierung und der WWF skeptisch gegenüber einer Aufnahme von CCS-Technologien in den CDM aussprechen, obwohl sie im Allgemeinen für die Entwicklung und den Einsatz von CCS-Technologien plädieren und somit tendenziell zur CCS-befürwortenden Koalition gezählt werden müssen. Um diesen Unterschied, der nur wenige Akteur_innen betrifft, nicht zu unterschlagen, verwende ich die Bezeichnungen der CCS-befürwortenden Koalition in den UNKlimaverhandlungen bzw. der CCS-kritischen Koalition in den UN-Klimaverhandlungen für die sich gegenüberstehenden Koalitionen in der CCS-CDM-Kontroverse.

\subsubsection{Die Konflikte um CCS-Technologien}

Die Bedeutung von CCS-Technologien ist keineswegs unumstritten. Vielmehr zeigen sozialwissenschaftliche Studien, dass die Entwicklung von CCS-Technologien von politischen Auseinandersetzungen begleitet wird, in denen sich prinzipiell eine CCS-befürwortende Koalition und eine CCS-kritische Koalition gegenüberstehen (vgl. Berger 2010: 147; Markusson/Shackley 2012: 36f; Markusson/Shackley/Evar 2012a: 5f; Meadowcroft/Langhelle 2009a: 267ff; Sachverständigenrat für Umweltfragen 2009: 14f, 18ff). Diese Interpretation ist eine Zuspitzung. Dennoch ermöglicht die knappe Darstellung der beiden Positionen, die ich in diesem Abschnitt vornehme, einen ersten Einblick in das kontroverse Politikfeld, innerhalb dessen um die Bedeutung von CCS-Technologien gerungen wird.

Die dominantere der beiden Positionen wird von einer breiten Koalition vertreten, die sich grundsätzlich für die Entwicklung von CCS-Technologien einsetzt (für den gesamten Absatz vgl. Markusson/Shackley 2012: 36; Markusson/Shackley/ Evar 2012a: 5f; Meadowcroft/Langhelle 2009a: 267ff). Die CCS-befürwortende Koalition wird gebildet von Regierungen, internationalen Institutionen des Energieund Klimabereichs, Energiekonzernen, technologieaffinen NGOs sowie an der Erforschung von CCS beteiligte Wissenschaftler_innen. Auch wenn die Akteur_innen die Reife, Relevanz und Risiken der CCS-Technologien teilweise etwas unterschiedlich einschätzen, hat sich dennoch ein geteiltes Set an Deutungen und Argumenten herausgebildet, mit dem die CCS-befürwortende Koalition staatliche Investitionen in die Erforschung und Entwicklung von CCS-Technologien fordert. Eine ihrer zentralen Annahmen lautet, dass grundsätzlich alle technologischen Klimaschutzoptionen vorangetrieben werden sollten, da die Herausforderungen des Klimawandels so groß sind, dass auf keine Klimaschutztechnologie verzichtet werden könne. Dabei wird davon ausgegangen, dass ein Mix an verschiedenen Optionen zur Kosteneffizienz beitrage und bislang nicht absehbar sei, welche Technologien sich letztlich durchsetzen werden. Als ein (Wettbewerbs-)Vorteil von CCS- 
Technologien wird die Kompatibilität mit den gegenwärtigen gesellschaftlichen Strukturen im Allgemeinen und den Energieinfrastrukturen im Besonderen hervorgehoben. Die CCS-befürwortende Koalition geht davon aus, dass die mit CCSTechnologien verbundenen Kosten, die aktuell einer breiten Anwendung entgegen stehen, durch technologische Innovationen in der Demonstrationsphase noch drastisch gesenkt werden können. Eine weitere geteilte Überzeugung bildet die Annahme, dass auf globaler Ebene die Abhängigkeit der Wirtschaft von fossilen Brennstoffen kurz- bis mittelfristig bestehen bleibe und CCS somit als Brückentechnologie für den Klimaschutz unverzichtbar sei. In diesem Zusammenhang gelten oftmals die Erhaltung des materiellen Wohlstands in Industrieländern und/oder die Erhöhung der Lebensqualität in Ländern des globalen Südens als übergeordnete Ziele, denen die Klimaschutzstrategien angepasst werden müssten. Weiterhin wird auf die mächtige Position der fossilistischen Wirtschaft verwiesen, die sich vehement für ihr Geschäftsmodell und ihre Wettbewerbsfähigkeit einsetze. Daraus wird - teilweise aus analytischen und teilweise aus strategischen Gründen - gefolgert, dass erfolgreicher Klimaschutz nur mit CCS-Technologien erfolgreich sein könne. Andernfalls wäre der Widerstand der fossilistischen Wirtschaft und die damit verbundenen politischen Kosten zu hoch. Die ökologischen und gesundheitlichen Risiken der CCS-Technologien hält die CCS-befürwortende Koalition grundsätzlich für beherrschbar. Entscheidend sei ein Risikomanagement, das adäquate Sicherheitsstandards, rechtliche Rahmenbedingungen, eine sorgfältige Wahl der Speicherstandorte und genaues Monitoring umfasse. Als Beleg wird häufig eine relativ optimistische Prognose des IPCC zur Permanenz des verpressten Kohlenstoffdioxids angeführt (vgl. Kapitel 5.3.3 und 5.5.1).

In Bezug auf die Risiken der $\mathrm{CO}_{2}$-Speicherung gibt es jedoch auch Studien, die mit sehr viel höheren Leckageraten rechnen. ${ }^{18}$ Insofern verwundert es nicht, dass die Diskussion der Risiken in vielen Auseinandersetzungen um CCS-Technologien eine große Rolle spielen. In der in Kapitel 5.4 analysierten CCS-CDM-Kontroverse in den UN-Klimaverhandlungen stellten die Risiken allerdings nicht den Schwerpunkt der Debatte dar, sondern bildete einen unter mehreren Aspekten, die alle ähnlich intensiv behandelt wurden. Gerade deshalb halte ich es für angebracht, an dieser Stelle auf diesbezüglich kritische Einschätzungen einzugehen. Denn erst das Wissen um die verschiedenen Diskursstränge ermöglicht einen Vergleich zwischen verschiedenen Politikarenen (zum Vergleich zwischen der CCS-CDM-Kontroverse und den CCS-Konflikten in anderen Arenen vgl. Kapitel 5.5.3).

18 So geht beispielsweise eine Studie der EU, die zu den aktivsten Unterstützer_innen der CCS-Technologien gehört, von 50 bis 500 Mal höheren Leckageraten als der IPCC aus (vgl. Meadowcroft/Langhelle 2009a: 283). 
Zur Darstellung der pessimistischeren Einschätzung der Risiken greife ich auf Stellungnahmen des Sachverständigenrates für Umweltfragen und des Umweltbundesamtes sowie auf einen in der Zeitschrift Leviathan erschienen Artikel des Sozialwissenschaftlers Hartwig Berger zurück (für den gesamten Absatz vgl. Berger 2010; Sachverständigenrat für Umweltfragen 2009; Umweltbundesamt 2009). Ähnliche Argumente finden sich auch in Publikationen kritischer Umwelt-NGOs (vgl. beispielsweise Greenpeace 2008a). In den genannten Texten wird davon ausgegangen, dass diverse Ursachen ein abruptes oder schleichendes Entweichen des verpressten Kohlenstoffdioxids zur Folge haben können. Prinzipiell würden defekte Bohrlöcher oder Risse eine Gefahrenquelle darstellen. Dabei könne die Verpressung von $\mathrm{CO}_{2}$ selber Brüche und Risse verursachen bzw. ausweiten - beispielsweise wenn es aufgrund der Verpressung zur Verschiebung von Bodenschichten und Grundwasserströmen komme und damit direkt oder über Kettenreaktionen Leckagen ausgelöst würden. Weiterhin könne sich das $\mathrm{CO}_{2}$ mit dem salzhaltigen Wasser der Erdschichten zu aggressiver Kohlensäure verbinden, die anliegende Bodenschichten, aber auch mechanische Abdichtungen des Erdlagers, angreift und dadurch wiederum zu Leckagen führen würde. Darüber hinaus könne die Verpressung von $\mathrm{CO}_{2}$ Erdbeben verursachen. Dies weise auf ein Grundproblem der Erforschung der $\mathrm{CO}_{2}$-Speicherung hin: Es könne immer nur untersucht werden, wie stabil die Gesteinsschichten vor der Verpressung von $\mathrm{CO}_{2}$ waren. Wie Gesteinsschichten auf die Verpressung von $\mathrm{CO}_{2}$ in großtechnischem Maßstab reagieren, könne nicht vorhergesehen werden. Damit nehme man prinzipiell die Gefahr einer plötzlichen Entweichung von $\mathrm{CO}_{2}$ in Kauf. Die darauf folgenden hohen $\mathrm{CO}_{2}$-Konzentrationen im Umkreis der Austrittsstelle könnten für Menschen und Tiere erstickend wirken. Unabhängig des nicht quantifizierbaren Risikos des plötzlichen Zutagetretens sei ein schleichender Prozess des Entweichens von $\mathrm{CO}_{2}$ mit Sicherheit anzunehmen. In Kombination mit der für die CCS-Technologien zusätzlich aufgewendeten Energie würde bereits bei einer Leckagerate von $0,01 \%$ jährlich das austretende $\mathrm{CO}_{2}$ den Klimanutzen von CCS zunichte machen (die Einsparungen werden durch die Erhöhung des $\mathrm{CO}_{2}$-Ausstoßes, der mit dem Energieverbrauch der CCS-Technologien einhergeht, zunichte gemacht). Insgesamt betonen die genannten Studien, dass die Auswirkungen der Lagerung von $\mathrm{CO}_{2}$ auf die direkte Speicherumgebung, beispielsweise das Grundwasser, nicht vorherzusehen seien.

Für alle vier im Betrieb befindlichen CCS-Projekte im großindustriellen Maßstab gibt es Studien und/oder Berichte, die diese skeptischen Einschätzungen bestätigen. Im Fall des ältesten CCS-Projekts Sleipner ist etwa ein Viertel des in den letzten zehn Jahren verpressten Kohlenstoffdioxids nicht mehr auffindbar. In $24 \mathrm{~km}$ Entfernung vom Ort der Injektion hat sich eine Fraktur von 3 km Länge, 10 m Brei- 
te und bis zu $200 \mathrm{~m}$ Tiefe gebildet (vgl. im Internet: www.pnas.org/content/111/24/ 8747.full.pdf, letzter Zugriff am 02.12.2014). Bei dem zweiten norwegischen CCSProjekt in Snøhvit musste die $\mathrm{CO}_{2}$-Verpressung eingestellt werden, weil die Deckschicht aufgrund des zunehmenden Drucks zu bersten drohte (vgl. im Internet: www.nationalpark-wattenmeer.de/sh/service/newsletter/1830_september-2012, letzter Zugriff am 02.12.2014). Im algerischen In-Salah-Projekt gibt es ein ähnliches Problem. Eine Studie über das In-Salah-Projekt geht davon aus, dass der Überdruck, der durch das Einpumpen des Kohlenstoffdioxids entsteht, Risse im Gestein verursacht hat (vgl. im Internet: www.pnas.org/content/111/24/8747.full, letzter Zugriff am 02.12.2014). Die EOR-Praktiken des Weyburn-Midale-Projekts in Kanada sind laut einer wissenschaftlichen Untersuchung für die erhöhte $\mathrm{CO}_{2}$-Konzentration in der Region verantwortlich (vgl. im Internet: www.ecojustice.ca/media-centre/ media-release-files/petro-find-geochem-ltd.-report/at_download/file, letzter Zugriff am 02.12.2014). Diese Studie löste eine Kontroverse aus, in der über die Ursache der hohen $\mathrm{CO}_{2}$-Konzentration gestritten wird (vgl. Scheer 2013: 151; im Internet: www.thetyee.ca/News/2011/01/ 19/CarbonStorage, letzter Zugriff am 02.12.2014).

Der Verweis auf unkalkulierbare Risiken der Endlagerung von $\mathrm{CO}_{2}$ ist Teil einer kritischen Perspektive auf CCS-Technologien, die jenseits von Umweltforschungsinstituten vor allem von kleineren, radikaleren lokalen Gruppen und einzelnen Wissenschaftler_innen eingenommen wird (für den gesamten Absatz vgl. Berger 2010: 147; Markusson/Shackley 2012: 36f; Meadowcroft/Langhelle 2009a: 271; Sachverständigenrat für Umweltfragen 2009: 14f, 18ff). Da sie selbst unter Umwelt-NGOs tendenziell eine Minderheitenmeinung darstellt, kann man von einer marginalisierten Position sprechen (vgl. Meadowcroft/Langhelle 2009a: 272). Einer der Hauptkritikpunkte dieser CCS-kritischen Koalition ist der Wirkungsgradverlust durch CCS-Technologien, der den Verbrauch fossiler Brennstoffe erhöht und damit die ökologischen und gesundheitlichen Schäden verschärft, die mit der Förderung fossiler Brennstoffe einhergehen. Weiterhin befürchten die CCS-Kritiker_innen, dass die Ankündigung von CCS-Technologien als Legitimation für den Bau neuer fossiler Kraftwerke diene und damit den konsequenten Ausbau von erneuerbaren Energien verhindern könne. Da die CCS-Technologien aufgrund ihrer Kapitalintensität stark von der Subventionierung durch öffentliche Gelder abhängig seien, würden staatliche Fördergelder von den zu bevorzugenden Klimaschutzoptionen (Energieeffizienz und erneuerbare Energien) abgezogen. Darüber hinaus käme es zu einer Verstetigung der Pfadabhängigkeiten und somit zur Aufschiebung der von der CCSkritischen Koalition als notwendig erachteten Transformation hin zu Gesellschaften mit weniger Ressourcenverbrauch und einer Ökonomie, die auf erneuerbaren Energien aufbaut. Diese Verzögerung sei auch aus ökonomischer Sicht zu kritisieren, da 
zum Zeitpunkt des großflächigen Einsatzes der CCS-Technologien Strom aus erneuerbaren Energien günstiger sein werde als Strom aus CCS-Kraftwerken. Weiterhin wären die CCS-Technologien zu spät einsatzfähig, da die Weichen für die Bremsung der Klimaerwärmung in den nächsten zehn Jahren gestellt werden müssten (und die CCS-kritische Koalition nicht mit der Möglichkeit eines großflächigen Einsatzes von CCS-Technologien innerhalb dieses Zeitraums rechnet). Schlussendlich sprächen Nutzungskonkurrenzen gegen die Subventionierung von CCS-Technologien, da potenzielle Speicherstandorte für die Energiegewinnung durch Geothermie und der Speicherung von Druckluft ${ }^{19}$ in Frage kämen.

\subsection{Die Politikberatung des IPCC zu CCS-Technologien}

In diesem Kapitel ${ }^{20}$ werde ich mich mit der Rolle des IPCC in der CCS-CDMKontroverse auseinandersetzen. Zu Beginn dieser Kontroverse wurde der IPCC von der COP 7 um die Erstellung eines Berichts zu CCS-Technologien gebeten. Dieser 2005 erschienene Sonderbericht zu CCS (IPCC Special Report on Carbon Dioxide Capture and Storage, IPCC SRCCS) stellt den zentralen Beitrag des IPCC in den Konflikten um CCS-Technologien dar.

\section{Vom Auftrag bis zur Publikation - Die Genese des IPCC SRCCS}

2001 wurde der IPCC von der COP 7 um die Erstellung eines Berichts zu CCS-Technologien gebeten. Daraufhin wurde in der 19. Plenumssitzung des IPCC im April 2002 zunächst beschlossen, einen IPCC Workshop on Carbon Dioxide Capture and Storage durchzuführen, der im November des selben Jahres in Kanada stattfand. Etwa 200 Expert_innen interessierten sich für den Workshop, aber nur 70 konnten eingeladen werden (vgl. IPCC 2002: 9). Von diesen 70 Teilnehmer_innen waren elf aus den USA, acht aus Japan, sieben

19 Mit der Speicherung von Druckluft soll das Problem der schwankenden Energieeinspeisung durch erneuerbare Energien angegangen werden. Als Beispiel für diesen Kritikpunkt führt der Sachverständigenrat für Umweltfragen an, dass erste Anträge von Unternehmen mit konkreten Plänen für Druckluftspeicher im Bereich Brunsbüttel an der Unterelbe vom Wirtschaftsministerium Schleswig-Holstein abgelehnt wurden. In der Begründung der Ablehnung wurde explizit argumentiert, dass in der Region neue Kohlekraftwerke geplant würden und es aus Sicht des Ministeriums einen Nutzungsvorrang für CCS geben müsse (vgl. Sachverständigenrat für Umweltfragen 2009: 14).

20 Einzelne Abschnitte dieses Kapitels wurden - in einer früheren Fassung - bereits veröffentlicht in Krüger 2011. 
aus den Niederlanden, sechs aus Großbritannien, fünf aus Kanada und vier aus Norwegen (vgl. IPCC 2002: 175ff). Diese sechs Länder stellten insgesamt 41 von 70 Teilnehmer_innen, alle anderen Länder waren mit maximal drei Expert_innen vertreten. Dies ist insofern relevant, als dass alle überproportional vertretenen Länder ein spezifisches Interesse an CCS haben - beispielsweise weil sie über Kohlereserven verfügen oder sich Erdölund/oder Erdgaslagerstätten auf ihrem Territorium befinden, die sich für EOR oder EGR eignen - und die Erforschung und Entwicklung von CCS fördern (vgl. Kapitel 5.2.1). Der IPCC Workshop wurde somit von Expert_innen dominiert, die tendenziell eine besonders optimistische Position zu CCS-Technologien einnehmen, weil sie bzw. ihre Arbeitgeber häufig direkt oder indirekt von einer positiven Einschätzung von CCS als wichtige Klimaschutzoption profitieren (vgl. dazu die Ausführungen zum developer optimism der CCSCommunity in Abschnitt 5.3.2). So waren beispielsweise Expert_innen von BP, Exxon, Japan Coal, dem MIT Programme on carbon capture and storage, Mitsubishi Heavy Industries, Shell, Statoil und dem IEA Weyburn $\mathrm{CO}_{2}$ project vertreten.

Als Ergebnis des Workshops wurde ein Scoping Paper erarbeitet, das eine Struktur des geplanten CCS-Berichts entwirft und einen Überblick über die wissenschaftliche Literatur zu CCS gibt. Das Scoping Paper enthält bereits eine erste Einschätzung der Relevanz von CCS-Technologien, die sehr positiv ausfällt:

„Carbon dioxide capture and storage is an emerging technological option with a very high mitigation potential. It has been suggested that about half the world cumulative emission to 2050 may be stored at costs comparable to other mitigation options." (IPCC 2002: 9f)

Aufgrund dieser Einschätzung und weiterer Argumente - wie dem ,Interesse führender Industrieländer" und der ,Menge an neuer wissenschaftlicher Literatur' nehmer_innen des Workshops für die Erstellung eines eigenen Sonderberichts zu CCSTechnologien (vgl. IPCC 2002: 9). In Bezug auf die alternative Möglichkeit, das Thema im Rahmen eines Kapitels im nächsten Sachstandsbericht zu behandeln, wurde befürchtet, dass nicht alle relevante Literatur berücksichtigt werden könne und man generell der Bedeutung von CCS und dem Interesse an dieser Technologie nicht gerecht werde (vgl. IPCC 2002: 9f). Diese Entscheidung ist keine Formsache, sondern Ausdruck einer Priorisierung schließlich entschied man sich erst 2008 für einen Sonderbericht zu erneuerbaren Energien, der 2011 erschien. Laut Manfred Treber, der für die Beobachterorganisation Germanwatch an den CCS-Verhandlungen teilnahm, sollte es diesen Bericht bereits zu einem früheren Zeitpunkt geben. Der ursprüngliche Termin wurde allerdings verschoben, weil man sich dazu entschlossen hatte, zunächst den Sonderbericht zu CCS-Technologien anzufertigen. ${ }^{21}$

21 Diese Einschätzung erfolgte in einem Interview, das ich am 16.03.2013 mit Manfred Treber geführt habe. 
Auf der 20. Sitzung des IPCC-Plenums im Februar 2003 folgte man dem Vorschlag der Workshop-Teilnehmer_innen und beschloss, von der Arbeitsgruppe III einen Sonderbericht zu CCS-Technologien anfertigen zu lassen. Die endgültige Fassung des IPCC SRCCS wurde im September 2005 vom IPCC-Plenum angenommen und im Dezember 2005 bei der COP 11 präsentiert.

Ein spezieller Reiz des IPCC als Untersuchungsgegenstand liegt in seiner Besonderheit als „boundary organization“ (Poloni 2009), als Grenzorganisation zwischen Wissenschaft und Politik. In dieser Besonderheit des IPCC spiegelt sich die hervorgehobene Bedeutung der Wissenschaft im Politikfeld Klimawandel. So waren es nicht zuletzt wissenschaftliche Debatten, die dem Klimawandel zur gesellschaftlichen Relevanz verhalfen und ihn damit zu einem Aufgabengebiet politischer Institutionen machten. Die Klimapolitik gilt darüber hinaus als ,verwissenschaftlicht', weil die politischen Akteur_innen im besonderen Maße auf wissenschaftliche Expertise als Problemlösungs- und Legitimationsressource zurückgreifen. Die Verwendung wissenschaftlicher Modelle und Deutungsmuster trägt zur Komplexität der klimapolitischen Auseinandersetzungen bei. Die darauf reagierenden komplexitätsreduzierenden Konzepte, die den Handlungsspielraum der Politik zugleich eröffnen und beschränken, stammen ebenfalls häufig aus der Wissenschaft. So basieren die marktorientierten Klimaschutzinstrumente auf der (natur-)wissenschaftlichen Perspektive, die von der universellen Wirkung von Treibhausgasen in der Atmosphäre ausgeht. Das Narrativ, dass es dem Klima egal sei, wo die Emissionen entstehen, ermöglichte die Klimaschutzinstrumente des Emissionsrechtehandels sowie der Kompensationsprojekte (CDM und JI) und -zahlungen. Weiterhin stellten die (natur-)wissenschaftlichen Berechnungen der Treibhausgaspotenziale verschiedener Gase eine wichtige Bedingung für die Konstruktion der $\mathrm{CO}_{2}$-Äquivalente dar, die den Handel zwischen verschiedenen Treibhausgasemissionen bzw. -einsparungen erst ermöglichten (vgl. Paterson 2011: 612). Diese Beispiele zeugen von der wichtigen Rolle, die wissenschaftliche Konzepte für die Klimapolitik spielen.

Vor diesem Hintergrund muss die Aufmerksamkeit betrachtet werden, die dem IPCC sowohl von der allgemeinen Öffentlichkeit als auch vom Politikbetrieb entgegen gebracht wird. Insgesamt ist von einem starken Einfluss des IPCC auf die internationalen Klimaverhandlungen auszugehen (vgl. Garrelts/Dietz 2013: 21). Dies macht den IPCC zu einem wichtigen Akteur im Konfliktfeld der ökologischen Krise. Aufgrund dieser besonderen Bedeutung wird die Politikberatung durch den IPCC hier in einem eigenen Kapitel behandelt. Dabei verfolge ich mein Erkenntnisinteresse an den re- und entpolitisierenden Prozessen im Konfliktfeld der ökologischen Krise (vgl. Kapitel 1.1) auf zwei Ebenen: 
- Was sind die zentralen Aussagen des IPCC über CCS-Technologien und wie lassen sich diese in Bezug auf die (Ent-)Politisierung der Auseinandersetzungen um die Bearbeitung der ökologischen Krise verorten? In welchem Verhältnis steht der IPCC SRCCS zum ökomodernen Hegemonieprojekt?

- Was zeichnet die Politikberatung der Grenzorganisation IPCC aus? Was bedeutet die enge Verknüpfung von Politik und Wissenschaft im Fall des IPCC für die (Ent-)Politisierung der gesellschaftlichen Naturverhältnisse?

Um diese Fragen bearbeiten zu können, stelle ich zunächst die Arbeitsweise des IPCC dar und diskutiere seinen besonderen intergouvernementalen Charakter, der ihn an der Schnittstelle zwischen Politik und Wissenschaft agieren lässt (5.3.1). Daran anschließend nehme ich die für die Ausrichtung des Berichts relevante Auswahl der Autor_innen des IPCC SRCCS in den Blick (5.3.2). Darauf folgt eine Nachzeichnung der Argumentationslinie des Berichts (5.3.3). Diese setze ich mit dem ökomodernen Hegemonieprojekt ins Verhältnis und analysiere, inwiefern im IPCC SRCCS die ökomodernen Grundannahmen und Hegemoniestrategien (re-)produziert werden (5.3.4). Abschließend fasse ich die Ergebnisse zusammen und interpretiere sie in Bezug auf mein Erkenntnisinteresse, das sich auf den Beitrag des Berichts zu den Auseinandersetzungen um die Bearbeitung der ökologischen Krise und den (ent-)politisierenden Folgen der engen Verknüpfung von Politik und Wissenschaft im IPCC bezieht (5.3.5).

\subsubsection{Der IPCC als Grenzorganisation}

Der IPCC wurde 1988 explizit als zwischenstaatlicher Sachverständigenrat vom UN-Umweltprogramm und der WMO gegründet. Der intergouvernementale Charakter des IPCC, der für ein wissenschaftliches Gremium sehr ungewöhnlich ist, zeigt sich in der Nominierung der mehr als 3.000 Expert_innen aus über 100 Ländern durch die Regierungen der Mitgliedsländer von UNEP und WMO. Darüber hinaus entsenden die Regierungen auch politische Vertreter_innen ins IPCCPlenum, dem obersten Entscheidungsgremium des IPCC (vgl. Beck 2009a: 98).

Die Hauptaufgabe des IPCC ist es, die Ergebnisse der wissenschaftlichen Forschung in Bezug auf den anthropogenen Klimawandel und seine Folgen sowie darauf reagierende Vermeidungs- und Anpassungsstrategien zusammenzutragen. Diese Arbeit geschieht in drei Arbeitsgruppen und mündet in den regelmäßig erscheinenden Sachstandsberichten sowie in Sonderberichten zu spezifischen Themen. Die Arbeitsgruppe I (Science of Climate Change) besteht aus Naturwissenschaftler_innen unterschiedlicher Disziplinen und arbeitet zu den physikalischnaturwissenschaftlichen Grundlagen des Klimasystems und der Klimaänderungen. 
In der Arbeitsgruppe II (Impacts, Adaption and Vulnerability), die vor allem aus Ökonom_innen und Ökolog_innen besteht, werden die daraus folgenden Auswirkungen, Anpassungsmöglichkeiten und Verwundbarkeiten beleuchtet. Ingenieur_innen und Ökonom_innen dominieren die Arbeitsgruppe III (Mitigation of Climate Change), in der die Möglichkeiten der Verminderung des Klimawandels analysiert werden. Den ausführlichen Berichten der Arbeitsgruppen werden jeweils die als politikrelevant eingestuften Informationen in einer Zusammenfassung für politische Entscheidungsträger_innen (Summary for Policymakers) vorangestellt. Diese Zusammenfassungen werden im IPCC-Plenum Zeile für Zeile nach dem Konsensprinzip verabschiedet (vgl. Conrad 2010: 102f).

Die Verortung des IPCC an der Schnittstelle zwischen Politik und Wissenschaft, zeigt sich nicht nur in der Zusammensetzung des Plenums, sondern schlägt sich auch in der Arbeitsweise nieder. Der Prozess des Zusammentragens von Forschungsergebnissen orientiert sich an wissenschaftlichen Konventionen wie beispielsweise dem Verfahren des Peer-Reviews, d. h. der Begutachtung durch Wissenschaftler_innen aus dem gleichen Fachgebiet (vgl. Poloni 2009). Die Ableitung der politikrelevanten Informationen in einer Zusammenfassung für politische Entscheidungsträger_innen erfolgt dagegen in ,hoch politisierten Verhandlungen“ (Beck 2009b: 138) des Plenums, in denen der ,,intergovernementale Status“ (Beck 2009b: 131) des IPCC deutlich wird. Im Plenum ringen Regierungsvertreter_innen um die Berücksichtigung ihrer nationalen Politik und sogenannte ,Bremserparteien“ nutzen das Konsensprinzip, um die Verhandlungen zu blockieren (vgl. Beck 2009b: 138).

Die Arbeitsweise des IPCC - insbesondere die konsensuelle Abstimmung der Zusammenfassungen für politische Entscheidungsträger_innen - zielt zum einen auf die Herstellung von Autorität und Glaubwürdigkeit gegenüber der Politik. Der Versuch, die Wissenschaft mit einer Stimme sprechen zu lassen, soll die Akzeptanz in der Öffentlichkeit erhöhen und das Vertrauen der nationalen Regierungen in die internationale Forschung fördern. Zum anderen weist sich der IPCC damit selber die Rolle des privilegierten Sprechers der Wissenschaft zu. Der IPCC schafft sich somit ein Monopol in Bezug auf die Fütterung der UN-Klimaverhandlungen mit wissenschaftlicher Expertise (vgl. Beck 2009b: 126).

Der „Politik der Inklusion“ (Beck 2009b: 129) liegt ein im politischen System bekannter Mechanismus zugrunde: die Erzeugung von Glaubwürdigkeit durch Repräsentation. Dabei kommen zum einen wissenschaftsinterne Kriterien wie die Vertretung verschiedener Disziplinen und Standpunkte zum Tragen. Zum anderen gelten aber auch explizit wissenschaftsexterne Kriterien, die in politischen Prozessen üblich sind, wie die Vertretung verschiedener gesellschaftlicher Gruppen und 
Nationen. Obwohl der IPCC versucht, diesen Kriterien gerecht zu werden, bleiben die Länder des globalen Südens unterrepräsentiert (vgl. Beck 2009b: 129).

Das Kriterium der Repräsentation verweist auf den politischen Charakter des IPCC. $\mathrm{Zu}$ Beginn umfasste das Mandat des IPCC zudem die Ausarbeitung konkreter politischer Handlungsempfehlungen. Im Zuge der Gründung des Intergovernmental Negotiation Committee (INC) als weiteres zwischenstaatliches Gremium zur Aushandlung der Klimarahmenkonvention wurde 1990 das Mandat des IPCC allerdings geändert. Bei diesem Versuch der Entkopplung wissenschaftlicher und politischer Verhandlungen strich man die Erarbeitung von Handlungsempfehlungen aus dem Mandat des IPCC (vgl. Beck 2009b: 132f; Poloni 2009: 251f). Dennoch ist der IPCC weiterhin - auf etwas indirektere Art und Weise - ein wichtiger Austragungsort politischer Verhandlungen. In der offiziellen Selbstdarstellung des IPCC wird allerdings - ganz im Sinne eines konventionellen Verständnisses linearer Politikberatung - von der Wertfreiheit und Neutralität der wissenschaftlichen Arbeit ausgegangen, welche politische Entscheidungen vorbereite, aber nicht vorentscheide (vgl. Beck 2009b: 140; im Internet: www.ipcc.ch/organization/organization.shtml, letzter Zugriff am 02.12.2014). Diese Selbstbeschreibung deckt sich allerdings nicht mit den empirisch beobachtbaren Prozessen, wie beispielsweise die oben beschriebenen Verhandlungen über die Zusammenfassungen der IPCC-Berichte zeigen (vgl. Beck 2009b: 141). Dort wird gerade deshalb um die Selektion der Inhalte und die konkreten Formulierungen gerungen, weil die Problemdeutungen und Konzepte sehr wohl Argumente für bestimmte politische Entscheidungen nahe legen bzw. bereits immer schon normative Setzungen beinhalten (für den IPCC SRCCS werde ich das in den Abschnitten 5.3.3 und 5.3.4 zeigen).

So konstatiert Matthew Paterson, dass der IPCC die Grenzen des Denk- und Machbaren in den Klimaverhandlungen definiere (vgl. Paterson 2011: 611). Aufgrund seiner privilegierten Position, als von den Mitgliedsstaaten von UNEP und WMO ins Leben gerufener und somit besonders legitimierter Akteur des wissenschaftlichen Bereichs, fällt dem IPCC eine starke Definitionsmacht zu. Insofern ist $\mathrm{zu}$ vermuten, dass der IPCC in der Lage ist, in einem relativ frühen Stadium der Verhandlungen Deutungsmuster zu prägen, auf die im weiteren Verlauf der politischen Auseinandersetzungen zurückgegriffen wird. Derart wird ein Rahmen vorgegeben, innerhalb dessen um politische Lösungen gerungen wird. Gerade bei einem technisch sehr komplexen Thema wie CCS ist davon auszugehen, dass die Politik im besonderen Maße auf wissenschaftliche Expertise angewiesen ist.

Verschiedene Beobachter_innen der UN-Klimaverhandlungen stimmen darüber überein, dass der IPCC SRCCS die wichtigste Grundlage für die Verhandlungen über die Aufnahme von CCS-Technologien in den CDM bildete (vgl. de Coninck/ 
Bäckstrand 2011; de Coninck/Bakker 2005: 5f; Meadowcroft/Langhelle 2009b: 6f). Auch über die UN-Klimaverhandlungen hinaus hatte der Sonderbericht zu CCS einen großen Einfluss auf die Auseinandersetzungen um CCS-Technologien. So interpretiert beispielsweise Treber die 2009 in Kraft getretene EU-Richtlinie zur geologischen Speicherung von Kohlenstoffdioxid (2009/31/EG) als ein Ergebnis der großen Wirkung des IPCC-Berichts. ${ }^{22}$ Die Sozialwissenschaftler Meadowcroft und Langhelle streichen ebenfalls den Einfluss des Berichts heraus:

„It is difficult to overstate the significance of the IPCC Special Report, which presented a comprehensive review of the technical and economic potential of CCS, and was communicated to a broad audience concerned with climate change and energy policy. The Special Report drew on a wide range of expertise, and integrated the technical consideration of CCS as a mitigation option into the wider discourse on climate change, in which the IPCC assessment reports and emissions scenarios occupy a central place." (Meadowcroft/Langhelle 2009b: 6; Hervorhebungen im Original)

Die besondere Position des IPCC als Grenzorganisation zwischen Politik und Wissenschaft macht ihn zu einem einflussreichen Akteur im Konfliktfeld der ökologischen Krise. Dabei ist eine Verschiebung politischer Konflikte aus den politischen Institutionen in den IPCC zu beobachten: „Politische Konflikte werden auf diese Weise auf die Ebene der Rekrutierung von Experten transponiert und letztlich zwischen Experten ausgetragen." (Beck 2009b: 132) Damit wird die Auswahl der Expert_innen in den Fokus gerückt.

\subsubsection{Die Autor_innen des Sonderberichts zu CCS}

Der folgenden Analyse zu den Autor_innen des IPCC SRCCS liegt die Annahme zugrunde, dass die Ausrichtung der Politikberatung maßgeblich von der Auswahl der Expert_innen abhängt. Dabei scheinen mir neben den individuellen Positionen der Autor_innen ihre Arbeitgeber, aber auch ihre Arbeitsstandorte entscheidend zu sein. Simon Shackley et al. haben für den europäischen Raum empirisch belegt, dass die Expert_innen aus Ländern, in denen es ein spezifisches Interesse an CCSTechnologien gibt, tendenziell eine besonders positive Position zu CCS-Technologien einnehmen. Sie nennen das Phänomen “developer optimism” (vgl. Shackley/ Waterman/Godfroij/Reiner/Anderson/Draxlbauer/Flach 2007: 5107). Der developer optimism ist zum einen auf eine generelle optimistische Stimmung - in Bezug auf die Entwicklung und Anwendung von CCS - in den Ländern zurückzuführen, in

22 Diese Einschätzung erfolgte in einem Interview, das ich am 16.03.2013 mit Manfred Treber geführt habe. 
denen CCS-Technologien als besonders wichtig gelten, verschiedene Akteur_innen große Hoffnungen in sie setzen und CCS-Projekte vom Staat gefördert und finanziell unterstützt werden. Zum anderen arbeiten relativ viele Expert_innen aus diesen Ländern selber an der Erforschung und Entwicklung der CCS-Technologien mit und profitieren somit direkt oder indirekt von einer positiven Bewertung von CCSTechnologien als wichtige Klimaschutzoption. Die Beteiligung an der Erforschung und Entwicklung bestimmter Technologien führt erfahrungsgemäß zu optimistischen Einschätzungen bezüglich des weiteren Entwicklungsverlaufs dieser Technologien im Allgemeinen und hier im Besonderen bezüglich der Beherrschbarkeit von Risiken, die mit den CCS-Technologien einhergehen (vgl. Hansson/Bryngelsson 2009: 2274, 2277; Shackley et al. 2007: 5106ff).

So identifizieren Jennie C. Stephens et al. analog zu vermehrten privaten und öffentlichen Investitionen in CCS-Technologien ein anwachsendes internationales Netzwerk von Personen, deren beruflicher Werdegang mit der Entwicklung von CCS verknüpft ist. Für diese Akteur_innen machen sie eine mehrheitlich geteilte Perspektive auf CCS-Technologien aus, die gekennzeichnet ist durch eine prinzipiell positive Bewertung von CCS-Technologien, durch optimistische Prognosen und durch ein Herunterspielen von Faktoren, die einer erfolgreichen Einführung von CCS entgegenstehen. Stephens et al. sprechen in Anlehnung an Peter Haas von einer CCS-spezifischen epistemic community (vgl. Stephens et al. 2011). Aufgrund der für den konkreten Fall unpassenden Konnotationen des Begriffs der epistemic community, die Stephens et al. auch in ihrem Aufsatz thematisieren, verwende ich im Folgenden die Formulierung CCS-Community. Innerhalb dieser CCSCommunity dreht sich die Diskussion nicht um die Frage, ob CCS-Technologien überhaupt entwickelt werden sollten, sondern um die Frage nach der bestmöglichen Umsetzung. Dementsprechend werden Risiken selten als Risiken interpretiert, die von CCS-Technologien ausgehen. Stattdessen werden Risiken in der Regel als Risiken, welche die Entwicklung von CCS-Technologien behindern könnten, gedeutet (vgl. Stephens et al. 2011: 386, 389). Insofern ist zu vermuten, dass ein CCSBericht desto optimistischer ausfällt, je größer der Anteil an Autor_innen ist, die in die Entwicklung von CCS-Technologien involviert sind.

Die Auswahl der Autor_innen des IPCC SRCCS erfolgte nach einem festgelegten Mechanismus, der für alle Berichte des IPCC gilt: Die Regierungen werden darum gebeten, eine Liste mit geeigneten Expert_innen zu erstellen. Dazu schreiben diese die einschlägigen Forschungsinstitute, Universitäten, Verbände und NGOs ihres Landes an und geben die erhaltenen Namen von Expert_innen, die für die Mitarbeit am IPCC-Bericht in Frage kommen (sich für diese ehrenamtliche Aufgabe 
also auch Zeit nehmen können), weiter. Das IPCC Bureau ${ }^{23}$ wählt anschließend aus diesen Vorschlägen die Autor_innen aus (vgl. IPCC 2002: 11; IPCC 2003: 3). Bei dieser Auswahl sollen laut den IPCC-Grundsätzen folgende Richtlinien leitend sein:

- „the range of scientific, technical and socio-economic views and expertise;

- geographical representation (ensuring appropriate representation of experts from developing and developed countries and countries with economies in transition); there should be at least one and normally two or more from developing countries;

- a mixture of experts with and without previous experience in IPCC;

- gender balance." (IPCC o. J.: 5f)

Beim IPCC wird zwischen Coordinating Lead Authors, Lead Authors und Contributing Authors unterschieden. Für die Ausrichtung eines IPCC-Berichts sind maßgeblich die Coordinating Lead Authors verantwortlich. Sie sind jeweils alleine oder als Team für ein Kapitel zuständig und entscheiden, mit welchen Inhalten es gefüllt wird. Die Lead Authors schreiben am Text mit und die Contributing Authors liefern technische Informationen zu bestimmten Punkten (vgl. die Selbstdarstellung des IPCC im Internet: www.ipcc.ch/organization/organization_structure.shtml\#, letzter Zugriff am 02.12.2014). ${ }^{24}$

Aufgrund ihrer besonderen Relevanz werde ich auf die am IPCC SRCCS beteiligten Coordinating Lead Authors näher eingehen, die Lead Authors und Contributing Authors dagegen vernachlässigen. Insgesamt arbeiteten 19 Coordinating Lead Authors am IPCC SRCCS - ausgenommen der Verantwortlichen für die Anhänge mit dem Glossar und den Abkürzungen. Diese 19 Autor_innen werde ich nun - in der Reihenfolge der Kapitel für die sie zuständig waren - daraufhin beleuchten, inwieweit sie in die Erforschung und Entwicklung von CCS-Technologien involviert und damit Teil der CCS-Community sind. Diese Recherche umfasst ihren Arbeitsstandort ${ }^{25}$, ihre Arbeitgeber und - wenn die Art ihrer Arbeitgeber und ihres

23 Das IPCC Bureau umfasst den IPCC-Vorsitzenden, die stellvertretenden IPCC-Vorsitzenden sowie die Ko-Vorsitzenden und stellvertretenden Vorsitzenden der Arbeitsgruppen sowie die Ko-Vorsitzenden der Task Force on National Greenhouse Gas Inventories. Die Mitglieder des IPCC Bureaus werden vom IPCC-Plenum gewählt (vgl. im Internet: www.ipcc.ch/organization/organization_structure.shtml, letzter Zugriff am 02.12.2014).

24 Die Arbeitsteilung variiert allerdings erheblich zwischen den Kapiteln und zwar je nach Handhabung der verantwortlichen Coordinating Lead Authors. Diese Einschätzung erfolgte in einem Interview, das ich am 16.05.2013 mit Heleen de Coninck, die selber eine der Coordinating Lead Authors des IPCC SRCCS war, geführt habe. 
Aufgabenbereichs keine naheliegenden Rückschlüsse auf ihre Positionierung bezüglich CCS-Technologien zulassen ${ }^{26}$ - ihre Publikationen und Vorträge zu CCS.

\section{Edward Rubin}

Kapitel: Technical Summary

Arbeitsstandort: USA

Arbeitgeber: Carnegie Mellon University

Positionierung zu CCS: CCS-Technologien waren bereits während seiner Mitarbeit am IPCC SRCCS Edward Rubins zentrales Forschungsinteresse und sind es bis heute, was sich an der großen Zahl seiner Publikationen zu diesem Thema zeigt (vgl. im Internet: www.epp.cmu.edu/people/faculty/rubin, letzter Zugriff am 02.12.2014). Dabei steht er den CCS-Technologien explizit positiv gegenüber. So macht er beispielsweise in seinem Vortrag „Overcoming Barriers to Widespread CCS Deployment with a focus on CO2 capture“ strategische Vorschläge, um CCS-Technologien zur kommerziellen Anwendung zu verhelfen (vgl. im Internet: www.cmu.edu/epp/iecm/rubin/PDF\%20files/2010/Rubin_CCS\%20Task \%20Force\%20Mtg_6\%20May\%202010.pdf, letzter Zugriff am 02.12.2014).

\section{Leo Meyer}

Kapitel: Technical Summary

Arbeitsstandort: Niederlande

Arbeitgeber: Netherlands Environmental Assessment Agency

Positionierung zu CCS: Das Netherlands Environmental Assessment Agency ist ein Forschungsinstitut, welches die niederländische Regierung berät. Leo Meyer scheint neben der Mitarbeit am IPCC SRCCS nicht direkt zu CCS-Technologien zu forschen oder zu publizieren. Allerdings hat er Vorträge zum IPCC SRCCS gehalten, beispielsweise beim side-event „Coal's Contribution in a Carbon Constrained World“ des World Coal Institute auf der COP 13 in Bali (2007). Dort schätzt er CCS-Technologien als eine wichtige Klimaschutz-Option

25 Alle Angaben zu den Arbeitsstandorten und Arbeitgebern beziehen sich auf den Zeitpunkt der Erstellung des IPCC SRCCS und stammen aus der Übersicht der Autor_innen im IPCC SRCCS (vgl. IPCC 2005: 417ff).

26 Aus forschungspragmatischen Gründen habe ich darauf verzichtet, nach Hinweisen auf die individuellen Positionen der Autor_innen zu suchen, die aufgrund ihres Arbeitsplatzes der CCS-Community zugerechnet werden können. Da ihr beruflicher Werdegang mit der Entwicklung von CCS verknüpft ist, kann m. E. in diesen Fällen tendenziell von einem sicherlich unterschiedlich stark ausgeprägten - developer optmism ausgegangen werden. Damit soll nicht behauptet werden, dass per se von der Anstellung bei einem bestimmten Arbeitgeber auf die vertretenen Positionen geschlossen werden kann. 
neben anderen ein und betont, dass die Energie-Produktion mit Kohle auch mit CCS-Technolgien immer noch konkurrenzfähig sei (vgl. im Internet: www.worldcoal.org/bin/pdf/original_pdf_file/wci_bali_2007_leo_meyer_ipcc(04_06_2009).pdf, letzter Zugriff am 02.12.2014).

\section{Heleen de Coninck}

Kapitel: Technical Summary

Arbeitsstandort: Niederlande

Arbeitgeber: Energy research Centre of the Netherlands (ECN)

Positionierung zu CCS: Heleen de Coninck forscht auch unabhängig von der Arbeit am IPCC SRCCS zu CCS-Technologien und spricht sich dabei prinzipiell für die Aufnahme in den CDM aus (vgl. Bakker/de Coninck/Groenenberg 2008). In einem Artikel aus dem Jahr 2008 macht sie einen konkreten Vorschlag, unter welchen Bedingungen ein diesbezüglicher Konsens erzielt werden könnte (vgl. de Coninck 2008).

\section{Paul Freund}

Kapitel: Introduction

Arbeitsstandort: Großbritannien

Arbeitgeber: -

Positionierung zu CCS: Als unabhängiger Berater arbeitet Paul Freund zu CCSTechnologien, denen er dabei insgesamt sehr positiv gegenüber steht. So fasst er beispiels weise auf seiner Power-Point-Präsentation, die er für einen Vortrag bei einer Konferenz ${ }^{27}$ der Europäischen Union im Jahr 2005 verwendete, die Folie zur öffentlichen Akzeptanz mit folgenden Worten zusammen: „Best Case = CCS regarded as one of the acceptable options.“ (vgl. Freund 2005)

\section{John Gale}

Kapitel: Sources of $\mathrm{CO}_{2}$

Arbeitsstandort: Großbritannien

Arbeitgeber: Internationale Energieagentur (IEA) - Greenhouse Gas R\&D Programme Positionierung zu CCS: Die IEA bietet eine Plattform für die Kooperation der OECDLänder in Energiefragen. Ihr Schwerpunkt liegt auf der Energieversorgung mit fossilen Brennstoffen. Das Greenhouse Gas R\&D Programme der IEA (IEA GHG) gehört zu den zentralen internationalen Forschungsprogrammen, die an der Entwicklung von CCS-Technologien arbeiten (vgl. De Conninck/Bäckstrand 2011: 369, 371; de Coninck/Bakker 2005:

27 Vgl. im Internet: www.ec.europa.eu/research/energy/print.cfm?file=/comm/research/ energy/gp/gp_events/co2_conf/article_2540_en.htm, letzter Zugriff am 02.12.2014. 
15; Meadowcroft/Langhelle 2009b: 5). Eine ausführliche Beschreibung des IEA GHG findet sich in Kapitel 5.2.1.

Juan Carlos Abanades

Kapitel: Capture

Arbeitsstandort: Spanien

Arbeitgeber: Instituto Nacional del Carbon (INCAR)

Positionierung zu CCS: Das INCAR ist ein Forschungsinstitut, das sich mit den Möglichkeiten der kommerziellen Nutzung von Kohlenstoff beschäftigt. Ein Schwerpunkt bildet dabei die Arbeit zu CCS-Technologien (vgl. im Internet: www.incar.csic.es, letzter Zugriff am 02.12.2014). Juan Carlos Abanades ist Mitglied des CCS European Industrial Initiative Team, das die technische und ökonomische Umsetzbarkeit von CCS-Projekten im industriellen Maßstab beweisen und kosteneffizientere CCS-Technologien entwickeln soll (vgl. im Internet: setis.ec.europa.eu/implementation/technology-roadmap/european-industrialinitiative-on-carbon-capture-and-storage， www.ec.europa.eu/energy/technology/initiatives/ doc/2011_ccs.pdf, letzter Zugriff am 02.12.2014).

\section{Mohammad Soltinieh}

Kapitel: Capture

Arbeitsstandort: Iran

Arbeitgeber: Environmental Research Centre

Positionierung zu CCS: Das Environmental Research Centre ist Teil des Climate Change Office, dessen Aufgabe darin besteht, die Aktivitäten der iranischen Regierung im Rahmen der UN-Klimaverhandlungen vorzubereiten. Die iranische Regierung wiederum nimmt bislang keine Vorreiterrolle in Bezug auf die Erforschung und Entwicklung von CCSTechnologien ein. Allerdings ist Iran aufgrund seiner Erdöl- und Erdgas-Vorkommen für die kommerzielle Nutzung von CCS als EOR oder EGR prädestiniert. Deshalb propagiert auch die National Iranian Oil Company (NIOC) in ihrem Beitrag auf dem 2nd International Symposium on Carbon Capture and Storage (CCS) ${ }^{28}$ den Einsatz von CCS-Technologien im Iran (vgl. im Internet: www.ief.org/_resources/files/events/2nd-ccs-symposium/mohsensaeed.pdf, letzter Zugriff am 02.12.2014).

Kelly (Kailai) Thambimuthu

Kapitel: Capture

Arbeitsstandort: Australien

28 Das Symposium fand 2010 in Algerien statt und wurde vom International Energy Forum und vom Global CCS Institute organisiert. 
Arbeitgeber: Centre for Low Emission Technology (cLET)

Positionierung zu CCS: Im Fokus des cLET steht die Entwicklung von Technologien zur emissionsarmen Stromerzeugung, worunter auch CCS-Technologien gezählt werden. Das cLET ist ein Joint Venture zwischen dem Bundesstaat Queensland und der Commonwealth Scientific and Industrial Research Organisation (CSIRO), die ihre Aufgabe in der wissenschaftsbasierten Beratung von Politik und Wirtschaft sieht. Weitere Partner sind unter anderem die University of Queensland, Tarong Energy, Stanwell und die Australian Coal Association. Stanwell und Tarong Energy betreiben Kohlekraftwerke. Die Australian Coal Association ist ein Zusammenschluss von 24 Unternehmen, der die Interessen der Kohleindustrie vertritt und die Erforschung und Entwicklung von CCS-Technologien finanziell fördert. Neben der Arbeit beim cLET hat Kelly Thambimuthu seit 1995 den Vorsitz über das IEA Greenhouse Gas R\&D Programme (vgl. www.ieaghg.org/about-us/members, www. bigthink.com/users/kellythambimuthu, letzter Zugriff am 13.12.2013), in dem auch John Gale arbeitet (zur Einordnung des IEA Greenhouse Gas R\&D Programme vgl. Kapitel 5.2.1). Thambimuthu sieht CCS als sinnvolle Brückentechnologie, ,as a bridge to sustainable energy futures“ (vgl. im Internet: www.cslforum.org/publications/documents/ ThambimuthuCO2CaptureSalvadorCBWSept2008.pdf, letzter Zugriff am 02.12.2014).

\section{Richard Doctor}

Kapitel: Transport of $\mathrm{CO}_{2}$

Arbeitsstandort: USA

Arbeitgeber: Argonne National Laboratory

Positionierung zu CCS: Das Argonne National Laboratory ist ein Forschungsinstitut des US-Energieministeriums. Richard Doctor leitete dort die Abteilung Hydrogen and Greenhouse Gas Engineering. Im Argonne National Laboratory wird seit über 20 Jahren an Technologien zur Verminderung von Emissionen, die bei der Nutzung fossiler Brennstoffe entstehen, geforscht. Dabei wurden Technologien zum EOR und zur Abscheidung von $\mathrm{CO}_{2}$ bei fossilen Kraftwerken entwickelt (vgl. im Internet: www.es.anl.gov/Energy_systems/ research/process_technology/process_tech_hydrogen.html, letzter Zugriff am 13.12.2013). Doctor selber arbeitet in diesem Bereich und spricht sich für die Entwicklung von CCSTechnologien aus, da sie eine Fortführung der Kohleverstromung ermöglichen. Dies würde laut Doctor zur Energiesicherheit beitragen, da die Abhängigkeit von Öl-Importen gesenkt werden könne. Darüber hinaus sieht er in CCS-Technologien einen zukünftigen Weltmarkt, der in den USA Arbeitsplätze schaffen könne (vgl. den Vortrag auf dem CO2 Capture Technology Meeting, das 2011 in Pittsburgh stattfand, im Internet: www.netl.doe.gov/publications/ proceedings/11/co2capture/presentations/3-Wednesday/24Aug11-Hanson-ANL-CCS\%20Tech\% 20at\%20Existing\%20PC.pdf, letzter Zugriff am 02.12.2014) 


\section{Andrew Palmer}

Kapitel: Transport of $\mathrm{CO}_{2}$

Arbeitsstandort: Großbritannien

Arbeitgeber: University of Cambridge

Positionierung zu CCS: Aktuell ist Andrew Palmer Professor am Department of Civil \& Environmental Engineering der National University of Singapore. 1985 gründete er Andrew Palmer and Associates, eine Firma die auf Pipelines im Meer spezialisiert ist (vgl. im Internet: $137.132 .5 .169 /$ index.php?option=com_content\&id=356\&tmpl=component\&task=preview, letzter Zugriff am 02.12.2014). Insofern ist davon auszugehen, dass ihn mit dem Thema des von ihm mitkoordinierten Kapitels ein unternehmerisches Interesse verbindet. Palmer spricht sich für Investitionen in CCS-Technologien aus. Dabei setzt er sich insbesondere für die umstrittene Speichermöglichkeit in tiefen Gewässern (ocean storage) ein, die er technisch für durchführbar hält (vgl. im Internet: www.keith.seas.harvard.edu/papers/91.Palmer. 2007.SeaBedEngineeredStorage.e.pdf， www.co2sense.co.uk/news/cbi-ippr-north-and-tucback-co2sense-s-ccs-report, www.neilcai1471.blogspot.de, letzter Zugriff am 02.12.2014).

\section{Sally Benson}

Kapitel: Underground geological storage

Arbeitsstandort: USA

Arbeitgeber: Lawrence Berkeley National Laboratory

Positionierung zu CCS: Das Lawrence Berkeley National Laboratory ist ein Forschungsinstitut des Energieministeriums der USA. Sally Benson steht CCS-Technologien sehr positiv gegenüber. So spricht sie sich z. B. im Vortrag „Carbon Dioxide Capture and Sequestration: Hype or Hope?“ beim Google Energy Seminar 2008 deutlich für CCS-Technologien aus:

,- CCS can result in $20 \%$ of needed emissions reductions over the next 100 years (yes)

- Without CCS, were [sic!] in trouble (probably) [...]

- Just do it! (yes, for large scale demonstration projects) [...]

- Environmental risks are unacceptably high (no, not if done carefully) [...]

CCS is an important part of the portfolio of technologies for reducing greenhouse gas emis sions“ (vgl. im Internet: pangea.stanford.edu/research/bensonlab/presentations/CCS - Hope or Hype.pdf, letzter Zugriff am 02.12.2014).

\section{Peter Cook}

Kapitel: Underground geological storage

Arbeitsstandort: Australien

Arbeitgeber: Cooperative Research Centre for Greenhouse Gas Technologies (CO2CRC) 
Positionierung zu CCS: Im CO2CRC arbeiten Vertreter_innen staatlicher Behörden Australiens und Neuseelands mit der Industrie zusammen. Partner des Instituts sind neben staatlichen Institutionen und Universitäten vor allem Öl-Konzerne und Energieunternehmen. Der Fokus liegt auf der Erforschung und Entwicklung von CCS-Technologien (vgl. im Internet: www.co2crc.com.au, letzter Zugriff am 02.12.2014). Im Rahmen seiner Arbeit im CO2CRC war Peter Cook maßgeblich am CCS-Demonstrationsprojekt Otway beteiligt. Aufgrund seines Rufs auf dem CCS-Gebiet ist ein Forschungszentrum zur Entwicklung von CCS-Technologien, das mit dem CO2CRC kooperiert, nach seinem Namen benannt: Peter Cook Centre for CCS Research (vgl. im Internet: www.petercook.unimelb. edu.au, letzter Zugriff am 02.12.2014).

\section{Ken Caldeira}

Kapitel: Ocean Storage

Arbeitsstandort: USA

Arbeitgeber: Carnegie Institution of Washington (seit 2007 Carnegie Institution for Science)

Positionierung zu CCS: In seinen eigenen Publikationen nennt Ken Caldeira CCSTechnologien als mögliche Klimaschutz-Option unter anderen, ist aber skeptisch in Bezug auf ihre Wirksamkeit (vgl. im Internet: dge.stanford.edu/labs/caldeiralab/Caldeira_research/ Myhrvold_Caldeira.html, letzter Zugriff am 02.12.2014).

\section{Makoto Akai}

Kapitel: Ocean Storage

Arbeitsstandort: Japan

Arbeitgeber: National Institute of Advanced Industrial Science and Technology

Positionierung zu CCS: Das National Institute of Advanced Industrial Science and Technology ist ein Forschungsinstitut, das hauptsächlich von der japanischen Regierung finanziert wird (vgl. im Internet: www.aist.go.jp, letzter Zugriff am 02.12.2014). Makoto Akai arbeitet seit über 20 Jahren zu CCS-Technologien und übt in dem Zusammenhang unter anderem die Funktion des Board Director beim Global CCS Institute aus (vgl. im Internet: www.decarboni.se/node/35911, www.globalccsinstitute.com/institute/about-theinstitute/board-directors, letzter Zugriff am 02.12.2014) (zur Einordnung des Global CCS Institute vgl. Kapitel 5.2.1).

\section{Marco Mazzotti}

Kapitel: Mineral carbonation and industrial uses of carbon dioxide Arbeitsstandort: Schweiz

Arbeitgeber: Eidgenössische Technische Hochschule Zürich 
Positionierung zu CCS: Marco Mazzotti forscht auch jenseits des IPCC-Berichts zu CCSTechnologien. CCS bezeichnet er als wichtige Brückentechnologie. Seine positive Einstellung gegenüber CCS-Technologien zeigt sich beispielsweise bei seiner Leitung eines CCS-Fokusprojekts, in dem es unter anderem darum geht, „unbegründete Ängste abzubauen“ (vgl. im Internet: www.ipe.ethz.ch/laboratories/spl/FocusCCS/index, www.ipe.ethz. ch/laboratories/spl/FocusCCS/Dossier_Fokusprojekt.pdf, letzter Zugriff am 02.12.2014). Um die Entwicklung von CCS-Technologien voran zu bringen, plädiert Mazzotti für ein CCS-Gaskraftwerk als Pilotprojekt in der Schweiz (vgl. im Internet: www.ethlife.ethz.ch/ archive_articles/120608_carboncapture1_mf/index, www.ethlife.ethz.ch/archive_articles/ 120611_carbonstorage2_mf, letzter Zugriff am 02.12.2014).

\section{Howard Herzog}

Kapitel: Costs and economic potential

\section{Arbeitsstandort: USA}

Arbeitgeber: Massachusetts Institute of Technology (MIT)

Positionierung zu CCS: Howard Herzog ist Direktor der Carbon Sequestration Initiative (CSI), eine Kooperation verschiedener Unternehmen, die im Jahr 2000 zur Erforschung und Entwicklung von CCS-Technologien ins Leben gerufen wurde. Das CSI wird primär von Öl- und Energiekonzernen gefördert (vgl. im Internet: sequestration.mit.edu, letzter Zugriff am 02.12.2014). Herzog ist davon überzeugt, dass CCS-Technologien sicher sind und sich in naher Zukunft - aufgrund eines Marktpreises für Emissionen - auch finanziell lohnen werden (vgl. im Internet: www.zeit.de/online/2008/37/interview_herzog-ccs, letzter Zugriff am 02.12.2014).

\section{Koen Smekens}

Kapitel: Costs and economic potential

Arbeitsstandort: Niederlande

Arbeitgeber: Energy research Centre of the Netherlands (ECN)

Positionierung zu CCS: Koen Smekens steht den CCS-Technologien positiv gegenüber. In einem Aufsatz aus dem Jahr 2004 - der also während der Arbeit am IPCC-Bericht erschien - bezeichnet er CCS als sinnvolle Brückentechnologie. In dem Artikel spricht er sich für CCS-Kohlekraftwerke aus. In Bezug auf die Verpressung hält Smekens das Verfahren des ECBM für vielversprechend (vgl. Smekens/Van der Zwaan 2004: 21ff).

\section{Balgis Osman-Elasha}

Kapitel: Implications of carbon dioxide capture and storage for greenhouse gas inventories and accounting

Arbeitsstandort: Sudan 
Arbeitgeber: Higher Council for Environment and Natural Resources

Positionierung zu CCS: Das Higher Council for Environment and Natural Resources ist Teil des sudanesischen Ministeriums für Umwelt und urbane Entwicklung. Balgis OsmanElasha publizierte weder vor noch nach dem IPCC-Bericht zu CCS-Technologien. Da auch ansonsten keine Hinweise für ihre Perspektive auf Energiepolitik im Allgemeinen und auf CCS-Technologien im Besonderen zu finden waren, schrieb ich sie per E-Mail an. In ihrer Antwort legt sie dar, dass der Einsatz von CCS-Technologien langfristig durchaus sinnvoll sein könne, sie kurzfristig aber andere Optionen bevorzuge. ${ }^{29}$

\section{Riitta Pipatti}

Kapitel: Implications of carbon dioxide capture and storage for greenhouse gas inventories and accounting

Arbeitsstandort: Finnland

Arbeitgeber: Statistics Finland

Positionierung zu CCS: Riita Pipatte ist bei Statistics Finland für die Bestandsaufnahme von Treibhausgasen zuständig. In meinen Recherchen konnte ich keine Positionierung Pipattis bezüglich CCS-Technologien ausfindig machen.

29 Hier die komplette E-Mail: Datum: 27.06.2012

Von: Balgis Elasha

An: Timmo Krüger

Betreff: Re: IPCC Special Report

Dear Timmo,

Thanks for your message and the interest on the IPCC Special Report on Carbon Dioxide Capture and Storage (CCS). As you mentioned, I was one of the Coordinating Lead Authors of Chapter 9 on Inventory and Accounting, so my focus was mainly on how to measure the GHG emissions and reductions upon the implementation of this mitigation measure/technologies. As what I think about it, I can say that it is a potentially useful option for mitigation. However, certain conditions need to be met before it should be adopted as a safe mitigation measure such as: 1) We need to ensure a maximum safety/ minimum risk to human and environment - this applies for all the steps involved in its operation: separation, capture, storage, transportation and dumping, (2) Establishment and mechanisms for enforcing the regulations and laws governing $\mathrm{CO} 2 \mathrm{~s}$ transportation across boarders, storage or use (3) Technology should be available at an affordable cost for both the developed and developing countries. I can see this happening in the long term future, for the time being we need to focus on less complicated, less risky and less costly options including renewable energies and clean technologies.

Regards Balgis 
Die Ergebnisse der Recherche zur Auswahl der Coordinating Lead Authors werde ich nun im Hinblick auf die genannten IPCC-Grundsätze zusammenfassen. Zunächst einmal ist zu bemerken, dass es nur vier Autorinnen (de Coninck, Benson, Osman-Elasha, Pipatti) und 15 Autoren sind. Insofern wurde das Kriterium der ausgewogenen Verhältnisses von Männern und Frauen (,gender balance“) nur bedingt, wenn überhaupt, erfüllt.

Des Weiteren ist auffällig, dass lediglich zwei Autor_innen in einem NichtAnnex-B-Staat arbeiteten (Iran, Sudan). 17 Autor_innen arbeiteten dagegen in einem Annex-B-Staat. Die Richtlinie der ausgewogenen Vertretung von Annex-Bund Nicht-Annex-B-Staaten (,geographical representation“) wurde somit nur minimal eingehalten. Laut de Coninck, die selber eine der Coordinating Lead Authors des Berichts war, gab es zum damaligen Zeitpunkt nur wenige CCS-Expert_innen aus Nicht-Annex-B-Staaten, weshalb auch auf Generalist_innen zurückgegriffen wurde, um der Vorgabe der ,geographical representation“ annähernd gerecht zu werden. ${ }^{30}$

In Bezug auf das Kriterium der Varianz an Perspektiven (,range of scientific, technical and socio-economic views and expertise") ergibt meine Recherche folgende Ergebnisse: 15 der 19 Autor_innen arbeiten in Ländern, die sich sehr aktiv für die Entwicklung von CCS-Technologien einsetzen (Australien, Großbritannien, Japan, Niederlande, Spanien, USA). Für den Iran habe ich die Interessen des staatlichen Öl-Konzerns beschrieben, denen bislang allerdings keine nennbaren Aktivitäten folgten. Lediglich drei Autor_innen arbeiten in Ländern, die sich bislang nicht in dem Maße für CCS-Technologien interessieren (Schweiz, Sudan, Finnland). Dieses Missverhältnis ist umso drastischer wenn man bedenkt, dass es insgesamt nur eine geringe Anzahl an Ländern gibt, die sich so eindeutig für CCS-Technologien engagieren bzw. in denen die Erforschung und Entwicklung von CCS-Technologien vorangetrieben wird (vgl. Kapitel 5.2.1). Dass sich ein Großteil der Autor_innen in Publikationen und Vorträgen eindeutig für CCS-Technologien ausspricht, habe ich im Einzelfall bereits dargelegt. An dieser Stelle möchte ich deshalb nur noch einmal zusammentragen, dass neun der 19 Autor_innen für ein Forschungsinstitut oder ein Unternehmen arbeiten, das ein spezifisches (v. a. auch kommerzielles) Interesse an der Entwicklung und Anwendung von CCS-Technologien hat. Zwei Autor_innen arbeiten für das Global CCS Institute und jeweils eine_r für das Argonne National Laboratory, das Greenhouse Gas R\&D Programme der IEA, das Instituto Nacional del Carbon, das Centre for Low Emission Technology, Andrew Palmer and Associates, das Cooperative Research Centre for Greenhouse Gas Technologies und die

30 Diese Einschätzung erfolgte in einem Interview, das ich am 16.05.2013 mit Heleen de Coninck geführt habe. 
Carbon Sequestration Initiative. Dagegen arbeitet keine_r der Autor_innen für einen Arbeitgeber, der sich prinzipiell gegen CCS-Technologien ausgesprochen oder zumindest skeptisch gegenüber CCS positioniert hat. Es sind - auch was die persönliche Positionierung betrifft - keine expliziten Kritiker_innen vertreten. Nur bei zwei Autor_innen ist sicher davon auszugehen, dass sie gewisse Zweifel an dem Potenzial von CCS-Technologien haben (Caldeira und Osman-Elasha). Beide haben allerdings keine prinzipiellen Vorbehalte gegenüber CCS und sprechen sich keineswegs allgemein gegen die Entwicklung und den Einsatz von CCS-Technologien aus.

Insgesamt hat die Recherche ergeben, dass die Auswahl der Coordinating Lead Authors des IPCC SRCCS einseitig war und den eigenen Richtlinien des IPCC nur sehr eingeschränkt, wenn überhaupt, gerecht wird. Da sehr viele explizite Befürworter_innen von CCS-Technologien an dem Bericht beteiligt waren, fällt die mangelnde Repräsentation kritischer Stimmen um so stärker ins Gewicht. Einen besonders großen Einfluss auf den IPCC-Bericht hatte das IEA GHG R\&D Programme (zum IEA GHG R\&D Programme vgl. Kapitel 5.2.1), für das zwei Coordinating Lead Authors des Berichts arbeiten (vgl. Meadowcroft/Langhelle 2009b: 6). De Coninck und Stefan Bakker betonen in einem Aufsatz die Bedeutung der IEA:

"The IPCC Special Report on Carbon dioxide Capture and Storage substantially based itself on direct and indirect results of projects developed by the IEA GHG R\&D Programme." (de Coninck/Bakker 2005: 15)

Ganz ähnlich lautet die Einschätzung in einem späteren Artikel, der erneut von de Coninck, dieses Mal zusammen mit Karin Bäckstrand, geschrieben wurde:

„For its Special Report, the IPCC drew heavily on both the studies commissioned by the IEA GHG, and its employees: most of the IEA GHG employees were authors.“ (de Coninck/ Bäckstrand 2011: 371)

Aber auch zu anderen Organisationen, Unternehmen, Wirtschaftsverbänden, Forschungsinstituten und Institutionen, die direkt oder indirekt von der Entwicklung der CCS-Technologien profitieren, gibt es Verbindungen. Laut de Coninck hatten die meisten Autor_innen des IPCC SRCCS eine positive Einstellung gegenüber CCS-Technologien. Dies ist ihrer Meinung nach darauf zurückzuführen, dass viele der Autor_innen an ihrem Arbeitsplatz mit der Erforschung und Entwicklung von CCS-Technologien betraut sind. Dies habe sowohl für die Wissenschaftler_innen aus den Universitäten als auch für die Expert_innen aus den Unternehmen 
zugetroffen. ${ }^{31}$ Vor dem Hintergrund des oben beschriebenen developer optimism der CCS-Community lässt die Auswahl der Autor_innen einen optimistischen Bericht erwarten. Inwieweit diese Vermutung zutrifft, interpretiere ich im nächsten $\mathrm{Ab}$ schnitt zur Argumentationslinie des IPCC SRCCS.

\subsubsection{Die Argumentationslinie des Sonderberichts zu CCS}

Auch beim Sonderbericht zu CCS gibt es, wie bei IPCC-Berichten üblich, eine $Z u$ sammenfassung für politischen Entscheidungsträger_innen, die im IPCC-Plenum Zeile für Zeile im Konsens beschlossen wurde. Da ich davon ausgehe, dass in erster Linie diese Zusammenfassung als Basis der politischen Aushandlungsprozesse fungiert - schließlich wurde sie genau für diesen Zweck erstellt - ist sie für die Beantwortung meiner Forschungsfragen besonders relevant. ${ }^{32}$ Deshalb unterzog ich sie einer Feinanalyse (für das methodische Vorgehen vgl. Kapitel 2.3.3), deren Ergebnisse ich im Folgenden darstelle. ${ }^{33}$

Gleich auf der ersten Seite der Zusammenfassung wird das Feld bereits weitestgehend abgesteckt, innerhalb dessen sich der Bericht mit CCS-Technologien auseinandersetzt. Im IPCC SRCCS wird die Erörterung der technologischen Option CCS im Rahmen des Status quo gesellschaftlicher Verhältnisse vorgenommen. Dahinter steht die Annahme, dass das Ziel der Klimapolitik durch ein Portfolio technologischer Lösungen erreicht werde (vgl. Enthymeme ${ }^{34}$ IPCC 1, IPCC 2; IPCC 2005: 3). Die Zielsetzung wird dabei von der Klimarahmenkonvention übernom-

31 Diese Einschätzung erfolgte in einem Interview, das ich am 16.05.2013 mit Heleen de Coninck geführt habe.

32 Angemerkt sei an dieser Stelle, dass die Zusammenfassung für politischen Entscheidungsträger_innen in Bezug auf den allgemeinen Tenor und die relevanten Argumente keine wesentlichen Unterschiede zur technischen Zusammenfassung, der Technical Summary, aufweist, an der keine Politiker_innen beteiligt waren und das auch keinem Konsensverfahren unterzogen wurde. Insofern liegt die Besonderheit der Zusammenfassung für politische Entscheidungsträger_innen nicht in ihrer inhaltlichen Ausrichtung, sondern in der stärken Selektion der Inhalte und ihrer breiteren Rezeption.

33 In Bezug auf die mit Hilfe der Feinanalyse herausgearbeiteten Enthymeme (vgl. Anhang A.2) ist interessant, dass bei über der Hälfte die Schlussfolgerungen implizit bleiben. Dies ist auf den Auftrag des IPCC zurückzuführen, lediglich ,politikrelevante Informationen “und nicht konkrete Handlungsempfehlungen - bereitzustellen (vgl. Kapitel 5.3.1). Über die Rekonstruktion der impliziten Schlussfolgerungen zeigt sich aber, wie durch die Auswahl und Darstellung der Informationen bestimmte Schlussfolgerungen suggeriert werden. 
men, in der die Stabilisierung der Treibhausgaskonzentration in der Atmosphäre auf einem Niveau anvisiert wird, auf dem eine gefährliche anthropogene Störung des Klimasystems verhindert werden kann. Diese Bezugnahme auf die Klimarahmenkonvention geschieht hier implizit, allerdings wird sie im Technical Summary expliziert (vgl. IPCC 2005: 20). Indem das zu lösende Problem als ein globales Problem definiert wird, geraten lokale Unterschiede in der Verursachung und den Konsequenzen des Klimawandels aus dem Blick. Gesellschaftspolitische Fragen, wie die nach Gerechtigkeit, werden darüber hinaus durch den Fokus auf ein Portfolio technologischer Lösungen ausgeklammert.

Die Politikberatung des IPCC baut auf der Setzung gesellschaftlicher Strukturen auf, die nicht Gegenstand der wissenschaftlichen Analyse sind, sondern ihr den Rahmen vorgeben. Unter der Annahme, dass diese Strukturen stabil bleiben und damit vorhersehbar sind, werden technologische Lösungen danach bewertet, wie gut sie sich darin implementieren lassen. In Bezug auf CCS-Technologien äußert sich dies in der positiven Beurteilung ihrer, Flexibilität'. Flexibilität meint hier das Vermögen, innerhalb der gegebenen Rahmenbedingungen auf den Klimawandel reagieren zu können. Im Gegensatz zu anderen Klimaschutzoptionen benötigt die Einführung von CCS-Technologien keine sozio-ökonomischen und institutionellen Veränderungen (vgl. Enthymem IPCC 5; IPCC 2005: 3, 12). Darin wird ein spezifischer Wettbewerbsvorteil von CCS gegenüber anderen Klimschutzoptionen gesehen. Im Bericht wird hervorgehoben, dass CCS-Technologien die Möglichkeit bieten, innerhalb des Status quo der Energieinfrastruktur flexibler auf den anthropogenen Klimawandel zu reagieren und somit die Kosten der Stabilisierung der Treibhausgaskonzentration in der Atmosphäre um mindestens $30 \% \mathrm{zu}$ senken (vgl. Enthymem IPCC 6; IPCC 2005: 3, 12).

An dieser Stelle wird bereits deutlich, dass das Potenzial zur Senkung der betriebswirtschaftlichen Kosten des Klimaschutzes als wichtigstes Kriterium für die Bedeutung von CCS-Technologien innerhalb des Portfolios gilt (vgl. Enthymem IPCC 3; IPCC 2005: 3, 10). Andere denkbare Kriterien werden im Rahmen dieser grundsätzlichen Bewertung technologischer Optionen zunächst einmal ausgeklammert und ihnen wird insgesamt kaum oder gar keine Aufmerksamkeit geschenkt. Dies betrifft beispielsweise: volkswirtschaftliche Kosten-Nutzen-Kalkulationen, über die Reduktion von Treibhausgasemissionen hinausgehende ökologische, gesundheitliche sowie soziale Folgen und Risiken, der Einfluss der Entwicklung

34 Die Analyse von Argumentationslinien basiert in dieser Arbeit auf der Herausarbeitung von Enthymemen, die im Anhang aufgelistet sind. Die Erläuterung des methodischen Vorgehens findet sich in Kapitel 2.3.3. 
und Anwendung einer bestimmten Technologie auf politische Entscheidungen ${ }^{35}$ und auf langfristige Strategien bezüglich einer klimaneutralen Lebensweise.

Die geringe Bedeutung dieser Aspekte zeigt sich auch in der Setzung der Abhängigkeit der Wirtschaft von fossilen Brennstoffen als unproblematische Rahmenbedingung. Im Bericht wird auf Szenario-Studien verwiesen, die prognostizieren, dass der Anteil fossiler Brennstoffe an der Deckung des Primärenergiebedarfs mindestens bis zur Mitte des Jahrhunderts dominant bleiben wird. Vor diesem Hintergrund wird der potenzielle Beitrag von CCS-Technologien zum Klimaschutz relativ hoch eingeschätzt (vgl. Enthymem IPCC 4; IPCC 2005: 3, 10ff).

Im IPCC SRCCS wird nicht der Verbrauch fossiler Brennstoffe, sondern nur die daraus folgenden Emissionen problematisiert (vgl. die Anmerkungen zur Trennung in die Input-Seite der Energie-Produktion mit fossilen Brennstoffen und die OutputSeite der daraus entstehenden Emissionen in Kapitel 3.4.3; Brunnengräber et al. 2008: 188ff). Weder die Endlichkeit der Ressourcen noch die sozialen und ökologischen Probleme ihrer Gewinnung ${ }^{36}$ werden erwähnt. Stattdessen wird das Potenzial von CCS-Technologien, in Kombination mit EOR und ECBM die Fördermenge von fossilen Brennstoffen zu erhöhen, als positiver Faktor für die betriebswirtschaftliche Kosten-Nutzen-Kalkulation aufgeführt (vgl. Enthymem IPCC 8; IPCC 2005: 6, 10). Die ungebremste Nutzung fossiler Brennstoffen wird damit festgeschrieben. Dies bedeutet wiederum, dass der Status quo der Energieinfrastruktur perpetuiert wird. Im Bericht wird keine Perspektive entwickelt, die über die bestehenden Institutionen hinausweist.

Es erfolgt somit auch keine Gegenüberstellung von zentralisierter und dezentraler Energieproduktion. Ausgeblendet werden damit Debatten über die Möglichkeit einer demokratischen Organisation von Energieproduktion, in denen Vorstellungen von Energiesouveränität und Energiedemokratie verhandelt werden. Ausgeklammert wird damit auch der Zusammenhang zwischen der Oligopol-Stellung der etablierten Energieunternehmen, dem großen Anteil der kapitalintensiven Nutzung fossiler Brennstoffe an der Erzeugung der Primärenergie und der zentralisierten Energieproduktion. Dabei könnten diese Aspekte auch in einer engen Klimaschutzperspektive - die allein auf die Verringerung der globalen $\mathrm{CO}_{2}$-Emissionen zielt problematisiert werden. Schließlich basiert die gängige Hauptkritik an der zentralisierten Energieproduktion nicht auf demokratietheoretischen Überlegungen, son-

35 Zum Beispiel auf die Entscheidung für oder gegen den Bau von neuen Kohlekraftwerken.

36 Mit der Ressourcengewinnung sind beispielsweise folgende Konsequenzen verbunden: Umsiedlungen ganzer Gemeinden, die Zerstörung ökologischer Systeme, die gesundheitliche Beeinträchtigung der Anwohner_innen, erhöhte Risiken und ökologische Schäden aufgrund der Abschöpfung unkonventioneller Öl- und Gasquellen. 
dern auf dem sogenannten Systemkonflikt von trägen Grundlastkraftwerken und erneuerbaren Energien. Die schwankende Einspeisung von Energie aus erneuerbaren Energien erfordert eine Flexibilisierung der Energieproduktion insgesamt. Kohlekraftwerke herunterzufahren oder abzuschalten ist zeitaufwendig und teuer. Deshalb sind sie nicht kompatibel mit einem großen Anteil an erneuerbaren Energien. Dies bedeutet, dass die Energieproduktion durch Grundlastkraftwerke - die als große punktuelle $\mathrm{CO}_{2}$-Quellen für CCS in Frage kommen - den Zuwachs an erneuerbaren Energien ab einem gewissen Level beschränkt. Derartige Vorbehalte oder Einschränkungen gegenüber dem Einsatz von CCS-Technologien finden im IPCC SRCCS keine Erwähnung. Stattdessen erscheint die prognostizierte Zunahme großer punktueller $\mathrm{CO}_{2}$-Quellen als positives Indiz für das Klimaschutz-Potenzial von CCS-Technologien (vgl. Enthymeme IPCC 7, IPCC 9; IPCC 2005: 3, 9, 10). Damit gilt der Status quo der Energieinfrastruktur als unproblematische Basis für die Bewertung von Klimaschutzoptionen.

Die bisherigen Ergebnisse der internationalen Klimaverhandlungen bilden ein weiteres Ensemble von Voraussetzungen, die im Bericht als Konstanten gesetzt werden. So wird an mehreren Stellen deutlich, dass die flexiblen Mechanismen des Kyoto-Protokolls als Rahmenbedingungen für die Bewertung technologischer Optionen gelten und zwar ungeachtet dessen, dass das Kyoto-Protokoll 2012 auslief $^{37}$ und der frühestmögliche großflächige Einsatz von CCS-Technologien für den Zeitraum 2020 bis 2030 prognostiziert wird. Die Setzung der flexiblen Mechanismen als Rahmenbedingung geschieht in der Zusammenfassung für politische Entscheidungsträger_innen implizit, wird aber durch die Referenz auf den Marktpreis von $\mathrm{CO}_{2}$-Äquivalenten eindeutig nahe gelegt. Im Technical Summary wird dann direkt auf die verschiedenen Emissionsberechtigungen des Kyoto-Protokolls verwiesen (vgl. IPCC 2005: 11, 48). Im Bericht wird davon ausgegangen, dass der größte Beitrag von CCS-Technologien zur Abschwächung des Klimawandels durch die Anwendung im Energiesektor geleistet werden könne. Anschließend wird darauf verwiesen, dass der großflächige Einsatz von CCS-Technologien im Energiesektor vom Marktpreis der Emissionsberechtigungen abhänge. Dabei wird auf Schätzungen rekurriert, die zeigen, dass es ab einem Marktpreis von ca. 25-30 US\$/ $\mathrm{tCO}_{2} \mathrm{zu}$ einem signifikanten Einsatz von CCS-Technologien im Energiesektor kommen würde. Bleiben die Preisanreize durch den Emissionsrechtehandel aus oder auf einem geringen Niveau, werde es nur zur Speicherung einer geringen Menge $\mathrm{CO}_{2}$ (bis zu $360 \mathrm{MtCO}_{2}$ pro Jahr) kommen, die bei kostengünstigen Abscheidungsprozessen

37 Mittlerweile gibt es tatsächlich viele Anzeichen dafür, dass die flexiblen Mechanismen weiterhin wirkmächtig bleiben (vgl. Kapitel 5.1.2). Zum Zeitpunkt der Arbeit am IPCC SRCCS war dies allerdings so konkret noch nicht abzusehen. 
entsteht (z. B. bei der Gasverarbeitung sowie der Wasserstoff- und Ammoniakherstellung wo die Abscheidung von $\mathrm{CO}_{2}$ bereits durchgeführt wird). Die Potenziale der technologischen Optionen werden hier nur im Zusammenhang mit den flexiblen Mechanismen, wie sie derzeit gelten, beschrieben (vgl. Enthymem IPCC 10; IPCC 2005: 11). Ausgeklammert werden damit alternative Klimaschutzstrategien, die nicht auf die Inwertsetzung von Natur bzw. Marktmechanismen setzen. Durch die konsequente Argumentation mit den flexiblen Mechanismen in einem Bericht, der zukünftige politische Entscheidungen vorbereiten soll, wird eine erst vor kurzem geschaffene Institution als unabänderliche Rahmenbedingung festgeschrieben.

Das Ziel der flexiblen Mechanismen besteht in der möglichst kostengünstigen Erfüllung der festgelegten Reduktionsziele. Wenn Klimaschutzoptionen auf dieser Basis beurteilt werden, hängt ihr Einsatz allein von ihrem Beitrag zur Senkung der betriebswirtschaftlichen Kosten der Emissionsreduktionen ab. Deshalb bezieht der IPCC - anders als beispielsweise der Sachverständigenrat für Umweltfragen (SRU) - auch nicht Stellung für die Anwendung von CCS-Technologien bei Bioenergiekraftwerken anstatt Kohlekraftwerken. Im Bericht wird konstatiert, dass der Einsatz von CCS-Technologien bei Kraftwerken, die mit Biomasse betrieben werden, zwar im Vergleich zum Einsatz bei Kohlekraftwerken zu einer niedrigeren oder gar zu einer negativen $\mathrm{CO}_{2}$-Bilanz führe, bislang aber teurer sei, da Biomassekraftwerke nach aktuellem Stand der Technik relativ klein sind. Deshalb wird auf den Marktpreis der Emissionsberechtigungen verwiesen, von dessen Entwicklung die betriebswirtschaftlichen Kosten der Anwendung von CCS-Technologien bei Biomassekraftwerken und damit ihr Einsatz abhänge (vgl. IPCC 2005: 10). Der SRU plädiert stattdessen explizit für eine langfristige Perspektive, in der die Inanspruchnahme geologischer Speicherorte nach dem volkswirtschaftlichen Kriterium des „höchsten gesellschaftlichen Nettonutzen[s]“ (Sachverständigenrat für Umweltfragen 2009: 20) erfolgen solle. Dahinter steht die Annahme, dass es zu Nutzungskonkurrenzen zwischen CCS und anderen Nutzungsmöglichkeiten wie Geothermieprojekten, Energiespeicherung in Druckluftspeichern und Bioenergie-CCS kommen werde (vgl. Sachverständigenrat für Umweltfragen 2009: 14, 20).

$\mathrm{Zu}$ unterschiedlichen Schlüssen kommt der SRU auch in Bezug auf die Frage nach den Möglichkeiten einer sicheren langfristigen Speicherung von $\mathrm{CO}_{2}$ innerhalb geologischer Formationen. Der IPCC prognostiziert, dass es sehr wahrscheinlich sei, dass $99 \%$ des durch CCS-Technologien verpressten Kohlenstoffdioxids über 100 Jahre und dass es wahrscheinlich sei, dass $99 \%$ über 1000 Jahre in adäquat ausgewählten geologischen Formationen verbleibt. Wahrscheinlich wird dabei als eine Wahrscheinlichkeit zwischen 66 und $90 \%$ und sehr wahrscheinlich als eine Wahrscheinlichkeit von 90 bis $99 \%$ präzisiert (vgl. IPCC 2005: 14). Die 
Prognose basiert auf Analogien mit in der Natur vorkommenden sowie mit anderen technisch hergestellten $\mathrm{CO}_{2}$-Speichern (vgl. Enthymem IPCC 11; IPCC 2005: 14). Im IPCC-Bericht wird implizit davon ausgegangen, dass man in der Natur vorkommende $\mathrm{CO}_{2}$-Speicher mit der Speicherung im Rahmen von CCS vergleichen könne. Dies ist problematisch, da den natürlich vorkommenden Speichern kein Prozess der Injektion vorausgeht. Schließlich ist es denkbar, dass die Verpressung von $\mathrm{CO}_{2}$ selber Brüche und Risse verursacht bzw. ausweitet und damit Leckagen auslöst (zur ausführlichen Darstellung der Risiken vgl. Kapitel 5.2.2). Insofern ist die Analogie zwischen natürlichen und künstlich geschaffenen Speichern nicht unumstritten. Aber selbst wenn man deren Vergleichbarkeit voraussetzt, können daraus unterschiedliche Schlussfolgerungen gezogen werden. Der SRU verweist in seinem Bericht darauf, dass es auch bei natürlichen $\mathrm{CO}_{2}$-Quellen zu einem plötzlichen Austritt von $\mathrm{CO}_{2}$ kommen könne. Sobald in einem kurzen Zeitraum größere Mengen $\mathrm{CO}_{2}$ freigesetzt werden, kann sich an der Austrittsstelle in Bodennähe ein $\mathrm{CO}_{2}$-See bilden, da $\mathrm{CO}_{2}$ schwerer als Luft ist. Solch ein See wirkt erstickend auf Lebewesen. Als 1986 in einem Vulkangebiet am Nyos-See in Kamerun $\mathrm{CO}_{2}$ austrat starben 1.700 Menschen (vgl. SRU 2009: 10).

Neben der Analogie zu natürlichen $\mathrm{CO}_{2}$-Speichern bezieht sich der IPCC SRCCS auf Erfahrungen mit technisch hergestellten Gasspeichern. In der Zusammenfassung für politische Entscheidungsträger_innen werden diese nicht näher präzisiert. Im Kapitel zur Speicherung wird allerdings auf Erfahrungen mit EOR und mit der unterirdischen Lagerung von Sauergas sowie auf Erfahrungen mit den drei bis dato angelaufenen CCS-Demonstrationsprojekten ${ }^{38}$ im industriellen Maßstab verwiesen (vgl. IPCC 2005: 197). Auch was diese zweite Quelle für die Beurteilung zukünftiger CCS-Projekte betrifft, vertritt der SRU eine skeptischere Position. Nach Meinung des SRU gebe es noch kein ausreichendes Wissen über Leckageraten und die langfristige Sicherheit der $\mathrm{CO}_{2}$-Speicherung (vgl. SRU 2009: 140f). Die Erfahrungen der drei Demonstrationsprojekte reichen - angesichts der angestrebten Speicherung von $\mathrm{CO}_{2}$ über mehrere tausend Jahre - noch nicht so lange zurück. Das Sleipner-Projekt operiert seit 1996, das Weyburn-Projekt seit 2000, das InSalah-Projekt seit 2004 und das Snøhvit-Feld seit 2008. Insgesamt bewertet der SRU CCS-Technologien weitaus kritischer als der IPCC, wie der letzte Absatz seiner Stellungnahme zum CCS-Gesetzentwurf der Bundesregierung aus dem Jahre 2009 deutlich zeigt:

38 Im Sleipner-Projekt (Norwegen) wird offshore in einem salinen Aquifer $\mathrm{CO}_{2}$ gespeichert, beim Weyburn-Projekt (Kanada) wird $\mathrm{CO}_{2}$ in eine Erdöllagerstätte gepumpt (EOR) und im In-Salah-Projekt (Algerien) wird $\mathrm{CO}_{2}$ onshore in einem salinen Aquifer verpresst. 
„Die Entscheidung über die Nutzung unterirdischer Räume ist wegweisend für die Frage nach dem zukünftigen Energieversorgungssystem in Deutschland, weil verschiedene Nutzungen wie $\mathrm{CO}_{2}$-Speicherung, Geothermie, Druckluft- und Gasspeicherung in Konkurrenz zueinander treten bzw. sich gegenseitig ausschließen können. Solche Entscheidungen können wesentliche strategische Weichenstellungen bedeuten und sollten daher in einem transparenten politischen und gesellschaftlichen Prozess und nach Durchführung einer die langfristigen ökologischen und ökonomischen Kosten einschließenden Folgenabschätzung getroffen werden. Die im Gesetzentwurf angelegte Bevorzugung heutiger Interessen aus dem Bereich der Nutzung fossiler Energieträger birgt zudem das Risiko, dass sowohl die in der langen Zeitperspektive notwendige Nutzung von Speicherstätten zur Erzielung negativer Gesamtemissionen als auch die Nutzung großer geothermischer Energiepotenziale und die Nutzung von Druckluftspeichern im Rahmen eines praktisch $\mathrm{CO}_{2}$-freien Energiesystems verhindert werden. Um einen nachhaltigen Klimaschutz nicht zu erschweren oder langfristig sogar unmöglich zu machen, sollte deshalb CCS zunächst nur im Rahmen von Demonstrationsprojekten zugelassen werden.“(SRU 2009: 34)

\section{Vergleich des IPCC SRCCS mit dem Bericht des SRU}

Was sind die Gründe für diese unterschiedliche Einschätzung von CCS in den Berichten? Ich sehe zwei zentrale Argumente, für die ich im Folgenden Plausibilität erzeugen möchte, da über den Vergleich mit dem SRU-Bericht bestimmte Charakteristika des IPCC-Berichts deutlich werden. Das erste Argument betrifft die Auswahl der Autor_innen und das zweite spezifische Unterschiede in der (Re-)Produktion ökomoderner Diskursstränge.

In Bezug auf die Selektion der Autor_innen des IPCC SRCCS - und auch der Teilnehmer_innen des Workshops, auf dem das Scoping Paper erstellt wurde - ist davon auszugehen, dass ihre in der Summe starke Affinität zu CCS-Technologien einen großen Einfluss auf die Auswahl, Gewichtung und Beurteilung verschiedener Aspekte wie die ökologischen und gesundheitlichen Risiken, die betriebswirtschaftlichen Kosten, die Reife der Technologie, mögliche Nutzungskonkurrenzen, etc. hatte.

Was den SRU betrifft, so wird eine derartige Präsenz von Expert_innen der CCSCommunity durch seine Rekrutierungsmechanismen verhindert. Zunächst einmal ist festzuhalten, dass der SRU stärker interdisziplinär aufgestellt und nicht von Ingenieur_innen und Ökonom_innen dominiert wird, wie Jobst Conrad das für die Arbeitsgruppe III des IPCC festgestellt hat (vgl. Conrad 2010: 103). ${ }^{39}$ Berufen werden die Ratsmitglieder vom Bundes-

39 Beim IPCC SRCCS war die Zahl an originären Sozialwisssenschaftler_innen laut de Coninck gering, da sich zum damaligen Zeitpunkt in den Sozialwissenschaften nur wenige CCS-Expert_innen finden ließen. (Diese Einschätzung erfolgte in einem Interview, das ich am 16.05.2013 mit Heleen de Coninck geführt habe.) 
ministerium für Umwelt, Naturschutz und Reaktorsicherheit. Das wichtigste Auswahlkriterium für die Ernennung zur Mitgliedschaft beim SRU ist die wissenschaftliche Qualifikation, was auf den IPCC genauso zutrifft. Im Unterschied zum IPCC müssen die Mitglieder des SRU aber ,über besondere wissenschaftliche Kenntnisse und Erfahrungen im Umweltschutz verfügen“ (vgl. im Internet: www.umweltrat.de, letzter Zugriff am 02.12.2014; Hervorhebung T. K.). Die Verortung des Rates als Umweltgremium führt zu einer ökologischen Ausrichtung, die sich in den Berichten des SRU niederschlägt. Entscheidend ist darüber hinaus, dass die Mitglieder des SRU in den sieben Jahren vor ihrer Ernennung nicht Repräsentant_in eines Wirtschaftsverbandes, einer Arbeitgeber- oder Arbeitnehmerorganisation gewesen sein und auch nicht zu diesen in einem ständigen Dienst- oder Geschäftsbesorgungsverhältnis gestanden haben dürfen - eine Auflage, die es beim IPCC nicht gibt. Damit ist eine enge Verschränkung der Wissenschaftler_innen mit Politik und Wirtschaft, die bei vielen Autor_innen des IPCC SRCCS zu finden ist, beim SRU unwahrscheinlicher. Im Vergleich zu den Autor_innen des IPCC SRCCS kann man also davon ausgehen, dass sie gar nicht oder zumindest weitaus weniger und indirekter von der Entwicklung, Forschung und Anwendung von CCS-Technologien profitieren.

Im zweiten Argument geht es mir um spezifische Muster der Diskursreproduktion, die weniger mit den konkreten Autor_innen, dafür aber umso mehr mit dem institutionellen Setting zu tun haben. Dabei ist zunächst einmal festzuhalten, dass der IPCC im UN-Kontext durch spezifische Diskursstränge geprägt ist. Wie ich in den Kapiteln 3 und 5.1.3 darlege, dominiert der ökomoderne Diskurs die Auseinandersetzung mit ökologischen Themen auf internationaler Ebene im Allgemeinen und die UN-Klimaverhandlungen im Besonderen. Hajer hebt hervor, dass besonders in den internationalen Institutionen verschiedene Diskursstränge zu einem kohärenten ökomodernen Konzept geformt und als Basis von Politikformulierung etabliert wurden (vgl. Hajer 1995: 101). Der IPCC agiert in einem stark ökomodern geprägten Feld und seine Perspektive ist durch eine aktive Re-Produktion - die auch immer bestimmte Abwandlungen und/oder Weiterentwicklungen beinhaltet - des internationalen ökomodernen Diskurses gekennzeichnet (vgl. Kapitel 5.3.4). Diese Dominanz des ökomodernen Diskurses findet sich auch im nationalstaatlichen Kontext. Allerdings spielen in verschiedenen Ländern Europas, und in besonderer Weise in Deutschland, die erneuerbaren Energien eine bedeutsame Rolle in umweltpolitischen Auseinandersetzungen. Dies wirkt sich auf die Debatte um CCS aus, weil ein großflächiger Einsatz von CCS-Technologien in Bezug auf verschiedene Aspekte mit einem großen Anteil an erneuerbaren Energien nicht kompatibel ist. Dies betrifft neben der vom SRU im obigen Zitat angesprochenen Nutzungskonkurrenz der Speicherplätze ganz allgemein den Systemkonflikt zwischen der schwankenden Stromeinspeisung durch erneuerbare Energien vs. einer Erzeugung von Energie durch Grundlastkraftwerke. So konstatieren Langhelle und Meadowcroft in Bezug auf die CCS-Debatte in Großbritannien, Niederlande und vor allem Deutschland: 
"The way CCS is framed is different because renewable energy has a larger place in the public sphere, and the organizations and stakeholders representing the renewable energy sector are more active. [...] The point is that in these countries, and especially in Germany, there is a perceived competition between renewables and CCS. [...] In the countries with large reserves of coal/oil and gas, and litte new renewable energy, the balance of forces is rather different.“ (Langhelle/Meadowcroft 2009: 261)

Das Argument der Konkurrenz zwischen CCS und erneuerbaren Energien zieht sich durch den gesamten SRU-Bericht. Die Gründe dafür liegen größtenteils in der Auswahl der Autor_innen und der ökologischen Ausrichtung des SRU als Umweltgremium. Darüber hinaus scheinen mir aber auch regionalspezifische Diskursstränge eine Rolle zu spielen. Sicherlich lässt sich nicht per se von der institutionellen Ansiedlung des SRU als Beratungsgremium der Bundesregierung auf die Relevanz regionalspezifischer Diskursstränge in seinen Arbeiten schließen. In dem konkreten Fall der Stellungnahme zum damali gen CCS-Gesetzentwurf der Bundesregierung knüpft der SRU allerdings explizit an Auseinandersetzungen um die Energiepolitik Deutschlands an, wie bereits der Titel anzeigt: „Abscheidung, Transport und Speicherung von Kohlendioxid. Der Gesetzentwurf der Bundesregierung im Kontext der Energiedebatte“ (SRU 2009; Hervorhebung T. K.). Im Vorwort des Berichts wird ein Bezug hergestellt zur Arbeit des SRU „an einem Gutachten zur Zukunft der Stromversorgung in Deutschland, das den Blick auf die Perspektive bis zum Jahr 2050 richtet. Im Mittelpunkt des Gutachtens steht die Frage, wie der Übergang zu einer nachhaltigen und sicheren Stromerzeugung gestaltet werden kann, und welche Systementscheidungen möglicherweise frühzeitig getroffen werden müssen." (SRU 2009: 3) Diese längerfristige Perspektive auf die Energieinfrastruktur in Deutschland bietet im SRU-Bericht die Hintergrundfolie für die Beurteilung von CCS-Technologien: „Angesichts der Bedeutung der anstehenden Weichenstellungen für die langfristige Entwicklung der Stromversorgung in Deutschland sollte Zeit für gründliche Diskussion und Abwägung sein.“ (SRU 2009: 5) Insofern kann man schließen, dass der SRU aufgrund des regionalspezifischen Kontexts an etwas anders gelagerte Diskursstränge als der IPCC anschließt wenngleich in beiden Fällen eine Dominanz des ökomodernen Diskurses vorliegt.

\subsubsection{Der Sonderbericht zu CCS und das ökomoderne Projekt}

In diesem Kapitel wird das Verhältnis des IPCC SRCCS zum ökomodernen Hegemonieprojekt beleuchtet. Im Folgenden analysiere ich, inwiefern der IPCC SRCCS die ökomodernen Grundannahmen - die technokratische Vorstellung von Politik, den Inkrementalismus und das Primat der Betriebsökonomie - sowie die ökomodernen Hegemoniestrategien - der reflexiven Naturbeherrschung, des reflexiven 
Fortschritts durch wissenschaftlich-technische Rationalität und des nachhaltigen Wachstums - (re-)produziert (für die Erläuterung der Grundannahmen und Hegemoniestrategien vgl. Kapitel 3).

Im IPCC SRCCS fallen keine expliziten Aussagen in Bezug auf die Bedeutung des Wirtschaftswachstums. Allerdings wird ein stetig steigender Primärenergieverbrauch angenommen, der die energetische Basis für Wirtschaftswachstum darstellt (vgl. IPCC 2005: 13). Weiterhin geht der IPCC davon aus, dass der Anteil fossiler Brennstoffe an der Deckung des Primärenergiebedarfs mindestens bis zur Mitte des Jahrhunderts dominant bleiben wird (vgl. IPCC 2005: 3). Damit stellt sich die Frage nach der Möglichkeit eines nachhaltigen Wachstums, nach der Entkopplung von Wirtschaftswachstum bzw. Primärenergieverbrauch und Treibhausgasemissionen. In den Modellen des IPCC SRCCS wird trotz des steigenden Primärenergieverbrauchs eine Reduktion der Treibhausgasemissionen prognostiziert. Diese soll angesichts des hohen Anteils fossiler Brennstoffe - in nicht unerheblichem Maß durch den großflächigen Einsatz von CCS-Technologien möglich werden (vgl. IPCC 2005: 13).

„In most scenarios for stabilization of atmospheric greenhouse gas concentrations between 450 and 750 ppmv $\mathrm{CO}_{2}$ and in a least-cost portfolio of mitigation options, the economic potential of $\mathrm{CCS}$ would amount to $220-2,200 \mathrm{GtCO}_{2}$ (60-600 GtC) cumulatively, which would mean that CCS contributes $15-55 \%$ to the cumulative mitigation effort worldwide until 2100, averaged over a range of baseline scenarios.“(vgl. IPCC 2005: 12)

Der IPCC verspricht sich von CCS-Technologien einen Beitrag zur Entkopplung von Primärenergieverbrauch und der Treibhausgaskonzentration in der Atmosphäre. ${ }^{40}$ Damit wird den CCS-Technologien im Bericht ein nicht unerheblicher Beitrag zum nachhaltigen Wachstum zugetraut.

Wachstum - konkret: steigender Primärenergieverbrauch - bildet im IPCC SRCCS die unhintergehbare Basis der Prognosen, Modelle und Bewertungen von Klimaschutztechnologien. Nur innerhalb der als gesetzt geltenden Wachstumsorientierung wird möglicher Klimaschutz verhandelt, der die Treibhausgaskonzentration in der Atmosphäre auf einem Niveau stabilisieren soll, ,auf dem eine gefährliche anthropogene Störung des Klimasystems verhindert wird [...] und die wirtschaftliche Entwicklung auf nachhaltige Weise fortgeführt werden kann." (UNFCCC 1992: 5; zitiert in IPCC 2005: 20) Wirtschaftswachstum und der dafür nötige Primärenergieverbrauch bilden somit im IPCC SRCCS die ökonomischen

40 Eine Senkung des Ressourcenverbrauchs ist mit CCS-Technologien nicht möglich. Weiterhin wird auch die Emission von Treibhausgasen nicht reduziert, sondern lediglich der Anteil an Emissionen, der in die Atmosphäre entweicht. 
Funktionslogiken, denen die Natur untergeordnet wird. Im Zentrum steht das wachstumsbasierte Entwicklungsmodell, das mit den Anforderungen, die sich aus den Klimaschutzzielen ergeben, kompatibel gemacht werden muss:

„CCS would be an option for countries that have significant sources of $\mathrm{CO}_{2}$ suitable for capture, that have access to storage sites and experience with oil or gas operations, and that need to satisfy their development aspirations in a carbon-constrained environment." (IPCC 2005: 22)

Im Sinne der Strategie der reflexiven Naturbeherrschung gelten CCS-Technologien als ein wichtiges Instrument, um die nicht-intendierten Nebenfolgen der Naturbeherrschung - konkret: die erhöhte Treibhausgaskonzentration in der Atmosphäre zu bearbeiten. Momente der Unverfügbarkeit bzw. Widerständigkeit der Natur haben darin keinen Platz - wie in der Einschätzung der Sicherheit der $\mathrm{CO}_{2}$ Speicherung deutlich wird:

„With appropriate site selection based on available subsurface information, a monitoring programme to detect problems, a regulatory system and the appropriate use of remediation methods to stop or control $\mathrm{CO}_{2}$ releases if they arise, the local health, safety and environment risks of geological storage would be comparable to the risks of current activities such as natural gas storage, EOR and deep underground disposal of acid gas.“ (IPCC 2005: 12)

Die ökologischen und gesundheitlichen Risiken der CCS-Technologien sollen durch strikte Auswahlkriterien und Monitoring der Speicherstätten gemanagt werden. Entsprechend der Strategie des reflexiven Fortschritts durch wissenschaftlichtechnische Rationalität wird im IPCC SRCCS eine Perfektionierung der technologischen Entwicklung durch Risikoabschätzung angestrebt. Die exakte Quantifizierung der Wahrscheinlichkeit, mit welcher ein bestimmter Anteil des verpressten Kohlenstoffdioxids in den Speicherstätten verbleibt, verleiht den Aussagen ,wissenschaftliche Legitimität‘. Über diese Mechanismen der Technikfolgenabschätzung und Risikokommunikation wird eine Steigerung des Sicherheitsempfindens hergestellt.

„For well-selected, designed and managed geological storage sites, the vast majority of the $\mathrm{CO}_{2}$ will gradually be immobilized by various trapping mechanisms and, in that case, could be retained for up to millions of years." (IPCC 2005: 14)

Die Sicherheitsrisiken, die der Anwendung von CCS-Technologien einhergehen, werden im Bericht nicht als mögliches Ausschlusskriterium oder als bedeutender Nachteil gegenüber sogenannten sanften Technologien diskutiert. Eine Ausnahme bildet allerdings die Speicherung von $\mathrm{CO}_{2}$ in der Tiefsee, die im IPCC SRCCS relativ skeptisch beurteilt wird, da sie weniger erforscht sei als andere Speicher- 
möglichkeiten und die Veränderungen der Ökosysteme im Ozean schwer zu prognostizieren seien (vgl. IPCC 2005: 8, 38). Laut de Coninck, die selber eine der Coordinating Lead Authors des Berichts war, waren nur an der Arbeit des Kapitels zum Ocean Storage explizit CCS-kritische Autor_innen beteiligt, was zu starken Konflikten und letztlich zu einer eher skeptischen Einschätzung dieser Speichermöglichkeit führte. Ihrer Meinung nach hatte der skeptische Einschlag des Kapitels zur Folge, dass Japan und die USA ihre Investitionen in die Tiefsee-Speicherung beendeten und dass man sich in den UN-Klimaverhandlungen schnell darauf einigte, diese Speichermöglichkeit für CDM-Projekte auszuschließen. ${ }^{41}$ Insofern werden im IPCC SRCCS sowohl risikovermeidende (in Bezug auf die TiefseeSpeicherung) als auch risikobewusste Praktiken (in Bezug auf die anderen Speicheroptionen) im Sinne einer Strategie des reflexiven Fortschritts durch wissenschaftlich-technische Rationalität artikuliert. Insgesamt werden ökologische und gesundheitliche Risiken der CCS-Technologien im IPCC SRCCS als relativ unproblematisch eingeschätzt. Dies liegt nicht nur an den optimistischen Prognosen des IPCC, sondern auch an der geringeren Gewichtung von Sicherheitsfragen im Vergleich zu betriebswirtschaftlichen Kosten-Nutzen-Kalkulationen.

Die prognostizierten betriebswirtschaftlichen Kosten pro verpresste Tonne $\mathrm{CO}_{2}$ stellen im IPCC SRCCS das Hauptkriterium für die Bedeutung von CCS als Klimaschutzoption dar. In Bezug auf Entscheidungen über den Einsatz bestimmter Technologien - beispielsweise der Anwendung von CCS bei Biomassekraftwerken anstatt Kohlekraftwerken - wird davon ausgegangen, dass diese von Marktpreisen und nicht etwa von Programmen politischer Steuerung abhängen (vgl. IPCC 2005: 10). Wie schon in der Klimarahmenkonvention und dem Kyoto-Protokoll (vgl. Kapitel 5.1.3) gilt im IPCC SRCCS ein Primat der Betriebsökonomie. Das Ziel der Stabilisierung der Treibhausgase in der Atmosphäre soll bei größtmöglicher Vermeidung betriebswirtschaftlicher Kosten erreicht werden. Dies hat zur Folge, dass Investitionen allein nach ihren kurzfristigen Emissionsreduktionen innerhalb des Status quo der Energieinfrastruktur bewertet werden. Die Möglichkeit einer grundsätzlichen Transformation derselben wird nicht thematisiert. Die zentralisierte Energieproduktion ist für die etablierten Energieunternehmen zumindest kurzfristig besonders kostengünstig und ihre Fortführung durch (die Hoffnung auf) CCSTechnologien wird im IPCC-Bericht nicht problematisiert. Unter einer langfristigen volkswirtschaftlichen Perspektive könnte allerdings eine dezentralisierte Energieproduktion aufgrund höherer Brennstoffeffizienz, weniger Abwärme, weniger Leitungsverlusten, weniger Gesundheitskosten und mehr regionalen Arbeitsplätzen

41 Diese Einschätzung erfolgte in einem Interview, das ich am 16.05.2013 mit Heleen de Coninck geführt habe. 
günstig erscheinen und hätte zusätzliche ökologische Vorteile sowie das Potenzial zur Demokratisierung der Energieproduktion.

Derartige gesellschaftspolitische Fragen kommen in der technokratischen Perspektive des IPCC SRCCS nicht vor. Die Stabilisierung der Treibhausgaskonzentration in der Atmosphäre bildet den alleinigen Fokus. Darüber hinausgehende ökologische Ziele werden nicht formuliert. Weiterhin werden soziale Probleme, demokratierelevante Aspekte oder Gerechtigkeitsfragen ausgeklammert. CCS wird als technologische Lösung für das isoliert betrachtete Phänomen des $\mathrm{CO}_{2}$-Austoßes bei großen punktuellen Quellen beleuchtet. Ökologische, gesundheitliche und soziale Probleme des Abbaus und der Verbrennung fossiler Brennstoffe werden nicht thematisiert, obwohl sie durch die Anwendung von CCS-Technologien verschärft werden - indirekt aufgrund der Fortführung der Energieinfrastruktur und direkt durch den erhöhten Ressourceneinsatz um bis zu $40 \%$ pro erzeugte Kilowattstunde (der aufgrund des Energieverlusts notwendig wird) sowie durch die gesteigerten Fördermengen im Rahmen der Anwendung bei EOR-, EGR- und ECBM-Projekten.

Im IPCC SRCCS zeigt sich, was Achim Brunnengräber et al. für die Arbeit des IPCC insgesamt beschreiben: Die sozialen, politischen und politökonomischen Dimensionen des Klimawandels bleiben außen vor (vgl. Brunnengräber et al. 2008: 57ff). Vom IPCC wird der anthropogene Klimawandel als rein ökologisches und als globales Problem angesehen, dem mit einem Emissions-Management begegnet werden soll. Aus dem Fokus geraten damit die lokal und sozial unterschiedliche Verursachung und Betroffenheit sowie die qualitativen Unterschiede der Ursachen von Treibhausgasen - die aus so verschiedenen Quellen wie dem Luftverkehr, der kleinbäuerlichen Landwirtschaft oder der Verbrennung fossiler Energieträger stammen können. Diese spezifische Komplexitätsreduktion bietet die Grundlage für eine „vorrangig technisch-ökonomische Perspektive und technical-fix Orientierung“ (Conrad 2010: 103).

Eng damit verknüpft ist die inkrementelle Herangehensweise - die Hoffnung, mit kleinen Schritten innerhalb der gegebenen Rahmenbedingungen in die richtige Richtung zur Lösung komplexer Probleme zu kommen. Die Ergebnisse bisheriger internationaler Klimapolitik und der Status quo der Energieinfrastruktur werden im IPCC SRCCS zur Erstellung von Prognosen und zur Einschätzung des zukünftigen Klimaschutzpotenzials von CCS-Technologien als konstante Rahmenbedingungen gesetzt. Insofern wird angenommen, dass die zentralisierte Energieproduktion, die Oligopolstellung einzelner Konzerne, der dominante Anteil fossiler Brennstoffe im Energiemix und wachsende Kohlenstoffmärkte auch in Zukunft zentrale Eckpfeiler bilden, mit denen die technologischen Klimaschutzoptionen vereinbar sein müssen. 
Aufgrund der Kompatibilität mit diesen Rahmenbedingungen werden den CCSTechnologien Wettbewerbsvorteile zugesprochen (vgl. IPCC 2005: 12). Unterlassen wird die Diskussion der Bedeutung von CCS-Technologien für alternative Entwicklungspfade. Es wird also nicht thematisiert, welchen Einfluss die Erforschung und Anwendung von CCS-Technologien auf die zukünftige Gestaltung der globalen Energie- und Klimapolitik hat - beispielsweise auf den Ausbau erneuerbarer Energien oder den Bau fossiler Kraftwerke. Stattdessen wird ausschließlich analysiert, inwiefern man innerhalb der gegebenen Rahmenbedingungen mit CCSTechnologien einen Schritt in Richtung Stabilisierung der Treibhausgaskonzentration in der Atmosphäre gehen kann.

Diese Perspektive nennen Anders Hansson und Marten Bryngelsson ,,pragmatic perspective“ (Hansson/Bryngelsson 2009: 2279). Ihrer Meinung nach ist der wichtigste Grund für die große Bedeutung von CCS-Technologien ihre Attraktivität für verschiedene einflussreiche Interessen. Eine pragmatic perspective einzunehmen bedeutet dann, CCS-Technologien als besonders wichtige Klimaschutztechnologien anzusehen, nicht weil diese Option den größten ökologischen und/oder sozialen Nutzen verspricht, sondern - angesichts der aktuellen gesellschaftlichen Strukturen und der sozialen Kräfteverhältnisse - den Weg des geringsten Widerstands darstellt (vgl. Hansson/Bryngelsson 2009: 2279).

Hinter der affirmativen (Re-)Produktion der bestehenden Institutionen steht die implizite Einschätzung, dass politische Entscheidungen nur im Rahmen bereits bestehender Strukturen Anreize geben können. Im IPCC SRCCS wird von der Weiterentwicklung aktuell beobachtbarer Prozess ausgegangen, die prognostiziert werden könnten und die bestimmte Konstanten, wie den Verbrauch fossiler Brennstoffe, aufweisen würden. Im Bericht gibt es keine Fokussierung auf eine gezielte (längerfristige) Transformation von technologischen Systemen oder sonstigen Maßnahmen, die zur Unabhängigkeit von fossilen Brennstoffen führen würden (vgl. Brunnengräber et al. 2008: 115f). Eine derartige konsequente Abkehr von fossilen Brennstoffen müsste aber laut Larry Lohmann im Kern jeder langfristig angelegten Klimapolitik stehen und würde bei ehrgeizigen Klimaschutzzielen als unabdingbar erscheinen (vgl. Lohmann 2010: 134).

Der IPCC setzt sich also nicht für ausgewählte Technologien und Maßnahmen im Rahmen einer gezielten langfristigen Transformationsstrategie ein. Damit wird die im UN-Klimaregime vorherrschende Idee eines Wettbewerbs, in dem die flexiblen Entscheidungen der Marktteilnehmer_innen auf verschiedenen Wegen zu möglichst kosteneffizienten Reduktionen der Treibhausgasemissionen führen sollen, reproduziert. Dementsprechend sieht der IPCC die Lösung auch nicht in der Suche nach der einen entscheidenden Wunderwaffe, einer silver bullet gegen den 
Klimawandel, sondern tritt für die Kombination verschiedener Klimaschutztechnologien ein. Im zweiten Sachstandsbericht aus dem Jahr 1995 verwendete der IPCC dafür zum ersten Mal die Bezeichnung des ,portfolio of options“ (IPCC 1996: 639). Seitdem wird der Begriff des Portfolios im Kontext der UN-Klimaverhandlungen von verschiedenen Akteur_innen zunehmend verwendet. Auch in vielen Stellungnahmen der Länder und Beobachterorganisationen zu den Verhandlungen über die Aufnahme von CCS in den CDM wird auf das Konzept des portfolio of technologies zurückgegriffen (vgl. Kapitel 5.4.2). Im IPCC SRCCS gelten CCS-Technologien stets als Teil eines Portfolios. Was die konkreten Formulierungen betrifft, so wird zwischen folgenden Varianten gewechselt: portfolio of mitigation options, portfolio of mitigation actions, mitigation portfolio, portfolio of mitigation measures, portfolio of energy technologies, portfolio of technology options, portfolio of methods, portfolio of technologies. Trotz unterschiedlicher Formulierungen beziehen sich alle Begriffe letztlich auf technologische Innovationen und werden im Bericht synonym verwendet. ${ }^{42}$

Die Betonung der Notwendigkeit eines Portfolios technologischer Optionen ist zum einen auf die Komplexität des Klimawandels als Querschnittsproblem (vgl. Kapitel 1.1) zurückzuführen. Die Idee des Portfolios hat aber zum anderen durch ihre Nähe zum ökomodernen Inkrementalismus Bedeutung gewonnen. Statt ganzheitlicher Lösungskonzepte, die eventuell bestimmte Maßnahmen und Technologien aufgrund ihrer strukturverändernden Eigenschaften präferieren, schlägt der IPCC die flexible Kombination verschiedener Technologien vor:

„The optimum portfolio of mitigation measures is likely to be different in different places and at different times. Given the variety of measures available, it seems likely that several will be used in a complementary fashion as part of the portfolio, and that there will not be a single clear ,winner' amongst them." (IPCC 2005: 68)

Die Optimierung des flexibel gewählten Portfolios soll sich dabei an der betriebswirtschaftlichen Kosteneffizienz orientieren, mit der die angestrebten Emissionsreduktionsziele erreicht werden können.

„Achieving this [a reduction in global emissions by 2100 of 7-70\%; T. K.] cost-effectively will be easier if we can choose flexibly from a broad portfolio of technology options of the kind described above.“ (IPCC 2005: 53)

42 Auch wenn an einigen wenigen Stellen des Berichts die Möglichkeit nicht-technischer Klimaschutzmaßnahmen anklingt, wird ihnen doch so gut wie keine Bedeutung beigemessen. 
Die Suche nach einem geeigneten Portfolio technologischer Optionen geschieht unter der Annahme, dass die bestehenden Rahmenbedingungen stabil bleiben. Dies birgt die Gefahr der Unterschätzung von Diskontinuitäten. ${ }^{43}$ Darüber hinaus wirkt die vom IPCC gewählte Beschränkung - auf die Bereitstellung von Informationen über das Potenzial technologischer Optionen im Rahmen des Status quo gesellschaftlicher Strukturen - transformationshemmend. Sie stärkt die geronnenen Strukturen und verschleiert den prinzipiell denkbaren politischen Gestaltungsspielraum. Eine Politikberatung, in der nur Optionen aufgezeigt werden, die von einem sehr begrenzten Handlungsspielraum ausgehen, hat den Effekt, dass der Gestaltungsspielraum de facto tatsächlich gering wird. Schließlich gelten Optionen, die jenseits der wissenschaftlichen Expertise liegen, in der Regel als unrealistisch oder werden gar nicht erst thematisiert. Umgekehrt erhalten mit der Beschränkung Klimaschutzoptionen, die sich geschmeidig in die gegebenen Rahmenbedingungen einfügen, besondere Aufmerksamkeit.

Eine Gestaltungsmöglichkeit jenseits von Pfadabhängigkeiten wird im IPCC SRCCS nicht in Erwägung gezogen. Mit der Ausklammerung alternativer Klimaschutzpolitiken, in denen beispielsweise Suffizienz, Postwachstum, Klimagerechtigkeit oder Energiedemokratie als Lösungsansätze verhandelt werden, und einem insgesamt geringen Glauben an politische Gestaltungsspielräume, bleibt als einzig realistische Position nur die ,technologische[n] Flucht nach vorn“ (Jänicke 1993: 18). Der IPCC setzt auf technologische Innovationen und ihren flexiblen Einsatz innerhalb der gegebenen Rahmenbedingungen. Als Vision bleibt eine ökologische Modernisierung, die es den etablierten politischen, ökonomischen und sozialen Institutionen ermöglichen soll, die Sorge für die Umwelt zu internalisieren und die ökologische Krise erfolgreich zu bearbeiten. Damit wird die Suche nach möglichen Reaktionen auf die ökologische Krise entpolitisiert. Als realistisch (im Sinne von konsensfähig) und wissenschaftlich (im Sinne von prognostizier- und modellierbar) gelten nur noch Vorschläge, die sich ohne politische Eingriffe in die gesellschaftlichen Kräfteverhältnisse im Rahmen der bestehenden gesellschaftlichen Strukturen implementieren lassen. Damit (re-)produziert der IPCC das Versprechen des ökomodernen Hegemonieprojekts, das sich gleichzeitig auf die Bewältigung der ökologischen Krise und auf die Stabilisierung gesellschaftlicher Strukturen bezieht (vgl. Kapitel 3.5).

43 Diese Unterschätzung von Diskontinuitäten zeigt sich beispielsweise in Bezug auf die geschätzten Kosten von CCS-Technologien im IPCC SRCCS. So zeigt der Vergleich mit neueren Studien, die nur wenige Jahre nach dem IPCC SRCCS erschienen, dass die Aussagen des IPCC zu optimistisch waren (vgl. Hansson 2012; Hansson/Bryngelsson 2009; Shackley/Evar 2012: 159f). 


\subsubsection{Die re- und entpolitisierenden Effekte des Sonderberichts zu CCS}

Zunächst einmal ist festzuhalten, dass die IPCC-Berichte großen Einfluss auf die UN-Klimaverhandlungen haben. Die Folge ist eine bewusste politische Einflussnahme von verschiedenen Akteur_innen auf die Arbeit des IPCC. Dies zeigt sich beispielsweise bei der Rekrutierung der Autor_innen und der Verabschiedung der Zusammenfassung für politische Entscheidungsträger_innen (vgl. Kapitel 5.3.1).

Was die Arbeitsweise betrifft, so gibt es in Bezug auf die „Politik der Inklusion“ (Beck 2009b: 129) eine Diskrepanz zwischen Anspruch und Wirklichkeit. Im Fall des Sonderberichts zu CCS wurden die IPCC-Richtlinien für die Auswahl der Expert_innen nur bedingt, wenn überhaupt, erfüllt. In der Konsequenz war die CCS-Community stark und CCS-kritische Perspektiven kaum vertreten. De facto reproduziert der IPCC damit asymmetrische Machtstrukturen und die Dominanz des ökomodernen Hegemonieprojekts in umweltpolitischen Aushandlungsprozessen.

Entsprechend seines eingeschränkten Mandats verzichtet der IPCC auf eine explizite Reflexion und Kritik politischer Ziele und Strategien. Dies hat die implizite Übernahme der politischen Setzungen des Status quo des internationalen Klimaregimes und der IPCC-Autor_innen zur Folge. Im IPCC SRCCS werden die CCS-Technologien als relevante Klimaschutztechnologien neben anderen im Rahmen eines ökomodernen Projekts interpretiert. Die Verankerung des Berichts im ökomodernen Diskurs zeigt sich in der (Re-)Produktion der ökomodernen Grundannahmen. Mit der Anbindung an bisherige Debatten in der internationalen Klimapolitik werden die ökomodernen Hegemoniestrategien aufgegriffen. Die Strategien werden dabei adaptiert, um den spezifischen Eigenschaften der CCS-Technologien gerecht zu werden.

Die politische Entscheidung zwischen verschiedenen Möglichkeiten, die ökologische Krise zu bearbeiten, wird im IPCC SRCCS auf die Entscheidung zwischen verschiedenen Kombinationen der Elemente eines Portfolios technologischer Optionen verkürzt. Insgesamt führt die enge Verknüpfung von Politik und Wissenschaft im Fall des IPCC SRCCS zu entpolitisierenden Effekten in Bezug auf die Auseinandersetzungen um die Bearbeitung der ökologischen Krise.

Inwieweit die vom IPCC vorgenommene Integration der CCS-Technologien in das ökomoderne Projekt von den Ländern und Beobachterorganisationen der UNKlimaverhandlungen übernommen wird, analysiere ich im nun folgenden Kapitel. Dort werde ich unter anderem prüfen, welche Bedeutung den vom IPCC formulierten Deutungsmustern zukommen und inwieweit sie die Auseinandersetzung um die Aufnahme von CCS in den CDM vorstrukturierten. 


\subsection{Die CCS-CDM-Kontroverse IN Den KLimaVerhandlungen}

In diesem Kapitel wird die CCS-CDM-Kontroverse in den UN-Klimaverhandlungen aus verschiedenen Perspektiven beleuchtet. Zunächst stelle ich den formalen Verlauf der CCS-CDM-Kontroverse dar, indem ich auf die verschiedenen Etappen und Entscheidungen der CCS-Verhandlungen eingehe (5.4.1). Anschließend gebe ich einen Überblick über die an der CCS-CDM-Kontroverse beteiligten Akteur_innen und ihre eingereichten Stellungnahmen (5.4.2). Der Fokus auf die schriftlichen Stellungnahmen entspricht der Funktionslogik der UN-Verhandlungen. Schließlich basieren die Klimaverhandlungen auf Textarbeit und zielen auf die Ausarbeitung und Verabschiedung schriftlich fixierter Abkommen. Es sollte allerdings nicht übersehen werden, dass sich die in den Verhandlungen vertretenen Positionen durchaus auch in anderen Kontexten herausbilden. Diesem Umstand trage ich Rechnung, indem ich in einem extra Kapitel die Positionierungen besonders wichtiger Akteur_innen vor dem Hintergrund der jeweils spezifischen Voraussetzungen ihrer Verhandlungspositionen beleuchte. Dabei gehe ich unter anderem auf die Energieinfrastruktur und die bisherige Klimapolitik einzelner Länder oder auf die Rolle von NGOs und BINGOs im UN-Klimaregime ein (5.4.3). In einem letzten Abschnitt interpretiere ich die Argumentationslinien der CCS-Verhandlungen im Hinblick auf die in Kapitel 3 herausgearbeiteten ökomodernen Grundannahmen und Hegemoniestrategien (5.4.4).

\subsubsection{Der Verlauf der CCS-CDM-Kontroverse}

Auf Grundlage der Protokolle der UN-Klimaverhandlungen gehe ich im Folgenden die einzelnen Schritte und Entscheidungen der CMPs bis zur endgültigen Aufnahme von CCS in den CDM durch. Wie bereits erwähnt, wurde der IPCC bereits 2001 von der COP 7 mit der Erstellung eines Berichts zu CCS-Technologien beauftragt. Zeitgleich mit der Publikation des Berichts fand 2005 die erste CMP statt. Bereits auf dieser ersten Tagung der Mitgliedsstaaten des Kyoto-Protokolls wurde die Frage diskutiert, ob CCS-Projekte in den CDM aufgenommen werden sollen oder nicht. Konkreter Auslöser war die Beantragung eines CCS-CDM-Projekts beim Exekutivrat des Mechanismus für umweltverträgliche Entwicklung (CDM EB) ${ }^{44}$, der die Anfrage an die CMP weiter reichte (vgl. im Internet: cdm.unfccc.int/EB/022/ eb22rep.pdf, letzter Zugriff am 02.12.2014). Ein erster Beschluss der CMP war der Auftrag an das Klimasekretariat, gemeinsam mit dem Nebenorgan für wissen-

44 Das CDM Executive Board ist ein Organ der CMP. Es überwacht die CDM-Projekte. Das CDM EB registriert die Projekte und vergibt zertifizierte Emissionsreduktionen. 
schaftliche und technologische Beratung (SBSTA) einen CCS-Workshop zu organisieren. Auf dem Workshop sollte erörtert werden, ob es sinnvoll ist, CCS als CDMMaßnahme ins Kyoto-Protokoll zu integrieren. Gleichzeitig wurden alle Regierungen dazu eingeladen, Stellungnahmen zur Fragestellung im Allgemeinen und zum Workshop im Speziellen abzugeben. Darüber hinaus wurde das CDM EB gebeten, bis zur nächsten CMP einen Vorschlag für die Regelung von CCS als CDMMaßnahme zu unterbreiten (vgl. im Internet: unfccc.int/resource/docs/2005/cmp1/ eng/08a01.pdf: 94f, letzter Zugriff am 02.12.2014).

Im Protokoll der zweiten CMP in Nairobi wird darauf verwiesen, dass der IPCC SRCCS einen guten Überblick über den Wissensstand zu CCS-Technologien biete (für den gesamten Absatz vgl. im Internet: unfccc.int/resource/docs/2006/cmp2/eng/ 10a01.pdf: 3, 6f, letzter Zugriff am 02.12.2014). Weiterhin halten die Vertragsparteien im Protokoll fest, dass es noch viele unsichere und ungeklärte Aspekte in Bezug auf die Frage der Aufnahme von CCS ins Kyoto-Protokoll gebe. Auch die Stellungnahmen der Regierungen, der Bericht des vom Klimasekretariat und vom SBSTA organisierten Workshops und der Bericht des Exekutivrats konnten keine abschließende Entscheidung ermöglichen. Dementsprechend wurde der Exekutivrat gebeten, weiter an Vorschlägen zur Umsetzung zu arbeiten. Darüber hinaus wird in dem Protokoll betont, dass es nötig sei, Expert_innenwissen über CCS-Technologien und ihre Anwendungsmöglichkeiten aufzubauen und zu verbreiten. Allerdings wird nicht expliziert, welche Akteur_innen zu welchem Zweck mehr Wissen über CCS-Technologien benötigen würden. In einer allgemein gehaltenen Formulierung wurden sowohl Regierungen als auch internationale Organisationen, NGOs und andere Institutionen dazu ermutigt, durch die Organisation von Workshops und die Verbreitung von Wissen über CCS weltweit zum Aufbau von Kompetenzen zu CCS-Technologien beizutragen. Weiterhin wurden internationale Organisationen und NGOs dazu eingeladen, dem Sekretariat ihr Expert_innenwissen zur Verfügung zu stellen. Wie bereits während der ersten CMP wurden die Regierungen gebeten, Stellungnahmen zu den kritischen Aspekten (die bei einer möglichen Aufnahme von CCS in den CDM problematisch wären) abzugeben. Darüber hinaus wurde das SBSTA aufgefordert, konkrete Vorschläge zu Regelungen für CCS-CDM-Projekte auszuarbeiten, die dann auf der nächsten, der dritten CMP verhandelt werden sollten. Eine Entscheidung wurde zum damaligen Zeitpunkt laut Protokoll für die vierte CMP angestrebt. Im Protokoll zur dritten CMP, die 2007 in Bali stattfand, finden sich keine Beschlüsse zum Thema CCS (vgl. im Internet: unfccc.int/ resource/docs/2007/cmp3/eng/09a01.pdf, letzter Zugriff am 02.12.2014). 
Die vierte CMP wurde 2008 in Posen abgehalten. Da absehbar war, dass es keine Konsensentscheidung für oder gegen die Aufnahme von CCS in den CDM geben würde, wurden alle im Vorfeld ausgearbeiteten Entwürfe verworfen und die Entscheidung vertagt (vgl. Treber o. J.). Als Ergebnis ist im Protokoll lediglich vermerkt, dass der Exekutivrat gebeten wurde, bis zur nächsten CMP einen Bericht zu erstellen, in dem Bedeutung und Implikationen der Aufnahme von CCS ins KyotoProtokoll untersucht werden sollen (vgl. im Internet: unfecc.int/resource/docs/ 2008/cmp4/eng/11a01.pdf: 9, letzter Zugriff am 02.12.2014).

Im Protokoll der fünften CMP, die 2009 in Kopenhagen stattfand, wird die Relevanz von CCS-Technologien zur Abschwächung des Klimawandels betont. Gleichzeitig wird darauf verwiesen, dass verschiedene Aspekte bezüglich einer möglichen Aufnahme in den CDM noch nicht geklärt werden konnten (vgl. im Internet: unfecc.int/resource/docs/2009/cmp5/eng/21a01.pdf: 7, letzter Zugriff am 02.12.2014). An dieser Stelle des Protokolls werden folgende Punkte, die weiterhin als problematisch betrachtet würden, aufgelistet: mangelnde Dauerhaftigkeit der Speicherung, Messung und Überprüfung der Projekte, Auswirkungen auf die Umwelt, Ziehung von Grenzen der Projekte, internationales Recht, Haftung, nichtintendierte Folgen, Sicherheit, Versicherungsfragen und Entschädigung von eventuellen Schäden durch Leckagen. Trotz der ungeklärten Probleme wurde angestrebt, auf der sechsten CMP eine Entscheidung herbei zu führen. Dazu wurde das SBSTA gebeten, weiter an Optionen der Eingliederung von CCS in den CDM zu arbeiten. Darüber hinaus wurden die Regierungen erneut dazu eingeladen, zu den aufgelisteten Problemfeldern Stellungnahmen einzureichen.

2010 wurde auf der CMP 6 in Cancún CCS vorläufig als mögliche Maßnahme im CDM zugelassen - unter der Voraussetzung, dass die bei der CMP 5 festgehaltenen Probleme gelöst werden können. Dementsprechend wird im Protokoll konstatiert, dass einzelne Vertragsstaaten Bedenken geäußert hätten, die bei der Ausarbeitung der genauen Modalitäten und der Umsetzung von CCS-Projekten beachtet werden müssen. So sollte sichergestellt werden, dass CCS-Projekte ökologisch sicher sind und keine kontraproduktiven Anreize (,perverse incentives“) bilden. Darüber hinaus sollte das vorrangige Ziel sein, jeglichen Austritt von $\mathrm{CO}_{2} \mathrm{zu}$ verhindern. Im Hinblick auf eine angestrebte endgültige Entscheidung auf der CMP 7 wurde das SBSTA damit beauftragt, konkrete Modalitäten zur Inklusion von CCS in den CDM zu entwickeln. Wiederum wurden die Länder und Beobachterorganisationen dazu eingeladen, weitere Stellungnahmen zu den aufgelisteten Problemen einzureichen. Abschließend wurde das Sekretariat aufgefordert, einen Workshop zu organisieren, auf dem technische und juristische Sachverständige die Zusammenfassung der eingereichten Stellungnahmen und der Vorschläge des 
SBSTA diskutieren sollten. Auf Grundlage dieses Workshops sollte das Sekretariat gemeinsam mit dem SBSTA einen Vorschlag zu den konkreten Modalitäten erstellen (vgl. im Internet: unfccc.int/resource/docs/2010/cmp6/eng/12a02.pdf: 27ff, letzter Zugriff am 02.12.2014). Die bei der sechsten CMP gefällte vorläufige Entscheidung wurde auf der CMP 7 in Durban bestätigt. CCS-Projekte sind damit endgültig für den CDM zugelassen (vgl. im Internet: unfccc.int/resource/docs/2011/cmp7/ eng/104.pdf, letzter Zugriff am 02.12.2014).

\subsubsection{Die Positionen in der CCS-CDM-Kontroverse}

Im Folgenden werden die am Aushandlungsprozess aktiv beteiligten Länder und Organisationen dargestellt sowie ihre Argumente, mit denen sie sich in die CCSCDM-Kontroverse einbrachten. Dazu analysiere ich alle diesbezüglich eingereichten Stellungnahmen (vgl. im Internet: cdm.unfccc.int/about/ccs/index.html, letzter Zugriff am 02.12.2014). Im Anhang befindet sich eine Übersicht über die insgesamt 49 Stellungnahmen (vgl. A.1). Auf Basis einer solchen Darstellung der allgemeinen Konfliktlinien und Akteurskonstellationen können tiefer gehende Analysen aufbauen - die Feinanalysen einzelner Akteur_innen (vgl. Kapitel 5.4.3) und die Untersuchung des Verhältnisses der Auseinandersetzungen um CCS-Technologien zum Hegemonieprojekt der ökologischen Modernisierung (vgl. Kapitel 5.4.4). Die Überblicksdarstellung ermöglicht die Auswahl relevanter Akteur_innen für die Feinanalyse und gibt erste Hinweise auf die entscheidenden Artikulationen in der CCSCDM-Kontroverse. Im Verlauf der Verhandlungen gab es von 2006 bis 2010 fünf mögliche Zeitfenster, in den die Länder und die Beobachterorganisation schriftliche Stellungnahmen einreichen konnten. Allerdings wurden in der ersten und vierten Anfrage der CMP nur die Länder aufgefordert, Positionspapiere einzureichen. ${ }^{45}$

45 Dennoch haben die BINGOs International Emissions Trading Association (IETA), International Petroleum Industry Environmental Conservation Association (IPIECA), das World Coal Institute (WCI) und das Hamburgische WeltWirtschaftsInstitut (HWWI) auch 2006 jeweils ein Papier eingereicht (vgl. im Internet: www.unfccc.int/resource/docs/2006/ smsn/ngo/001.pdf, www.unfecc.int/resource/docs/2006/smsn/ngo/002.pdf, www.unfecc. int/resource/docs/2006/smsn/ngo/003.pdf, www.unfccc.int/files/meetings/workshops/ other_meetings/application/pdf/ccs7feb2006ieta_vfinal_.pdf, letzter Zugriff am 02.12.2014). Inwieweit diese im weiteren Verhandlungsprozess eine Rolle spielten ist unklar. Auf der Homepage der Klimarahmenkonvention, auf der alle Dokumente des CCS-Verhandlungsstrangs aufgelistet sind, werden sie nicht aufgeführt (vgl. im Internet: cdm.unfccc.int/ about/ccs/index.html, letzter Zugriff am 02.12.2014). In meiner Analyse werde ich nicht näher auf sie eingehen. 
Tabelle 1 Übersicht über die Stellungnahmen der Länder

\begin{tabular}{|l|l|}
\hline Annex-B-Staaten (Stellungnahmen: 18) & Nicht-Annex-B-Staaten (Stellungnahmen: 11) \\
\hline EU (4) & Brasilien (3) \\
\hline Norwegen (4) & Saudi-Arabien (3) \\
\hline Australien (3) & Bangladesch (1) \\
\hline Japan (2) & Indonesien (1) \\
\hline Kanada (2) & Katar (1) \\
\hline Neuseeland (2) & Südkorea (1) \\
\hline Schweiz (1) & Venezuela (1) \\
\hline
\end{tabular}

In dem Untersuchungszeitraum von 2006 bis 2010 haben 14 Länder (darunter zählt hier auch die EU als ein Land) insgesamt 29 schriftliche Stellungnahmen eingereicht. In dieser Form beteiligten sich jeweils sieben Annex-B- und Nicht-Annex-BStaaten am Aushandlungsprozess. Allerdings formulierten erstere 18 und letztere nur elf Stellungnahmen (vgl. Tabelle 1). Von der bloßen Anzahl der eingereichten Stellungnahmen lässt sich nicht unmittelbar auf die Bedeutung der einzelnen Länder für die Verhandlungen schließen. Die Stellungnahmen sind unterschiedlich elaboriert. So trug die Delegation Saudi-Arabiens mit ihren drei Stellungnahmen kaum zur inhaltlichen Debatte bei. Ihre Stellungnahmen bestehen aus sehr wenigen Sätzen, in denen sie lediglich ihr großes Interesse an den CCS-Technologien und ihre Befürwortung der Aufnahme in den CDM bekunden. Am stärksten brachten sich Australien, Brasilien, die EU und Norwegen ein. Sie reichten relativ häufig umfangreiche Stellungnahmen ein, in denen Argumente vorgebracht werden, die den Verlauf der Debatte entscheidend beeinflussten.

Eine große Rolle für die Positionierung in der CCS-CDM-Kontroverse spielte die Bedeutung von CCS-Technologien in der nationalen Klima- und Energiepolitik der Länder. Bangladesch, die Schweiz und Venezuela sind die einzigen Länder, die eine Stellungnahme eingereicht haben ohne besonders stark in die Entwicklung von CCS-Technologien involviert zu sein (vgl. Tabelle 2). Alle anderen Länder beteiligen sich an der Entwicklung von CCS-Technologien und führen CCS-Projekte durch (vgl. Kapitel 5.2.1 und im Internet: www.globalccsinstitute.com/projects/ browse, letzter Zugriff am 02.12.2014). Das CCS-Engagement spiegelt sich auch in ihrer Mitgliedschaft bei wichtigen internationalen CCS-Netzwerken wie dem Global CCS Institute und dem Carbon Sequestration Leadership Forum wider (vgl. im Internet: www.globalccsinstitute.com/sites/default/files/pages/321/master-web-all-members -list-june2013.pdf, www.cslforum.org/aboutus/index.html, letzter Zugriff am 02.12.2014). 
Tabelle 2 Übersicht über die CCS-Aktivitäten der Länder

\begin{tabular}{|l|l|}
\hline Länder mit CCS-Aktivitäten & Länder ohne CCS-Aktivitäten \\
\hline Australien & Bangladesch \\
\hline Brasilien & Schweiz \\
\hline EU & Venezuela \\
\hline Indonesien & \\
\hline Japan & \\
\hline Kanada & \\
\hline Katar & \\
\hline Neuseeland & \\
\hline Norwegen & \\
\hline Saudi-Arabien & \\
\hline Südkorea & \\
\hline
\end{tabular}

Neben den Ländern haben 17 verschiedene - im Rahmen der UN-Klimaverhandlungen als ,Beobachterorganisationen“ bezeichnete - Organisationen insgesamt 20 schriftliche Stellungnahmen eingereicht. Greenpeace, die International Emissions Trading Association (IETA) und das World Coal Institute (WCI) nahmen in je zwei Positionspapieren Stellung, alle anderen reichten eine Stellungnahme ein. Das Feld der Akteur_innen ist hier sehr breit und umfasst Umwelt-NGOs, Forschungsinstitute, eine zwischenstaatlichen Organisation, ein Unternehmen und sechs BINGOs (vgl. Tabelle 3).

Tabelle 3 Übersicht über die Stellungnahmen der Beobachterorganisationen

\begin{tabular}{|l|l|l|l|l|}
\hline NGOs & Forschungsinstitute & $\begin{array}{l}\text { zwischenstaatliche } \\
\text { Organisationen }\end{array}$ & $\begin{array}{l}\text { Unter- } \\
\text { nehmen }\end{array}$ & BINGOs \\
\hline Bellona & IRGC & CSLF & Eskom & CCSA \\
\hline ForUM & IEEP & & & EURELECTRIC \\
\hline Greenpeace (2) & SACCCS & & & ICC \\
\hline SustainUS & $\begin{array}{l}\text { Indian Institute of } \\
\text { Technology Kharagpur }\end{array}$ & & & IETA (2) \\
\hline WWF & & & & IPIECA \\
\hline & & & & WCI (2) \\
\hline
\end{tabular}


Dementsprechend sind die umweltpolitischen Positionierungen der Beobachterorganisationen sehr divers, wie Tabelle 4 in einem vereinfachenden Schema abbildet. Dabei muss nicht nur zwischen, sondern auch innerhalb der verschiedenen Organisationsgruppen differenziert werden $-\mathrm{d}$. h. innerhalb der Gruppe der BINGOs gibt es durchaus unterschiedliche Positionen genauso wie die Forschungsinstitute oder die Umwelt-NGOs keine homogenen Blöcke darstellen.

\section{Tabelle 4 Die umweltpolitischen Positionen der Beobachterorganisationen ${ }^{46}$}

\begin{tabular}{|c|l|c|}
\hline Grün & \multicolumn{1}{|c|}{ Hellgrün - Hellgrau } & Grau \\
\hline ForUM & Bellona & CCSA \\
\hline Greenpeace & IEEP & CSLF \\
\hline SustainUS & RGC IETA & Eskom \\
\hline & WWF & EURELECTRIC \\
\hline & & Indian Institute of \\
\hline & & Technology Kharagpur \\
\hline & & IPIECA \\
\hline & & SACCCS \\
\hline & & WCI \\
\hline
\end{tabular}

So lassen sich bei den fünf Umwelt-NGOs starke Unterschiede hinsichtlich ihrer Arbeitsweise und ihrer umweltpolitischen Ausrichtung erkennen. SustainUS ist eine nordamerikanische Jugendorganisation, die sich allgemein für Sustainable Development einsetzt und die Mitsprache Jugendlicher bei politischen Entscheidungen durch Empowerment und Leadership-Trainings stärken möchte (vgl. im Internet: www.sustainus.org, letzter Zugriff am 02.12.2014). Greenpeace und WWF zählen zu den großen Umwelt-NGOs aus dem globalen Norden, die im Climate Action Network (CAN), dem größten Zusammenschluss von NGOs im Rahmen der UN-Klimaverhandlungen, den Ton angeben und dessen konfliktiv-kooperierenden Politikstil prägen. Ihr Einfluss basiert auf ihren hohen Mitgliederzahlen und den

46 Bei der Einordnung in umweltpolitische Positionen orientiere ich mich grundsätzlich an den Einteilungen in ,grüne‘ und,graue‘ Akteur_innen, die in vielen sozialwissenschaftlichen Studien zur Klimapolitik vorgenommen werden (vgl. beispielsweise Brunnengräber 2009: 187ff; Vormedal 2008). Die konkrete Zuordnung einer Organisation in eine der Kategorien erfolgte aufgrund meiner eigenen Analyse der eingereichten Stellungnahmen. 
umfangreichen personellen und finanziellen Mitteln. Beide finanzieren sich in erster Linie über Privatspenden. Darüber hinaus hat der WWF auch Einnahmen durch Kooperationen mit Unternehmen und Unternehmensverbänden. Greenpeace lehnt dagegen jegliche finanzielle Unterstützung durch die Wirtschaft ab. Diese Differenz zeigt sich auch in der programmatischen Ausrichtung. Der WWF zeichnet sich im Gegensatz zu den meisten Umwelt-NGOs durch eine relativ starke Nähe zu Unternehmen und der Initiierung interner Reformen aus. Greenpeace setzt dagegen stärker auf Unabhängigkeit und öffentlichkeitswirksame Kampagnen, um Druck auf Unternehmen oder Regierungen aufzubauen (vgl. Bedall 2014: 115, 139, 143, 244ff; Koch 2006: 96ff). Die Bellona Foundation ist eine Umwelt-NGO, die zu den frühesten und engagiertesten Befürworter_innen von CCS-Technologien zählt (für weitere Infos zur Bellona Foundation vgl. Kapitel 5.2.1). Im Forum for Utvikling og Miljø (ForUM) sind verschiedene norwegische NGOs Mitglied. Es sieht sich als Netzwerk und Thinktank, das politische Strategien zu Umwelt- und Entwicklungsthemen erarbeitet. Über diese Koordinierungsarbeit hinaus versucht das ForUM, durch eigene Lobbyarbeit die norwegische Regierung und ihre Positionierung in internationalen Prozessen zu beeinflussen (vgl. im Internet: www.forumfor.no, letzter Zugriff am 02.12.2014).

Neben den Umwelt-NGOs beteiligten sich vier Forschungsinstitute mit eigenen Stellungnahmen. Das International Risk Governance Council (IRGC) wird von Regierungen, Unternehmen und anderen Organisationen finanziert. Die Schweizer Stiftung verfolgt als politikberatender Thinktank das Ziel, wissenschaftliches Wissen zusammenzutragen und darauf aufbauend Empfehlungen für den Umgang mit Risiken zu formulieren (vgl. im Internet: www.irgc.org, letzter Zugriff am 02.12.2014). Das Institute for European Environmental Policy (IEEP) agiert ebenfalls als politikberatender Thinktank. Der Fokus des Instituts liegt auf europäischer Umweltpolitik (vgl. im Internet: www.ieep.eu, letzter Zugriff am 02.12.2014). Das IEEP wurde vom WWF mit der Erstellung einer Studie zur Frage der Aufnahme von CCS in den CDM beauftragt. Da der WWF diese Studie seiner eigenen Stellungnahmen beilegte, wurde sie wie die Stellungnahmen der Beobachterorganisationen behandelt - sprich, den an den Verhandlungen teilnehmenden Akteur_innen zugänglich gemacht und auf der Seite der Klimarahmenkonvention veröffentlicht.

Weiterhin wurde jeweils eine Stellungnahme von zwei Forschungsinstituten eingereicht, die mit CCS ein unternehmerisches Interesse verbinden: vom South African Centre for Carbon Capture and Storage (SACCCS) und vom Indian Institute of Technology Kharagpur in Kooperation mit dem Indian Institute of Management Indore. Das SACCCS setzt sich allgemein für CCS-Technologien ein und arbeitet an einem Demonstrationsprojekt in Südafrika. Finanziert wird das SACCCS primär 
durch die südafrikanische und norwegische Regierung sowie durch die südafrikanischen Energiekonzerne Sasol und Eskom. Auch die weiteren Projektpartner sind vor allem Konzerne aus dem fossilen Sektor (vgl. im Internet www.sacccs.org.za/aboutus, letzter Zugriff am 02.12.2014). Bei dem Positionspapier des Indian Institute of Technology Kharagpur wird Prateek Bumb in der Funktion als Mitarbeiter einer indischen Hochschule als Hauptautor angeführt. Bumb ist gleichzeitig Direktor von Carbon Clean Solutions, einer von ihm mitgegründeten Firma, die im Bereich der Abscheidung von $\mathrm{CO}_{2}$ tätig ist (vgl. im Internet: network.carboncapture journal. com/profile/PrateekBumb, www.carboncleansolutions.com/boardofdirectors.html, letzter Zugriff am 02.12.2014). Da das SACCCS eine große Nähe zu klassischen BINGOs aufweist und Prateek Bumb einem CCS-Unternehmen angehört, verstärken diese beiden Stellungnahmen die Dominanz der Wirtschaftsakteur_innen.

Sieben weitere Unternehmen und Wirtschaftsverbände reichten eine eigene Stellungnahmen ein: Carbon Capture and Storage Association (CCSA), Eskom, EURELECTRIC, International Chamber of Commerce (ICC), International Emissions Trading Association (IETA), International Petroleum Industry Environmental Conservation Association (IPIECA) und das World Coal Institute (WCI). Mit der ICC brachte sich der weltweit größte Wirtschaftsverband in die Debatte ein. Die ICC vertritt Unternehmen aus den unterschiedlichen Branchen. Darüber hinaus meldeten sich verschiedene Wirtschaftsverbände aus dem Energiesektor zu Wort. EURELECTRIC vertritt die europäische Elektrizitätswirtschaft, IPIECA die Öl- und Gasindustrie und das WCI die Kohleindustrie. Ebenfalls im Energiebereich tätig ist das südafrikanische Stromversorgungsunternehmen Eskom, das etwa $95 \%$ des in Südafrika und ca. $45 \%$ des in ganz Afrika verbrauchten Stroms produziert. Der Strom wird vor allem in Kohlekraftwerken erzeugt (vgl. im Internet: www.eskom. co.za, letzter Zugriff am 02.12.2014). Bei der CCSA sind verschiedene Unternehmen Mitglied, die im Bereich der CCS-Technologien arbeiten. CCSA setzt sich für die Förderung, Entwicklung und Anwendung von CCS-Technologien ein (vgl. im Internet: www.ccsassociation.org, letzter Zugriff am 02.12.2014). Die IETA ist ein Lobbyverband für unterschiedliche Unternehmen, deren Gemeinsamkeit darin liegt, dass sie am Kyoto-Kohlenstoffmarkt partizipieren. Darunter fallen beispielsweise Finanzmarktakteur_innen, die sich auf den Handel mit Emissionsberechtigungen spezialisiert haben, Agenturen, die für die Akkreditierung von Offset-Projekten zuständig sind oder Unternehmen, die viele Emissionen verursachen und deshalb auf die Zuteilung und/oder den Handel mit Emissionsberechtigungen angewiesen sind (für mehr Informationen zur IETA vgl. Kapitel 5.2.1). Das Carbon Sequestration Leadership Forum (CSLF) hat zwar als zwischenstaatliche Organisation einen anderen Status, ist aber in der Ausrichtung den BINGOs sehr ähnlich. Das CSLF ist 
eine Initiative, die sich für die Entwicklung kostengünstiger Technologien einsetzt. Ihre Aufgabenbereiche betreffen die Kohlenstoffabscheidung und -speicherung sowie den Transport und die langfristig sichere Lagerung von $\mathrm{CO}_{2}$ (für mehr Informationen zum CSLF vgl. Kapitel 5.2.1).

\section{Tabelle 5 Positionen bezüglich CCS-Technologien im Allgemeinen ${ }^{47}$}

\begin{tabular}{|c|c|c|c|c|c|}
\hline Jahr & Sehr positiv & Positiv & Ambivalent & Skeptisch & Sehr skeptisch \\
\hline 2006 & $\begin{array}{l}\text { Australien } \\
\text { Japan } \\
\text { Kanada } \\
\text { Katar } \\
\text { Neuseeland } \\
\text { Norwegen } \\
\text { Saudi-Arabien }\end{array}$ & $\begin{array}{l}\text { Bangladesch } \\
\text { Brasilien } \\
\text { EU }\end{array}$ & & & \\
\hline 2007 & $\begin{array}{l}\text { Japan } \\
\text { Kanada } \\
\text { Norwegen } \\
\text { Saudi-Arabien } \\
\text { Bellona } \\
\text { IETA } \\
\text { IPIECA } \\
\text { IRGC } \\
W C I \\
W W F\end{array}$ & $\begin{array}{l}\text { EU } \\
\text { Südkorea } \\
\text { IEEP }\end{array}$ & Greenpeace & ForUM & \\
\hline 2008 & $\begin{array}{l}\text { Norwegen } \\
\text { Saudi-Arabien } \\
C C S A \\
C S L F \\
\text { ICC } \\
\text { IETA } \\
W C I\end{array}$ & $\begin{array}{l}\text { Brasilien } \\
\text { EU } \\
\text { Neuseeland }\end{array}$ & & $\begin{array}{l}\text { Greenpeace } \\
\text { SustainUS }\end{array}$ & \\
\hline 2009 & $\begin{array}{l}\text { Australien } \\
\text { Indian Institute }\end{array}$ & & & Venezuela & \\
\hline 2010 & $\begin{array}{l}\text { Australien } \\
\text { Indonesien } \\
\text { Norwegen } \\
\text { Eskom } \\
\text { EURELECTRIC } \\
\text { SACCCS }\end{array}$ & EU & Brasilien & & \\
\hline
\end{tabular}

47 Für alle folgenden Tabellen gilt: Länder sowie der IPCC sind in gerader, Beobachterorganisationen in kursiver Schrift geschrieben. Stellungnahmen, die sich nicht einordnen lassen (weil sie keine Position zu dem Thema der Tabelle beinhalten), sind nicht aufgeführt. Im Anhang befindet sich eine Auflistung der Stellungnahmen inklusive Quellenangaben. 
Vor dem Hintergrund der Zusammensetzung der Länder und Beobachterorganisationen, die sich aktiv in die Debatte einbrachten, verwundert es nicht, dass die allgemeine Einschätzung von CCS-Technologien in fast allen Stellungnahmen (42 von 49) positiv ausfällt (vgl. Tabelle 5). Sowohl die Akteur_innen, die an der Entwicklung von CCS-Technologien arbeiten, als auch die wirtschaftsnahen Umwelt-NGOs halten CCS grundsätzlich für eine wichtige Klimaschutztechnologie. Die brasilianische Regierung ist eine Ausnahme, da sie trotz eines CCS-Projekts im eigenen Land in ihren Stellungnahmen zwischen einer positiven und einer ambivalenten allgemeinen Einschätzung von CCS schwankt (zur Position Brasiliens vgl. Kapitel 5.4.3.2). Lediglich vier Stellungnahmen - von Venezuela und den Umwelt-NGOs Forum for Utvikling og Miljø, Greenpeace und SustainUS - stehen den CCS-Technologien skeptisch bis ablehnend gegenüber.

Tabelle 6 Positionen bezüglich der Aufnahme von CCS in den CDM

\begin{tabular}{|c|c|c|c|c|c|}
\hline Jahr & Sehr positiv & Positiv & Ambivalent & Skeptisch & Sehr skeptisch \\
\hline 2006 & $\begin{array}{l}\text { Australien } \\
\text { Japan } \\
\text { Kanada } \\
\text { Katar } \\
\text { Norwegen } \\
\text { Saudi-Arabien }\end{array}$ & EU & $\begin{array}{l}\text { Bangladesch } \\
\text { Schweiz }\end{array}$ & Brasilien & \\
\hline 2007 & $\begin{array}{l}\text { Japan } \\
\text { Kanada } \\
\text { Norwegen } \\
\text { Saudi-Arabien } \\
\text { Bellona } \\
\text { IETA } \\
\text { WCI }\end{array}$ & $\begin{array}{l}\mathrm{EU} \\
\text { IEEP } \\
\text { IRGC }\end{array}$ & Südkorea & $\begin{array}{l}\text { Greenpeace } \\
W W F\end{array}$ & ForUM \\
\hline 2008 & $\begin{array}{l}\text { Norwegen } \\
\text { Saudi-Arabien } \\
C C S A \\
C S L F \\
I C C \\
I E T A \\
W C I\end{array}$ & $\begin{array}{l}\text { EU } \\
\text { Neuseeland }\end{array}$ & & & $\begin{array}{l}\text { Brasilien } \\
\text { Greenpeace } \\
\text { SustainUS }\end{array}$ \\
\hline 2009 & $\begin{array}{l}\text { Australien } \\
\text { Indian Institute }\end{array}$ & & & & Venezuela \\
\hline 2010 & $\begin{array}{l}\text { Australien } \\
\text { Indonesien } \\
\text { Norwegen } \\
\text { EURELECTRIC } \\
\text { SACCCS }\end{array}$ & $\begin{array}{l}\text { EU } \\
\text { Eskom }\end{array}$ & & & Brasilien \\
\hline
\end{tabular}


Was die konkrete Frage der Aufnahme in den CDM betrifft, so fallen die Einschätzungen ähnlich, aber leicht skeptischer aus (vgl. Tabelle 6). So argumentiert beispielsweise der WWF, dass der Einsatz von CCS-Technologien - auch in Ländern des globalen Südens - zwar ein notwendiges Übel in einer Übergangsphase sei, allerdings würde eine Aufnahme von CCS-Projekten in den CDM die ökologische Integrität und die Wirksamkeit des Kyoto-Protokolls gefährden. Deshalb sollten CCS-Projekte durch öffentlich-private Partnerschaften und Joint Ventures finanziert werden (vgl. WWF 2007: 2).

Insgesamt beurteilen die Umwelt-NGOs - mit Ausnahme der CCS-affinen NGO Bellona - sowie Brasilien und Venezuela eine mögliche Aufnahme skeptisch bis ablehnend. Die Länder ohne eigenen CCS-Aktivitäten stehen einer Aufnahme von CCS-Technologien in den CDM ambivalent gegenüber. Die überwiegende Mehrheit von 35 Stellungnahmen sieht die Aufnahme allerdings positiv bis sehr positiv (vgl. Tabelle 6). In den meisten Fällen wird uneingeschränkt für eine Aufnahme von CCS-Technologien in den CDM plädiert. Die vier Stellungnahmen der EU und eine von Neuseeland fallen etwas zurückhaltender, aber dennoch insgesamt positiv aus. Sie befürworten die Aufnahme mit einschränkendem Verweis auf einzelne offene Fragen, die noch geklärt werden müssten. Die Befürworter_innen sehen in der Aufnahme in den CDM einen wichtigen Schritt für die weitere Entwicklung von CCSTechnologien. In 30 Stellungnahmen wird dieses Argument angeführt (vgl. Bellona Foundation 2007; CCSA 2008; CSLF 2008; EURELECTRIC 2010; ICC 2008; IEEP 2007; IETA 2007; IETA 2008; Indian Institute 2009; SACCCS 2010; UNFCCC 2006; UNFCCC 2007a; UNFCCC 2007b; UNFCCC 2007c; UNFCCC 2008; UNFCCC 2009b; UNFCCC 2010b; WCI 2007; WCI 2008) ${ }^{48}$. Brasilien und Venezuela waren somit die einzigen Länder, die sich in Form von schriftlichen Stellungnahmen gegen die Aufnahme von CCS in den CDM positionierten. Allerdings wurde diese Skepsis zu Beginn der Verhandlungen von mehreren anderen Ländern geteilt (v. a. von AOSIS-Staaten und den sogenannten Least Developed Countries). Diesen war das Thema allerdings vergleichsweise weniger wichtig, weshalb sie sich auch vor der endgültigen Abstimmung von der CCS-befürwortenden Koalition in den UN-Klimaverhandlungen umstimmen ließen. ${ }^{49}$

48 Ein UNFCCC-Dokument enthält meistens mehrere Stellungnahmen, da die Stellungnahmen der Regierungen gebündelt veröffentlicht werden. Deshalb sind hier nicht 30 verschiedene Literaturverweise aufgeführt.

49 Diesen Hinweis bekam ich in einem Interview, das ich am 16.05.2013 mit Heleen de Coninck, die den Verhandlungsstrang zu CCS-Technologien als Wissenschaftlerin beobachtete, geführt habe. 
Die Beurteilung von CCS wird vor dem Hintergrund der teils expliziten, teils impliziten Annahme getroffen, dass die Klimaschutzziele durch ein Portfolio technologischer Optionen erreicht werden. Es wird davon ausgegangen, dass die Kombination verschiedener Technologien den größtmöglichen Klimaschutz zu möglichst geringen Kosten sicherstellt. In 22 Stellungnahmen werden die CCS-Technologien explizit als wichtiges Element eines solchen Portfolios tituliert (vgl. Tabelle 7). ${ }^{50}$ Dabei wird in neun Stellungnahmen - meist mit Verweis auf die Wahrscheinlichkeitsaussage des IPCC (vgl. Enthymem IPCC 6; IPCC 2005: 3, 12; Kapitel 5.3.3) hervorgehoben, dass CCS als Teil des Portfolios dazu beitrage, die Gesamtkosten des Klimaschutzes zu reduzieren (vgl. Tabelle 7).

\section{Tabelle 7 Das Argument der Bedeutung von CCS als Element des Portfolios}

\begin{tabular}{|c|c|c|}
\hline Jahr & Wichtiges Portfolio-Element & Reduktion der Kosten \\
\hline 2006 & $\begin{array}{l}\text { Brasilien } \\
\text { EU } \\
\text { Kanada }\end{array}$ & Kanada \\
\hline 2007 & $\begin{array}{l}\text { EU } \\
\text { Japan } \\
\text { Bellona } \\
\text { IETA } \\
\text { WCI }\end{array}$ & IETA \\
\hline 2008 & $\begin{array}{l}\text { Brasilien } \\
\text { EU } \\
\text { Neuseeland } \\
C C S A \\
\text { ICC } \\
\text { IETA } \\
W C I\end{array}$ & $\begin{array}{l}I C C \\
I E T A \\
W C I\end{array}$ \\
\hline 2009 & Australien & \\
\hline 2010 & $\begin{array}{l}\text { Australien } \\
\text { Brasilien } \\
\text { EU } \\
\text { Indonesien } \\
\text { Norwegen } \\
\text { EURELECTRIC }\end{array}$ & $\begin{array}{l}\text { Australien } \\
\text { EU } \\
\text { Eskom } \\
\text { EURELECTRIC }\end{array}$ \\
\hline
\end{tabular}

50 Die mit Abstand häufigste Formulierung für das Portfolio lautet ,portfolio of technologies“, daneben gibt es auch „full range of mitigation technologies“ und „key options“. 
Gleichzeitig werden in zwölf Stellungnahmen - von sehr unterschiedlichen Akteur_innen - die hohen Kosten des Ausbaus von CCS-Technologien als Herausforderung, nicht aber als unüberwindbares Hindernis angeführt (vgl. Tabelle 8). In dem Zusammenhang wird von der CCS-befürwortenden Koalition in den UNKlimaverhandlungen auch auf die finanziellen Anreize des CDM als mögliche Lösung verwiesen.

\section{Tabelle 8 Das Argument der hohen Kosten von CCS}

\begin{tabular}{|l|l|l|l|}
\hline Jahr & Kosten als Problem & Kosten als Herausforderung & Kosten kein Problem \\
\hline 2006 & & Bangladesch & \\
\hline 2007 & & $\begin{array}{l}\text { Norwegen } \\
\text { Bellona Foundation } \\
\text { Greenpeace } \\
\text { IEEP } \\
\text { IRGC }\end{array}$ & \\
\hline 2008 & Greenpeace & Neuseeland & \\
\hline 2009 & & $\begin{array}{l}\text { Venezuela } \\
\text { Indian Institute }\end{array}$ & IETA \\
\hline 2010 & & $\begin{array}{l}\text { Brasilien } \\
\text { EU } \\
\text { SACCCS }\end{array}$ & \\
& & & \\
\hline
\end{tabular}

Für die IETA stellt die Frage der Kosten kein Problem dar, da Kohlenstoffmärkte automatisch zur Anwendung der kosteneffizientesten Technologien führen würden. Der CDM biete dabei Anreize für die Durchführung kosteneffizienter „early opportunities“ in den Nicht-Annex-B-Staaten. Langfristig entscheide aber die Technologieentwicklung über die Wettbewerbsfähigkeit von CCS (vgl. IETA 2008). Greenpeace schätzt dagegen in einer Stellungnahme den hohen Subventionsbedarf von CCS sehr kritisch ein. CCS sei im Vergleich zu anderen Klimaschutztechnologien alles andere als eine kostengünstige Option. Weiterhin könne eine großzügige Förderung von CCS-Projekten dazu führen, dass weniger Geld für erneuerbare Energien zur Verfügung steht (vgl. Greenpeace 2008b).

Die brasilianische Regierung und das FoUM warnen ebenfalls davor, dass die Aufnahme von CCS in den CDM zu geringeren Investitionen in erneuerbare Energien führen könne (vgl. Tabelle 9). An diesem Argument wird der Unterschied zwischen den sogenannten ,grünen“ und den wirtschaftsnäheren Umwelt-NGOs deutlich. Der WWF und die Bellona Foundation räumen dem Zielkonflikt zwischen den verschiedenen Technologieformen nicht diese Bedeutung ein. 
Tabelle 9 Das Argument des Zielkonflikts zwischen Erneuerbaren und CCS

\begin{tabular}{|l|l|l|l|}
\hline Jahr & Zielkonflikt als Gefahr & Regelungsbedarf & Zielkonflikt widersprochen \\
\hline 2006 & & & \\
\hline 2007 & ForUM & & $\begin{array}{l}\text { IEEP } \\
\text { IETA }\end{array}$ \\
\hline 2008 & Brasilien & & Norwegen \\
& Greenpeace & Neuseeland & WCI \\
\hline 2009 & & & Australien \\
\hline 2010 & Brasilien & & $\begin{array}{l}\text { Eskom } \\
\text { EURELECTRIC }\end{array}$ \\
\hline
\end{tabular}

Die brasilianische Regierung wiederum setzt - als Initiatorin des CDM - große Hoffnungen auf die durch den CDM ermöglichte Förderung erneuerbarer Energien in Nicht-Annex-B-Staaten. Folgerichtig drückt die brasilianische Regierung in zwei ihrer Stellungnahmen die Befürchtung aus, dass diese Investitionen mit einer Aufnahme von CCS geringer ausfallen könnten (vgl. Tabelle 9). Auf diese Möglichkeit des Zielkonflikts weisen auch die EU und die neuseeländische Regierung in jeweils einer Stellungnahme hin (vgl. Tabelle 9). Allerdings geben sie sich optimistischer und betonen lediglich, dass eine derartige Entwicklung bei der Aufnahme von CCS in den CDM durch eine entsprechende Regelung verhindert werden müsse. Australien und Norwegen wiederum schätzen den Sachverhalt ganz anders ein. Ihre Regierungen greifen in jeweils einer Stellungnahme die geäußerten Befürchtungen auf, widersprechen ihnen aber grundsätzlich. Sie sehen - wie auch die Beobachterorganisationen Eskom, EURELECTRIC, IEEP und WCI - keinen Zielkonflikt, da es ihrer Meinung nach nur zu einer geringen Anzahl an CCS-CDM-Projekten kommen werde (vgl. Tabelle 9). Die IETA argumentiert marktradikal: Die kosteneffizienteste Technologie - egal ob CCS oder erneuerbar - werde sich durchsetzen und gerade dies sei der Zweck der flexiblen Mechanismen des Kyoto-Protokolls (vgl. Tabelle 9).

In engem Zusammenhang mit den Einschätzungen über einen möglichen Zielkonflikt steht die Frage, ob CCS-Technologien das Kriterium der Nachhaltigkeit erfüllen. Die brasilianische Regierung sieht die ökologische Integrität des CDM in Gefahr und bezieht - gemeinsam mit Venezuela - eindeutig Position: CCS-Technologien tragen ihrer Meinung nach nicht zu einer nachhaltigen Entwicklung bei. Eine zentrale Bedingung für die Aufnahme in den CDM werde somit nicht erfüllt. Die Umwelt-NGOs außer Bellona teilen diese Auffassung (vgl. Tabelle 10). Sie halten an dem Kriterium fest, dass Projekttypen nur dann in den CDM aufgenommen 
werden können, wenn sie über die Reduktion von Treibhausgasemissionen hinaus eine nachhaltige Entwicklung vorantreiben. Dass die CCS-Technologien dies aus ihrer Sicht nicht leisten können, wird von ihnen als gewichtiger Nachteil gegenüber erneuerbaren Energien gewertet und stellt für sie ein zentrales Argument gegen die Aufnahme in den CDM dar. Das Forschungsinstitut IEEP mildert diese Kritik mit der Begründung ab, dass bisherige CDM-Projekte auch nicht in jedem Fall Impulse für eine positive Entwicklung in sozialen, ökologischen und ökonomischen Bereichen gäben (vgl. IEEP 2007). Der WWF - in dessen Auftrag IEEP ihre Studie erstellte - betont allerdings, dass die mangelnde Fähigkeit von CCS-Technologien, zu einer nachhaltigen Entwicklung beizutragen, gegen eine Aufnahme in den CDM spreche - unabhängig davon, ob bisherige CDM-Projekte das Kriterium erfüllten oder nicht (vgl. WWF 2007).

Tabelle 10 Das Argument der mangelnden Nachhaltigkeit

\begin{tabular}{|l|l|l|l|}
\hline Jahr & $\begin{array}{l}\text { Mangelnde Nachhaltigkeit } \\
\text { ist Ausschlusskriterium }\end{array}$ & $\begin{array}{l}\text { Mangelnde Nachhaltigkeit } \\
\text { kein Ausschlusskriterium }\end{array}$ & $\begin{array}{l}\text { CCS führt zu nach- } \\
\text { haltiger Entwicklung }\end{array}$ \\
\hline 2006 & Brasilien & & \\
\hline 2007 & $\begin{array}{l}\text { Greenpeace } \\
\text { ForUM } \\
\text { WWF }\end{array}$ & IEEP & $\begin{array}{l}\text { Bellona } \\
\text { IETA }\end{array}$ \\
\hline 2008 & $\begin{array}{l}\text { Brasilien } \\
\text { Greenpeace } \\
\text { SustainUS }\end{array}$ & & $\begin{array}{l}\text { CSLF } \\
\text { IETA } \\
\text { WCI }\end{array}$ \\
\hline 2009 & Venezuela & & \\
\hline 2010 & Brasilien & & \\
\hline
\end{tabular}

Diesem Argument widerspricht die CCS-befürwortende Koalition in den UNKlimaverhandlungen in fünf Stellungnahmen (vgl. Tabelle 10). Die Bellona Foundation geht dabei sehr ausführlich auf die Kritik ein und führt folgende Gründe an, warum CCS-Technologien ihrer Meinung nach sehr wohl zu einer nachhaltigen Entwicklung beitragen können (vgl. Bellona Foundation 2007): CCS-Technologien könnten Nicht-Annex-B-Staaten zur Elektrifizierung und damit zur Erhöhung des Lebensstandards und zum Aufbau von Infrastruktur verhelfen. Weiterhin würden neue Beschäftigungsmöglichkeiten geschaffen werden. Darüber hinaus werde durch CCS-Projekte der wichtige Technologietransfer in Nicht-Annex-B-Staaten vorangetrieben und eine nachhaltigere Nutzung fossiler Brennstoffe ermöglicht. Dabei könnte CCS als Brückentechnologie fungieren, bis langfristige Alternativen wie erneuerbare Energien weiter entwickelt sind. 
In dieser Argumentation wird deutlich, was den Kern der Debatte darstellt: die Nutzung fossiler Brennstoffe. Der Konflikt zwischen den Befürworter_innen und den Kritiker_innen entzündet sich letztlich an der Frage, ob die fortgesetzte Nutzung fossiler Brennstoffe möglichst schnell ausgesetzt werden sollte oder nicht. Die CCS-kritische Koalition in den UN-Klimaverhandlungen hält eine Überwindung der fossilen Energieinfrastruktur für notwendig, um die Klimaschutzziele zu erreichen. Bei der CCS-befürwortenden Koalition in den UN-Klimaverhandlungen finden sich zwei verschiedene Begründungsmuster, zwischen denen es fließende Übergänge gibt: Die Fortführung der fossilen Energieinfrastruktur gilt als wünschenswert und/oder als realistische Annahme, die jede seriöse Klimapolitik vorauszusetzen habe.

Tabelle 11 Das Argument der Brückentechnologie

\begin{tabular}{|c|c|c|c|}
\hline Jahr & $\begin{array}{l}\text { Steigender Verbrauch } \\
\text { fossiler Brennstoffe }\end{array}$ & $\begin{array}{l}\text { CCS ist } \\
\text { Brückentechnologie }\end{array}$ & $\begin{array}{l}\text { CCS ist wichtig für nach- } \\
\text { haltiges Wachstum }\end{array}$ \\
\hline 2006 & Kanada & Kanada & Kanada \\
\hline 2007 & $\begin{array}{l}\text { EU } \\
\text { Kanada } \\
\text { Norwegen } \\
\text { Bellona Foundation } \\
\text { IEEP } \\
\text { IRGC } \\
W C I\end{array}$ & $\begin{array}{l}\text { Kanada } \\
\text { Norwegen } \\
\text { Bellona Foundation } \\
\text { IETA } \\
\text { WWF }\end{array}$ & $\begin{array}{l}\text { Norwegen } \\
\text { Bellona Foundation } \\
\text { WCI }\end{array}$ \\
\hline 2008 & $\begin{array}{l}\text { Neuseeland } \\
\text { CCSA } \\
\text { CSLF } \\
\text { ICC } \\
\text { IETA } \\
\text { WCI }\end{array}$ & $\begin{array}{l}\text { (Brasilien) } \\
\text { Norwegen } \\
\text { CCSA }\end{array}$ & $\begin{array}{l}I C C \\
I E T A \\
W C I\end{array}$ \\
\hline 2009 & $\begin{array}{l}\text { Australien } \\
\text { Indian Institute }\end{array}$ & Australien & $\begin{array}{l}\text { Australien } \\
\text { Indian Institute }\end{array}$ \\
\hline 2010 & $\begin{array}{l}\text { Australien } \\
\text { EU } \\
\text { EURELECTRIC }\end{array}$ & $\begin{array}{l}\text { EU } \\
\text { (Brasilien) }\end{array}$ & EU \\
\hline
\end{tabular}

In 19 Stellungnahmen werden Studien zitiert, in denen ein Anstieg des globalen Verbrauchs fossiler Brennstoffe prognostiziert wird (vgl. Tabelle 11). Aus dieser Annahme wird in zehn Stellungnahmen geschlussfolgert, dass CCS-Technologien wichtig seien, um Entwicklung bzw. Wirtschaftswachstum ohne steigende Emissionen $\mathrm{zu}$ ermöglichen (vgl. Tabelle 11). In insgesamt zwölf Stellungnahmen wird 
CCS vor dem Hintergrund dieser Prognosen CCS als wichtige Brückentechnologie bezeichnet (vgl. Tabelle 11). Neben wichtigen Akteuer_innen der CCS-befürwortenden Koalition in den UN-Klimaverhandlungen greifen auch Brasilien und der WWF diesen Begriff auf. Aus Sicht der brasilianischen Regierung erfüllt CCS allerdings nur in den Annex-B-Staaten die Funktion einer Brückentechnologien. In den Nicht-Annex-B-Staaten dagegen würden CCS-CDM-Projekte kontraproduktive Anreize (,perverse incentives“) für die Förderung fossiler Brennstoffe bieten (vgl. Kapitel 5.4.3.2 zur Positionierung Brasiliens).

Was die ökologischen und gesundheitlichen Risiken der CCS-Technologien betrifft, verlaufen die Konfliktlinien parallel zu der allgemeinen Beurteilung einer möglichen Aufnahme von CCS in den CDM. Aus der Sicht von Greenpeace und SustainUS sowie der Regierungen Brasiliens und Venezuelas stellen die ökologischen und gesundheitlichen Risiken eine ernst zu nehmende Gefahr dar, die man den Zielländern der CDM-Projekte nicht zumuten könne (vgl. Tabelle 12).

Tabelle 12 Das Argument der ökologischen und gesundheitlichen Risiken

\begin{tabular}{|l|l|l|l|}
\hline Jahr & Risiken als Gefahr & Risiken als Herausforderung & Risiken unproblematisch \\
\hline 2006 & Brasilien & EU & $\begin{array}{l}\text { Kanada } \\
\text { Katar } \\
\text { Norwegen }\end{array}$ \\
\hline 2007 & Greenpeace & Südkorea & $\begin{array}{l}\text { EU } \\
\text { Kanada } \\
\text { Bellona Foundation } \\
\text { IETA }\end{array}$ \\
\hline 2008 & $\begin{array}{l}\text { Brasilien } \\
\text { SustainUS }\end{array}$ & Neuseeland & $\begin{array}{l}\text { CSLF } \\
\text { IETA } \\
\text { WCI }\end{array}$ \\
\hline 2009 & Venezuela & & Australien \\
\hline 2010 & Brasilien & EU & $\begin{array}{l}\text { Norwegen } \\
\text { EURELECTRIC }\end{array}$ \\
\hline
\end{tabular}

Dieser Einschätzung wird in Stellungnahmen der CCS-befürwortenden Koalition in den UN-Klimaverhandlungen widersprochen (vgl. Tabelle 12). Sie gehen davon aus, dass CCS-Technologien sicher eingesetzt werden können und die ökologischen und gesundheitlichen Risiken auf ein unproblematisches Niveau minimiert werden können. Den Bedenken halten sie die Prognosen des IPCC zur Sicherheit der Endlagerung des Kohlenstoffdioxids in geologischen Formationen entgegen - teilweise mit implizitem und teilweise mit explizitem Verweis auf den IPCC SRCCS. Die EU, Neuseeland und Südkorea nehmen eine Zwischenposition ein (vgl. Tabelle 12). 
Neuseeland und die EU erwähnen lediglich mögliche Risiken, gehen aber grundsätzlich davon aus, dass diese handhabbar seien. Südkorea sieht in den Risiken ein Problem, das in der weiteren Entwicklung der Technologien gelöst werden müsse und könne.

Im engen Zusammenhang mit der Frage der Risiken steht ein Argument, das bei CCS-Konflikten in anderen Diskursarenen großen Raum einnimmt: die Befürchtung, dass eine mangelnde Akzeptanz in der Bevölkerung CCS-Projekte verhindern könnte. Vermutlich scheint dieser Aspekt auf der internationalen Ebene keine bedeutende Rolle zu spielen, da die Akzeptanzprobleme schließlich erst bei der konkreten Umsetzung auftauchen und damit auf regionaler und nationaler Ebene verhandelt werden. Lediglich der WWF geht knapp darauf ein und fordert die Involvierung der Zivilgesellschaft (vgl. WWF 2007: 1).

Abschließend fasse ich den Überblick über die Akteuer_innen und ihre Positionen kurz zusammen: Wenn man die an der CCS-CDM-Kontroverse beteiligten Beobachterorganisationen und ihre eingereichten Stellungnahmen insgesamt betrachtet, so sind die wirtschaftsnahen Akteur_innen eindeutig in der Überzahl. Selbst von den fünf Umwelt-NGOs arbeiten Bellona und der WWF eng mit Unternehmen zusammen. Dies spiegelt sich auch in ihren Positionen zu CCS wider. Für den WWF sind CCS-Technologien eine wichtige Klimaschutztechnologie und ein notwendiges Übel. Dennoch spricht sich der WWF gegen die Aufnahme in den CDM aus. Bellona setzt sich vehement für CCS-Technologien ein und befürwortet die Aufnahme in den CDM. Diese eindeutige Position vertreten auch die anderen Beobachterorganisationen, die sich neben den fünf Umwelt-NGOs aktiv in die CCS-CDM-Kontroverse einbrachten - mit Ausnahme vom Forschungsinstitut IEEP, deren Studie nur moderat pro-CCS argumentiert. Es ist anzunehmen, dass dabei sehr konkrete unternehmerische Interessen und Strategien eine entscheidende Rolle spielen, denn die an der Debatte beteiligten wirtschaftsnahen Akteuer_innen sind größtenteils mit der fossilen Industrie vernetzt. Sie halten CCS für eine wichtige Klimaschutztechnologie, da sie mit anderen Interessen - dem Wirtschaftswachstum und dem Verbrauch fossiler Brennstoffe - kompatibel ist. Durch die Hoffnung auf CCS-Technologien scheint Klimaschutz nicht im Widerspruch zum Fortbestand oder gar Wachstum ihrer Branchen zu stehen (vgl. Vormedal 2008: 40). Auf der Seite der CCS-befürwortenden Koalition in den UN-Klimaverhandlungen stach IETA durch lange und ausgefeilte Stellungnahmen hervor. Von den (gegenüber der Aufnahme) kritischen Beobachterorganisationen brachte sich Greenpeace am stärksten in die Debatte ein. 
Bei den Ländern spielten Australien, Brasilien, die EU und Norwegen wichtige Rollen, indem sie in mehreren Stellungnahmen zahlreiche Argumente einbrachten und paradigmatisch für unterschiedliche Positionen stehen. Norwegen wendet CCSTechnologien selber bereits im industriellen Maßstab an und interessiert sich für die Anwendung von CCS im Erdgas- und Erdöl-Sektor. Australien und die EU streben die Anwendung von CCS bei Kohlekraftwerken an. Die EU hatte innerhalb der CCS-befürwortenden Koalition in den UN-Klimaverhandlungen insofern eine Sonderrolle, als dass sie viele Kritikpunkte aufgriff und sich in vielen Punkten zurückhaltend positionierte oder vage blieb. Dies war sicherlich ein Grund, warum die EU in der Schlussphase der Verhandlungen vormals kritische Regierungen umstimmen konnte. Insgesamt war die CCS-befürwortende Koalition stark vertreten. Sicherlich auch um ihre eigenen CCS-Projekte voran zu bringen, waren Länder, die in die Entwicklung von CCS involviert sind, besonders engagiert. Von den Ländern, die Stellungnahmen einreichten, haben nur Bangladesch, die Schweiz und Venezuela keine eigenen CCS-Aktivitäten. Dennoch vertraten Bangladesch und die Schweiz keineswegs CCS-kritische Positionen. Die venezolanische Regierung positionierte sich als einzige Regierung allgemein gegen CCS-Technologien. Auch der Aufnahme in den CDM standen die meisten Länder, die sich aktiv in die Debatte einbrachten, positiv gegenüber. Die brasilianische Regierung wehrte sich am vehementesten gegen die Aufnahme in den CDM.

\subsubsection{Verhandlungspositionen in ihrem akteursspezifischen Kontext}

In diesem Kapitel greife ich einzelne Akteur_innen heraus und analysiere ihre Positionierungen in der CCS-CDM-Kontroverse vor dem Hintergrund der jeweils spezifischen Voraussetzungen ihrer Verhandlungspositionen. Mit dieser Analyse relevanter Akteur_innen verfolge ich verschiedene Ziele. Zunächst einmal ermöglicht sie mir, die verschiedenen Argumentationslinien und ihre Verhältnisse zueinander herauszuarbeiten. Weiterhin kann ich über den Fokus auf die Akteur_innen die Kontexte von Argumenten in den Blick nehmen und damit meine Analyse erweitern. Gerade in Arenen wie den UN-Klimaverhandlungen, in denen von stark strategischem Handeln der Akteur_innen ausgegangen werden muss, können Aushandlungsprozesse nicht allein durch eine Interpretation der ausgetauschten Argumente verstanden und erklärt werden. Deshalb dient mir der akteurszentrierte Fokus in diesem Kapitel zur Untersuchung von darüber hinausgehenden Faktoren für verschiedene Positionierungen und Verhandlungsverläufe. Insgesamt ist eine solche tiefer gehende Analyse sinnvoll, um die Forschungsfragen, die das Verhältnis der 
CCS-Konflikte mit dem Hegemonieprojekt betreffen, beantworten zu können (zu den Forschungsfragen vgl. die Kapitel 1.1 und 4).

Die Auswahl der genauer untersuchten Akteur_innen soll folgende Bedingungen erfüllen: Die verschiedenen Positionen zur Frage, ob CCS-Technologien in den CDM aufgenommen werden sollen, müssen vertreten sein. Darüber hinaus sollte die Auswahl die an den Aushandlungen beteiligten Akteursgruppen (Annex-BStaaten, Nicht-Annex-B-Staaten, NGOs, BINGOs) abbilden. Es sollten zudem Akteur_innen analysiert werden, die eine wichtige Rolle in den Verhandlungen spielten. Die Auswahl der Akteur_innen - Brasilien, der EU, Greenpeace, IETA und Norwegen - begründe ich im Einzelnen:

Norwegen zählt zu den Ländern mit der größten CCS-Expertise. Das weltweit erste CCS-Projekt im Industriemaßstab (Sleipner) wurde in Norwegen umgesetzt. Norwegen steht damit für das Interesse an CCS-Technologien im Öl- und Gassektor. Weiterhin ist Norwegen ein Annex-B-Staat, der auf die projektbasierten Mechanismen des Kyoto-Protokolls angewiesen ist, um seine Klimaschutzziele zu erfüllen. Insofern hat die norwegische Regierung ein besonderes Interesse an CDMProjekten. In den Verhandlungen gehörte die norwegische Regierung zu den wichtigsten Befürworter_innen der Aufnahme von CCS in den CDM.

Die brasilianische Regierung war dagegen die aktivste und schärfste Kritikerin. Brasilien zählt zu den Nicht-Annex-B-Staaten, in denen viele CDM-Projekte durchgeführt werden. Das Engagement der brasilianischen Regierung in der CCS-CDMKontroverse rührt über die eigene Betroffenheit hinaus auch daher, dass sie die Idee des CDM in die Kyoto-Verhandlungen einbrachte.

Die EU gehörte ebenfalls zu den Akteur_innen, die intensiv an den CCSVerhandlungen beteiligt waren. Innerhalb der CCS-befürwortenden Koalition in den UN-Klimaverhandlungen stach die EU durch ihre vergleichsweise zurückhaltenden und vagen Formulierungen hervor. Dies könnte ein Grund dafür gewesen sein, warum sie in der Lage war, skeptische Regierungen von der Zustimmung zur Aufnahme von CCS in den CDM zu überzeugen. In dieser Rolle beeinflusste die EU den Ausgang der Verhandlungen entscheidend. Wie Norwegen setzt die EU auf CCS und sieht sie als wichtige Klimaschutz-Technologie - allerdings nicht im Ölund Gassektor, sondern in der Anwendung bei Kohlekraftwerken.

Von den Beobachterorganisationen war Greenpeace die wichtigste kritische Kraft. Greenpeace zählt zu den wenigen NGOs, die sich zum Zeitpunkt der CCSCDM-Kontroverse bereits CCS-Expertise angeeignet hatten und vertrat mit der Kritik an der Aufnahme von CCS in den CDM eine Position aus dem NGOSpektrum. 
Es beteiligten sich zwar nicht sehr viele Umwelt-NGOs an der CCS-CDMKontroverse, dafür aber umso mehr BINGOs, die sich für die Aufnahme von CCS in den CDM aussprachen. Die IETA gehörte zu den aktivsten BINGOs und brachte sich mit besonders elaborierten und facettenreichen Stellungnahmen ein.

Mit dieser Auswahl an Akteur_innen sind die oben aufgeführten Kriterien erfüllt. In ihren Stellungnahmen sind alle Argumente und Gegenargumente der CCSCDM-Kontroverse enthalten (vgl. die Tabellen in Kapitel 5.4.2). Eine Ausnahme bilden die Kritikpunkte von SustainUS. Die NGO vertrat als einzige eine Position, die über die Grundannahmen und Hegemoniestrategien des ökomodernen Projekts hinausweist (vgl. Kapitel 5.4.4). Allerdings spricht der allgemein geringe Einfluss der Jugendorganisation und ihre marginale Rolle in der CCS-CDM-Kontroverse gegen eine Feinanalyse ihrer Positionierung.

\subsubsection{Norwegens Positionierung in der CCS-CDM-Kontroverse}

Verschiedene Faktoren sind dafür verantwortlich, ob und wie sich eine Regierung bzw. die Delegation eines Landes in einzelne Verhandlungsstränge innerhalb der Klimarahmenkonvention einbringt. Insofern ist es wichtig, die Voraussetzungen ihrer konkreten Verhandlungsposition und -argumentation zu betrachten. Deshalb gehe ich im Folgenden zunächst auf die Rolle Norwegens für das UN-Klimaregime ein. Dabei werde ich herausarbeiten, inwieweit die norwegische Regierung eine eher passive oder eher aktive Akteurin war und welche klimapolitischen Positionen sie generell vertritt. Daran schließt eine Analyse der norwegischen Aktivitäten im Energie- und Klimabereich an. Über die Beschreibung der norwegischen Energieinfrastruktur und klimapolitischen Maßnahmen lassen sich Präferenzen und Pfadabhängigkeiten ableiten, die für die politische Einschätzung von CCS-Technologien relevant sind. In einem darauf folgenden Abschnitt beleuchte ich die konkreten Aktivitäten zur Entwicklung und Anwendung von CCS-Technologien. Dabei interessiert mich nicht nur, welche CCS-Projekte es in Norwegen gibt, sondern auch von wem sie unterstützt und umgesetzt werden. Im Anschluss an die Beschreibung der genannten Kontextfaktoren gehe ich kurz auf die prinzipielle Position der norwegischen Regierung in den CCS-Verhandlungen ein. Abschließend zeichne ich die Argumentationsstruktur ihrer schriftlichen Stellungnahmen nach.

\section{Die Rolle Norwegens im UN-Klimaregime}

Die norwegische Regierung brachte sich bereits sehr früh in internationale Debatten über die ökologische Krise ein und war in der Herausbildung des internationalen Klimaregimes Ende der 1980er und Anfang der 90er Jahre eine wichtige Impulsgeberin. Dies könnte damit zusammenhängen, dass Norwegen als eher kleines Land 
bei bilateralen Verhandlungen im Nachteil ist und man somit in der norwegischen Außenpolitik traditionell eine Affinität zu multilateralen Lösungen von Konflikten und Herausforderungen feststellen kann (vgl. Sydnes 1996: 293). Vor allem aber gab es in der norwegischen Gesellschaft zu dem genannten Zeitpunkt bereits eine große Zustimmung zu klimapolitischen Maßnahmen, da die Bevölkerung den ökologischen Problemen große Bedeutung beimaß und Umwelt-NGOs sehr aktiv waren (vgl. Andresen/Butenschøn 2001: 342f). Darüber hinaus hatte Norwegen auch bei anderen ökologischen Themen auf internationaler Ebene eine Führungsrolle übernommen, beispielsweise bei der Bekämpfung des sauren Regens. So lange die Zielkonflikte internationaler Umweltpolitik mit spezifischen norwegischen Wirtschaftsinteressen - die in erster Linie den Export von Gas und Öl betreffen - noch nicht so offensichtlich waren, sah sich Norwegen als ,grüner Vorreiterstaat' (vgl. Andresen/ Butenschøn 2001: 351, 354; Andresen/Kolshus/Torvanger 2002: 1).

Die norwegische Politikerin Gro Harlem Brundtland, die 1981, 1986-1989 und 1990-1996 Ministerpräsidentin war, forcierte die internationale Auseinandersetzung mit der ökologischen Krise. Als Vorsitzende des WCED war sie hauptverantwortlich zuständig für die Erstellung des einflussreichen Berichts Our Common Future, der 1987 publiziert wurde (vgl. Tjernshaugen/Langhelle 2009: 101). Für diese Frühphase des klimapolitischen Engagements steht das 1989 verabschiedete Weißbuch $^{51}$ zu Umwelt und Entwicklung, in dem die Regierung das Ziel formuliert, Norwegen zu einem Pusher auf dem Weg zu einem internationalen Klimaabkommen zu machen (vgl. Christiansen 2002: 237). Norwegen war 1990 Gastgeberland einer der Vorbereitungstreffen für die wichtige Rio-Konferenz. Bei dieser Bergen Conference on Sustainable Development setzte sich Norwegen für quantitative Obergrenzen der Treibhausgasemissionen in den Industrieländern ein (vgl. Andresen/Butenschøn 2001: 339). Weiterhin plädierte Norwegen bereits in den Anfängen der internationalen Klimapolitik für zusätzliche Finanztransfers von Industrie- zu Entwicklungsländern, um im globalen Süden klimapolitische Maßnahmen finanzieren zu können (vgl. Sydnes 1996: 179). Dieser Fokus auf die entwicklungspolitische Dimension entsprach der Tradition norwegischer Außenpolitik (vgl. Andresen/Kolshus/Torvanger 2002: 1).

Mit der zunehmenden Erkenntnis, dass ein ambitionierter Klimaschutz Norwegens ökonomischen Interessen zuwider läuft, wandelte sich in den 1990er Jahren die norwegische Klimapolitik sowohl auf nationaler als auch auf internationaler Ebene (vgl. Andresen/Butenschøn 2001: 351, 354). Im Verlauf der internationalen Verhandlungen nahm die norwegische Regierung immer weniger eine progressive

51 Als ,Weißbuch“ gilt im Politikbetrieb eine Sammlung von Vorschlägen, konkreten Vorhaben und Umsetzungsplänen zu einem bestimmten Politikbereich. 
Position ein, da sie fürchtete, damit einhergehende Reduktionsverpflichtungen im eigenen Land nur mit hohen Kosten erreichen zu können. Vor diesem Hintergrund brachte die norwegische Regierung 1991 die Idee der Gemeinsamen Umsetzung in die UN-Klimaverhandlungen ein. und erklärte die Einigung auf den flexibilisierenden Mechanismus zur Bedingung für die Unterzeichnung eines Abkommens. Die norwegische Regierung setzte sich insgesamt für die Einführung flexibler Mechanismen ein, denn aufgrund der spezifischen Energieinfrastruktur befürchtete sie erheblichen Kosten, die mit der Reduktion von Treibhausgasemissionen im eigenen Land verbunden wären. Mit dieser Position wechselte Norwegen auch seine Bündnispartner_innen. Hatte die norwegische Regierung lange Zeit an der Seite der ökologisch orientierten EU-Länder agiert, so vertrat sie in den KyotoVerhandlungen eher bremsende Positionen im Verbund der JUSSCANNZ-Länder bzw. der Umbrella Group (zur Unterscheidung vgl. Abkürzungs- und Begriffsverzeichnis). Gemeinsam mit den anderen JUSSCANNZ-Ländern wehrte sich die norwegische Regierung gegen eine quantifizierte Obergrenze für den Anteil der Treibhausgasreduktionen, die durch flexible Mechanismen erbracht werden können. In dieser Auseinandersetzung setzte sich die Umbrella Group 2001 gegen die Länder durch, die für einen Mindestanteil der im eigenen Land zu erbringenden Reduktionen stritten (vgl. Andresen/Butenschøn 2001: 340f; Andresen/Kolshus/Torvanger 2002: 8f; Oberthür/Ott 2000: 373ff; Tjernshaugen/Langhelle 2009: 102).

Neben den Forderungen nach flexiblen Mechanismen setzte sich Norwegen in den UN-Klimaverhandlungen für ein Abkommen mit länderspezifischen und verbindlichen Reduktionszielen ein, wie es letztlich auch verabschiedet wurde. Zusätzlich sprach sich Norwegen für gemeinsame quantitative Reduktionsverpflichtungen für Länder-Gruppen aus, um die Möglichkeiten der Kooperation zu stärken. Diese im Kyoto-Protokoll verankerte Möglichkeit des Bubbling nimmt ausschließlich die Europäische Union in Anspruch. Der Wunsch Norwegens, eine Bubble zu bilden beispielsweise mit allen OECD-Ländern - erfüllte sich nicht. Der Vorschlag der norwegischen Regierung, eine Harmonisierung der Klimaschutz-Maßnahmen mittels einer Verbreitung der norwegischen $\mathrm{CO}_{2}$-Steuer voranzutreiben, wurde in den Verhandlungen schnell abgelehnt. Weiterhin war es ihr ein Anliegen, alle wichtigen direkten Treibhausgase in die Reduktionsverpflichtungen aufzunehmen. Da in Norwegen die $\mathrm{CO}_{2}$-Emissionen stark ansteigen, andere Treibhausgasemissionen dagegen stabil bleiben oder sinken, kam der norwegischen Regierung die Einbeziehung von insgesamt sechs wichtigen Treibhausgasen im Kyoto-Protokoll zugute. Ein alleiniger Fokus auf $\mathrm{CO}_{2}$ hätte es Norwegen weitaus schwerer gemacht, Reduktionsziele einzuhalten (vgl. Andresen/Butenschøn 2001: 339f). 
Darüber hinaus sicherte sich die norwegische Regierung die Möglichkeit, bis zum Ende der ersten Verpflichtungsperiode des Kyoto-Protokolls (2012) die Treibhausgasemissionen im Vergleich zum Basisjahr 1990 um $1 \%$ zu steigern. Allerdings entschied die norwegische Regierung im Jahre 2007, das Kyoto-Ziel um 10 \% überzuerfüllen. Dieses Ziel konnte aber nur über den Ankauf von Emissionsberechtigungen erreicht werden (vgl. Tjernshaugen/Langhelle 2009: 102, 104). Die Treibhausgasemissionen in den norwegischen Energie-Industrien (worunter die Erzeugung und Distribution von Energie inklusive der Öl- und Gasförderung, Gasentnahmestellen, Erdölraffinerien und Kohleabbau fallen) sind zwischen 1990 und 2006 um fast $87 \%$ gestiegen, was vor allem auf den Anstieg der Öl- und Gasförderung zurückzuführen ist. Insgesamt sind die Treibhausgasemissionen in Norwegen im gleichen Zeitraum um ca. 7,7 \% gestiegen, weshalb Norwegen auf die flexiblen Mechanismen angewiesen war, um das Kyoto-Ziel zu erreichen (vgl. Langhelle/Meadowcroft 2009: 250ff). ${ }^{52}$

\section{Die norwegischen Aktivitäten im Energie- und Klimabereich}

Wie bereits angedeutet, nahm Norwegen zu Beginn der Auseinandersetzungen um die Bearbeitung der ökologischen Krise eine Vorreiterrolle ein - ohne dass der Umweltschutz in einem Zielkonflikt mit wirtschaftlichen Interessen gesehen wurde (vgl. Andresen/Butenschøn 2001: 351, 354). Dementsprechend war auch der anthropogene Klimawandel in Norwegen bereits sehr früh ein wichtiges politisches Thema. Die Ministerpräsidentin Brundtland setzte sich für die Auseinandersetzung mit der ökologischen Krise auf internationaler Ebene ein und der von ihr als Vorsitzende des WCED verantwortete Bericht Our Common Future hatte in Norwegen großen Einfluss. Diese frühe Anerkennung der Dringlichkeit der Abschwächung des anthropogenen Klimawandels führte bereits 1989 zur Verabschiedung eines $\mathrm{CO}_{2-}$ Ziels durch das norwegische Parlament. Es wurde angestrebt, die $\mathrm{CO}_{2}$-Emissionen bis zum Jahr 2000 auf dem Niveau des Basisjahres 1989 zu stabilisieren. Damit war Norwegen das erste Land mit einem unilateralen Stabilisierungsziel. Um dieses Vorhaben realisieren zu können wurde 1991 eine $\mathrm{CO}_{2}$-Steuer für bestimmte Sektoren eingeführt (vgl. Andresen/Butenschøn 2001: 339; Sydnes 1996: 276; Tjernshaugen/Langhelle 2009: 101f). Allerdings fällt es Norwegen bislang schwer, die selbst gesteckten Ziele zu erreichen, seien es das eben genannte $\mathrm{CO}_{2}$-Ziel, die Reduktionsverpflichtungen im Rahmen des Kyoto-Protokolls oder andere Reduktionsziele. Dies liegt an den Pfadabhängigkeiten der Energieinfrastruktur, von der sich bislang keine norwegische Regierung lösen konnte.

52 Bis 2012 war Norwegen beispielsweise an 88 CDM-Projekten beteiligt (vgl. im Internet: cdm.unfccc.int/Projects/projsearch.html, letzter Zugriff am 02.12.2014). 
In Norwegen wird fast der komplette Strombedarf durch Wasserkraft gedeckt, weshalb im Stromsektor nur sehr wenige Treibhausgasemissionen entstehen. Dabei wird Strom oftmals auch zum Heizen verwendet. Das ist nicht besonders energieeffizient und nur aufgrund der niedrigen Energiepreise und einem großen Stromangebot möglich. Daraus resultiert der sehr hohe Pro-Kopf-Energieverbrauch in Norwegen. Neben der Wasserkraft spielt Öl eine wichtige Rolle - insbesondere für den Transportsektor, der in Norwegen aufgrund langer Wege von besonderer Bedeutung ist. Etwa $60 \%$ des Primärenergiebedarfs werden nicht durch Wasserkraft, sondern durch andere Energieträger, vor allem Öl und Gas, gedeckt. Was die Treibhausgasemissionen betrifft, so ist der Eigenenergiebedarf - da Wasserkraft sehr emissionsarm ist - nicht unbedingt ausschlaggebend für Norwegens hohen Pro-Kopf-Ausstoß von etwa 13 bis 15 Tonnen $\mathrm{CO}_{2}$ - ̈̈quivalenten. Stattdessen fällt vor allem die energieintensive Förderung fossiler Brennstoffe ins Gewicht (vgl. Teir et al. 2010: 92; Tjernshaugen/Langhelle 2009: 99; im Internet: mdgs.un.org/unsd/ $\mathrm{mdg} /$ SeriesDetail.aspx?srid=751\&crid=, letzter Zugriff am 02.12.2014).

In Norwegen wird viel Öl und Gas gefördert, welches vor allem exportiert wird (für den gesamten Absatz vgl. US Energy Information Agency 2012). Der wichtige Öl- und Gassektor wird von Statoil, dem größten norwegischen Unternehmen, dominiert. Statoil ist eine staatlich kontrollierte Aktiengesellschaft, der norwegische Staat besitzt $67 \%$ der Aktien. In Europa hat Norwegen die größten Erdgas- und Erdöl-Reserven und fördert einen großen Anteil der in Europa konsumierten Mengen. Weltweit betrachtet ist Norwegen der viertgrößte Gasproduzent bzw. der zweitgrößte Gasexporteur. Aufgrund kontinuierlicher Entdeckungen neuer Gasvorkommen stieg die Gasproduktion seit 1993 stetig an und erreichte 2011 5,25 Billionen Kubikfuß. Davon wurden allerdings 1,38 Billionen Kubikfuß wieder verpresst, um die Ölforderung durch das EOR-Verfahren zu steigern. Von dem verbliebenen Gas wurde das meiste (3,5 Billionen Kubikfuß) exportiert. Was die weltweite Ölförderung betrifft, steht Norwegen an vierzehnter Stelle und ist der siebtgrößte Ölexporteur. Allerdings hatte die norwegische Ölproduktion im Jahre 2001 mit 3,4 Millionen Barrel pro Tag ihren Peak, das Ölfördermaximum, bereits erreicht. Auch wenn weiterhin neue Ölfelder entdeckt werden - wie beispielsweise das Johan Sverdrup Ölfeld, das als weltweit größter Ölfund des Jahres 2011 gilt - sinken die Ölförderungen kontinuierlich. 2011 produzierte Norwegen noch 2 Millionen Barrel pro Tag und exportierte davon 1,45 Millionen. Insgesamt machen Erdöl, Erdgas und Pipeline-Transportleistungen $50 \%$ der norwegischen Exporteinnahmen, $21 \%$ des Bruttoinlandsprodukt und $26 \%$ der staatlichen Einnahmen aus. Es gibt kein anderes Industrieland, in dem ein so großer Anteil der Wirtschaft an die Förderung fossiler Brennstoffe gekoppelt ist (vgl. Tjernshaugen/Langhelle 2009: 99). 
Lange Zeit galt die Wasserkraft in Norwegen als ideale Form der Energieproduktion für den Eigenbedarf. Dies änderte sich in den 1970er und 1980er Jahren aufgrund der Auseinandersetzungen um den Neubau von Dämmen. Dabei setzte sich die Überzeugung durch, dass es aus ökologischen Gründen kaum Spielraum für neue große Wasserkraftprojekte gebe.

Traditionell verfolgten norwegische Regierungen aber die Strategie, durch die Bereitstellung günstiger Energie das Wirtschaftswachstum zu befördern. Dadurch entwickelte sich unter anderem eine Metallindustrie, die nach den fossilen Brennstoffen den zweitgrößten Anteil der Exporteinnahmen einfährt, viele Arbeitsplätze stellt und dementsprechend einflussreich ist. Um weiterhin günstigen Strom für die Privathaushalte und die energieintensiven Industrien (wie beispielsweise die Metallindustrie) produzieren zu können, wurde in den 1990er Jahren die heimische Nutzung des Erdgases zu einem politischen Ziel. Man versprach sich davon Wachstum, Jobs und technische Innovationen. Deshalb wurde die politische Unterstützung für den Bau von Gaskraftwerken selbst in einer Zeit aufrecht erhalten, in der kein privatwirtschaftlicher Akteur profitable Investitionsmöglichkeiten sah (vgl. Andresen/Butenschøn 2001: 350; Tjernshaugen/Langhelle 2009: 100f). Andreas Tjernshaugen und Oluf Langhelle kommen in ihrer Untersuchung der norwegischen CCS-Politik zu dem Schluss, dass in der Debatte um das Erdgas oftmals die heimische Nutzung zu einem Wert an sich, zu einem Selbstzweck wurde (vgl. Tjernshaugen/Langhelle 2009: 100). Mit den Gaskraftwerks-Plänen änderte sich auch die klimapolitische Position der norwegischen Regierung. Gas wurde - im Rahmen einer globalen Perspektive, in der die Reduktion der eigenen Emissionen nicht mehr als primäres Ziel angesehen wurde - zunehmend klimapolitisch aufgewertet. Die Energieproduktion durch Erdgas in Norwegen wurde der Verbrennung von Kohle in anderen Ländern gegenüber gestellt. Um die klimaschädlichere Kohle zu verdrängen, die in vielen osteuropäischen Ländern die wichtigste Energiequelle darstellt, aber auch in Deutschland eine große Rolle spielt, sollten neue Gaskraftwerke gebaut werden (vgl. Andresen/Butenschøn 2001: 344).

Durch die neue Energiestrategie der norwegischen Regierung hatte sich auch der Fokus der umweltpolitischen Auseinandersetzungen von den Kämpfen für den Naturschutz und gegen neue Wasserkraft-Dämme auf den Einsatz für den Klimaschutz und gegen die $\mathrm{CO}_{2}$-Emissionen möglicher Gaskraftwerke verschoben. Umweltschützer_innen schlossen mit ihrem Widerstand gegen Gaskraftwerke an die erfolgreichen Kämpfe gegen den Neubau von Dämmen an und aktivierten damit alte Konfliktlinien (vgl. Tjernshaugen/Langhelle 2009: 103). Neben der Lobby- und Kampagnenarbeit der NGOs gab es eine soziale Bewegung, die mit Aktionen zivilen Ungehorsams drohte, sollten die Gaskraftwerke tatsächlich gebaut werden. 
Nicht zuletzt aufgrund des politischen Widerstandes wurde lange kein Gaskraftwerk gebaut (vgl. Andresen/Butenschøn 2001: 350f). Erst 2007 ging Kårstø, das erste großtechnische mit Erdgas betriebene Kraftwerk Norwegens, ans Netz (vgl. im Internet: www.power-technology.com/projects/karsto/, letzter Zugriff am 02.12.2014).

Für die norwegische Umweltbewegung und ihre Bündnispartner_innen ist eine zentrale Forderung, die angestrebten Treibhausgasreduktionen im eigenen Land zu reduzieren. Dabei verweisen sie auf das nationale Stabilisierungsziel, das 1989 beschlossen wurde. Die Öl- und Gasindustrie rekurriert dagegen auf das KyotoProtokoll und fordert die Erfüllung der Ziele über die flexiblen Mechanismen, um die Treibhausgasreduktionen kostengünstig erreichen zu können. Bereits in den 1990er Jahren wurde deutlich, dass es für Norwegen schwierig werden würde, das Stabilisierungziel zu erreichen. Durch ein Wachstum der Öl- und Gasförderung stiegen die Emissionen. Da die Produktion der Energie für den heimischen Verbrauch schon relativ emissionsarm war, wären die Kosten zur weiteren Reduktion sehr hoch gewesen (vgl. Tjernshaugen/Langhelle 2009: 102). Im Vorfeld der Verabschiedung eines nationalen Klimaaktionsplans bildeten Akteur_innen aus der Metallindustrie, dem Transport-Sektor, der Öl- und Gasindustrie sowie der norwegische Industrie- und Handelsverband eine informelle Koalition, um über Lobbyarbeit Einfluss auf Entscheidungen zu üben und strikte Reduktionsvorgaben oder andere Instrumente zur Senkung der heimischen Treibhausgasemissionen zu verhindern (vgl. Andresen/Butenschøn 2001: 349).

Die Forderungen aus der Industrie wurden von vielen Politiker_innen, inklusive der Ministerpräsidentin Brundtland und wichtigen Forschungseinrichtungen, aufgegriffen (vgl. Andresen/Butenschøn 2001: 344). Anfang der 1990er Jahre publizierten zwei zentrale Kommissionen, die vor allem aus Regierungs- und Ministeriumskreisen sowie ihnen nahestehenden Wirtschaftswissenschaftler_innen bestand, ihre Berichte über norwegische Klimapolitik. Darin postulierten sie, dass Norwegen kaum vom Klimawandel betroffen sein werde und Emissionsreduktionen sehr teuer sein würden. Als Konsequenz daraus sollte das Stabilisierungsziel flexibel gehandhabt werden, also über die flexiblen Mechanismen und nicht durch Emissionsreduktionen im eigenen Land angestrebt werden. Gegen diese Position wehrte sich das norwegische Umweltministerium, das seit der Rio-Konferenz zunehmend in Konflikt mit anderen Regierungsorganen stand und insgesamt an Einfluss verlor (vgl. Andresen/Butenschøn 2001: 347).

Neben dem Umweltministerium verlor mit der Umweltbewegung eine weitere Akteurin, die in der euphorischen Phase der norwegischen Klimapolitik eine wichtige Rolle spielte, nach und nach an Bedeutung. In Kapitel 3.2.6 habe ich darauf hingewiesen, dass Umweltbewegungen im Allgemeinen dann eine wichtige Rolle 
spielten, wenn es um die Etablierung eines neuen politischen Themas ging. Sobald aber die Dringlichkeit des Klimawandels von einer Mehrheit in der Gesellschaft anerkannt wird und es um die Frage der Umsetzung in konkrete klimapolitische Maßnahmen geht, verlieren Umweltbewegungen an Deutungshoheit und damit an Einfluss. Dies trifft auch auf die Auseinandersetzungen um die Klimapolitik in Norwegen zu (vgl. Andresen/Butenschøn 2001: 349). Der mit dem Wandel der Kräfteverhältnisse einhergehende Umbruch in der Energie- und Klimapolitik zeigt sich in dem Weißbuch von 1995, in dem sich Norwegen offiziell vom eigenen Stabilisierungsziel verabschiedet und die Treibhausgasreduktionen auf internationaler Ebene - also mit Hilfe der flexiblen Mechanismen - angestrebt werden (vgl. Andresen/Butenschøn 2001: 340; Christiansen 2002: 238). Symptomatisch für diesen Wandel steht auch der Werdegang der Ministerpräsidentin Brundtland, die sich immer weniger für konsequenten Klimaschutz einsetzte. Stattdessen war sie beispielsweise diejenige, die bei den Kyoto-Verhandlungen die Haltung vertrat, dass Norwegen ein Abkommen ohne die Möglichkeit der Gemeinsamen Umsetzung nicht unterschreiben würde (vgl. Andresen/Butenschøn 2001: 340. 348).

Vor dem Hintergrund der dargestellten klimapolitischen Auseinandersetzungen verwundert es nicht, dass Norwegens Regierungen bislang primär auf marktorientierte Instrumente setzten. Allerdings mahnte die OECD bereits 1993, dass Norwegen stärker auf direkte Regulierung durch administrative Instrumente setzen sollte, da es nahezu unmöglich sei, die $\mathrm{CO}_{2}$-Reduktionsziele allein durch marktwirtschaftliche Instrumente zu erreichen (vgl. Sydnes 1996: 288). Effektive Klimaschutzmaßnahmen müssten sich gegen die staatliche Unterstützung des Exports von fossilen Brennstoffen und Produkten der energieintensiven Industrien wenden, aber eine derartige Neuausrichtung Norwegens ist bislang nicht absehbar bzw. spielt in den Auseinandersetzungen um die norwegische Energie- und Klimapolitik keine Rolle. Hier trifft die in Kapitel 3.4.3 beschriebene Beobachtung zu, dass die ökomoderne Klimapolitik versucht, Treibhausgasreduktionen zu erreichen, ohne die Input-Seite, die Förderung fossiler Brennstoffe, zu regulieren. Stattdessen wird allein an der Output-Seite, den daraus entstehenden Emissionen, angesetzt. Damit die wirtschaftlichen Interessen nicht beeinträchtigt werden, die mit dem Input der fossilen Brennstoffe verknüpft sind, setzt die norwegische Politik auf flexibilisierende Maßnahmen. Dadurch wird die Pflicht zur Reduktion von Treibhausgasemissionen im eigenen Land abgewehrt, die eine Änderung der Energieinfrastruktur zur Folge hätte.

Einem derartigen Eingriff stehen in Norwegen einflussreiche gesellschaftliche Kräfte entgegen. Bis hinein in die Ebene der Ministerien der Regierung gibt es eine Privilegierung der wirtschaftlichen Interessen, die mit der Öl- und Gasförderung verknüpft sind. Dies zeigt sich auch an der Anzahl an Mitarbeiter_innen im 
Ministerium für Öl und Energie sowie anderen staatlichen Behörden, die für den fossilen Sektor zuständig sind. Die Folge ist eine bevorzugte Unterstützung der wirtschaftlichen Aktivitäten rund um fossile Brennstoffe durch staatliche Institutionen. Die Bedeutung der Öl- und Gasindustrie für die aktuelle norwegische Wirtschaft führt dazu, dass ein beträchtlicher Anteil öffentlicher und privater Investitionen in die Förderung fossiler Brennstoffe fließt (vgl. Christiansen 2002: 241).

\section{CCS-Technologien in Norwegen}

In Norwegen steht die Anwendung bei Gaskraftwerken im Zentrum der CCSAktivitäten (vgl. Tjernshaugen/Langhelle 2009: 120f). Vor dem Hintergrund der kontrovers geführten Debatte um Gaskraftwerke rückte die Aussicht auf sogenannte $\mathrm{CO}_{2}$-arme Gaskraftwerke die CCS-Technologien in den Fokus der norwegischen Politik. Dabei spielte die Bellona Foundation (für Infos zur Bellona Foundation vgl. Kapitel 5.2.1) eine Schlüsselrolle, da sie besonders prominent die CCS-Technologien als möglichen Kompromiss vorschlug, der die Klimaschutz-Argumente gegen Gaskraftwerke ausräumen könne (vgl. Tjernshaugen/Langhelle 2009: 107ff).

Es gibt in Norwegen eine sehr breite pro-CCS-Fraktion, die über die wichtigsten Parteien, Wirtschaftsverbände und Gewerkschaften bis zu NGOs wie Bellona reicht. Die Umwelt-NGO Friends of the Earth Norway spricht sich ebenfalls für den Einsatz von CCS-Technologien aus. In den 1990er Jahren geschah dies noch aus strategischen Gründen, um die Kosten des Gaskraftwerkprojekts in die Höhe zu treiben und damit das Vorhaben zum Scheitern zu bringen. Mittlerweile hat sich Friends of the Earth Norway die CCS-affine Position allerdings zu eigen gemacht. Dagegen sind CCS-kritische Position in Norwegen nur relativ schwach vertreten. Greenpeace, als NGO, die auf internationaler Ebene zu den wichtigsten CCSKritiker_innen gehört, hat in Norwegen aufgrund des Konflikts um den Walfang nur wenig Unterstützung (vgl. Tjernshaugen/Langhelle 2009: 110, 116). Mit der Zustimmung zu einem Koalitionsvertrag, der CCS-Technologien für zukünftige Gaskraftwerke vorsieht, schwenkte mit der Sozialistischen Linkspartei (Sosialistisk Venstreparti) auch die letzte CCS-kritische Partei um. Bei ihrer ersten Regierungsbeteiligung im Jahre 2005 einigte man sich in einem Kompromiss zu Klima- und Energiefragen auf die Förderung der CCS-Technologien. In den weiteren Verhandlungen der Regierungskoalition wurden staatliche Subventionen für CCS-Technologien inklusive einer Finanzierung von $\mathrm{CO}_{2}$-Pipelines zur offshore-Speicherung beschlossen (vgl. Tjernshaugen/Langhelle 2009: 116f). Insgesamt sind in Norwegen spätestens seit 2005 CCS-kritische Positionen marginalisiert (vgl. Tjernshaugen/ Langhelle 2009: 119). Insofern geht es in norwegischen Debatten nicht um die Frage, ob CCS-Technologien überhaupt wünschenswert sind. Auch die ökologische 
Integrität der geologischen Speicherung wird kaum in Frage gestellt. Die entscheidende Frage lautet stets, ob CCS-Technologien bereits für eine großtechnische Anwendung bei Gaskraftwerken verfügbar seien und wie man ihre Entwicklung beschleunigen könne (vgl. Tjernshaugen/Langhelle 2009: 110f).

So entwickelten sich CCS-Technologien in Norwegen zu einer wiederholt angewandten Kompromissformel bei Konflikten um den Bau von Gaskraftwerken. Dabei wurden CCS-Technologien teilweise auch aus strategischen Gründen als Bedingung für einen Kraftwerksbau gefordert. Tjernshaugen und Langhelle sprechen von einem political glue, einem politischen Klebstoff, der Parteien und Koalitionen zusammenhält. CCS-Technologien wurden zum hegemonialen Konsens, zur Kompromisslösung für das Dilemma der norwegischen Klimapolitik - dem Anspruch, eine Vorreiterrolle einzunehmen, ohne auf die Förderung und den Export fossiler Brennstoffe verzichten zu wollen (vgl. Tjernshaugen/Langhelle 2009: 111). Diese politische Funktion erklärt die Bereitschaft aller norwegischen Regierungen, viel Geld in die Entwicklung von CCS-Technologien zu investieren. Norwegen gehört damit zu den Ländern mit dem höchsten öffentlichen Mitteleinsatz für CCSTechnologien (vgl. Tjernshaugen 2008: 8; Tjernshaugen/Langhelle 2009: 113).

Trotz der massiven Subventionierung gibt es bislang erst zwei kommerzielle CCS-Projekte. Die norwegische Regierung hat sich mehrmals für den Einsatz von CCS-Technologien bei Gaskraftwerken eingesetzt. Allerdings wurden diese Pläne bislang noch nicht realisiert, da sich die CCS-Gaskraftwerke - trotz der staatlichen Subventionen - betriebswirtschaftlich nicht rentieren würden (vgl. Tjernshaugen/ Langhelle 2009: 110ff). Auch EOR-Projekte scheinen sich nicht so schnell realisieren zu lassen wie erhofft. Zum einen wurde bereits ein großer Teil des EORPotenzials mit Meerwasser und Erdgas ausgeschöpft. Zum anderen wären CCSEOR-Projekte letztlich nicht rentabel, da die Kosten für die in Norwegen benötigte offshore-Anwendung besonders hoch sind (vgl. Tjernshaugen/Langhelle 2009: 119f).

Das erste norwegische CCS-Projekt im großtechnischen Maßstab wurde hauptsächlich durch die $\mathrm{CO}_{2}$-Steuer auf die offshore Öl- und Gasförderung vorangetrieben (vgl. Tjernshaugen/Langhelle 2009: 106). Bereits seit 1996 wird das Sleipner-Projekt in der Nordsee von Statoil betrieben. Es ist damit das weltweit erste Projekt im Industriemaßstab mit geologischer Speicherung von $\mathrm{CO}_{2}$ in salinen Aquiferen. Das Erdgas des Sleipner-West-Feldes weist eine $\mathrm{zu}$ hohe $\mathrm{CO}_{2}$-Konzentration auf, um es ohne Weiteres exportieren zu können. Deshalb war es gängige Praxis, $\mathrm{CO}_{2}$ abzuscheiden und in die Atmosphäre zu entlassen. Seit 1996 wird das abgeschiedene $\mathrm{CO}_{2}$ etwa 800 bis 1.000 Meter unter dem Meeresboden verpresst, um weniger $\mathrm{CO}_{2}$-Steuer zahlen zu müssen (vgl. Teir et al. 2010: 75; Tjernshaugen/ 
Langhelle 2009: 105f). Ein ähnliches Verfahren wendet Statoil seit 2008 beim Snøhvit-Feld in der Barentssee an. Das dort geförderte Gas wird an Land in einer Flüssiggasanlage verarbeitet. Das bei der Produktion von Flüssiggas abgeschiedene $\mathrm{CO}_{2}$ wird in einer Sandsteinformation ca. 2.600 Meter unter dem Meeresboden verpresst. Auch hier ist die $\mathrm{CO}_{2}$-Steuer der ausschlaggebende Grund für die Anwendung der CCS-Technologien. Darüber hinaus wollte Statoil der norwegischen Regierung ein vergleichsweise umweltfreundliches Projekt vorschlagen, da die Expansion der Förderung in der Barentssee umstritten war (vgl. Teir et al. 2010: 78f; Tjernshaugen/Langhelle 2009: 106).

\section{Norwegens Position in den CCS-Verhandlungen}

Die norwegische Regierung brachte sich sehr aktiv in die CCS-Verhandlungen ein. Nicht nur aufgrund der durch die eigenen Projekte erworbenen CCS-Expertise war die norwegische Regierung eine einflussreiche Befürworterin der Aufnahme von CCS in den CDM. Der Ruf als ,grüner Vorreiterstaat' hallte noch nach und verlieh der Selbstverortung der norwegischen Pro-CCS-Position als ambitioniertem Klimaschutz eine gewisse Glaubwürdigkeit. ${ }^{53}$ Darüber hinaus zeichnete sich die norwegische Position durch ihre explizite Bezugnahme auf entwicklungspolitische Argumente aus.

\section{Norwegens Argumentationslinie in den Stellungnahmen}

Die norwegische Regierung reichte vier Stellungsnahmen ein: 2006, 2007, 2008 und 2010. Die erste Stellungnahme war mit drei Seiten noch vergleichsweise kurz und basierte auf wenigen Argumenten. Dennoch spricht sich die norwegische Regierung bereits dort implizit für die Aufnahme von CCS-Technologien in den CDM aus, da sie die zu fällende Entscheidung als eine Frage der Art und Weise der Umsetzung (wie?) rahmt. Damit wird die prinzipielle Frage nach der Befürwortung oder Ablehnung (ob?) gar nicht erst gestellt:

„Norway looks forward to taking part in constructive discussions on how to obtain sound solutions on outstanding issues in the agreed process towards COP/MOP 2 in November 2006. Our aim is that a decision should be adopted at that session, including guidance to the EB on how to consider $\mathrm{CO}_{2}$ capture and storage as CDM project activities." (UNFCCC 2006: 28; Hervorhebungen T. K.)

53 Diese Einschätzung erfolgte in einem Interview, das ich am 16.03.2013 mit Manfred Treber geführt habe. 
Die drei weiteren Stellungnahmen sind deutlich länger (zwischen sieben und zehn Seiten) und führen mehr Argumente an. Im zeitlichen Verlauf wird die Befürwortung der Aufnahme von CCS-Technologien in den CDM auch expliziter formuliert:

„CCS is already a mitigation option available to Annex I countries. Norway has stored $\mathrm{CO}_{2}$ for the last 14 years, and several Annex I countries plan to use CCS in their national mitigating strategies. The technology should also be a part of a comprehensive portfolio of mitigation action options available to non-Annex I countries. In order to mobilise the financial resources needed to enable this technology to reach its full potential, we must create financial incentives for private investments in CCS. The inclusion of CCS project activities under the $\mathrm{CDM}$ will give one important contribution to the dissemination and deployment of this technology in non-Annex I countries.“ (UNFCCC 2010b: 24)

In der zweiten Stellungnahme aus dem Jahr 2007 werden die meisten politischen Gründe angeführt, die für die Aufnahme von CCS-Technologien in den CDM sprechen. In den Stellungnahmen drei und vier wird dagegen technischer argumentiert. Mit Verweisen auf eigene CCS-Projekte sowie auf bereits geschaffene rechtliche Rahmenbedingungen wird dort verstärkt versucht, die Machbarkeit von CCSProjekten nachzuweisen.

Im Folgenden wird die Kernargumentation in den Stellungnahmen der norwegischen Regierung nachgezeichnet. Dabei fokussiere ich auf die politische Begründung der postulierten Notwendigkeit einer Aufnahme von CCS-Technologien in den CDM. Die Position der norwegischen Regierung basiert auf zwei Prinzipien des UN-Klimaregimes. Die erste wesentliche Grundannahme ihrer Argumentation ist die Bedrohlichkeit des Klimawandels und die daraus abgeleitete Pflicht zum Klimaschutz im Rahmen eines globalen Abkommens. In ihrer dritten Stellungnahme bezieht sich die norwegische Regierung dabei explizit auf das in Artikel 2 formulierte Endziel der Klimarahmenkonvention (vgl. UNFCCC 2008: 11). Zur Erreichung dieses Klimaschutzziels der Stabilisierung der Treibhausgaskonzentration in der Atmosphäre schlägt die norwegische Regierung die Entwicklung eines Portfolios von Klimaschutztechnologien vor (vgl. Enthymem NOR 3-1; UNFCCC 2008: 11).

Der zweite Eckpfeiler der norwegischen Argumentation ist das spezifische Recht der Länder des globalen Südens auf nachholende Entwicklung, das sowohl in der Klimarahmenkonvention als auch im Kyoto-Protokoll verankert ist (vgl. z. B. die Einleitung der Klimarahmenkonvention in UNFCCC 1992: 2ff). Die klassische Vorstellung von Entwicklungspolitik, wie sie in den UN-Dokumenten formuliert ist, liegt auch der Position der norwegischen Regierung zugrunde. Sie konstatiert, dass die Länder des globalen Südens ein Recht auf Entwicklung haben und dass die Klimaschutzinstrumente mit diesem Recht in Einklang stehen müssen. Als 
prioritäres Ziel der Entwicklung nennt die norwegische Regierung dabei die Armutsbekämpfung, die angesichts der Herausforderungen des Klimawandels besonderer Anstrengungen bedürfe. Dabei gilt Wirtschaftswachstum als Entwicklungsmotor und damit als Mittel der Armutsbekämpfung (vgl. Enthymeme NOR 2-3, NOR 2-4; UNFCCC 2007b: 12). Die norwegische Regierung prognostiziert in Anlehnung an den IPCC und die IEA einen Anstieg des Verbrauchs fossiler Brennstoffe, der mit dem steigenden Wirtschaftswachstum zwangsläufig einhergehe. Dieser zunehmende Verbrauch fossiler Brennstoffe sei allerdings unter den aktuellen Rahmenbedingungen nicht mit den Klimaschutzzielen vereinbar. Insofern diagnostiziert die norwegische Regierung einen Zielkonflikt zwischen Klimaschutz und nachholender Entwicklung, hält allerdings beides für unverzichtbar (vgl. Enthymem NOR 2-5; UNFCCC 2007b: 12).

Eine Synthese beider Ziele ist ihrer Meinung nach nur über Technologien zu erreichen, die eine emissionsärmere Energieproduktion ermöglichen. Dabei spielen CCS-Technologien für die norwegische Regierung eine Schlüsselrolle. In Bezug auf das Potenzial zur Einsparung von Treibhausgasemissionen sieht sie, mit Verweis auf Prognosen der IEA und des IPCC, die CCS-Technologien an zweiter Stelle möglicher Klimaschutzmaßnahmen - direkt nach der Energieeffizienz. Deshalb gilt für die norwegische Regierung der weltweite Einsatz von CCS-Technologien als unerlässlich, um das Zwei-Grad-Ziel erreichen zu können (vgl. Enthymeme NOR 2-1, NOR 2-2, NOR 2-6, NOR 2-7, NOR 2-9, NOR 3-3, NOR 4-1; UNFCCC 2007b: 11ff; UNFCCC 2008: 11f; UNFCCC 2010b: 23).

Die norwegische Regierung spricht den CCS-Technologien eine besondere Bedeutung beim Übergang in eine kohlenstoffarme Wirtschaft zu. Insofern klassifiziert sie CCS als Brückentechnologie. Im Gegensatz zur brasilianischen Regierung sieht sie den Bedarf an Brückentechnologien allerdings nicht auf die Länder des globalen Nordens beschränkt. Im Gegenteil sei die Anwendung von CCS-Technologien gerade in den Ländern des globalen Südens notwendig, um eine nachholende Entwicklung zu ermöglichen, die auf dem steigenden Verbrauch fossiler Brennstoffe basiere und dennoch mit den Klimaschutzzielen vereinbar sei (vgl. Enthymeme NOR 2-8, NOR 2-9, NOR 3-2; UNFCCC 2007b: 12f; UNFCCC 2008: 11).

Allerdings geht die norwegische Regierung davon aus, dass CCS-Technologien ohne zusätzliche ökonomische Anreize nicht in Ländern des globalen Südens angewendet werden. Da diese Länder keine Reduktionsverpflichtungen haben, würden sich CCS-Technologien dort nicht rentieren. Erst die Aufnahme von CCSTechnologien in den CDM würde einen finanziellen Anreiz für den Wissens- und Technologietransfer darstellen und die Umsetzung von CCS-Projekten in Nicht- 
Annex-B-Ländern rentabel machen (vgl. Enthymeme NOR 2-10, NOR 3-4, NOR 4-2; UNFCCC 2007b: 13; UNFCCC 2008: 12; UNFCCC 2010b: 24).

Für die norwegische Regierung gibt es keine Einwände, die prinzipiell gegen den Einbezug von CCS-Technologien in den CDM sprechen. Sie sieht zwar spezifische Besonderheiten der CCS-Technologien, für die Lösungen gefunden werden müssen, um sie mit den CDM-Modalitäten und -Verfahren in Einklang zu bringen (vgl. Enthymeme NOR 1-2, NOR 2-12; UNFCCC 2006: 28; UNFCCC 2007b: 14). Eine Einigung auf derartige Lösungen scheint für die norwegische Regierung allerdings unproblematisch. So schlägt sie beispielsweise in der kontroversen Frage der langfristigen Haftung vor, dass die konkreten Absprachen direkt zwischen den Projektteilnehmer_innen und den jeweiligen Zielländern getroffen werden sollten (vgl. Enthymeme NOR 3-6, NOR 4-4; UNFCCC 2008: 16; UNFCCC 2010b: 29). Auch die ökologischen Risiken stellen für die norwegische Regierung allein eine Frage des adäquaten Managements dar. Dabei beruft sie sich auf den IPCC, um die Realisierbarkeit eines derartigen Risiko-Managements zu belegen (vgl. UNFCCC 2006: 29; UNFCCC 2007b: 15; UNFCCC 2008: 15; UNFCCC 2010b: 27).

„The IPCC Special Report on Carbon Dioxide Capture and Storage states that ,the proportion of $\mathrm{CO}_{2}$ retained in appropriately selected and managed sites is [...] likely to exceed $99 \%$ over 1,000 years'. Over time, it is also possible that the $\mathrm{CO}_{2}$ will be immobilised by various trapping mechanisms.“(UNFCCC 2010b: 27)

Laut norwegischer Regierung bedürfe es einer sorgfältigen und transparenten Auswahl geeigneter Speicherorte sowie eines genauen und langfristigen Monitorings, um mögliche $\mathrm{CO}_{2}$-Austritte vermeiden bzw. frühzeitig bemerken und darauf reagieren zu können. Diese Maßnahmen zur Reduktion ökologischer Risiken hält sie für wichtig, um einem Preisverfall von CERs aus CCS-Projekten vorzubeugen (vgl. Enthymeme NOR 1-1, NOR 2-11, NOR 3-5, NOR 4-3; UNFCCC 2006: 28, 30; UNFCCC 2007b: 13f; UNFCCC 2008: 12; UNFCCC 2010b: 24). In dieser Formulierung drückt sich auch die Absicht aus, die eigenen Reduktionsziele mit CCSProjekten in Nicht-Annex-B-Ländern zu erreichen.

Insgesamt spricht aus Sicht der norwegischen Regierung einiges für und nichts gegen die Aufnahme von CCS-Technologien in den CDM. Auch die im Verhandlungsprozess - beispielsweise von der brasilianischen Regierung - geäußerten Bedenken, dass die Aufnahme von CCS-Technologien zu einem Preisverfall von CERs führen könne, hält die norwegische Regierung für unbegründet. Zwar hält die norwegische Regierung langfristig das Potenzial für die Anwendung von CCSTechnologien für sehr hoch. Allerdings geht sie - in Anlehnung an Studien, unter anderem von Carbon Point und der IEA - davon aus, dass kurzfristig nur wenige CCS-Projekte umgesetzt werden können. Insofern sieht sie für die erste 
Verpflichtungsperiode des Kyoto-Protokolls keine Gefahr der Überschwemmung des Kohlenstoffmarktes durch CERs aus CCS-Projekten. Mit der Begründung, dass Argumente, die nicht auf die erste Verpflichtungsperiode zutreffen, keinen Einfluss auf die Ausarbeitung der CDM-Regeln und -Modalitäten eben für diese erste Periode haben sollten, verwirft sie die geäußerten Bedenken (vgl. Enthymeme NOR 3-7, NOR 4-5; UNFCCC 2008: 17; UNFCCC 2010b: 29f). Mit dieser Argumentation werden die Bedeutung und die Fortführung der flexiblen Mechanismen - jenseits einer möglichen zweiten Verpflichtungsperiode im Rahmen des UN-Klimaregime - ignoriert (vgl. Kapitel 5.1.2).

\subsubsection{Brasiliens Positionierung in der CCS-CDM-Kontroverse}

Bei der Analyse der Positionierung der brasilianischen Regierung in der CCSCDM-Kontroverse verfahre ich größtenteils analog zur Darstellung der norwegischen Positionierung. Zusätzlich lege ich die Bedeutung von CDM-Projekten in Brasilien dar. Da in Brasilien viele CDM-Projekte durchgeführt werden erscheint es mir wichtig, die Relevanz dieses Mechanismus für das Land herauszuarbeiten. Schließlich würde die Aufnahme eines neuen Projekt-Typus auch den CDM selber verändern. Weiterhin verweise ich auf bestimmte Dynamiken im Verhandlungsstrang zum Schutz von Wäldern, die möglicherweise die CCS-Verhandlungsstrategie Brasiliens beeinflusst haben.

\section{Die Rolle Brasiliens im UN-Klimaregime}

Brasilien spielte eine wichtige Rolle bei der Etablierung des Klimaregimes auf UNEbene (für den gesamten Absatz vgl. Friberg 2009: 398). Als Gastgeberland der Rio-Konferenz brachte es sich aktiv in die damaligen Verhandlungen ein, in denen unter anderem die Agenda 21 verabschiedet und die Klimarahmenkonvention ins Leben gerufen wurde (für weitere Infos zur Rio-Konferenz vgl. Kapitel 3.2.3). Brasilien war auch das erste Land, das die Klimarahmenkonvention ratifizierte. In den folgenden COP-Verhandlungen der UNFCCC, in denen das Kyoto-Protokoll beschlossen wurde, waren es vor allem drei Themengebiete, bei denen sich Brasilien besonders intensiv in die Verhandlungen einbrachte. Zum einen betonte die brasilianische Regierung die historische ökologische Schuld der Industrieländer und forderte dementsprechend, dass sich zukünftige Treibhausgasreduktionsverpflichtungen von Ländern an deren Beiträge zum anthropogenen Klimawandel seit der industriellen Revolution orientieren sollten. Ein weiteres wichtiges Anliegen der brasilianischen Regierung war der Finanz- und Technologietransfer, der Entwicklungs- und Schwellenländern helfen soll, eine kohlenstoffarme Wirtschaft aufzubauen. Daraus leitete sie die Forderung nach einem Clean Development Fund 
ab. Diese Forderung wurde in einen Vorschlag der USA integriert und als Marktmechanismus (CDM) ins Kyoto-Protokoll aufgenommen (vgl. Oberthür/Ott 2000: 218ff). In der Folge hatte die brasilianische Regierung - als Miturheberin - ein besonderes Interesse an der Ausgestaltung des CDM. ${ }^{54}$ Zusätzlich war sie in den Verhandlungen immer dann besonders aktiv, wenn Abholzung oder andere waldbezogene Themen behandelt wurden. So schlug Brasilien 2006 bei den COP-12Verhandlungen einen Waldfonds vor, der tropische Länder dafür entschädigen sollte, dass sie die Zerstörung ihres Regenwaldes verlangsamen. Dieser Vorschlag floss bei der COP 13 in Bali in die Diskussionen um die Reduktion von Emissionen aus Entwaldung und Schädigung von Wäldern (Reducing Emissions from Deforestation and forest Degradation, REDD) ein.

Bei der COP 13, die 2007 in Bali stattfand, gab es einen bemerkenswerten Wechsel in der brasilianischen Verhandlungsstrategie. Gemeinsam mit China und Südafrika verkündete Brasilien zum ersten Mal die Bereitschaft, messbare, berichtspflichtige und verifizierbare Klimaschutzmaßnahmen in ihre Verpflichtungen innerhalb der Bali Roadmap aufzunehmen. Bis dahin hatte Brasilien stets die historische Verantwortung der Industrieländer betont und Reduktionsvorgaben jeglicher Art für Schwellenländer abgelehnt (vgl. Friberg 2009: 399).

\section{Die brasilianischen Aktivitäten im Energie- und Klimabereich}

Der Zusicherung auf UN-Ebene folgte 2008 der brasilianische Nationalplan zum Klimawandel (für den gesamten Absatz vgl. Friberg 2009: 399f). Darin zeigt sich eine vorher nicht dagewesene Bereitschaft, die Ursachen des Klimawandels auch im eigenen Land ernsthaft anzugehen. Dem stehen jedoch einflussreiche wirtschaftliche Interessen in der brasilianischen Gesellschaft gegenüber, die sich weiterhin gegen nationale Klimaschutzmaßnahmen stellen. Insgesamt fand der Klimawandel - nach der Ratifizierung der Klimarahmenkonvention im Jahre 1994 - nur noch wenig Beachtung in der brasilianischen Öffentlichkeit. Lediglich eine kleine Gruppe von Expert_innen widmete sich dem Thema. Bis heute dominieren diese Expert_innen, insbesondere eine Handvoll einflussreicher Naturwissenschaftler_innen, die brasilianische Klimawandel-Community. Der 2008 verabschiedete Nationalplan zum Klimawandel stellt diesbezüglich eine Ausnahme dar, da er in der Entwicklungsphase in öffentlichen Anhörungen auch mit verschiedenen Organisationen der Zivilgesellschaft diskutiert wurde. Inhaltlich ist der Plan

54 Das besondere Engagement in Bezug auf den CDM wird durch den Ökonom und Ingenieur José Domingos Miguez personifiziert, der nicht nur in Brasilien selber, sondern auch auf UN-Ebene eine wichtige Rolle spielte, beispielsweise als Mitglied und zeitweise auch als Vorsitzender des CDM EB (vgl. Friberg 2009: 407). 
bedeutsam, weil in ihm das Ziel formuliert wurde, die Abholzungsraten bis 2017 um $70 \%$ zu reduzieren - gegenüber den durchschnittlichen Abholzungsraten der Jahre 1996 bis 2005. Dies ist insofern ein wichtiger Schritt, als dass in Brasilien die Abholzung und Landnutzungsänderungen den größten Anteil an Treibhausgasemissionen ausmachen.

Über $80 \%$ der klimaschädlichen Gase entstehen in Brasilien in den Bereichen Landwirtschaft und Landnutzungsänderungen (vgl. Román 2011: 391, 394). Im Amazonasbecken erstreckt sich mit fast 5,8 Millionen $\mathrm{km}^{2}$ Fläche der größte zusammenhängende tropische Wald, der ca. 20 \% der globalen Pflanzen- und Tierarten beherbergt. In den letzten 30 Jahren ist allein auf brasilianischem Gebiet eine Fläche von $600.000 \mathrm{~km}^{2}$ abgeholzt worden (vgl. IPCC 2007: 604). Der Hauptgrund für die Abholzung liegt in der extensiven Viehwirtschaft. Dazu kommen Brandrodungen für sonstige landwirtschaftliche Flächen sowie die expansive Zunahme der Sojaproduktion für den Weltmarkt (vgl. Friberg 2009: 401). Weiterhin gehen Studien zunehmend davon aus, dass auch die Ausweitung von Bioenergie indirekt zur Abholzung beiträgt bzw. in Zukunft verstärkt beitragen wird - über die Verdrängung von Weideland, dem dann wiederum Regenwald weichen muss (vgl. Lapola et al. 2010). Dennoch kann konstatiert werden, dass der brasilianische Energiesektor im Vergleich zu anderen Industrie- oder Schwellenländern relativ wenig Treibhausgasemissionen produziert, da die Wasserkraft eine große Bedeutung hat. Allerdings gehen mit den überdimensionierten Wasserkraftprojekten in Brasilien soziale und ökologische Probleme einher: Menschen werden zwangsumgesiedelt und ganze Täler werden geflutet. Der zerstörerische Eingriff in die Lebensweise von (v. a. in indigenen Gemeinschaften lebenden) Menschen und das lokale Ökosystem ist enorm.

Brasiliens Energieinfrastruktur zeichnet sich durch einen relativ hohen Anteil erneuerbarer Energien aus (für den gesamten Abschnitt zur Primärenergieproduktion vgl. Empresa de Pesquisa Energética 2009: 18; Friberg 2009: 403; Román 2011: 393; US Energy Information Agency 2012). Zwischen 70 und 80 \% der Stromerzeugung basiert auf Wasserkraft, die damit ca. $13 \%$ der Primärenergieproduktion bereitstellt. Darüber hinaus macht die Energieerzeugung durch Biomasse etwa $31 \%$ der Primärenergieproduktion aus. Innerhalb dessen hat die Energieerzeugung aus Zuckerrohr, in erster Linie in Form von Agrotreibstoff, mit ca. $19 \%$ den größten Anteil an der Primärenergieproduktion. Brasilien ist nach den USA der weltweit zweitgrößte Produzent von Agrotreibstoff und mit Abstand der größte Exporteur. Auch wenn Agrotreibstoff eine erneuerbare Energie ist, so sind dessen Klimaneutralität und vermeintliche ökologische Vorzüge - wie bereits angedeutet - stark umstritten. Die restliche Bioenergie wird vor allem mit Holz 
produziert. Erdöl stellt mit ca. $40 \%$ den größten Anteil der Primärenergieproduktion. So produzierte Brasilien im Jahr 2010 über 2 Millionen Barrel Öl pro Tag, vor allem mittels Offshore-Anlagen in großen Wassertiefen. Der vom Staat kontrollierte Mineralölkonzern Petrobras ${ }^{55}$ war bis 1997 Monopolist und ist auch nach der Öffnung des Ölsektors für den Wettbewerb wichtigster Akteur geblieben. In den letzten Jahren wurden neue Ölquellen mit vermutlich sehr großen Ölvorkommen entdeckt. Die größten Reserven werden für das im Jahr 2007 entdeckte TupiFeld angenommen, heute Lula-Feld genannt. Etwa $9 \%$ der Primärenergieproduktion fällt auf die Erdgas-Förderung. Dabei fördert Brasilien weniger Erdgas als es tatsächlich verbraucht, ein Teil wird also importiert. Das Erdgas wird wie das Erdöl größtenteils in Offshore-Anlagen gefördert. In Pre-Salt-Formationen, beispielsweise im Lula-Feld, werden große Gasvorkommen vermutet. Petrobras begann dort 2010 mit der Gasförderung in Pilotprojekten und hat weitere Investitionen geplant. Der Anteil von Kohle, Kernenergie und den bisher nicht erwähnten erneuerbaren Energien wie Wind- oder Solarkraft an der Primärenergieproduktion ist marginal.

Zusammenfassend wird etwa die Hälfte der Primärenergieproduktion Brasiliens aus Erdöl und Erdgas gewonnen. Insofern kommen CCS-Technologien für Brasilien insbesondere in Form von Enhanced Oil Recovery (EOR) und Enhanced Gas Recovery (EGR) in Betracht. Auf den größten Teil der brasilianischen Treibhausgasemissionen, die durch die Entwaldung entstehen, hätten CCS-Technologien keinen Einfluss. Klimapolitik bedeutet in Brasilien in erster Linie Waldschutz, weshalb die brasilianische Regierung auch auf die Etablierung eines Waldschutzinstruments durch die Klimarahmenkonvention drängt. Allerdings ist der brasilianische Energiemix im Wandel begriffen. Aktuelle Schätzungen gehen davon aus, dass der Anteil fossiler Brennstoffe an der Energieproduktion steigen wird (vgl. Friberg 2009: 396f; Román 2011: 395).

\section{CCS-Technologien in Brasilien}

Mikael Román zieht deshalb in einem Artikel über Brasiliens CCS-Politik die Schlussfolgerung, dass Brasilien unter anderem aufgrund des steigenden Anteils fossiler Brennstoffe in CCS-Technologien investiert. Das Ziel bestünde seiner Meinung nach darin, weiteres Wirtschaftswachstum vom Anstieg der Treibhausgasemissionen zu entkoppeln. Er geht davon aus, dass sich Brasilien angesichts der Erwartung eines zukünftigen globalen Post-Kyoto-Klimaregimes Wettbewerbsvorteile erhofft, da andere Volkswirtschaften dann mit der Einhaltung ihrer Reduktions-

55 Petrobras ist eine Aktiengesellschaft, deren Aktienkapital sich teilweise in Privatbesitz befindet, aber zur Mehrheit im Besitz der brasilianischen Regierung ist. 
verpflichtungen zu kämpfen hätten (vgl. Román 2011: 395). Allerdings ist ein solches Regime - in dem sich auch die Nicht-Annex-B-Länder zu Treibhausgasreduktionen verpflichten - derzeit nicht absehbar. Es ist denkbar, dass zum Zeitpunkt der ersten Investitionen in CCS-Technologien die Verabschiedung eines PostKyoto-Abkommens von brasilianischen Akteur_innen als wahrscheinlich angesehen wurde. Es ist aber auch durchaus möglich, dass es primär andere Gründe waren, die zu Brasiliens CCS-Engagement führten.

Tatsächlich ist Brasilien eines der wenigen Länder aus dem globalen Süden, das mit eigenen Projekten die Erforschung und Entwicklung von CCS-Technologien vorantreibt (vgl. Global CCS Institute 2012: 93, 96). Die Initiative dazu kam aus dem Unternehmen Petrobras, das bereits zwei CCS-Pilotprojekte initiierte. Gleichzeitig koordiniert Petrobras über das Forschungszentrum CENPES ein Netzwerk von elf Forschungsinstituten an brasilianischen Universitäten, die an der technologischen Entwicklung von CCS arbeiten (vgl. Román 2011: 391, 396). Erst nachdem Petrobras bereits in CCS-Technologien investiert hatte, wurde von der brasilianischen Regierung Unterstützung zugesagt (vgl. Román 2011: 391f). Bislang gibt es allerdings weder eine CCS-spezifische Politik noch eine entsprechende Gesetzgebung und auch keine finanzielle Unterstützung (vgl. im Internet: www.zeroco2. no/projects/countries/brazil, letzter Zugriff am 02.12.2014). Dies ist insofern bemerkenswert, als dass CCS-Initiativen in anderen Ländern meist von Beginn an finanzielle Unterstützung vom Staat erhalten oder direkt von staatlichen Stellen ausgehen. Diese Feststellung trifft auf den brasilianischen Fall nur eingeschränkt zu: Die brasilianische Regierung besitzt die Mehrheit der Petrobras-Aktien, insofern unterstützt der Staat die CCS-Technologie mittelbar. In der offiziellen brasilianischen Klimaschutzpolitik spielen CCS-Technologien allerdings eine untergeordnete Rolle. Dennoch hat die Regierung die betreffenden Öl- und Gasunternehmen sowie den brasilianischen Steinkohleverband (Associação Brasileira do Carvão Mineral, ABCM) dazu ermuntert, CCS-Technologien zu entwickeln und zu implementieren (vgl. Román 2011: 393).

Petrobras hat mittlerweile bereits im Demonstrationsprojekt Miranga die Verpressung von $\mathrm{CO}_{2}$ in Erdöl- und Erdgaslagerstätten sowie in salinen Aquiferen erprobt. Aktuell entwickelt das Unternehmen eine Anlage, die auf dem Prinzip des Enhanced Coal Bed Methane Recovery (ECBM) basiert (vgl. Román 2011: 393). Das CEPAC Carbometano Porto Batista Project soll - mit dem frei gesetzten Grubengas, das vor allem aus Methan besteht - die Gasversorgung der Region erhöhen und damit zur Energiesicherheit beitragen (vgl. Ketzer/Heemann 2009). Insgesamt zielt die Entwicklung von CCS-Technologien in Brasilien aber eher weniger auf die Kohleverstromung und mehr auf den Öl- und Gassektor (vgl. Román 2011: 395). 
Dies ist insofern nicht verwunderlich, als dass CCS-Technologien sich am ehesten in diesem Bereich auch ohne einen Kohlenstoffmarkt bzw. ohne einen Preis für $\mathrm{CO}_{2}$-Äquivalente rentieren können. Außerdem gibt es in Brasilien bislang kaum Kohlekraftwerke. Im Ölsektor bietet die Abscheidung von $\mathrm{CO}_{2}$ durch CCSTechnologien eine Alternative zur Abfackelung. Die Abscheidung von $\mathrm{CO}_{2}$ wäre damit eine geeignete Methode, um den vom Markt geforderten niedrigen $\mathrm{CO}_{2}$ Gehalt des Öls zu erreichen. Darüber hinaus steigern CCS-Technologien in der Anwendung als EOR oder EGR die Fördermengen von Öl und Gas. EOR- und EGRProjekte könnten Petrobras zusätzliche Einnahmen und der brasilianischen Regierung eine größere Energieversorgungssicherheit versprechen (vgl. Román 2011: 396). Diese Gründe scheinen mir gewichtiger für das brasilianische CCSEngagement zu sein als eine mögliche Spekulation der Regierung auf ein PostKyoto-Abkommen.

Für die Einführung von CCS im großtechnischen Maßstab - worunter auch eine mögliche Entwicklung von CCS-Technologien für Bioenergiekraftwerke fallen würde $^{56}$ - ist der sogenannte source and sink match von großer Bedeutung. In Brasilien liegen besonders viele der potenziellen $\mathrm{CO}_{2}$-Speicher in der Nähe großer punktueller $\mathrm{CO}_{2}$-Quellen. Was die Speicherkapazitäten insgesamt betrifft, bietet Brasilien relativ gute Möglichkeiten für die Anwendung von CCS-Technologien. Die Schätzungen der Speicherkapazitäten, die nur bedingt belastbar sind (vgl. IPCC 2005: 221), belaufen sich im Falle Brasiliens auf ca. 2.000 Gigatonnen $\mathrm{CO}_{2}$, was fast $20 \%$ der geschätzten globalen geologischen Speicherkapazitäten ausmacht. Bei den dafür vorgesehenen Gebieten handelt es sich um Ölfelder, saline Aquifere und tiefe Kohleflöze, die sich sowohl an Land (onshore) als auch auf hoher See (offshore) befinden (vgl. Román 2011: 395).

Die Offshore-Verpressung von $\mathrm{CO}_{2}$ ist zwar teurer, dennoch geht Román davon aus, dass sie in Brasilien bevorzugt angewendet werden wird. Dies begründet er damit, dass Onshore-Projekte stärker öffentlichen Gegenwind und politischen Widerstand, zum Beispiel von Anwohner_innen, provozieren würden (vgl. Román 2011: 393, 396, 399). Außerdem hat Petrobras im Offshore-Bereich besondere Expertise. Petrobras war das erste Unternehmen, das die Technologien für die Ölförderung in der Tiefsee entwickelte, die auch bei der Offshore-Verpressung angewendet werden würden. Insofern hätte Petrobras in dem Bereich eventuell Wettbewerbsvorteile (vgl. Román 2011: 396).

56 Laut den Angaben des Global CCS Institute wurde in Brasilien ein BECCS-Projekt durchgeführt. Dabei wurde $\mathrm{CO}_{2}$, das bei der Agro-Ethanol-Produktion durch Zuckerrohr entsteht, in saline Aquifere verpresst (vgl. im Internet: www.globalccsinstitute.com/publi cations/global-status-beccs-projects-2010/online/27091, letzter Zugriff am 02.12.2014). 
Petrobras hat bereits seit über 25 Jahren Erfahrungen mit EOR, allerdings war bislang die Frage des Verbleibs des Kohlenstoffdioxids in den Ölfeldern irrelevant und wurde nicht kontrolliert. Diese EOR-Projekte zielten allein auf die Erhöhung der Fördermenge. Dies ist ein erheblicher Unterschied zur Anwendung von EOR als CCS-Technologie. Die Speicherung von $\mathrm{CO}_{2}$ durch EOR testet Petrobras im Rahmen des 2007 ins Leben gerufenen Projekts Miranga, in dem auch die Speicherung in erschöpften Gaslagerstätten und in salinen Aquiferen erprobt wird. Damit geht eine Erhöhung der Fördermenge im Ölfeld Miranga einher. Das Projekt wird als Testlauf für die Anwendung von EOR in dem neu entdeckten Lula-Feld gesehen. Petrobras plant so, die $\mathrm{CO}_{2}$-Emissionen zu reduzieren und gleichzeitig die Produktionsmengen zu erhöhen (vgl. Global CCS Institute 2012: 93, 138; im Internet: www.panacea-co2.org/tstsites.cshtml\#11_Miranga und www.zeroco2.no/projects/ countries/brazil, letzter Zugriff am 02.12.2014).

Obwohl Petrobras viel Geld in CCS-Technologien investiert, war das Unternehmen gegen die Aufnahme von CCS in den CDM. Diese Position war sehr ungewöhnlich und wurde von keinem anderen Ölkonzern vertreten (vgl. Friberg 2009: 413). Román verweist in dem Zusammenhang darauf, dass sich die von Petrobras primär angestrebten CCS-Technologien EOR, EGR und ECBM als profitabel erweisen könnten auch ohne als CDM-Projekte zu gelten. Gleichzeitig erhöht sich durch die Aufnahme von CCS-Technologien in den CDM der Wettbewerb aufgrund der zusätzlich geschaffenen Anreize. Dies könnte dazu führen, dass Petrobras mit anderen Unternehmen aus den Annex-B-Staaten um CCS-Projekte in Brasilien konkurrieren müsste. Petrobras müsste also stärker um seine spezifischen Wettbewerbsvorteile, seinen firstmover advantage kämpfen (vgl. Román 2011: 397). Es ist davon auszugehen, dass Petrobras' CCS-Engagement und Petrobras' ablehnende Haltung gegenüber einer Aufnahme von CCS in den CDM einen Einfluss auf die Verhandlungsstrategie der brasilianischen Regierung hatte.

\section{Brasilien als Zielland für CDM-Projekte}

Seit es die flexiblen Mechanismen gibt, war Brasilien ein beliebtes Zielland für CDM-Projekte und auch aktuell ist Brasilien eines der Länder, in denen am meisten CDM-Projekte umgesetzt werden. Was die Anzahl der Projekte betrifft, rangiert Brasilien an dritter Stelle hinter China und Indien. Vergleicht man die Summe der vergebenen CERs steht Brasilien an vierter Position hinter China, Indien und Südkorea. $^{57}$ Die meisten brasilianischen CDM-Projekte sind in den Bereichen Bio-

57 In Brasilien wurden bislang 277 von weltweit insgesamt 6.755 CDM-Projekten initiiert, was einem Anteil von etwas mehr als $4 \%$ entspricht (Stand: 30.04.2013). Mit Abstand die meisten CDM-Projekte gibt es in China (ca. $53 \%$ ) und Indien (ca. $18 \%$ ). Für die 
energie und Landnutzung angesiedelt (vgl. Román 2011: 397). In Bezug auf die in Brasilien weit verbreitete Zuckerrohrproduktion ergaben sich mit dem CDM weitere Einnahmequellen. Zuckerrohr wurde vor Einführung des CDM nur zu Zucker und Agrotreibstoff verarbeitet. Mit dem CDM wurde auch die Nutzung des abfallenden Nebenprodukts, die Bagasse, als Brennstoff für die Stromgewinnung rentabel (vgl. Friberg 2009: 417). Im Bereich Aufforstung und Wiederaufforstung gibt es bislang nur drei CDM-Projekte (Stand 26.06.2013). ${ }^{58}$ Dies ist vor allem darauf zurückzuführen, dass sie innerhalb des europäischen Emissionsrechtehandels nicht angerechnet werden können, weshalb es eine geringe Nachfrage nach den durch sie generierten CERs gibt (vgl. Friberg 2009: 405).

Der CDM wird von der brasilianischen Regierung als Erfolg gesehen, unter anderem da durch ihn eine größere Stromerzeugungskapazität geschaffen wurde als durch ein eigens dafür ins Leben gerufene Regierungsprogramm. Der CDM stellt eine zusätzliche Einnahmequelle dar und steht an zwanzigster Stelle der brasilianischen Exporteinnahmen (vgl. Friberg 2009: 413). Die positive Bewertung des bisherigen CDM-Regimes durch die brasilianische Regierung bestimmte die brasilianische Position in den CCS-Verhandlungen. ${ }^{59}$ Die brasilianische Regierung war stark darauf bedacht, die für sie bislang gewinnträchtigen Projekttypen nicht zu gefährden. Dies wird einer der Hauptgründe gewesen sein, warum die brasilianische Regierung mehrfach die Sorge äußerte, dass die Integration von CCS-Technologien in den CDM zu sinkenden CER-Preisen führen würde (vgl. Román 2011: 397).

CDM-Projekte in Brasilien wurden 83.924.164 CERs vergeben. Insgesamt wurden 1.307.846.088 CERs durch CDM-Projekte generiert. Brasilien hat damit in Bezug auf die CERs einen Anteil von ca. 6,4\%. Die meisten CERs gingen nach China (ca. $62 \%$ ), Indien (ca. 13,5\%) und Südkorea (ca. 8,3\%) (vgl. im Internet: cdm.unfccc.int/ Statistics/Public/CDMinsights/index.html, letzter Zugriff am 02.12.2014).

58 Project 2569: Reforestation as Renewable Source of Wood Supplies for Industrial Use in Brazil (vgl. im Internet: cdm.unfccc.int/Projects/DB/TUEV-SUED1242052712.92/view, letzter Zugriff am 02.12.2014), Project 3887: AES Tietê Afforestation/Reforestation Project in the State of São Paulo, Brazil (vgl. im Internet: cdm.unfccc.int/Projects/DB/ SGS-UKL1280399804.71/view, letzter Zugriff am 02.12.2014), Project 7258: Vale Florestar. Reforestation of degraded tropical land in Brazilian Amazon (vgl. im Internet: cdm.unfccc.int/Projects/Validation/DB/FZ5GZY6K7SKEAIC5K67IX4AU1S4X2H/view. html, letzter Zugriff am 02.12.2014)

59 Die Zivilgesellschaft beschäftigt sich kaum mit dem CDM und dem Kyoto-Kohlenstoffmarkt. Dies trifft auch auf die brasilianischen umwelt- und entwicklungspolitischen NGOs zu - vermutlich weil sie andere Auseinandersetzungen für relevanter halten (vgl. Friberg 2009: 409). 


\section{Der Verhandlungsstrang zum Schutz von Wäldern}

Zwischen der CCS-CDM-Kontroverse auf der einen und den Auseinandersetzungen um die Aufforstungs- und Wiederaufforstungs-CDM-Projekten und den REDDVerhandlungen auf der anderen Seite ist eine wechselseitige Beeinflussung - vor allem für die brasilianische Delegation - anzunehmen. Nach Einschätzung von de Coninck, die den Verhandlungsstrang zu CCS-Technologien als Wissenschaftlerin beobachtete, war die strikte Ablehnung der Aufnahme von CCS in den CDM Teil einer Verhandlungsstrategie der brasilianischen Regierung, Druck auf die Verhandlungen zu den von ihnen angestrebten Aufforstungsprojekte aufzubauen. ${ }^{60}$ Die brasilianische Regierung drängt seit der COP 14 in Poznań (2008) darauf, weitere Aufforstungsprojekte in den CDM aufzunehmen. Bislang kann nur die Aufforstung oder Wiederaufforstung einer brachliegenden Fläche als CDM-Projekt gelten. Bei den COP-14-Verhandlungen führte die brasilianische Regierung das Konzept der forests in exhaustion ein, um die Kriterien für die Aufnahme von Aufforstungs- und Wiederaufforstungs-Projekten in den CDM aufzuweichen.

Forests in exhaustion bezeichnet bereits vor 1990 aufgeforstete Flächen, die mit Hilfe der CDM-Gelder weiterhin oder erneut forstwirtschaftlich betrieben werden sollen. Das für die Anerkennung als CDM-Projekt relevante Kriterium der Zusätzlichkeit würde in einem solchen Fall in dem Nachweis liegen, dass die betreffenden Flächen ohne CDM-Projekt sich selbst überlassen oder einer Endernte anheim fallen würden (vgl. im Internet: cdm.unfccc. int/EB/050/eb50annagan3.pdf, letzter Zugriff am 02.12.2014). De facto trifft dies auf existierende Plantagen, die weitergeführt werden sollen oder auf ehemalige Plantagen, die reaktiviert werden sollen, zu. Derartige Flächen sind bislang vom CDM ausgeschlossen, da nur für solche Aufforstungsflächen CDM-Projekte beantragt werden kann, die nach dem 01.01.1990 auf vorher nicht bewaldete Flächen angelegt wurden. Die Ausweitung des CDM auf Projekte der forests in exhaustion würde vermutlich zu einer starken Zunahme von CERs führen.

Der ehemalige Vorsitzende des CDM EB, José Domingos Miguez, setzte sich als Mitglied der brasilianischen Delegation erfolgreich für einen CMP-Beschluss ein, der besagt, dass die Aufnahme von Projekten zu forests in exhaustion in den CDM geprüft wird. Gleichzeitig war er Vorsitzender der Arbeitsgruppe Aufforstung und Wiederaufforstung (Afforestation and Reforestation Working Group), die dem CDM EB bei genau diesem Thema zuarbeitete (vgl. im Internet: www.reddmonitor.org/2009/12/01/forests-in-exhaustion-a-guide, letzter Zugriff am 02.12.2014).

60 Diese Einschätzung äußerte sie in einem Interview, das ich am 16.05.2013 mit Heleen de Coninck geführt habe. 
Wie Treber, der als Beobachter an den Verhandlungen teilnahm, in seinen Kurzberichten im Auftrag von Germanwatch schreibt, deutete sich bei den Zwischenverhandlungen 2010 (im Vorfeld der COP 16, auf der die Entscheidung bezüglich der Aufnahme von CCS in den CDM fiel) ein Tauschgeschäft an. Die Delegation Saudi-Arabiens votierte gegen den Einbezug von forests in exhaustion, um Brasilien zum Einlenken in der CCS-CDM-Kontroverse zu bewegen. Im Gegenzug würde sie dann ihren Widerstand gegen die Ausweitung der Aufforstungs- und Wiederaufforstungsprojekte aufgeben. Aber da sich die EU prinzipiell gegen die Aufnahme von forests in exhaustion in den CDM stellte, kam es nicht zu diesem Tauschgeschäft (vgl. Treber o. J.). Dennoch kann man davon ausgehen, dass die im gleichen Zeitraum stattfindenden Verhandlungen zu verschiedenen Projekttypen des CDM aufeinander wirken. Für Brasilien sind die Auseinandersetzungen um die Förderung von Aufforstungs- und Wiederaufforstungsprojekten von großer Bedeutung.

Dies trifft auch auf die REDD-Verhandlungen zu. Das bei der COP 13 in Bali eingeführte Klimaschutzinstrument REDD soll die Erhaltung großflächiger Wälder als Kohlenstoffspeicher finanziell attraktiv machen. Im Verlauf der Verhandlungen hat sich die Bezeichnung REDD+ etabliert, um anzuzeigen, dass nicht nur Schutzmaßnahmen, sondern auch Waldbewirtschaftungsformen und die Verbesserung der Wirtschaftslage der Menschen in den betroffenen Gebieten mit einbezogen werden sollen. Bislang gibt es allerdings keine Einigung auf einen konkreten Finanzierungsmechanismus. Die diesbezügliche Position der brasilianischen Regierung ist eindeutig. Sie kritisiert die mögliche Einführung handelbarer Emissionsgutschriften, auch wenn sich einige brasilianische Bundesstaaten des Amazonasgebietes für marktbasierte Instrumente aussprechen. Die brasilianische Regierung plädiert stattdessen für Finanztransfers von Industrieländern zu tropischen Ländern. $\mathrm{Zu}$ diesem Zweck hat Brasilien 2008 einen Amazonas Fonds eingerichtet (vgl. Friberg 2009: 402). Die norwegische Regierung war Unterstützerin der ersten Stunde und hat sich verpflichtet, bis 2015 insgesamt eine Milliarde US Dollar in den Fonds einzuzahlen. Diese finanzielle Unterstützung ist ein Element von Norwegens globalem Engagement für den Erhalt von Wäldern. Da die (Regen-)Wälder nur unzureichend durch das Kyoto-Protokoll geschützt sind, rief der norwegische Ministerpräsident Jens Stoltenberg während der UN-Klimaverhandlungen 2007 in Bali eine eigene Klima- und Wälder-Initiative (Norway's International Climate and Forest Initiative, NICFI) ins Leben (vgl. im Internet: www.regjeringen.no/en/dep/ $\mathrm{md} /$ Selected-topics/climate/the-government-of-norways-international-/norway-amazonfund.html?id=593978, letzter Zugriff am 02.12.2014). Diese Zusammenarbeit der brasilianischen mit der norwegischen Regierung erscheint mir relevant, da beide gleichzeitig zentrale Gegenspielerinnen in $\operatorname{der} C C S$-CDM-Kontroverse waren. 


\section{Brasiliens Position in den CCS-Verhandlungen}

Brasilien war das Land, das die Aufnahme von CCS-Technologien in den CDM am beharrlichsten ablehnte. Dabei verstärkte die brasilianische Regierung ihren Widerstand im Laufe der Verhandlungen. In ihrer ersten Stellungnahme aus dem Jahre 2006 äußert sich die brasilianische Regierung skeptisch und verweist auf Unsicherheiten. Später positioniert sie sich kategorisch gegen eine Aufnahme in den CDM, da CCS-Technologien nicht mit den Prinzipien des CDM vereinbar seien (vgl. de Coninck 2008: 932). Letztlich stimmte Brasilien aber bei der entscheidenden Abstimmung während der Verhandlungen in Cancún (2010) dennoch zu. Die brasilianische Delegation betonte, dass siegrundsätzlich gegen die Aufnahme von CCSTechnologien in den CDM sei, aber die Verhandlungen nicht blockieren wolle (vgl. Treber 2011: 15). Die Beweggründe für diesen Wandel in der Verhandlungsstrategie lassen sich nur schwer rekonstruieren. Offensichtlich gab es im Vorfeld der endgültigen Abstimmung informelle Gespräche (vgl. Treber 2011: 14f), was nicht ungewöhnlich ist. Deshalb ist es kaum möglich, die letztlich entscheidenden Momente für die Einigung zu rekonstruieren. Treber führt an, dass der öffentliche Druck, Ergebnisse zu produzieren, in Cancún immer stärker die Verhandlungen prägte und Brasiliens Einlenken möglicherweise befördert habe (vgl. Treber 2011: 6).

Inwieweit die Verhandlungen zu Aufforstung und Landnutzung einen Grund für Brasiliens Strategiewechsel in der CCS-Frage darstellten, ist unklar. Die Ergebnisse der COP 16 sind aus brasilianischer Sicht ambivalent zu bewerten. In Bezug auf die Aufnahme von forests in exhaustion in den CDM gab es keine nennenswerten Fortschritte. ${ }^{61}$ Die Verankerung von REDD+ in den Klimaverhandlungen wurde dagegen vorangetrieben. Die Reduktion von Emissionen aus Entwaldung und Schädigung von Wäldern wird in den Ergebnissen der Ad Hoc Working Group on longterm Cooperative Action under the Convention behandelt und ist somit Teil der Cancún Agreements. In dem Dokument werden Nicht-Annex-B-Staaten dazu aufgefordert, nationale Umsetzungspläne, Berichte über den Einfluss ihrer Wälder auf die Treibhausgasemissionen sowie transparente Monitoringsysteme über Ausdehnung und Zustand ihrer Wälder zu erarbeiten (vgl. UNFCCC 2011: 12ff). Allerdings wurde die Entscheidung über einen Finanzierungsmechanismus vertagt. Brasilien und andere Akteur_innen konnten also die Einführung handelbarer Emissionsgutschriften verhindern, allerdings ohne dass alternative Finanzierungsmöglichkeiten festgeschrieben worden wären. Damit blieb REDD+ ohne konkreten Umsetzungsmechanismus (vgl. Friends of the Earth International 2010: 2).

61 Das Nebenorgan der UNFCCC für wissenschaftliche und technologische Beratung (Subsidiary Body for Scientific and Technological Advice, SBSTA) lud Mitgliedsländer und NGOs dazu ein, Stellungnahmen einzureichen. 
Als wichtiges Element für die Erzeugung eines Konsenses in der CCS-Debatte ist zu nennen, dass die EU (und evtl. weitere Befürworter_innen) vormals kritische Länder (v. a. die AOSIS-Staaten und die sogenannten Least Developed Countries) überzeugen konnte, sich nicht weiter gegen die Aufnahme von CCS-Technologien in den CDM zu stellen. ${ }^{62}$ Für dieses Szenario spricht, dass im Anschluss an diesen Beschluss bereits im Februar 2011 eine Konferenz in einem AOSIS-Mitgliedsland (Trinidad und Tobago) stattfand, auf der die CCS-Technologien zu den Hauptthemen gehörten (vgl. Carbon Market Watch 2011: 17f).

\section{Brasiliens Argumentationslinie in den Stellungnahmen}

Die brasilianische Regierung reichte drei schriftliche Stellungnahmen zu CCSTechnologien ein: 2006, 2008 und 2010. Im Verlauf der Verhandlungen positionierte sich die brasilianische Regierung immer deutlicher gegen die Aufnahme von CCS in den CDM. Die erste Stellungnahme ist nur eine Seite lang und vergleichsweise zurückhaltend formuliert. Dort weist die brasilianische Regierung auf offene Fragen und Wissenslücken hin. Starke Urteile sind in dem Text nicht zu finden, nur an einer Stelle äußert sich die brasilianische Regierung, besorgt":

„Brazil is concerned with the acceptance of CCS as CDM project activities without careful consideration of these issues and development of convenient modalities, if appropriate." (UNFCCC 2006: 14)

Die zweite Stellungnahme ist mit knapp über vier Seiten schon deutlich ausführlicher und die Argumentation um einiges kritischer. Die dritte Stellungnahme ist mit sieben Seiten noch einmal umfangreicher, allerdings kommen kaum neue Argumente hinzu. Auch inhaltlich besteht eine Diskrepanz zwischen der ersten Stellungnahme auf der einen und der zweiten und dritten Stellungnahme auf der anderen Seite. Endet die erste Stellungnahme noch vage mit der Erwartung, die offenen Punkte beim CCS-Workshop diskutieren zu können, so schließen die zweite und dritte Stellungnahme mit einer eindeutigen Positionierung gegen die Aufnahme von CCS-Technologien in den CDM: „Brazil [sic!] proposal is that CCS shall not be eligible under the CDM.“(UNFCCC 2008: 7; UNFCCC 2010c: 8)

Die brasilianische Regierung spricht sich allerdings nicht prinzipiell gegen CCS-Technologien aus. Für die Erreichung der Klimaschutzziele schlägt die brasilianische Regierung das bei den UN-Klimaverhandlungen häufig genannte Portfolio technologischer Optionen vor. Im Rahmen eines solchen Portfolios an Klimaschutztechnologien können aus Sicht der brasilianischen Regierung CCS-Projekte

62 Diesen Hinweis bekam ich in einem Interview, das ich am 16.05.2013 mit Heleen de Coninck geführt habe. 
durchaus eine sinnvolle Option darstellen (vgl. Enthymeme BRA 1-1, BRA 2-1, BRA 2-2, BRA 3-1, BRA 3-2; UNFCCC 2006: 14; UNFCCC 2008: 3; UNFCCC 2010c: 2). Allerdings sollten CCS-Technologien nicht über den CDM gefördert werden. In ihrer Begründung rekurriert die brasilianische Regierung primär auf zwei Basisannahmen der UN-Klimaverhandlungen. Erstens auf den Grundsatz 1 in Artikel 3 der Klimarahmenkonvention:

„Die Vertragsparteien sollen auf der Grundlage der Gerechtigkeit und entsprechend ihren gemeinsamen, aber unterschiedlichen Verantwortlichkeiten und ihren jeweiligen Fähigkeiten das Klimasystem zum Wohl heutiger und künftiger Generationen schützen. Folglich sollen die Vertragsparteien, die entwickelte Länder sind, bei der Bekämpfung der Klimaänderungen und ihrer nachteiligen Auswirkungen die Führung übernehmen.“ (UNFCCC 1992: 5)

Zweitens auf die Zweckbestimmung des CDM in Artikel 12 des Kyoto-Protokolls:

„Zweck des Mechanismus für umweltverträgliche Entwicklung ist es, die nicht in Anlage I aufgeführten Vertragsparteien dabei zu unterstützen, eine nachhaltige Entwicklung zu erreichen und zum Endziel des Übereinkommens beizutragen, und die in Anlage I aufgeführten Vertragsparteien dabei zu unterstützen, die Erfüllung ihrer quantifizierten Emissionsbegrenzungs- und -reduktionsverpflichtungen aus Artikel 3 zu erreichen.“ (UNFCCC 1997: 17)

Die hier zitierte Zielstellung der nachhaltigen Entwicklung kann in den Augen der brasilianischen Regierung nur durch die Sicherstellung der ökologischen Integrität des CDM erreicht werden. Deshalb fordert sie in ihrer ersten Stellungnahme, dass die Implikationen einer Aufnahme von CCS-Technologien im Hinblick auf die ökologische Integrität des CDM geprüft werden (vgl. Enthymem BRA 1-4; UNFCCC 2006: 14). In der zweiten Stellungnahme macht die brasilianische Regierung deutlich, dass ihrer Meinung nach CCS-Technologien nicht zu einer nachhaltigen Entwicklung beitragen können und deshalb nicht in den CDM aufgenommen werden sollten. An dieser Stelle verweist sie auf ein Argument, das in den Verhandlungen wiederholt geäußert wurde. So wiesen mehrere Länder auf die Festlegungen in den CDM-Bestimmungen hin, dass die Zielländer freiwillig am CDM teilnehmen und selber die Kriterien nachhaltiger Entwicklung für ihr Land spezifizieren dürfen, weshalb sie auch über CCS-Projekte in ihren Ländern entscheiden könnten. Die brasilianische Regierung hält dagegen, dieses Prinzip der Freiwilligkeit bedeute nicht, dass jedes einzelne Land selber entscheide, ob ein bestimmter Projekt-Typus prinzipiell den CDM-Kriterien entspricht. Die Aufnahme eines neuen Typus in den CDM bedürfe dagegen einer CMP-Entscheidung (vgl. Enthymeme BRA 2-8, BRA 2-17, BRA 3-8; UNFCCC 2008: 4ff; UNFCCC 2010c: 5f). 
Der Grundsatz der gemeinsamen, aber unterschiedlichen Verantwortlichkeiten stellt einen Eckpfeiler dar, auf den in den Verhandlungen immer wieder verwiesen wird - meistens von Seiten der Nicht-Annex-B-Staaten, beispielsweise um Reduktionsverpflichtungen für Entwicklungs- und Schwellenländer abzulehnen. Die brasilianische Regierung greift in ihrer zweiten schriftlichen Stellungnahme auf diesen Grundsatz zurück:

„Developed countries, which shall lead the process of combating climate change, should be the first to use CCS in geological formation on large scale in their territories in order to acquire knowledge about the risks related to leakage, monitoring and liability before exporting premature experiences to developing countries.“(UNFCCC 2008: 3)

Damit macht die brasilianische Regierung deutlich, dass für sie die Führung in der Bekämpfung des Klimawandels zu übernehmen bedeutet, für die Entwicklung des Portfolios technologischer Optionen verantwortlich zu sein. Gleichzeitig kommt in dem Statement die Einschätzung zum Ausdruck, dass die CCS-Technologien insgesamt noch unreif seien. An anderer Stelle wird differenziert, EOR sei die einzige reife Variante zur geologischen Speicherung von $\mathrm{CO}_{2}$ (vgl. UNFCCC 2008: 5). Dennoch lehnt die brasilianische Regierung auch die Aufnahme von EOR in den CDM ab, da EOR- oder ECBM-Projekte (EGR wird nicht erwähnt) die Förderung fossiler Brennstoffe in Nicht-Annex-B-Staaten lukrativer werden ließe.

Die brasilianische Regierung geht davon aus, dass CCS in der Phase des Übergangs in eine kohlenstoffarme Wirtschaft eine sinnvolle Brückentechnologie darstelle. Dies gelte allerdings nur für die Industrieländer mit ihrer enormen Infrastruktur, die auf dem Verbrauch fossiler Brennstoffe basiere. Für Nicht-Annex-B-Staaten träfe dies allerdings nicht zu. Dort würden EOR- und ECBM-Projekte Anreize für die Steigerung der Produktion fossiler Brennstoffe schaffen. Deshalb widerspräche die Aufnahme von CCS-Technologien der zentralen Idee des CDM, nämlich der langfristigen Unterstützung in der Entwicklung hin zu einer kohlenstoffarmen Wirtschaft (vgl. UNFCCC 2008: 5ff).

Damit verweist die brasilianische Regierung auf den aus Artikel 12 des KyotoProtokolls bereits zitierten Zweck des CDM, „eine nachhaltige Entwicklung zu erreichen und zum Endziel des Übereinkommens beizutragen“ (UNFCCC 1992: 5). Dieses Endziel wird in Artikel 2 der Klimarahmenkonvention als „Stabilisierung der Treibhausgaskonzentrationen in der Atmosphäre auf einem Niveau [...], auf dem eine gefährliche anthropogene Störung des Klimasystems verhindert wird“ (UNFCCC 1992: 5) präzisiert. Sowohl in ihrer ersten als auch in ihrer dritten schriftlichen Stellungnahme führt die brasilianische Regierung mit explizitem Verweis auf Artikel 12.5 (b) des Kyoto-Protokolls den Beitrag zur tatsächlichen und langfristigen Reduktion von Treibhausgasemissionen als eines der wichtigsten 
Kriterien für die Aufnahme einer Technologie in den CDM an. Dabei wird in der Stellungnahme aus dem Jahr 2006 noch angemahnt, dass nur dann eine korrekte Messung der langfristigen Reduktion von Treibhausgasemissionen durch CCSTechnologien möglich sei, wenn die Implikationen eines eventuellen Austritts von $\mathrm{CO}_{2}$ eingeschätzt werden können. Deshalb sei es vor der Aufnahme in den CDM wichtig, die Möglichkeiten einer solchen Einschätzung sorgfältig zu prüfen (vgl. Enthymem BRA 1-3; UNFCCC 2006: 14). In der dritten Stellungnahme wird verschärft argumentiert, dass CCS-Technologien aufgrund nicht vorhersehbarer $\mathrm{CO}_{2}$ Austritte langfristig nicht unbedingt zu tatsächlichen und messbaren Reduktionen von Treibhausgasemissionen führen und folglich eine der wichtigsten Bedingungen für die Aufnahme in den CDM nicht erfüllt sei (vgl. Enthymem BRA 3-5; UNFCCC 2010c: 3).

In dem Zusammenhang verweist die brasilianische Regierung darauf, dass die ökonomische Logik, auf der die CDM-Modalitäten und -Verfahren basieren, komplexe langfristige Entwicklungen nicht adäquat bearbeiten könne. Die Komplexität der CCS-Projekte zeichne sich dadurch aus, dass ihre langfristigen Entwicklungen weder prognostizierbar (weil die Möglichkeit eines plötzlichen Austritts von $\mathrm{CO}_{2}$ statistisch nicht erfasst werden kann) noch direkt messbar (sondern nur in Modellen darstellbar) seien (vgl. Enthymeme BRA 2-9, BRA 2-10, BRA 2-11, BRA 3-4, BRA 3-6, BRA 3-7; UNFCCC 2008: 4f; UNFCCC 2010c: 3f). Die CDM-Modalitäten und -Verfahren sehen aber gerade vor, dass der Austritt von $\mathrm{CO}_{2}$ gemessen werde, um die Vergabe der CERs berechnen zu können.

Die Leckage-Risiken stehen aus Sicht der brasilianischen Regierung aber nicht nur im Widerspruch zur Zweckbestimmung des CDM, sondern stellen auch unzumutbare Risiken für Nicht-Annex-B-Staaten dar. Als CDM-Zielländer müssten diese - laut den Vorschlägen, die im Kontext der Verhandlungen diskutiert und in Stellungnahmen anderer Akteur_innen erwähnt wurden - eine langfristige Haftung für CCS-Projekte übernehmen. Die Kosten der Haftung seien aber unberechenbar. Außerdem gebe es neben dem ökonomischen Risiko der Kompensationszahlungen für das ausgetretene $\mathrm{CO}_{2}$ auch ökologische und gesundheitliche Risiken (vgl. Enthymeme BRA 2-12, BRA 3-9; UNFCCC 2008: 5; UNFCCC 2010c: 6).

„These externalities cannot be measured, not even estimated ex-ante and the host country would have to afford them, which is unacceptable for it means that private profit in the short term will be supported by public loss in the long term." (UNFCCC 2008: 5; UNFCCC 2010c: 6)

Insbesondere in Bezug auf die langfristige Bürde vergleicht die brasilianische Regierung CCS-Technologien mit der Atomkraft, die bei der COP 7 in Marrakesch (2001) vom CDM ausgeschlossen wurde. Mit dem Vergleich zur Atomkraft 
verknüpft die brasilianische Regierung in den Stellungnahmen ihre beiden Hauptargumente, die sich auf die Unterschiede zwischen Annex-B- und Nicht-Annex-BStaaten sowie auf die spezifischen Charakteristika des CDM beziehen. Zum einen verweist sie darauf, dass die spezifischen langfristigen Risiken der Atomkraft durch elaborierte Versicherungssysteme und staatliche Überwachung gelöst worden seien und dass die dafür notwendigen stabilen politischen, ökonomischen und institutionellen Strukturen in vielen Nicht-Annex-B-Staaten nicht vorhanden seien. Zum anderen verdeutliche der Vergleich mit der Atomkraft, dass CCS-Projekte nicht mit den CDM-Modalitäten und -Prozessen vereinbar seien (Enthymeme BRA 2-5, BRA 2-6, BRA 2-7, BRA 3-3, BRA 3-16, BRA 3-17; UNFCCC 2008: 3f; UNFCCC 2010c: 2ff, 8).

Neben der bis hierin dargestellten Grundargumentation warnt die brasilianische Regierung davor, dass CCS-CDM-Projekte große Mengen CERs generieren würden und damit einen Preisverfall verursachen könnten. Sinkende CER-Preise wiederum würden die Investitionen in kleinere dezentrale CDM-Projekte und damit in erneuerbare Energien, Energieeffizienz und kohlenstoffarme Formen des Wirtschaftens unterminieren (vgl. Enthymeme BRA 2-15, BRA 3-10; UNFCCC 2008: 5f; UNFCCC 2010c: 6). Da Brasilien eines der Hauptzielländer bisheriger CDMProjekte ist, drückt sich in der Warnung sicherlich auch die Sorge um die bislang so gewinnträchtigen Projekttypen aus.

Abschließend sei noch darauf hingewiesen, dass die brasilianische Regierung in den Stellungnahmen explizit auf die Möglichkeit verweist, innerhalb der Klimarahmenkonvention einen passenderen Rahmen für die Finanzierung von CCSTechnologien in Nicht-Annex-B-Staaten zu finden. Damit stellt die brasilianische Regierung klar, dass sie sich nicht grundsätzlich gegen den Einsatz von CCS-Technologien in Nicht-Annex-B-Staaten positioniert, sondern allein gegen die Aufnahme von CCS-Technologien in einen Kompensationsmechanismus wie den CDM, der zusätzliche Emissionsberechtigungen für die Annex-B-Länder generiert (vgl. UNFCCC 2008: 6; UNFCCC 2010c: 7f).

\subsubsection{Die Positionierung der EU in der CCS-CDM-Kontroverse}

Bei der folgenden Analyse der Positionierung der EU in der CCS-CDMKontroverse arbeite ich ebenfalls die zentralen Kontextfaktoren heraus, die Einfluss auf die Verhandlungsposition und -argumentation der EU hatte. Anschließend zeichne ich die Argumentationslinie der schriftlichen Stellungnahmen der EU nach. 


\section{Die Rolle der EU im UN-Klimaregime}

Die EU spielt aus verschiedenen Gründen eine wichtige Rolle im UN-Klimaregime. Zunächst einmal haben die EU-Mitgliedsstaaten zusammen mit den USA seit Beginn der Industrialisierung die meisten Treibhausgase emittiert. In Bezug auf den Pro-Kopf-Ausstoß zählt die EU weiterhin zu den Hauptverursacher_innen des anthropogenen Klimawandels (vgl. Geden/Kremer 2009: 30). Dementsprechend wird von verschiedenen Seiten (auch aus den EU-Organen heraus) immer wieder formuliert, dass die EU in der Verantwortung stehe, den Klimaschutz voranzutreiben. Darüber hinaus sieht die EU aber auch ökonomische Chancen, die sich durch ihre Technologieführerschaft bei einer möglichen globalen Transformation der Energiesysteme ergeben könnten. Insofern bedingen auch wirtschafts- und industriepolitische Interessen das vergleichsweise engagierte Auftreten der EU in den Klimaverhandlungen (vgl. Geden/Kremer 2009: 30f).

Die EU reklamiert für sich eine Vorreiterrolle in den Klimaverhandlungen und war eine treibende Kraft bei der Aushandlung des Kyoto-Protokolls. Dabei setzte sich die EU für strikte Reduktionsziele ein, die sie mit einer Emissionsbesteuerung erreichen wollte. Den flexiblen Mechanismen stand sie dagegen zunächst skeptisch gegenüber, schwenkte zum Ende der Verhandlungen aber auf die Linie der JUSSCANNZ-Länder ein und unterstützte deren Vorschläge (vgl. Kapitel 5.1.2). Die EU-Länder verpflichteten sich im Kyoto-Protokoll, die Treibhausgasemissionen bis 2012 gegenüber dem Basisjahr 1990 um acht Prozent zu senken. Trotz der Absage der USA hielt die EU am Protokoll fest. Durch die schnelle Ratifizierung aller Mitgliedsländer und den auf Russland ausgeübten Druck, es ebenfalls zu ratifizieren, war die EU maßgeblich daran beteiligt, dass das Kyoto-Protokoll in Kraft treten konnte. Seitdem entwickelte sich die EU, entgegen ihrer früheren Skepsis, zu einer starken Anhängerin der flexiblen Mechanismen. So wurde bereits zum 1. Januar 2005 mit dem EU-Emissionshandel der erste grenzüberschreitende und bis heute weltweit größte Emissionsrechtehandel eingeführt (vgl. Brunnengräber 2009: 158; Claes/Frisvold 2009: 217). Diesen Emissionsrechtehandel würde die EU gerne bis 2015 auf alle Staaten der OECD und bis 2020 auch auf die Nicht-OECD-Staaten erweitern. Insgesamt setzt sich die EU für die Ausweitung der flexiblen Mechanismen des Kyoto-Protokolls ein (vgl. Dröge 2010: 70; Geden/Kremer 2009: 33).

Im Vorfeld der Klimakonferenz in Kopenhagen (COP 15) verkündete die EU, 20 \% ihrer Emissionen bis zum Jahr 2020 reduzieren zu wollen - im Vergleich zum Basisjahr 1990. Abhängig vom Ergebnis der Verhandlungen über ein Post-KyotoAbkommen stellte sie eine Erhöhung des Reduktionsziels auf $30 \%$ in Aussicht unter der Bedingung, dass andere Industrieländer, vergleichbare‘ Minderungsziele und die Schwellenländer , angemessene“ Vorgaben akzeptieren (vgl. Geden/Kremer 
2009: 35). Die damaligen Bemühungen einiger Umwelt-NGOs, die EU dazu zu bewegen, von sich aus $30 \%$ Reduktionen anzustreben, waren nicht erfolgreich. Aktuell wird in den Gremien der EU über das Ziel verhandelt, bis zum Jahr 203040 \% der Emissionen einzusparen - gegenüber dem Basisjahr 1990 (vgl. im Internet: ww w.ec.europa.eu/energy/consultations/doc/com_2013_0169_green_paper_2030_de.pdf, letzter Zugriff am 02.12.2014).

Bei den UN-Klimaverhandlungen tritt die EU mit einer Stimme auf, was aufgrund der unterschiedlichen Prioritäten der Mitgliedsländer nicht selbstverständlich ist. Das einheitliche Auftreten ist das Ergebnis von komplexen Abstimmungen zwischen den Mitgliedsstaaten (vgl. Geden/Kremer 2009: 30).

\section{Die Aktivitäten der EU im Energie- und Klimabereich}

Auch wenn es die EU immer wieder schaffte, sich als wichtiger Akteur mit klaren Positionen in die Verhandlungen einzubringen, so ist die Klimapolitik der verschiedenen Mitgliedsländer doch sehr unterschiedlich. Die nordeuropäischen Länder formulieren tendenziell ehrgeizigere Klimaschutzziele, während die süd- und osteuropäischen Länder für sich ein Recht auf nachholende Entwicklung reklamieren und sich gegen $\mathrm{zu}$ hohe Auflagen wehren. Beim Kyoto-Protokoll löste man diese Schwierigkeiten durch den sogenannten Bubble-Ansatz. Das für die gesamte EU geltende Reduktionsziel von acht Prozent wurde intern aufgeteilt. Die drastischsten Reduktionen nahmen dabei Luxemburg, Dänemark, Deutschland, Österreich und Großbritannien in Kauf. Italien, Niederlande und Belgien verpflichteten sich zu moderaten Reduktionen. Frankreich und Finnland sollten ihren Ausstoß stabil halten, wohingegen Irland und vor allem Griechenland und Portugal Emissionserhöhungen zugestanden wurden. Die ost- und mitteleuropäischen Länder traten erst nach den Kyoto-Verhandlungen der EU bei, haben aber aufgrund der mit dem Zusammenbruch der Sowjetunion einhergehenden Deindustrialisierung ohnehin keine Probleme, ihre Vorgaben zur Stabilisierung der Emissionen einzuhalten bzw. verfügen sogar noch über ungenutzte Emissionsberechtigungen. Der Rückbau der energieintensiven alten Industriebetriebe betrifft auch den Osten Deutschlands und war der Grund, warum Deutschland sich zu relativ hohen Reduktionszielen verpflichten und diese auch erfüllen konnte (vgl. Brunnengräber et al. 2008: 100; Claes/Frisvold 2009: 212). Die EU versucht die unterschiedlichen Positionen der Mitgliedsländer durch das „Zieldreieck“ aus Nachhaltigkeit, Versorgungssicherheit und Wettbewerbsfähigkeit in Einklang zu bringen. Diese „Konsensformel“ (Geden 2012: 24) der europäischen Energiepolitik ermöglicht prinzipiell die Kompromissfindung, auch wenn in Fällen der konkreten Umsetzung Konflikte über die Gewichtung der Ziele entstehen (vgl. Geden 2012: 24). 
Die EU hat sich auf rechtsverbindliche energie- und klimapolitische Ziele geeinigt. Bis zum Jahr 2020 sollen die Treibhausgasemissionen um $20 \%$ gegenüber dem Basisjahr 1990 reduziert werden - mit der bereits erwähnten Option der Erhöhung auf $30 \%$ in Abhängigkeit von den internationalen Verhandlungen. Weiterhin soll der Anteil der erneuerbaren Energien auf $20 \%$ ausgebaut werden. Darüber hinaus sollen $20 \%$ des Energieverbrauchs eingespart werden - letzteres stellt allerdings nur ein rechtlich unverbindliches Ziel dar (vgl. Geden 2012: 26). Die Zielvorgaben sollen durch die Ausweitung des Emissionsrechtehandels, die Förderung erneuerbarer Energien und die Entwicklung und Anwendung von CCS-Technologien erreicht werden (vgl. im Internet: ec.europa.eu/clima/policies/package/ index_en.htm, letzter Zugriff am 02.12.2014).

Allerdings ist die Energieinfrastruktur der EU von fossilen Brennstoffen abhängig und der Energieverbrauch steigt momentan weiter an. Die EU-Länder verbrauchen - im Verhältnis zu ihrem Anteil an der Weltbevölkerung - überproportional viel Öl, Gas und Kohle (vgl. Claes/Frisvold 2009: 211f). Dabei liegt ihre Importabhängigkeit von Öl bei über $80 \%$ und von Gas fast bei $60 \%$. Um sich nicht noch abhängiger von Importen und den Ölpreisschwankungen zu machen, kam es in den letzten Jahren wieder zu einem wachsenden Interesse an der Ausweitung der Kohleförderung (vgl. Claes/Frisvold 2009: 215f). Allerdings würde die verstärkte Kohleverstromung, in Kombination mit dem steigenden Energieverbrauch, die Reduktionsziele der EU in Frage stellen.

\section{CCS-Technologien in der EU}

Angesichts dieser Ausgangslage setzt die EU große Hoffnungen in CCS-Technologien. Dabei steht die Anwendung von CCS bei Kohlekraftwerken im Vordergrund. So gehen verschiedene Akteur_innen davon aus, dass CCS die Bedeutung der Kohleverstromung drastisch ändern könnte. Kohle müsse dann nicht länger als klimaschädlichster Energieträger angesehen werden, sondern könnte in der EU womöglich als ergiebigste, verlässlichste und günstigste ${ }^{63}$ Energiequelle gelten (vgl. Claes/ Frisvold 2009: 211). Insgesamt, so diagnostizieren Langhelle und Meadowcraft, erfüllen CCS-Technologien für die EU verschiedene politische Funktionen. In erster

$63 \mathrm{Da}$ CCS-Technologien momentan sehr teuer sind, müsste es gewaltige Innovationssprünge und einen hohen Preis für eingesparte $\mathrm{CO}_{2}$-Äquivalente geben, bis die Kohleverstromung mit CCS tatsächlich günstiger als andere Formen der Energiegewinnung ist. Generell sind derartige Prognosen sehr unsicher und in Bezug auf CCS-Technologien lagen den Zukunftsszenarien bislang tendenziell sehr optimistische Annahmen zugrunde, die in jeweils späteren Studien revidiert wurden (vgl. Hansson 2012; Hansson/ Bryngelsson 2009; Shackley/ Evar 2012: 159f). 
Linie stellen sie eine Klimaschutzstrategie dar. Darüber hinaus verspricht sich die EU von CCS eine Erhöhung der Energieversorgungssicherheit und - in Verbindung mit der Anwendung bei Kohlekraftwerken - eine Minderung der durch die Abhängigkeit von Erdgas- und Erdölimporten bedingten externen Verwundbarkeit der EU (vgl. Langhelle/Meadowcraft 2009: 257).

Dass die EU den CCS-Technologien eine große Relevanz beimisst, schlägt sich in starken Anreizen für die Entwicklung von CCS nieder. Die erste Forschungsinitiative geht bis ins Jahr 1990 zurück. Seitdem gab es von Seiten der EU immer wieder Förderprogramme zu den verschiedenen technischen Elementen der CCSTechnologien sowie zu Fragen der öffentlichen Akzeptanz (vgl. Claes/Frisvold 2009: 222f). Auf der politischen Ebene spielte CCS ab 2005, als es zum ersten Mal in einem Weißbuch ${ }^{64}$ auftauchte, eine zunehmend wichtigere Rolle. Im Januar 2006 stellte Russland für wenige Tage die Gaslieferungen an die Ukraine ein, was auch zu einem Rückgang der Lieferungen an verschiedene EU-Länder führte. Seitdem wird in der EU der Energiesicherheit noch einmal mehr Bedeutung beigemessen. Kurz darauf, im März 2006, bezeichnete die EU-Kommission in einem Grünpapier $^{65} \mathrm{zu}$ Energiefragen CCS als ein Klimaschutzinstrument, das zur Sicherheit der zukünftigen Energieversorgung beitrage. Im selben Jahr wurde die CCSfördernde Politik von den Regierungschefs der Mitgliedsländer forciert, die CCSTechnologien für notwendig halten, um die selbstgesteckten Klimaziele erreichen zu können. 2009 wurden schließlich auf EU-Ebene rechtliche Rahmenbedingungen zur geologischen Speicherung von $\mathrm{CO}_{2}$ geschaffen. Die Richtlinie 2009/31 zur geologischen Speicherung von Kohlendioxid regelt die Auswahl, das Genehmigungsverfahren und den Betrieb von $\mathrm{CO}_{2}$-Speichern. Durch die Verabschiedung der Richtlinie wird CCS in den EU-Emissionsrechtehandel integriert, d. h. für verpresstes $\mathrm{CO}_{2}$ müssen Kraftwerksbetreiber keine Emissionsberechtigungen erwerben. Darüber hinaus hat die EU Finanzierungssysteme aufgelegt, um die geplanten zwölf Demonstrationsprojekte mit bis zu zwölf Milliarden Euro fördern zu können. Insgesamt kann festgehalten werden, dass die EU viele Maßnahmen ergriffen hat, um die Entwicklung von CCS-Technologien zu unterstützen (vgl. Claes/Frisvold 2009: $211 \mathrm{ff}$; de Coninck 2008: 929; Langhelle/Meadowcraft 2009: 244).

64 Die von der EU-Kommission veröffentlichten Weißbücher gelten als Vorschläge für ein gemeinschaftliches Vorgehen in einem bestimmten Politikbereich.

65 Die Grünbücher der EU-Kommission stellen Diskussionspapiere zu bestimmten Themen dar. Sie sollen öffentliche und wissenschaftliche Diskussionen initiieren. Als nächster Schritt kann ein Weißbuch folgen, in dem konkrete Ziele, Vorhaben und Instrumente vorgeschlagen werden. 
Auch wenn letztlich ohne die Regierungen der einzelnen Mitgliedsländer, deren Regierungschefs im Europäischen Rat und deren Minister_innen im Rat der Europäischen Union sitzen, keine Entscheidungen zustande kämen, stellt die EU-Kommission die treibende Kraft in Bezug auf die CCS-Politik der EU dar. CCS-Technologien bieten für sie die Lösung des Dilemmas, einerseits in Zukunft mehr Energie bereitstellen und andererseits weniger Treibhausgase emittieren zu wollen. Schließlich geht die EU-Kommission davon aus, dass fossile Brennstoffe einen großen Anteil am europäischen Energiemix behalten werden, da alle Energiequellen nötig seien, um den steigenden Energiebedarf decken zu können. Auf dieser Basis rechnet sie damit, dass CCS-Technologien die Kosten zur Erreichung der Reduktionsziele um $40 \%$ senken würden. Weiterhin ist das Kriterium der Wettbewerbsfähigkeit für die EU-Kommission entscheidend. So hat sie vor allem den steigenden Energiebedarf und die Kohlevorkommen der sogenannten Schwellenländer im Blick, wenn sie darauf setzt, dass europäische Technologieanbieter eines Tages CCSTechnologien in den Rest der Welt exportieren könnten (vgl. Claes/Frisvold 2009: 221f).

\section{Die Position der EU in den CCS-Verhandlungen}

In den UN-Klimaverhandlungen hat die EU die Aufnahme von CCS in den CDM prinzipiell befürwortet. Dabei äußerte sie sich aber in Bezug auf die zu klärenden technischen und rechtlichen Probleme vorsichtiger als andere Akteur_innen, die ohne Vorbehalte die Aufnahme unterstützten. Dennoch ließ die EU keine Zweifel daran, dass sie letztlich mit einer Aufnahme von CCS in den CDM rechnete (vgl. de Coninck 2008: 933; Vormedal 2008: 58). Aufgrund ihrer moderaten, aber bestimmten Pro-CCS-Position war die EU vor den entscheidenden Abstimmungen in Cancún in der Lage, vormals kritische Länder (v. a. die AOSIS-Staaten und die sogenannten Least Developed Countries) zu überzeugen, sich nicht weiter gegen die Aufnahme von CCS-Technologien in den CDM zu stellen. ${ }^{66}$ Dabei scheint die EU im Verlauf der Verhandlungen eindeutiger Position bezogen zu haben. So berichtete Treber von den Verhandlungen in Kopenhagen: „Auffallend war, dass Schweden für die EU sich ohne Wenn und Aber (also ohne einschränkende Kriterien) für CCS im CDM aussprach.“ (Treber o. J.)

66 Diese Einschätzung erfolgte in einem Interview, das ich am 16.05.2013 mit Heleen de Coninck geführt habe. 


\section{Argumentationslinie der EU in den Stellungnahmen}

Die EU reichte vier schriftliche Stellungnahmen ein: 2006, 2007, 2008 und 2010. Die Positionierungen sind mit zwischen vier und zwölf Seiten recht ausführlich. Dennoch lassen sich in ihnen nur wenige politische Argumente finden. Stattdessen werden noch zu klärende oder zu beachtende Aspekte aufgelistet sowie Erfahrungen mit verschiedenen Elementen der CCS-Technologien angeführt. Dies trifft besonders auf die erste Stellungnahme zu, in der Anforderungen an CCS-Projekte und Themen bzw. offene Fragen für den anstehenden SBSTA-Workshop zu CCS benannt werden (vgl. UNFCCC 2006). Dennoch gilt bereits in dieser ersten Stellungnahme die Aufnahme von CCS in den CDM als realistische Option - sobald letzte Unklarheiten ausgeräumt seien:

„Provided that appropriate procedures can be elaborated to address those outstanding issues, the EU believes that project activities involving carbon capture and geological storage could be considered under the CDM." (UNFCCC 2006: 10)

Diese Schlussfolgerung findet sich sinngemäß in allen Stellungnahmen der EU (vgl. UNFCCC 2007b: 27; UNFCCC 2008: 26; UNFCCC 2010b: 39). Trotz der zurückhaltenden Positionierung ist auch in den schriftlichen Stellungnahmen erkennbar, dass die EU letztlich die CCS-Technologien für förderungswürdig hält. Schließlich wird in der Argumentation implizit davon ausgegangen, dass es zur Aufnahme in den CDM kommen werde. Die Pro-CCS-Position der EU wird auch durch ihren Vorschlag einer CCS-CDM-Pilotphase deutlich. Von dieser Testphase verspricht sich die EU die Generierung von Wissen und Erfahrung, um die Bedenken, die von einigen Ländern ausgedrückt wurden, ausräumen zu können (vgl. UNFCCC 2008: 22f). Der Vorschlag einer solchen Pilotphase spricht dafür, dass sich die Zurückhaltung in den Stellungnahmen lediglich auf die Frage der richtigen Umsetzung bezieht und nicht auf die Frage, ob CCS-Technologien prinzipiell in den CDM aufgenommen werden sollten. In naher Zukunft kann wahrscheinlich in jedem Fall nur eine geringe Anzahl an CCS-Projekten umgesetzt werden - da ist es aus der Perspektive der EU unerheblich, ob diese im Rahmen des CDM oder im Rahmen einer Testphase mit entsprechenden Beschränkungen durchgeführt werden. Inwieweit die EU tatsächlich davon ausging, dass durch eine Pilotphase Befürchtungen ausgeräumt werden könnten, ist unklar. Schließlich lassen sich beispielsweise Bedenken, die sich auf die Sicherheit und die Haftung für die langfristige Speicherung beziehen, in einer Pilotphase mit begrenzter Zeitdauer ohnehin nicht beseitigen. Eine Pilotphase würde bereits den ersten Schritt zur weltweiten Verbreitung von CCS-Technologien darstellen - vorausgesetzt es würden tatsächlich CCS-Projekte 
umgesetzt werden. Dies ist zumindest die Hoffnung, welche die EU mit ihrem Vorschlag verknüpft:

„In our view, this could offer a way to build practical capacity and close knowledge gaps while contributing to the worldwide demonstration and diffusion of this potentially important mitigation technology.“ (UNFCCC 2008: 23)

Im Folgenden fasse ich nun die Argumentationslinie der EU zusammen. Ihren Kern bildet das Ziel der Stabilisierung der Treibhausgaskonzentration in der Atmosphäre. Dabei verweist die EU auch auf das Zwei-Grad-Ziel (vgl. UNFCCC 2007b: 18: UNFCCC 2008: 22), an dem sich auch die EU-Energiepolitik orientiert (vgl. Geden 2012: 25). Jede der vier Stellungnahmen beginnt mit der Feststellung, dass die CCS-Technologien zu diesem Ziel beitragen können (vgl. Enthymeme EU 1-1, EU 1-2, EU 2-1, EU 2-4, EU 3-1, EU 4-1; UNFCCC 2006: 10; UNFCCC 2007b: 18; UNFCCC 2008: 22; UNFCCC 2010b: 32). Unter Bezugnahme auf die IEA zählt die EU CCS-Technologien - nach Energieeffizienz und erneuerbaren Energien - zu den drei wichtigsten Optionen, um die globalen Treibhausgasemissionen reduzieren zu können. Insgesamt stellt in den Statements der EU die Stabilisierung der Treibhausgaskonzentration in der Atmosphäre das absolut übergeordnete Ziel der Klimapolitik dar, welches durch ein Portfolio technologischer Lösungen erreicht werden soll. Andere Aspekte der Klimapolitik bzw. der Klimaschutztechnologien spielen eine sehr untergeordnete Rolle.

Insofern geht die EU auch kaum auf die besondere Zielstellung des CDM, nämlich zu einer nachhaltigen Entwicklung in den Nicht-Annex-B-Staaten beizutragen, ein. In drei Stellungnahmen wird lediglich mit einem Satz erwähnt, dass CCSProjekte zu allen Zielen des CDM beitragen sollten, inklusive der nachhaltigen Entwicklung (vgl. UNFCCC 2006: 10; UNFCCC 2007b: 20; UNFCCC 2010b: 31).

Die EU vertritt die Position, dass wichtige Klimaschutztechnologien - und das meint solche mit großem Potenzial zur Verminderung von Treibhausgasemissionen - weltweit eingesetzt werden sollten (vgl. Enthymem EU 3-5; UNFCCC 2008: 23). Mit Verweis auf die Prognose des Stern Reports, dass der Anteil fossiler Brennstoffe an der Deckung des Primärenergiebedarfs bis zur Mitte des Jahrhunderts dominant bleiben werde, schätzt die EU das Klimaschutzpotenzial von CCS-Technologien hoch ein (vgl. Enthymem EU 2-2; UNFCCC 2007b: 18). Die mit den fossilen Brennstoffen verknüpften Emissionen können ihrer Meinung nach durch CCSTechnologien vermindert werden. Dabei legt sie einen Fokus auf die Notwendigkeit der Einsparung von Treibhausgasemissionen bei Kohlekraftwerken. Wenn die steigenden $\mathrm{CO}_{2}$-Emissionen der fossilen Brennstoffe verhindert werden könnten, hätte das aus Sicht der EU auch den Vorteil, dass fossile Brennstoffe weiterhin eine sichere und zuverlässige Energieversorgung garantieren könnten (vgl. Enthymem 
EU 2-3; UNFCCC 2007b: 18). Bei diesem Argument spielt sicherlich die strategische Bedeutung der Kohle für die EU, die im Abschnitt zu den Aktivitäten der EU im Energie- und Klimabereich behandelt wurde, eine Rolle.

Insgesamt spricht sich die EU dafür aus, dass CCS-Technologien dort angewendet werden, wo fossile Kraftwerke bzw. insbesondere Kohlekraftwerke existieren oder entstehen. Da die EU von einem starken Anstieg fossiler Kraftwerke in den Nicht-Annex-B-Staaten ausgeht, plädiert sie dafür, dass CCS-Technologien auch in diesen Ländern in Demonstrationsprojekten entwickelt und angewendet werden (vgl. Enthymeme EU 2-7, EU 3-2, EU 3-3, EU 4-2, EU 4-6; UNFCCC 2007b: 20; UNFCCC 2008: 22; UNFCCC 2010b: 32, 40).

Für die Demonstration, Verbreitung und Anwendung von CCS-Technologien bedürfe es allerdings verschiedener Unterstützungsmechanismen. In dem Zusammenhang sieht die EU in der Aufnahme von CCS in den CDM eine adäquate Möglichkeit, den Technologietransfer zu unterstützen und eine geeignete Anschubfinanzierung, die insbesondere für den Einsatz in Nicht-Annex-B-Staaten entscheidend sei, bereit zu stellen (vgl. Enthymeme EU 3-4, EU 4-3; UNFCCC 2008: 23; UNFCCC 2010b: 32).

Als ersten Schritt schlägt die EU eine Pilotphase vor. In einer solchen Testphase könnte eine begrenzte Anzahl von Demonstrationsprojekten in den Nicht-Annex-BStaaten installiert und somit die Verbreitung der CCS-Technologien unterstützt werden. Dies würde die CCS-Kompetenzen in verschiedenen Ländern stärken und demzufolge auch eine präzisere Einschätzung des Klimaschutz-Potenzials von CCS ermöglichen. Darüber hinaus verspricht sich die EU von einer Pilotphase, dass man durch den erweiterten Erfahrungsschatz und Wissensstand die Befürchtungen der Länder ausräumen könne, die einer Aufnahme in den CDM skeptisch gegenüber stehen (vgl. Enthymeme EU 3-6, EU 3-7, EU 3-8; UNFCCC 2008: 23, 25f).

Auf folgende Bedenken bezüglich der Aufnahme von CCS in den CDM geht die EU in ihren Stellungnahmen explizit ein: Erfüllen EOR- und EGR-Projekte das Kriterium der Zusätzlichkeit? Ist die Endlagerung von $\mathrm{CO}_{2}$ in geologischen Formationen sicher? Könnte die Förderung von CCS-Technologien den Ausbau der erneuerbaren Energien oder die Anstrengungen zur Erhöhung der Energieeffizienz bremsen? Was die EOR- und EGR-Projekte betrifft, so konstatiert die EU, dass diese Projekte möglicherweise nicht der Anreize des CDM bedürften und somit möglicherweise nicht das Kriterium der Zusätzlichkeit erfüllen würden:

„The only market technology for geological storage listed by the IPCC in its Special Report on CCS is enhanced oil recovery (EOR)/enhanced gas recovery (EGR), and this type of project activity may not depend on CDM incentives and/or may not be additional.“ (UNFCCC 2010b: 37) 
Auch wenn das an dieser Stelle implizit bleibt, spricht der Kontext dafür, dass hier auf das CDM-Kriterium der Zusätzlichkeit verwiesen wird (zum Kriterium der Zusätzlichkeit vgl. Kapitel 5.1.2). Insofern wirft die EU die Frage auf, ob EOR- und EGR-Projekte von der Aufnahme des CCS in den CDM ausgeschlossen sein sollten, weil nicht garantiert werden könne, dass sie ohne die finanzielle Unterstützung im Rahmen des CDM nicht umgesetzt werden würden (vgl. Enthymem EU 4-4; UNFCCC 2010b: 37). Somit greift die EU ein ähnliches Argument wie die brasilianische Regierung auf, die sich gegen die Aufnahme von EOR-Projekten ausspricht, weil diese Anreize für die Steigerung der Produktion fossiler Brennstoffe schaffen und damit der zentralen Idee des CDM widersprechen würden (vgl. UNFCCC 2008: 5ff). Möglicherweise strebt die EU diesbezüglich einen Kompromiss an, der ihr entgegenkommt, da sie auf die Anwendung von CCS-Technologien bei Kohlekraftwerken setzt. Auf das Argument der brasilianischen Regierung, dass die anderen CCS-Projekte, die nicht auf dem Prinzip des EOR basieren, noch unreife Varianten seien und deshalb nicht zum CDM zugelassen werden dürften (vgl. UNFCCC 2008: 5), geht die EU wiederum nicht ein. Sie erwähnt zwar, dass EOR und EGR vom IPCC als einzige reife Varianten der geologischen Speicherung kategorisiert werden, zieht daraus aber keine Schlussfolgerungen - vermutlich weil damit die Förderung der von ihr angestrebten Anwendung von CCS-Technologien bei Kohlekraftwerken in Frage gestellt werden würde.

In Bezug auf die Frage der Sicherheit der geologischen Speicherung von $\mathrm{CO}_{2}$ verweist die EU auf den Sonderbericht des IPCC zu CCS. Dabei führt sie lange direkte Zitate des IPCC an, in denen aus bisher gesammelten Erfahrungen mit CCSDemonstrationsprojekten, EOR-Projekten und der unterirdischen Lagerung von Sauergas geschlossen wird, dass mit CCS-Technologien verpresstes $\mathrm{CO}_{2}$ sicher in adäquat ausgewählten geologischen Formationen verbleibe (vgl. Enthymeme EU 25, EU 2-6; UNFCCC 2007b: 19, 21).

Mögliche Befürchtungen, dass sich die Förderung der CCS-Technologien negativ auf den Ausbau der erneuerbaren Energien oder auf die Anstrengungen zur Erhöhungen der Energieeffizienz auswirken könne, hält die EU für unbegründet. Für sie stellen CCS-Technologien kein Substitut für Energieeffizienz oder erneuerbare Energien dar, sondern ermöglichen eine zusätzliche Reduktion der Treibhausgasemissionen in der Phase des Übergangs zu einer kohlenstoffarmen Wirtschaft. Damit erhält CCS die Funktion einer Brückentechnologie (vgl. Enthymem EU 4-5; UNFCCC 2010b: 40). 


\subsubsection{IETAs Positionierung in der CCS-CDM-Kontroverse}

Um die Positionierung der IETA in der CCS-CDM-Kontroverse adäquat einschätzen zu können gehe ich im Folgenden zunächst allgemein auf die Bedeutung von BINGOs in der CCS-CDM-Kontroverse ein. Anschließend stelle ich IETAs Rolle im Klimaregime dar. Darauf folgt eine kurze Einordnung der Position IETAs in den Verhandlungen. Abschließend zeichne ich die Argumentationslinie der schriftlichen Stellungnahmen nach.

\section{BINGOs in der CCS-CDM-Kontroverse}

Viele einflussreiche BINGOs hatten ein großes Interesse an der Aufnahme von CCS in den CDM (für den gesamten Absatz vgl. de Coninck 2008: 930ff; Vormedal 2008: 52). Fossile Energieunternehmen verbinden mit CCS-Technologien die Erwartung, ihr Kerngeschäft mit den Vorgaben und Reduktionszielen eines Klimaschutzregimes in Einklang bringen zu können. Sie plädierten deshalb für CCSCDM-Projekte, weil sie sich davon Anreize für Investitionen in die Entwicklung und Kommerzialisierung ihrer Technologien versprachen. In ihrer Argumentationskette gehen sie davon aus, dass die Anwendung von CCS-Technologien im Industriemaßstab kaum negative Auswirkungen habe, die Speicherung von $\mathrm{CO}_{2}$ sicher sei und CCS-CDM-Projekte die ökologische Integrität des CDM nicht gefährden würden.

Weiterhin haben sich Unternehmen und Verbände, die an den Umsätzen des Kohlenstoffmarktes verdienen, für die Aufnahme von CCS in den CDM ausgesprochen (für den gesamten Absatz vgl. de Coninck 2008: 932). CCS-CDMProjekte werden voraussichtlich große Mengen CERs generieren. Davon versprechen sich Akteur_innen aus dem Finanzsektor oder Akkreditierungsunternehmen, die für die Zertifizierung von CDM-Projekten zuständig sind, zusätzliche Einnahmen. Nur wenige Handelsgesellschaften sprachen sich gegen CCS-CDM-Projekte aus, weil sie sich auf spezifische Projekttypen (beispielsweise erneuerbare Energien) fokussieren oder weil sie allgemein auf die ökologische Integrität des CDM als Grundlage ihres Geschäftsmodells - bedacht sind.

Insbesondere zu Beginn der Auseinandersetzungen um die Aufnahme von CCS in den CDM traten die BINGOs in Erscheinung (für den gesamten Absatz vgl. Vormedal 2008: 53f). Zu einem Zeitpunkt, an dem noch sehr wenige Akteur_innen das Thema verfolgten, arbeiteten sie auf verschiedenen Ebenen daran, CCS auf die Tagesordnung zu setzen und Delegierte von den Vorzügen der CCS-Technologien zu überzeugen. Im Februar 2006 schrieben die IETA und die IPIECA einen Brief an das UNFCCC-Sekretariat. Weiterhin organisierten sie im gleichen Jahr zu Beginn der COP 12 in Nairobi zwei side-events zu CCS-Technologien. Die IETA meldete 
sich auch in den Plenarsitzungen zu Wort. Ene Gruppe Expert_innen aus unterschiedlichen BINGOs verfasste ein Positionspapier, das auf der Konferenz breit gestreut wurde. Darin schlugen sie die Gründung einer Working Group vor, um die CCS-Kompetenzen zu stärken, die Entwicklung von CCS-Technologien zu fördern und ihre Aufnahme in den CDM zu ermöglichen. Darüber hinaus betrieben die IETA und die IPIECA klassische Lobbyarbeit und versuchten, in direkten Gesprächen mit den Delegierten aus der EU und Norwegen sowie mit lateinamerikanischen und einigen afrikanischen Delegationen deren Positionen zu beeinflussen.

Nach Einschätzung von Vormedal war die Einflussnahme auf afrikanische Delegierte besonders erfolgreich (für den gesamten Absatz vgl. Vormedal 2008: 55ff). Im September 2007 wurden in Botswana und Senegal Workshops durchgeführt. Die Workshops mit dem Titel "CCS and CDM: A Capacity Building Effort in Africa" dienten offiziell dazu, eine informierte Entscheidung über CCS-Technologien zu ermöglichen. Die Ausrichtung der Workshops zielte dabei eindeutig darauf ab, Delegierte davon zu überzeugen, dass sie die Aufnahme von CCS in den CDM unterstützen. Organisiert wurden die Workshops von Shell, Statoil ${ }^{67}$ und dem Energy Research Centre of the Netherlands (ECN). Diese Workshops scheinen für die Änderung der Positionen afrikanischer Delegationen, die sich bei der COP 13 in Bali für die Aufnahme von CCS in den CDM aussprachen, maßgeblich gewesen zu sein. Die 2007 gegründete Initiative CCS Africa - A CCS Capacity Building Effort in Africa führte 2010 drei weitere Workshops durch, die in Botswana, Mosambik und Namibia stattfanden (vgl. im Internet: www.ccs-africa.org, letzter Zugriff am 02.12.2014).

Gerade bei der fachlich komplexen Debatte um CCS-Technologien übten die BINGOs eine spezifische Form der Macht aus, die Vormedal als technological power bezeichnet (für den gesamten Absatz vgl. Vormedal 2008: 61). Diese technologische Macht der Privatwirtschaft basiert auf ihrer Verfügung über Energietechnologien, technologischem Wissen und Expertise zur Anwendung. Innovationsprozesse der Industrie haben einen großen Einfluss auf die Entwicklung neuer Klimaschutztechnologien und regulativer Instrumente. So werden CCS-Technologien zunehmend als wichtige Option mit großem Potenzial zur Reduktionen von Treibhausgasemissionen betrachtet. Ihre Expertise verschaffte beispielsweise der IETA und der IPIECA privilegierte Positionen gegenüber den Umwelt-NGOs, die sich erst nach und nach in die Thematik einarbeiten mussten. So konnten BINGOs bereits in einem frühen Stadium ihr Wissen und - damit verknüpft - ihre Sichtweise in die Verhandlungen einbringen. Als technologische Innovator_innen wird ihnen spezifische Expertise und Urteilungsvermögen über technische Fragen zugesprochen,

67 Für einen Überblick über Statoils CCS-Engagement vgl. die Kapitel 5.2.1 und 5.4.3.1. 
was sie zu einer als legitim erachteten Quelle für politikrelevantes Wissen macht. In dieser Funktion führten sie Workshops in Kooperation mit hoch angesehenen Forschungsinstitutionen und internationalen Organisation wie der IEA, dem IPCC und dem UN-Umweltprogramm durch. Dabei konnten sie ihre Informationen streuen und Lobbyarbeit betreiben. Diese Formen der technologischen Macht ermöglichen es den BINGOs, eine entscheidende Rolle in der Aushandlung von umweltpolitischen Zielen und Instrumenten zu spielen. Diese besondere Bedeutung des Branchenwissens verdeutlicht Vormedal mit dem Verweis auf eine Aussage vom CCS-Verhandlungsführer der EU:

„While we always attempt to consider the views of all the major observer groups, in the case of CCS it was industry that had practical experience and expertise to share." (Matt Allen, zitiert in Vormedal 2008: 59; Hervorhebung im Original)

\section{IETAs Rolle im UN-Klimaregime}

Die International Emissions Trading Association wurde 1999 gegründet und entwickelte sich zur größten und aktivsten BINGO des UN-Klimaregimes. Unter dem Dach der IETA versammeln sich sehr unterschiedliche Unternehmen, die am KyotoKohlenstoffmarkt beteiligt sind: Finanzmarktakteur_innen, die sich auf den Handel mit Emissionsberechtigungen spezialisiert haben, Agenturen, die für die Akkreditierung von Offset-Projekten zuständig sind oder Unternehmen, die viele Emissionen verursachen und deshalb auf die Zuteilung und/oder den Handel mit Emissionsberechtigungen angewiesen sind (vgl. Vormedal 2008: 40ff). Die IETA plädiert für die Ausweitung des Handelssystems. Dahinter steht das unternehmerische Interesse an der Vergrößerung des Marktvolumens. Die umweltpolitische Begründung dafür lautet, dass Kohlenstoffmärkte zu einer kosteneffizienten Reduktion von Treibhausgasemissionen führen. Da sich die IETA für das wirksame Funktionieren der flexiblen Mechanismen des Kyoto-Protokolls einsetzt, wird sie tendenziell als ,gemäßigt grüne' Organisation eingestuft (vgl. Vormedal 2008: 40ff). Die Haltung zur Verbesserung der Marktmechanismen kennzeichnet aber zugleich die Grenze ihres klimapolitischen Engagements. Die IETA unterstützt keine weitergehenden oder anders gelagerten Klimaschutzmaßnahmen. Wie der Name bereits deutlich macht, ist die Arbeit der IETA mit den marktwirtschaftlichen Instrumenten des Kyoto-Protokolls verknüpft. Insofern steht die IETA für eine ungebrochene Fortführung des internationalen Klimaregimes in seiner jetzigen Form und damit für die Fixierung der neoliberalen Ausrichtung des ökomodernen Projekts (zur Neoliberalisierung des ökomodernen Diskurses vgl. Kapitel 3.2.5). 


\section{IETAs Position in den CCS-Verhandlungen}

Bei den Verhandlungen über die Aufnahme von CCS in den CDM gehörte die IETA zu den aktivsten BINGOs. Sie sprach sich eindeutig für die Aufnahme aus, argumentierte dabei aber für klare Regelungen zur Überwachung der CCS-Projekte. Diese Haltung spiegelt die Interessen der Mitglieder der IETA wider, die von einer Ausweitung des Kohlenstoffmarktes profitieren und denen gleichzeitig die ökologische Integrität der CDM-Projekte als Legitimationsquelle wichtig ist. Die von der IETA ebenfalls vertretenen Zertifizierungsunternehmen (designated operational entities, DOEs) haben zusätzlich ein spezifisches Eigeninteresse. Sie profitieren von umfangreichen Verfahrensvorschriften, die ihnen lukrative Aufträge sichern (vgl. de Coninck 2008: 932).

Unter den Mitgliedern der IETA befinden sich einige Unternehmen, die an der Entwicklung von CCS-Technologien arbeiten. Insofern steht der IETA auch spezifisches Wissen und Expertise zur Verfügung, auf das sie bei ihren Lobby-Aktivitäten zurückgreifen kann (vgl. Vormedal 2008: 59). Folgerichtig positionierte sich die IETA auch in Detailfragen, wie die ausführlichen schriftlichen Stellungnahmen zeigen. Insgesamt hat sich die IETA stark in die CCS-Verhandlungen eingebracht. Gemeinsam mit der IPIECA war sie bereits vor und während der COP 12 aktiv (2006) - als Verfasserin des Briefes an das UNFCCC-Sekretariat, als Organisatorin zweier side-events, als Teilnehmerin an den Plenarsitzungen und als Miturheberin des bereits erwähnten Positionspapiers. Seitdem organisierte die IETA regelmäßig weitere side-events, meldete sich in den Plenarsitzungen zu Wort, traf sich mit diversen Delegationen und beteiligte sich auch über die CMPs hinaus an verschiedenen Aktivitäten und Initiativen (vgl. Vormedal 2008: 53f; im Internet: www.ieta. org/past-events, letzter Zugriff am 02.12.2014).

Die IETA gehört mit Greenpeace und dem WCI zu den Beobachterorganisationen, die in dem untersuchten Zeitraum zwei schriftliche Stellungnahmen eingereicht haben. Darüber hinaus hatte die IETA bereits eine Stellungnahme eingereicht, bevor die Beobachterorganisationen explizit dazu aufgerufen wurden (vgl. im Internet: www.unfccc.int/resource/docs/2006/smsn/ngo/004.pdf, letzter Zugriff am 02.12.2014). Auch nachdem die grundsätzliche Entscheidung für die Aufnahme von CCS in den CDM gefallen war, brachte sich die IETA weiterhin ein und bezog Stellung in Bezug auf die Fragen der Ausgestaltung der Modalitäten (vgl. im Internet: www.unfccc.int/resource/docs/2012/smsn/ngo/156.pdf, letzter Zugriff am 02.12.2014). Die IETA ist also auch in der CCS-CDM-Kontroverse eine besonders aktive BINGO gewesen. Dabei nahm sie einen Gegenpart zu Greenpeace ein. So wie SustainUS auf die Stellungnahme von Greenpeace verwies, nahm die Carbon Capture and Storage Association (CCSA) auf die IETA Bezug. Die CCSA betont in 
ihrer eigenen Stellungnahme, dass sie IETAs Position unterstützen und bekräftigen möchte (vgl. CCSA 2008). Diese Anlehnung an IETAs Position spricht meiner Meinung nach für die besondere Bedeutung der IETA im Kreis der CCSbefürwortenden Koalition in den UN-Klimaverhandlungen.

\section{IETAs Argumentationslinie in den Stellungnahmen}

Bereits die Stellungnahme aus dem Jahr 2007, in der die IETA auf die verschiedenen offenen Fragen bezüglich der Aufnahme von CCS in den CDM eingeht, ist mit 14 Seiten ziemlich umfangreich. Die Stellungnahme aus dem Jahr 2008 ist mit 24 Seiten noch einmal ausführlicher. In beiden Stellungnahmen spricht sich die IETA klar für die Aufnahme von CCS-Technologien in den CDM aus. So heißt es beispielsweise in der Zusammenfassung der Stellungnahme aus dem Jahr 2007:

„CCS should be adopted into the CDM framework as soon as possible for the benefit of rapid deployment of it as a promising mitigation method and a unique opportunity for willing and qualified Non-Annex I countries to participate as early movers.“ (IETA 2007: 13)

Die IETA argumentiert in den Stellungnahmen in einem Dreischritt. Dabei bildet die Stabilisierung der Treibhausgaskonzentration in der Atmosphäre als Ziel der Klimarahmenkonvention den Ausgangspunkt. Um dieses Ziel zu erreichen, sollen alle zur Verfügung stehenden Klimaschutztechnologien bis zu ihrem vollen Potenzial ausgeschöpft werden. IETAs Hauptargument ist, dass CCS-Technologien ein wichtiger Teil dieses Portfolios darstellen würden. Der zweite Argumentationsschritt besteht darin, bereits geäußerte oder antizipierte Befürchtungen und Argumente, die gegen die Aufnahme von CCS in den CDM sprechen, zu entkräften. In einem dritten Argumentationsschritt betont die IETA die Dringlichkeit einer möglichst schnellen Anwendung von CCS-Technologien und die dafür notwendige Aufnahme in den CDM.

Die Stellungnahmen der IETA zeichnen sich durch eine starke Bezugnahme auf die Dokumente des UN-Klimaregimes aus. Insofern wird die Stabilisierung der Treibhausgaskonzentration in der Atmosphäre als das Ziel der internationalen Klimapolitik an mehreren Stellen wiederholt, teilweise mit explizitem Verweis auf die Klimarahmenkonvention (vgl. IETA 2007: 7; IETA 2008: 5, 15). Die für die Erreichung des Ziels nötige Reduktion der Treibhausgasemissionen soll durch ein Portfolio technologischer Optionen erreicht werden. Angesichts der Dringlichkeit drängt die IETA darauf, das volle Potenzial aller zur Verfügung stehenden Optionen auszuschöpfen. Dabei plädiert sie dafür, nicht einzelne Technologien prinzipiell zu bevorzugen, sondern in den verschiedenen Ländern jeweils die Technologien anzuwenden, die verfügbar sind und quantitativ den größten Beitrag zur Reduktion der 
Treibhausgasemissionen leisten. Mit diesem Entscheidungskriterium wird von den qualitativen Unterschieden der Technologien abgesehen - ob sie über die Reduktion von Treibhausgasemissionen hinaus ökologisch zukunftsweisend oder vertretbar sind, ob sie im Hinblick auf soziale oder demokratische Aspekte Vor- oder Nachteile aufweisen oder ob sie einen Strukturwandel zur geringeren Abhängigkeit von fossilen Brennstoffen einleiten wird nicht thematisiert (vgl. Enthymem IETA 2-20; IETA 2008: 13f):

„Whereas for some countries, protecting their bio-sequestration capability may be the largest contribution they can make in combating climate change, for other countries with less significant bio-production, it may be their potential to store large volumes of $\mathrm{CO}_{2}$ which offers the most promising option. Our view is that all countries should take the responsibility to allow an enabling framwork to develop which enhances the fullest abatement potential to be realised within the different individual countries, and not to discourage important mitigation options which may not be readily available to themselves.“ (IETA 2008: 13f)

Die IETA postuliert die Neutralität von Technologien und abstrahiert damit von der Wechselwirkung zwischen technischen Artefakten und Sozialstrukturen (vgl. Gill 1998: 233f). Daraus resultiert ihre technokratische Sichtweise, dass sich die Länder passende Technologien aus einem Portfolio an Klimaschutzoptionen auswählen sollen, die möglichst unkompliziert innerhalb der gegebenen Rahmenbedingungen umgesetzt werden können. Für die IETA stellen CCS-Technologien eine wichtige Option innerhalb dieses Portfolios dar (vgl. Enthymeme IETA 1-17, IETA 2-1, IETA 2-2, IETA 2-9, IETA 2-13; IETA 2007: 12f, IETA 2008: 1-3, 5, 13). Diese allgemeine positive Einschätzung untermauert die IETA durch spezifische positiv konnotierte Charakteristika, die sie den CCS-Technologien zuschreibt. Zunächst einmal wird die den CCS-Technologien zugesprochene Fähigkeit hervorgehoben, die angestrebten Emissionsreduktionsziele möglichst kosteneffizient zu erreichen. Hier erscheint das Potenzial von Technologien zur Senkung der betriebswirtschaftlichen Kosten des Klimaschutzes als Hauptkriterium für ihre Bedeutung als Optionen des Portfolios (vgl. Enthymeme IETA 1-9, IETA 1-11, IETA 2-10, IETA 2-22; IETA 2007: 7f; IETA 2008: 3, 13ff). In diesem Zusammenhang wird an manchen Stellen auf die Verankerung des Kriteriums der Kosteneffizienz in der Klimarahmenkonvention (vgl. IETA 2007: 7; IETA 2008: 15) und den flexiblen Mechanismen des Kyoto-Protokolls (vgl. IETA 2007: 6f; IETA 2008: 7, 15) verwiesen.

Ebenfalls mit Bezugnahme auf die Klimarahmenkonvention betont die IETA, dass CCS-Technologien eine nachhaltigen Entwicklung ermöglichen können. Dabei werden die Förderung einer wirtschaftlichen Entwicklung in den Nicht-Annex-BStaaten, die Elektrifizierung ländlicher Gebiete und Armutsbekämpfung genannt. Unter nachhaltiger Entwicklung wird die Bereitstellung von Energie in einer Weise, 
die das Klima nicht beeinträchtigt, verstanden. Im Zuge dieser Argumentation bezeichnet die IETA CCS-Technologien auch als nachhaltige Form der Nutzung fossiler Ressourcen (vgl. Enthymeme IETA 1-9, IETA 1-19, IETA 2-3, IETA 2-21, IETA 2-22; IETA 2007: 7, 12; IETA 2008: 1, 14f).

Weiterhin verweist die IETA vor dem Hintergrund von Prognosen, die davon ausgehen, dass der Anteil fossiler Brennstoffe an der Deckung des steigenden globalen Primärenergiebedarfs dominant bleiben wird, auf das spezifische Klimaschutz-Potenzial der CCS-Technologien. Bei der Nutzung fossiler Brennstoffe könne durch die Kombination mit CCS-Technologien ein Anstieg der Treibhausgasemissionen vermieden werden (vgl. Enthymeme IETA 2-8, 2-16; IETA 2008: 2f, 8).

Als weitere Besonderheit der CCS-Technologien erscheint in der Argumentation der IETA ihre Kompatibilität mit der zentralisierten Energieproduktion. Die zentralisierte Energieproduktion wird zwar nicht explizit als solche benannt, aber die CCS-Projekte werden als ,large in nature“ (IETA 2007: 8) bezeichnet. Daraus wird als Vorteil abgeleitet, dass sie das Potenzial hätten, große Mengen von Treibhausgasemissionen einsparen zu können (vgl. Enthymem IETA 1-13; IETA 2007: 8).

Die IETA führt als Argument für CCS-Technologien an, dass diese die Flexibilität bei der Reduktion der globalen Treibhausgasemissionen erhöhen würden. Worin genau die Flexibilisierung besteht, wird dabei nicht erläutert. Vor dem Hintergrund der Gesamtargumentation liegt aber nahe, dass die IETA in den CCS-Technologien eine wichtige Option sieht, um innerhalb des Status quo der Energieinfrastruktur die notwendige Reduzierung der Treibhausgasemissionen erreichen zu können. Die Flexibilisierung bestünde dann in der Vermehrung der technischen Optionen, die keiner Änderung sozio-ökonomischer Strukturen bedürfen (vgl. Enthymem IETA 112; IETA 2007: 8).

Insgesamt vertritt die IETA die eindeutige Position, dass CCS-Technologien einen wichtigen Bestandteil des Portfolios technologischer Optionen bilden. Ehrgeizige Emissionsreduktionsziele können der IETA zufolge nur mit Hilfe eines großflächigen Einsatzes von CCS-Technologien erreicht werden. Mit Verweis auf die als ehrgeizig bezeichneten Reduktionsziele der EU und einzelner Länder erscheinen der IETA CCS-Technologien als notwendige Ergänzungen des Portfolios technologischer Optionen (vgl. Enthymeme IETA 1-3, IETA 2-17; IETA 2007: 3; IETA 2008: 8). Die Notwendigkeit der Anwendung von CCS-Technologien wird in der Stellungnahme aus dem Jahr 2007 auch mit dem Brückentechnologie-Argument begründet. Konkret ist die Aussage IETAs, dass CCS eine notwendige Brückentechnologie sei, bis die erneuerbaren Energien die nötige Reife und das nötige Quantum erreicht haben, um den globalen Energiebedarf decken zu können (vgl. Enthymem IETA 1-4; IETA 2007: 5f). 
Auf den steigenden globalen Energiebedarf kommt die IETA im Verlauf der Stellungnahme noch einmal zurück. Um diesen decken zu können, hält sie ein Wachstum aller Energiequellen für nötig. Explizit benennt sie dabei CCS-Technologien und erneuerbare Energien (vgl. Enthymem IETA 1-10; IETA 2007: 7). Insbesondere unter Berücksichtigung von ehrgeizigen Reduktionszielen sieht sie keine Konkurrenz zwischen CCS und erneuerbaren Energien um Investitionen und Anreize (vgl. Enthymem IETA 1-5; IETA 2007: 6). Die erneuerbaren Energien hätten den Vorteil, dass sie große Emissionseinsparungen erreichen und einen wichtigen Beitrag zur Energiesicherheit leisten können. Allerdings würde ihr Einsatz aufgrund ihrer fluktuierenden Einspeisung und der Notwendigkeit einer Grundlastenergie begrenzt sein. An diesem Punkt würden CCS-Technologien ins Spiel kommen, die zusätzlich die einzige realistische Möglichkeit darstellen würden, die Prozessemissionen bestimmter Industriezweige anzugehen. Deshalb würden CCS und erneuerbare Energien sich nicht ersetzen, sondern gegenseitig ergänzen (vgl. Enthymem IETA 2-15; IETA 2008: 7). Gleichzeitig führt die IETA die Idee des Wettbewerbs ins Feld, um zu begründen, warum eine partielle Verdrängung der erneuerbaren Energien durch CCS-Technologien im Prinzip nicht negativ zu beurteilen wäre:

„IETA finds that both renewable energies and CCS are necessary to fight the threat imposed by climate change. However, the crucial aspect of the Kyoto mechanisms is that being market based, market participants will choose the most cost effective mitigation strategies. In that sense cheaper mitigation technologies might grow more rapidly at the cost of others. IETA acknowledges the debate that CCS might have a negative impact on employment of renewables, but as a promoter of market based instrument does not see this as a hindrance to introduce CCS into market based mechanisms. The overall goal of the framework being to achieve GHG reductions at lowest possible costs, while facilitating technology transfer and promoting sustainable development will be attained.“ (IETA 2007: 7)

Hier positioniert sich die IETA ganz klar als Verfechterin des Marktprinzips und damit als Anhängerin des Status quo des UN-Klimaregimes. Die Marktorientierung wird als das zentrale Charakteristikum der flexiblen Mechanismen des KyotoProtokolls hervorgehoben. Dementsprechend würden die Marktteilnehmer_innen die kosteneffizientesten Klimaschutzstrategien wählen, weshalb günstigere Technologien schneller und zu Lasten von anderen wachsen (vgl. Enthymeme IETA 1-7, IETA 1-8; IETA 2007: 7). Diese Passage steht im Widerspruch zu den beschwichtigenden Abschnitten, in denen die IETA begründet, warum CCS und erneuerbare Energien nicht im Konkurrenzverhältnis stehen und warum der Ausbau erneuerbarer Energien nicht durch die Aufnahme von CCS in den CDM gebremst werden würde. Die IETA tritt damit den Befürchtungen anderer Akteur_innen, dass die Aufnahme von CCS in den CDM zu geringeren Investitionen in erneuerbare Energien 
führen würde, auf doppelte Weise entgegen. Zum einen begründet sie an mehreren Stellen, warum diese Situation nicht eintreten werde. Zum anderen argumentiert sie, dass eine derartige Verlagerung des Wachstums von erneuerbaren Energien zu CCSTechnologien nicht schädlich wäre, sondern geradezu dem Marktprinzip des KyotoProtokolls entspräche. Damit relativiert die IETA allerdings ihr erstes Argument.

Mit dieser Form der doppelten Entgegnung reagiert die IETA auch auf die Befürchtungen, dass die Aufnahme von CCS in den CDM zur Verdrängung anderer Projekttypen führen könnte. Allerdings führt sie eine zeitliche Abfolge ein, so dass sich die beiden Argumente hier nicht widersprechen. So geht die IETA davon aus, dass CCS-Projekte aufgrund ihrer langen Projektdurchlaufzeiten kurzfristig den CDM-Markt nicht überschwemmen werden. In der ersten Verpflichtungsperiode bis 2012 könnten nur einige wenige CCS-Projekte realisiert werden. Langfristig müssten laut der IETA sowieso stärkere $\mathrm{CO}_{2}$-Reduktionen eingefordert werden und CCSProjekte würden dann dort mit anderen Klimaschutzoptionen konkurrieren wo sie kosteneffizient wären (vgl. Enthymem IETA 2-6; IETA 2008: 1, 6f).

Mit der Thematisierung des Verbrauchs fossiler Brennstoffe geht die IETA auf eine weitere Befürchtung ein, die in der Debatte um die Aufnahme von CCS in den CDM regelmäßig geäußert wurde. In der 2007er Stellungnahme argumentiert sie dabei allein quantitativ. Da durch EOR-Projekte nur geringe Mengen Erdöl zusätzlich gefördert werden würden, hätte das keinen Einfluss auf die Nachfrage an Erdöl und Erdölprodukten (vgl. Enthymem IETA 1-16; IETA 2007: 10). In der Stellungnahme aus dem Jahr 2008 entfaltet die IETA eine komplexere Position. Dort wird die Annahme, dass durch CCS-Projekte (in der Anwendung als EOR, EGR, ECBM) zusätzlich generiertes Öl oder Gas mit erneuerbaren Energien oder Atomkraft konkurriert, in Frage gestellt. Stattdessen geht die IETA davon aus, dass dieses zusätzliche Öl oder Gas Energiequellen mit einem höheren Kohlenstoffgehalt, wie beispielsweise Kohle oder unkonventioneller Ölressourcen, ersetzen würde. Dieses Argument fußt auf der Prognose, dass fossile Brennstoffe auch in Zukunft einen großen Anteil des globalen Energiemixes ausmachen. Ein Verzicht auf CCSTechnologien würde in der Konsequenz laut der IETA zu höheren Treibhausgasemissionen führen (vgl. Enthymem IETA 2-16; IETA 2008: 8).

Auch was die ökologischen und gesundheitlichen Risiken von CCS-Projekten betrifft, teilt sie keine der Sorgen der CCS-kritischen Koalition. Mit Verweis auf Aussagen des IPCC SRCCS und des IEA GHG Programme prognostiziert die IETA, dass mit CCS-Technologien verpresstes $\mathrm{CO}_{2}$ sicher in adäquat ausgewählten geologischen Formationen verbleibt. Als Referenz gelten ihr die Erfahrungen mit in der Natur vorkommenden $\mathrm{CO}_{2}$-Speichern, mit EOR-Projekten und mit der unterirdischen Lagerung von Sauergas. Für den Fall, dass es doch zu einer Leckage 
kommen sollte, vertraut die IETA auf Monitoring-Technologien (vgl. Enthymeme IETA 1-14, IETA 2-19, IETA 2-23; IETA 2007: 8; IETA 2008: 11f, 15). Sie sieht bei der Anwendung von CCS nur geringe lokale Risiken, die man ihrer Meinung nach eingehen sollte, um die globalen Risiken des Klimawandels zu bekämpfen:

„We believe that the risks to human development and the natural environment associated with climate change significantly outweigh those associated with CCS projects, which will be needed along with other mitigation options to achieve the levels of emissions reduction needed to stabilize atmospheric $\mathrm{CO}_{2}$ concentrations this century." (IETA 2008: 15)

Im Zusammenhang mit den Leckage-Risiken steht die Frage nach der langfristigen Haftung für CCS-Projekte. In dem Punkt vertritt die IETA eine ähnliche Position wie die norwegische Regierung. Sie befürwortet den Vorschlag, dass die Zielländer der CDM-Projekte die langfristige Haftung übernehmen. Sie seien die einzigen, die angesichts der langen Zeiträume dafür in Frage kämen. Anders als die brasilianische Regierung geht sie nicht davon aus, dass damit eine übermäßige Belastung der Nicht-Annex-B-Staaten verbunden wäre. Weiterhin plädiert die IETA - wie Norwegen - in Bezug auf die konkreten Umsetzungskriterien für direkte Absprachen zwischen den Zielländern und den Projektteilnehmer_innen. Insofern sieht sie in den Besonderheiten der CCS-Technologien, zu denen in erster Linie die Möglichkeit von Leckagen und die dafür notwendige langfristige Haftung zählen, keinen Hinderungsgrund in Bezug auf die Aufnahme in den CDM. Für die IETA hat oberste Priorität, dass Lösungen gefunden werden, die sowohl für die Projektteilnehmer_innen als auch für den Kohlenstoffmarkt Planungssicherheit gewährleisten. Diese Planungssicherheit sei - so IETAs Position - durch die diskutierten Lösungsvorschläge gesichert (vgl. Enthymeme IETA 1-15, IETA 2-18; IETA 2007: 8ff; IETA 2008: 9).

Insgesamt ist die IETA optimistisch in Bezug auf die weitere Entwicklung der CCS-Technologien. Ihren Optimismus, dass für Fragen, die Unsicherheiten und Risiken der CCS-Technologien betreffen, befriedigende Antworten gefunden werden, begründet sie unter anderem damit, dass viele verschiedene Akteur_innen an der Weiterentwicklung arbeiten. Dabei erwähnt sie die Europäische Union, allgemein die EU-Mitgliedsstaaten sowie Australien, USA, Kanada, Großbritannien, Norwegen, den IPCC, die IEA und die European Technology Platform on Zero Emission Fossil Fuel Power Plants (ZEP). Die IETA zählt in ihrer Stellungnahme viele Programme, Ereignisse und Fortschritte auf. Diesbezüglich führt sie an, dass eine solche Aufzählung einen Einblick gebe, welches Vertrauen die genannten Akteur_innen in die Umsetzbarkeit und schnelle Anwendung von CCS-Projekten haben und mit welcher Intensität sie die CCS-Technologien vorantreiben. Damit würde die Aufzählung die Akzeptanz und Bedeutung von CCS als wichtiger Klimaschutztechnologie deutlich machen (vgl. Enthymeme IETA 1-1, IETA 1-2; IETA 2007: 2ff). 
Neben der Begründung der Notwendigkeit von CCS-Technologien zur Abschwächung des Klimawandels und der Begründung der Machbarkeit einer großflächigen Anwendung von CCS-Technologien zielt IETAs Argumentationslinie auf die Begründung der Erfordernis der Aufnahme von CCS in den CDM. Angesichts der vielversprechenden Potenziale zur Reduzierung von Treibhausgasemissionen hält sie einen schnellen Einsatz von CCS-Technologien für wichtig. Dem stünden aber die hohen Kosten der CCS-Technologien entgegen, die wiederum durch ihre frühe Anwendung gesenkt werden würden. Deshalb sei die Aufnahme von CCSTechnologien in den CDM, insbesondere in einem frühen Stadium ihrer Entwicklung, wichtig. Die IETA geht davon aus, dass der CDM als Katalysator für eine Anschubfinanzierung sorgen und damit einen schnellen und frühen Einsatz von CCSTechnologien unterstützen könne. Erst wenn im Zuge einer ersten Welle von CCSProjekten die Kosten für CCS-Technologien sinken, wäre ein großflächiger, weltweiter Einsatz möglich. Die Aufnahme in den CDM würde finanzielle Anreize für den Einsatz von CCS-Technologien in Nicht-Annex-B-Staaten schaffen. Dies sei aus verschiedenen Gründen relevant. Zum einen hält die IETA den CDM und die JI prinzipiell für wichtig, weil es Länder wie Norwegen gebe, die ihre Emissionsreduktionsziele nicht allein durch Investitionen im eigenen Land erfüllen könnten. Deshalb würden CDM und JI im großen Maßstab gebraucht, wobei ein Gleichgewicht zwischen erneuerbaren Energien und CCS-Technologien angestrebt werden sollte. Zum anderen befänden sich eine große Zahl der kosteneffizientesten Möglichkeiten für frühzeitige CCS-Projekte in den Nicht-Annex-B-Staaten. Um diese Möglichkeiten zu nutzen, wäre der CDM ein passender Finanzierungsmechanismus und gegenwärtig auch der einzige. Darüber hinaus ist die IETA der Auffassung, dass die Aufnahme von CCS in den CDM entscheidend sei, um die Emissionen bei industriellen Prozessen reduzieren zu können (vgl. Enthymeme IETA 1-6, IETA 118, IETA 2-4, IETA 2-5, IETA 2-7, IETA 2-12, IETA 2-14; IETA 2007: 6f, 12f; IETA 2008: 1, 4ff).

„[...] in the short term the CDM can act as a much needed catalyst to help build technical understanding of CCS applications, reduce technology costs and develop the confidence needed for widespread deployment. Critically, the CDM represents the main means available for allowing CCS to become commercially available in those developing countries where $\mathrm{CO}_{2}$ emissions will rise most rapidly in future years. Further, if the decision from the Conference of Parties was to disallow the inclusion of CCS in the CDM, the negative message sent by such a decision could adversely impact the widespread deployment of this important mitigation option. We therefore view CCS inclusion in the CDM as a critical bridging opportunity towards a low-carbon future in which CCS is deployed on a large scale as part of a portfolio of mitigation options." (IETA 2008: 5f) 
Die IETA kommt zu dem Schluss, dass CCS-Technologien angesichts der Dringlichkeit, die globalen Treibhausgasemissionen reduzieren zu müssen, ein unverzichtbares Element im Portfolio der Klimaschutzoptionen darstellen. Für die schnelle Entwicklung und den großflächigen Einsatz von CCS-Technologien wiederum sei die Aufnahme in den CDM eine wichtige Voraussetzung. Langfristig betrachtet die IETA CCS als eine Klimaschutzstrategie neben anderen, aus denen die Akteur_innen - im Rahmen eines funktionierenden Kohlenstoffmarktes - die für sie kosteneffizienteste Lösung wählen werden.

\subsubsection{Greenpeace' Positionierung in der CCS-CDM-Kontroverse}

Zeitgleich mit den BINGOs (wie in 5.4.3.4 beschrieben) intensivierten die UmweltNGOs ihr CCS-Engagement bei der COP 12 in Nairobi (2006). Das Climate Action Network (CAN) brachte sich in die Plenarsitzungen zu CCS ein und traf sich mit ausgewählten Delegationen. Dabei erhielten die Umwelt-NGOs von den AOSISStaaten und einigen Ländern aus Lateinamerika Unterstützung für ihre ablehnende Position gegenüber der Aufnahme von CCS in den CDM. Mit dem Versuch, die Position der EU oder Norwegens zu beeinflussen, scheiterten sie allerdings. Im Newsletter ECO, mit dem die NGOs die UN-Klimaverhandlungen kritisch begleiten, wurde mehrfach gegen die Position der CCS-befürwortenden Koalition in den UN-Klimaverhandlungen Stellung bezogen. Weiterhin ging der fossil-of-the-dayPreis, der während der COPs an die größten Bremser der Verhandlungen verliehen wird, mehrere Male an Delegationen, welche die Aufnahme von CCS in den CDM befürworteten (vgl. Vormedal 2008: 54f). Dennoch haben sich, im Vergleich zu anderen Themengebieten, verhältnismäßig wenige NGOs an der CCS-CDMKontroverse beteiligt. Eine Ausnahme bildete Greenpeace. Im Folgenden gehe ich auf Greenpeace' Rolle im UN-Klimaregime ein. Anschließend stelle ich Greenpeace' allgemeine Position gegenüber CCS-Technologien und speziell Greenpeace' Position in der CCS-CDM-Kontroverse dar, bevor ich zum Schluss die Argumentationslinie in Greenpeace'Stellungnahmen nachzeichne.

\section{Die Rolle Greenpeace' im UN-Klimaregime}

Greenpeace gehört zu den großen weltweit agierenden und ressourcenstärksten umweltpolitischen NGOs. Greenpeace wurde 1971 gegründet und finanziert sich primär über Privatspenden. Eine finanzielle Unterstützung durch staatliche Behörden oder Unternehmen lehnt Greenpeace ab. Für ihre umweltpolitischen Ziele setzt sich Greenpeace mit Lobbyarbeit, Expertise, Öffentlichkeitsarbeit und Protesten ein (vgl. Bedall 2014: 247). Die in den Niederlanden gegründete Stiftung Greenpeace Council fungiert dabei als Zentrale auf internationaler Ebene, darunter agieren 
Regional- und Länderbüros. In der Zentrale werden die Kampagnen geplant und koordiniert (vgl. im Internet: www.greenpeace.org/international/en/about/how-isgreenpeace-structured, letzter Zugriff am 02.12.2014). Greenpeace zeichnet sich im Gegensatz zu vielen kleineren NGOs oder Basisgruppen von sozialen Bewegungen durch eine hierarchische Struktur aus, die schnelle Entscheidungen, Effizienz und eine Corporate Identity garantieren soll (vgl. Bode 1996: 264).

Bei den UN-Klimaverhandlungen ist Greenpeace eine einflussreiche Beobachterorganisation und gehört zu den treibenden Kräften des CAN. Dabei pflegt Greenpeace einen konfliktiv-kooperierenden Politikstil. Die Kritik und die Protestaktionen werden damit durch den Willen zur Teilnahme an den offiziellen Verhandlungen begrenzt (vgl. Bedall 2014: 247). Zentrale Forderungen sind Maßnahmen zur Steigerung der Energieeffizienz und zum Wandel von fossilen zu erneuerbaren Energien. Im Rahmen von CAN und der tcktcktck-Kampagne, zu deren Gründungsmitgliedern Greenpeace gehört, setzt sich Greenpeace für ein ,faires, ambitioniertes und bindendes‘ Klimaabkommen ein (vgl. Bedall 2014: 244f). Dabei liegt der Fokus auf ökologische Fragen, wohingegen Fragen sozialer Gerechtigkeit eine weitaus geringere Rolle spielen (vgl. Bedall 2014: 246). Die marktorientierten Mechanismen, zu denen der CDM zählt, lehnte Greenpeace zunächst ab. Allerdings wandelte sich die Position, nachdem die flexiblen Mechanismen Eingang ins Kyoto-Protokoll gefunden hatten. Gemeinsam mit anderen NGOs ließ sich Greenpeace prinzipiell auf die Marktmechanismen ein, um Einfluss auf ihre Ausgestaltung nehmen zu können (vgl. Bedall 2014: 156). So gehört Greenpeace auch zu den Unterstützer_innen des Gold Standards, einem Label zur Zertifizierung der Umweltverträglichkeit von CDM-Projekten (vgl. de Lucia 2009: 235). Greenpeace übt also weiterhin Kritik an der Ausgestaltung der flexiblen Mechanismen, stellt sie aber nicht mehr generell in Frage.

\section{Greenpeace'Position zu CCS-Technologien}

In der Frage der Beurteilung der CCS-Technologien gibt es relativ große Unterschiede zwischen den umweltpolitischen NGOs, von denen manche auch keine eindeutige Position beziehen. Greenpeace gehört jedoch $\mathrm{zu}$ den konsequenten Kritiker_innen. 2008 veröffentlichte Greenpeace einen Bericht, in dem sie ihre fünf zentralen Kritikpunkte ausformuliert (vgl. Greenpeace 2008a):

1) CCS-Technologien kommen zu spät, um einen gefährlichen Klimawandel zu verhindern. Es wird prognostiziert, dass CCS-Technologien frühestens $2030 \mathrm{im}$ industriellen Maßstab eingesetzt werden können, allerdings müssen bereits ab 2015 die globalen Treibhausgasemissionen sinken, um die schlimmsten Auswirkungen des Klimawandels zu verhindern. 
2) CCS-Technologien verschwenden Energie. Ihr Einsatz verbraucht zwischen 10 und $40 \%$ der im Kraftwerk produzierten Energie, was den Ressourceneinsatz um etwa ein Drittel erhöht.

3) Die Speicherung von $\mathrm{CO}_{2}$ ist risikoreich. Es gibt keine Garantie für eine sichere und permanente $\mathrm{CO}_{2}$-Speicherung. Dabei können auch sehr geringe Leckageraten die Klimaschutzeffekte unterminieren.

4) CCS-Technologien sind teuer. Die Investitionen in CCS entziehen nachhaltigen Lösungen finanzielle Mittel.

5) CCS-Technologien bringen Haftungsrisiken mit sich. Sie stellen eine Gefahr für die Gesundheit, das Ökosystem und das Klima dar.

Aus den genannten Gründen kritisiert Greenpeace CCS-Technologien als eine falsche Hoffnung, die das Klima nicht retten werde. Stattdessen sieht sie in erneuerbaren Energien und Energieeffizienz die adäquate Lösung für das Klimaproblem (vgl. Greenpeace 2008a: 5; Meadowcroft/Langhelle 2009b: 13f).

\section{Greenpeace' Position in den CCS-Verhandlungen}

Greenpeace gehört zu den wenigen umweltpolitischen NGOs, die sich intensiv in die Kontroverse um die Aufnahme von CCS-Technologien in den CDM einbrachten. Besonders in der Anfangsphase der Debatte gab es auf der Ebene der UNKlimaverhandlungen kaum Positionen aus dem zivilgesellschaftlichen Feld. Greenpeace rief gemeinsam mit CAN Europe, Friends of the Earth und WWF bereits 2006 in einem Brief die Delegationsleiter_innen dazu auf, sich gegen die Aufnahme von CCS-Technologien in den CDM auszusprechen (vgl. de Coninck 2008: 932). 2007 reichten der WWF und Greenpeace als einzige Umwelt-NGOs auch offizielle Stellungnahmen ein. Beide äußerten sich in ihren Stellungnahmen skeptisch gegenüber der Aufnahme von CCS-Technologien in den CDM. Allerdings unterschieden sie sich in der prinzipiellen Einschätzung. Der WWF sprach sich explizit für die Anwendung von CCS-Technologien sowohl in Annex-B- als auch in Nicht-AnnexB-Staaten aus (vgl. WWF 2007). Greenpeace nahm dagegen eine kritischere Position ein.

Diese eindeutig kritische Einschätzung war sicherlich auch der Grund, warum SustainUS, ein nordamerikanisches Netzwerk von Jugendlichen, in seiner eigenen Stellungnahme auf die Ausführungen von Greenpeace verwies (vgl. SustainUS 2008). Dies interpretiere ich als Zeichen für die herausragende Bedeutung und den starken Einfluss von Greenpeace innerhalb der NGO-Szene (vgl. Bedall 2014: 143). Auch nach der vorläufigen Entscheidung auf der COP 16 in Cancún (2010) bzw. der endgültigen Bestätigung 2011 in Durban meldete sich Greenpeace zu 
Wort. In ihrer Stellungnahme aus dem Jahr 2012 betont die Organisation, dass sie weiterhin gegen die Aufnahme von CCS-Technologien in den CDM sei. Gleichzeitig versucht Greenpeace die Ausgestaltung der konkreten Regelungen zu beeinflussen (vgl. Greenpeace 2012: 1). Zusammenfassend lässt sich also sagen, dass Greenpeace auch bei der CCS-CDM-Kontroverse ihrem konfliktiv-kooperierenden Politikstil treu blieb.

\section{Greenpeace' Argumentationslinie in den Stellungnahmen}

Im hier untersuchten Zeitraum hat Greenpeace zwei Stellungnahmen eingereicht, eine im Jahr $2007^{68}$ und eine im Jahr 2008. Beide Stellungnahmen beginnen mit Ausführungen zu dem Zweck der internationalen Klimapolitik. Dabei zitiert Greenpeace Artikel 2 der Klimarahmenkonvention, in dem als Ziel festgeschrieben ist, eine „Stabilisierung der Treibhausgaskonzentrationen in der Atmosphäre auf einem Niveau zu erreichen, auf dem eine gefährliche anthropogene Störung des Klimasystems verhindert wird“ (UNFCCC 1992: 5). Diese Zielstellung wird mit einem Verweis auf den IPCC als Reduktion der globalen Treibhausgasemissionen um 85 \% (gegenüber dem Basisjahr 2000) bis 2050 konkretisiert. Dies bildet den Ausgangspunkt für die Bewertung der CCS-Technologien (vgl. Enthymeme GRE 1-1, GRE 2-1; Greenpeace 2007a: 1; Greenpeace 2008b: 1).

In der ersten Stellungnahme bleibt die Umwelt-NGO dabei noch ambivalent bezüglich der allgemeinen Einschätzung von CCS-Technologien. Greenpeace äußert sich dort zwar skeptisch gegenüber der Aufnahme von CCS-Technologien in den CDM, spricht sich aber auch nicht prinzipiell gegen die Förderung ihres Einsatzes in Nicht-Annex-B-Staaten aus:

„Carbon dioxide capture and storage might help achieving this goal [stabilization of greenhouse gas concentrations in the atmosphere]. However, use of CCS may also pose risks. [...] CCS than might not be the right technology for CDM. Should CCS be banned from the CDM? Bode \& Jung state that this would decrease the storage potential and may conflict with the objective of technology transfer to non-Annex I countries. A technology like CCS, however, that is not sustainable may need another way of technology transfer than CDM." (Greenpeace 2007a: 1; Greenpeace 2007c: 2)

68 Auf der Homepage der UNFCCC ist Greenpeace' Stellungnahme aus dem Jahr 2007 auf drei Dateien aufgesplittet. Tatsächlich handelt es sich um drei separate Schreiben, in denen jeweils ein Aspekt behandelt wird. Da diese jedoch auf die gleiche Einladung zur Abgabe von Stellungnahmen reagieren und vermutlich auch gleichzeitig eingereicht wurden, behandele ich sie als eine. 
In der zweiten Stellungnahme werden die CCS-Technologien prinzipiell skeptischer eingeschätzt und ihre Aufnahme in den CDM wird kategorisch abgelehnt.

„To establish whether carbon dioxide capture and storage (CCS) could help achieving this goal [stabilization of greenhouse gas concentrations in the atmosphere], further exploration is valid. However, the CDM is the wrong forum for this technology." (Greenpeace 2008b: 1)

In ihren Stellungnahmen nimmt Greenpeace detailliert zur Frage Stellung, ob CCSTechnologien in den CDM aufgenommen werden sollen und welche Voraussetzungen dafür zu erfüllen wären. Allgemeine Einschätzungen über CCS-Technologien findet man in den Stellungnahmen nicht - abgesehen vom jeweils ersten Absatz. Mit Verweis auf die konkreten Bestimmungen des CDM, wie sie 2001 auf der COP 7 im sogenannten Marrakesch-Abkommen festgeschrieben wurden, werden eine Reihe von Kriterien und Voraussetzungen genannt, die CCS-Technologien (noch) nicht erfüllen bzw. die für CCS-Technologien schwierig zu erfüllen seien. So wird betont, dass bislang nicht nachgewiesen werden konnte, ob CCS-Technologien umweltfreundlich und sicher seien. Dazu wird angeführt, dass es in Bezug auf die Anwendung von CCS auf Kohlekraftwerke noch keine Demonstrationsanlagen im Industriemaßstab gebe und zudem auch keine Erfahrungen mit großflächigen Speicherstätten oder dem Verhalten großer Mengen verpresstem $\mathrm{CO}_{2}$ (vgl. Enthymem GRE 2-2; Greenpeace 2008b: 1).

Das Fehlen empirischer Daten führt Greenpeace ebenfalls an um zu begründen, dass eine Risikoabschätzung bei CCS-Technologien besonders schwierig sei. Da es noch keine Langzeit-Studien gebe, könnten keine belastbaren Aussagen über das Verhalten von $\mathrm{CO}_{2}$ in geologischen Formationen getroffen werden. In dem Zusammenhang verweist Greenpeace auch auf die Schwierigkeiten bei der Berechnung der eingesparten Emissionen (vgl. Enthymem GRE 1-4; Greenpeace 2007a: 1f).

Eine wichtige Rolle spielt in den Stellungnahmen die Frage der kurz- und langfristigen Haftung. Gerade die Verantwortung für die langfristige Haftung von CCSProjekten - die noch lange nach dem Anrechnungszeitraum als CDM-Projekt relevant bleibt - sei mit vielen Risiken und unkalkulierbaren Kosten verbunden (vgl. Enthymem GRE 1-6; Greenpeace 2007c: 1f). Greenpeace befürchtet für den Fall, dass keine anderen Vereinbarungen getroffen werden, dass die langfristige Haftung bei den Zielländern hängen bleibe. Diese Bürde würde den Zweck des CDM, nämlich eine nachhaltige Entwicklung zu fördern, unterminieren. Unabhängig davon würden CCS-Projekte nicht zum sozialen, wirtschaftlichen und ökologischen Wohl beitragen, da sie beispielsweise nur wenige Arbeitsplätze schaffen sowie die Energiepreise und den Ressourcenverbrauch erhöhen würden. Für Greenpeace ist somit klar, dass CCS-Technologien nicht zu einer nachhaltigen Entwicklung führen (vgl. Enthymeme GRE 1-7, GRE 2-4; Greenpeace 2007c: 2; Greenpeace 2008b: 2f). 
An anderer Stelle wird diese Aussage noch einmal zugespitzt, indem auf die Gefahr hingewiesen wird, dass die Länder des globalen Nordens durch die Entwicklung und Anwendung der CCS-Technologien Gewinne einfahren könnten, während die Nicht-Annex-B-Staaten dagegen die langfristigen Lasten zu tragen hätten. Greenpeace wendet sich hier dagegen, dass Nicht-Annex-B-Staaten als Versuchskaninchen“ (,guinea pigs“ Greenpeace 2008b: 2) missbraucht werden. Unreife Technologien, zu denen Greenpeace CCS zählt, sollten demnach erst in den AnnexB-Staaten selber zum Einsatz kommen (vgl. Enthymem GRE 2-3; Greenpeace 2008b: 1f).

Insgesamt schätzt Greenpeace die CCS-Technologien als risikoreiche Technologien ein. Für Greenpeace steht außer Frage, dass es bei CCS-Projekten zu Leckagen kommen werde. Die entscheidende Frage sei aber, ob es nur zu allmählichen langfristigen Freisetzungen oder auch zu einem plötzlichen Austreten von $\mathrm{CO}_{2}$ käme und in welchen Mengen. Die komplexen Prozesse in geologischen Formationen hält Greenpeace für kaum vorhersehbar. Deshalb bergen CCS-Technologien ihrer Meinung nach das Risiko unerwarteter Treibhausgasemissionen. Falls es zu derartigen nicht einkalkulierte Emissionen kommen würde, wäre das ein ernsthaftes Problem, das entweder durch eine noch $\mathrm{zu}$ entwickelnde Energietechnologie mit negativen Emissionen oder durch eine drastische Reduktion der Emissionen des globalen Energie- und Landwirtschaftssystems kompensiert werden müsste (vgl. Enthymeme GRE 1-2, GRE 1-3; Greenpeace 2007a: 1).

Neben diesen inhärenten Risiken der CCS-Technologien verweist Greenpeace auch auf mögliche nicht-intendierte Nebenfolgen. CCS-Technologien sind im Moment sehr teuer und Greenpeace beobachtet ihre Förderung durch öffentliche Mitteln mit Skepsis, da sie als Folge dessen die Kürzung der Mittel für erneuerbare Energien befürchtet. $\mathrm{Ob}$ es zu einem großflächigen Einsatz von CCS-Technologien kommen werde, hängt laut Greenpeace letztlich vom Marktpreis der Emissionszertifikate ab. Nur bei einem hohen Marktpreis würden sich CCS-Projekte rentieren (vgl. Enthymem GRE 2-7; Greenpeace 2008b: 3).

Da die durch CCS-Projekte generierten CERs besonders teuer sein würden, geht Greenpeace davon aus, dass sie nur von Akteur_innen gekauft würden, die ein ernsthaftes Interesse an der Entwicklung und Anwendung von CCS-Technologien haben. Daraus abgeleitet wertet Greenpeace CCS-Pilotprojekte im Rahmen des CDM als versteckte Subventionierung der Kohleindustrie in Industrieländern. Greenpeace sieht also einen Zielkonflikt bei der Finanzierung der verschiedenen Technologien und bezieht eindeutig Position für den Ausbau der erneuerbaren Energien und gegen CCS (vgl. Enthymem GRE 2-5; Greenpeace 2008b: 3). 
Interessant ist an dieser Stelle, dass auch die brasilianische Regierung von einem Zielkonflikt zwischen CCS-CDM-Projekten und der Finanzierung erneuerbarer Energien ausgeht. Allerdings basiert das Argument der brasilianischen Regierung auf gegenteiligen Annahmen. Sie vermutet, dass CCS-Projekte eine große Menge CERs generieren und damit einen Preisverfall verursachen würden. Sinkende CER-Preise wiederum würden die Investitionen in kleinere dezentrale CDM-Projekte sowie in erneuerbare Energien, Energieeffizienz und kohlenstoffarme Formen des Wirtschaftens unterminieren (vgl. Enthymeme Bra 2-15, BRA 310; UNFCCC 2008: 5f; UNFCCC 2010c: 6).

Abschließend greift Greenpeace in ihrer zweiten Stellungnahme noch eine allgemeine Kritik am CDM auf. Dem CDM ist es als Offset-Mechanismus inhärent, dass die durch ihn generierten CERs auf die Reduktionsziele der Annex-B-Staaten angerechnet werden. Durch den CDM können also fortgeführte Emissionen der Annex-B-Staaten kompensiert werden. Je mehr CERs generiert werden, desto weniger Klimaschutzmaßnahmen müssen die Annex-B-Staaten in ihren eigenen Ländern durchführen. Greenpeace befürchtet, dass bei CCS-Projekten große Mengen CERs erzeugt werden, was den Annex-B-Staaten die Fortführung des business-as-usual ermöglichen würde. In den Ländern des globalen Nordens würden konventionelle Kohlekraftwerke weiterlaufen, während die CCS-Technologien in den NichtAnnex-B-Staaten angewandt werden würden (vgl. Enthymem GRE 2-6; Greenpeace 2008b: 3). Insgesamt positioniert sich Greenpeace eindeutig gegen die Aufnahme von CCS in den CDM: „To conclude, CCS does not fulfill the requirements for inclusion in the $\mathrm{CDM}$. Greenpeace therefore recommends to exclude CCS from the CDM.“" (Greenpeace 2008b: 3)

\subsubsection{Die CCS-CDM-Kontroverse und das ökomoderne Projekt}

Im Folgenden setze ich die CCS-CDM-Kontroverse insgesamt zum ökomodernen Hegemonieprojekt ins Verhältnis. Dazu greife ich sowohl auf die Analyse des IPCC SRCCS (vgl. Kapitel 5.3) als auch auf den Überblick über die an der CCS-CDMKontroverse aktiv beteiligten Akteur_innen und ihre Positionen (vgl. Kapitel 5.4.2) sowie auf die Detailanalysen einzelner Positionierungen (vgl. Kapitel 5.4.3) zurück. In diesem Kapitel beschränke ich meine Analyse - wie in Kapitel 5.4.2 - auf die Oberfläche der Verhandlungspositionen. In der anschließenden Synthese der Analyse von CCS in der internationalen Klimapolitik (Kapitel 5.5) beziehe ich den Kontext der Verhandlungen wieder mit ein. Die Darstellung des Verhältnisses der CCSCDM-Kontroverse zum ökomodernen Projekt beginne ich mit einem Überblick über ökomoderne Basis-Artikulationen (vgl. Tabelle 13). 
Tabelle 13 Ökomoderne Basis-Artikulationen

\begin{tabular}{|c|c|c|c|}
\hline Ökomoderne Basis-Artikulationen & Zustimmung & Einschränkung & Skepsis \\
\hline $\begin{array}{l}\text { Das Ziel der Klimapolitik ist, die Stabili- } \\
\text { sierung der Treibhausgaskonzentration in } \\
\text { der Atmosphäre auf einem Niveau zu } \\
\text { erreichen, auf dem eine gefährliche } \\
\text { anthropogene Störung des Klimasystems } \\
\text { verhindert wird. }\end{array}$ & $\begin{array}{l}\text { Australien } \\
\text { Brasilien } \\
\text { EU } \\
\text { Indonesien } \\
\text { Japan } \\
\text { Kanada } \\
\text { Neuseeland } \\
\text { Norwegen } \\
\text { Bellona } \\
\text { CCSA } \\
\text { EURELECTRIC } \\
\text { Greenpeace } \\
\text { ICC } \\
\text { IEEP } \\
\text { IETA } \\
\text { SustainUS } \\
\text { WCI } \\
\text { IPCC }\end{array}$ & & \\
\hline $\begin{array}{l}\text { Das Ziel der Klimapolitik wird durch ein } \\
\text { Portfolio technologischer Optionen } \\
\text { erreicht. }\end{array}$ & $\begin{array}{l}\text { Australien } \\
\text { Brasilien } \\
\text { EU } \\
\text { Indonesien } \\
\text { Japan } \\
\text { Kanada } \\
\text { Neuseeland } \\
\text { Norwegen } \\
\text { Bellona } \\
\text { CCSA } \\
\text { EURELECTRIC } \\
\text { ICC } \\
\text { IEEP } \\
\text { IETA } \\
\text { WCI } \\
\text { IPCC }\end{array}$ & SustainUS & \\
\hline $\begin{array}{l}\text { CCS ist ein wichtiges Element des Port- } \\
\text { folios. }\end{array}$ & $\begin{array}{l}\text { Australien } \\
\text { EU } \\
\text { Indonesien } \\
\text { Japan } \\
\text { Kanada } \\
\text { Neuseeland } \\
\text { Norwegen } \\
\text { Bellona } \\
\text { CCSA } \\
\text { EURELECTRIC } \\
\text { ICC } \\
\text { IETA } \\
\text { WCI } \\
\text { IPCC }\end{array}$ & Brasilien & $\begin{array}{l}\text { Greenpeace } \\
\text { SustainUS }\end{array}$ \\
\hline
\end{tabular}


Ich bezeichne diese Deutungsmuster als Basis-Artikulationen, weil sie zum einen in sehr vielen Stellungnahmen vorkommen. Zum anderen stellen sie eine Basis dar, weil sie für die (Re-)Produktion der ökomodernen Grundannahmen und Hegemoniestrategien von großer Bedeutung sind. Diese Basis-Artikulationen bilden den ökomodernen Konsens ab, der das UN-Klimaregime prägt und auf den in den Verhandlungen immer wieder rekurriert wird, um Legitimität für die eigene Position herzustellen. $\mathrm{Zu}$ diesem Zweck werden wichtige Instanzen internationaler Klimapolitik - wie der IPCC, die Klimarahmenkonvention und das Kyoto-Protokoll zitiert. Gerade bei der Formulierung des Ziels der Klimapolitik wird häufig direkt oder indirekt Artikel 2 der Klimarahmenkonvention zitiert (vgl. IETA 2008; UNFCCC 2007a; UNFCCC 2007b; UNFCCC 2008; WCI 2008). Damit wird eine globale Deutung des Klimaproblems übernommen, in der die lokal und sozial unterschiedliche Verursachung und Betroffenheit sowie die qualitativen Unterschiede der Ursachen von Treibhausgasemissionen aus dem Blick geraten (zur Deutung des Klimaproblems als globale Krise vgl. Kapitel 3.2.1 und 5.3.4). Diese Verengung auf ein spezifisches ökologisches Problem legt eine technokratische Lösung nahe, in der damit zusammenhängende andere ökologische und soziale Probleme ausgeklammert werden.

Weiterhin wird in dem Ziel der Stabilisierung auf einem konkreten Niveau, auf dem eine gefährliche anthropogene Störung des Klimasystems verhindert werde, die Nichtidentität der Natur negiert. Der Versuch, den anthropogenen Eingriff ins Klimasystem beherrschbar zu machen, d. h. die damit verknüpften negativen Konsequenzen für den Menschen zu kontrollieren, verweist auf die Strategie der reflexiven Naturbeherrschung. Dieses grundlegende Ziel internationaler Klimapolitik ist im UN-Klimaregime fest verankert. Alle hier untersuchten Stellungnahmen stimmen diesem Ziel zu. SustainUS vertritt alleine die Position, dass dieses Ziel mit weiteren Ansprüchen an Klimapolitik ergänzt werden müsse. Klimaspolitik ist laut SustainUS nur dann erfolgreich, wenn sie soziale Gerechtigkeit und die Einhaltung von Menschenrechten fördert (vgl. SustainUS 2008: 3). Damit greift SustainUS Aspekte auf, die in der antagonistischen Forderung nach Klimagerechtigkeit eine zentrale Rolle spielen (vgl. Kapitel 5.1.4).

Diese Zielformulierung von SustainUS, die über eine ökologischen Modernisierung hinaus weist, hat Einfluss auf die Einschätzung, mit welchen Instrumenten das Ziel der Klimapolitik erreicht werden kann. Wie im UN-Klimaregime insgesamt, so wird auch in fast allen Stellungnahmen zur CCS-CDM-Kontroverse davon ausgegangen, dass mit einem Portfolio technologischer Lösungen die Treibhausgaskonzentration in der Atmosphäre stabilisiert und damit das Ziel internationaler Klimapolitik erreicht werden könne. In dieser Vorstellung schwingt der Optimismus mit, 
die durch die Industrialisierung geschaffenen Probleme durch fortschreitende technologische Innovationen in den Griff kriegen zu können. Der Lösungsweg wird in einem reflexiven Fortschritt durch wissenschaftich-technische Rationalität gesucht.

Mit der Betonung des Portfolios wird auf eine Bandbreite technologischer Optionen verwiesen, die parallel entwickelt und flexibel kombiniert werden sollen. In dieser inkrementellen Perspektive geht es nicht darum, einzelne Maßnahmen und Technologien aufgrund ihrer strukturverändernden Eigenschaften zu präferieren. Stattdessen soll das Ziel einer kohlenstoffarmen Wirtschaft über den Ausbau bestehender Strukturen und Entwicklungspfade erreicht werden. Nicht zur Debatte stehen dagegen weitreichende Eingriffe in Produktions- und Konsummuster, die gesamtgesellschaftliche Transformationsprozesse anstoßen könnten. Allein SustainUS stellt Verknüpfungen zu anderen gesellschaftlichen Problemen her und thematisiert Fragen sozialer Gerechtigkeit. Dementsprechend nimmt SustainUS eine Einschränkung vor, welche Klimaschutzoptionen sie als sinnvolle Elemente des Portfolios erachten. In Bezug auf ihre Ansprüche an eine gelungene Klimapolitik bezieht SustainUS klar Stellung für erneuerbare Energien und gegen CCS-Technologien:

„There is no risk of Carbon leaking out of a solar panel or a wind turbine. In addition, renewables have substantial secondary benefits other than solely reducing greenhouse gas emissions and replacing fossil fuel energy sources. Long-term effects of implementing renewable projects in non-Annex I countries can help to develop long-term technical and intellectual capacities of local communities. The shared planning and management of renewable projects will build the necessary skills within the community so that they may implement their own clean energy projects in the future. Empowering local communities to take control of their energy future in a sustainable way is essential for long-term social and environmental progress. Carbon Capture and Storage does not meet the same benchmarks that the aforementioned renewables do. [...] Carbon emissions must be decreased rapidly to attain safe atmospheric carbon concentrations of $350 \mathrm{ppm}$. Doing so will require a just transition from fossil fuel dependence, a transition that is easily attainable given appropriate political, financial, and institutional commitments. Clean sustainable energy development on a massive scale is required to reach this critical goal." (SustainUS 2008: 3)

Greenpeace ist ebenfalls skeptisch, ob CCS-Technologien ein sinnvolles Element des Portfolios darstellen können. Allerdings argumentiert Greenpeace im Gegensatz zu SustainUS innerhalb des ökomodernen Diskurses. Greenpeace stellt in Frage, ob CCS-Technologien den reflexiven Elementen ökologischer Modernisierung gerecht werden. So bedarf es laut Greenpeace weiterer Forschung um abschätzen zu können, ob CCS-Technologien den risikovermeidenden und risikobewussten Ansprüchen einer ökologischen Modernisierung genügen oder ob sie nicht tatsächlich als Risikotechnologien einzuordnen seien, deren klassischer Versuch der (nicht- 
reflexiven) Naturbeherrschung scheitern werde. Darüber hinaus warnt Greenpeace davor, dass die für CCS-Technologien notwendigen hohen Subventionssummen zu einer Reduktion der Fördermittel für erneuerbare Energien führen könnten. Für Greenpeace steht außer Frage, dass die sicheren und einsatzbereiten erneuerbaren Technologien Vorrang haben sollten (vgl. Greenpeace 2008b).

Im Gegensatz dazu werden in allen anderen Stellungnahmen (der von SustainUS ausgenommen) CCS-Technologien als wichtiges Element des Portfolios gehandelt (vgl. Tabelle 13). Schließlich, so wird argumentiert, sollten alle Optionen entwickelt werden, die zur Stabilisierung der Treibhausgaskonzentration in der Atmosphäre beitragen können. Darüber hinaus seien CCS-Technologien mit der derzeit vorherrschenden zentralisierten Energieinfrastruktur kompatibel. Damit habe CCS das Potenzial, große Mengen an Treibhausgasemissionen zu verhindern. In dieser Argumentation gelten CCS-Technologien als ein wichtiges Element innerhalb des ökomodernen Projekts. Kritische Aspekte werden in manchen Stellungnahmen angesprochen, allerdings ist Greenpeace allein mit der Einschätzung, dass CCS-Technologien den Ansprüchen einer ökologischen Modernisierung nicht genügen. Dennoch gibt es neben Greenpeace und SustainUS weitere Akteur_innen, die sich gegen die Aufnahme von CCS-Technologien in den CDM aussprechen. Brasilien, das Forum for Utvikling og Miljø, Venezuela und der WWF positionieren sich ebenfalls gegen CCS-CDM-Projekte. Da aber weder das Forum for Utvikling og Miljø noch die venezolanische Regierung noch der WWF auf der etwas abstrakteren Ebene die Bedeutung von CCS-Technologien im Portfolio der Klimaschutztechnologien diskutieren, tauchen sie in der Tabelle 13 nicht auf. Die brasilianische Regierung formuliert die Position aus, dass CCS-Technologien zwar ein wichtiges Element des Portfolios seien, zunächst aber in den Industrieländern entwickelt und erprobt werden sollten. Damit schränkt die brasilianische Regierung die Bedeutung von CCS-Technologien auf die Annex-B-Staaten ein. In Nicht-Annex-B-Staaten sollten unreife Technologien dagegen zunächst nicht exportiert werden. Und wenn dies irgendwann doch sinnvoll sein sollte - was die brasilianische Regierung nicht per se ausschließt - dann eigne sich dafür nicht der CDM. Schließlich gelten für die Aufnahme einer Technologie in den CDM über den Beitrag zur Reduktion von Treibhausgasemissionen hinaus noch weitere Kriterien, die CCS-Technologien nicht erfüllen würden (vgl. UNFCCC 2008; UNFCCC 2010c).

Nach dieser allgemeinen Einschätzung anhand ökomoderner Basis-Artikulationen folgt nun eine etwas detailliertere Analyse, in der ich die verschiedenen Dimensionen der CCS-CDM-Kontroverse in Beziehung zu den einzelnen ökomodernen Grundannahmen und Hegemoniestrategien setze. Ich beginne mit einem Überblick über technokratische Artikulationen in den Stellungnahmen (vgl. Tabelle 14). 
Tabelle 14 Technokratische Artikulationen

\begin{tabular}{|c|c|c|c|}
\hline Technokratische Artikulationen & Zustimmung & Einschränkung & Skepsis \\
\hline $\begin{array}{l}\text { CCS ist wichtig, weil der Anteil fossiler } \\
\text { Brennstoffe an der Deckung des globalen } \\
\text { Energiebedarfs hoch bleiben wird. }\end{array}$ & $\begin{array}{l}\text { Australien } \\
\text { EU } \\
\text { Kanada } \\
\text { Neuseeland } \\
\text { Norwegen } \\
\text { Bellona } \\
\text { CCSA } \\
\text { CSLF } \\
\text { EURELECTRIC } \\
\text { ICC } \\
\text { IEEP } \\
\text { IETA } \\
\text { Indian Institute } \\
\text { IRGC } \\
\text { WCI } \\
\text { IPCC }\end{array}$ & & SustainUS \\
\hline $\begin{array}{l}\text { Es gibt keinen Zielkonflikt zwischen der } \\
\text { Förderung von CCS und der Förderung } \\
\text { von erneuerbaren Energien. }\end{array}$ & $\begin{array}{l}\text { Australien } \\
\text { Norwegen } \\
\text { Eskom } \\
\text { EURELECTRIC } \\
\text { IEEP } \\
\text { IETA } \\
\text { WCI }\end{array}$ & $\begin{array}{l}\text { Brasilien } \\
\text { ForUM }\end{array}$ & Greenpeace \\
\hline
\end{tabular}

Das Argument, dass CCS-Technologien wichtig seien, weil der Anteil fossiler Brennstoffe an der Deckung des globalen Energiebedarfs hoch bleiben werde, interpretiere ich als technokratische Artikulation. In fast allen Stellungnahmen wird die gegenwärtige Dominanz fossiler Brennstoffe in die Zukunft projiziert (vgl. Tabelle 14). Diese Artikulation zementiert zentrale gesellschaftliche Strukturen als unveränderbare Konstanten. Gesamtgesellschaftliche Transformationsprozesse gelten damit als außerhalb des realisier- und durchsetzbaren Bereichs. Die gegeben Machtverhältnisse sowie die Produktions- und Konsummuster werden der Bewertung von Klimaschutzoptionen zugrunde gelegt. Die Möglichkeit der Veränderung von Machtverhältnissen, Wirtschaftsstrukturen und Lebensstilen sowie der potenzielle Beitrag von Klimaschutzstrategien zu dieser Veränderung wird nicht in Betracht gezogen. Unter diesen Voraussetzungen gilt CCS als wichtiges Instrument, um die durch die Verbrennung von fossilen Brennstoffen entstehenden Treibhausgasemissionen zu senken. Andere negative Folgen des Verbrauchs fossiler Brennstoffe werden nicht thematisiert, da in der technokratischen Perspektive Lösungen lediglich für isolierte ökologische Probleme - in der Klimapolitik das Problem der erhöhten 
Treibhausgaskonzentration in der Atmosphäre - gesucht werden. Aufgrund dieser Fokussierung auf die Treibhausgasemissionen (vgl. Kapitel 3.4.3 zur Trennung der Input- von der Output-Seite) bleibt die Bedeutung von fossilen Brennstoffen als zentrales Element einer klimaschädigenden Wirtschafts- und Lebensweise außen vor.

Dieser technokratischen Position begegnet SustainUS in ihrer Stellungnahme mit Skepsis (für den gesamten Absatz vgl. SustainUS 2008). Für SustainUS ist die Output-Dimension der Treibhausgasemissionen nicht von der Input-Dimension der Verbrennung fossiler Brennstoffe zu trennen. Um eine Senkung der Treibhausgasemissionen zu erreichen, fordert SustainUS, die Abhängigkeit von fossilen Brennstoffen zu verringern. Ein solcher Transformationsprozess soll durch entsprechende politische, finanzielle sowie institutionelle Anreize und Maßnahmen angestoßen werden. Damit sieht SustainUS durchaus Spielräume für einen aktiven, gestaltenden Politikstil. Weiterhin ist für SustainUS das Problem der erhöhten Treibhausgaskonzentration in der Atmosphäre mit anderen gesellschaftlichen Fragen, wie denen nach sozialer Gerechtigkeit und Energiesouveränität, verknüpft. Insofern fließen für SustainUS die transformationshemmenden oder -fördernden Eigenschaften in die Bewertung von Klimaschutztechnologien ein. Vor dem Hintergrund dieser Annahmen und Vorstellungen, die über das ökomoderne Projekt hinaus weisen, gelten CCS-Technologien lediglich als letztes Mittel. Im Vordergrund steht für SustainUS der Aufbau einer neuen Energieinfrastruktur auf Basis der erneuerbaren Energien.

Auch die brasilianische Regierung, Greenpeace und das Forum for Utvikling og Miljø bevorzugen den Ausbau erneuerbarer Energien gegenüber dem Einsatz von CCS-Technologien in den Nicht-Annex-B-Staaten (vgl. Tabelle 14). Sie befürchten, dass die Aufnahme von CCS-Technologien in den CDM zu weniger CDMProjekten mit erneuerbaren Energien führen würde. Greenpeace verallgemeinert diese Diagnose eines Zielkonflikts. Für Greenpeace konkurrieren erneuerbare Energien und CCS-Technologien prinzipiell um Fördermittel, weshalb die NGO auch skeptisch bleibt, ob CCS-Technologien tatsächlich eine sinnvolle Ergänzung innerhalb eines ökomodernen Projekts darstellen können.

Auf Seiten der CCS-befürwortenden Koalition in den UN-Klimaverhandlungen wird die Frage der Konkurrenz um Subventionen entweder nicht angesprochen oder als unproblematisch eingestuft. In mehreren Stellungnahmen wird betont, dass es keinen Zielkonflikt zwischen der Förderung von CCS und der Förderung von erneuerbaren Energien gebe (vgl. Tabelle 14). Beide Klimaschutzoptionen seien wichtig, um ehrgeizige Klimaschutzziele erreichen zu können. Da der Energiebedarf weiter steigen werde, müsste die Ausschöpfung aller Energiequellen gesteigert werden. Im Sinne eines Portfolios, aus dem verschiedene Akteur_innen ihre 
Klimaschutzstrategie flexibel wählen sollen, würden sich erneuerbare Energien und CCS-Technologien gegenseitig ergänzen. Dies begründet beispielsweise IETA damit, dass die Anwendung erneuerbarer Energien mit ihrer fluktuierenden Energieeinspeisung durch die Erfordernis eines Grundlastbetriebs limitiert wäre. Dafür seien CCS-Technologien notwendig, die darüber hinaus bei industriellen Prozessen angewendet werden könnten (vgl. IETA 2008: 7). In dieser technokratischen Artikulation reagieren Klimaschutzstrategien auf gesellschaftliche sowie ökonomische Entwicklungen und nicht umgekehrt. Die Auswahl der Klimaschutzoptionen erfolgt nicht nach dem Gesichtspunkt, inwieweit sie bestimmte gesellschaftliche Transformationsprozesse anstoßen. Klimaschutztechnologien werden damit als neutrale Werkzeuge verstanden, die es für den flexiblen Einsatz zu entwickeln gelte.

\section{Tabelle 15 Artikulationen des Primats der Betriebsökonomie}

\begin{tabular}{|l|l|l|l|}
\hline $\begin{array}{l}\text { Artikulationen des Primats der } \\
\text { Betriebsökonomie }\end{array}$ & Zustimmung & Einschränkung & Skepsis \\
\hline $\begin{array}{l}\text { Das wichtigste Entscheidungskriterium } \\
\text { für die Bewertung von Technologien ist } \\
\text { ihr Potenzial zur Senkung der betriebs- }\end{array}$ & Eustralien & & \\
wirtschaftlichen Kosten des Klima- & Eskom & SustainUS \\
schutzes. & EURELECTRIC & & \\
& Greenpeace & & \\
& ICC & & \\
& IETA & & \\
& WCI & & \\
& IPCC & & Greenpeace \\
CCS hat das Potenzial, die betriebswirt- & Australien & & \\
schaftlichen Kosten des Klimaschutzes & EU & & \\
zu senken. & Kanada & & \\
& Eskom & & \\
& EURELECTRIC & & \\
& ICC & & \\
& IETA & & \\
& WCI & & \\
& IPCC & & \\
& & & \\
\end{tabular}

Für die Auswahl der Klimaschutztechnologien gilt im ökomodernen Diskurs das Primat der Betriebsökonomie. Auch in vielen Stellungnahmen der CCS-CDMKontroverse wird sich dafür ausgesprochen, die Technologien als mögliche Optionen des Portfolios in Betracht zu ziehen, die Potenzial zur Senkung der betriebswirtschaftlichen Kosten des Klimaschutzes haben (vgl. Tabelle 15). Daraus wird gefolgert, dass es für einen weltweiten Einsatz von CCS-Technologien in erster Linie entscheidend sei, inwieweit die Kosten von CCS-Projekten gesenkt werden können 
(vgl. IEEP 2007; UNFCCC 2006; UNFCCC 2007b; UNFCCC 2008). Weiterhin wird mehrfach auf die Marktpreise von Emissionsberechtigungen verwiesen, die ab einer bestimmten Höhe CCS-Projekte rentabel machen würden (vgl. Eskom 2010; EURELECTRIC 2010; Greenpeace 2008b; Indian Institute of Technology Kharagpur/Indian Institute of Management Indore 2009, SACCCS 2010; UNFCCC 2009b; WCI 2007; WCI 2008). Die längerfristige Existenz und Bedeutung von Kohlenstoffmärkten wird hierbei vorausgesetzt.

Die Stellungnahme von SustainUS gibt auch in diesem Punkt eine antagonistische Artikulation wieder. Für SustainUS spielen Gerechtigkeitsfragen und die Vermeidung ökologischer und gesundheitlicher Risiken eine größere Rolle als betriebswirtschaftliche Kosteneffizienz. Darüber hinaus setzt die Organisation auf eine dezentrale Energieversorgung, die langfristig zu sozialen und ökologischen Verbesserungen führen soll (vgl. SustainUS 2008).

Die IETA repräsentiert den entgegengesetzten Pol der marktradikalen Logik. Mit Verweis auf die Funktion der flexiblen Mechanismen argumentiert sie, dass es von Vorteil sei, wenn der Anteil von kosteneffizienten Klimaschutztechnologien zu Lasten von weniger kosteneffizienten Technologien wachsen würde (für den gesamten Absatz vgl. IETA 2007; IETA 2008). Dies gilt für die IETA explizit auch bezüglich einer möglichen Verdrängung erneuerbarer Energien durch CCS-Technologien. Mit dem Primat der Betriebsökonomie begründet sie weiterhin die Anwendung von CCS-Technologien in den Ländern des globalen Südens. Da sich in diesen Ländern eine große Zahl der kosteneffizientesten Möglichkeiten für CCS-Projekte befände, müsse man Anreize wie die Aufnahme in den CDM schaffen, damit diese Möglichkeiten auch genutzt würden.

Insgesamt geht die CCS-befürwortende Koalition in den UN-Klimaverhandlungen davon aus, dass CCS-Technologien das Potenzial haben, die betriebswirtschaftlichen Kosten des Klimaschutzes zu senken - auch wenn es für die weitere Entwicklung der Technologien zunächst finanzielle Anreize bedürfe (vgl. Tabelle 15). Dabei berufen sie sich regelmäßig auf die Aussage des IPCC, dass CCS-Technologien die Kosten für die Stabilisierung der Treibhausgaskonzentration in der Atmosphäre um mindestens 30 \% senken könnten (vgl. IPCC 2005: 3, 12).

Dieser Einschätzung widerspricht Greenpeace. Für Greenpeace ist offensichtlich, dass CCS bislang keine kosteneffiziente Technologie darstelle und die Organisation ist skeptisch, wann und in welchem Maße sich das ändern könne. Dies ist einer der Gründe, warum CCS-Technologien für Greenpeace keine bedeutende Rolle in einem ökomodernen Projekt spielen. CCS-CDM-Projekte interpretiert Greenpeace als Subventionierung der fossilen Energiewirtschaft. Dies sei unsinnig, 
da mit den erneuerbaren Energien kostengünstigere und sichere Technologien bereit stehen würden (vgl. Greenpeace 2007c: 1f; Greenpeace 2008b: 3).

\section{Tabelle 16 Inkrementelle Artikulationen}

\begin{tabular}{|l|l|l|l|}
\hline Inkrementelle Artikulationen & Zustimmung & Einschränkung & Skepsis \\
\hline CCS ist eine Brückentechnologie. & Australien & Brasilien & ForUM \\
& EU & & SustainUS \\
& Norwada & & \\
Bellona & & \\
CCSA & & \\
IETA & WWF & & \\
\hline CCS sollte dort eingesetzt werden wo der & Australien & Brasilien & \\
Verbrauch fossiler Brennstoffe wächst & EU & Greenpeace & \\
bzw. wo fossile Kraftwerke entstehen - & Indonesien & WWF & \\
also auch und gerade in Schwellenländern. & Japan & & \\
& Kanada & & \\
Bellona & & \\
CCSA & & \\
& CSLF & & \\
EURELECTRIC & & \\
Es ist von Vorteil, dass sich CCS in die be- & EU & \\
stehende Energieinfrastruktur einfügt und \\
auf dem Status quo der energie- und klima- \\
politischen Rahmenbedingungen basiert.
\end{tabular}

Die unterschiedlichen Einschätzungen zur Kosteneffizienz von CCS-Technologien korrelieren mit unterschiedlichen Prognosen zum globalen Energiebedarf und Annahmen über zukünftige Energieinfrastrukturen. So bezeichnet der IPCC die Kompatibilität von CCS-Technologien mit dem Status quo der Energieinfrastruktur als Wettbewerbsvorteil (vgl. IPCC 2005: 12). Dieses Argument wird von anderen Akteur_innen der CCS-befürwortenden Koalition in den UN-Klimaverhandlungen übernommen (vgl. Tabelle 16). In Tabelle 16 führe ich dies als inkrementelle Artikulation an, die Lösungen präferiert, die sich möglichst unkompliziert innerhalb der gegebenen Rahmenbedingungen umsetzen lassen.

Die Hoffnung, mit kleinen Schritten die Lösung ökologischer Probleme voranzutreiben, zeigt sich ebenfalls in der positiven Bezugnahme auf den Begriff der Brückentechnologie. In einigen Stellungnahmen der CCS-befürwortenden 
Koalition in den UN-Klimaverhandlungen wird auf die Bedeutung von Brückentechnologien im Übergang zu einer kohlenstoffarmen Wirtschaft hingewiesen (vgl. Tabelle 16). Schließlich werde es noch einige Zeit dauern, bis erneuerbare Energien den Energiebedarf decken könnten. Dabei wird CCS als wichtige Brückentechnologie eingeordnet, die angesichts des weiter zunehmenden Verbrauchs fossiler Brennstoffe ein besonders großes Potenzial habe.

Mit Verweis auf den Neubau fossiler Kraftwerke in Schwellenländern wird in vielen Stellungnahmen geschlussfolgert, dass CCS-Technologien dort entwickelt und angewendet werden sollten, wo Kohlekraftwerke entstehen und es insgesamt einen steigenden Verbrauch fossiler Brennstoffe gebe (vgl. Tabelle 16). Dem widersprechen die brasilianische Regierung, Greenpeace und der WWF (vgl. Tabelle 16). Sie halten dagegen, dass CCS-Technologien zunächst in den Annex-B-Staaten erprobt werden sollten. Die brasilianische Regierung argumentiert in diesem Zusammenhang mit einem modifizierten Brückentechnologie-Argument. CCS könnte eine sinnvolle Brückentechnologie in Industrieländern sein, deren enorme Infrastrukturen auf dem Verbrauch fossiler Brennstoffen basiere. In Nicht-Annex-BStaaten würden CCS-Technologien aber unter Umständen erst zum Aufbau einer fossilen Wirtschaftsstruktur beitragen (vgl. UNFCCC 2008; UNFCCC 2010c).

Sowohl das Forum for Utvikling og Miljø als auch SustainUS sprechen CCSTechnologien prinzipiell ab, zur Transformation der fossilen Energieinfrastruktur in eine Versorgungsstruktur mit erneuerbaren Energien beitragen zu können (vgl. ForUM 2007; SustainUS 2008). Stattdessen perpetuiere CCS die Nutzung fossiler Brennstoffe. Damit kritisieren sie Versuche der schrittweisen Verbesserung im Sinne eines ökomodernen Inkrementalismus. Aus ihrer Perspektive ist es wenig sinnvoll, gegenwärtige fossile Energieinfrastrukturen klimaneutraler gestalten zu wollen, da nur eine aktive Umgestaltung derselben in erneuerbare Energieinfrastrukturen einen wirklichen Beitrag zur Erreichung der Klimaschutzziele leisten könne.

Die Änderung der Energieinfrastruktur ist für SustainUS eine politische Vorgabe, die der Auswahl der Klimaschutzstrategien vorauszugehen habe. Mit Verweis auf das Vorsorgeprinzip begründet die Organisation die Notwendigkeit von Transformationsprozessen. Folglich setzt sie einen steigenden Verbrauch fossiler Brennstoffe nicht voraus, sondern betont die Dringlichkeit der Überwindung der fossilistischen Wirtschaftsstruktur (vgl. SustainUS 2008). Damit vertritt sie eine marginalisierte Position. Tatsächlich wird in sehr vielen Stellungnahmen genau umgekehrt argumentiert (vgl. Tabelle 17). 
Tabelle 17 Artikulationen der reflexiven Naturbeherrschung

\begin{tabular}{|c|c|c|c|}
\hline $\begin{array}{l}\text { Artikulationen der reflexiven Natur- } \\
\text { beherrschung }\end{array}$ & Zustimmung & Einschränkung & Skepsis \\
\hline $\begin{array}{l}\text { CCS ist wichtig, weil der globale Ver- } \\
\text { brauch fossiler Brennstoffe ansteigen } \\
\text { wird. }\end{array}$ & $\begin{array}{l}\text { Australien } \\
\text { EU } \\
\text { Kanada } \\
\text { Neuseeland } \\
\text { Norwegen } \\
\text { Bellona } \\
\text { CCSA } \\
\text { CSLF } \\
\text { EURELECTRIC } \\
\text { ICC } \\
\text { IEEP } \\
\text { IETA } \\
\text { Indian Institute } \\
\text { IRGC } \\
\text { WCI } \\
\text { IPCC }\end{array}$ & & SustainUS \\
\hline $\begin{array}{l}\text { Mit Hilfe von CCS könnten viele Volks- } \\
\text { wirtschaften weiterhin fossile Brenn- } \\
\text { stoffe zur sicheren und zuverlässigen } \\
\text { Energieversorgung nutzen. }\end{array}$ & $\begin{array}{l}\text { EU } \\
\text { Bellona } \\
\text { CCSA } \\
\text { ICC } \\
\text { Indian Institute } \\
\text { IPIECA } \\
\text { WCI }\end{array}$ & & \\
\hline $\begin{array}{l}\text { Klimaschutzinstrumente müssen im Ein- } \\
\text { klang mit dem Recht der Entwicklungs- } \\
\text { und Schwellenländer auf Wirtschafts- } \\
\text { wachstum stehen. }\end{array}$ & $\begin{array}{l}\text { Norwegen } \\
\text { Bellona } \\
\text { ICC } \\
\text { Indian Institute } \\
\text { WCI }\end{array}$ & & \\
\hline $\begin{array}{l}\text { Die Speicherung von } \mathrm{CO}_{2} \text { in geolo- } \\
\text { gischen Formationen ist sicher. }\end{array}$ & $\begin{array}{l}\text { Australien } \\
\text { EU } \\
\text { Kanada } \\
\text { Katar } \\
\text { Norwegen } \\
\text { Bellona } \\
\text { CSLF } \\
\text { EURELECTRIC } \\
\text { IETA } \\
\text { WCI } \\
\text { IPCC }\end{array}$ & Brasilien & $\begin{array}{l}\text { Venezuela } \\
\text { Greenpeace } \\
\text { SustainUS }\end{array}$ \\
\hline
\end{tabular}


Ausgangspunkt ist in diesen Stellungnahmen der steigende Verbrauch fossiler Brennstoffe, der notwendig sei, um ein stetiges Wirtschaftswachstum zu garantieren. Damit wird der steigende Verbrauch fossiler Brennstoffe zum einen - mit Verweis auf wissenschaftliche Studien - als realistische Prognose und zum anderen als Voraussetzung für erwünschte gesellschaftliche Entwicklungsprozesse präsentiert. In dieser Artikulation im Sinne einer ökomodernen reflexiven Naturbeherrschung werden aktuelle Wirtschaftsstrukturen und Lebensstile in die Zukunft projiziert. Damit werden historisch gewachsene gesellschaftliche Funktionslogiken gesetzt, deren nicht-intendierten Nebenfolgen gemanagt werden sollen, ohne die Funktionslogiken selber ändern zu müssen. Auf diese Konstanten müssten die Klimaschutzstrategien reagieren, weshalb den CCS-Technologien besondere Aufmerksamkeit entgegen gebracht wird. CCS-Technologien gelten als Möglichkeit, fossile Brennstoffe weiterhin zur sicheren und zuverlässigen Energieversorgung zu nutzen und gleichzeitig die Klimaschutzziele erreichen zu können.

In diesem Zusammenhang geht beispielsweise die norwegische Regierung auf die Situation der Länder des globalen Südens ein (vgl. UNFCCC 2007b). In diesen Ländern sei Wirtschaftswachstum in besonderer Weise nötig, um Armut zu bekämpfen. Deshalb hätten die Nicht-Annex-B-Staaten ein Recht auf Wirtschaftswachstum, mit dem die Klimaschutzinstrumente im Einklang stehen müssen. Das naturbeherrschende Element besteht hier in der einseitigen Subsumtion der Natur unter gesellschaftliche Entwicklungsziele. Gleichzeitig sollen aber die ökologischen Folgeprobleme der Nutzung fossiler Brennstoffe bearbeitet werden. Diese reflexive Naturbeherrschung verfolgt somit einen ökologisch-ökonomischen Doppelnutzen.

Mit der reflexiven Naturbeherrschung wird zwar die Möglichkeit einer absoluten Kontrolle der Natur angesichts der ökologischen Krise ausgeschlossen, allerdings wird an dem Ziel festgehalten, die Kontrolle der Natur optimieren zu können. Diese Annahme zeigt sich in sehr vielen Stellungnahmen der CCS-CDMKontroverse, laut derer die Speicherung von $\mathrm{CO}_{2}$ in geologischen Formationen als sicher eingestuft werden könne (vgl. Tabelle 17). In der Regel wird dabei auf die diesbezüglichen Wahrscheinlichkeitsaussagen des IPCC verwiesen (vgl. Kapitel 5.3.3 und 5.5.1). Aus diesen Artikulationen einer reflexiven Naturbeherrschung ergeben sich Herausforderungen, für deren Bearbeitung ökomoderne Strategien eines reflexiven Fortschritts durch wissenschaftlich-technische Rationalität ins Feld geführt werden. Um Wiederholungen zu vermeiden, diskutiere ich deshalb im Folgenden die letzte Zeile von Tabelle 17 gemeinsam mit Tabelle 18. 
Tabelle 18 Artikulationen des reflexiven Fortschritts

\begin{tabular}{|c|c|c|c|}
\hline $\begin{array}{l}\text { Artikulationen des reflexiven } \\
\text { Fortschritts }\end{array}$ & Zustimmung & Einschränkung & Skepsis \\
\hline $\begin{array}{l}\text { Mit CCS-Technologien verbundene } \\
\text { Risiken können durch risikobewusste } \\
\text { Praktiken gemanagt werden. }\end{array}$ & $\begin{array}{l}\text { Australien } \\
\text { EU } \\
\text { Kanada } \\
\text { Katar } \\
\text { Norwegen } \\
\text { Bellona } \\
\text { CSLF } \\
\text { EURELECTRIC } \\
\text { IETA } \\
\text { WCI }\end{array}$ & Brasilien & $\begin{array}{l}\text { Venezuela } \\
\text { Greenpeace } \\
\text { SustainUS }\end{array}$ \\
\hline $\begin{array}{l}\text { Risiken können vermieden werden, in- } \\
\text { dem unreife Technologien wie CCS zu- } \\
\text { nächst nur in den Industrieländern zum } \\
\text { Einsatz kommen. }\end{array}$ & $\begin{array}{l}\text { Brasilien } \\
\text { Greenpeace } \\
W W F\end{array}$ & & \\
\hline
\end{tabular}

Als Voraussetzung für die sichere Speicherung wird von der CCS-befürwortenden Koalition in den UN-Klimaverhandlungen auf die Bedeutung risikobewusster Praktiken verwiesen. Die mit CCS-Technologien verbundenen Risiken sollen durch eine sorgfältige Auswahl geeigneter Speicherorte und ein sorgfältiges Monitoring gemanagt werden (vgl. Tabelle 18).

Für Greenpeace, SustainUS und die venezolanische Regierung reicht ein solcher risikobewusster Umgang allerdings nicht aus (vgl. Tabelle 18). Sie sehen in der Gefahr durch Leckagen ein nicht kalkulierbares Risiko, das ihrer Meinung nach gegen den Einsatz von CCS-Technologien - bzw. mindestens gegen die Aufnahme in den CDM - spreche. Greenpeace und SustainUS untermauern diese Einschätzung ebenfalls mit einem IPCC-Zitat, in dem der Mangel an direkter empirischer Beobachtung von $\mathrm{CO}_{2}$-Speicherung über längere Zeitspannen hinweg betont wird (vgl. Greenpeace 2007a: 2; IPCC 2005: 246; SustainUS 2008: 2).

Die Argumentation der brasilianischen Regierung geht in eine ähnliche Richtung, fokussiert aber auf die regionalspezifischen Kontextfaktoren, die aus ihrer Sicht entscheidend für den adäquaten Umgang mit Leckage-Risiken seien. Aus dem Vergleich mit dem Management von Atomkraftwerken schließt sie, dass elaborierte Versicherungssysteme und eine staatliche Überwachung nötig seien, um CCS-Technologien sicher anwenden zu können. Da diese beiden Aspekte ihrer Meinung nach derzeit nur von Industrieländern gewährleistet werden könnten, schränkt sie die Möglichkeit der sicheren Speicherung von $\mathrm{CO}_{2}$ in geologischen Formationen 
(vorerst) auf CCS-Projekte in Annex-B-Staaten ein (vgl. UNFCCC 2008; UNFCCC 2010c).

Als Konsequenz fordert die brasilianische Regierung - wie auch Greenpeace und der WWF - CCS-Technologien zunächst in Industrieländern weiter zu erproben (vgl. Tabelle 18). Insofern auf diese Weise die Perfektionierung der technologischen Entwicklung vorangetrieben werden soll, zeigen sich hier risikovermeidende Praktiken eines reflexiven Fortschritts im Sinne des ökomodernen Diskurses. Die unterschiedliche Gewichtung von risikobewussten und risikovermeidenden Praktiken in den Stellungnahmen der CCS-CDM-Kontroverse verweisen auf Aushandlungen innerhalb des ökomodernen Projekts. In erster Linie Greenpeace, aber auch die brasilianische Regierung und der WWF, setzen sich für eine vorsichtige Variante ökologischer Modernisierung ein. Im Großteil der Stellungnahmen wird dagegen der reflexive Anteil - hier vor allem die Relevanz, die risikovermeidenden Praktiken zugestanden wird - tendenziell zurückgedrängt.

Dies zeugt von einem generellen Vertrauen in die wissenschaftlich-technische Rationalität, von der man annimmt, dass sie ökologische und gesundheitliche Risiken erfolgreich managen könne. Allein die Sorge um gefährliche Folgen einer hohen Treibhausgaskonzentration in der Atmosphäre hat in der CCS-CDMKontroverse einen hohen Stellenwert. Symptomatisch dafür steht die Abwägung verschiedener Risiko-Arten in einer Stellungnahme der IETA (vgl. IETA 2008: 15). Dort plädiert die IETA für die Inkaufnahme der mit CCS-Projekten verbundenen Risiken, um deren Beitrag zur Reduzierung der Treibhausgasemissionen nutzen zu können. Schließlich würden im Vergleich zu den Risiken durch die CCS-Projekte von einem fortschreitenden Klimawandel weitaus größere Gefahren für die menschliche Entwicklung und die natürliche Umwelt ausgehen. In dieser Argumentation sollen die Klimaschutz- mit den Wachstumszielen in Einklang gebracht werden, um eine bestimmte, auf Wirtschaftswachstum basierende, gesellschaftliche Entwicklung zu schützen. Damit wird - wie in Tabelle 19 dargestellt - die ökomoderne Hegemoniestrategie des nachhaltigen Wachstums (re-)produziert.

Als Lösung für diesen Zielkonflikt zwischen Entwicklung und Klimaschutz gelten Technologien, die eine kohlenstoffarme Wirtschaft ermöglichen sollen. Entwicklung wird dabei mit Wirtschaftswachstum gleichgesetzt und Wirtschaftswachstum wiederum mit der Bereitstellung von Energie. Als nachhaltig gilt dann jede Form der Energieproduktion, die keine oder wenige Treibhausgasemissionen verursacht. Für die CCS-befürwortende Koalition in den UN-Klimaverhandlungen steht außer Frage, dass CCS eine der Technologien sei, die zu einem nachhaltigen Wachstum beitragen (vgl. Tabelle 19). 
Tabelle 19 Artikulationen des nachhaltige Wachstums

\begin{tabular}{|c|c|c|c|}
\hline $\begin{array}{l}\text { Artikulationen des nachhaltigen } \\
\text { Wachstums }\end{array}$ & Zustimmung & Einschränkung & Widerspruch \\
\hline $\begin{array}{l}\text { Um die Gefahr eines schwerwiegenden } \\
\text { Klimawandels abzuschwächen muss das } \\
\text { Wirtschaftswachstum in den Ländern des } \\
\text { globalen Südens nachhaltig sein. }\end{array}$ & $\begin{array}{l}\text { EU } \\
\text { Kanada } \\
\text { Norwegen } \\
\text { CCSA } \\
\text { Indian Institute } \\
\text { WCI }\end{array}$ & & \\
\hline $\begin{array}{l}\text { CCS-Technologien tragen } \mathrm{zu} \text { einem } \\
\text { nachhaltigen Wachstum bei. }\end{array}$ & $\begin{array}{l}\text { Australien } \\
\text { Kanada } \\
\text { Norwegen } \\
\text { Bellona } \\
\text { ICC } \\
\text { IETA } \\
\text { Indian Institute } \\
\text { WCI }\end{array}$ & Brasilien & $\begin{array}{l}\text { Venezuela } \\
\text { Greenpeace } \\
\text { SustainUS }\end{array}$ \\
\hline
\end{tabular}

Aus Sicht der brasilianischen Regierung trifft diese Argumentation nur auf die Anwendung in den Industrieländern zu, die aufgrund ihrer Abhängigkeit von fossilen Brennstoffen und ihrem großen Energieverbrauch auf Brückentechnologien wie CCS angewiesen seien (vgl. UNFCCC 2008; UNFCCC 2010c). In Ländern des globalen Südens würde der Einsatz von CCS-Technologien dagegen Anreize für einen vermehrten Verbrauch fossiler Brennstoffe schaffen. In diesen Ländern könnten CCS-Technologien nicht zu einem nachhaltigen Wachstum beitragen.

Für SustainUS gilt dieses Argument für CCS-Projekte generell - unabhängig vom Einsatzort. Die Organisation kritisiert, dass CCS-Technologien den Verbrauch fossiler Brennstoffe verstetigen und insofern nicht zu einer nachhaltigen Entwicklung beitragen würden (vgl. SustainUS 2008). Eine nachhaltige Entwicklung ist für SustainUS gerade durch die langfristige Abkehr von fossilen Brennstoffen und die Verwendung sicherer, erneuerbarer Technologien gekennzeichnet. Deshalb widerspricht sie der Einschätzung, dass CCS-Technologien ein nachhaltiges Wachstum schaffen würden.

Die venezolanische Regierung kommt zum gleichen Schluss, argumentiert aber mit den Risiken der CCS-Technologie. Aufgrund der Gefahr von Leckagen könne nicht von einer permanenten Emissionsreduktion ausgegangen werden. Eine solche gesicherte Reduktion gilt in ihrer Stellungnahme als Grundvoraussetzung, damit Technologien als nachhaltig klassifiziert werden können. Weiterhin verweist die venezolanische Regierung auf die negativen lokalen Folgen von Leckagen, die der Idee des nachhaltigen Wachstums entgegen stünde (vgl. UNFCCC 2009a). 
Greenpeace argumentiert ebenfalls mit den lokalen Auswirkungen von CCSProjekten. Dabei behandelt Greenpeace die drei Aspekte des sogenannten Nachhaltigkeits-Dreiecks und artikuliert damit einen relativ umfassenden Nachhaltigkeitsbegriff (vgl. Greenpeace 2007c; Greenpeace 2008b). Greenpeace befürchtet einen Anstieg von Energie- und Rohstoffpreisen sowie vermehrte Umweltschäden durch Kohleabbau. Weiterhin spräche gegen CCS-Projekte, dass sie nur wenige Arbeitsplätze in den Zielländern schaffen würden. Greenpeace widerspricht damit der Einschätzung, dass CCS-Technologien zu einem nachhaltigen Wachstum beitragen könnten. Greenpeace und SustainUS vergleichen an mehreren Stellen CCSTechnologien mit erneuerbaren Energien und kommen zu dem Schluss, dass letztere nachhaltiges Wachstum generieren können und erstere nicht (vgl. Greenpeace 2008b; SustainUS 2008).

Dieser Vergleich wird in den Stellungnahmen der CCS-befürwortenden Koalition in den UN-Klimaverhandlungen nicht gezogen. Dort herrscht die Annahme vor, dass der Energiebedarf so hoch sei, dass sowohl erneuerbare Energien als auch CCS-Technologien angewendet werden müssten (vgl. Tabelle 14). Dies gelte insbesondere auch für die Länder des globalen Südens. Die norwegische Regierung beispielsweise betont, dass in diesen Ländern Wirtschaftswachstum unumgänglich für die Reduzierung von Armut sei. Gleichzeitig drohe die Gefahr eines schwerwiegenden Klimawandels, da Wirtschaftswachstum unweigerlich an den Anstieg des Primärenergieverbrauchs gekoppelt sei. Angesichts der Dringlichkeit der Klimaproblematik müsse der Zielkonflikt von Wachstum und Klimaschutz gerade auch in den Ländern des globalen Südens gelöst werden - was nur durch den Einsatz von Technologien wie CCS gelingen werde (vgl. UNFCCC 2007b).

Zusammenfassend lassen sich von der Analyse der verschiedenen Artikulationen in der CCS-CDM-Kontroverse Rückschlüsse auf die allgemeinen Positionen zum ökomodernen Projekt schließen. Wie Tabelle 20 zeigt, beziehen sich so gut wie alle Akteur_innen auf die Grundannahmen und Hegemoniestrategien des ökomodernen Projekts. ${ }^{69}$ Allein die Position von SustainUS lässt sich nicht im ökomodernen Projekt verorten. Sie ist die einzige Organisation, die an Klimaschutztechnologien Kriterien anlegt, die über ein ökomodernes Projekt hinausweisen. Im Hinblick auf die von ihr geforderte gerechte Transformation zu einer Gesellschaft, die gar nicht oder weniger von fossilen Brennstoffen abhängig ist, schätzt sie den mög-

69 Einige Akteur_innen tauchen in Tabelle 20 gar nicht auf, weil ihre Stellungnahmen so kurz und/oder detailliert sind, dass eine allgemeine Einordnung auf dieser abstrakten Ebene nicht möglich ist. WWF steht in Klammern, weil auch dort nur wenige allgemeine Aussagen zum Klimawandel und zur (angestrebten) Klimapolitik getroffen werden, mir aber eine Zuordnung dennoch möglich scheint. 
lichen Beitrag von CCS-Technologien, die lediglich die Ultima Ratio sein könne, sehr skeptisch ein (vgl. SustainUS 2008). Damit greift SustainUS auf die antagonistische Forderung nach Klimagerechtigkeit zurück und thematisiert prinzipiell die Notwendigkeit umfassender Transformationsprozesse, die über ökomoderne Lösungsvorschläge deutlich hinaus gehen.

\section{Tabelle 20 Positionen zum ökomodernen Projekt}

\begin{tabular}{|l|l|l|l|}
\hline Positionen zum ökomodernen Projekt & Zustimmung & Einschränkung & Skepsis \\
\hline Ein Projekt der ökologischen Moderni- & Australien & & SustainUS \\
sierung ist die adäquate Reaktion auf & Brasilien & & \\
die ökologische Krise. & EU & & \\
& Indonesien & & \\
& Japan & & \\
& Kanada & & \\
& Neuseeland & & \\
& Norwegen & & \\
& Bellona & & \\
& CCSA & & \\
& EURELECTRIC & & \\
& Greenpeace & & \\
& ICC & & \\
& IEEP & & \\
& IETA & & \\
& WCI & & \\
& (WWF) & & \\
& IPCC & & \\
\hline
\end{tabular}

Dennoch kann man festhalten, dass die CCS-CDM-Kontroverse letztlich innerhalb des ökomodernen Projekts ausgetragen wurde. Antagonistische, politisierende Artikulationen finden sich lediglich an den Rändern des UN-Klimaregimes - bei so wenig einflussreichen Akteur_innen wie SustainUS - und in anderen Arenen. Dies ist unter anderem auf die große Bedeutung von Schlüsseldokumenten wie der Klimarahmenkonvention oder des Kyoto-Protokolls zurückzuführen, in denen ökomoderne Prinzipien verankert wurden (vgl. Kapitel 5.1.3). Auf die in diesen Dokumenten erzielten Konsense wird bei der Positionierung regelmäßig Bezug genommen, um Legitimität für die eigene Position herzustellen. Sie bilden somit einen Rahmen innerhalb dessen Aussagen als legitim und konsensfähig gelten. Über diesen permanenten Rückgriff wird wiederum die Bedeutung der zitierten Dokumente stetig (re-)produziert.

In der CCS-CDM-Kontroverse gab es also eine weitestgehende Übereinstimmung in Bezug auf den (ökomodernen) Deutungsrahmen. Die Konflikte entzündeten sich an der Frage der weiteren Ausgestaltung des ökomodernen Projekts. 
In Tabelle 21 sind die verschiedenen Positionen zur Frage abgebildet, ob CCSTechnologien ein sinnvolles Element des ökomodernen Projekts darstellen oder nicht.

Tabelle 21 Positionen zur Einbeziehung von CCS ins ökomoderne Projekt

\begin{tabular}{|l|l|l|l|}
\hline $\begin{array}{l}\text { Positionen zur Einbeziehung von } \\
\text { CCS ins ökomoderne Projekt }\end{array}$ & Zustimmung & Einschränkung & Skepsis \\
CCS-Technologien stellen ein sinn- & Australien & Brasilien & Greenpeace \\
volles Element des ökomodernen & EU & $(W W F)$ & \\
Projekts dar. & Indonesien & & \\
& Japan & & \\
Kanada & Neuseeland & & \\
Norwegen & & \\
Bellona & & \\
& CCSA & & \\
& EURELECTRIC & & \\
ICC & & \\
IEEP & & \\
IETA & WCI & & \\
& IPCC & & \\
\hline
\end{tabular}

In Tabelle 21 sind allein die Akteur_innen vertreten, die sich prinzipiell ökomodern positioniert haben - SustainUS ist also nicht aufgeführt. Für die meisten von ihnen gehören CCS-Technologien, aufgrund ihres vom IPCC diagnostizierten großen Potenzials zur Senkung von Treibhausgasemissionen, zu den sinnvollen Elementen des Portfolios technologischer Optionen, die es weiter zu fördern und zu entwickeln gelte (vgl. Tabelle 21).

Die brasilianische Regierung und Greenpeace argumentieren zwar ebenfalls innerhalb des ökomodernen Diskurses, allerdings bewerten sie CCS-Technologien etwas skeptischer. Für die brasilianische Regierung beschränkt sich die Bedeutung von CCS als Brückentechnologie zunächst auf die Annex-B-Staaten (vgl. UNFCCC 2008; UNFCCC 2010c). Langfristig schließt sie den Einsatz von CCS-Technologien in Nicht-Annex-B-Staaten zwar nicht aus, allerdings sollten sie nicht über den CDM gefördert werden. Damit schränkt sie die Bedeutung von CCS-Technologien innerhalb des ökomodernen Projekts ein. Der WWF vertritt eine ähnliche Position, arbeitet aber die Bezüge der CCS-CDM-Kontroverse zur internationalen Klimapolitik insgesamt kaum heraus, weshalb die Organisation hier in Klammern aufgeführt ist (vgl. WWF 2007). 
Für Greenpeace ist noch nicht entschieden, ob CCS-Technologien tatsächlich zu einer ökologischen Modernisierung beitragen können. Deshalb stehen sie der Förderung von CCS-Technologien insgesamt kritisch gegenüber, vor allem wenn dies zu einer Kürzung der Fördermittel für erneuerbare Technologien führt. Die Zielkonflikte mit erneuerbaren Energien und die Risiken, welche die brasilianische Regierung für die Anwendung in Nicht-Annex-B-Staaten sieht, sind für Greenpeace allgemein gültige Probleme von CCS-Technologien, die unabhängig vom Einsatzort zu negativen Konsequenzen führen können. Deshalb ist Greenpeace skeptisch, ob CCS-Technologien ein sinnvolles Element des ökomodernen Projekts darstellen können (vgl. Greenpeace 2008b).

\subsection{SyNTHESE: CCS-KonflikTE IN DER KLIMAPOLITIK}

Über die nun folgende Zusammenführung der Ergebnisse aus den vorangegangenen Kapiteln werden die Besonderheiten des UN-Klimaregimes als spezifische Diskursarena deutlich. Darüber hinaus stellt die Synthese eine wichtige Ergänzung zur bisherigen Analyse des Verhältnisses der CCS-CDM-Kontroverse zum ökomodernem Projekt (vgl. Kapitel 5.4.4) dar.

Konkret rekapituliere ich im Folgenden den Einfluss des IPCC in der CCSCDM-Kontroverse (5.5.1). Anschließend beschreibe ich am Beispiel der CCSCDM-Kontroverse die arenenspezifische Diskurs-Strukturierung des UN-Klimaregimes (5.5.2) und gehe auf die damit verbundenen Unterschiede zwischen der CCS-CDM-Kontroverse in den UN-Klimaverhandlungen und den CCS-Konflikten in anderen Arenen ein (5.5.3). Abschließend arbeite ich den grundlegenden Konflikt über die Ausgestaltung des ökomodernen Projekts heraus, welcher sich paradigmatisch in den Auseinandersetzungen um CCS-Technologien zeigt (5.5.4).

\subsubsection{Die Bedeutung des IPCC in der CCS-CDM-Kontroverse}

So wie der IPCC insgesamt einen starken Einfluss auf die UN-Klimaverhandlungen hat (vgl. Kapitel 5.3.1), war der CCS-Sonderbericht des IPCC wichtig für den Verlauf der CCS-CDM-Kontroverse. In vielen Stellungnahmen wird auf den IPCC SRCCS verwiesen, um die eigene Position mit wissenschaftlichen Aussagen und Prognosen zu untermauern und zu legitimieren (vgl. Tabelle 22). 
Tabelle 22 Verweise auf den IPCC und die IEA und in den Stellungnahmen

\begin{tabular}{|c|c|c|}
\hline Jahr & Verweis auf IPCC & Verweis auf IEA \\
\hline 2006 & \begin{tabular}{|l} 
Brasilien \\
EU \\
Japan \\
Kanada \\
Katar \\
Norwegen \\
Schweiz
\end{tabular} & Kanada \\
\hline 2007 & \begin{tabular}{|l} 
EU \\
Japan \\
Kanada \\
Norwegen \\
Saudi-Arabien \\
Südkorea \\
Bellona \\
ForUM \\
Greenpeace \\
IEEP \\
IETA \\
WCI
\end{tabular} & $\begin{array}{l}\text { EU } \\
\text { Japan } \\
\text { Norwegen } \\
\text { Bellona } \\
\text { IEEP } \\
\text { IETA } \\
\text { WCI }\end{array}$ \\
\hline 2008 & $\begin{array}{l}\text { Brasilien } \\
\text { EU } \\
\text { Neuseeland } \\
\text { Norwegen } \\
\text { Saudi-Arabien } \\
\text { CCSA } \\
\text { CSLF } \\
\text { Greenpeace } \\
\text { IETA } \\
\text { SustainUS } \\
\text { WCI }\end{array}$ & $\begin{array}{l}\text { Neuseeland } \\
\text { Norwegen } \\
\text { CCSA } \\
\text { CSLF } \\
\text { ICC } \\
\text { IETA } \\
\text { WCI }\end{array}$ \\
\hline 2009 & \begin{tabular}{|l} 
Australien \\
Venezuela \\
Indian Institute
\end{tabular} & Indian Institute \\
\hline 2010 & \begin{tabular}{|l|} 
Australien \\
Brasilien \\
EU \\
Indonesien \\
Norwegen \\
EURELECTRIC
\end{tabular} & \begin{tabular}{|l|} 
Australien \\
EU \\
Norwegen \\
Eskom \\
EURELECTRIC \\
SACCCS
\end{tabular} \\
\hline
\end{tabular}

In insgesamt 39 von 49 Stellungnahmen wird auf den IPCC - vor allem auf den CCS-Sonderbericht - zurückgegriffen (vgl. Tabelle 22). Interessant ist dabei, dass der IPCC sowohl von der CCS-befürwortenden Koalition in den UN-Klima- 
verhandlungen als auch von der CCS-kritischen Koalition in den UN-Klimaverhandlungen zitiert wird. Es stützen sich beispielsweise so unterschiedliche Organisationen wie Greenpeace und die IETA auf Zahlen des IPCC, um die Notwendigkeit drastischer Emissionsreduktionen zu betonen. Greenpeace leitet daraus die Präferenz für den schnellen Ausbau erneuerbarer Energien ab (vgl. Greenpeace 2008b), wohingegen die IETA damit die gleichberechtigte Förderung aller Klimaschutztechnologien, inklusive der CCS-Technologien, begründet (vgl. IETA 2007; IETA 2008). Von Seiten der CCS-befürwortenden Koalition in den UNKlimaverhandlungen ist der IPCC SRCCS eine bedeutsame Referenz, um das Potenzial von CCS-Technologien deutlich zu machen. Insgesamt sind Prognosen und Szenarien, die in der CCS-CDM-Kontroverse als objektive, weil wissenschaftlich geprüfte, Rahmenbedingungen artikuliert wurden, besonders wichtige Referenzpunkte. Diese Aussagen, beispielsweise über die zukünftige Energieinfrastruktur, suggerieren eine Planbarkeit und liefern die Parameter für Kosten-NutzenBerechnungen. Folgende vier Prognosen und Szenarien stellen wichtige thematische Fixpunkte der CCS-CDM-Kontroverse dar.

Tabelle 23 Verweise auf Prognosen des IPCC ${ }^{70}$

\begin{tabular}{|c|c|c|c|c|}
\hline Jahr & $\begin{array}{l}\text { Dominanz der fossilen } \\
\text { Energieversorgung }\end{array}$ & Potenzial & $\begin{array}{l}\text { Reduktion der } \\
\text { Kosten }\end{array}$ & $\begin{array}{l}\text { Sicherheit der } \\
\text { Endlagerung }\end{array}$ \\
\hline 2006 & Kanada & $\begin{array}{l}\text { EU } \\
\text { Kanada } \\
\text { Katar } \\
\text { Saudi-Arabien* }\end{array}$ & Kanada & $\begin{array}{l}\text { Japan } \\
\text { Kanada } \\
\text { Norwegen* }\end{array}$ \\
\hline 2007 & $\begin{array}{l}\text { Kanada } \\
\text { Norwegen }\end{array}$ & Bellona* & IETA & $\begin{array}{l}\text { EU } \\
\text { Kanada } \\
\text { Norwegen* } \\
\text { Bellona } \\
\text { IETA }\end{array}$ \\
\hline 2008 & & $\begin{array}{l}\text { Norwegen* } \\
\text { Saudi-Arabien* } \\
\text { CSLF } \\
\text { IETA } \\
\text { WCI }\end{array}$ & IETA & $\begin{array}{l}\text { Norwegen* } \\
\text { IETA }\end{array}$ \\
\hline 2009 & Australien & & & \\
\hline 2010 & Australien & $\begin{array}{l}\text { Norwegen* } \\
\text { EURELECTRIC }\end{array}$ & EURELECTRIC & $\begin{array}{l}\text { Australien } \\
\text { Norwegen }\end{array}$ \\
\hline
\end{tabular}

70 Bei den mit * markierten Stellungnahmen werden die Prognosen des IPCC nur indirekt zitiert. Die konkreten Zahlenwerte werden dort nicht genannt. 
1) Der Anteil fossiler Brennstoffe am Primärenergieverbrauch wird dominant bleiben.

Die Akteur_innen der CCS-befürwortenden Koalition in den UN-Klimaverhandlungen verweisen häufig auf die Prognose, dass mindestens bis zur Mitte des Jahrhunderts der Anteil fossiler Brennstoffe am Primärenergieverbrauch dominant bleiben wird (vgl. Tabelle 23). Konkret wird stets folgender Satz aus der Zusammenfassung für politische Entscheidungsträger_innen zitiert: „Most scenarios project that the supply of primary energy will continue to be dominated by fossil fuels until at least the middle of the century." (IPCC 2005: 3) In solchen Szenarien wird die gegenwärtige Energieinfrastruktur als Ausgangspunkt genommen und in die $\mathrm{Zu}$ kunft extrapoliert (vgl. Scheer 2013: 138). In der CCS-CDM-Kontroverse werden diese Szenarien, zumindest von der CCS-befürwortenden Koalition in den UNKlimaverhandlungen, als unveränderliche Rahmenbedingung interpretiert, innerhalb derer die Bedeutung von CCS-Technologien diskutiert wird.

\section{2) CCS-Technologien haben großes Potenzial zur Reduktion von Treibhausgas-} emissionen.

Die Annahme über die Fortführung der fossilen Energieinfrastruktur ist entscheidend für das Brückentechnologie-Argument und für die Abschätzung des Potenzials von CCS-Technologien (zur Reduktion von Treibhausgasemissionen beitragen zu können). Auch für diesen Punkt gibt es eine zentrale Stelle in der Zusammenfassung, die mehrfach zitiert wird (vgl. Tabelle 23; bei den mit* markierten Stellungnahmen wird die Aussage des IPCC zum Potenzial der CCS-Technologien allerdings nur indirekt zitiert, die konkreten Zahlenwerte werden dort nicht genannt). Aufgrund der langen und komplizierten Satzkonstruktion werden dabei stets ausschließlich die hier kursiv gedruckten Teile wiedergegeben:

„In most scenarios for stabilization of atmospheric greenhouse gas concentrations between 450 and 750 ppmv $\mathrm{CO}_{2}$ and in a least-cost portfolio of mitigation options, the economic potential of CCS would amount to 220-2,200 $\mathrm{GtCO}_{2}(60-600 \mathrm{GtC})$ cumulatively, which would mean that CCS contributes $15-55 \%$ to the cumulative mitigation effort worldwide until 2100, averaged over a range of baseline scenarios." (IPCC 2005: 12; Hervorhebungen T. K.)

Mit dem Verweis auf die Mengen- und Prozentangaben begründet die CCSbefürwortende Koalition in den UN-Klimaverhandlungen das große Potenzial von CCS-Technologien. Insgesamt ist auffällig, dass besonders häufig quantitative Aussagen und Prognosen des IPCC zur Untermauerung eigener Argumente verwendet werden. Hier zeigt sich, ,dass konkrete Zahlenwerte als thematischer Anker für 
Begründungszusammenhänge und Argumentationen einen zentralen Stellenwert haben, weil sie Sachverhalte zuspitzen und dadurch ,Fakten schaffen“" (Scheer 2013: 245f). Über die regelmäßige Wiederholung sind solche mit Zahlen unterlegten Aussagen in der Lage, Bezugspunkte der Auseinandersetzungen zu fixieren (vgl. Scheer 2013: 246). Die Prognose zum großen Potenzial von CCS-Technologien ist eine solche Aussage, die in mehreren Stellungnahmen verschiedener Akteur_innen auftaucht (vgl. Tabelle 23).

\section{3) CCS-Technologien senken die Kosten der Emissionsreduktionen.}

Ein weiterer Eckpunkt in der Argumentationslinie der CCS-befürwortenden Koalition in den UN-Klimaverhandlungen ist die Prognose des IPCC, dass CCS-Technologien als Element des Portfolios die Kosten der Reduktion von Treibhausgasemissionen senken können (vgl. Tabelle 23). Dazu wird ein konkreter Satz aus der Zusammenfassung in einigen Stellungnahmen direkt oder indirekt zitiert: „CCS has the potential to reduce overall mitigation costs and increase flexibility in achieving greenhouse gas emission reductions.“ (IPCC 2005: 3) Unter welchen Bedingungen und bei welchen Reduktionszielen diese Aussage zutreffen könnte, wird in der CCS-CDM-Kontroverse nicht diskutiert.

\section{4) Die $\mathrm{CO}_{2}$-Speicherung ist sicher.}

Die vermutlich wichtigste Prognose im IPCC SRCCS - zumindest die in der CCSCDM-Kontroverse am meisten zitierte - behandelt die Frage der Sicherheit der Endlagerung von $\mathrm{CO}_{2}$ in geologischen Formationen (vgl. Tabelle 23):

„Observations from engineered and natural analogues as well as models suggest that the fraction retained in appropriately selected and managed geological reservoirs is very likely to exceed $99 \%$ over 100 years and is likely to exceed $99 \%$ over 1,000 years." (IPCC 2005: 14)

Diese Wahrscheinlichkeitsaussage hat einen besonderen Stellenwert, weil sie als Gegenargument gegen mögliche Bedenken und geäußerte Kritik in Bezug auf die mit CCS-Technologien verbundenen Risiken verwendet wird. Dabei ist es nicht überraschend, dass die CCS-befürwortende Koalition in den UN-Klimaverhandlungen exakt diese Stelle wiederholt zitiert (vgl. Tabelle 23; bei den mit * markierten Stellungnahmen der norwegischen Regierung wird die Aussage des IPCC zur Sicherheit der Endlagerung allerdings nur indirekt zitiert, die konkreten Zahlenwerte werden dort nicht genannt). Schließlich vermitteln Zahlen „einen wissenschaftlichen Anspruch auf Neutralität, Objektivität und Exaktheit - und besitzen so eine große Überzeugungskraft" (Scheer 2013: 174). 
Dieser „Glaubwürdigkeitsvorsprung“ (Scheer 2013: 176) variiert allerdings je nach Perspektive des/der Rezipient_in und hängt von dessen eigener Überzeugung sowie von dessen Einschätzung der Vertrauenswürdigkeit der Urheberschaft ab (vgl. Scheer 2013: 176f). In dem Zusammenhang ist die Autorität des IPCC eine entscheidende Größe. Aufgrund seiner bedeutenden Stellung in den UN-Klimaverhandlungen ist der IPCC in der Lage, über Zahlen, Szenarien und Prognosen Deutungsmuster zu prägen (vgl. Kapitel 5.3.1). Diese Definitionsmacht des IPCC zeigt sich in der CCS-CDM-Kontroverse auch insofern, als dass sich die CCSkritische Koalition in den UN-Klimaverhandlungen ebenfalls auf den IPCC SRCCS bezieht, obwohl dieser Sonderbericht im Vergleich zu einigen Studien anderer Institutionen tendenziell optimistisch ausfiel. ${ }^{71}$ Da Greenpeace und SustainUS die Sicherheit der Endlagerung von $\mathrm{CO}_{2}$ in geologischen Formationen skeptisch einschätzen, zitieren sie - im Gegensatz zur CCS-befürwortenden Koalition in den UN-Klimaverhandlungen - nicht die genannte diesbezügliche Wahrscheinlichkeitsaussage aus der Zusammenfassung des IPCC SRCCS. Sie verweisen auf eine Stelle im Hauptteil des Sonderberichts, in der die kurzen Laufzeiten der bisherigen CCSProjekte als Grund für das Fehlen direkter empirischer Erkenntnisse über die Sicherheit der $\mathrm{CO}_{2}$-Lagerung angegeben werden (vgl. Greenpeace 2007a: 2; IPCC 2005: 246; SustainUS 2008: 2).

Nach der Übersicht über die konkreten Prognosen und Szenarien, die besonders häufig zitiert werden, fasse ich nun mit drei allgemeinen Beobachtungen die spezifische Bedeutung des IPCC für die CCS-CDM-Kontroverse zusammen.

\section{1) Es werden in erster Linie konkrete Zahlenwerte und Wahrscheinlichkeits- aussagen zitiert.}

Durch ihre Wiederholung in verschiedenen Stellungnahmen haben die konkreten Zahlenwerte und Wahrscheinlichkeitsaussagen als ,thematische Anker ${ }^{6}$ und ,geschaffene Fakten“ (vgl. Scheer 2013: 245f) eine strukturierende Wirkung auf die UN-Klimaverhandlungen. Die Folge ist, dass beispielsweise über maximal zulässige Risiken und Leckageraten, über Monitoring sowie über die Vergabe bzw. Rückgabe von permanenten oder temporären Emissionsberechtigungen verhandelt wird. Die Risiken sollen abgeschätzt und gemanagt werden. Eine strikte Vermeidung des Risikos aufgrund unvollständiger Wissensbasis (im Sinne des Vorsorgeprinzips) hat sich bei der CCS-CDM-Kontroverse dagegen allein in Bezug auf die TiefseeSpeicherung durchgesetzt.

71 In einer Studie der EU aus dem Jahr 2008 wird beispielsweise mit 50 bis 500 mal höheren Leckageraten gerechnet (vgl. Meadowcroft/Langhelle 2009a: 283). 
2) Die Zusammenfassungen für politische Entscheidungsträger_innen sind besonders relevant für politische Aushandlungsprozesse.

In den Stellungnahmen der CCS-CDM-Kontroverse wird in nahezu allen Fällen auf die Zusammenfassungen für politische Entscheidungsträger_innen des IPCC SRCCS zurückgegriffen. Es ist eine große Ausnahme wenn Stellen aus den Hauptteilen der IPCC-Berichte zitiert werden. Im genannten Beispiel verweisen Greenpeace und SustainUS auf Aussagen aus dem Hauptteil des IPCC SRCCS, um der zahlenbasierten Prognose, mit der die CCS-befürwortende Koalition in den UNKlimaverhandlungen die Sicherheit der Speicherung in geologischen Formationen untermauerte, etwas entgegensetzen zu können.

\section{3) Der IPCC genießt bei allen Akteur_innen Autorität.}

Sowohl die CCS-befürwortende Koalition in den UN-Klimaverhandlungen als auch die CCS-kritische Koalition in den UN-Klimaverhandlungen greifen auf den IPCC als Legitimationsressource zurück. Für die CCS-befürwortende Koalition in den UN-Klimaverhandlungen stellt die IEA ebenfalls eine wichtige Referenz dar, die in insgesamt 22 Stellungnahmen als Informationsquelle angeführt wird (vgl. Tabelle 22). Allerdings taucht die IEA in keiner der Stellungnahmen der CCS-kritischen Koalition auf. Dieser Vergleich verdeutlicht die besondere Stellung des IPCC als von allen Akteur_innen anerkannte Autorität. Der IPCC stellt die wissenschaftliche Basis der Klimaverhandlungen bereit und definiert damit die Grenzen des Denkund Machbaren in den Klimaverhandlungen. Wie die Klimarahmenkonvention und das Kyoto-Protokoll stellt der IPCC eine wichtige Institution der UN-Klimaverhandlungen dar, auf die Bezug genommen wird, um die Legitimität und Konsensfähigkeit der eigenen Position zu demonstrieren.

\subsubsection{Die Diskurs-Strukturierung des UN-Klimaregimes}

Neben dem IPCC SRCCS sind die beiden Schlüsseldokumente der internationalen Klimapolitik - die Klimarahmenkonvention und das Kyoto-Protokoll - wichtige Referenzen in der CCS-CDM-Kontroverse. In den UN-Klimaverhandlungen beziehen sich die Akteur_innen häufig und stets positiv auf diese Dokumente. Dies trifft auch auf Länder und Beobachterorganisationen $\mathrm{zu}$, die in anderen Arenen ${ }^{72}$ eine

72 Die anderen Arenen können sich hinsichtlich ihrer skalaren Ebene unterscheiden, sind also beispielsweise auf der nationalstaatlichen oder regionalen Ebene angesiedelt. Ein weiterer Unterschied kann in der Einbettung in ein anderes Politikfeld, beispielsweise der Wirtschaftspolitik, bestehen. 
differente Position vertreten und sich dabei auch auf andere Institutionen berufen. Jede Diskursarena ist durch etablierte Sprecher_innenpositionen und durch bestimmte Grenzen des Legitimen geprägt, so auch die UN-Klimaverhandlungen. Die Grenzen werden durch die beteiligten Akteur_innen (re-)produziert. Im Falle des UN-Klimaregimes erfolgt dies über die Bezugnahme auf die Prinzipien und Ziele der Klimarahmenkonvention, die Klimaschutzziele und -instrumente des KyotoProtokolls sowie die Problemdefinitionen und Szenarien des IPCC. Die arenenspezifische Diskurs-Strukturierung sorgt für die Dominanz ökomoderner Artikulationen in den UN-Klimaverhandlungen. Schließlich liegen sowohl der Klimarahmenkonvention und dem Kyoto-Protokoll (vgl. Kapitel 5.1.3) als auch der Arbeit des IPCC (vgl. Kapitel 5.3.4) ökomoderne Grundannahmen und Hegemoniestrategien zugrunde. Innerhalb der CCS-CDM-Kontroverse vertreten nahezu alle Akteur_innen - mit Ausnahme der Beobachterorganisation SustainUS - ihre jeweilige Position innerhalb eines ökomodernen Grundkonsenses. In anderen Arenen, beispielsweise auf nationalstaatlicher Ebene oder in ökonomischen Regimen greifen einige Akteur_innen durchaus andere Argumente auf, wie im anschließenden Kapitel 5.5.3 deutlich wird.

Die Anpassung an eine arenenspezifische Diskursstruktur wird durch die textbasierte Arbeit der UN-Klimaverhandlungen und den Zwang zu Konsensentscheidungen verstärkt. Dabei gibt es einen fließenden Übergang zur intendierten, strategisch eingesetzten Artikulationsweise. Als Beispiel für eine solche strategische Positionierung könnte man die brasilianische Regierung anführen, die in ihrem eigenen Land CCS-Projekte fördert, in den UN-Klimaverhandlungen sich aber gegen die Anwendung von CCS-Technologien in Nicht-Annex-B-Staaten ausspricht. Ein Grund dafür ist ihre Befürchtung, dass die Aufnahme von CCS in den CDM andere CDM-Projekte, von denen Brasilien bislang stark profitiert, verdrängen würde. Dieses Argument würde allerdings in dieser Form in den Verhandlungen nicht als legitim erachtet werden. Unter anderem deshalb stellt die brasilianische Regierung die gesundheitlichen und ökologischen Risiken in den Vordergrund und bezweifelt die klimapolitische Wirkung von CCS-Technologien in Ländern des globalen Südens. ${ }^{73}$ Umgekehrt geht es vielen Akteur_innen der CCS-befürwortenden Koalition in den UN-Klimaverhandlungen in erster Linie um die Absicherung der fossilen Industrie und den Bau neuer fossiler Kraftwerke (vgl. Kapitel 5.5.3). Auch derartige Argumente würden nicht als legitim gelten und werden deshalb in klimapolitische Begründungen von CCS-Technologien übersetzt. Der Effekt der ökomodernen Artikulationen ist in jedem Fall - unabhängig der ihnen zugrunde liegenden

73 Es gibt daneben auch andere Gründe für die Positionierung Brasiliens, beispielsweise das besondere Interesse an der ökologischen Integrität des CDM (vgl. Kapitel 5.4.3.2). 
Intentionen - eine (Re-)Produktion des ökomodernen Diskurses. Allerdings ist mit jeder (Re-)Artikulierung eines Diskurses auch eine Abwandlung oder eine Akzentverschiebung verbunden. Das lässt sich auch im Fall der CCS-CDM-Kontroverse zeigen, worauf ich in Kapitel 6 näher eingehen werde.

Wie in Kapitel 3.2.3 bereits betont, wurde das ökomoderne Projekt insbesondere auf der Ebene inter- und transnationaler Politik geformt und durchgesetzt (vgl. Hajer 1995: 101). Diese besondere Dominanz des ökomodernen Diskurses findet sich in den UN-Klimaverhandlungen bis heute. Das bedeutet allerdings nicht, dass keine abweichenden Positionen möglich wären, wie das Beispiel SustainUS zeigt. Für eine Verbreitung alternativer Positionen und eine damit verbundene Änderung der Diskurs-Strukturierung bedürfte es allerdings starker Dislokationen.

\subsubsection{CCS-Konflikte im UN-Klimaregime und in anderen Arenen}

Die in 5.5.2 herausgearbeitete arenenspezifische Diskurs-Strukturierung prägte die CCS-CDM-Kontroverse auf eine bestimmte Weise, wodurch sie sich von Auseinandersetzungen um CCS-Technologien, die in anderen Arenen (vgl. Fußnote 72 auf Seite 317) geführt werden, unterscheidet. Im Folgenden werde ich auf drei zentrale Unterschiede eingehen und damit die Analyse der CCS-CDM-Kontroverse um eine allgemeinere Betrachtung der politischen Konflikte um CCS-Technologien ergänzen. Dies ist hilfreich, um anschließend in Kapitel 5.5.4 diskutieren zu können, welche Bedeutung CCS-Technologien für die Auseinandersetzungen bezüglich der Bearbeitung der ökologischen Krise haben.

1) Die Artikulation der Kosten als bewältigbare Herausforderung vs. als entscheidender Grund für das Scheitern von CCS-Projekten.

Im Vergleich zu den meisten wissenschaftlichen Studien, in denen die hohen Kosten von CCS-Technologien als Hauptgrund für das Scheitern konkreter CCS-Projekte ausgemacht werden (für den gesamten Absatz vgl. Markusson/Ishii/Stephens 2012: 223, 238, 243; Shackley/Evar 2012: 161ff; Tjernshaugen/Langhelle 2009: 110ff), wird die Frage der Kosten in der CCS-CDM-Kontroverse weniger skeptisch thematisiert. In den UN-Klimaverhandlungen spielen andere Kritikpunkte eine weitaus größere Rolle. So wird in der CCS-CDM-Kontroverse zum einen befürchtet, dass der Einsatz von CCS-Technologien erneuerbare Energien ausbremsen und damit die fossilistische Energieinfrastruktur verstetigen würde. Zum anderen werden die mit CCS-Technologien verbundenen Risiken thematisiert. Diese beiden Kritikpunkte sind neben den Kosten tatsächlich wichtige Gründe für das Scheitern konkreter CCS-Projekte - allerdings nur dann, wenn sie erfolgreich in lokalem Widerstand 
von NGOs, Bürgerinitiativen und Klimaaktivist_innen artikuliert werden (vgl. Markusson/Ishii/Stephens 2012: 238). Häufig scheitern CCS-Projekte aber letztlich am Geld. Zum einen benötigen CCS-Projekte hohe Investitionssummen. Zum anderen wird oftmals davon ausgegangen, dass der laufende Betrieb der CCS-Projekte auf absehbare Zeit hohe Kosten verursachen würde. Tatsächlich rentieren sich CCSProjekte in fast allen Fällen betriebswirtschaftlich nur dann, wenn es strikte Klimaschutzziele gibt, die über Emissionsobergrenzen, Steuern, hohe Marktpreise für Emissionen oder auf andere Weise operationalisiert werden. ${ }^{74}$ Deshalb fokussieren Unternehmen in ihrem CCS-Engagement oftmals auf die Anwendung von CCSTechnologien in EOR-, EGR- oder ECBM-Projekten, in denen die verbesserte Förderung fossiler Brennstoffe die Kosten der CCS-Technologien senkt und unter gewissen Umständen - insbesondere in Kombination mit staatlichen Subventionen - zusätzliche Gewinne erwarten lässt (vgl. IPCC 2005: 10f).

Vor diesem Hintergrund könnte man vermuten, dass auch in der Arena der UNKlimaverhandlungen die hohen Kosten von CCS-Technologien als starkes Hemmnis für ihre Entwicklung und Anwendung artikuliert werden (vgl. Markusson/ Shackley/Evar 2012c: 267). Interessanterweise werden aber in der CCS-CDMKontroverse die hohen Kosten nur von Greenpeace als tatsächlich problematisch bezeichnet, wenngleich sie von vielen Akteur_innen als Herausforderung angesehen werden (vgl. Tabelle 8). Dies hängt sicherlich damit zusammen, dass in dieser Kontroverse über die Aufnahme von CCS in den CDM verhandelt wird und damit über zusätzliche finanzielle Anreize, die das Problem abmildern könnten - zumindest für CCS-Projekte in Nicht-Annex-B-Staaten. Allerdings kann dies nicht allein die geringe Bedeutung der Kostenfrage in der CCS-CDM-Kontroverse erklären. Offen bleibt, warum das Argument von Greenpeace, demzufolge die CDM-Förderung kostengünstigeren Klimaschutztechnologien vorbehalten bleiben soll, nicht stärker aufgegriffen wurde.

Die Beobachtung konkreter CCS-Aktivitäten gibt Aufschluss über Gründe, warum bestimmte Unternehmen und Länder CCS-Technologien trotz ihrer relativ hohen Kosten gegenüber anderen Klimaschutzmaßnahmen präferieren:

74 Zwei der vier existierenden CCS-Projekte im großindustriellen Maßstab - Sleipner und Snøhvit - befinden sich mit Norwegen in einem Land mit einer $\mathrm{CO}_{2}$-Steuer. Diese beiden Projekte sind aber auch dort nur profitabel, weil sie an Erdgasaufbereitungsanlagen angegliedert sind, in denen die Abscheidung des Kohlenstoffdioxids vergleichsweise günstig ist. Die Anwendung von CCS bei Gaskraftwerken würde sich dagegen auch in Norwegen trotz staatlicher Subventionen betriebswirtschaftlich nicht rentieren. Deshalb gibt es bis heute in Norwegen keine CCS-Gaskraftwerke, obwohl dies politisch angestrebt wurde (vgl. Kapitel 5.2.1 und 5.4.3.1). 
- Für die (fossilistischen) Energiekonzerne steht die mittel- und langfristige Absicherung ihres bisherigen Kerngeschäfts und die damit verknüpfte Oligopolstellung auf dem Spiel.

- Die Fortführung der fossilen Wirtschaft ist in Ländern mit einer starken fossilen Industrie - vermittelt über enge Verflechtungen - oftmals im gleichen Maße ein Interesse des Staates wie der Energiekonzerne. Darüber hinaus haben auf staatlicher Seite Energiesicherheit, Planungssicherheit und Steuerbarkeit der Energieinfrastruktur eine hohe Priorität (vgl. Langhelle/Meadowcroft 2009: 257ff). Um diese und andere politischen Ziele zu erreichen, subventionieren Staaten bestimmte Energieformen (vgl. Meadowcroft/Langhelle 2009a: 278). Viele Länder und die EU sehen in CCS-Projekten eine subventionierungswürdige Form der Energieproduktion, die - aufgrund ihrer Kompatibilität mit dem Status quo der zentralisierten Energieinfrastruktur - für die Durchsetzung ihrer politischen Ziele prädestiniert sei.

Diese Gründe für die Präferenz von CCS-Technologien verweisen bereits auf den zweiten Unterschied.

2) Die Wertschätzung von CCS-Technologien als Beitrag zum Klimaschutz vs. als Beitrag zur Energiesicherheit.

Zwischen den Begründungen der Förderwürdigkeit von CCS-Technologien auf nationalstaatlicher Ebene und in der CCS-CDM-Kontroverse lassen sich unterschiedliche Gewichtungen ausmachen. In der CCS-CDM-Kontroverse steht die Notwendigkeit von CCS-Technologien zur Erreichung von Klimaschutzzielen ganz klar im Vordergrund. Die CCS-befürwortende Koalition in den UN-Klimaverhandlungen argumentiert, dass CCS-Technologien aufgrund ihres Potenzials zur Vermeidung großer Mengen an Treibhausgasemissionen und ihrer wichtigen Funktion als Brückentechnologien zu einer kohlenstoffarmen Wirtschaft in den CDM aufgenommen werden sollten. Die EU und einige Beobachterorganisationen führen zwar auch in der CCS-CDM-Kontroverse zusätzlich das Argument an, dass viele Volkswirtschaften mit Hilfe von CCS-Technologien weiterhin fossile Brennstoffe zur sicheren und zuverlässigen Energieversorgung nutzen könnten (vgl. Tabelle 17). Dieses Argument der Energiesicherheit steht auf nationalstaatlicher Ebene bzw. auf EU-Ebene aber weitaus stärker im Vordergrund. Dabei werden Interessen und Vorstellungen artikuliert, die sehr viel mit aktuellen wirtschaftlichen Einschätzungen und eher wenig mit der Brücke zu einer neuen Energieinfrastruktur zu tun haben. Vergleichende Studien und Einzelfallanalysen haben deutlich gezeigt, dass das CCS-Engagement primär mit der mittel- bis langfristigen Absicherung der fossilen Wirtschaft begründet wird (für den gesamten Absatz vgl. Meadowcroft/ 
Langhelle 2009a: 277f). Dahinter stehen nicht nur die Interessen einer einflussreichen fossilen Industrie. Aufgrund enger Verflechtungen - die sich beispielsweise durch die Abhängigkeit von Steuereinnahmen, staatlichen Unternehmen oder staatlichen Anteilen an Konzernen ergeben - haben auch die Kommunen und Regierungen in Ländern mit fossiler Industrie ein anhaltendes Interesse an der Stabilisierung der fossilen Energiebasis. Neben diesen politischen und ökonomischen Pfadabhängigkeiten besteht in einigen Ländern und in der EU darüber hinaus der Wunsch, die Förderung fossiler Brennstoffe unter Umständen sogar zu erhöhen, wenn die fossilen Reserven dies zulassen. Je nach Region sollen CCS-Technologien dazu beitragen, den Export fossiler Brennstoffe fortzusetzen oder umgekehrt die Importabhängigkeit zu verringern (vgl. Kapitel 5.2.1 und 5.4.3). Die Hoffnung, mit CCS-Technologien die Nutzung fossiler Brennstoffe auf unbestimmte Zeit fortführen zu können, motiviert Länder mit fossilen Reserven, sich für CCSTechnologien einzusetzen - unabhängig davon, ob dies gerade als kostengünstigster oder als besonders ökologischer oder gerechter Weg zur Reduktion der Treibhausgasemissionen erscheint oder nicht.

Aus den genannten Gründen investieren einige Länder und die EU viel Geld in die Förderung von CCS-Technologien. Diese finanziellen und anderen Anreize der Staaten sind eine wichtige Voraussetzung für die Entwicklung von CCS-Technologien, da die Energieunternehmen nicht bereit sind, alleine die dafür nötigen Investitionskosten zu übernehmen. Energiekonzerne haben zwar durchaus ein Interesse daran, dass CCS-Technologien in der Zukunft für den Fall strikter Klimaschutzvorgaben zur Verfügung stehen und sie benötigen auch das Versprechen auf $\mathrm{CO}_{2}$-arme Kraftwerke, um ihr aktuelles Geschäft legitimieren zu können. Allerdings ist für Energiekonzerne die Entwicklung und Anwendung von CCS-Technologien ein zusätzlicher Kostenfaktor, den sie nur zu zahlen gewillt sind, wenn strikte - aktuelle oder für die nahe Zukunft angenommene - Klimaschutzvorgaben die Verbrennung fossiler Brennstoffe ohne CCS unmöglich oder unrentabel machen (vgl. Meadowcroft/Langhelle 2009a: 289). Die Folge ist, dass viele CCS-Projekte zu großen Teilen aus öffentlichen Mitteln finanziert werden (vgl. Stephens/Liu 2012: 139ff). Dies trifft vor allem auf den Einsatz von CCS bei Kohlekraftwerken zu. Einige Länder haben ein besonders großes Interesse an der Anwendung von CCSTechnologien bei Kohlekraftwerken, da sie ihre Kohlereserven ausschöpfen wollen, ohne extreme Emissionssteigerungen in Kauf nehmen zu müssen. Dieser Bereich wird auch deshalb verhältnismäßig stark staatlich gefördert, weil sich die Kohleindustrie in geringerem Maße als die Öl- und Gasindustrie für die Entwicklung von CCS-Technologien engagiert. Dieser Unterschied geht auf die technologische Nähe der Öl- und Gasindustrie zu CCS-Technologien zurück, die mit vielen CCS- 
Komponenten bereits in ihrem Kerngeschäft arbeiten. Ein weiterer Grund sind die höheren Kosten, die mit der Anwendung von CCS-Technologien bei Kohlekraftwerken verbunden sind (vgl. Stephens 2009: 36f; Vormedal 2008: 51f).

3) Die Fortführung der fossilen Energieinfrastruktur als unausweichliche Rahmenbedingung vs. als politisches Ziel.

Die Verfügbarkeit über fossile Reserven spielt eine große Rolle für den Einsatz von Regierungen und Konzernen für CCS-Technologien. Gleichzeitig ist die Verknüpfung von CCS-Technologien mit der fossilen Energieinfrastruktur ein entscheidender Kritikpunkt der CCS-kritischen Koalition. Auf diese Kritik reagiert die CCS-befürwortende Koalition in den UN-Klimaverhandlungen mit dem Argument, dass die Förderung fossiler Reserven eine unausweichliche Rahmenbedingung sei, mit der man zu rechnen habe. Auf der Ebene nationalstaatlicher oder konzernstrategischer Entscheidungen wird die Fortführung der fossilen Industrie allerdings als Ziel formuliert, für dessen Erreichung auf CCS-Technologien zurückgegriffen werden sollte.

Die weiter oben angeführten nationalstaatlichen und industriespezifischen Gründe für das CCS-Engagement sind in einem internationalen Umweltgremium wie den UN-Klimaverhandlungen nicht konsensfähig. Deshalb wird in dieser Arena das Klimaschutzpotenzial von CCS-Technologien, ihre Unersetzbarkeit als Brückentechnologie und ihr langfristiger Beitrag zur Senkung der Kosten des Klimaschutzes in den Vordergrund gerückt. Für diese Argumente ist allerdings die Annahme unerlässlich, dass die fossilen Brennstoffe mindestens bis Mitte des Jahrhunderts einen großen Anteil des globalen Energiebedarfs abdecken. Für die CCSbefürwortende Koalition in den UN-Klimaverhandlungen ist diese Annahme unstrittig, als Belege werden Prognosen des IPCC und der IEA angeführt (vgl. Tabellen 22 und 23). Damit wird die Dominanz der fossilen Energieversorgung in der CCSCDM-Kontroverse entpolitisiert und als gegebene Rahmenbedingung für CCSSzenarien artikuliert. Damit erscheint sie auf der Ebene der internationalen Klimaverhandlungen als Ausgangsbedingung für die Bewertung von CCS-Technologien.

Allerdings wird diese Annahme der Dominanz fossiler Brennstoffe - zumindest was die quantitative Ebene der konkreten Höhe des Anteils betrifft - von der CCSkritischen Koalition nicht im gleichen Maße geteilt. Dort wird die Argumentation umgekehrt und der Effekt von CCS-Technologien auf die Fortführung der fossilen Wirtschaft kritisiert (vgl. ForUM 2007; SustainUS 2008). Für NGOs wie Greenpeace ist nicht überzeugend, dass ausgerechnet fossile Brennstoffe Energiesicherheit garantieren sollten. Greenpeace gehört - anders als die Bellona Foundation oder der WWF - zu den Umweltorganisationen, die in der Abhängigkeit von fossi- 
len Brennstoffen die zentrale Ursache des Klimawandels sehen (vgl. Corry/Riesch 2012: 97). Deshalb bekommen in ihrer Positionierung die negativen Aspekte von CCS-Technologien mehr Gewicht. Aus ökologischen Gründen und im Hinblick auf eine Transformation zu einer kohlenstoffarmen Wirtschaft favorisieren NGOs wie Greenpeace die Förderung erneuerbarer Energien. In anderen Arenen artikulieren Umwelt-NGOs auch die Befürchtung, dass die Hoffnung auf CCS-Technologien zum Bau neuer fossiler Kraftwerke - die als ,CCS-Ready gelten - beitrage, ohne dass CCS letztlich erfolgreich umgesetzt werde (vgl. Corry/Riesch 2012: 104ff).

\subsubsection{Die Konflikte über die Ausgestaltung des ökomodernen Projekts}

In den Auseinandersetzungen um CCS-Technologien zeigen sich paradigmatisch zentrale Konflikte über die Ausgestaltung des ökomodernen Projekts. Die Konflikte entzünden sich letztlich an der Gewichtung der beiden Aspekte des ökomodernen Hegemonieversprechens: 1) der Bewältigung der ökologischen Krise und 2) der Stabilisierung gesellschaftlicher Strukturen (vgl. Kapitel 3.5).

Die CCS-kritische Koalition bezweifelt den Beitrag von CCS-Technologien zur Bewältigung der ökologischen Krise.

Aufgrund der Risiken und des Zielkonflikts mit erneuerbaren Energien schätzen Greenpeace und andere Akteur_innen CCS-Technologien nicht als sinnvolles Element eines ökomodernen Projekts ein. Die CCS-kritische Koalition plädiert stattdessen für eine Transformation der Energieinfrastruktur durch den massiven Ausbau erneuerbarer Energien (vgl. Corry/Riesch 2012: 104). Inwieweit damit ein Wandel gesellschaftlicher Strukturen und Kräfteverhältnisse einhergeht, wird vom ökomodernen Spektrum der CCS-kritischen Koalition nicht offensiv thematisiert. Allein radikalere NGOs - wie SustainUS in der CCS-CDM-Kontroverse - und Klimaaktivist_innen, die sich kritisch gegenüber dem ökomodernen Projekt positionieren, fordern explizit gesamtgesellschaftliche Transformationsprozesse. Beim ökomodernen Spektrum der CCS-kritischen Koalition bleibt offen, inwieweit sie einen solchen Wandel begrüßen würden. Bei einigen Akteur_innen ist allerdings anzunehmen, dass sie sich zum Teil aus strategischen Gründen nicht offensiv für gesamtgesellschaftliche Transformationsprozesse stark machen (vgl. Kapitel 3.2.6). 
Die CCS-befürwortende schätzt an CCS-Technologien ihr Versprechen auf eine fortgeführte Nutzung fossiler Brennstoffe.

Die CCS-befürwortende Koalition setzt sich für die Einbeziehung von CCS in das ökomoderne Projekt ein, da sie an CCS-Technologien gerade ihr Versprechen auf eine fortgeführte Nutzung fossiler Brennstoffe - als Garant für die Stabilisierung gesellschaftlicher Strukturen - schätzt. In den UN-Klimaverhandlungen wird diese Position nicht offensiv vertreten. Vielmehr wird die große Bedeutung fossiler Brennstoffe für zukünftige Energieinfrastrukturen als gegeben vorausgesetzt, als unveränderliche Tatsache, auf die reagiert werden muss. Damit wird der Konflikt über die Ausgestaltung des ökomodernen Projekts in der CCS-CDM-Kontroverse über die Wahl der adäquaten Technologien ausgetragen. Dabei war gerade der Fokus auf technologische Lösungen eine wichtige Voraussetzung für die breite Zustimmung verschiedener sozialer Kräfte zum ökomodernen Projekt.

In seiner Etablierungsphase ermöglichte die Hoffnung auf Lösungspotenziale durch innovative Technologien dem ökomodernen Diskurs, die Bedrohlichkeit der Ökologieproblematik anzuerkennen, ohne die als Sachzwang präsentierten Vorgaben ökonomischer Diskurse (Wirtschaftswachstum, Standortpolitik usw.) in Frage zu stellen. Mit dem ökomodernen Projekt entwickelte sich eine Umweltpolitik, die den Anspruch vertritt, die ökologische Krise mit den etablierten modernen Institutionen der Gesellschaft erfolgreich bearbeiten zu können. Mit der Durchsetzung des ökomodernen Konsenses in der Umweltpolitik wurde die Forderung nach gesamtgesellschaftlichen Transformationsprozessen auch bei Akteur_innen der Umweltbewegungen zurückgedrängt. In der Folge fokussierten viele NGOs, Umweltgruppen, Wissenschaftler_innen und ökologische Thinktanks auf die ökomoderne Forderung nach Effizienzsteigerung und der Förderung technologischer Innovationen (vgl. Kapitel 3.2.6).

Symptomatisch dafür ist der breite Konsens zur prinzipiellen Förderung erneuerbarer Energien. Allerdings lassen sich in den Auseinandersetzungen um die konkrete Ausrichtung und Förderung erneuerbarer Energien - zentral vs. dezentral, von großen Konzernen umgesetzt vs. in Bürgerhand, Offshorewindparks vs. Solargenossenschaften - Konflikte um gesellschaftliche Strukturen und soziale Kräfteverhältnisse ausmachen. Diese Konflikte wurden innerhalb des ökomodernen Projekts entpolitisiert, indem sie von vielen Akteur_innen nicht offensiv als Konflikte über gesellschaftliche Strukturen und soziale Kräfteverhältnisse geführt wurden. Stattdessen wurden die verschiedenen technologischen Optionen an dem unangefochten wichtigsten Entscheidungskriterium, der möglichst kostengünstigen Reduktion von Treibhausgasemissionen, gemessen. Dabei kamen die verschiedenen Akteur_innen durchaus zu unterschiedlichen Einschätzungen. Die Divergenzen in 
der Bewertung verschiedener Optionen lassen sich auf unterschiedliche Annahmen und Prognosen über zukünftige technologische, volkswirtschaftliche, klimapolitische und energiepolitische Entwicklungen zurückführen.

In Bezug auf CCS-Technologien gibt es ebenfalls unterschiedliche Aussagen zu den voraussichtlichen Kosten pro eingesparte Tonne Kohlenstoffdioxid. Dem liegen zum Teil unterschiedliche Annahmen über zu erwartende Entwicklungssprünge bei CCS-Technologien zugrunde, in erster Linie ergeben sie die Differenzen aber durch unterschiedliche Annahmen über die Entwicklung von Energieinfrastrukturen.

Im Fall von CCS ist aber nicht nur die Bedeutung gesellschaftlicher Strukturen für die Kosten der Technologien besonders evident, sondern auch umgekehrt der Effekt von den Technologien auf gesellschaftliche Transformationsprozesse. Mit CCS-Technologien wird die Trennung in die Input-Seite der Energieproduktion mit fossilen Brennstoffen und die Output-Seite der daraus entstehenden Emissionen (vgl. Brunnengräber et al. 2008: 188ff; Kapitel 3.4.3) auf die Spitze getrieben. CCS-Technologien sind allein unter der Voraussetzung, dass die Input-Seite unverändert bleibt, eine notwendige und je nach Kontextfaktoren unter Umständen auch vergleichsweise kostengünstige Klimaschutzoption. Deshalb brechen an CCSTechnologien die Konflikte um die Ausgestaltung des ökomodernen Projekts auf. Der ökomoderne Konsens, dass die Output-Seite, die Reduktion der Treibhausgasemissionen, für die Bedeutung von Klimaschutzoptionen entscheidend sei, bedeutet für kritische ökomoderne Diskursträger_innen wie Greenpeace keineswegs, dass die Input-Seite nicht angetastet werden dürfe. Für andere ökomoderne Diskursträger_innen wiederum ist die Möglichkeit der Fortführung der Input-Seite der Energieproduktion mit fossilen Brennstoffen eine zentrale Säule des ökomodernen Hegemonieversprechens.

Der Konflikt über die Ausgestaltung des ökomodernen Projekts ist Ausdruck einer Politisierung gesellschaftlicher Naturverhältnisse. Mit der vermehrten Planung und Durchführung konkreter CCS-Projekte besteht die Möglichkeit, dass sich die Konflikte über CCS-Technologien und damit über die Gewichtung der beiden Aspekte des ökomodernen Hegemonieversprechens zuspitzen. Entscheidend ist dabei, inwieweit explizit über die Bedeutung der fossilen Energieinfrastruktur als Garant bestimmter gesellschaftlicher Strukturen und Kräfteverhältnisse verhandelt wird. Je expliziter darüber gestritten wird, desto stärker tritt das Moment des Politischen hervor, in dem das doppelte ökomoderne Hegemonieversprechen als Ergebnis von Machtbeziehungen und als Entscheidung gegen alternative Möglichkeiten zur Bewältigung der ökologischen Krise artikuliert wird. 


\section{CCS und das ökomoderne Hegemonieprojekt}

Im Folgenden untersuche ich die Bedeutung der Auseinandersetzungen um CCSTechnologien für das ökomoderne Hegemonieprojekt. Durch die Analyse dieses Verhältnisses sollen Rückschlüsse auf den Status quo der hegemonialen Kämpfe um die Bearbeitung der ökologischen Krise gezogen werden. Die empirischen Ergebnisse aus Kapitel 5 werden somit in Bezug auf die in Kapitel 1.1 formulierten (und in Kapitel 4 präzisierten) Forschungsfragen zwei und drei zusammengefasst.

2) Welche Bedeutung haben die Konflikte um CCS-Technologien in den Auseinandersetzungen um die weitere Entwicklung des ökomodernen Projekts?

3) Welche Auswirkungen haben die Konflikte um CCS-Technologien auf die Auseinandersetzungen um die Bearbeitung der ökologischen Krise?

Dazu diskutiere ich in einem ersten Schritt das Scheitern vieler CCS-Projekte und arbeite heraus, inwiefern sich darin die Charakteristika und Grenzen des ökomodernen Projekts empirisch beobachten lassen (6.1). Anschließend interpretiere ich die Aufnahme von CCS in den CDM als Indiz für einen allgemeinen Trend der Einbeziehung von CCS-Technologien in das ökomoderne Projekt. Dabei zeige ich, wie durch die Einbeziehung von CCS bestimmte Tendenzen des ökomodernen Projekts verstärkt, abwandelt oder abgemildert werden. Weiterhin gehe ich auf den Einfluss der CCS-Community ein, die sich für die Förderung von CCS-Technologien einsetzt und erfolgreich die Aufnahme in den CDM vorantrieb (6.2). In einem letzten Schritt stelle ich Überlegungen über die mögliche Bedeutung von CCS für die weitere Entwicklung des ökomodernen Projekts an und fokussiere dabei auf die Abhängigkeit vom Erfolg von Technofixes (6.3). 


\subsection{Die Bedeutung des Scheiterns von CCS-Projekten}

In den letzten Jahren scheiterten einige CCS-Projekte in verschiedenen Industrieländern (vgl. Andresen/Butenschøn 2001: 350f; Markusson/Ishii/Stephens 2012: 223, 238, 243; Scrase/Watson 2009: 178; Shackley/Evar 2012: 161ff; Stephens/Liu 2012: 146; Tjernshaugen/Langhelle 2009: 110ff). Aufgrund der relativ hohen Anzahl dieser Fälle scheint mir deren Berücksichtigung eine wichtige Ergänzung zur Analyse der CCS-CDM-Kontroverse zu sein. Wie bereits dargelegt, scheitern die CCS-Projekte vor allem aufgrund zu hoher Investitionskosten und lokaler Proteste (vgl. Kapitel 5.2.1, 5.4.3 und 5.5.3). Dies bestätigt einige der in Kapitel 3 beschriebenen Grenzen und Charakteristika des ökomodernen Projekts.

Das Problem der hohen Investitionskosten verweist zunächst einmal auf das ökomoderne Primat der Betriebsökonomie. Da sich die CCS-Projekte unter den gegenwärtigen Bedingungen nur selten betriebswirtschaftlich rentieren, wurden viele CCS-Vorhaben verschoben, in verkleinertem Umfang umgesetzt oder ganz eingestellt. Es werden in erster Linie solche CCS-Projekte umgesetzt, die geringere Kosten verursachen (in der Anwendung bei Erdgasaufbereitungsanlagen) oder zu einer verbesserten Förderung fossiler Brennstoffe beitragen (EOR- und EGR-Projekte).

Dass sich CCS-Projekte betriebswirtschaftlich nicht rentieren, geht auf den eingeschränkten Einfluss ökologischer Diskurse innerhalb der Agglomeration hegemonialer Diskurse zurück. Selbst in stark ökomodern geprägten Ländern wie Dänemark, Deutschland, Großbritannien, Niederlande und Norwegen scheiterten CCSProjekte, weil sich die Geltung des ökomodernen Diskurses auf den Bereich der Umweltpolitik beschränkt. Jenseits der Gremien, Institutionen und Maßnahmenkonzepte, in denen explizit nach adäquaten Reaktionen auf ökologische Probleme gesucht wird, ist der Einfluss des ökomodernen Projekts gering. Dementsprechend unterliegen umweltpolitische Maßnahmen weiterhin der Dominanz ökonomischer Diskurse und damit den Vorgaben der Profitorientierung und der Standortpolitik (vgl. Kapitel 3.6). Die Folge ist, dass die Klimaschutzziele und ihre Operationalisierung über Steuern, Emissionsobergrenzen oder Marktmechanismen nicht strikt genug sind, um konventionelle fossile Kraftwerke unrentabel bzw. umgekehrt CCSProjekte rentabel werden zu lassen. Insofern verweist das Scheitern von CCSProjekten nicht nur auf die hohen Kosten von CCS-Technologien im Vergleich zu anderen Klimaschutzmaßnahmen, sondern auch insgesamt auf den mangelnden Einfluss ökologischer Diskurse jenseits umweltpolitischer Arenen.

Eine weitere Grenze des ökomodernen Projekts betrifft die Art des Konsenses, der durch den ökomodernen Diskurs hergestellt wird. Das ökomoderne Projekt zeichnet sich bislang durch einen passiven Konsens aus (vgl. Kapitel 3.6). Das be- 
deutet, dass einflussreiche gesellschaftliche Kräfte das ökomoderne Projekt zwar ohne aktive Zustimmung großer Teile der Bevölkerung etablieren, dabei jedoch auch nicht auf großen Widerstand treffen. Ein solcher passiver Konsens kann unter bestimmten Voraussetzungen durchaus stabil sein, insbesondere wenn eine gewisse Gleichgültigkeit gegenüber dem Thema herrscht. Diese Gleichgültigkeit kann aber schnell kippen, sobald es zu Situationen der Betroffenheit durch konkrete Entscheidungen kommt. So zeigt sich bei einigen CCS-Vorhaben die potenzielle Brüchigkeit eines passiven Konsenses im lokalen Widerstand von Anwohner_innen, Umweltgruppen und Klimaaktivist_innen. Im Vergleich zu ähnlich gelagerten Protesten gegen Windkraftanlagen oder Stromtrassen kommt bei CCS-Projekten verstärkend hinzu, dass es innerhalb der Anhänger_innen des ökomodernen Projekts größere Uneinigkeit als bei anderen Technologien gibt. Dementsprechend ist es für lokale Proteste leichter, die Umsetzung von CCS-Vorhaben zu verhindern. Um derartige Rückschläge zu vermeiden wird teilweise angestrebt, auf Offshore-Projekte auszuweichen, obwohl damit höhere Kosten verbunden sind (vgl. Román 2011: 396, 399; Shackley/Evar 2012: 161ff).

\subsection{Die Bedeutung des Erfolgs der CCS-Community}

Trotz der genannten Widerstände gibt es in Politik, Wirtschaft und Wissenschaft weiterhin eine starke CCS-Community, die sich erfolgreich für CCS-Technologien engagiert. Sie setzt nationale, EU-weite und internationale Förderprogramme durch und erreichte die Aufnahme von CCS in den CDM. In diesem Kapitel soll deshalb der Frage nachgegangen werden, was die anhaltende Unterstützung von CCS-Technologien durch eine CCS-befürwortende Koalition im Hinblick auf die weitere Entwicklung des ökomodernen Projekts bedeutet.

Wie in Kapitel 5.4.4 ausgeführt, wurde die Aufnahme von CCS in den CDM auf der Basis ökomoderner Grundannahmen und Hegemoniestrategien verhandelt. Dabei setzte sich die CCS-befürwortende Koalition in den UN-Klimaverhandlungen durch, für die CCS ein wichtiges Element des ökomodernen Projekts darstellt. Dies werte ich als starkes Indiz für einen arenenübergreifenden Trend zur Einbeziehung von CCS-Technologien in das ökomoderne Projekt. Dafür spricht der Einfluss, den internationale und transnationale Institutionen bei der Entwicklung der Umweltpolitik in den letzten beiden Jahrzehnten hatten (vgl. Busch/Jörgens/Tews 2005; Hajer 1995: 101). Allerdings ist davon auszugehen, dass die Bedeutung von CCSTechnologien für das ökomoderne Projekt weiterhin umkämpft ist und auf ganz verschiedenen Ebenen weiter ausgehandelt werden wird, in erster Linie anhand kon- 
kreter CCS-Vorhaben. Trotz dieser Einschränkung werde ich nun versuchen, aus der Beobachtung der CCS-CDM-Kontroverse in den UN-Klimaverhandlungen allgemeine Rückschlüsse darauf zu ziehen, wie in den Konflikten um CCS-Technologien ökomoderne Grundannahmen und Hegemoniestrategien (re-)produziert werden. Wie bei jeder Reproduktionsleistung werden auch hier bestimmte Tendenzen des ökomodernen Projekts verstärkt, abgewandelt oder abgemildert.

Der Einsatz für CCS-Technologien stellt eine Bestätigung des ökomodernen Inkrementalismus dar. CCS-Technologien lassen als klassische End-of-pipe-Technologien den bisherigen Produktionsprozess unangetastet. Dass sich CCS-Technologien so unkompliziert innerhalb des Status quo der Energieinfrastruktur implementieren lassen, wird vom IPCC und von anderen Akteur_innen der CCS-befürwortenden Koalition als spezifischer Wettbewerbsvorteil hervorgehoben. Von der CCS-kritischen Koalition wird dagegen die Blockierung von Transformationsprozessen als Nachteil von CCS-Technologien kritisiert. Insofern bedeutet eine Einbeziehung von CCS-Technologien ins ökomoderne Projekt eine Verstärkung des Inkrementalismus als favorisierten Entwicklungspfad.

Eng damit verknüpft ist die technokratische Vorstellung von Politik. CCS-Technologien stellen eine technologische Lösung für das isolierte Problem der erhöhten Treibhausgaskonzentration in der Atmosphäre dar. Ausgeklammert werden dabei sowohl Zusammenhänge zwischen verschiedenen ökologischen Problemen als auch gesamtgesellschaftliche Zusammenhänge, die beispielsweise soziale Kräfteverhältnisse betreffen. Die sozialen und ökologischen Problemlagen, die jenseits von Emissionen an die Förderung und den Verbrauch fossiler Brennstoffe gekoppelt sind, werden außen vor gelassen - obwohl oder gerade weil sie aufgrund des erhöhten Ressourceneinsatzes, der mit CCS-Technologien einhergeht, verstärkt werden. Die Dominanz fossiler Brennstoffe wird als gegebene Bedingung akzeptiert, die jenseits der Einflusssphäre gestaltender Politik gilt.

Vor diesem Hintergrund werden technologische Innovationen gesucht, um Treibhausgasemissionen reduzieren zu können. Dabei nehmen CCS-Technologien eine besondere Rolle ein, weil sie eine $\mathrm{CO}_{2}$-arme Nutzung fossiler Brennstoffe versprechen. In Bezug auf die Hegemoniestrategie des reflexiven Fortschritts durch wissenschaftlich-technische Rationalität lässt sich festhalten, dass die darin verankerten risikobewussten Praktiken wie Risikoabschätzung, Risikokommunikation und Risikomanagement von der CCS-befürwortenden Koalition durchaus ernst genommen werden. Allerdings geraten die risikovermeidenden Praktiken mit der Einbeziehung von CCS-Technologien ins ökomoderne Projekt in den Hintergrund. Schließlich sind mit der Anwendung von CCS-Technologien stets ökologische und gesundheitliche Risiken verbunden. Über diese Risiken gibt es keine direkten empi- 
rischen Daten aufgrund fehlender Langzeitstudien. Die bislang diskutierten Risikoprognosen beruhen auf ersten Monitoringergebnissen von CCS-Projekten über verhältnismäßig kurze Zeitspannen, auf Analogien zu anderen natürlichen oder künstlichen Speichervorgängen und auf Computersimulationen. Leckage-Risiken und damit beispielsweise auch die Verunreinigung von Grundwasserleitern können also nicht ausgeschlossen werden. Insofern stellen CCS-Technologien als Element eines ökomodernen Projekts die Schwächung seiner reflexiven (z. B. risikovermeidenden) Praktiken und eine forcierte Anpassung an ökonomisch begründete ,Sachzwänge‘ (z. B. Standortpolitik, Wachstum) dar.

Im Sinne einer Kontinuität der (reflexiven) Naturbeherrschung wird die (Re-)Produktion der gesellschaftlichen Naturverhältnisse weiterhin durch die Subsumtion der Natur unter die (historisch institutionalisierten) gesellschaftlichen Funktionslogiken bestimmt. Gleichzeitig zeugen die hohen Investitionssummen in CCS-Technologien davon, dass - vor allem in Umweltinstitutionen wie den UNKlimaverhandlungen und in stark ökomodern geprägten Staaten wie Norwegen eine fossile Energieversorgung ohne das Versprechen auf die Verringerung der Treibhausgasemissionen immer schwerer zu legitimieren ist. Damit ist allerdings keine prinzipielle Reflexion der Abhängigkeit von Natur bzw. der Nichtidentität der Natur als Quelle von Unsicherheit verbunden. Die Bedeutung von CCS-Technologien für das ökomoderne Projekt steht dagegen für die Bearbeitung der nicht-intendierten Nebenfolgen der Naturbeherrschung unter Inkaufnahme neuer Risiken, die berechnet und gemanagt werden sollen. Der Sachzwang zur „Erzielung eines ökologisch-ökonomischen Doppelnutzens“ (Jänicke 1988: 23) zeigt sich im Fall der CCS-Technologien nicht in Form eines direkten ökonomischen Nutzens, da CCSTechnologien als End-of-pipe-Technologien neben der Verringerung von Treibhausgasemissionen keine ökonomisch verwertbare Funktion haben - als Ausnahmen müssen hier die Anwendungen als EOR, EGR, ECBM sowie die Hoffnungen auf die Einnahmen durch den Export von CCS-Technologien genannt werden. Zentral ist aber der erhoffte indirekte Nutzen, durch CCS-Technologien die fossile Energieversorgung ungebremst fortführen zu können.

Dahinter steht die ungebrochene Bedeutung von Wirtschaftswachstum als Ziel gesellschaftlicher Entwicklung. Nur unter dieser Prämisse können CCS-Technologien als attraktiv gelten. Im Rahmen von Suffizienzstrategien, die unter den Labels Postwachstum, Degrowth oder Décroissance verhandelt werden, spielen CCS-Technologien dagegen keine Rolle. Umgekehrt stärkt die Hoffnung auf CCS-Technologien das wachstumsorientierte Entwicklungsmodell, das durch ökologische Modernisierungsprozesse nachhaltig gestaltet werden soll. 
In Bezug auf die Frage, welche Rolle dem Staat bei der Verfolgung dieses Entwicklungspfades zukommt, gab und gibt es innerhalb des ökomodernen Projekts verschiedene Positionen. So kann die Implementierung des ökomodernen Projekts durch staatliche Investitionen und/oder starre Obergrenzen für eingesetzte Ressourcen oder entstehende Emissionen forciert werden. Alternativ sind aber auch marktkonforme Anreizstrukturen denkbar. In den 1990er Jahren setzte sich - im Zuge eines allgemeinen Trends zur Neoliberalisierung - tendenziell der marktwirtschaftliche Weg durch, der über freiwillige Verpflichtungen der Unternehmen sowie marktorientierte Instrumente führt (vgl. Kapitel 3.2.5). Dieser Tendenz zum Trotz wird die Entwicklung und Anwendung von CCS-Technologien durch ein starkes Engagement einzelner Regierungen und der EU voran getrieben. Aufgrund der hohen Investitionssummen und der mit CCS-Projekten verbundenen ökonomischen, ökologischen und gesundheitlichen Risiken werden marktorientierte Instrumente alleine - zumindest unter den aktuellen Voraussetzungen - nicht zu einem großflächigen Einsatz von CCS-Technologien führen (für das Beispiel Großbritanniens vgl. Scrase/Watson 2009). CCS-Projekte werden in den meisten Fällen durch hohe Subventionszahlungen und andere staatliche Maßnahmen direkt unterstützt. Regierungen sind durchaus bereit, CCS-Projekte fördern, wenn diese ihren spezifischen Interessen entsprechen (vgl. Kapitel 5.2.1). Insofern kann man festhalten, dass mit einer Einbeziehung von CCS-Technologien in das ökomoderne Projekt eine Stärkung der staatlichen Regulierung der Energiewirtschaft bzw. eine Schwächung der marktliberalen Ausprägung des ökomodernen Projekts verbunden ist.

Dennoch ist es keineswegs so, dass die Entwicklung und Anwendung von CCSTechnologien allein auf staatliche Initiativen zurückgeht. Die meisten CCS-Projekte basieren auf Public-Private-Partnerships (vgl. Stephens/Liu 2012: 143ff). Vorangetrieben werden sie durch ein Netzwerk von Personen, deren beruflicher Werdegang mit der Entwicklung von CCS-Technologien verknüpft ist. In dieser international agierenden CCS-Community wirken Vertreter_innen von Energiekonzernen, Wirtschaftsverbänden, Regierungen, Hochschulen und Forschungsinstituten sowie in weitaus geringerer Zahl auch von NGOs wie Bellona (vgl. Stephens/Liu 2012: 146; Kapitel 5.3.2). $\mathrm{Zu}$ ihren geteilten Überzeugungen gehören die Annahmen, dass der Klimawandel eine ernsthafte Bedrohung darstelt und dass die fortgesetzte Nutzung fossiler Brennstoffe unvermeidbar ist (vgl. Stephens et al. 2011: 389). Aus ihrer Perspektive sind allein CCS-Technologien in der Lage, das doppelte ökomoderne Hegemonieversprechen zu garantieren - die Bearbeitung der ökologischen Krise (durch eine Verringerung der Emissionen) und die gleichzeitige Stabilisierung gesellschaftlicher Strukturen (durch die fortgeführte Nutzung fossiler Brennstoffe). 
Wie in Kapitel 5.5.4 ausgeführt, wird diese Einschätzung zwar von vielen, aber nicht von allen Diskursträger_innen des ökomodernen Projekts geteilt. Vor allem im NGO-Spektrum gibt es teilweise Zweifel, inwieweit CCS-Technologien tatsächlich zur Bewältigung der ökologischen Krise beitragen können. Trotz dieser Kritik, den Akzeptanzproblemen auf lokaler Ebene, den hohen Kosten der CCS-Technologien und der nicht gerade kleinen Anzahl gescheiterter CCS-Projekte, bleibt das CCSEngagement von Staaten, Unternehmen, Wissenschaftler_innen und einigen NGOs auf einem hohen Niveau. Dies ist nicht zuletzt auf den großen Einfluss der CCSCommunity zurückzuführen:

„It could be argued that compared to other energy technologies with climate mitigation potential CCS has among the highest levels of powerful, entrenched actors involved in a focused way in its advancement. The CCS innovation system therefore has an advantage in terms of resource mobilization, as compared to other low-carbon energy technologies." (Stephens/Liu 2012: 148)

Eine solche Machtbasis ist von entscheidender Bedeutung für den Ausgang hegemonialer Kämpfe um bestimmte Entwicklungspfade und Technologien. Insofern verwundert es nicht, dass die CCS-Technologien trotz Widerstände und technologischer Herausforderungen in den CDM aufgenommen wurden. Innerhalb der Arena des UN-Klimaregimes gelten CCS-Technologien damit aktuell als wichtiges Element des ökomodernen Projekts. Allerdings können solche Grenzziehungen unter bestimmten Voraussetzungen immer wieder revidiert werden - auch gegen den Willen der einflussreichen CCS-Community.

\subsection{Die (ent-)Politisierenden EfFekTe der CCS-KonfLiKTe}

Vor dem Hintergrund des in Kapitel 5.5.4 beschriebenen Konflikts über die Ausgestaltung des ökomodernen Projekts ist zu vermuten, dass CCS-Technologien langfristig nur dann von einer breiten ökomodernen Diskurskoalition unterstützt werden, wenn sie zur Glaubwürdigkeit des doppelten ökomodernen Hegemonieversprechens beitragen. Dafür müssten CCS-Technologien allerdings günstiger werden, als sicher gelten (sowohl bei Expert_innen aus Wissenschaft, Wirtschaft, Politik und dem NGO-Spektrum als auch bei der lokalen Bevölkerung im Umfeld von CCS-Projekten) und nicht als Gefährdung erneuerbarer Technologien wahrgenommen werden. Da diese Kriterien zumindest kurzfristig nicht erfüllt werden, bleibt weiterhin offen, in welchem Verhältnis die CCS-Konflikte zur weiteren 
Entwicklung des ökomodernen Projekts stehen werden. Prinzipiell scheinen mindestens drei verschiedene Szenarien denkbar:

1) Die CCS-Konflikte könnten durch CCS-Projekte, die von vielen Akteur_innen als erfolgreich eingestuft werden, an Kontroversität verlieren. Damit würden CCS-Technologien als wichtiges Element des ökomodernen Projekts etabliert werden.

2) Das Scheitern weiterer CCS-Projekte könnte dazu führen, dass CCS-Technologien an Relevanz für das ökomoderne Projekt verlieren und andere Klimaschutzoptionen dafür attraktiver werden.

3) Eine Verschärfung der CCS-Konflikte könnte dazu beitragen, dass das ökomoderne Projekt die Unterstützung durch einen Teil der bisherigen Diskursträger_innen verliert.

Das erste Szenario würde den Hoffnungen der CCS-befürwortenden Koalition entsprechen. Es ist durchaus realistisch, dass die Kritik an CCS-Technologien abebbt, wenn eine Reihe von Demonstrationsprojekten in Betrieb sind, die als sicher und betriebswirtschaftlich rentabel gelten. Ein möglicher Kompromiss, der sich bereits in einigen Positionierungen von Expert_innen aus verschiedenen Gesellschaftsbereichen andeutet, wäre der Fokus auf den Einsatz von CCS-Technologien in Schwellenländern, die ihren steigenden Energiebedarf durch eine große Anzahl neuer fossiler Kraftwerke decken (vgl. beispielsweise im Internet: www.brandenburg.nabu.de/naturschutz/energie/12504.html, www.germanwatch.org/ klima/ccsdeu09.pdf, www.ufz.de/index.php?de=18404, letzter Zugriff am 02.12.2014). Im Hinblick darauf ist die Aufnahme von CCS in den CDM besonders relevant, da der CDM eine Finanzierungsmöglichkeit für CCS-Projekte in NichtAnnex-B-Staaten darstellt. Der großflächige Einsatz von CCS-Technologien hätte in einem solchen Szenario eine befriedende Wirkung auf die Auseinandersetzungen um die Ausgestaltung des ökomodernen Projekts. Die in Kapitel 6.2 beschriebene Momentaufnahme der spezifischen (Re-)Produktion des ökomodernen Projekts würde sich stabilisieren.

Wenn allerdings weiterhin viele CCS-Projekte scheitern und als Folge die CCSbefürwortende Koalition schrumpft, hätte die CCS-Community zunehmend Probleme, die nötigen finanziellen Mittel und die politische Unterstützung für die Fortentwicklung und Anwendung von CCS-Technologien zu erhalten. Die Einbeziehung von CCS in das ökomoderne Projekt könnte in diesem Szenario durch politische Beschlüsse rückgängig gemacht werden oder das CCS-Engagement könnte auslaufen. Unter diesen Bedingungen wäre das ökomoderne Projekt darauf angewiesen, alternative Klimaschutztechnologien aufzuwerten. Die weitere Ent- 
wicklung des ökomodernen Projekts würde dann von der Art und Weise abhängen, wie der Wegfall von CCS als Klimaschutzoption kompensiert werden würde.

Im dritten Szenario würde eine Verschärfung der CCS-Konflikte dazu beitragen, dass das ökomoderne Projekt die Unterstützung durch einen Teil der bisherigen Diskursträger_innen - beispielsweise durch einige Umwelt-NGOs - verliert. Die von Stephens et al. konstatierte Kommunikationslücke zwischen der CCS-Community und der kritischen Öffentlichkeit verweist auf diese Möglichkeit (vgl. Stephens et al. 2011: 389). Inwieweit diese Kommunikationslücke zu einer Steigerung des Konfliktpotenzials führt, hängt davon $\mathrm{ab}$, in welchem Maß der Konflikt über die Gewichtung der beiden Aspekte des ökomodernen Hegemonieversprechens artikuliert wird (vgl. Kapitel 5.5.4). Wenn innerhalb des ökomodernen Projekts explizit darüber gestritten werden würde, inwieweit die Bewältigung der ökologischen Krise als unvereinbar mit der Beibehaltung der fossilen Energieinfrastruktur erscheint, würden sich die Risse in der ökomodernen Diskurskoalition vertiefen. Bricht ein Teil der bisherigen Diskursträger_innen weg, so würde die Tendenz des ökomodernen Projekts verstärkt, keinen aktiven, sondern allein einen passiven Konsens durch einflussreiche gesellschaftliche Kräfte herauszubilden. Dies würde den Charakter des ökomodernen Projekts als technokratisches Eliten-Projekt festschreiben, das allein auf Output-Legitimität und damit auf den Erfolg von technologischen Lösungen basiert. CCS-Projekte würden unter diesen Bedingungen vermutlich bevorzugt an Orten umgesetzt werden, in denen der lokale Widerstand als gering eingeschätzt wird - beispielsweise als Offshore-Projekte und/oder in Ländern mit einer vergleichsweise marginalisierten Umweltbewegung. Sollte der Widerstand gegen CCS in Annex-B-Staaten ein zu großes Investitionsrisiko darstellen, wäre der CDM ein wichtiges Instrument, um CCS-Projekte in Nicht-Annex-B-Staaten finanzieren zu können.

In einem solchen Szenario könnten CCS-Technologien die Brüche und Risse des ökomodernen Projekts eventuell trotz der Widerstände kitten, solange ihr Versprechen für die Absicherung eines passiven Konsenses ausreicht - ihr Versprechen auf eine Lösung für die nicht-intendierten Nebenfolgen der Nutzung fossiler Brennstoffe. Mit der Hoffnung auf CCS-Technologien könnten die bestehenden gesellschaftlichen Strukturen mit dem ökomodernen Hegemonieversprechen der Schwächung des menschengemachten Klimawandels in Einklang gebracht werden. Damit würden aktuelle Entscheidungen über die Fortführung der fossilen Energieinfrastruktur mit der Erwartung an zukünftige Innovationen legitimiert, ohne die ein flächendeckender Einsatz von CCS-Technologien nicht möglich sein wird. Dieses Phänomen ist keineswegs neu. So konstatiert Dingler, dass viele der im ökomodernen Diskurs vorgeschlagenen Lösungskomponenten noch gar nicht existent 
sind (vgl. Dingler 2003: 304). Das ökomoderne Projekt einer nachhaltigen Entwicklung basiert seiner Meinung nach ,auf dem metaphysischen Grundvertrauen der Moderne, das auf der Hoffnung aufbaut, alle zukünftig auftauchenden Probleme könnten durch Rationalität bewältigt werden“ (Dingler 2003: 304; Hervorhebung im Original).

Mit der ökomodernen Vermeidung gesamtgesellschaftlicher Transformationsprozesse und der Priorisierung technologischer Innovationen sind allerdings Lockin-Effekte verbunden: Die Fortführung von Energieinfrastrukturen sowie Produktions- und Konsummustern verschlechtert die Ausgangsbedingungen für spätere Transformationsprozesse. Insofern weist das ökomoderne Projekt eine geringe Fehlertoleranz auf. Ein Scheitern von Umweltschutztechnologien wie CCS ist nicht vorgesehen. Schließlich hängt die Stabilität und Glaubwürdigkeit des ökomodernen Projekts vom Erfolg von Technofixes ab. Dementsprechend würden gescheiterte CCS-Projekte in diesem dritten Szenario, in dem ein Teil der bisherigen Diskursträger_innen dem ökomodernen Projekt die Zustimmung entzieht, dem ökomodernen Projekt erheblich schaden und die Wahrscheinlichkeit von Politisierungseffekten deutlich erhöhen.

Sobald die Glaubwürdigkeit des doppelten Hegemonieversprechens bröckelt, vergrößert sich zwar einerseits die Gefahr, dass die schwindende Zustimmung zum ökomodernen Projekt durch Zwang und Repression kompensiert wird. Andererseits vergrößern sich aber auch die Möglichkeiten für gegenhegemoniale Projekte. Schließlich würde eine Vertiefung der Risse und Brüche im ökomodernen Hegemonieprojekt neue Gelegenheitsstrukturen eröffnen. Darüber hinaus gäbe es mit den Akteur_innen, die sich im Zuge der CCS-Konflikte vom ökomodernen Projekt distanziert hätten, eine breitere Basis sozialer Kräfte, die sich für Alternativen zur ökologischen Modernisierung stark machen würde. Dies könnte eine ähnliche Dynamisierung bewirken wie die Enttäuschung von der COP 15 in Kopenhagen, die bei einigen NGOs und Umweltgruppen eine Hinwendung zu radikaleren Positionen, protestorientierter Arbeit und der verstärkten Zusammenarbeit mit Bewegungsaktivist_innen nach sich zog (vgl. Kapitel 3.2.6). In einer derart politisierten Situation könnten antagonistische Konzepte wie Klimagerechtigkeit oder Buen Vivir wichtige Anknüpfungspunkte bieten (vgl. Kapitel 5.1.4).

Insgesamt zeigt die Varianz an möglichen Szenarien, dass noch nicht abzusehen ist, in welchem Verhältnis die CCS-Konflikte zur weiteren Entwicklung des ökomodernen Projekts stehen werden. Sowohl eine Stabilisierung des Hegemonieprojekts (Szenario 1) als auch die Auslösung interner Verschiebungen (Szenario 2) als auch eine Destabilisierung, die zu Zwang und/oder Erstarken gegenhegemonialer Projekte führen würde (Szenario 3), sind mögliche Entwicklungspfade. 


\section{Resümee und Ausblick}

„Jeder Versuch, den Naturzwang zu brechen, indem Natur gebrochen wird, gerät nur um so tiefer in den Naturzwang hinein.“

(Horkheimer/Adorno 2009: 19)

In diesem abschließenden Kapitel fasse ich zunächst wichtige Ergebnisse der Arbeit zusammen (7.1). Anschließend greife ich den in der Einleitung zitierten Artikel auf, in dem die Anwendung von CCS-Technologien als ein ,Faustscher Pakt ${ }^{\star}$ interpretiert wird. Diese Interpretation basiert auf impliziten Annahmen, die ich herausarbeite. Darauf aufbauend begründe ich, warum der Pakt m. E. ausgeschlagen und auf den Einsatz von CCS-Technologien verzichtet werden sollte (7.2).

\subsection{ZuSAMmENFASSUng DER ERgEBNISSE}

Die Forschungsfragen dieser Arbeit zielen auf die Analyse der Prozesse der re- und entpolitisierenden Prozesse im Konfliktfeld der ökologischen Krise. Die in den verschiedenen Kapiteln gewonnenen Erkenntnisse sollen hier nicht in ihrer Gänze rekapituliert werden. Einige zentrale Ergebnisse fasse ich jedoch im Hinblick auf die in der Einleitung formulierten Forschungsfragen noch einmal zusammen.

1) Wie und bis zu welchem Grad konnte das ökomoderne Projekt hegemonial werden und die gesellschaftlichen Reaktionen auf die ökologische Krise bestimmen?

In Kapitel 3 habe ich nachgezeichnet, wie sich der ökomoderne Diskurs als Reaktion auf die ökologische Krise in verschiedenen gesellschaftlichen Bereichen herausbildete und im Rahmen eines Hegemonieprojekts universalisiert wurde. Für die Verbreitung und Durchsetzung des ökomodernen Diskurses waren und sind drei Hegemoniestrategien von entscheidender Bedeutung: reflexive Naturbeherrschung, 
reflexiver Fortschritt durch wissenschaftlich-technische Rationalität und nachhaltiges Wachstum. Mit diesen Hegemoniestrategien wurde die von den Umweltbewegungen artikulierte Kritik in strategisch-selektiver Weise aufgegriffen und in den ökomodernen Diskurs integriert. Dabei wird im ökomodernen Diskurs die ökologische Krise in ihrer Bedrohlichkeit durchaus ernst genommen und als große gesellschaftliche Herausforderung postuliert. Allerdings schließt das ökomoderne Projekt antagonistische Forderungen, die auf eine Neuaushandlung der sozialen Ordnung drängen, aus (vgl. Kapitel 3.4).

Die ökomoderne Grundüberzeugung lautet, dass ökologische Probleme am besten durch eine ökologische Restrukturierung der Institutionen der ,westlichen“ Moderne gelöst werden können. Dabei gelten die etablierten gesellschaftlichen Strukturen als Garant für die fortschreitende gesellschaftliche Entwicklung. Das ökomoderne Hegemonieversprechen bezieht sich damit gleichzeitig auf die Bearbeitung der ökologischen Krise und auf die Stabilisierung gesellschaftlicher Strukturen. Diese ökomoderne Vorstellung des Gemeinwohls und der idealen Ordnung des Sozialen stellt die Basis für die Schaffung attraktiver Subjektpositionen dar. Die Subjektpositionen werden von verschiedenen Akteur_innen eingenommen, die damit als Diskursträger_innen zur Verbreitung des ökomodernen Diskurses beitragen (vgl. Kapitel 3.5).

Es ist auffällig, dass die Entwicklung des ökomodernen Diskurses vor allem durch einflussreiche Akteur_innen geprägt wird, die nicht auf Massenmobilisierung zielen: Wissenschaftler_innen, einzelne Entscheidungsträger_innen in Politik und Wirtschaft sowie Institutionen der Politikberatung. Die Folge ist, dass die Hegemoniepraktiken des ökomodernen Projekts einen passiven (und keinen aktiven) Konsens erzeugen. Damit ist gemeint, dass relevante gesellschaftliche Kräfte das ökomoderne Projekt zwar ohne aktive Zustimmung großer Teile der Bevölkerung etablieren, dabei jedoch auch nicht auf großen Widerstand treffen (vgl. These 1 in Kapitel 3.6).

In Bezug auf die umweltpolitischen Aushandlungsprozesse kann man konstatieren, dass sich der ökomoderne Diskurs sowohl auf internationaler Ebene als auch auf der nationalstaatlichen bzw. regionalen Ebene vieler Industrieländer durchgesetzt hat. Spätestens seit den 1990er Jahren fungiert das Konzept der ökologischen Modernisierung als Leitprinzip für innovative Politikformulierung im Umweltbereich (vgl. These 2 in Kapitel 3.6).

Dabei ist allerdings einschränkend anzumerken, dass sich die Dominanz des ökomodernen Diskurses primär auf den Bereich der Umweltpolitik beschränkt. Dies erklärt die Diskrepanz zwischen den Ansprüchen und den tatsächlichen Erfolgen des ökomodernen Projekts. Dessen Wirkung bleibt begrenzt, weil umweltpolitische 
Maßnahmen weiterhin dem Primat ökonomischer Diskurse und damit der Profitorientierung und der Standortpolitik unterliegen (vgl. These 3 in Kapitel 3.6).

Dieser Befund geht nicht allein auf die Stärke ökonomischer Diskurse, sondern auch auf die Ausrichtung des ökomodernen Projekts zurück. Schließlich wird der ökomoderne Diskurs gerade deshalb von bestimmten sozialen Kräften getragen, weil er weder die hegemonialen Strukturen in Frage stellt noch auf die Verschiebung gesellschaftlicher Kräfteverhältnisse drängt. Dies stellt vor dem Hintergrund der fossilistischen Wirtschaft eine starke Selbstbeschränkung dar, welche die bis dato geringen ökologischen Erfolge des ökomodernen Projekts erklärt (vgl. These 4 in Kapitel 3.6).

Trotz stetiger Zunahme ökologischer Probleme sind Forderungen, die über eine ökologische Modernisierung hinaus gehen, marginalisiert. Mit der Hegemonialisierung des ökomodernen Diskurses in den umweltpolitischen Arenen verloren antagonistische Positionen an Attraktivität. Viele (ehemalige) Protagonist_innen der Umweltbewegungen (re-)artikulieren ihre Forderungen innerhalb des ökomodernen Diskurses, um sich Gehör und Einfluss zu verschaffen. Die partielle Hegemonie des ökomodernen Diskurses verhinderte die Herausbildung wirkungsmächtiger gegenhegemonialer Projekte, die in der Lage wären, strukturverändernde Maßnahmen durchzusetzen und/oder gesellschaftliche Kräfteverhältnisse zu verschieben (vgl. These 5 in Kapitel 3.6). Insofern kann im Vergleich zur politisierten Situation, die sich in den 1970er Jahren mit der Verbreitung der ökologischen Krisendiagnose einstellte, eine Schließung des Diskurshorizonts beobachtet werden. Diese Entpolitisierung zeigt sich in der Marginalisierung antagonistischer Artikulationen. Somit steht das ökomoderne Hegemonieprojekt für eine Phase, die ich als reflexive Reproduktion fasse. Das ökomoderne Hegemonieprojekt hat seit den 1970er Jahren gegenüber dem ehemals hegemonialen Projekt der Modernisierung mit nachgeschaltetem Umweltschutz an Deutungshoheit gewonnen. Damit sind durchaus Veränderungen in der Organisation der gesellschaftlichen Naturverhältnisse verbunden. Allerdings steht die Kernforderung nach fortschreitender Entwicklung - in modifizierter Form als nachhaltige Entwicklung - weiterhin im Zentrum der Vorstellungen vom Gemeinwohl (vgl. Kapitel 3.7).

Innerhalb des ökomodernen Projekts wird weiter darum gerungen, was unter ,nachhaltiger Entwicklung'verstanden und eingefordert werden soll. Dabei zeichnet sich aktuell eine Ablösung von Sustainable Development durch Green Economy als leerer Signifikant der ökomodernen Kernforderung ab. Damit wird der selbstbeschränkende Charakter des ökomodernen Projekts vermutlich festgeschrieben und das Potenzial zur Transformation gesellschaftlicher Verhältnisse weiter eingeschränkt. Nichtsdestotrotz verspricht die Forderung nach einer Green 
Economy einen - zwar keinen radikalen oder strukturellen, jedoch zumindest einen inkrementellen - Wandel der Weltwirtschaft. Wenn dieser Wandel ausbleibt, könnte ein solcher Widerspruch durchaus zu dislozierenden Effekten führen und (re-)politisierende Prozesse anstoßen (vgl. These 6 in Kapitel 3.6).

2) Welche Bedeutung haben die Konflikte um CCS-Technologien in den Auseinandersetzungen um die weitere Entwicklung des ökomodernen Projekts?

Die Frage nach dem Stellenwert von CCS-Technologien innerhalb des ökomodernen Projekts ist weiterhin umkämpft und wird voraussichtlich in erster Linie anhand konkreter CCS-Vorhaben ausgehandelt werden. Insofern muss an dieser Stelle offen bleiben, welche Bedeutung CCS-Technologien innerhalb des ökomoderne Projekts mittel- bis langfristig haben werden (für eine Übersicht möglicher Szenarien vgl. Kapitel 6.3 und den weiter unten folgenden Abschnitt zur Beantwortung der dritten Forschungsfrage). Nichtsdestotrotz haben sich bereits in der CCS-CDM-Kontroverse zentrale Konfliktlinien dieser Auseinandersetzung gezeigt (vgl. Kapitel 5.4 und 5.5). Die Kontroverse, ob CCS-CDM-Projekte zugelassen werden sollen oder nicht, wurde nahezu ausschließlich mit ökomodernen Argumentationslinien geführt. Dies ist auf die Dominanz des ökomodernen Diskurses in umweltpolitischen Auseinandersetzungen im Allgemeinen und innerhalb des UNKlimaregimes im Besonderen zurückzuführen. Das Kontroverse an der CCS-CDMKontroverse betraf also nicht die Frage des prinzipiellen (ökomodernen) Deutungsrahmens, sondern speiste sich aus Konflikten über die Ausgestaltung des ökomodernen Projekts (vgl. Kapitel 5.4.4). In den Konflikten über den (möglichen) Beitrag von CCS für eine ökologische Modernisierung treten die Unterschiede in den Prioritäten verschiedener ökomoderner Diskursträger_innen deutlich hervor. Um diese Konflikte nachvollziehen zu können, soll hier zunächst auf die Effekte eingegangen werden, die mit der Einbeziehung von CCS-Technologien ins ökomoderne Projekt verbunden wären (für die folgende Auflistung vgl. Kapitel 6.2):

- Aufgrund der hohen Investitionskosten hat die staatliche Förderung in der Regel einen großen Anteil an der Finanzierung von CCS-Projekten. Insofern würde die Integration von CCS-Technologien in das ökomoderne Projekt eine Stärkung der staatlichen Regulierung der Energiewirtschaft bzw. eine Schwächung der marktliberalen Ausprägung des ökomodernen Projekts bedeuten.

- Die Einbeziehung von CCS-Technologien ins ökomoderne Projekt würde den inkrementellen Entwicklungspfad verstärken, welcher Umbrüche vermeidet und stattdessen auf die Optimierung bestehender Strukturen - in diesem Fall der zentralisierten, fossilen Energieinfrastruktur - zielt. 
- CCS-Technologien können die Treibhausgasemissionen, die bei der Förderung und/oder dem Verbrauch fossiler Brennstoffe entstehen, verringern. Darüber hinausgehende ökologische, gesundheitliche und soziale Probleme, die mit der fossilen Energieinfrastruktur verbunden sind, können mit CCS-Technologien nicht bearbeitet werden. Im Gegenteil werden diese negativen Konsequenzen durch CCS-Technologien verschärft, da ihre Anwendung zu einem erhöhten Ressourceneinsatz führt. Somit stehen CCS-Technologien für eine technokratische Vorstellung von Politik, in der für ein isoliertes Problem - dem Anstieg von Treibhausgasemissionen - eine technische Lösung gesucht wird. Dabei wird die Dominanz fossiler Brennstoffe von der CCS-befürwortenden Koalition als unabänderliche Rahmenbedingung vorausgesetzt, die jenseits der Einflusssphäre gestaltender Politik gilt.

- Die CCS-befürwortende Koalition greift die risikobewussten Praktiken der ökomodernen Hegemoniestrategie des reflexiven Fortschritts durch wissenschaftlich-technische Rationalität auf. Risikoabschätzung, Risikokommunikation und Risikomanagement spielen in der Bewertung und Durchführung von CCS-Projekten durchaus eine wichtige Rolle. Allerdings geraten risikovermeidende Praktiken zwangsläufig ins Abseits, da mit der Anwendung von CCSTechnologien stets ökologische und gesundheitliche Risiken verbunden sind. Dem Ziel der Risikovermeidung würde man mit alternativen Klimaschutzmaßnahmen wie beispielsweise erneuerbaren Energien, Effizienzsteigerungen oder Energieeinsparungen weitaus näher kommen.

- Mit CCS-Technologien ist die Hoffnung verbunden, die fossile Energieinfrastruktur zum Zwecke der Profit- und Wohlstandsmaximierung fortführen zu können. Dies verstärkt die Kontinuität der (reflexiven) Naturbeherrschung, mit der die (Re-)Produktion der gesellschaftlichen Naturverhältnisse weiterhin durch die Subsumtion der Natur unter diegesellschaftlichen Funktionslogiken bestimmt wird.

- Dabei wird Wirtschaftswachstum als Ziel gesellschaftlicher Entwicklung vorausgesetzt. Stetiges Wirtschaftswachstum impliziert einen steigenden Energiebedarf, der laut der CCS-befürwortenden Koalition kurz- bis mittelfristig zu einem Großteil mit fossilen Brennstoffen gedeckt werden wird. Erst vor diesem Hintergrund erscheinen CCS-Technologien als attraktive Klimaschutzmaßnahme, mit der das wachstumsorientierte Entwicklungsmodell nachhaltig gestaltet werden soll.

Insgesamt würde die Einbeziehung von CCS-Technologien ins ökomoderne Projekt die Schwächung seiner reflexiven (z. B. risikovermeidenden) Praktiken und eine forcierte Anpassung an ökonomisch begründete ,Sachzwänge‘ (z. B. Standort- 
politik, Wachstum) bedeuten. Wie die Analyse der CCS-CDM-Kontroverse gezeigt hat, gibt es zwischen den ökomodernen Diskursträger_innen Differenzen, inwieweit eine solche Transformation des ökomodernen Projekts abgelehnt, in Kauf genommen oder begrüßt werden sollte. Insofern werden in den Auseinandersetzungen um CCS-Technologien Risse und Brüche des ökomodernen Diskurses virulent.

Die Konflikte über die Ausgestaltung des ökomodernen Projekts entzünden sich an der Frage der Gewichtung der beiden Aspekte des ökomodernen Hegemonieversprechens: 1) der Bewältigung der ökologischen Krise und 2) der Stabilisierung gesellschaftlicher Strukturen. So bezweifelt die CCS-kritische Koalition den Beitrag von CCS-Technologien zur Bewältigung der ökologischen Krise. Umgekehrt plädiert die CCS-befürwortende Koalition für die Einbeziehung von CCS ins ökomoderne Projekt, da sie an CCS-Technologien gerade ihr Versprechen auf eine fortgeführte Nutzung fossiler Brennstoffe - und damit die Stabilisierung gesellschaftlicher Strukturen als Garant fortschreitender Entwicklung - schätzt (vgl. Kapitel 5.5.4).

An diesem Konflikt zeigt sich, dass der ökomoderne Diskurs, wie jeder andere Diskurs auch, gleichzeitig unterbestimmt und überdeterminiert ist. Der ökomoderne Konsens, dass Klimaschutzmaßnahmen an der Output-Seite - der Reduktion der globalen Treibhausgasemissionen - ansetzen sollen, ist insofern unterbestimmt, als er die Bewertung der Input-Seite der fossilen Energieinfrastruktur ausklammert. Ein Konsens zu der Frage, inwieweit die Reglementierung der Output-Seite indirekt auf die Transformation der Input-Seite zielt oder umgekehrt diese möglichst lange erhalten soll, wäre innerhalb der breiten ökomodernen Diskurskoalition nicht möglich gewesen. In der Folge ist der ökomoderne Konsens überdeterminiert, das heißt ihm liegen unterschiedliche Begründungsmuster der verschiedenen ökomodernen Diskursträger_innen zugrunde. Während diese Differenzen in Bezug auf marktbasierte Klimaschutzinstrumente - nach einer Phase kontroverser Auseinandersetzungen - ruhig gestellt wurden (vgl. Kapitel 5.1.3), werden sie in den Konflikten um CCS-Technologien (re-)artikuliert. Für die CCS-kritische Koalition innerhalb des ökomodernen Projekts, zu denen beispielsweise Greenpeace zählt, stellt der Erhalt der fossilen Energieinfrastruktur kein politisch wünschenswertes Ziel dar. Gerade diese Möglichkeit der Fortführung der Input-Seite der Energieproduktion mit fossilen Brennstoffen ist allerdings ein zentrales Argument der CCS-befürwortenden Koalition. Damit wird in den CCS-Konflikten der ansonsten relativ stabile ökomoderne Konsens über die Trennung der Input- von der Output-Seite politisiert (vgl. Kapitel 5.5.4). 
Welche Effekte diese Politisierung auf die weitere Entwicklung des ökomodernen Projekts hat, wird sich in den zukünftigen Auseinandersetzungen zeigen, die mit der vermehrten Planung und Durchführung konkreter CCS-Projekte vermutlich zunehmen werden. Entscheidend für die (re-)politisierende Wirkung der CCSKonflikte wird sein, inwieweit explizit über die Bedeutung der fossilen Energieinfrastruktur als Garant bestimmter gesellschaftlicher Strukturen und Kräfteverhältnisse verhandelt wird. Je expliziter darüber gestritten wird, desto stärker tritt das Moment des Politischen hervor, in dem das doppelte ökomoderne Hegemonieversprechen als Ergebnis von Machtbeziehungen und als Entscheidung gegen alternative Möglichkeiten zur Bewältigung der ökologischen Krise artikuliert wird (vgl. Kapitel 5.5.4).

3) Welche Auswirkungen haben die Konflikte um CCS-Technologien auf die Auseinandersetzungen um die Bearbeitung der ökologischen Krise?

Die Frage nach der Bedeutung von CCS-Technologien in den Auseinandersetzungen um die Bearbeitung der ökologischen Krise kann zu diesem Zeitpunkt nicht abschließend geklärt werden, da der Ausgang der CCS-Konflikte weiterhin offen ist. Einerseits scheitern viele CCS-Projekte aufgrund hoher Investitionskosten und lokaler Widerstände (vgl. Kapitel 6.1). Anderseits gibt es eine einflussreiche CCS-Community, die sich erfolgreich für Förderprogramme einsetzt und auch die Aufnahme von CCS in den CDM durchsetzte (vgl. Kapitel 6.2). Angesichts der Herausforderungen des Klimawandels und der mangelnden Erfolge bisheriger Klimaschutzmaßnahmen plädieren viele Akteur_innen dafür, sich alle technischen Optionen - inklusive CCS - offen zu halten (vgl. Meadowcroft/Langhelle 2009a: 269). Dahinter steht die Hoffnung auf einen Technofix, da strukturverändernde Maßnahmen, die beispielsweise auf einen Wandel der Produktions- und Konsummuster zielen, entweder nicht erwünscht sind oder als unrealistisch gelten (vgl. Methmann 2011: 161ff). Angesichts dieser Skepsis gegenüber der Gestaltungsfähigkeit der Politik ist eine zunehmende Relevanz von CCS-Technologien in politischen Debatten sowie wissenschaftlichen Studien und Szenarien zu beobachten. Symptomatisch dafür ist die gestiegene Bedeutung von CCS im aktuellen IPCC-Sachstandsbericht im Vergleich zu früheren Berichten (vgl. Kapitel 1.1). Was die konkrete Anzahl der geplanten und durchgeführten CCS-Projekte betrifft, sind allerdings keine eindeutigen Tendenzen erkennbar. Es wird weiter in CCS-Technologien investiert; von einem Boom kann aber keine Rede sein. Das Global CCS Institute macht dafür das Fehlen finanzieller Anreize und Planungssicherheiten aus. Daher fordert die Lobbyorganisation verbindliche Reduktionsziele und/oder stabile Preise für $\mathrm{CO}_{2}$-Äquivalente (vgl. Global CCS Institute 2014). 
Inwieweit die Konflikte um CCS-Technologien zur Re- oder Entpolitisierung der gesellschaftlichen Naturverhältnisse beitragen, hängt in erster Linie von ihren Effekten auf die Auseinandersetzungen um die Ausgestaltung des ökomodernen Projekts ab. Dabei sind mindestens drei Szenarien denkbar (für die folgende Auflistung vgl. Kapitel 6.3):

\section{1) Die Einbeziehung von CCS-Technologien ins ökomoderne Projekt könnte über} die verschiedenen Spektren der ökomodernen Diskurskoalition hinweg Unterstützung finden.

Eine wichtige Voraussetzung für eine solche breite Zustimmung wären sicherlich Erfahrungen mit CCS-Projekten, die von vielen Akteur_innen als erfolgreich eingestuft werden. Die Artikulation von CCS als wichtige Brückentechnologie hätte in einem solchen Szenario eine befriedende Wirkung auf die Konflikte um die Ausgestaltung des ökomodernen Projekts. Damit wäre eine spezifische (Re-)Produktion des ökomodernen Diskurses verbunden, wie sie im letzten Abschnitt zur zweiten Forschungsfrage zusammengefasst wurde. Die Fokussierung auf die Reglementierung der Output-Seite der Treibhausgasemissionen und die Vernachlässigung der Input-Seite der fossilen Brennstoffe wäre als Konstante des ökomodernen Projekts fixiert. Insgesamt würden in diesem ersten Szenario vom ökomodernen Projekt nur noch sehr wenige Impulse in Richtung Transformation der gesellschaftlichen Naturverhältnisse ausgehen. Diese Entpolitisierung und die damit verbundene Schließung des Diskurshorizonts könnte allerdings zur Attraktivität und Stärkung gegenhegemonialer Projekte beitragen, die Alternativen zur ökologischen Modernisierung artikulieren. Die geringere Offenheit des ökomodernen Projekts gegenüber kritischen Impulsen könnte die Chancen für die Bildung einflussreicher und/oder breiter Diskurskoalitionen erhöhen, die entsprechende gegenhegemoniale Projekte verbreiten und universalisieren könnten. In diesem Szenario könnten die Konflikte um CCSTechnologien (re-)politisierende Prozesse nur außerhalb des ökomodernen Diskurses anstoßen.

\section{2) CCS-Technologien könnten an Relevanz für das ökomoderne Projekt verlieren.}

CCS-Technologien könnten insbesondere dann an Relevanz für das ökomoderne Projekt verlieren, wenn weiterhin viele CCS-Projekte scheitern bzw. von vielen Akteur_innen als zu risikoreich und/oder zu teuer eingeschätzt werden. Dementsprechend würden in diesem zweiten Szenario alternative Klimaschutzmaßnahmen an Bedeutung gewinnen. Die weitere Entwicklung des ökomodernen Projekts würde dann von der Art und Weise abhängen, wie der Wegfall von CCS als Klimaschutzoption kompensiert werden würde. In diesem zweiten Szenario sind also 
sowohl re- als auch entpolitisierende Effekte und zwar innerhalb wie außerhalb des ökomodernen Projekts denkbar. Beispielsweise könnte verstärkt um eine Begrenzung der Förderung und/oder des Verbrauchs fossiler Brennstoffe gerungen werden. Solche Auseinandersetzungen könnten von außen an das ökomoderne Projekt herangetragen oder als Richtungsstreit innerhalb des ökomodernen Diskurses ausgetragen werden.

3) Eine Verschärfung der CCS-Konflikte könnte dazu führen, dass ein Teil der bisherigen ökomodernen Diskursträger_innen wegbricht.

Wenn die aktuell beobachtbaren Auseinandersetzungen um die weitere Entwicklung des ökomodernen Projekts nicht ruhig gestellt und die Konflikte um CCS-Technologien verschärft werden, könnte ein Teil der bisherigen ökomodernen Diskursträger_innen wegbrechen. Wenn beispielsweise Umwelt-NGOs wie Greenpeace aus der ökomodernen Diskurskoalition ausscheren, würde das den Charakter des ökomodernen Projekts als technokratisches Eliten-Projekt festschreiben, welches allein auf technische Lösungen im Top-down-Modus setzt. In Bezug auf das ökomoderne Projekt wäre damit eine Entpolitisierung verbunden. Kritische Stimmen, die sich für eine weitreichende ökologische Restrukturierung gesellschaftlicher Institutionen und Strukturen einsetzen, hätten im ökomodernen Projekt keinen Platz mehr. Diese Schließung des ökomodernen Diskurshorizonts könnte allerdings durchaus (re-)politisierende Prozesse außerhalb des ökomodernen Projekts anstoßen - insbesondere wenn die Glaubwürdigkeit des ökomodernen Hegemonieversprechens bröckelt. Für gegenhegemoniale Projekte würden sich neue Gelegenheitsstrukturen eröffnen. Mit den vom ökomodernen Projekt abgespaltenen Akteur_innen gäbe es auch neue potenzielle Bündnispartner_innen für antagonistische Diskurskoalitionen.

Zusammenfassend kann konstatiert werden, dass mit einer breiten Unterstützung von CCS-Technologien zunächst einmal entpolitisierende Effekte verbunden wären - d. h. die hegemoniale Strukturierung der gesellschaftlichen Naturverhältnisse würde stabilisiert werden. Darüber hinaus hätte ein großflächiger Einsatz von CCS-Technologien Lock-in-Effekte: Die Fortführung der fossilen Energieinfrastruktur würde die Ausgangsbedingungen für Transformationsprozesse verschlechtern.

Umgekehrt würde eine zunehmende Kritik an CCS-Technologien und/oder das Scheitern vieler CCS-Vorhaben politisierende Effekte haben: Der ökomoderne Konsens über die Trennung der Input- von der Output-Seite würde disloziert werden. Schließlich trägt die alleinige Fokussierung auf die Emissionen ohne Berücksichtigung der fossilen Energieinfrastruktur einen Widerspruch in sich, da gerade die 
Abhängigkeit der Wirtschaft von fossilen Brennstoffen die Umstellung auf eine klimaneutrale Lebensweise schwierig macht. Die Versuche, den Widerspruch durch marktbasierte Instrumente im Rahmen der flexiblen Mechanismen des KyotoProtokolls abzumildern, sind bislang gescheitert. Fiele zusätzlich CCS als Technofix aus, würden bestimmte Risse und Brüche in der hegemonialen Struktur der gesellschaftlichen Naturverhältnisse virulent werden. Solch eine Dislokation könnte das Terrain des Politischen für antagonistische Artikulationen öffnen und die Handlungsmöglichkeiten gegenhegemonialer Projekte erhöhen.

\subsection{Ausblick}

Im nun folgenden Ausblick werde ich die bereits in der Einleitung zitierte Interpretation diskutieren, derzufolge die Entwicklung und der Einsatz von CCS-Technologien einen ,Faustschen Pakt` darstellen würde:

„CSS appears to be a classic Faustian Bargain. But, as in Faust's initial bargain, it need not mean that our soul is left to the devil. It should mean that we accept the challenge of continual striving and vigilance, striving for more durable answers to global climate change and vigilance in assuring that stored carbon is not subsequently released to the climate system." (Spreng/Marland/Weinberg 2007: 854)

Diese Interpretation stellt eine pointierte Zuspitzung des ökomodernen Deutungsrahmens dar und impliziert bestimmte Prämissen, die dem Plädoyer für die Annahme des Pakts und dem Einsatz von CCS-Technologien zugrunde liegen. Diese Prämissen werde ich im Sinne einer dekonstruktiven Analyse herausarbeiten. Dabei verweise ich auf alternative Deutungsrahmen, die zu dem umgekehrten Schluss führen, dass der Pakt ausgeschlagen und der Einsatz von CCS-Technologien abgelehnt werden sollte.

In dem Artikel „CO2 capture and storage: Another Faustian Bargain?“ gehen Spreng, Marland und Weinberg davon aus, dass Faust seinen Teufelspakt mit einer Wette verknüpft (vgl. Spreng/Marland/Weinberg 2007: 852). Daraus schlussfolgern sie, dass der Abschluss des Paktes nicht unbedingt bedeuten müsse, dass die Seele dem Teufel überlassen werde. Der Abschluss des Paktes - so die Argumentation der drei Naturwissenschaftler - enthält somit auf der einen Seite reizvolle Verlockungen. Auf der anderen Seite stehen aber auch die Verpflichtungen der Wette nach permanenter Wachsamkeit und stetigem Streben, die den Verlust der Seele an den Teufel verhindern sollen (vgl. Spreng/Marland/Weinberg 2007: 852). 
Um nicht auf fossile Brennstoffe verzichten zu müssen, setzen Spreng, Marland und Weinberg auf technischen Fortschritt, d. h. auf den Einsatz von CCS-Technologien. Dabei betonen sie die Notwendigkeit, die doppelte Herausforderung des Paktes anzunehmen. Daraus ergäbe sich erstens die Verantwortung, wachsam dafür zu sorgen, dass das gespeicherte $\mathrm{CO}_{2}$ permanent dem Klimasystem entzogen bleibt. Zweitens bestünde die Pflicht, stetig nach der Entwicklung nachhaltigerer Lösungen des Klimaproblems zu streben (vgl. Spreng/Marland/Weinberg 2007: 854).

Bei ihrem Plädoyer für Wachsamkeit und stetiges Streben unterschlagen die Wissenschaftler allerdings zweierlei: 1) Der Faustsche Weg des Kolonialismus und der Naturbeherrschung ist gescheitert. 2) Die Alternative zum Faustschen Pakt muss nicht Verzicht und Stagnation bedeuten. Diese beiden Argumente werde ich im Folgenden ausführen und begründen, warum der Pakt ausgeschlagen werden sollte. Der wiederkehrende Verweis auf Goethes Tragödie dient dabei als Illustration der Argumente.

\section{Der Faustsche Weg des Kolonialismus und der Naturbeherrschung ist gescheitert.}

Faust wird im zweiten Teil der Tragödie zum Kolonisator, der durch ein Projekt der Naturbeherrschung Wachstum und Wohlstand generieren möchte (vgl. Böhme 2005: 31). Faust setzt sein Kolonialisierungsprojekt auf einem Küstenstreifen um, für den er vom Kaiser als Eigentümer und Herrscher ernannt wurde. Mit Hilfe der Arbeitskraft der dort lebenden Bevölkerung und neuen Technologien lässt er Dämme und Kanäle bauen, um dem Meer weiteres Land abzutrotzen. In diesem Vorhaben aus der Dichtung zeigen sich zentrale Annahmen und Elemente, die auch für die außerliterarischen Projekte des Kolonialismus und der Naturbeherrschung kennzeichnend sind.

Am Beginn der Planung steht die Ignoranz gegenüber der Nichtidentität der Natur und der überhebliche Glaube an die Möglichkeit der Kontrolle von Natur. Die Gezeiten des Meeres stellen für Faust eine ,[z]wecklose Kraft unbändiger Elemente" (Goethe 1973: 182) dar. Dieser vermeintlich sinnlosen Abfolge von Ebbe und Flut möchte Faust ein Ende bereiten. Er ist fest davon überzeugt, dass es möglich sei, die in seinen Augen nutzlose Kraft der Natur zu „besiegen“ (Goethe 1973: 182) und das Watt dauerhaft trocken zu legen. Das derart gewonnene Land soll anschließend menschlichen Zwecken dienen. Während der Bauphase geht Faust nicht nur rücksichtslos mit der Natur, sondern auch mit den Menschen um. Die bestehende Natur- und Kulturlandschaft muss weichen und die darin lebenden Menschen werden zwangsumgesiedelt. Die Arbeiter_innen erleiden Repressionen und werden wie Knechte behandelt (vgl. Böhme 2005: 156ff). Trotz der Anstrengungen und Opfer bzw. gerade aufgrund des gewalttätigen Vorgehens gegenüber Mensch und 
Natur ist das Kolonialisierungsprojekt zum Scheitern verurteilt. Faust selber wird zunächst blind und stirbt schließlich. Sein Kolonialisierungsprojekt wird den Naturgewalten nicht standhalten, sondern untergehen, wie Mephistopheles voraussagt (vgl. Goethe 1973: 224).

Diese Geschichte illustriert, wie der Glaube an die Beherrschbarkeit der Natur durch Naturkatastrophen konterkariert wird, die mit dem Paradigma der Naturbeherrschung aus zwei Gründen zugenommen haben. Zum einen hat sich der Mensch „im Schutz der Technik“ in Gefahrenzonen gewagt, in denen Naturereignisse „erst eigentlich für den Menschen zu Katastrophen geworden sind“ (Böhme 2005: 165). Zum anderen erleben wir mit der ökologischen Krise eine drastische Zunahme der gesellschaftlichen Verursachung ökologischer Probleme, die bereits jetzt verheerende Folgen für Menschen haben und die weiter zunehmen werden (vgl. Böhme 2005: 165). Die Folgen des Klimawandels treffen tendenziell sozial benachteiligte Bevölkerungsgruppen - insbesondere in den Ländern des globalen Südens - stärker als Bevölkerungsgruppen, die über mehr (v. a. finanzielle) Ressourcen verfügen. Umgekehrt ist die anthropogene Verursachung primär auf die imperiale Lebensweise der Ober- und Mittelschichten - insbesondere in den Ländern des globalen Nordens - zurückzuführen (vgl. Bedall 2014: 141f). Diese Asymmetrien verweisen bereits auf die (neo-)koloniale Dimension der ökologischen Krise und dem sie verursachenden Paradigma der Naturbeherrschung, worauf ich weiter unten eingehen werde.

Das Paradigma der Naturbeherrschung hat die ökologische Krise nicht nur verursacht, sondern scheitert bislang auch an der Bearbeitung derselben. Sicherlich haben auch Umweltschutzmaßnahmen, die mit dem Prinzip der Naturbeherrschung nicht brechen, einzelne Erfolge vorzuweisen. Eine effektive Abschwächung der ökologischen Krise ist aber bislang nicht abzusehen. Auch CCS-Technologien werden keinen relevanten Beitrag zur Lösung sozialer und ökologischer Probleme beitragen können. Vielleicht mag es gelingen, mit Hilfe von CCS-Projekten kurzfristig Treibhausgasemissionen zu reduzieren. Allerdings werden diese Projekte die negativen sozialen, gesundheitlichen und ökologischen Konsequenzen der Ressourcenausbeutung verschärfen (vgl. Kapitel 5.2). Darüber hinaus verstärkt der Einsatz von CCS-Technologien genau jene Deutungs- und Handlungsmuster, die historisch zur ökologischen Krise geführt haben und - das ist meine persönliche Überzeugung - diese auch in Zukunft nicht werden lösen können. 
Die Alternative zum Faustschen Pakt muss nicht Verzicht und Stagnation bedeuten.

Die Verlockungen des Faustschen Paktes basieren auf einer bestimmten Vorstellung von Fortschritt und Entwicklung sowie damit verbundenen Partikularinteressen. Dies trifft sowohl auf den Pakt in Goethes Tragödie zu als auch auf die von Spreng, Marland und Weinberg vorgenommene Übertragung auf die aktuellen Konflikte um CCS-Technologien.

Zunächst zur Dichtung: Die primäre Motivation für das Kolonialisierungsprojekt ist Fausts Streben nach Herrschaft und Eigentum (vgl. Böhme 2005: 160; Goethe 1973: 181). Dazu tritt zu einem späteren Zeitpunkt zusätzlich der Wunsch, einen Modernisierungsprozess einzuleiten, der auch anderen Menschen zu einer Wohlstandssteigerung verhelfen soll. Dabei geht Faust davon aus, dass letztlich selbst die zwangsumgesiedelten Menschen irgendwann die Modernisierung als Verbesserung ihrer Wohn- und Lebenssituation erkennen werden (vgl. Böhme 2005: 162f). Dahinter steht die Überzeugung, dass sich der Mut zur Überwindung der bestehenden Verhältnisse in Freiheit und Wohlstand für alle Menschen auszahlen werde (vgl. Goethe: 225). Die von Faust beschworene Freiheit des Tätigen besteht in der vermeintlichen Überwindung der Abhängigkeit von Natur. ${ }^{1}$

Diese für Faust handlungsleitende Vorstellung von Gemeinwohl und der idealen Gesellschaftsordnung findet sich auch in den Annahmen der CCS-befürwortenden Koalition. Die Autoren des zitierten Artikels behandeln diesen Aspekt allerdings kaum. Für sie scheinen die Vorzüge der Nutzung fossiler Brennstoffe derart selbstverständlich zu sein, dass sie auf die mit CCS-Technologien verknüpften Verlockungen nur mit einem Satz eingehen: „The temptation that CCS offers is the extension of the fossil-fuel era by perhaps a few 100 years." (Spreng/Marland/ Weinberg 2007: 853) Für die CCS-befürwortende Koalition enthalten CCS-Technologien das Versprechen, das wachstumsorientierte Entwicklungsmodell fortsetzen zu können, ohne die Treibhausgaskonzentration in der Atmosphäre zu erhöhen. Neben diesem Streben nach fortschreitender Entwicklung durch Modernisierungsprozesse und technologischen Innovationen zeigt sich im Einsatz für CCS-Technologien auch der Faustsche Wunsch nach Herrschaft und Eigentum. So spielt die Absicherung des Geschäftsmodells der Energiekonzerne im

1 Mit dem Konzept der gesellschaftlichen Naturverhältnisse ist eine solche Überwindung der Abhängigkeit allerdings nicht denkbar. Stattdessen wird mit dieser Perspektive davon ausgegangen, dass gesellschaftliche Prozesse stets auf die Aneignung von Natur angewiesen bleiben und sich in jeder Naturaneignung Momente der Unverfügbarkeit und Widerständigkeit zeigen. Wird die damit verbundene Abhängigkeit von Natur geleugnet, um (vermeintliche) Selbstständigkeit zu erlangen, so führt dies nicht zu gesellschaftlicher Freiheit, sondern zur Festigung von Herrschaftsverhältnissen (vgl. Kapitel 2.2.3). 
Allgemeinen und der mit CCS verknüpften persönlichen Karriere im Besonderen eine wichtige Rolle für die CCS-Community (vgl. die Ausführungen zur CCSCommunity in Kapitel 5.3.2). Darüber hinaus zielt die CCS-befürwortende Koalition auf den Erhalt bestimmter gesellschaftlicher Strukturen und sozialer Kräfteverhältnisse, die mit der Abhängigkeit der Weltwirtschaft von fossilen Brennstoffen verknüpft sind. Eine Überwindung der fossilistischen Energieinfrastruktur hätte unabsehbare dislozierende Effekte, die sie zu vermeiden sucht (vgl. Kapitel 5.5).

Welche alternativen Vorstellungen von Gemeinwohl und idealer Gesellschaftsordnung sprechen umgekehrt dafür, den Faustschen Pakt auszuschlagen und die dislozierenden Effekte in Kauf zu nehmen bzw. sogar zu begrüßen? Was motiviert den Protest gegen das Kolonialisierungsprojekt im Faust bzw. gegen den Einsatz von CCS-Technologien?

In Goethes Tragödie gibt es ein älteres Ehepaar, das Widerstand gegen das Kolonialisierungsprojekt leistet: Philemon und Baucis. Sie sind nicht bereit, ihr Haus aufzugeben und dem Projekt zu weichen. Die diesbezügliche Interpretation von Spreng, Marland und Weinberg lautet, dass die Eheleute den sozialen Wandel scheuen und ihr bekanntes, wenn auch ärmliches Leben fortführen möchten (vgl. Spreng/Marland/Weinberg 2007: 852). Auch wenn die drei Naturwissenschaftler durchaus Sympathien für das Ehepaar hegen und sie als bescheiden und großzügig charakterisieren, unterschlagen sie die politischen Gründe ihres Widerstandes, auf die ich weiter unten eingehen werde. Damit konstruieren sie die Entscheidung über den Einsatz von CCS-Technologien als eine falsche Alternative ${ }^{2}$ zwischen einer fortschreitenden Entwicklung durch fossile Brennstoffe und der Stagnation durch Verzicht auf fossile Brennstoffe. Auf der einen Seite der Alternative steht das ökomoderne Hegemonieversprechen auf Stabilisierung des wachstumsbasierten Entwicklungsmodells (vgl. Kapitel 3.5). Die andere Seite kann aus Sicht der drei Autoren nur im Verzicht auf technischen Fortschritt bestehen - den sie in bestimmten Einzelfällen auch durchaus für eine sinnvolle Option halten (vgl. Spreng/ Marland/Weinberg 2007: 853). Was sie allerdings systematisch ausblenden ist der Zugewinn an neuen Optionen, der mit einer Überwindung der Abhängigkeit von fossilen Brennstoffen verbunden wäre.

2 Mit dieser Formulierung knüpfe ich bewusst an Görgs Begriff der ,falschen Alternative“ an, der sich auf die vorherrschenden Konstruktionen des Verhältnisses von Mensch und Natur bezieht. Wie in Kapitel 2.2.3 dargestellt, kritisiert Görg sowohl die Forderung nach Unterordnung unter eine vermeintliche Ordnung der Natur als auch die Forderung nach Unterwerfung der Natur. 
Die von den drei Naturwissenschaftlern konstruierte Entscheidung fasse ich als falsche Alternative, weil mit ihr die Kontingenz der Gesellschaft geleugnet wird und somit gesellschaftliche Freiheitspotenziale eingeschränkt werden. Die hegemoniale soziale Ordnung und die hegemoniale Vorstellung des Gemeinwohls werden als alternativloser Orientierungsrahmen für die Bewertung von CCS-Technologien universalisiert - und zwar sowohl in dem konkreten zitierten Artikel als auch allgemein im ökomodernen Diskurs. Unter dieser Prämisse setzt das ökomoderne Projekt auf technische Innovationen, um die Nutzung fossiler Brennstoffe fortführen zu können ohne den Klimawandel weiter anzuheizen. Damit ist das ökomoderne Projekt abhängig vom Erfolg sogenannter Technofixes (vgl. Kapitel 6.3), die als Fortschritt artikuliert werden. Wenn man unter Fortschritt allerdings die Vergrößerung alternativer Handlungsoptionen und die Verringerung der Abhängigkeit von Zwängen versteht (vgl. Kapitel 2.2.3), verstellt das ökomoderne Projekt fortschrittliche Entwicklungspfade. Fortschritt in diesem Sinne kann erst dort beginnen, wo der Zwang zum Fortschritt endet (vgl. Adorno 2003: 625, 638). Aus dieser Perspektive gebietet es der Wunsch nach Freiheit, den Faustschen Pakt auszuschlagen und auf den Einsatz von CCS-Technologien zu verzichten. Denn was bedeutet der von Spreng, Marland und Weinberg formulierte Wetteinsatz der permanenten Wachsamkeit und des stetigen Strebens anderes als einen Zwang zum Fortschritt? CCS-Technologien stehen symptomatisch für die Abhängigkeit von immer neuen technischen Innovationen, um die Naturbeherrschung aufrecht erhalten und die nicht-intendierten Nebenfolgen der Naturbeherrschung abmildern zu können. Darüber hinaus beinhalten sie bestimmte ökologische und gesundheitliche Risiken, die durch risikobewusste Praktiken abgeschwächt, aber nicht grundsätzlich vermieden werden können (vgl. Kapitel 5.2). CCS-Technologien bilden damit eine weitere Windung in der Abhängigkeitsspirale des naturbeherrschenden Paradigmas, die Adorno und Horkheimer in ihrer „Dialektik der Aufklärung“ aufzeigen: „Jeder Versuch, den Naturzwang zu brechen, indem Natur gebrochen wird, gerät nur um so tiefer in den Naturzwang hinein." (Horkheimer/Adorno 2009: 19)

Um die falsche Alternative aufzubrechen, komme ich zunächst wieder auf Goethes Tragödie zurück. Philemon und Baucis formulieren drei Argumente für ihren Widerstand gegen das Kolonialisierungsprojekt (für den gesamten Absatz vgl. Goethe 1973: 210f). Erstens werfen sie Faust Ignoranz und Respektlosigkeit vor, weil er weder die existierende Natur- und Kulturlandschaft noch deren Bewohner_innen achtet. Dies machen sie an der Brutalität und Rücksichtslosigkeit fest, mit der Faust das Bestehende zerstört und seine Arbeiter_innen behandelt. Zweitens kritisieren sie den Herrschaftsanspruch Fausts, der nicht nur das Land und die Häuser, sondern auch den Gehorsam der Bewohner_innen einfordert. Ihr drittes 
Argument bezieht sich auf das Angebot, im neu gewonnenen Land wohnen zu dürfen. Dies ist in ihren Augen kein fairer Tausch, da sie das Leben auf dem ehemaligen Meeresboden als besonders risikoreich einschätzen. Aus Furcht vor Überschwemmungen beharren sie auf ihrem Wohnort auf der Anhöhe einer Düne.

Diese Argumentation illustriert einige zentrale antagonistische Forderungen: Anerkennung der Nichtidentität der Natur und der Vielfalt der Lebensweisen, Demokratisierung und Gerechtigkeit sowie Durchsetzung des Vorsorgeprinzips (vgl. Kapitel 5.1.4). Diese Forderungen gehen über die Reduktion des Verbrauchs fossiler Brennstoffe und die Ablehnung von CCS hinaus. Sie sind positive Elemente einer alternativen Vorstellung von der idealen sozialen Ordnung und des Gemeinwohls. Derartige Alternativen zum hegemonialen Entwicklungsmodell werden in der falschen Alternative ausgeblendet. Daher gilt es, die Konstruktion scheinbarer Sachzwänge aufzudecken und als Ergebnis von institutionalisierten Machtbeziehungen zu begreifen. Nur so können die gesellschaftlichen Reflexionsmöglichkeiten gesteigert werden und Gestaltungsspielräume wachsen (vgl. Kapitel 2.2.3).

Für dieses Anliegen spielt die Überwindung der Abhängigkeit von fossilen Brennstoffe, auf denen das wachstumsorientierte Entwicklungsmodell basiert, eine entscheidende Rolle. Ihre exzessive Nutzung stellt nicht nur die primäre Ursache der ökologischen Krise, sondern auch eine wichtige Grundlage für die Stabilität hegemonialer Strukturen und sozialer Kräfteverhältnisse dar. Dabei sollte nicht vergessen werden, dass sich diese hegemonialen Formationen historisch als koloniale Strukturen und Kräfteverhältnisse herausgebildet haben (vgl. Klein 2014 169f). Die Ausbeutung natürlicher Ressourcen - insbesondere in seinen rücksichtslosesten Formen - findet seit Beginn des Kolonialismus bis heute vorwiegend in Ländern des globalen Südens statt. ${ }^{3}$ Weiterverarbeitet und verbraucht werden diese Ressourcen dagegen vor allem in den Ländern des globalen Nordens (vgl. Lambert 2012). (Neo-)Extraktivismus ${ }^{4}$ kann also nicht unabhängig von (Neo-)Kolonialismus

3 Naomi Klein weist zurecht darauf hin, dass es diesbezüglich im letzten Jahrzehnt eine neue Entwicklung gab. Fossile Brennstoffe werden zunehmend auch in wohlhabenderen Regionen gefördert, die davon bislang weitestgehend verschont blieben. Klein bezieht sich dabei in erster Linie auf die massive Ausweitung der Ausbeutung unkonventioneller Öl- und Gaslagerstätten in den USA und in Kanada (vgl. Klein 2014: 310ff). Nichtsdestotrotz findet weiterhin der Großteil der extraktivistischen Ausbeutung von Rohstoffen und Agrarland in Ländern des globalen Südens statt (vgl. Lambert 2012).

4 Mit Extraktivismus wird eine Entwicklungsstrategie bezeichnet, die auf eine höchstmögliche Ausbeutung von Rohstoffen und Agrarland für den Export ausgerichtete ist. Dieses Wirtschaftsmodell geht auf die Kolonialzeit zurück und prägt viele Länder des globalen Südens bis heute. 
betrachtet werden. Deshalb können antikoloniale Perspektiven in besonderer Weise zur Hinterfragung und Veränderung hegemonialer Strukturen beitragen.

Eine solche antikoloniale Perspektive findet sich laut Facundo Martín in der Lateinamerikanischen Politischen Ökologie, deren wissenschaftliche Arbeit auf dem Widerstand gegen die Kolonialisierung von Natur und Leben basiere (vgl. Martín 2013: 5). In diese Strömung ordnet er unter anderem die wissenschaftliche und politische Artikulation von Buen Vivir als Gegenentwurf zum kolonialen wachstumsorientierten Entwicklungsmodell ein (vgl. Martín 2013: 14; Kapitel 5.1.4). Diese antagonistischen Artikulationen aus Lateinamerika können meiner Meinung nach auch wichtige Impulse für emanzipatorische Prozesse in Europa geben. Erforderlich ist eine antikoloniale Perspektive die sich nicht scheut, bestimmte Grundannahmen, Institutionen und Basisprinzipien der ,westlichen “ Moderne als Ursache der ökologischen Krise zu benennen und ihre Überwindung einzufordern. Ihr spezifischer Beitrag besteht in der Insistenz, dass der Weg zu einer anderen Welt - die stets möglich und angesichts der ökologischen Krise akut notwendig ist - nicht über alternative Entwicklungsmodelle, sondern über Alternativen zur Entwicklung führt. 



\section{Abkürzungs- und Begriffsverzeichnis}

Im Folgenden werden Abkürzungen und Begriffe erläutert, die für das Verständnis der Arbeit wichtig sind. Das Verzeichnis umfasst Eigennamen von Institutionen und Organisationen, feststehende Ausdrücke sowie selbst definierte Begriffe.

\begin{tabular}{|l|l|}
\hline Annex-B-Staaten & $\begin{array}{l}\text { Als Annex-B-Staaten gelten die Länder, die im Annex B zum Kyoto- } \\
\text { Protokoll aufgelistet sind, weil sie sich zur Einhaltung von Emissionso- } \\
\text { bergrenzen verpflichtet haben. Dies trifft auf alle Industrie- und Trans- } \\
\text { formationsländer zu. }\end{array}$ \\
\hline AOSIS & $\begin{array}{l}\text { Die Allianz der kleinen Inselstaaten (Alliance of Small Island States) ist } \\
\text { eine Gruppe kleiner Insel- und niedrig liegender Küstenstaaten, die bei } \\
\text { den UN-Klimaverhandlungen als informeller Zusammenschluss ge- } \\
\text { meinsame Positionen vertritt. Die Länder eint, dass sie besonders stark } \\
\text { vom steigenden Meeresspiegel und anderen Folgen des anthropogenen } \\
\text { Klimawandels betroffen sind. Aktuell hat die Gruppe 39 Mitglieder und } \\
\text { fünf Staaten mit Beobachterstatus aus Afrika, dem Indischen Ozean, der } \\
\text { Karibik, dem Pazifischen Ozean und der Südchinesischen See. }\end{array}$ \\
\hline BECCS & $\begin{array}{l}\text { Die Abkürzung BECCS (Bio-energy with carbon capture and storage) } \\
\text { steht für die Anwendung von CCS-Technologien bei Bioenergiekraft- } \\
\text { werken. }\end{array}$ \\
\hline Bellona & $\begin{array}{l}\text { Die Bellona Foundation ist eine Umwelt-NGO, die sich sowohl in } \\
\text { ihrem Ursprungsland Norwegen als auch auf internationaler Ebene für } \\
\text { den Einsatz von CCS-Technologien einsetzt. }\end{array}$ \\
\hline BINGO & $\begin{array}{l}\text { Mit dem Begriff der Business and Industry NGO werden die Lobbyver- } \\
\text { bände der Wirtschaft von anderen zivilgesellschaftlichen Gruppen (bei- } \\
\text { spielsweise Umwelt- und Entwicklungs-NGOs) abgegrenzt. }\end{array}$ \\
\hline CAN & $\begin{array}{l}\text { Innerhalb des Climate Action Networks koordinieren NGOs ihre Interes- } \\
\text { sen und formulieren gemeinsame Positionen. Mit seinen über 900 Mit- } \\
\text { gliedern bildet CAN den größten Zusammenschluss von NGOs im Rah- } \\
\text { men der UN-Klimaverhandlungen. }\end{array}$ \\
\hline
\end{tabular}




\begin{tabular}{|c|c|}
\hline CCS & $\begin{array}{l}\text { Mit Hilfe von Carbon Capture and Storage (CCS) sollen ca. 85-95\% } \\
\text { des entstehenden } \mathrm{CO}_{2} \text { einzelner Verbrennungsanlagen abgeschieden und } \\
\text { anschließend in unterirdischen Speicherstätten oder in Tiefseegebieten } \\
\text { eingelagert werden. Die Anwendung von CCS-Technologien geht aller- } \\
\text { dings aufgrund des erhöhten Energiebedarfs von } 10-40 \% \text { mit einem } \\
\text { Wirkungsgradverlust einher. Die Reduktion des in die Atmosphäre } \\
\text { emittierten Kohlenstoffdioxids liegt demnach - eine sichere } \\
\text { Speicherung vorausgesetzt - bei ca. 80-90\%. Der Ressourceneinsatz } \\
\text { erhöht sich dabei um bis zu } 40 \% \text { pro erzeugte Kilowattstunde. }\end{array}$ \\
\hline CCSA & $\begin{array}{l}\text { Die Carbon Capture and Storage Association ist ein Wirtschafts- } \\
\text { verband, der sich für die Förderung, Entwicklung und Anwendung von } \\
\text { CCS-Technologien einsetzt. }\end{array}$ \\
\hline $\begin{array}{l}\text { CCS-befürwor- } \\
\text { tende Koalition }\end{array}$ & $\begin{array}{l}\text { Mit dem Begriff der CCS-befürwortenden Koalition bezeichne ich die } \\
\text { Akteur_innen, die sich im Allgemeinen für CCS-Technologien ein- } \\
\text { setzen. }\end{array}$ \\
\hline $\begin{array}{l}\text { CCS-befürwor- } \\
\text { tende Koalition in } \\
\text { den UN-Klima- } \\
\text { verhandlungen }\end{array}$ & $\begin{array}{l}\text { Der Begriff der CCS-befürwortenden Koalition in den UN-Klima- } \\
\text { verhandlungen steht in dieser Arbeit für die Akteur_innen, die sich in } \\
\text { der CCS-CDM-Kontroverse für die Aufnahme von CCS ins Kyoto- } \\
\text { Protokoll positioniert haben. }\end{array}$ \\
\hline $\begin{array}{l}\text { CCS-CDM-Kon- } \\
\text { troverse }\end{array}$ & $\begin{array}{l}\text { Mit dem Begriff der CCS-CDM-Kontroverse bezeichne ich die Debatte } \\
\text { um CCS-Technologien, die von } 2005 \text { bis } 2011 \text { in den UN-Klimaver- } \\
\text { handlungen geführt wurde. In diesem Verhandlungsstrang wurde die } \\
\text { Frage diskutiert, ob CCS-Projekte als mögliche Maßnahmen im Sinne } \\
\text { des CDM zugelassen werden sollen oder nicht. Die Verhandlungen } \\
\text { endeten mit der Entscheidung, CCS-Technologien nachträglich ins } \\
\text { Kyoto-Protokoll aufzunehmen und als mögliche CDM-Projekte zuzu- } \\
\text { lassen. }\end{array}$ \\
\hline $\mathrm{CCS}-\mathrm{C}$ & $\begin{array}{l}\text { Als CCS-Community bezeichne ich das internationale Netzwerk von } \\
\text { Personen, deren beruflicher Werdegang mit der Entwicklung und An- } \\
\text { wendung von CCS-Technologien verknüpft ist. }\end{array}$ \\
\hline $\begin{array}{l}\text { CCS-kritische } \\
\text { Koalition }\end{array}$ & $\begin{array}{l}\text { Der Begriff der CCS-kritischen Koalition steht in dieser Arbeit für die } \\
\text { Akteur_innen, die sich im Allgemeinen gegen den Einsatz von CCS- } \\
\text { Technologien aussprechen. }\end{array}$ \\
\hline $\begin{array}{l}\text { CCS-kritische } \\
\text { Koalition in den } \\
\text { UN-Klimaver- } \\
\text { handlungen }\end{array}$ & $\begin{array}{l}\text { Mit dem Begriff der CCS-kritischen Koalition in den UN-Klimaver- } \\
\text { handlungen bezeichne ich die Akteur_innen, die sich in der CCS-CDM- } \\
\text { Kontroverse gegen die Aufnahme von CCS ins Kyoto-Protokoll positio- } \\
\text { niert haben. }\end{array}$ \\
\hline $\mathrm{CDM}$ & $\begin{array}{l}\text { Der Mechanismus für umweltverträgliche Entwicklung (Clean } \\
\text { Development Mechanism) ist Teil der flexiblen Mechanismen des } \\
\text { Kyoto-Protokolls. Mit dem CDM wird es Industrieländern ermöglicht, } \\
\text { ihre Emissionsreduktionsziele durch Projekte in Nicht-Annex-B-Staaten } \\
\text { zu erfüllen. Wie der Name bereits andeutet, soll mit dem CDM im Ziel- } \\
\text { land eine nachhaltige Entwicklung gefördert werden. Auf der anderen } \\
\text { Seite werden dem beteiligten Industrieland CERs gutgeschrieben. }\end{array}$ \\
\hline
\end{tabular}




\begin{tabular}{|c|c|}
\hline CDM EB & $\begin{array}{l}\text { Das CDM Executive Board ist ein Organ der CMP. Es überwacht die } \\
\text { CDM-Projekte. Es registriert die Projekte und vergibt die CERs. }\end{array}$ \\
\hline CER & $\begin{array}{l}\text { Zertifizierte Emissionsreduktionen (Certified Emissions Reductions) } \\
\text { werden über den CDM erworben und auf die Reduktionsziele der } \\
\text { Annex-B-Staaten angerechnet. }\end{array}$ \\
\hline $\mathrm{COP}$ & $\begin{array}{l}\text { Die Vertragsstaatenkonferenz der Klimarahmenkonvention (Conference } \\
\text { of the Parties) ist die jährliche Tagung der Mitgliedsstaaten der Klima- } \\
\text { rahmenkonvention. Diese Treffen werden auch als UN-Klimakonferen- } \\
\text { zen oder Weltklimagipfel bezeichnet. Es gibt im Rahmen der UN zwar } \\
\text { auch Konferenzen zu anderen Politikfeldern, die ebenfalls mit COP ab- } \\
\text { gekürzt werden. Diese anderen COPs werden in dieser Arbeit allerdings } \\
\text { nicht erwähnt. Insofern steht die Abkürzung COP stets für die Vertrags- } \\
\text { staatenkonferenz der Klimarahmenkonvention. }\end{array}$ \\
\hline CMP & $\begin{array}{l}\text { Seit Inkrafttreten des Kyoto-Protokolls (2005) findet zeitgleich zu den } \\
\text { COPs die Tagung der Mitgliedsstaaten des Kyoto-Protokolls } \\
\text { (Conference of the Parties serving as the Meeting of the Parties to the } \\
\text { Protocol) statt. }\end{array}$ \\
\hline CSLF & $\begin{array}{l}\text { Das Carbon Sequestration Leadership Forum ist eine zwischenstaat- } \\
\text { liche Organisation, die sich für die Entwicklung von CCS-Technologien } \\
\text { im globalen Maßstab einsetzt. Aktuelle Mitglieder sind Australien, Bra- } \\
\text { silien, China, Deutschland, die EU, Frankreich, Griechenland, Groß- } \\
\text { britannien, Indien, Italien, Japan, Kanada, Mexiko, Niederlande, Neu- } \\
\text { seeland, Norwegen, Polen, Russland, Saudi-Arabien, Südafrika, Süd- } \\
\text { korea, die USA und die Vereinigten Arabischen Emirate. }\end{array}$ \\
\hline ECBM & $\begin{array}{l}\text { Enhanced Coal Bed Methane Recovery meint die Speicherung von } \mathrm{CO}_{2} \\
\text { in Kohleflözen und die sich daraus ergebende Methanförderung. }\end{array}$ \\
\hline EGR & $\begin{array}{l}\text { Mit Enhanced Gas Recovery wird die Injektion von } \mathrm{CO}_{2} \text { in Erdgaslager- } \\
\text { stätten bezeichnet. Durch dieses Verfahren erhöht sich der Druck in den } \\
\text { Lagerstätten und die Fördermenge steigt. }\end{array}$ \\
\hline EOR & $\begin{array}{l}\text { Enhanced Oil Recovery steht für die Injektion von } \mathrm{CO}_{2} \text { in Erdöllager- } \\
\text { stätten. Durch dieses Verfahren erhöht sich der Druck in den Lager- } \\
\text { stätten und die Fördermenge steigt. }\end{array}$ \\
\hline ERU & $\begin{array}{l}\text { Emissionsreduktionseinheiten (Emission Reduction Units) werden aus } \\
\text { Projekten der JI gewonnen. }\end{array}$ \\
\hline Eskom & Eskom ist ein südafrikanisches Stromversorgungsunternehmen. \\
\hline EURELECTRIC & $\begin{array}{l}\text { EURELECTRIC ist ein Wirtschaftsverband, der die Interessen der euro- } \\
\text { päischen Elektrizitätswirtschaft vertritt. }\end{array}$ \\
\hline EU & $\begin{array}{l}\text { Im Staatenverbund der Europäischen Union sind aktuell } 28 \text { Länder Mit- } \\
\text { glied. Zum Zeitpunkt der Unterzeichnung des Kyoto-Protokolls hatte } \\
\text { die EU allerdings nur } 15 \text { Mitglieder. Die } 15 \text { damaligen Mitgliedsländer } \\
\text { verpflichteten sich im Rahmen des Kyoto-Protokolls, bis } 2012 \text { ihre } \\
\text { Treibhausgasemissionen gegenüber dem Basisjahr } 1990 \text { um } 8 \% \text { zu re- } \\
\text { duzieren. }\end{array}$ \\
\hline
\end{tabular}




\begin{tabular}{|c|c|}
\hline EUA & $\begin{array}{l}\text { EU-Emissionsberechtigungen (European Unit Amounts) werden im } \\
\text { Rahmen des EU ETS an die am Emissionsrechtehandel beteiligten } \\
\text { Produktionsstandorte verteilt. }\end{array}$ \\
\hline EU ETS & $\begin{array}{l}\text { Der EU-Emissionshandel (European Union Emissions Trading System) } \\
\text { ist der erste grenzüberschreitende und weltweit größte Emissionsrechte- } \\
\text { handel. }\end{array}$ \\
\hline $\begin{array}{l}\text { Flexible } \\
\text { Mechanismen }\end{array}$ & $\begin{array}{l}\text { Mit dem Begriff der flexiblen Mechanismen werden die drei markt- } \\
\text { basierten Instrumente des Kyoto-Protokolls bezeichnet, deren Zweck es } \\
\text { ist, die Einhaltung der Reduktionsziele für die Annex-B-Staaten mög- } \\
\text { lichst kostengünstig zu gestalten: der Emissionsrechtehandel, der CDM } \\
\text { und die JI. }\end{array}$ \\
\hline ForUM & $\begin{array}{l}\text { Das Forum for Utvikling og Miljø ist ein Netzwerk von norwegischen } \\
\text { Entwicklungs- und Umwelt-NGOs. }\end{array}$ \\
\hline G77 & $\begin{array}{l}\text { Die Gruppe der } 77 \text { ist ein loser Zusammenschluss von Ländern des glo- } \\
\text { balen Südens. } 1964 \text { gründeten } 77 \text { Staaten die Gruppe während der ers- } \\
\text { ten Welthandelskonferenz, um in internationalen Verhandlungen ge- } \\
\text { meinsame Positionen vertreten zu können. Mittlerweile sind } 133 \text { Länder } \\
\text { Mitglied der G77. }\end{array}$ \\
\hline G8-Gipfel & $\begin{array}{l}\text { Auf den G8-Gipfeln treffen sich die Staats- und Regierungschefs der als } \\
\text {,führend“' geltenden acht Industrienationen (Deutschland, Frankreich, } \\
\text { Großbritannien, Italien, Japan, Kanada, Russland und die USA). }\end{array}$ \\
\hline GCCSI & $\begin{array}{l}\text { Das Global CCS Institute ist eine internationale Organisation, die sich } \\
\text { für die Entwicklung und den Einsatz von CCS-Technologien einsetzt. } \\
\text { Zu den Mitgliedern aus über } 40 \text { Ländern zählen Regierungen, multi- } \\
\text { nationale Konzerne, kleine Unternehmen, NGOs, Forschungsinstitute } \\
\text { und Universitäten. }\end{array}$ \\
\hline Greenpeace & $\begin{array}{l}\text { Greenpeace zählt zu den größten international agierenden Umwelt- } \\
\text { NGOs. }\end{array}$ \\
\hline ICC & $\begin{array}{l}\text { Die Internationale Handelskammer (International Chamber of } \\
\text { Commerce) ist der weltweit größte Wirtschaftsverband. Sie vertritt } \\
\text { Unternehmen aus den verschiedensten Branchen. }\end{array}$ \\
\hline IEA & $\begin{array}{l}\text { Die Internationale Energieagentur (International Energy Agency) ist } \\
\text { eine Kooperatonsplattform der OECD-Länder für Energiefragen. Sie } \\
\text { verfügt außerdem über strategische Ölreserven, um in den Ölmarkt ein- } \\
\text { greifen zu können. }\end{array}$ \\
\hline IEA GHG & $\begin{array}{l}\text { Das Greenhouse Gas R\&D Programme der IEA ist ein Forschungs- } \\
\text { programm, in dem technologische Innovationen zur Reduktion von } \\
\text { Treibhausgasen, die bei der Nutzung fossiler Brennstoffe anfallen, ent- } \\
\text { wickelt werden. }\end{array}$ \\
\hline IEEP & $\begin{array}{l}\text { Das Institute for European Environmental Policy ist ein politik- } \\
\text { beratender Thinktank, dessen inhaltlicher Schwerpunkt auf der euro- } \\
\text { päischen Umweltpolitik liegt. }\end{array}$ \\
\hline
\end{tabular}




\begin{tabular}{|c|c|}
\hline IETA & $\begin{array}{l}\text { Die International Emissions Trading Association vertritt die Interessen } \\
\text { von Unternehmen, die am Kyoto-Kohlenstoffmarkt agieren. Darunter } \\
\text { fallen beispielsweise Finanzmarktakteur_innen, die sich auf den Handel } \\
\text { mit Emissionsberechtigungen spezialisiert haben, Agenturen, die für die } \\
\text { Akkreditierung von Offset-Projekten zuständig sind oder Unternehmen, } \\
\text { die viele Emissionen verursachen und deshalb auf die Zuteilung } \\
\text { und/oder den Handel mit Emissionsberechtigungen angewiesen sind. }\end{array}$ \\
\hline IPCC & $\begin{array}{l}\text { Der Zwischenstaatliche Ausschuss für Klimaänderungen (Intergovern- } \\
\text { mental Panel on Climate Change) ist ein Sachverständigenrat, der vom } \\
\text { UNEP und der WMO gegründet wurde. In seinen Berichten trägt der } \\
\text { IPCC die Ergebnisse der wissenschaftlichen Forschung in Bezug auf } \\
\text { den anthropogenen Klimawandel und seine Folgen sowie darauf rea- } \\
\text { gierende Vermeidungs- und Anpassungsstrategien zusammen. Diese Be- } \\
\text { richte spielen in den UN-Klimaverhandlungen eine zentrale Rolle. }\end{array}$ \\
\hline IPCC SRCCS & $\begin{array}{l}\text { Der Sonderbericht des IPCC über CCS (IPCC Special Report on } \\
\text { Carbon Dioxide Capture and Storage) ist } 2005 \text { erschienen. Er stellt den } \\
\text { einflussreichsten Beitrag des IPCC zu den Auseinandersetzungen um } \\
\text { CCS-Technologien dar. }\end{array}$ \\
\hline Indian Institute & $\begin{array}{l}\text { Das Indian Institute of Technology Kharagpur ist eine technische Hoch- } \\
\text { schule in Indien. }\end{array}$ \\
\hline IPIECA & $\begin{array}{l}\text { Die International Petroleum Industry Energy Conservation Association } \\
\text { ist ein Wirtschaftsverband, der die Interessen der Öl- und Gasindustrie } \\
\text { in den UN-Gremien vertritt. }\end{array}$ \\
\hline IRGC & $\begin{array}{l}\text { Das International Risk Governance Council ist ein Thinktank, der } \\
\text { politische Institutionen beim Umgang mit Risiken berät. }\end{array}$ \\
\hline JI & $\begin{array}{l}\text { Der Mechanismus der Gemeinsamen Umsetzung (Joint Implementation) } \\
\text { ist Teil der flexiblen Mechanismen des Kyoto-Protokolls. Die JI ermög- } \\
\text { licht den Transfer von ERUs zwischen Annex-B-Staaten. Industrie- und } \\
\text { Transformationsländer erhalten für die Investitionen in emissionsredu- } \\
\text { zierende Projekte in anderen Annex-B-Staaten Reduktionszertifikate, } \\
\text { die sie auf ihre eigenen Minderungspflichten anrechnen können. }\end{array}$ \\
\hline JUSSCANNZ & $\begin{array}{l}\text { Mit JUSSCANNZ wird eine Gruppe von Ländern bezeichnet, die bei } \\
\text { den UN-Klimaverhandlungen als informeller Zusammenschluss ge- } \\
\text { meinsame Positionen vertreten. JUSSCANNZ steht für die Abkürzung } \\
\text { der Namen der ersten Mitgliedsstaaten: Japan, USA, Schweiz, Kanada, } \\
\text { Australien, Norwegen und Neuseeland. Ihre gemeinsamen Interessen er- } \\
\text { geben sich dadurch, dass sie Industrieländer sind und nicht zur EU } \\
\text { gehören. Darüber hinaus sind sie durch eine verhältnismäßig hohe Ab- } \\
\text { hängigkeit von der Produktion und/oder vom Verbrauch fossiler Brenn- } \\
\text { stoffe gekennzeichnet. } 1998 \text { stieg die Schweiz aus dem Verhandlungs- } \\
\text { verbund aus, dafür kamen Russland und die Ukraine hinzu. Seitdem } \\
\text { spricht man von der Umbrella Group. }\end{array}$ \\
\hline
\end{tabular}




\begin{tabular}{|c|c|}
\hline Kyoto-Protokoll & $\begin{array}{l}\text { Das Protokoll von Kyoto zum Rahmenübereinkommen der Vereinten } \\
\text { Nationen über Klimä̈nderungen ist ein Zusatzprotokoll zur Ausgestal- } \\
\text { tung der UNFCCC. Es wurde } 1997 \text { auf der COP } 3 \text { beschlossen. Aller- } \\
\text { dings konnte es erst } 2005 \text { in Kraft treten, nachdem die vereinbarte Min- } \\
\text { destbeteiligungshürde erreicht wurde, laut der mindestens } 55 \text { Länder, } \\
\text { die mehr als } 55 \% \text { der Treibhausgas-Emissionen des Jahres } 1990 \text { verur- } \\
\text { sachten, das Abkommen ratifiziert hatten. Seitdem finden zeitgleich mit } \\
\text { den COPs auch die CMPs statt. Im Annex B des Kyoto-Protokolls sind } \\
\text { völkerrechtlich verbindliche Emissionsobergrenzen für die Annex-B- } \\
\text { Staaten festgeschrieben. Für die erste Verpflichtungsperiode (die von } \\
2008 \text { bis } 2012 \text { galt) hatten sich die Annex-B-Staaten dazu verpflichtet, } \\
\text { ihre Emissionen um durchschnittlich 5,2\% gegenüber dem Basisjahr } \\
1990 \text { zu verringern. }\end{array}$ \\
\hline $\begin{array}{l}\text { Nicht-Annex-B- } \\
\text { Staaten }\end{array}$ & $\begin{array}{l}\text { Mit Nicht-Annex-B-Staaten werden die Länder bezeichnet, die nicht im } \\
\text { Annex B zum Kyoto-Protokoll aufgelistet sind, weil sie sich nicht zur } \\
\text { Einhaltung von Emissionsobergrenzen verpflichtet haben. Dies trifft auf } \\
\text { alle Länder des globalen Südens zu. }\end{array}$ \\
\hline NGO & $\begin{array}{l}\text { Als Nichtregierungsorganisation (non-governmental organisation, } \\
\text { NGO) werden zivilgesellschaftliche Organisationen bezeichnet, die } \\
\text { nicht profitorientiert sind. Eingeführt wurde der Begriff in der UN, um } \\
\text { die Akteur_innen aus der Zivilgesellschaft von den staatlichen } \\
\text { Vertreter_innen abzugrenzen. In dieser Arbeit steht die Abkürzung NGO } \\
\text { in der Regel für Entwicklungs- und Umwelt-NGOs. }\end{array}$ \\
\hline OECD & $\begin{array}{l}\text { In der Organisation für wirtschaftliche Zusammenarbeit und Entwick- } \\
\text { lung (Organisation for Economic Co-operation and Development) sind } \\
34 \text { Staaten Mitglied. Das Bekenntnis zu Demokratie und Marktwirt- } \\
\text { schaft gilt als Basis der Zusammenarbeit. Die meisten OECD-Mit- } \\
\text { glieder sind Länder des globalen Nordens und zeichnen sich durch ein } \\
\text { vergleichsweise hohes Pro-Kopf-Einkommen aus. }\end{array}$ \\
\hline OPEC & $\begin{array}{l}\text { Die Organisation erdölexportierender Länder (Organisation of the } \\
\text { Petroleum Exporting Countries) ist ein Kartell von Staaten, die insge- } \\
\text { samt etwa für } 40 \% \text { der weltweiten Erdölproduktion verantwortlich sind } \\
\text { und über drei Viertel der weltweiten Erdölreserven verfügen. Die } \\
\text { aktuellen Mitgliedsländer sind Algerien, Angola, Ecuador, Irak, Iran, } \\
\text { Katar, Kuwait, Libyen, Nigeria, Saudi-Arabien, Venezuela und die } \\
\text { Vereinigten Arabischen Emirate. }\end{array}$ \\
\hline REDD & $\begin{array}{l}\text { Das Klimaschutzinstrument der Reduktion von Emissionen aus Entwal- } \\
\text { dung und Schädigung von Wäldern (Reducing Emissions from } \\
\text { Deforestation and forest Degradation) soll die Erhaltung großflächiger } \\
\text { Wälder als Kohlenstoffspeicher finanziell attraktiv machen. }\end{array}$ \\
\hline SACCCS & $\begin{array}{l}\text { Das South African Centre for Carbon Capture and Storage ist ein For- } \\
\text { schungsinstitut, das zu CCS-Technologien forscht und an einem } \\
\text { Demonstrationsprojekt in Südafrika beteiligt ist. }\end{array}$ \\
\hline Saline Aquifere & $\begin{array}{l}\text { Saline Aquifere sind unterirdische Sedimentgesteine, deren Poren mit } \\
\text { stark salzhaltigem Wasser gefüllt sind. Im Rahmen von CCS-Projekten } \\
\text { werden sie als } \mathrm{CO}_{2} \text {-Lager genutzt. Von den verschiedenen Möglichkei- } \\
\text { ten der Endlagerung besitzt diese Option das größte Speicherpotenzial. }\end{array}$ \\
\hline
\end{tabular}




\begin{tabular}{|c|c|}
\hline SBSTA & $\begin{array}{l}\text { Das Nebenorgan für wissenschaftliche und technologische Beratung } \\
\text { (Subsidiary Body for Scientific and Technological Advice) ist eines von } \\
\text { zwei ständigen Nebenorganen der UNFCCC. }\end{array}$ \\
\hline SustainUS & $\begin{array}{l}\text { SustainUS ist eine nordamerikanische umweltpolitische Jugend- } \\
\text { organisation. }\end{array}$ \\
\hline Umbrella Group & $\begin{array}{l}\text { Als Umbrella Group wird eine Gruppe von Ländern bezeichnet, die bei } \\
\text { den UN-Klimaverhandlungen als informeller Zusammenschluss ge- } \\
\text { meinsame Positionen vertreten. Die Mitgliedsstaaten sind Australien, } \\
\text { Japan, Kanada, Neuseeland, Russland, Norwegen, Ukraine und die } \\
\text { USA. Ihre gemeinsamen Interessen ergeben sich dadurch, dass sie In- } \\
\text { dustrieländer sind und nicht zur EU gehören. Darüber hinaus sind sie } \\
\text { durch eine verhältnismäßig hohe Abhängigkeit von der Produktion } \\
\text { und/oder vom Verbrauch fossiler Brennstoffe gekennzeichnet. Die } \\
\text { Umbrella Group ist aus dem JUSSCANNZ-Bündnis hervorgegangen. }\end{array}$ \\
\hline UN & $\begin{array}{l}\text { Die Vereinte Nationen (United Nations) sind eine zwischenstaatliche } \\
\text { Organisation mit aktuell } 193 \text { Mitgliedsstaaten. Laut UN-Charta zielt } \\
\text { ihre Arbeit auf die Sicherung des Weltfriedens, die Einhaltung des } \\
\text { Völkerrechts, den Schutz der Menschenrechte und die Förderung der } \\
\text { internationalen Zusammenarbeit. }\end{array}$ \\
\hline UNDP & $\begin{array}{l}\text { Das Entwicklungsprogramm der Vereinten Nationen (United Nations } \\
\text { Development Programme) ist ein Exekutivausschuss innerhalb der UN- } \\
\text { Generalversammlung. Die Arbeit des Programms zielt auf die } \\
\text { Erreichung bestimmter globaler Entwicklungsziele, beispielsweise der } \\
\text { Millenniums-Ziele. }\end{array}$ \\
\hline UNEP & $\begin{array}{l}\text { Das Umweltprogramm der Vereinten Nationen (United Nations } \\
\text { Environment Programme) wurde } 1972 \text { auf der Konferenz der Vereinten } \\
\text { Nationen über die Umwelt des Menschen ins Leben gerufen und ver- } \\
\text { folgt die Umsetzung der ökologischen Ziele der UN. }\end{array}$ \\
\hline UNFCCC & $\begin{array}{l}\text { Die Klimarahmenkonvention der Vereinten Nationen (United Nations } \\
\text { Framework Convention on Climate Change) wurde } 1992 \text { auf der } \\
\text { Konferenz der Vereinten Nationen über Umwelt und Entwicklung } 1992 \\
\text { in Rio de Janeiro gegründet. Bis heute sind } 195 \text { Staaten plus die EU als } \\
\text { supranationale Organisation der Klimarahmenkonvention beigetreten. } \\
\text { Einmal im Jahr findet die Vertragsstaatenkonferenz der Klimarahmen- } \\
\text { konvention (COP) statt. }\end{array}$ \\
\hline WCA \& WCI & $\begin{array}{l}\text { Die World Coal Association ist ein internationaler Wirtschaftsverband, } \\
\text { der die Interessen der Kohleindustrie vertritt. Im November } 2010 \\
\text { änderte der Verband seinen Namen von World Coal Institute (WCI) zu } \\
\text { World Coal Association. }\end{array}$ \\
\hline WCED & $\begin{array}{l}\text { Der Sachverständigenrat der Weltkommission für Umwelt und Entwick- } \\
\text { lung (World Commission on Environment and Development) wurde } \\
1983 \text { von der UN eingerichtet. } 1987 \text { publizierte der Sachverständigenrat } \\
\text { den Bericht Our Common Future, der bis heute eine wichtige Referenz } \\
\text { in den Auseinandersetzungen um Sustainable Development darstellt. }\end{array}$ \\
\hline
\end{tabular}




\begin{tabular}{|l|l|}
\hline WMO & $\begin{array}{l}\text { Die Weltorganisation für Meteorologie (World Meteorological } \\
\text { Organization) ist eine Sonderorganisation der Vereinten Nationen. Sie } \\
\text { fördert die Kooperation und den wissenschaftlichen Austausch in Bezug } \\
\text { auf die Erdatmosphäre. }\end{array}$ \\
\hline WTO & $\begin{array}{l}\text { In der Welthandelsorganisation (World Trade Organisation) sind aktuell } \\
160 \text { Staaten Mitglied. Im Rahmen der WTO handeln die Mitglieds- } \\
\text { staaten internationale Handels- und Wirtschaftsabkommen aus. }\end{array}$ \\
\hline WWF & $\begin{array}{l}\text { Der World Wide Fund for Nature ist eine der größten international } \\
\text { agierenden Umwelt-NGOs. }\end{array}$ \\
\hline
\end{tabular}




\section{Literatur}

Adorno, Theodor W. (2003): Fortschritt, in: Tiedemann, Rolf/Adorne, Gretel/BuckMorss, Susan/Schultz, Klaus (Hg_innen): Theodor W. Adorno. Gesammelte Schriften, Bd. 10.2, Kulturkritik und Gesellschaft II, Frankfurt a. M., 617-638. Altmann, Philipp (2013): Das Gute Leben als Alternative zum Wachstum? Der Fall Ecuador, in: Sozialwissenschaften und Berufspraxis, Jg. 36, Nr. 1, 101-111.

Andresen, Steinar/Butenschøn, Siri Hals (2001): Norwegian Climate Policy: From Pusher to Laggard?, in: International Environmental Agreements: Politics, Law and Economics, Jg. 1, Nr. 3, 337-356.

Andresen, Steinar/Kolshus, Hans H./Torvanger, Asbjørn (2002): The feasibility of ambitious climate agreements. Norway as an early test case, CICERO Working Paper 2002:03, Oslo.

Bäckstrand, Karin/Lövbrand, Eva (2006): Planting Trees to Mitigate Climate Change. Contested Discourses of Ecological Modernization, Green Governmentality and Civic Environmentalism, in: Global Environmental Politics, Jg. 6, Nr. 1, 50-75.

Bäckstrand, Karin/Meadowcroft, James/Oppenheimer, Michael (2011): The politics and policy of carbon capture and storage: Framing an emergent technology, in: Global Environmental Change, Jg. 21, Nr. 2, 275-281.

Bakker, Stefan/De Coninck, Heleen/Groenenberg, Heleen (2008): Carbon Capture and Storage, im Internet: www.theclimategroup.org/_assets/files/CarbonCapture-and-Storage.pdf, letzter Zugriff am 02.12.2014.

Beck, Silke (2009a): Das Klimaexperiment und der IPCC. Schnittstellen zwischen Wissenschaft und Politik in den internationalen Beziehungen, Marburg.

Beck, Silke (2009b): Von der Beratung zur Verhandlung - Der Fall IPCC, in: Halfmann, Jost/Schützenmeister, Falk (Hg.): Organisation der Forschung. Der Fall der Atmosphärenwissenschaft, Wiesbaden, 120-144.

Beck, Ulrich (1986): Risikogesellschaft. Auf dem Weg in eine andere Moderne, Frankfurt a. M.

Beck, Ulrich (2010): Climate for Change, or How to Create a Green Modernity?, in: Theory, Culture \& Society, Jg. 27, Nr. 2-3, 254-266. 
Becker, Egon/Jahn, Thomas (2003): Umrisse einer kritischen Theorie gesellschaftlicher Naturverhältnisse, in: Böhme, Gernot/Manzei, Alexandra (Hg_innen): Kritische Theorie der Technik und der Natur, München, 91-112.

Becker, Egon/Jahn, Thomas (2006): Krisendiskurse, in: dies. (Hg.): Soziale Ökologie. Grundzüge einer Wissenschaft von den gesellschaftlichen Naturverhältnissen, Frankfurt a. M./New York, 54-69.

Becker, Egon/Hummel, Diana/Jahn, Thomas (2011): Gesellschaftliche Naturverhältnisse als Rahmenkonzept, in: Groß, Matthias (Hg.): Handbuch Umweltsoziologie, Wiesbaden, 75-96.

Bedall, Philip (2013): ,Climate justice‘, ,green economy' or ,a one planet lifestyle‘ - Hegemonic narratives in transnational NGOs and social movements, in: Methmann, Chris/Rothe, Delf/Stephan, Benjamin: Interpretive Approaches to Global Climate Governance. (De-)Constructing the Greenhouse, Abingdon/New York, 198-216.

Bedall, Philip (2014): Climate Justice vs. Klimaneoliberalismus? Klimadiskurse im Spannungsfeld von Hegemonie und Gegen-Hegemonie, Bielefeld.

Bedall, Philip/Austen, Martina (2010): Climate Justice. Bezugspunkt einer Gegenhegemonie oder wolkige Leerformel?, in: Analyse \& Kritik - Zeitung für linke Debatte und Praxis, Nr. 549.

Bedorf, Thomas/Röttgers, Kurt (Hg.) (2010): Das Politische und die Politik, Berlin.

Bellona Foundation (2007): Bellona's comments on Carbon dioxide Capture and Storage under the Clean Development Mechanism, im Internet: www.unfccc.int/files/kyoto_protocol/mechanisms/clean_development_mechanisms/ application/pdf/bellonas_comments_on_co2_capture_and_storage_under_the_clean_ development_mechanism.pdf, letzter Zugriff am 02.12.2014.

Berger, Hartwig (2010): Verkehrte Kreisläufe. Das Dilemma der KohlendioxidAbscheidung und -Lagerung, in: Leviathan, Jg. 38, Nr. 2, 143-155.

Berger, Peter L./Luckmann, Thomas (2004) [1969]: Die gesellschaftliche Konstruktion der Wirklichkeit, Frankfurt a. M.

Bernstein, Steven (2000): Ideas, Social Structure and the Compromise of Liberal Environmentalism, in: European Journal of International Relations, Jg. 6, Nr. 4, 464-512.

Bitzer, Lloyd F. (1959): Aristotle's enthymeme revisited, in: Quarterly Journal of Speech, Jg. 45, Nr. 4, 399-408.

Bode, Thilo (1996): Am Wendepunkt - Zur Stellung von Greenpeace in der Gesellschaft, in: Greenpeace e. V. (Hg.): Das Greenpeace Buch, München.

Böhme, Gernot (2005): Goethes Faust als philosophischer Text, Zug.

Brand, Karl-Werner (2008): Umweltbewegung (inkl. Tierschutz), in: Roth, Roland/ Rucht, Dieter (Hg.): Die sozialen Bewegungen in Deutschland seit 1945, Frankfurt a. M./New York, 219-244. 
Brand, Karl-Werner/Eder, Klaus/Poferl, Angelika (1997): Ökologische Kommunikation in Deutschland, Opladen.

Brand, Ulrich (2009): Environmental crisis and the ambiguous postneoliberalising of nature, in: Brand, Ulrich/Nicola Sekler (Hg_innen): Postneoliberalism - A beginning debate, development dialogue, Nr. 51, 103-117.

Brand, Ulrich (2010) Sustainable development and ecological modernization: The limits to a hegemonic policy knowledge, in: Innovation. The European Journal of Social Science Research, Jg. 23, Nr. 2, 135-152.

Brand, Ulrich/Görg, Christoph (2003): Postfordistische Naturverhältnisse. Konflikte um genetische Ressourcen und die Internationalisierung des Staates, Münster.

Brand, Ulrich/Wissen, Markus (2011): Die Regulation der ökologischen Krise. Theorie und Empirie der Transformation gesellschaftlicher Naturverhältnisse, in: Österreichische Zeitschrift für Soziologie, Jg. 36, Nr. 2, 12-34.

Brunnengräber, Achim (2009): Die politische Ökonomie des Klimawandels, München.

Brunnengräber, Achim (2012): Ein neuer Bewegungszyklus. Von der NGOisierung zur Occupy-Bewegung, in: Forschungsjournal Soziale Bewegungen, Jg. 25, Nr. $1,42-50$.

Brunnengräber, Achim (2013): Klimaskeptiker in Deutschland und ihr Kampf gegen die Energiewende, IPW Working Paper 1/2013, Institut für Politikwissenschaft, Wien.

Brunnengräber, Achim/Dietz, Kristina/Hirschl, Bernd/Walk, Heike/Weber, Melanie (2008): Das Klima neu denken. Eine sozial-ökologische Perspektive auf die lokale, nationale und internationale Klimapolitik, Münster.

Brunnengräber, Achim/Haas, Tobias (2014): Die Klima- und Energiepolitik in der Krise? Zu Kohärenzproblemen am Beispiel der EU, in: Bieling, Hans-Jürgen/ Haas, Tobias/Lux, Julia (Hg_innen): Die Internationale Politische Ökonomie nach der Weltfinanzkrise: Theoretische, geopolitische und politikfeldspezifische Implikationen, Wiesbaden, 211-230.

Bundesministerium für Umwelt, Naturschutz und Reaktorsicherheit (2009): GreenTech made in Germany 2.0. Umwelttechnologie-Atlas für Deutschland, München.

Busch, Per-Olof/Jörgens, Helge/Tews, Kerstin (2005): The Global Diffusion of Regulatory Instruments: The Making of a New International Environmental Regime, in: The ANNALS of the American Academy of Political and Social Science, Nr. 598, 146-167.

Bütikofer, Reinhard (2011): Green New Deal: aber wie?, in: Altner, Günter/ Leitschuh, Heike/Michelsen, Gerd/Simonis, Udo E./Weizsäcker, Ernst U. von (Hg_innen): Grüner Umbau. Neue Allianzen für die Umwelt, Jahrbuch Ökologie 2012, Stuttgart, 29-32. 
Candeias, Mario (2007): Gramscianische Konstellationen. Hegemonie und die Durchsetzung neuer Produktions- und Lebensweisen, in: Merkens, Andreas/Rego Diaz, Victor (Hg.): Mit Gramsci arbeiten. Texte zur politischpraktischen Aneignung Antionio Gramscis, Hamburg, 15-32.

CDM Watch (2010): The Clean Development Mechanism (CDM) Toolkit. A resource for citizens, activists and NGOs, im Internet: www.carbonmarket watch.org/wp-content/uploads/2010/04/CDM_Toolkit_EN3.pdf, letzter Zugriff am 02.12.2014.

Carbon Market Watch (2011): Newsletter \#1/February 2011. CDM News for Civil Society and Policy Makers in the context of the 59th Meeting of the CDM Executive Board, im Internet: www.carbonmarketwatch.org/wp-content/ uploads/2011/02/cdm_watch_newsletter_15_febru ary_2011.pdf, letzter Zugriff am 02.12.2014.

Carbon Market Watch (2013): Recommendations for the CDM Reform: End Climate Finance for Coal Power, im Internet: www.carbonmarketwatch.org/wpcontent/uploads/2013/11/RECOMMENDATIONS-FOR-THE-CDM-REFORMweb..pdf, letzter Zugriff am 02.12.2014.

CCSA (2008): Submission to the UNFCCC Secretariat on carbon dioxide capture and geological storage as a Clean Development Mechanism Project Activity, im Internet: www.unfccc.int/resource/docs/2008/smsn/ngo/024.pdf, letzter Zugriff am 02.12.2014.

Christiansen, Atle Christer (2002): New renewable energy developments and the climate change issue: a case study of Norwegian politics, in: Energy Policy, Vol. 30, Nr. 3, 235-243.

Claes, Dag Harald/Frisvold, Paal (2009): CCS and the European Union: magic bullet or pure magic?, in: Meadowcroft, James/Langhelle, Oluf: Caching the Carbon. The Politics and Policy of Carbon Capture and Storage, Cheltenham/Northampton, 211-235.

Conrad, Jobst (2010): Sozialwissenschaftliche Analyse von Klimaforschung, -diskurs und -politik am Beispiel des IPCC, in: Voss, Martin (Hg.): Der Klimawandel. Sozialwissenschaftliche Perspektiven, Wiesbaden, 101-115.

Corry, Olaf/Riesch, Hauke (2012): Beyond, for or against ${ }^{6}$ : environmental NGOevaluations of CCS as a climate change solution, in: Markusson, Nils/Shackley, Simon/Evar, Benjamin (Hg.): The Social Dynamics of Carbon Capture and Storage. Understanding CCS Representations, Governance and Innovation, London/New York, 91-108.

CSLF (2008): June 13, 2008, im Internet: www.unfccc.int/resource/docs/2008/ smsn/ngo/026.pdf, letzter Zugriff am 02.12.2014.

De Coninck, Heleen (2008): Trojan horse or horn of plenty? Reflections on allowing CCS in the CDM, in: Energy Policy, Vol. 36, Nr. 3, 929-936. 
De Coninck, Heleen/Bäckstrand, Karin (2011): An International Relations perspective on the global politics of carbon dioxide capture and storage, in: Global Environmental Change, Jg. 21, Nr 2, 368-378.

De Coninck, Heleen/Bakker, Stefan (2005): CO2 capture and storage. State-of-theart in the climate negotiations, Energy research centre of the Netherlands.

De Lucia, Vito (2009): Hegemony and Climate Justice. A Critical Analysis, in: Böhm, Steffen/Dabhi, Siddhartha (Hg.): Upsetting the Offset. The Political Economy of Carbon Markets, London, 230-243.

De Lucia, Vito (2013): Die Klimagerechtigkeitsbewegung und der hegemoniale Diskurs über Technologie, in: Dietz, Matthias/Garrelts, Heiko (Hg.): Die internationale Klimabewegung: Ein Handbuch, Wiesbaden, 107-133.

Dietz, Kristina (2013): (Neo-)Extraktivismus, in: Peripherie. Zeitschrift für Politik und Ökonomie in der Dritten Welt, Jg. 33, Nr. 132, 511-513.

Dietz, Matthias/Garrelts, Heiko (2013): Die internationale Klimabewegung. Ein Handbuch, Wiesbaden.

Dingler, Johannes (2003): Postmoderne und Nachhaltigkeit. Eine diskurstheoretische Analyse der sozialen Konstruktionen von nachhaltiger Entwicklung, München.

Dröge, Susanne (2010): Die Ergebnisse der Klimakonferenz in Kopenhagen - Wie weiter in der internationalen Klimapolitik?, in: Politische Studien. Zweimonatsschrift für Politik und Zeitgeschehen, Jg. 61, Nr. 430, 64-74.

Eglin, Richard (1995): Trade and Environment in the World Trade Organisation, in: The World Economy, Jg. 18, Nr. 6, 769-779.

Ekardt, Felix (2011): Theorie der Nachhaltigkeit. Rechtliche, ethische und politische Zugänge - am Beispiel von Klimawandel, Ressourcenknappheit und Welthandel, Baden-Baden.

EKD (2009): Turning to life. Sustainable Development in the Context of Climate Change. A Memorandum of the Council of the Evangelical Church in Germany, Hannover.

Empresa de Pesquisa Energética (2009): Balanço Energético Nacional 2009: Ano base 2008, Ministério de Minas e Energia do Brasil, Rio de Janeiro.

Engels, Anita/Weingart, Peter (1997): Die Politisierung des Klimas. Zur Entstehung von anthropogenem Klimawandel als politischem Handlungsfeld, in: Hiller, Petra/Krücken, Georg (Hg_innen): Risiko und Regulierung. Soziologische Beiträge zu Technikkontrolle und präventiver Umweltpolitik, Frankfurt a. M.

Eskom (2010): Eskom Comments. Possible Implications of Inclusion of CCS as CDM Project Activity, im Internet: cdm.unfccc.int/about/ccs/docs/ccs_esk.pdf, letzter Zugriff am 02.12.2014. 
EURELECTRIC (2010): EURELECTRIC responses to the invitation in Draft decision -/CMP.5 to make submissions to the UNFCCC secretariat on: 1. Inclusion of CCS in Clean Development project activities 2. Standardized baselines for Clean Development Mechanisms, im Internet: cdm.unfccc.int/about/ccs/docs/ ccs_eur.pdf, letzter Zugriff am 02.12.2014.

Evar, Benjamin/Armeni, Chiara/Scott, Vivian (2012): An introduction to key developments and concepts in CCS: history, technology, economics and law, in: Markusson, Nils/Shackley, Simon/Evar, Benjamin (Hg.): The Social Dynamics of Carbon Capture and Storage. Understanding CCS Representations, Governance and Innovation, London/New York, 18-30.

Fauset, Claire (2008): Techno-Fixes. A critical guide to climate change technologies, London, im Internet: www.corporatewatch.org/sites/default/files/Techno fixes.pdf, letzter Zugriff am 02.12.2014.

Feldman, Martha S./Sköldberg, Kaj/Brown, Ruth Nicole/Debra, Horner (2004): Making Sense of Stories: A Rhetorical Approach to Narrative Analysis, in: Journal of Public Administration Research and Theory, Jg. 14, Nr. 2, 147-170.

ForUM (2007): Potential inclusion of Carbon Dioxide Capture and Storage (CCS) in the Clean Development Mechanism (CDM), im Internet: www.unfccc.int/files/ kyoto_mechanisms/cdm/application/pdf/nfed_unfccc_ccs_in_cdm_310507.pdf, letzter Zugriff am 02.12.2014.

Freund, Paul (2005): Future of CCS, im Internet: ec.europa.eu/research/energy/pdf/ 15_1100_freund_en.pdf, letzter Zugriff am 02.12.2014.

Friberg, Lars (2009): Varieties of Carbon Governance: The Clean Development Mechanism in Brazil - a Success Story Challenged, in: The Journal of Environment \& Development, Jg. 18, Nr. 4, 395-424.

Friends of the Earth International (2010): Initial Analysis of Cancun Outcome: Long-term Cooperative Action and Kyoto Protocol Texts, im Internet: www. comitatoscientifico.org/temi\%20CG/documents/foe_int_on_Cancun.pdf, letzter Zugriff am 02.12.2014.

Galis, Vasilis/Hansson, Anders (2012): Partisan Scholarship in Technoscientific Controversies: Reflections on Research Experience, in: Science as Culture, Jg. 21, Nr. 3, 335-364.

Garrelts, Heiko/Dietz, Matthias (2013): Konturen der internationalen Klimabewegung - Einführung in Konzeption und Inhalte des Handbuchs, in: Dietz, Matthias/Garrelts, Heiko: Die internationale Klimabewegung. Ein Handbuch, Wiesbaden, 15-35.

Geden, Oliver (2012): Vor dem Paradigmenwechsel. Die internationalen Klimaverhandlungen und ihr Einfluss auf die Energiepolitik der EU, in: KAS-Auslandsinformationen, Jg. 28, Nr. 9, 24-36. 
Geden, Oliver/Kremer, Martin (2009): Europäische Union: Vorreiter für eine ehrgeizige internationale Klimapolitik, in: Dröge, Susanne (Hg.): Die internationale Klimapolitik. Prioritäten wichtiger Verhandlungsmächte, Berlin, 30-37.

Germanwatch (2014): kLIMApolitik - Wo stehen wir? Wohin gehen wir? Ausblick auf die Klimakonferenz COP 20 in Peru, im Internet: www.germanwatch.org/ de/download/10320.pdf, letzter Zugriff am 02.12.2014.

Glaab, Katharina/Fuchs, Doris (2014): Green Faith? The influence of faith-based actors on sustainable development discourse, Vortrag auf der Tagung „Globaler Wandel und Macht“" des AK Umweltpolitik/Global Change der DVPW, FU Berlin, 11.02.2014.

Global CCS Institute (2012): The Global Status of CCS: 2012, Canberra.

Global CCS Institute (2014): The Global Status of CCS: 2014, Melbourne.

Gilbertson, Tamra/Reyes, Oscar (2009): Carbon Trading. How it works and why it fails, Critical Currents, Nr. 7, Uppsala.

Gill, Bernhard (1998): Paradoxe Natur. Zur Vieldeutigkeit der Unterscheidung von Natur und Gesellschaft, in: Brand, Karl-Werner (Hg.): Soziologie und Natur. Theoretische Perspektiven, Opladen, 223-247.

Gill, Bernhard (2003): Streitfall Natur. Weltbilder in Technik- und Umweltkonflikten, Wiesbaden.

Glasze, Georg/Mattissek, Annika (2009): Die Hegemonie- und Diskurstheorie von Laclau und Mouffe. Potenziale der Hegemonie- und Diskurstheorie für humangeographische Arbeiten, in: dies. (Hg_innen): Handbuch Diskurs und Raum. Theorien und Methoden für die Humangeographie sowie die sozial- und kulturwissenschaftliche Raumforschung, Bielefeld, 153-179.

Glynos, Jason/Howarth, David (2007): Logics of Critical Explanation in Social and Political Theory, London/New York.

Goethe, Johann Wolfgang (1973): Faust: Der Tragödie zweiter Teil, Leipzig.

Görg, Christoph (2003a): Regulation der Naturverhältnisse. Zu einer kritischen Theorie der ökologischen Krise, Münster.

Görg, Christoph (2003b): Nichtidentität und Kritik - Zum Problem der Gestaltung der Naturverhältnisse, in: Böhme, Gernot/Manzei, Alexandra (Hg_innen): Kritische Theorie der Technik und der Natur, München, 113-133.

Görg, Christoph (2003c): Dialektische Konstellationen. Zu einer kritischen Theorie gesellschaftlicher Naturverhältnisse, in: Demirovic, Alex (Hg.): Modelle kritischer Gesellschaftstheorie. Traditionen und Perspektiven der Kritischen Theorie, Stuttgart/Weimar, 39-62. 
Greenpeace (2007a): Further guidance relating to the clean development mechanism - carbon dioxide capture and storage technologies. (a) Long-term physical leakage (seepage) levels of risks and uncertainty, im Internet: www.unfccc.int/resource/docs/2007/smsn/ngo/015.pdf, letzter Zugriff am 02.12.2014.

Greenpeace (2007b): Further guidance relating to the clean development mechanism - carbon dioxide capture and storage technologies. (c) Long-term responsibility for monitoring the reservoir and any remediation measures that may be necessary after the end of the crediting period, im Internet: www.unfccc.int/resource/docs/2007/smsn/ngo/017.pdf, letzter Zugriff am 02.12 .2014

Greenpeace (2007c): Further guidance relating to the clean development mechanism - carbon dioxide capture and storage technologies. (d) Long-term liability for storage sites, im Internet: www.unfccc.int/resource/docs/2007/smsn/ ngo/016.pdf, letzter Zugriff am 02.12.2014.

Greenpeace (2008a): False Hope: Why Carbon Capture and Storage Won't Save the Climate, Amsterdam: Greenpeace International.

Greenpeace (2008b): Carbon dioxide capture and storage in geological formations as clean development mechanism project activities, im Internet: www.unfccc. int/resource/docs/2008/smsn/ngo/025.pdf, letzter Zugriff am 02.12.2014.

Greenpeace (2012): Eligibility of carbon dioxide and storage projects activities which involve the transport of carbon dioxide from one country to another or which involve geological storage sites that are located in more than one country, im Internet: www.unfccc.int/resource/docs/2012/smsn/ngo/157.pdf, letzter Zugriff am 02.12.2014.

Greven, Michael Th. (2010): Verschwindet das Politische in der politischen Gesellschaft? Über Strategien der Kontingenzverleugnung, in: Bedorf, Thomas/ Röttgers, Kurt (Hg.): Das Politische und die Politik, Berlin, 68-88.

Gudynas, Eduardo (2012): Buen Vivir. Das gute Leben jenseits von Entwicklung und Wachstum, in der Reihe ,Analysen', herausgegeben von der Rosa-Luxemburg-Stiftung, im Internet: www.rosalux.de/fileadmin/rls_uploads/pdfs/ Analysen/Analyse_buenvivir.pdf, letzter Zugriff am 02.12.2014.

Haas, Tobias/Sander, Hendrik (2013): ,Grüne Basis‘. Grüne Kapitalfraktionen in Europa - Eine empirische Untersuchung, Berlin.

Ha-Duong, Minh/Nadaï, Alain/Campos, Ana Sofía (2009): A survey on the public perception of CCS in France, in: International Journal of Greenhouse Gas Control, Vol. 3, Nr. 5, 633-640. 
Halfmann, Jost (1998): Einleitung. Technische Zivilisation. Zur Wiederaufnahme eines klassischen Topos, in: ders. (Hg.): Technische Zivilisation. Zur Aktualität der Technikreflexion in der gesellschaftlichen Selbstbeschreibung, Opladen, 712 .

Hajer, Maarten A. (1995): The Politics of Environmental Discourse. Ecological Modernization and the Policy Process, New York.

Hajer, Maarten A. (1997): Ökologische Modernisierung als Sprachspiel. Eine institutionellkonstruktivistische Perspektive zum Umweltdiskurs und zum institutionellen Wandel, in: Soziale Welt, Jg. 48, Nr. 2, 107-132.

Hannesson, Rögnvaldur (2002): Energy use and GDP growth, 1950-97, in: OPEC review, Jg. 26, Nr. 3, 215-233.

Hansson, Anders (2012): Colonizing the future: The case of CCS, in: Markusson, Nils/Shackley, Simon/Evar, Benjamin (Hg.): The Social Dynamics of Carbon Capture and Storage. Understanding CCS Representations, Governance and Innovation, London/New York, 74-90.

Hansson, Anders/Bryngelsson, Marten (2009): Expert opinions on carbon dioxide capture and storage - A framing of uncertainties and possibilities, in: Energy Policy, Vol. 37, Nr. 6, 2273-2282.

Hirsch, Joachim (2011): Ein grüner Kapitalismus? Auch das neue ,Modell Deutschland' ist eine expansive Wachstumsökonomie, in: iz3w, Nr. 327, 19-21.

Hmaidan, Wael (2012): Statement NGOs (Plenary session - 20th of June), im Internet: www.uncsd2012.org/content/documents/859RIo20\%20Conference $\% 20 \mathrm{NGO} \% 20$ MG\%20Statement\%20PrepCom\%20Statements.pdf, letzter Zugriff am 02.12.2014.

Horkheimer, Max (1990): Zur Kritik der instrumentellen Vernunft. Aus den Vorträgen und Aufzeichnungen seit Kriegsende, Frankfurt a. M.

Horkheimer, Max/Adorno Theodor W. (2009) [1969]: Dialektik der Aufklärung. Philosophische Fragmente, Frankfurt a. M.

Huber, Joseph (1993): Ökologische Modernisierung: Zwischen bürokratischem und zivilgesellschaftlichem Handeln, in: Prittwitz, Volker von (Hg.): Umweltpolitik als Modernisierungsprozeß. Politikwissenschaftliche Umweltforschung und -lehre in der Bundesrepublik, Opladen, 51-69.

Huber, Joseph (2011a): Ökologische Modernisierung und Umweltinnovation, in: Groß, Matthias (Hg.): Handbuch Umweltsoziologie, Wiesbaden, 279-302.

Huber, Joseph (2011b): Allgemeine Umweltsoziologie, Wiesbaden.

ICC (2008): Carbon Capture and Storage: The Case for Recognition within the Clean Development Mechanism. A Submission by the International Chamber of Commerce (ICC) to the Subsidiary Body for Scientific and Technical Advice of the UNFCCC in response to decision FCCC/SBSTA/2007/L.19, im Internet: www.unfccc.int/resource/docs/2008/smsn/ngo/020.pdf, letzter Zugriff am 02.12.2014. 
IEEP (2007): $\mathrm{CO}_{2}$ Capture and Storage in Developing Countries and the role of the Clean Development Mechanism. A paper for WWF European Policy Office, im Internet: www.unfccc.int/files/kyoto_mechanisms/cdm/application/x-zip-compr essed /wwf_ccs_issues.zip, letzter Zugriff am 02.12.2014.

IETA (2007): Submission on the Inclusion of Carbon Capture Ctorage (CCS) as a CDM Project Activity: $\mathrm{CO}_{2}$ Storage in Subsurface Geological Formation, im Internet: www.unfecc.int/resource/docs/2007/smsn/ngo/018.pdf, letzter Zugriff am 02.12.2014.

IETA (2008): Carbon Dioxide Capture and Geological Storage as a Clean Development Mechanism Project Activity. Submission to the UNFCCC Secretariat by the International Emissions Trading Association (IETA), im Internet: www. unfccc.int/resource/docs/2008/smsn/ngo/021.pdf, letzter Zugriff am 02.12.2014.

Ihlen, Øyvind (2009): Business and Climate Change: The Climate Response of the World's 30 Largest Corporations, in: Environmental Communication: A Journal of Nature and Culture, Jg. 3, Nr. 2, 244-262.

Indian Institute of Technology Kharagpur/Indian Institute of Management Indore (2009): Carbon dioxide capture and storage (CCS) in geological formations as clean development mechanism (CDM) projects activities (SBSTA), im Internet: cdm.unfccc.int/about/ccs/docs/CCS_geo.pdf, letzter Zugriff am 02.12.2014.

Informationsstelle Peru (2014): Internationale Klimaverhandlungen COP 20 in Peru. Die gestörte Gesellschaft und ihre ziemlich letzte Chance, im Internet: www.infostelle-peru.de, letzter Zugriff am 02.12.2014.

IPCC (o. J.): Appendix A to the Principles Governing IPCC Work. Procedures for the preparation, review, acceptance, adoption, approval and publication of IPCC reports, im Internet: www.ipcc.ch/pdf/ipcc-principles/ipcc-principles-appendixa-final.pdf, letzter Zugriff am 02.12.2014.

IPCC (1996): Climate Change 1995. Impacts, Adaptation and Mitigation of Climate Change: Scientific-Technical Analyses. Contribution of Working Group II to the Second Assessment Report of the Intergovernmental Panel on Climate Change, Cambridge.

IPCC (2002): Workshop on Carbon Dioxide Capture and Storage. Proceedings, im Internet: www.ipcc.ch/pdf/supporting-material/ipcc-workshop-proceedings-cdcsregina-2002.pdf, letzter Zugriff am 02.12.2014.

IPCC (2003): Proposals for special reports, methodology reports and technical papers. Proposal for a Special Report on carbon capture and storage. IPCCXX/Doc.19, im Internet: www.ipcc.ch/meetings/session20/doc19.pdf, letzter Zugriff am 02.12.2014.

IPCC (2005): Special Report on Carbon Dioxide Capture and Storage, Cambridge. IPCC (2007): Contribution of Working Group II to the Fourth Assessment Report of the Intergovernmental Panel on Climate Change, Cambridge. 
IPCC (2014): Summary for Policymakers, in: Climate Change 2014. Mitigation of Climate Change. Contribution of Working Group III to the Fifth Assessment Report of the Intergovernmental Panel on Climate Change, Cambridge/New York.

IPIECA (2007): IPIECA's Response to the UNFCCC Invitation for Information on Issues Related to CO2 Capture and Storage (CCS) Projects in the CDM and Interest in Capacity-Building Activities, im Internet: www.unfccc.int/resource/ docs/2007/smsn/ngo/019.pdf, letzter Zugriff am 02.12.2014.

IRGC (2007): IRGC submission to the UNFCCC Regarding Carbon Capture and Storage as a Clean Development Project Mechanism, im Internet: www.unfccc. $\mathrm{int} /$ resource/docs/2007/smsn/ngo/020.pdf, letzter Zugriff am 02.12.2014.

Ishii, Atsushi/Langhelle, Oluf (2011): Toward policy integration: Assessing carbon capture and storage policies in Japan and Norway, in: Global Environmental Change, Jg. 21, Nr. 2, 358-367.

Jaccard, Mark/Sharp, Jacqueline (2009): CCS in Canada, in: Meadowcroft, James/Langhelle, Oluf: Caching the Carbon. The Politics and Policy of Carbon Capture and Storage, Cheltenham/Northampton, 75-97.

Jacob, Klaus/Volkery, Axel (2006): Institutions and Instruments for Government Self-Regulation: Environmental Policy Integration in a Cross-CountryPerspective, in: Jänicke, Martin/Jacob, Klaus (Hg.): Environmental Governance in Global Perspective. New Approaches to Ecological and Political Modernisation, Berlin, 291-309.

Jahn, Thomas/Wehling, Peter (1998): Gesellschaftliche Naturverhältnisse - Konturen eines theoretischen Konzepts, in: Brand, Karl-Werner (Hg.): Soziologie und Natur. Theoretische Perspektiven, Opladen, 75-93.

Jänicke, Martin (1988): Ökologische Modernisierung. Optionen und Restriktionen präventiver Umweltpolitik, in: Simonis, Udo Ernst (Hg.): Präventive Umweltpolitik, Frankfurt a. M./New York, 13-26.

Jänicke, Martin (1993): Ökologische und politische Modernisierung in entwickelten Industriegesellschaften, in: Prittwitz, Volker von: Umweltpolitik als Modernisierungsprozeß. Politikwissenschaftliche Umweltforschung und -lehre in der Bundesrepublik, Opladen, 15-29.

Jänicke, Martin (2001): Ökologische Modernisierung als Innovation und Diffusion in Politik und Technik: Möglichkeiten und Grenzen eines Konzepts, Berlin.

Kaufmann, Stefan/Müller, Tadzio (2009): Grüner Kapitalismus. Krise, Klimawandel und kein Ende des Wachstums, Berlin.

Keller, Reiner (2008): Wissenssoziologische Diskursanalyse. Grundlegung eines Forschungsprogramms, Wiesbaden. 
Ketzer, Marcelo/Heemann, Roberto (2009): Clean Coal Technologies Projects in CEPAC/PUCRS. 3rd Symposium on Gondwana Coals, Porto Alegre, im Internet: www.pucrs.br/cepac/download/3SGC/Ketzer_Heemann_CCT_in_CEPAC.pdf, letzter Zugriff am 02.12.2014.

Khesghi, Haroon/Crookshank, Steve/Cunha, Paulo/Lee, Arthur/Bernstein, Leonard/ Siveter, Robert (2009): Carbon capture and storage business models, in: Energy Procedia, Nr. 1, 4481-4486.

Kirchhoff, Thomas (2011): Naturethik, Ökologie und Naturästhetik. Eine kritische Analyse des Ökozentrismus und seiner kulturellen Basis, in: Evangelische Studiengemeinschaft e. V. (Hg.): FEST-Jahresbericht, Heidelberg.

Klein, Naomi (2014): This Changes Everythin. Capitalism vs. The Climate, New York.

Koch, Svenja (2006): Umweltkampagnen mit Herz und Verstand. Strategien der Greenpeace-Kommunikation, in: Röttger, Ulrike (Hrsg.): PR-Kampagnen. Über die Inszenierung von Öffentlichkeit, 3. überarbeitete und erweiterte Auflage, Wiesbaden, 109-115.

Kolk, Ans/Levy, David (2001): Winds of Change: Corporate Strategy, Climate Change and Oil Multinationals, in: European Management Journal, Jg. 19, Nr. 5, 501-509.

Konferenz der Vereinten Nationen über Umwelt und Entwicklung 1992: RioErklärung über Umwelt und Entwicklung, im Internet: www.un.org/Depts/ german/conf/agenda21/rio.pdf, letzter Zugriff am 02.12.2014.

Krüger, Timmo (2011): Die Schlüsselrolle von Carbon Capture and Storage (CCS) in der internationalen Klimapolitik, in: SWS-Rundschau 51, Nr. 3, 326-348.

Krüger, Timmo (2012): Die Stabilisierung des hegemonialen Diskurses der ökologischen Modernisierung in der internationalen Klimapolitik durch Carbon Capture and Storage (CCS), in: Christ, Tamina/Gellrich, Angelika/Ide, Tobias (Hg_innen): Zugänge zur Klimadebatte in Politikwissenschaft, Soziologie und Psychologie, Marburg, 101-127.

Krüger, Timmo (2013): Das Hegemonieprojekt der ökologischen Modernisierung, in: Leviathan. Berliner Zeitschrift für Sozialwissenschaft, Jg. 41, Nr. 3, 422456.

Krüger, Timmo (2014): Das Hegemonieprojekt der ökologischen Modernisierung und antagonistische Artikulationen in der internationalen Klimapolitik, in: Bemmann, Martin/Metzger, Birgit/Detten, Roderich von (Hg_innen): Ökologische Modernisierung. Zur Geschichte und Gegenwart eines Konzepts in Umweltpolitik und Sozialwissenschaften, Frankfurt a. M./ New York, 97-126.

Laclau, Ernesto (1990a): New Reflections on the Revolution of Our Time, in: ders.: New Reflections on the Revolution of Our Time, London/New York, 3-85. 
Laclau, Ernesto (1990b): The impossibility of Society, in: ders.: New Reflections on the Revolution of Our Time, London/New York, 89-92.

Laclau, Ernesto (1996): Why do Empty Signifiers Matter to Politics, in: ders.: Emancipation(s), London/New York, 36-46.

Laclau, Ernesto (2005): On Populist Reason, London/New York.

Laclau, Ernesto (2007): Ideologie und Post-Marxismus, in: Nonhoff, Martin (Hg.):

Diskurs, radikale Demokratie, Hegemonie. Zum politischen Denken von Ernesto Laclau und Chantal Mouffe, Bielefeld, 25-39.

Laclau, Ernesto/Mouffe, Chantal (2001) [1985]: Hegemony and Socialist Strategy.

Towards a Radical Democratic Politics, London/New York.

Lambert, Tobias (2012): Ressourcen für Europa. Die Rohstoffstrategien der EU und

Deutschlands gehen auf Kosten des globalen Südens, in: Forschungs- und Dokumentationszentrum Chile-Lateinamerika/Rosa-Luxemburg-Stiftung (Hg_innen):

Der Neue Extraktivismus. Eine Debatte über die Grenzen des Rohstoffmodells in Lateinamerika, Berlin, 128-141.

Langhelle, Oluf/Meadowcroft, James (2009): CCS in comparative perspective, in: Meadowcroft, James/Langhelle, Oluf: Caching the Carbon. The Politics and Policy of Carbon Capture and Storage, Cheltenham/Northampton, 236-266.

Lapola, David M./Schaldach, Rüdiger/Alcamo, Joseph/Bondeau, Alberta/Koch, Jennifer/Kölking, Christina/Priess, Jörg A. (2010): Indirect land-use changes can overcome carbon savings from biofuels in Brazil, in: Proceedings of the National Academy of Sciences Jg. 107, Nr. 8, 3388-3393.

Latour, Bruno (2001): Das Parlament der Dinge. Für eine politische Ökologie, Frankfurt a. M.

Lemke, Thomas (2005): Die Bedeutung von ideellen Grundüberzeugungen und Themen für den Erfolg von Parteiorganisation, in: Schmid, Josef/Zolleis, Udo (Hg.): Zwischen Anarchie und Strategie. Der Erfolg von Parteiorganisationen, Wiesbaden, 130-142.

Lohmann, Larry (2006): Carbon Trading. A critical conversation on climate change, privatisation and power, in: Development Dialogue, Nr. 48.

Lohmann, Larry (2009): Kohlenstoffmärkte und Finanzmärkte: Variationen über Polanyi, in: Das Argument 283, Jg. 51.

Lohmann, Larry (2010): Climate Crisis: Social Science Crisis, in: Voss, Martin (Hg.): Der Klimawandel. Sozialwissenschaftliche Perspektiven, Wiesbaden, 133-153.

Marchart, Oliver (2010): Die politische Differenz. Zum Denken des Politischen bei Nancy, Lefort, Badiou, Laclau und Agamben, Berlin.

Marchart, Oliver (2013): Das unmögliche Objekt. Eine postfundamentalistische Theorie der Gesellschaft, Berlin. 
Markusson, Nils/Ishii, Atsushi/Stephens, Jennie C. (2012): Learning in CCS demonstration projects: social and political dimensions, in: Markusson, Nils/Shackley, Simon/Evar, Benjamin (Hg.): The Social Dynamics of Carbon Capture and Storage. Understanding CCS Representations, Governance and Innovation, London/New York, 222-244.

Markusson, Nils/Shackley, Simon (2012): Introduction to Part I: Perceptions and representations, in: Markusson, Nils/Shackley, Simon/Evar, Benjamin (Hg.): The Social Dynamics of Carbon Capture and Storage. Understanding CCS Representations, Governance and Innovation, London/New York, 33-44.

Markusson, Nils/Shackley, Simon/Evar, Benjamin (2012a): Introduction, in: dies. (Hg.): The Social Dynamics of Carbon Capture and Storage. Understanding CCS Representations, Governance and Innovation, London/New York, 1-17.

Markusson, Nils/Shackley, Simon/Evar, Benjamin (Hg.) (2012b): The Social Dynamics of Carbon Capture and Storage. Understanding CCS Representations, Governance and Innovation, London/New York.

Markusson, Nils/Shackley, Simon/Evar, Benjamin (2012c): Conclusions, in: dies. (Hg.): The Social Dynamics of Carbon Capture and Storage. Understanding CCS Representations, Governance and Innovation, London/New York, 245-273.

Martín, Facundo (2013): Latin American Political Ecology and the World Ecological Crisis. Recent developments, contributions and dialogues with the Global Field, Paper for the 8th Pan-European Conference on International Relations, 18. - 21. September, Warschau.

Meadowcroft, James/Langhelle, Oluf (2009a): The politics and policy of CCS: the uncertain road ahead, in: dies. (Hg.): Caching the Carbon. The Politics and Policy of Carbon Capture and Storage, Cheltenham/Northampton, 267-296.

Meadowcroft, James/Langhelle, Oluf (2009b): The politics and policy of carbon capture and storage, in: dies. (Hg.): Caching the Carbon. The Politics and Policy of Carbon Capture and Storage, Cheltenham/Northampton, 1-21.

Meadowcroft, James/Langhelle, Oluf (Hg.) (2009c): Caching the Carbon. The Politics and Policy of Carbon Capture and Storage, Cheltenham/Northampton.

Meadows, Dennis/Meadows, Donella/Zahn, Erich/Milling, Peter (1972): Die Grenzen des Wachstums. Bericht des Club of Rome zur Lage der Menschheit, Stuttgart.

Meckling, Jonas (2011): Carbon Coalitions. Business, Climate Politics, and the Rise of Emissions Trading, Cambridge.

Methmann, Chris (2011): We are all green now. Hegemony, governmentality and fantasy in the global climate polity, Dissertation, Universität Hamburg.

MITI (Ministry of International Trade and Industry) (1974): Direction for Japan's Industrial Structure, Tokyo. 
Mol, Arthur P.J./Jänicke, Martin (2009): The Origins and Theoretical Foundations of Ecological Modernisation Theory, in: Mol, Arthur P.J./Sonnenfeld, David A./Spaargaren, Gert (Hg.): The Ecological Modernisation Reader. Environmental reform in theory and practice, London/New York, 17-27.

Mol, Arthur P.J./Sonnenfeld, David A./Spaargaren, Gert (2009): The Ecological Modernisation Reader. Environmental reform in theory and practice, London/ New York.

Mol, Arthur P.J./Spaargaren, Gert/Sonnenfeld, David A. (2009) Ecological Modernisation: Three Decades of Policy, Practice and Theoretical Refelction, in: Mol, Arthur P.J./Sonnenfeld, David A./Spaargaren, Gert (Hg.): The Ecological Modernisation Reader. Environmental reform in theory and practice, London/New York, 3-14.

Najam, Adil (2013): World Business Council for Sustainable Development: The Greening of Business or a Greenwash?, in: Jermier, John M. (Hg.): Corporate Environmentalism and the Greening of Organizations, Bd. 6, Critical Perspectives on Corporate Environmentalism and the Greening of Organizations, Los Angeles/London/New Delhi/Singapore/Washington DC, 29-48.

Newell, Peter (2009): Varieties of CDM Governance: Some Reflections, in: The Journal of Environment \& Development, Jg. 18, Nr. 4, 425-435.

Nonhoff, Martin (2006): Politischer Diskurs und Hegemonie. Das Projekt »Soziale Marktwirtschaft «, Bielefeld.

Nonhoff, Martin (2007): Politische Diskursanalyse als Hegemonieanalyse, in: ders. (Hg.): Diskurs, radikale Demokratie, Hegemonie. Zum politischen Denken von Ernesto Laclau und Chantal Mouffe, Bielefeld, 173-193.

Nonhoff, Martin (2010): Chantal Mouffe und Ernesto Laclau: Konfliktivität und Dynamik des Politischen, in: Bröckling, Ulrich/Feustel, Robert (Hg.): Das Politische denken. Zeitgenössische Positionen, Bielefeld, 33-58.

Oberthür, Sebastian/Ott, Hermann E. (2000): Das Kyoto-Protokoll. Internationale Klimapolitik für das 21. Jahrhundert, Opladen.

Oels, Angela (2010): Die Gouvernementalität der internationalen Klimapolitik: Biomacht oder fortgeschritten liberales Regieren?, in: Voss, Martin (Hg.): Der Klimawandel. Sozialwissenschaftliche Perspektiven, Wiesbaden, 171-186.

Oels, Angela (2014): Klimaflüchtlinge? Nein - „Climate Warriors“!, in: politische ökologie, Nr. 139, 79-83.

Öko-Institut (2007): Is the CDM fulfilling its environmental and sustainable development objectives? An evaluation of the CDM and options for improvement, im Internet: www.oeko.de/oekodoc/622/2007-162-en.pdf, letzter Zugriff am 02.12.2014. 
Paterson, Matthew (2011): Selling Carbon: From International Climate Regime to Global Carbon Market, in: Dryzek, John/Norgaard, Richard B./Schlosberg, David (Hg.): The Oxford Handbook of Climate Change and Society, Oxford, 611624.

Pelfini, Alejandro (2005): Kollektive Lernprozesse und Institutionenbildung. Die deutsche Klimapolitik auf dem Weg zur ökologischen Modernisierung, Berlin.

Pelfini, Alejandro (2006): Bruno Latours politische Ökologie als Beitrag zu einer reflexiven ökologischen Modernisierung, in: Voss, Martin/Peuker, Birgit (Hg_innen): Verschwindet die Natur? Die Akteur-Netzwerk-Theorie in der umweltsoziologischen Diskussion, Bielefeld.

Peters, Glen/Minx, Jan/Weber, Christopher/Edenhofer, Ottmar (2011): Growth in emission transfers via international trade from 1990 to 2008, in: Proceedings of the National Academy of Sciences of the United States of America, Vol. 108, Nr. 21, 8903-8908.

Petersen, Arthur (2014): The Emergence of the Geoengineering Debate Within the IPCC. Case Study, Geoengineering Our Climate? Working Paper and Opinion Article Series, im Internet: www.wp.me/p2zsRk-bp, letzter Zugriff am 02.12.2014.

Plessner, Helmuth (1975) [1928]: Die Stufen des Organischen und der Mensch. Einleitung in die philosophische Anthropologie, Berlin/New York.

Plessner, Helmuth (1981) [1931]: Macht und menschliche Natur. Ein Versuch zur Anthropologie der geschichtlichen Weltsicht, in: Dux, Günter (Hg.): Gesammelte Schriften/Helmuth Plessner, Bd. 5, Frankfurt a. M., 135-234.

Plessner, Helmuth (1983) [1969]: Homo absconditus, in: Dux, Günter (Hg.): Gesammelte Schriften/Helmuth Plessner, Bd. 8, Frankfurt a. M., 353-366.

Pollak, Melisa/Phillips, Sarah Johnson/Vajjhala, Shalini (2011): Carbon capture and storage policy in the United States: A new coalition endeavors to change existing policy, in: Global Environmental Change, Jg. 21, Nr. 2, 313-323.

Poloni, Verena (2009): Das IPCC als Boundary Organization, in: Halfmann, Jost/Schützenmeister, Falk (Hg.): Organisation der Forschung. Der Fall der Atmosphärenwissenschaft. Wiesbaden, 250-271.

Poppe, Marcelo/Galvão, Antônio/Juruá, Mayra/Alfredsson, Eva/Voituriez, Tancrède/Sénit, Carole-Anne/Tubiana, Laurence (2013): Is something wrong with the green economy?, in: IDDRI, Working Paper, Nr. 2, Paris.

Praetorius, Barbara/Stechow, Christoph von (2009): Electricity gap versus climate change: electricity politics and the potential role of CCS in Germany, in: Meadowcroft, James/Langhelle, Oluf: Caching the Carbon. The Politics and Policy of Carbon Capture and Storage, Cheltenham/Northampton, 125-157. 
Prittwitz, Volker von (1993): Reflexive Modernisierung und öffentliches Handeln, in: ders. (Hg.): Umweltpolitik als Modernisierungsprozeß. Politikwissenschaftliche Umweltforschung und -lehre in der Bundesrepublik, Opladen, 31-49.

Pulver, Simon (2011): Corporate Responses, in: Dryzek, John S./Norgaard, Richard B./Schlosberg, David (Hg.): The Oxford handbook of climate change and society, Oxford/New York, 581-593.

Radhuber, Isabella Margerita/Schilling-Vacaflor, Almut (2012): Plurinationale Demokratie in Bolivien. Gesellschaftliche und staatliche Transformationen - Zur Einleitung, in: Brand, Ulrich/Radhuber, Isabella Margerita/Schilling-Vacaflor, Almut (Hg_innen): Plurinationale Demokratie in Bolivien. Gesellschaftliche und staatliche Transformationen, Münster, 13-40.

Radkau, Joachim (2011): Die Ära der Ökologie. Eine Weltgeschichte, München.

Reckwitz, Andreas (2006): Ernesto Laclau: Diskurse, Hegemonien, Antagonismen, in: Moebius, Stephan/Quadflieg, Dirk (Hg.): Kultur: Theorien der Gegenwart, Wiesbaden, 339-349.

Rest, Jonas (2011): Grüner Kapitalismus? Klimawandel, globale Staatenkonkurrenz und die Verhinderung der Energiewende, Wiesbaden.

Román, Mikael (2011): Carbon capture and storage in developing countries: A comparison of Brazil, South Africa and India, in: Global Environmental Change, Jg. 21, Nr. 2, 391-401.

SACCCS (2010): Inclusion of CCS under CDM. Comments by South African Centre for Carbon Capture and Storage, im Internet: cdm.unfccc.int/about/ccs/ docs/ccs_sa.pdf, letzter Zugriff am 02.12.2014.

Sachverständigenrat für Umweltfragen (2009): Abscheidung, Transport und Speicherung von Kohlendioxid. Der Gesetzesentwurf der Bundesregierung im Kontext der Energiedebatte. Stellungnahme, Berlin.

Santarius, Tilman (2012): Der Rebound-Effekt. Über die unerwünschten Folgen der erwünschten Energieeffizienz, Wuppertal.

Santarius, Tilman/Dalkmann, Holger/Steigenberger, Markus/Vogelpohl, Karin (2003): Grüne Grenzen für den Welthandel. Eine ökologische Reform der WTO als Herausforderung an eine Sustainable Global Governance, Wuppertal.

Schäfer, Alfred (2004): Theodor W. Adorno. Ein pädagogisches Porträt, Weinheim/Basel/Berlin.

Scheer, Dirk (2013): Computersimulationen in politischen Entscheidungsprozessen. Zur Politikrelevanz von Simulationswissen am Beispiel der $\mathrm{CO}_{2}$-Speicherung, Wiesbaden.

Scheer, Hermann (2000): Solare Weltwirtschaft. Strategie für die ökologische Moderne, München. 
Scherrer, Christoph (2007): Hegemonie: empirisch fassbar?, in: Merkens, Andreas/Rego Diaz, Victor (Hg.): Mit Gramsci arbeiten. Texte zur politischpraktischen Aneignung Antonio Gramscis, Hamburg, 71-84.

Schiemann, Greoger (2004): Natur - Kultur und ihr Anderes, in: Jaeger, Friedrich/Liebsch, Burkhard (Hg.): Handbuch der Kulturwissenschaften, Grundlagen und Schlüsselbegriffe, Stuttgart/Weimar, 60-75.

Scrase, Ivan/Watson, Jim (2009): CCS in the UK: squaring coal use with climate change?, in: Meadowcroft, James/Langhelle, Oluf: Caching the Carbon. The Politics and Policy of Carbon Capture and Storage, Cheltenham/Northampton, 158-210.

Shackley, Simon/Evar, Benjamin (2012): Up and down with CCS: the issue-attention cycle and the political dynamics of decarbonisation, in: Markusson, Nils/ Shackley, Simon/Evar, Benjamin (Hg.): The Social Dynamics of Carbon Capture and Storage. Understanding CCS Representations, Governance and Innovation, London/New York, 149-171.

Shackley, Simon/Waterman, Holly/Godfroij, Per/Reiner, David/Anderson, Jason/Draxlbauer, Kathy/Flach, Todd (2007): Stakeholder perceptions of CO2 capture and storage in Europe: Results from a survey, in: Energy Policy, Jg. 35, Nr. 10, 5091-5108.

Sinclair, Darren/Gunningham, Neil (2009): CCS in Australia: from political posturing to policy potential, in: Meadowcroft, James/Langhelle, Oluf: Caching the Carbon. The Politics and Policy of Carbon Capture and Storage, Cheltenham/Northampton, 50-74.

Smekens, Koen/Van der Zwaan, Bob (2004): Environmental Externalities of Geological Carbon Sequestration Effects on Energy Scenarios. FEEM Working Paper, Nr. 58.04, im Internet: papers.ssrn.com/sol3/Delivery.cfm/SSRN_ID541123 code114544.pdf?abstractid=541123\&mirid=1, letzter Zugriff am 02.12.2014.

Smerecnik, Karl R./Renegar, Valerie R. (2010): Capitalistic Agency: The Rhetoric of BP's Helios Power Campaign, in: Environmental Communication: A Journal of Nature and Culture, Jg. 4, Nr. 2, 152-171.

Spaargaren, Gert/Mol, Arthur P.J. (2009): Sociology, Environment, and Modernity: Ecological Modernization as a Theory of Social Change, in: Mol, Arthur P.J./Sonnenfeld, David A./Spaargaren, Gert (Hg.): The Ecological Modernisation Reader. Environmental reform in theory and practice, London/New York, 56-79.

Spreng, Daniel/Marland, Gregg/Weinberg, Alvin M. (2007): CO2 capture and storage: Another Faustian Bargain?, in: Energy Policy, Vol. 35, Nr. 2, 850-854. 
Stephens, Jennie C. (2009): Technology leader, policy laggard: CCS development for climate mitigation in the US political context, in: Meadowcroft, James/Langhelle, Oluf: Caching the Carbon. The Politics and Policy of Carbon Capture and Storage, Cheltenham/Northampton, 22-49.

Stephens, Jennie C./Hansson, Anders/Liu, Yue/De Coninck, Heleen/Vajjhala, Shalini (2011): Characterizing the international carbon capture and storage community, in: Global Environmental Change, Jg. 21, Nr 2, 379-390.

Stephens, Jennie C./Liu, Yue (2012): The evolving international CCS community, in: Markusson, Nils/Shackley, Simon/Evar, Benjamin (Hg.): The Social Dynamics of Carbon Capture and Storage. Understanding CCS Representations, Governance and Innovation, London/New York, 127-148.

Strauss, Anselm L. (1998): Grundlagen qualitativer Sozialforschung. Datenanalyse und Theoriebildung in der empirischen soziologischen Forschung, München.

SustainUS (2008): Views on issues relevant to the consideration of Carbon Capture and Storage in geological Formations as CDM project activities, im Internet: www.unfccc.int/resource/docs/2008/smsn/ngo/022.pdf, letzter Zugriff am 02.12.2014.

Sydnes, Anne Kristin (1996): Norwegian climate policy. Environmental idealism and economic realism, in: O'Riordan, Tim/Jäger, Jill (Hg_innen): Politics of Climate Change. A European Perspective, London/New York, 268-297.

Teir, Sebastian/Hetland, Jens/Lindeberg, Erik/Torvanger, Asbjørn/Buhr, Katarina/ Koljonen, Tiina/Gode, Jenny/Onarheim, Kristin/Tjernshaugen, Andreas/Arasto, Antti/Liljeberg, Marcus/Lehtilä, Antti/Kujanpää, Lauri/Nieminen, Matti (2010): Potential for carbon capture and storage (CCS) in the Nordic region, Helsinki.

Thomas, William I. (1928): The Methodology of Behavior Study, in: The Child in America: Behavior Problems and Programs, New York, 553-576.

Tjernshaugen, Andreas (2008): Political commitment to $\mathrm{CO}_{2}$ capture and storage: evidence from government RD\&D budgets, in: Mitigation and Adoption Strategies for Global Change, Jg. 13, Nr. 1, 1-21.

Tjernshaugen, Andreas/Langhelle, Oluf (2009): Technology as political glue: CCS in Norway, in: Meadowcroft, James/Langhelle, Oluf: Caching the Carbon. The Politics and Policy of Carbon Capture and Storage, Cheltenham/Northampton, 98-124.

Treber, Manfred (2011): Bewegung in der CCS-Debatte. Eine Bewertung der Entscheidungen beim Klimagipfel in Cancún, im Internet: www.germanwatch.org/ $\mathrm{klima} /$ cancun-ccs.htm, letzter Zugriff am 02.12.2014.

Treber, Manfred (o. J.): Kurzberichte: CCS in den UN-Klimaverhandlungen, im Internet: www.germanwatch.org/klima/ccs-kber.htm, letzter Zugriff am 02.12.2014.

Umweltbundesamt (2009): CCS - Rahmenbedingungen des Umweltschutzes für eine sich entwickelnde Technik, Dessau-Roßlau. 
UNEP (2011): Towards a Green Economy: Pathways to Sustainable Development and Poverty Eradication. A Synthesis for Policy Makers, im Internet: www. unep.org/greeneconomy, letzter Zugriff am 02.12.2014.

UNFCCC (1992): Rahmenübereinkommen der Vereinten Nationen über Klimaänderungen, im Internet: www.unfccc.int/resource/docs/convkp/convger.pdf, letzter Zugriff am 02.12.2014.

UNFCCC [Herausgegeben vom Sekretariat der Klimarahmenkonvention mit Unterstützung des deutschen Bundesumweltministeriums] (1997): Das Protokoll von Kyoto zum Rahmenübereinkommen der Vereinten Nationen über Klimaänderungen, im Internet: www.unfccc.int/resource/docs/convkp/kpger.pdf, letzter Zugriff am 02.12.2014.

UNFCCC (2006): Consideration of carbon capture and storage as clean development mechanism project activities. Submissions from Parties. FCCC/KP/CMP/2006/MISC.2, im Internet: www.unfccc.int/resource/docs/ 2006/cmp2/eng/misc02.pdf, letzter Zugriff am 02.12.2014.

UNFCCC (2007a): Consideration of carbon capture and storage as clean development mechanism project activities. Submissions from Parties. FCCC/SBSTA/ 2007/MISC.18, im Internet: www.unfccc.int/resource/docs/2007/sbsta/eng/ misc18.pdf, letzter Zugriff am 02.12.2014.

UNFCCC (2007b): Consideration of carbon capture and storage as clean development mechanism project activities. Submissions from Parties. Addendum 1. FCCC/SBSTA/2007/MISC.18/Add.1, im Internet: www.unfccc.int/resource/ docs/2007/sbsta/eng/misc18a01.pdf, letzter Zugriff am 02.12.2014.

UNFCCC (2007c): Consideration of carbon capture and storage as clean development mechanism project activities. Submissions from Parties. Addendum 2. FCCC/SBSTA/2007/MISC.18/Add.2, im Internet: www.unfccc.int/resource/ docs/2007/sbsta/eng/misc18a02.pdf, letzter Zugriff am 02.12.2014.

UNFCCC (2008): Technological, methodological, legal, policy and financial issues relevant to the consideration of carbon dioxide capture and storage in geological formations as project activities under the clean development mechanism. Submissions from Parties. FCCC/SBSTA/2008/MISC.10, im Internet: www.unfccc. int/resource/docs/2008/sbsta/eng/misc 10.pdf, letzter Zugriff am 02.12.2014.

UNFCCC (2009a): Technological, methodological, legal, policy and financial issues relevant to the consideration of carbon dioxide capture and storage in geological formations as project activities under the clean development mechanism. Submissions from Parties. Addendum. FCCC/SBSTA/2008/ MISC.10/Add.1, im Internet: www.unfecc.int/resource/docs/2008/sbsta/eng/ misc10a01.pdf, letzter Zugriff am 02.12.2014. 
UNFCCC (2009b): Furhter views on issues related to the consideration of carbon dioxide capture and storage in geological formations as project activities under the clean development mechanism. Submission from Parties. FCCC/SBSTA/ 2009/MISC.11, im Internet: www.unfccc.int/resource/docs/2009/sbsta/eng/ misc11.pdf, letzter Zugriff am 02.12.2014.

UNFCCC (2010a): Additional views on which the Chair may draw in preparing text to facilitate negotiations among Parties. FCCC/AWGLCA/2010/MISC.2, im Internet: www.unfccc.int/resource/docs/2010/awglca10/eng/misc02.pdf, letzter Zugriff am 02.12.2014.

UNFCCC (2010b): Views related to carbon dioxide capture and storage in geological formations as a possible mitigation technology. Submission from Parties. FCCC/SBSTA/2010/MISC.2, im Internet: www.unfccc.int/resource/docs/2010/ sbsta/eng/misc02.pdf, letzter Zugriff am 02.12.2014.

UNFCCC (2010c): Views related to carbon dioxide capture and storage in geological formations as a possible mitigation technology. Submission from Parties. Addendum. FCCC/SBSTA/2010/MISC.2/Add.1, im Internet: www.unfccc.int/ resource/docs/2010/sbsta/eng/misc02a01.pdf, letzter Zugriff am 02.12.2014.

UNFCCC (2011): Report of the Conference of the Parties on its sixteenth session, held in Cancun from 29 November to 10 December 2010. FCCC/CP/2010/7/ Add.1, im Internet: www.unfccc.int/resource/docs/2010/cop16/eng/07a01. pdf\#page=2 letzter Zugriff am 02.12.2014.

US Energy Information Agency (2012a): Country Analysis Briefs: Brazil, im Internet: www.eia. gov/countries/cab.cfm?fips=BR, letzter Zugriff am 02.12.2014.

Vergragt, Philip J. (2009): CCS in the Netherlands: glass half empty or half full?, in: Meadowcroft, James/Langhelle, Oluf: Caching the Carbon. The Politics and Policy of Carbon Capture and Storage, Cheltenham/Northampton, 186-210.

Vormedal, Irja (2008): The influence of Business and Industry NGOs in the Negotiation of the Kyoto Mechanisms: the Case of Carbon Capture and Storage in the CDM, in: Global Environmental Politics, Jg. 8, Nr. 4, 36-65.

Weingart, Peter/Engels, Anita/Pansegrau, Petra (2008): Von der Hypothese zur Katastrophe. Der anthropogene Klimawandel im Diskurs zwischen Wissenschaft, Politik und Massenmedien, Opladen/Farmington Hills.

WCI (2007): WCI Submission. CCS as CDM Activities - May 07, im Internet: www.unfccc.int/resource/docs/2007/smsn/ngo/021.pdf, letzter Zugriff am 02.12.2014.

WCI (2008): CCS \& the Clean Development Mechanism. A Submission About Carbon Dioxide Capture and Storage in Geological Formations as Clean Development Mechanism Project Activities, im Internet: www.unfccc.int/resource/docs/ 2008/smsn/ngo/023.pdf, letzter Zugriff am 02.12.2014. 
WCC (2010): Climate Change and the World Council of Churches. Background information and recent statements. March 2010, im Internet: www.climatejustice online.org/wp-content/uploads/WCC-climate-change-booklet.pdf, letzter $\mathrm{Zu}$ griff am 02.12.2014.

Weltkommission für Umwelt und Entwicklung (1987): Unsere gemeinsame $\mathrm{Zu}$ kunft, Greven.

Welzer, Harald (2011): Mentale Infrastrukturen. Wie das Wachstum in die Welt und in die Seelen kam, herausgegeben von der Heinrich-Böll-Stiftung, Schriften zur Ökologie, Nr. 14.

Wissen, Markus (2012): Post-neoliberale Hegemonie? Zur Rolle des GreenEconomy-Konzepts in der Vielfachkrise, in: Kurswechsel. Zeitschrift für gesellschafts-, wirtschafts- und umweltpolitische Alternativen, Nr. 2, 28-36.

Wissen, Markus/Röttger, Bernd/Heeg, Susanne (Hg_innen) (2008): Politics of Scale. Räume der Globalisierung und Perspektiven emanzipatorischer Politik, Münster.

Wullweber, Joscha (2010): Hegemonie, Diskurs und Politische Ökonomie. Das Nanotechnologie-Projekt, Baden-Baden.

WWF (2007): CCS in the CDM? presently no option for low-carbon sustainable development, im Internet: www.unfccc.int/files/kyoto_mechanisms/cdm/application/ X-zip-compressed/wwf_ccs_issues.zip, letzter Zugriff am 02.12.2014.

York, Richard/Rosa, Eugene A. (2013): Key Challenges to Ecological Modernization Theory: Institutional Efficacy, Case Study Evidence, Units of Analysis, and the Pace of Eco-Efficiency, in: Jermier, John M. (Hg.): Corporate Environmentalism and the Greening of Organizations. Volume 6. Critical Perspectives on Corporate Environmentalism and the Greening of Organizations, Los Angeles/London/New Delhi/Singapore/Washington DC, 283-300. 


\section{Anhang}

\section{A.1 Verzeichnis der analysierten Stellungnahmen}

Die UNFCCC archiviert alle Dokumente der CCS-CDM-Kontroverse (vgl. im Internet: cdm.unfccc.int/about/ccs/index.html, letzter Zugriff am 02.12.2014). In mein Sample fallen alle dort aufgelisteten Stellungnahmen, die bis 2010 zur sechsten CMP eingereicht wurden.

\section{Tabelle 24 Verzeichnis der Stellungnahmen der Länder}

\begin{tabular}{|c|c|c|c|}
\hline Jahr & Land & $\begin{array}{l}\text { im Literatur- } \\
\text { verzeichnis }\end{array}$ & im Internet \\
\hline 2006 & Australien & UNFCCC 2006 & unfccc.int/resource/docs/2006/cmp2/eng/misc02.pdf \\
\hline 2006 & $\begin{array}{l}\text { Österreich } \\
(\mathrm{EU})\end{array}$ & UNFCCC 2006 & unfccc.int/resource/docs/2006/cmp2/eng/misc02.pdf \\
\hline 2006 & Bangladesch & UNFCCC 2006 & unfccc.int/resource/docs/2006/cmp2/eng/misc02.pdf \\
\hline 2006 & Brasilien & UNFCCC 2006 & unfccc.int/resource/docs/2006/cmp2/eng/misc02.pdf \\
\hline 2006 & Kanada & UNFCCC 2006 & unfccc.int/resource/docs/2006/cmp2/eng/misc02.pdf \\
\hline 2006 & Japan & UNFCCC 2006 & unfccc.int/resource/docs/2006/cmp2/eng/misc02.pdf \\
\hline 2006 & Neuseeland & UNFCCC 2006 & unfccc.int/resource/docs/2006/cmp2/eng/misc02.pdf \\
\hline 2006 & Norwegen & UNFCCC 2006 & unfccc.int/resource/docs/2006/cmp2/eng/misc02.pdf \\
\hline 2006 & Katar & UNFCCC 2006 & unfccc.int/resource/docs/2006/cmp2/eng/misc02.pdf \\
\hline 2006 & Saudi-Arabien & UNFCCC 2006 & unfccc.int/resource/docs/2006/cmp2/eng/misc02.pdf \\
\hline 2006 & Schweiz & UNFCCC 2006 & unfccc.int $/$ resource $/$ docs $/ 2006 / \mathrm{cmp} 2 / \mathrm{eng} / \mathrm{misc} 02$.pdf \\
\hline 2007 & Japan & UNFCCC 2007a & unfccc.int/resource/docs/2007/sbsta/eng/misc18.pdf \\
\hline 2007 & Saudi-Arabien & UNFCCC 2007a & unfccc.int/resource/docs/2007/sbsta/eng/misc18.pdf \\
\hline 2007 & Kanada & UNFCCC $2007 b$ & unfecc.int/resource/docs/2007/sbsta/eng/misc18a01.pdf \\
\hline 2007 & Norwegen & UNFCCC $2007 \mathrm{~b}$ & unfccc.int/resource/docs/2007/sbsta/eng/misc18a01.pdf \\
\hline
\end{tabular}




\begin{tabular}{|l|l|l|l|}
\hline 2007 & Portugal (EU) & UNFCCC 2007b & unfccc.int/resource/docs/2007/sbsta/eng/misc18a01.pdf \\
\hline 2007 & Südkorea & UNFCCC 2007c & unfccc.int/resource/docs/2007/sbsta/eng/misc18a02.pdf \\
\hline 2008 & Brasilien & UNFCCC 2008 & unfccc.int/resource/docs/2008/sbsta/eng/misc10.pdf \\
\hline 2008 & Neuseeland & UNFCCC 2008 & unfccc.int/resource/docs/2008/sbsta/eng/misc10.pdf \\
\hline 2008 & Norwegen & UNFCCC 2008 & unfccc.int/resource/docs/2008/sbsta/eng/misc10.pdf \\
\hline 2008 & Saudi-Arabien & UNFCCC 2008 & unfccc.int/resource/docs/2008/sbsta/eng/misc10.pdf \\
\hline 2008 & Slowenien & UNFCCC 2008 & unfccc.int/resource/docs/2008/sbsta/eng/misc 10.pdf \\
\hline (EU) & & & \\
\hline 2009 & Venezuela & UNFCCC 2009a & unfccc.int/resource/docs/2008/sbsta/eng/misc10a01.pdf \\
\hline 2009 & Australien & UNFCCC 2009b & unfccc.int/resource/docs/2009/sbsta/eng/misc11.pdf \\
\hline 2010 & Australien & UNFCCC 2010b & unfccc.int/resource/docs/2010/sbsta/eng/misc02.pdf \\
\hline 2010 & Norwegen & UNFCCC 2010b & unfccc.int/resource/docs/2010/sbsta/eng/misc02.pdf \\
\hline 2010 & Spanien (EU) & UNFCCC 2010b & unfccc.int/resource/docs/2010/sbsta/eng/misc02.pdf \\
\hline 2010 & Brasilien & UNFCCC 2010c & unfccc.int/resource/docs/2010/sbsta/eng/misc02a01.pdf \\
\hline
\end{tabular}

Tabelle 25 Verzeichnis der Stellungnahmen der Beobachterorganisationen

\begin{tabular}{|l|l|l|l|}
\hline Jahr & $\begin{array}{l}\text { Beobachter- } \\
\text { organisation }\end{array}$ & $\begin{array}{l}\text { im Literaturver- } \\
\text { zeichnis }\end{array}$ & im Internet \\
\hline 2007 & Greenpeace & $\begin{array}{l}\text { Greenpeace 2007a, } \\
\text { 2007b, 2007c }\end{array}$ & $\begin{array}{l}\text { unfccc.int/resource/docs/2007/smsn/ngo/015.pdf } \\
\text { unfccc.int/resource/docs/2007/smsn/ngo/017.pdf } \\
\text { unfccc.int/resource/docs/2007/smsn/ngo/016.pdf }\end{array}$ \\
\hline 2007 & IETA & IETA 2007 & unfccc.int/resource/docs/2007/smsn/ngo/018.pdf \\
\hline 2007 & IPIECA & IPIECA 2007 & unfccc.int/resource/docs/2007/smsn/ngo/019.pdf \\
\hline 2007 & IRGC & IRGC 2007 & unfccc.int/resource/docs/2007/smsn/ngo/020.pdf \\
\hline 2007 & WCI & WCI 2007 & unfccc.int/resource/docs/2007/smsn/ngo/021.pdf \\
\hline 2007 & IEEP & IEEP 2007 & $\begin{array}{l}\text { unfccc.int/files/kyoto_mechanisms/cdm/applica } \\
\text { tion/x-zip-compressed/wwf_ccs_issues.zip }\end{array}$ \\
\hline 2007 & WWF & WWF 2007 & $\begin{array}{l}\text { unfccc.int/files/kyoto_mechanisms/cdm/applica } \\
\text { tion/x-zip-compressed/wwf_cc_issues.zip }\end{array}$ \\
\hline 2007 & Bellona & $\begin{array}{l}\text { Bellona Foundation } \\
\text { 2007 }\end{array}$ & $\begin{array}{l}\text { unfccc.int/files/kyoto_protocol/mechanisms/clea } \\
\text { n_development_mechanism/application/pdf/bell } \\
\text { onas_comments_on_co2_capture_and_storage } \\
\text { under_the_clean_development_mechanism.pdf }\end{array}$ \\
\hline
\end{tabular}




\begin{tabular}{|l|l|l|l|}
\hline 2007 & ForUM & ForUM 2007 & $\begin{array}{l}\text { unfccc.int/files/kyoto_mechanisms/cdm/applica } \\
\text { tion/pdf/nfed_unfccc_ccs_in_cdm_310507.pdf }\end{array}$ \\
\hline 2008 & CCSA & CCSA 2008 & unfccc.int/resource/docs/2008/smsn/ngo/024.pdf \\
\hline 2008 & Greenpeace & Greenpeace 2008b & unfccc.int/resource/docs/2008/smsn/ngo/025.pdf \\
\hline 2008 & ICC & ICC 2008 & unfccc.int/resource/docs/2008/smsn/ngo/020.pdf \\
\hline 2008 & IETA & IETA 2008 & unfccc.int/resource/docs/2008/smsn/ngo/021.pdf \\
\hline 2008 & SustainUS & SustainUS 2008 & unfccc.int/resource/docs/2008/smsn/ngo/022.pdf \\
\hline 2008 & WCI & WCI 2008 & unfccc.int/resource/docs/2008/smsn/ngo/023.pdf \\
\hline 2008 & CSLF & CSLF 2008 & unfccc.int/resource/docs/2008/smsn/ngo/026.pdf \\
\hline 2009 & Indian & $\begin{array}{l}\text { Indian Institute of } \\
\text { Technology Kharag- } \\
\text { pur/Indian Institute } \\
\text { of Management } \\
\text { Indore 2009 }\end{array}$ & cdm.unfccc.int/about/ccs/docs/CCS_geo.pdf \\
\hline 2010 & $\begin{array}{l}\text { EURELEC- } \\
\text { TRIC }\end{array}$ & $\begin{array}{l}\text { EURELECTRIC } \\
\text { 2010 }\end{array}$ & cdm.unfccc.int/about/ccs/docs/ccs_eur.pdf \\
\hline 2010 & SACCCS & SACCCS 2010 & cdm.unfccc.int/about/ccs/docs/ccs_sa.pdf \\
\hline 2010 & Eskom & Eskom 2010 & cdm.unfccc.int/about/ccs/docs/ccs_esk.pdf \\
\hline
\end{tabular}

\section{A.2 LISTE DER IDENTIFIZIERTEN ENTHYMEME}

\section{A.2.1 Enthymeme im IPCC SRCCS}

\section{Enthymem IPCC 1 (Seite 3)}

Erste Prämisse: DAS ZIEL DER KLIMAPOLITIK IST DIE STABILISIERUNG DER TREIBHAUSGASKONZENTRATION IN DER ATMOSPHÄRE.

Zweite Prämisse: Die Stabilisierung der Treibhausgaskonzentration in der Atmosphäre wird durch ein Portfolio technologischer Optionen erreicht.

Schlussfolgerung: DAS ZIEL DER KLIMAPOLITIK WIRD DURCH EIN PORTFOLIO TECHNOLOGISCHER OPTIONEN ERREICHT.

\section{Enthymem IPCC 2 (Seite 3)}

Erste Prämisse: DAS ZIEL DER KLIMAPOLITIK IST DIE STABILISIERUNG DER TREIBHAUSGASKONZENTRATION IN DER ATMOSPHÄRE.

Zweite Prämisse: CCS kann dazu beitragen, die Treibhausgaskonzentration in der Atmosphäre zu stabilisieren. 
Schlussfolgerung: CCS KANN DAZU BEITRAGEN, DAS ZIEL DER KLIMAPOLITIK ZU ERREICHEN.

\section{Enthymem IPCC 3 (Seite 3, 10, inklusive Fußnote 15)}

Erste Prämisse: ES WERDEN DIE TECHNOLOGIEN ALS MÖGLICHE OPTIONEN DES PORTFOLIOS IN BETRACHT GEZOGEN, DIE POTENZIAL ZUR SENKUNG DER BETRIEBSWIRTSCHAFTLICHEN KOSTEN DES KLIMASCHUTZES HABEN.

Zweite Prämisse: CCS hat das Potenzial, die betriebswirtschaftlichen Kosten des Klimaschutzes zu senken.

Schlussfolgerung: CCS wird als mögliche Option des Portfolios in Betracht gezogen.

\section{Enthymem IPCC 4 (Seite 3, 10ff)}

Erste Prämisse: DAS KLIMASCHUTZ-POZENZIAL VON CCS ERGIBT SICH AUS DEM (IN SZENARIO-STUIDEN) PROGNOSTIZIERTEN ANTEIL FOSSILER BRENNSTOFFE AN DER DECKUNG DES PRIMÄRENERGIEBEDARFS.

Zweite Prämisse: In Szenario-Studien wird prognostiziert, dass der Anteil fossiler Brennstoffe an der Deckung des Primärenergiebedarfs mindestens bis zur Mitte des Jahrhunderts dominant bleiben wird.

Schlussfolgerung: DAS KLIMASCHUTZ-POTENZIAL VON CCS IST, ENTSPRECHEND DES PROGOSTIZIERTEN DOMINANTEN ANTEILS FOSSILER BRENNSTOFFE AN DER DECKUNG DES PRIMÄRENERGIEBEDARFS, HOCH.

\section{Enthymem IPCC 5 (Seite 3, 12)}

Erste Prämisse: EINE ÄNDERUNG DER ENERGIEINFRASTRUKTUR IST NICHT NOTWENDIG, INSOWEIT DIE FLEXIBILITÄT INNERHALB DES STATUS QUO DER ENERGIEINFRASTRUKTUR HOCH GENUG IST, UM DIE NOTWENDIGE REDUKTION DER TREIBHAUSGASEMISSIONEN ZU ERREICHEN.

Zweite Prämisse: Die Entwicklung von CCS erhöht die Flexibilität, innerhalb des Status quo der Energieinfrastruktur die notwendige Reduktion der Treibhausgasemissionen zu erreichen. Schlussfolgerung: DIE ENTWICKLUNG VON CCS VERRINGERT DIE NOTWENDIGKEIT DER ÄNDERUNG DER ENERGIEINFRASTRUKTUR.

\section{Enthymem IPCC 6 (Seite 3, 12)}

Erste Prämisse: Technologien, die mit dem Status quo der Energieinfrastruktur kompatibel sind, haben einen spezifischen Wettbewerbsvorteil. 
Zweite Prämisse: Im Gegensatz zu anderen technologischen Optionen des Portfolios ist CCS mit dem Status quo der Energieinfrastruktur kompatibel.

Schlussfolgerung: CCS hat einen spezifischen Wettbewerbsvorteil gegenüber anderen technologischen Optionen des Portfolios.

\section{Enthymem IPCC 7 (Seite 3, 9, 10)}

Erste Prämisse: DIE ZENTRALISIERTE ENERGIEPRODUKTION IST UNPROBLEMATISCH.

Zweite Prämisse: $\mathrm{CCS}$ wird auf große punktuelle $\mathrm{CO}_{2}$-Quellen angewendet werden und basiert damit auf der zentralisierten Energieproduktion.

Schlussfolgerung: ES IST UNPROBLEMATISCH, DASS CCS AUF GROSSE PUNKTUELLE CO2-QUELLEN ANGEWENDET WERDEN WIRD UND DAMIT AUF DER ZENTRALISIERTEN ENERGIEPRODUKTION BASIERT.

\section{Enthymem IPCC 8 (Seite 6, 10)}

Erste Prämisse: DIE ABHÄNGIGKEIT DER WIRTSCHAFT VOM VERBRAUCH FOSSILER BRENNSTOFFE IST UNPROBLEMATISCH, INSOWEIT DIE BETRIEBSWIRTSCHAFTLICHEN KOSTEN DES NOTWENDIGEN KLIMASCHUTZES GESENKT WERDEN KÖNNEN.

Zweite Prämisse: Die Kombination von CCS mit EOR und ECBM senkt die betriebswirtschaftlichen Kosten des notwendigen Klimaschutzes.

Schlussfolgerung: DIE KOMBINATION VON CCS MIT EOR UND ECBM MACHT DIE ABHÄNGIGKEIT DER WIRTSCHAFT VOM VERBRAUCH FOSSILER BRENNSTOFFE WENIGER PROBLEMATISCH.

\section{Enthymem IPCC 9 (Seite 9, 10)}

Erste Prämisse: DAS KLIMASCHUTZ-POTENZIAL VON CCS ERGIBT SICH AUS DER (IN SZENARIO-STUIDEN) PROGNOSTIZIERTEN ANZAHL GROSSER PUNKTUELLER CO2-QUELLEN.

Zweite Prämisse: In Szenario-Studien wird prognostiziert, dass die Anzahl großer punktueller $\mathrm{CO}_{2}$-Quellen zunimmt.

Schlussfolgerung: DAS KLIMASCHUTZ-POTENZIAL VON CCS IST, ENTSPRECHEND DER PROGNOSTIZIERTEN ZUNAHME GROSSER PUNKTUELLER CO2-QUELLEN, HOCH. 


\section{Enthymem IPCC 10 (Seite 11)}

Erste Prämisse: DER GROSSFLÄCHIGE EINSATZ VON CCS HÄNGT VON DER WIRKUNG DER FLEXIBLEN MECHANISMEN DES KYOTO-PROTOKOLLS AB.

Zweite Prämisse: DIE FLEXIBLEN MECHANISMEN DES KYOTO-PROTOKOLLS ENTFALTEN IHRE WIRKUNG ÜBER DEN MARKTPREIS DER EMISSIONSZERTIFIKATE. Schlussfolgerung: Der großflächige Einsatz von CCS hängt vom Marktpreis der Emissionszertifikate $\mathrm{ab}$.

\section{Enthymem IPCC 11 (Seite 14)}

Erste Prämisse: DIE BISHER GESAMMELTEN ERFAHRUNGEN MIT IN DER NATUR VORKOMMENDEN SOWIE MIT TECHNISCH HERGESTELLTEN GASSPEICHERN LASSEN SICH AUF CO2 ÜBERTRAGEN, DAS MIT CCS-TECHNOLOGIEN IN ADÄQUAT AUSGEWÄHLTEN GEOLOGISCHEN FORMATIONEN VERPRESST WIRD.

Zweite Prämisse: Die bisher gesammelten Erfahrungen mit in der Natur vorkommenden sowie mit technisch hergestellten Gasspeichern zeigen, dass Gase sicher in ihren Speichern verbleiben.

Schlussfolgerung: Mit CCS-Technologien verpresstes $\mathrm{CO}_{2}$ verbleibt sicher in adäquat ausgewählten geologischen Formationen.

\section{A.2.2 Enthymeme in Norwegens Stellungnahmen}

\section{Enthymem NOR 1-1 (Seite 28, 30)}

Erste Prämisse: DIE VERMEIDUNG ÖKOLOGISCHER RISIKEN IST ENTSCHEIDEND FÜR DIE STABILITÄT DER CERs EINES CDM-PROJEKTS.

Zweite Prämisse: Die Vermeidung ökologischer Risiken wird bei CCS-Projekten durch eine sorgfältige und transparente Auswahl der Speicherorte sowie ein genaues und langfristiges Monitoring sichergestellt.

Schlussfolgerung: Eine sorgfältige und transparente Auswahl der Speicherorte sowie ein genaues und langfristiges Monitoring ist entscheidend für die Stabilität der CERs von CCSProjekten.

\section{Enthymem NOR 1-2 (Seite 28)}

Erste Prämisse: TECHNOLOGIEN KÖNNEN IN DEN CDM AUFGENOMMEN WERDEN, WENN IHRE IMPLIKATIONEN UND BESONDERHEITEN MIT DEN FESTGELEGTEN CDM-MODALITÄTEN UND -VERFAHREN VEREINBAR SIND. 
Zweite Prämisse: Für einige wenige Implikationen und Besonderheiten von CCS müssen noch Lösungen gefunden werden, damit sie mit den CDM-Modalitäten und -Verfahren vereinbar werden.

Schlussfolgerung: FÜR EINIGE WENIGE IMPLIKATIONEN UND BESONDERHEITEN VON CCS MÜSSEN NOCH LÖSUNGEN GEFUNDEN WERDEN, DAMIT CCS IN DEN CDM AUFGENOMMEN WERDEN KANN.

\section{Enthymem NOR 2-1 (Seite 10f)}

Erste Prämisse: Das Ziel der Klimapolitik ist die Begrenzung des globalen Temperaturanstiegs auf maximal zwei Grad gegenüber dem Niveau vor Beginn der Industrialisierung.

Zweite Prämisse: Der großflächige Einsatz von CCS ist unerlässlich, um die Begrenzung des globalen Temperaturanstiegs auf maximal zwei Grad gegenüber dem Niveau vor Beginn der Industrialisierung zu erreichen.

Schlussfolgerung: Der großflächige Einsatz von CCS ist unerlässlich, um das Ziel der Klimapolitik zu erreichen.

\section{Enthymem NOR 2-2 (Seite 11, 13)}

Erste Prämisse: DIE AUFNAHME EINER KLIMASCHUTZTECHNOLOGIE IN DEN CDM IST ENTSCHEIDEND FÜR IHREN GLOBALEN EINSATZ.

Zweite Prämisse: Angesichts der Herausforderung des Klimawandels ist der globale Einsatz von CCS enorm wichtig.

Schlussfolgerung: Angesichts der Herausforderung des Klimawandels ist die Aufnahme von $\mathrm{CCS}$ in den CDM enorm wichtig.

\section{Enthymem NOR 2-3 (Seite 12)}

Erste Prämisse: ZUR REDUZIERUNG VON ARMUT BEDARF ES WIRTSCHAFTSWACHSTUM

Zweite Prämisse: Angesichts der Herausforderung des Klimawandels bedarf es besonderer Anstrengungen, um die Reduzierung von Armut in den Entwicklungsländern voranzutreiben.

Schlussfolgerung: Angesichts der Herausforderung des des Klimawandels bedarf es besonderer Anstrengungen, um das Wirtschaftswachstum in den Entwicklungsländern voranzutreiben.

\section{Enthymem NOR 2-4 (Seite 12)}

Erste Prämisse: KLIMASCHUTZINSTRUMENTE MÜSSEN IM EINKLANG MIT BESTIMMTEN RECHTEN DER ENTWICKLUNGSLÄNDER STEHEN. 
Zweite Prämisse: Die Entwicklungs- und Schwellenländer haben ein Recht auf Wirtschaftswachstum.

Schlussfolgerung: Klimaschutzinstrumente müssen im Einklang mit dem Recht der Entwicklungsländer auf Wirtschaftswachstum stehen.

\section{Enthymem NOR 2-5 (Seite 12)}

Erste Prämisse: Ein Anstieg des Primärenergieverbrauchs birgt die Gefahr eines schwerwiegenden Klimawandels.

Zweite Prämisse: Die Reduzierung von Armut und das damit verbundene Wirtschaftswachstum in den Entwicklungsländern führt zu einem Anstieg des Primärenergieverbrauchs.

Schlussfolgerung: Die Reduzierung von Armut und das damit verbundene Wirtschaftswachstum in den Entwicklungsländern birgt die Gefahr eines schwerwiegenden Klimawandels.

\section{Enthymem NOR 2-6 (Seite 12)}

Erste Prämisse: DIE ENTWICKLUNG ZU EINER KOHLENSTOFFARMEN WIRTSCHAFT ERFOLGT ÜBER DIE ÄNDERUNG DER ENERGIEPRODUKTIONS- UND ENERGIEKONSUMMUSTER.

Zweite Prämisse: Die Anwendung existierender Technologien - beispielsweise CCS - ermöglicht die Änderung der Energieproduktions- und Energiekonsummuster.

Schlussfolgerung: Die Entwicklung zu einer kohlenstoffarmen Wirtschaft wird durch die Anwendung existierender Technologien - beispielsweise CCS - ermöglicht.

\section{Enthymem NOR 2-7 (Seite 12)}

Erste Prämisse: DER ZIELKONFLIKT ZWISCHEN ENTWICKLUNG UND KLIMASCHUTZ KANN DURCH EINE KOHLENSTOFFARME WIRTSCHAFT GELÖST WERDEN.

Zweite Prämisse: Technologien wie CCS ermöglichen eine kohlenstoffarme Wirtschaft.

Schlussfolgerung: TECHNOLOGIEN WIE CCS KÖNNEN DEN ZIELKONFLIKT ZWISCHEN ENTWICKLUNG UND KLIMASCHUTZ LÖSEN.

\section{Enthymem NOR 2-8 (Seite 12f)}

Erste Prämisse: DER ÜBERGANG ZU EINER KOHLENSTOFFARMEN WIRTSCHAFT KANN ÜBER BRÜCKENTECHNOLOGIEN ERFOLGEN.

Zweite Prämisse: CCS ist eine Brückentechnologie.

Schlussfolgerung: Der Übergang zu einer kohlenstoffarmen Wirtschaft kann über CCS erfolgen. 


\section{Enthymem NOR 2-9 (Seite 12f)}

Erste Prämisse: DIE BEDEUTUNG VON CCS ALS BRÜCKENTECHNOLOGIE ENTSPRICHT DEM PROGNOSTIZIERTEN GLOBALEN VERBRAUCH FOSSILER BRENNSTOFFE.

Zweite Prämisse: Laut Prognosen wird der globale Verbrauch fossiler Brennstoffe wird ansteigen.

Schlussfolgerung: Die Bedeutung von CCS als Brückentechnologie ist groß.

\section{Enthymem NOR 2-10 (Seite 13)}

Erste Prämisse: Für einen Einsatz von CCS in Entwicklungsländern sind finanzielle Anreize nötig.

Zweite Prämisse: Die Aufnahme von CCS in den CDM bietet finanzielle Anreize.

Schlussfolgerung: Für einen Einsatz von CCS in Entwicklungsländern ist die Aufnahme von CCS in den CDM nötig.

\section{Enthymem NOR 2-11 (Seite 13f)}

Erste Prämisse: DIE VERMEIDUNG ÖKOLOGISCHER RISIKEN IST ENTSCHEIDEND FÜR DIE STABILITÄT DER CERs EINES CDM-PROJEKTS.

Zweite Prämisse: Die Vermeidung ökologischer Risiken wird bei CCS-Projekten durch eine sorgfältige und transparente Auswahl der Speicherorte sowie genaues und langfristiges Monitoring sichergestellt.

Schlussfolgerung: Eine sorgfältige und transparente Auswahl der Speicherorte sowie ein genaues und langfristiges Monitoring ist entscheidend für die Stabilität der CERs von CCSProjekten.

\section{Enthymem NOR 2-12 (Seite 14)}

Erste Prämisse: TECHNOLOGIEN KÖNNEN IN DEN CDM AUFGENOMMEN WERDEN, WENN IHRE IMPLIKATIONEN UND BESONDERHEITEN MIT DEN FESTGELEGTEN CDM-MODALITÄTEN UND -VERFAHREN VEREINBAR SIND.

Zweite Prämisse: Für einige wenige Implikationen und Besonderheiten von CCS müssen noch Lösungen gefunden werden, damit sie mit den CDM-Modalitäten und -Verfahren vereinbar werden.

Schlussfolgerung: FÜR EINIGE WENIGE IMPLIKATIONEN UND BESONDERHEITEN VON CCS MÜSSEN NOCH LÖSUNGEN GEFUNDEN WERDEN, DAMIT CCS IN DEN CDM AUFGENOMMEN WERDEN KANN. 


\section{Enthymem NOR 3-1 (Seite 11)}

Erste Prämisse: Das Ziel der Klimapolitik ist die Stabilisierung der Treibhausgaskonzentration in der Atmosphäre.

Zweite Prämisse: Die Stabilisierung der Treibhausgaskonzentration in der Atmosphäre wird durch ein Portfolio technologischer Optionen erreicht.

Schlussfolgerung: Das Ziel der Klimapolitik wird durch ein Portfolio technologischer Optionen erreicht.

\section{Enthymem NOR 3-2 (Seite 11)}

Erste Prämisse: DER ÜBERGANG ZU EINER KOHLENSTOFFARMEN WIRTSCHAFT KANN ÜBER BRÜCKENTECHNOLOGIEN ERFOLGEN.

Zweite Prämisse: CCS ist eine Brückentechnologie.

Schlussfolgerung: Der Übergang zu einer kohlenstoffarmen Wirtschaft kann über CCS erfolgen.

\section{Enthymem NOR 3-3 (Seite 11f)}

Erste Prämisse: UM DEN GLOBALEN TEMPERATURANSTIEG AUF 2 GRAD BEGRENZEN ZU KÖNNEN IST ES UNERLÄSSLICH, DIE TECHNOLOGISCHEN OPTIONEN MIT DEN GRÖßTEN POTENZIALEN ZUR REDUZIERUNG VON TREIBHAUSGASEN WELTWEIT EINZUSETZEN.

Zweite Prämisse: CCS ist eines der technologischen Optionen mit den größten Potenzialen zur Reduzierung von Treibhausgasen.

Schlussfolgerung: Um den globalen Temperaturanstieg auf 2 Grad begrenzen zu können ist der weltweite Einsatz von CCS unerlässlich.

\section{Enthymem NOR 3-4 (Seite 12)}

Erste Prämisse: Für einen Einsatz von CCS in Entwicklungsländern sind finanzielle Anreize nötig.

Zweite Prämisse: Die Aufnahme von CCS in den CDM bietet finanzielle Anreize.

Schlussfolgerung: Für einen Einsatz von CCS in Entwicklungsländern ist die Aufnahme von CCS in den CDM nötig.

\section{Enthymem NOR 3-5 (Seite 12)}

Erste Prämisse: DIE VERMEIDUNG ÖKOLOGISCHER RISIKEN IST ENTSCHEIDEND FÜR DIE STABILITÄT DER CERs EINES CDM-PROJEKTS. 
Zweite Prämisse: Die Vermeidung ökologischer Risiken wird bei CCS-Projekten durch eine sorgfältige und transparente Auswahl der Speicherorte sowie genaues und langfristiges Monitoring sichergestellt.

Schlussfolgerung: Eine sorgfältige und transparente Auswahl der Speicherorte sowie ein genaues und langfristiges Monitoring ist entscheidend für die Stabilität der durch CCS-Projekte generierten CERs.

\section{Enthymem NOR 3-6 (Seite 16)}

Erste Prämisse: EINE ERFÜLLUNG DER FESTGELEGTEN CDM-MODALITÄTEN UND -VERFAHREN IST IM PRINZIP AKZEPTABEL WENN SICH DIE BETROFFENEN ENTWICKLUNGSLÄNDER UND DIE PROJEKTTEILNEHMER AUF DIE KONKRETEN UMSETZUNGSKRITERIEN EINIGEN.

Zweite Prämisse: In Bezug auf die konkreten Umsetzungskriterien der langfristigen Haftung der Zielländer für CCS-Projekte sollten sich die betroffenen Entwicklungsländer und die Projektteilnehmer einigen.

Schlussfolgerung: DIE ERFÜLLUNG DER FESTGELEGTEN CDM-MODALITÄTEN UND -VERFAHREN DURCH EINE LANGFRISTIGE HAFTUNG DER ZIELLÄNDER FÜR CCS-PROJEKTE IST IM PRINZIP AKZEPTABEL.

\section{Enthymem NOR 3-7 (Seite 17)}

Erste Prämisse: ARGUMENTE, DIE NICHT AUF DIE ERSTE VERPFLICHTUNGSPERIODE ZUTREFFEN, SOLLTEN AUCH KEINEN EINFLUSS AUF DIE REGELN UND MODALITÄTEN DER ERSTEN VERPFLICHTUNGSPERIODE HABEN.

Zweite Prämisse: Das Argument der Verdrängung anderer CDM-Projekte durch die Aufnahme von CCS in den CDM trifft auf die erste Verpflichtungsperiode nicht zu.

Schlussfolgerung: Das Argument der Verdrängung anderer CDM-Projekte durch die Aufnahme von CCS in den CDM sollte keinen Einfluss auf die Regeln und Modalitäten der ersten Verpflichtungsperiode haben.

\section{Enthymem NOR 4-1 (Seite 23)}

Erste Prämisse: UM DEN GLOBALEN TEMPERATURANSTIEG AUF 2 GRAD BEGRENZEN ZU KÖNNEN IST ES UNERLÄSSLICH, DIE TECHNOLOGISCHEN OPTIONEN MIT DEN GRÖßTEN POTENZIALEN ZUR REDUZIERUNG VON TREIBHAUSGASEN WELTWEIT EINZUSETZEN.

Zweite Prämisse: CCS ist eines der technologischen Optionen mit den größten Potenzialen zur Reduzierung von Treibhausgasen. 
Schlussfolgerung: Um den globalen Temperaturanstieg auf 2 Grad begrenzen zu können ist der weltweite Einsatz von CCS unerlässlich.

\section{Enthymem NOR 4-2 (Seite 24)}

Erste Prämisse: Für einen Einsatz von CCS in Entwicklungsländer sind finanzielle Anreize nötig.

Zweite Prämisse: Die Aufnahme von CCS in den CDM bietet finanzielle Anreize.

Schlussfolgerung: Für einen Einsatz von CCS in Entwicklungsländer ist die Aufnahme von CCS in den CDM nötig.

\section{Enthymem NOR 4-3 (Seite 24)}

Erste Prämisse: DIE VERMEIDUNG ÖKOLOGISCHER RISIKEN IST ENTSCHEIDEND FÜR DIE STABILITÄT DER CERs EINES CDM-PROJEKTS.

Zweite Prämisse: Die Vermeidung ökologischer Risiken wird bei CCS-Projekten durch eine sorgfältige und transparente Auswahl der Speicherorte sowie genaues und langfristiges Monitoring sichergestellt.

Schlussfolgerung: Eine sorgfältige und transparente Auswahl der Speicherorte sowie ein genaues und langfristiges Monitoring ist entscheidend für die Stabilität der durch CCS-Projekte generierten CERs.

\section{Enthymem NOR 4-4 (Seite 29)}

Erste Prämisse: EINE ERFÜLLUNG DER FESTGELEGTEN CDM-MODALITÄTEN UND -VERFAHREN IST IM PRINZIP AKZEPTABEL WENN SICH DIE BETROFFENEN LÄNDER UND DIE PROJEKTTEILNEHMER_INNEN AUF DIE KONKRETEN UMSETZUNGSKRITERIEN EINIGEN.

Zweite Prämisse: In Bezug auf die konkreten Umsetzungskriterien der langfristigen Haftung der Zielländer für CCS-Projekte sollten sich die betroffenen Länder und die Projektteilnehmer_innen einigen.

Schlussfolgerung: DIE ERFÜLLUNG DER FESTGELEGTEN CDM-MODALITÄTEN UND -VERFAHREN DURCH EINE LANGFRISTIGE HAFTUNG DER ZIELLÄNDER FÜR CCS-PROJEKTE IST IM PRINZIP AKZEPTABEL.

\section{Enthymem NOR 4-5 (Seite 29f)}

Erste Prämisse: ARGUMENTE, DIE NICHT AUF DIE ERSTE VERPFLICHTUNGSPERIODE ZUTREFFEN, SOLLTEN AUCH KEINEN EINFLUSS AUF DIE REGELN UND MODALITÄTEN DER ERSTEN VERPFLICHTUNGSPERIODE HABEN. 
Zweite Prämisse: Das Argument der Verdrängung anderer CDM-Projekte durch die Aufnahme von CCS in den CDM trifft auf die erste Verpflichtungsperiode nicht zu.

Schlussfolgerung: Das Argument der Verdrängung anderer CDM-Projekte durch die Aufnahme von CCS in den CDM sollte keinen Einfluss auf die Regeln und Modalitäten der ersten Verpflichtungsperiode haben.

\section{A.2.3 Enthymeme in Brasiliens Stellungnahmen}

\section{Enthymem BRA 1-1 (Seite 14)}

Erste Prämisse: DAS ZIEL DER KLIMAPOLITIK IST DIE STABILISIERUNG DER TREIBHAUSGASKONZENTRATION IN DER ATMOSPHÄRE .

Zweite Prämisse: Die Stabilisierung der Treibhausgaskonzentration in der Atmosphäre wird durch ein Portfolio technologischer Optionen erreicht.

Schlussfolgerung: DAS ZIEL DER KLIMAPOLITIK WIRD DURCH EIN PORTFOLIO TECHNOLOGISCHER OPTIONEN ERREICHT.

\section{Enthymem BRA 1-2 (Seite 14)}

Erste Prämisse: DAS ZIEL DER KLIMAPOLITIK IST DIE STABILISIERUNG DER TREIBHAUSGASKONZENTRATION IN DER ATMOSPHÄRE.

Zweite Prämisse: CCS kann dazu beitragen, die Treibhausgaskonzentration in der Atmosphäre zu stabilisieren.

Schlussfolgerung: CCS KANN DAZU BEITRAGEN, DAS ZIEL DER KLIMAPOLITIK ZU ERREICHEN.

\section{Enthymem BRA 1-3 (Seite 14)}

Erste Prämisse: VOR DER AUFNAHME EINER TECHNOLOGIE IN DEN CDM SOLLTEN DIE MÖGLICHKEITEN DER KORREKTEN MESSUNG IHRES BEITRAGS ZUR LANGFRISTIGEN REDUKTION VON TREIBHAUSGASEMISSIONEN SORGFÄLTIG GEPRÜFT WERDEN.

Zweite Prämisse: Um die langfristige Reduktion von Treibhausgasemissionen durch CCSProjekte korrekt messen zu können, müssen die Implikationen eines eventuellen Austritts von $\mathrm{CO}_{2}$ eingeschätzt werden können.

Schlussfolgerung: Vor der Aufnahme von CCS in den CDM sollten die Möglichkeiten der Einschätzung eines eventuellen Austritts von $\mathrm{CO}_{2}$ sorgfältig geprüft werden. 


\section{Enthymem BRA 1-4 (Seite 14)}

Erste Prämisse: VOR DER AUFNAHME EINER TECHNOLOGIE IN DEN CDM SOLLTEN IHRE IMPLIKATIONEN IM HINBLICK AUF DIE ZIELSTELLUNG DES CDM (NACHHALTIGE ENTWICKLUNG) SORGFÄLTIG GEPRÜFT WERDEN.

Zweite Prämisse: Die Zielstellung des CDM (nachhaltige Entwicklung) beruht auf der ökologischen Integrität des CDM.

Schlussfolgerung: Vor der Aufnahme einer Technologie in den CDM sollten ihre Implikationen im Hinblick auf die ökologische Integrität des CDM sorgfältig geprüft werden.

\section{Enthymem BRA 2-1 (Seite 3)}

Erste Prämisse: DAS ZIEL DER KLIMAPOLITIK IST DIE STABILISIERUNG DER TREIBHAUSGASKONZENTRATION IN DER ATMOSPHÄRE.

Zweite Prämisse: Die Stabilisierung der Treibhausgaskonzentration in der Atmosphäre wird durch ein Portfolio technologischer Optionen erreicht.

Schlussfolgerung: DAS ZIEL DER KLIMAPOLITIK WIRD DURCH EIN PORTFOLIO TECHNOLOGISCHER OPTIONEN ERREICHT.

\section{Enthymem BRA 2-2 (Seite 3)}

Erste Prämisse: DAS ZIEL DER KLIMAPOLITIK IST DIE STABILISIERUNG DER TREIBHAUSGASKONZENTRATION IN DER ATMOSPHÄRE.

Zweite Prämisse: CCS kann dazu beitragen, die Treibhausgaskonzentration in der Atmosphäre zu stabilisieren.

Schlussfolgerung: CCS KANN DAZU BEITRAGEN, DAS ZIEL DER KLIMAPOLITIK ZU ERREICHEN.

\section{Enthymem BRA 2-3 (Seite 3)}

Erste Prämisse: DIE FÜHRUNG IN DER BEKÄMPFUNG DES KLIMAWANDELS ZU ÜBERNEHMEN BEDEUTET, FÜR DIE ENTWICKLUNG DES PORTFOLIOS TECHNOLOGISCHER OPTIONEN VERANTWORTLICH ZU SEIN.

Zweite Prämisse: Die Industrieländer sollten die Führung in der Bekämpfung des Klimawandels übernehmen.

Schlussfolgerung: DIE INDUSTRIELÄNDER SIND FÜR DIE ENTWICKLUNG DES PORTFOLIOS TECHNOLOGISCHER OPTIONEN VERANTWORTLICH. 


\section{Enthymem BRA 2-4 (Seite 3)}

Erste Prämisse: NOCH UNREIFE TECHNOLOGIEN DES PORTFOLIOS SOLLTEN ZUNÄCHST NUR IN DEN INDUSTRIELÄNDERN SELBER ZUM EINSATZ KOMMEN, BEVOR SIE IN ENTWICKLUNGSLÄNDER EXPORTIERT WERDEN.

Zweite Prämisse: CCS ist noch eine unreife Technologie.

Schlussfolgerung: CCS sollte zunächst nur in den den Industrieländern selber zum Einsatz kommen, bevor es in Entwicklungsländer exportiert wird.

\section{Enthymem BRA 2-5 (Seite 3f)}

Erste Prämisse: Die Lösung hinsichtlich der Problematik der langfristigen Bürde der Atomkraft lässt sich auf CCS-Projekte übertragen.

Zweite Prämisse: Die Problematik der langfristigen Bürde der Atomkraft wurde durch elaborierte Versicherungssysteme und staatliche Überwachung gelöst.

Schlussfolgerung: Die Problematik der langfristigen Bürde der CCS-Projekte kann durch elaborierte Versicherungssysteme und staatliche Überwachung gelöst werden.

\section{Enthymem BRA 2-6 (Seite 3f)}

Erste Prämisse: Elaborierte Versicherungssysteme und staatliche Überwachung der CCS-Projekte können nur von Ländern gewährleistet werden, die stabile politische, ökonomische und institutionelle Strukturen haben.

Zweite Prämisse: Viele Entwicklungsländer haben keine stabilen politischen, ökonomischen und Institutionen.

Schlussfolgerung: VIELE ENTWICKLUNGSLÄNDER KÖNNEN ELABORIERTE VERSICHERUNGSSYSTEME UND STAATLICHE ÜBERWACHUNG DER CCS-PROJEKTE NICHT GEWÄHRLEISTEN.

\section{Enthymem BRA 2-7 (Seite 4ff)}

Erste Prämisse: BEDENKEN HINSICHTLICH DER AUFNAHME EINER TECHNOLOGIE IN DEN CDM SIND DANN HINREICHEND FÜR EINE ABHLEHNUNG, WENN SIE IMPLIKATIONEN UND BESONDERHEITEN DER TECHNOLOGIE AUFZEIGEN, DIE NICHT MIT DEN FESTGELEGTEN CDM-MODALITÄTEN UND -PROZESSEN VEREINBAR SIND.

Zweite Prämisse: CCS hat bestimmte Implikationen und Besonderheiten, die mit den festgelegten CDM-Modalitäten und -Prozessen nicht vereinbar sind.

Schlussfolgerung: Die Bedenken hinsichtlich der Aufnahme von CCS in den CDM sind hinreichend für eine Ablehnung. 


\section{Enthymem BRA 2-8 (Seite 4, 6)}

Erste Prämisse: Die Aufnahme eines neuen Projekt-Typus in den CDM bedarf einer CMPEntscheidung.

Zweite Prämisse: CCS ist ein neuer Projekt-Typus.

Schlussfolgerung: Die Aufnahme von CCS in den CDM bedarf einer CMP-Entscheidung.

\section{Enthymem BRA 2-9 (Seite 4f)}

Erste Prämisse: Komplexe langfristige Entwicklungen sind nicht mit den festgelegten CDMModalitäten und -Verfahren vereinbar.

Zweite Prämisse: CCS-Projekte zeichnen sich durch komplexe langfristige Entwicklungen aus. Schlussfolgerung: CCS-Projekte sind nicht mit den festgelegten CDM-Modalitäten und -Verfahren vereinbar.

\section{Enthymem BRA 2-10 (Seite 4f)}

Erste Prämisse: LANGFRISTIGE ENTWICKLUNGEN SIND DANN KOMPLEX, WENN SIE WEDER PROGNOSTIZIERBAR NOCH DIREKT MESSBAR SIND.

Zweite Prämisse: Die langfristigen Entwicklungen von CCS-Projekten sind weder prognostizierbar noch direkt messbar.

Schlussfolgerung: CCS-Projekte zeichnen sich durch komplexe langfristige Entwicklungen aus.

\section{Enthymem BRA 2-11 (Seite 5)}

Erste Prämisse: DIE CDM-MODALITÄTEN UND -VERFAHREN BASIEREN AUF DER ÖKONOMISCHEN LOGIK.

Zweite Prämisse: Die Ökonomische Logik kann komplexe langfristige Entwicklungen nicht adäquat bearbeiten.

Schlussfolgerung: Die CDM-Modalitäten und -Verfahren können komplexe langfristige Entwicklungen nicht adäquat bearbeiten.

\section{Enthymem BRA 2-12 (Seite 5)}

Erste Prämisse: EINE ERFÜLLUNG DER FESTGELEGTEN CDM-MODALITÄTEN UND -VERFAHREN IST NICHT AKZEPTABEL, WENN SIE DEN ENTWICKLUNGSLÄNDERN SCHADET.

Zweite Prämisse: Die langfristige Haftung der Zielländer für CCS-Projekte schadet den Entwicklungsländern.

Schlussfolgerung: Die Erfüllung der festgelegten CDM-Modalitäten und -Verfahren durch eine langfristige Haftung der Zielländer für CCS-Projekte ist nicht akzeptabel. 


\section{Enthymem BRA 2-13 (Seite 5)}

Erste Prämisse: Die Risiken, die neuen Technologien immanent sind, können minimiert werden, indem nur bereits reife Varianten kommerziell umgesetzt werden.

Zweite Prämisse: Die einzige reife Variante zur geologischen Speicherung von $\mathrm{CO}_{2}$ ist EOR.

Schlussfolgerung: DIE RISIKEN, DIE DER GEOLOGISCHEN SPEICHERUNG VON CO2 IMMANENT SIND, KÖNNEN MINIMIERT WERDEN, INDEM NUR EOR KOMMERZIELL UMGESETZT WIRD.

\section{Enthymem BRA 2-14 (Seite 5f)}

Erste Prämisse: In den CDM sollten keine Technologien aufgenommen werden, die Anreize schaffen für die Steigerung der Produktion fossiler Brennstoffe.

Zweite Prämisse: EOR- und ECBM-Projekte schaffen Anreize für die Steigerung der Produktion fossiler Brennstoffe.

Schlussfolgerung: EOR- und ECBM-Projekte sollten nicht in den CDM aufgenommen werden.

\section{Enthymem BRA 2-15 (Seite 5f)}

Erste Prämisse: Sinkende CER-Preise unterminieren Investitionen in kleinere dezentrale CDM-Projekte, in erneuerbare Energien, Energieeffizienz und kohlenstoffarme Formen des Wirtschaftens.

Zweite Prämisse: Die Aufnahme von CCS in den CDM führt zum Preisverfall von CERs.

Schlussfolgerung: Die Aufnahme von CCS in den CDM unterminiert Investitionen in kleinere dezentrale CDM-Projekte, in erneuerbare Energien, Energieeffizienz und kohlenstoffarme Formen des Wirtschaftens.

\section{Enthymem BRA 2-16 (Seite 6)}

Erste Prämisse: FÜR INDUSTRIELÄNDER KANN ES IN DER PHASE DES ÜBERGANGS IN EINE KOHLENSTOFFARME WIRTSCHAFT SINNVOLL SEIN, AUF BRÜCKENTECHNOLOGIEN ZURÜCK ZU GREIFEN.

Zweite Prämisse: CCS ist eine Brückentechnologie.

Schlussfolgerung: In der Phase des Übergangs in eine kohlenstoffarme Wirtschaft kann es für Industrieländer sinnvoll sein, auf CCS zurück zu greifen.

\section{Enthymem BRA 2-17 (Seite 6f)}

Erste Prämisse: Es sollten nur Technologien in den CDM aufgenommen werden, die prinzipiell der Zielstellung des CDM (nachhaltige Entwicklung) entsprechen. 
Zweite Prämisse: CCS entspricht prinzipiell nicht der Zielstellung des CDM (nachhaltige Entwicklung).

Schlussfolgerung: CCS sollte nicht in den CDM aufgenommen werden.

\section{Enthymem BRA 2-18 (Seite 6f)}

Erste Prämisse: Die zentrale Idee des CDM ist die langfristige Unterstützung in der Entwicklung zu einer kohlenstoffarmen Wirtschaft.

Zweite Prämisse: Die Aufnahme von CCS in den CDM steht der Entwicklung zu einer kohlenstoffarmen Wirtschaft entgegen.

Schlussfolgerung: Die Aufnahme von CCS in den CDM steht der zentralen Idee des CDM entgegen.

\section{Enthymem BRA 3-1 (Seite 2)}

Erste Prämisse: DAS ZIEL DER KLIMAPOLITIK IST DIE STABILISIERUNG DER TREIBHAUSGASKONZENTRATION IN DER ATMOSPHÄRE .

Zweite Prämisse: Die Stabilisierung der Treibhausgaskonzentration in der Atmosphäre wird durch ein Portfolio technologischer Optionen erreicht.

Schlussfolgerung: DAS ZIEL DER KLIMAPOLITIK WIRD DURCH EIN PORTFOLIO TECHNOLOGISCHER OPTIONEN ERREICHT.

\section{Enthymem BRA 3-2 (Seite 2)}

Erste Prämisse: DAS ZIEL DER KLIMAPOLITIK IST DIE STABILISIERUNG DER TREIBHAUSGASKONZENTRATION IN DER ATMOSPHÄRE.

Zweite Prämisse: CCS kann dazu beitragen, die Treibhausgaskonzentration in der Atmosphäre zu stabilisieren.

Schlussfolgerung: CCS KANN DAZU BEITRAGEN, DAS ZIEL DER KLIMAPOLITIK ZU ERREICHEN.

\section{Enthymem BRA 3-3 (Seite 2ff)}

Erste Prämisse: BEDENKEN HINSICHTLICH DER AUFNAHME EINER TECHNOLOGIE IN DEN CDM SIND DANN HINREICHEND FÜR EINE ABLEHNUNG WENN SIE BESONDERHEITEN DER TECHNOLOGIE AUFZEIGEN, DIE NICHT MIT DEN FESTGELEGTEN VORAUSSETZUNGEN EINES CDM-PROJEKTS KOMPATIBEL SIND.

Zweite Prämisse: CCS hat bestimmte Implikationen und Besonderheiten, die mit den festgelegten Voraussetzungen eines CDM-Projekts nicht kompatibel sind. 
Schlussfolgerung: Die Bedenken hinsichtlich der Aufnahme von CCS in den CDM sind hinreichend für eine Ablehnung.

\section{Enthymem BRA 3-4 (Seite 3)}

Erste Prämisse: Komplexe langfristige Entwicklungen sind nicht mit den festgelegten CDMModalitäten und -Verfahren vereinbar.

Zweite Prämisse: CCS-Projekte zeichnen sich durch komplexe langfristige Entwicklungen aus.

Schlussfolgerung: CCS-Projekte sind nicht mit den festgelegten CDM-Modalitäten und -Verfahren vereinbar.

\section{Enthymem BRA 3-5 (Seite 3)}

Erste Prämisse: Eine der wichtigsten Bedingungen für die Aufnahme einer Technologie in den CDM ist, dass sie langfristig zur tatsächlichen und messbaren Reduktion von Treibhausgasemissionen führt.

Zweite Prämisse: CCS führt langfristig nicht zu tatsächlichen und messbaren Reduktionen von Treibhausgasemissionen.

Schlussfolgerung: CCS erfüllt eine der wichtigsten Bedingungen für die Aufnahme in den CDM nicht.

\section{Enthymem BRA 3-6 (Seite 4)}

Erste Prämisse: LANGFRISTIGE ENTWICKLUNGEN SIND DANN KOMPLEX, WENN SIE WEDER PROGNOSTIZIERBAR NOCH DIREKT MESSBAR SIND.

Zweite Prämisse: Die langfristigen Entwicklungen von CCS-Projekten sind weder prognostizierbar noch direkt messbar.

Schlussfolgerung: CCS-Projekte zeichnen sich durch komplexe langfristige Entwicklungen aus.

\section{Enthymem BRA 3-7 (Seite 4)}

Erste Prämisse: DIE CDM-MODALITÄTEN UND -VERFAHREN BASIEREN AUF DER ÖKONOMISCHEN LOGIK.

Zweite Prämisse: Die Ökonomische Logik kann komplexe langfristige Entwicklungen nicht adäquat bearbeiten.

Schlussfolgerung: Die CDM-Modalitäten und -Verfahren können komplexe langfristige Entwicklungen nicht adäquat bearbeiten. 


\section{Enthymem BRA 3-8 (Seite 5f)}

Erste Prämisse: Die Aufnahme eines neuen Projekt-Typus in den CDM bedarf einer CMPEntscheidung.

Zweite Prämisse: CCS ist ein neuer Projekt-Typus.

Schlussfolgerung: Die Aufnahme von CCS in den CDM bedarf einer CMP-Entscheidung.

\section{Enthymem BRA 3-9 (Seite 6)}

Erste Prämisse: EINE ERFÜLLUNG DER FESTGELEGTEN CDM-MODALITÄTEN UND -VERFAHREN IST NICHT AKZEPTABEL, WENN SIE DEN ENTWICKLUNGSLÄNDERN SCHADET.

Zweite Prämisse: Die langfristige Haftung der Zielländer für CCS-Projekte schadet den Entwicklungsländern.

Schlussfolgerung: Die Erfüllung der festgelegten CDM-Modalitäten und -Verfahren durch eine langfristige Haftung der Zielländer für CCS-Projekte ist nicht akzeptabel.

\section{Enthymem BRA 3-10 (Seite 6)}

Erste Prämisse: Sinkende CER-Preise unterminieren Investitionen in kleinere dezentrale CDM-Projekte, in erneuerbare Energien, Energieeffizienz und kohlenstoffarme Formen des Wirtschaftens.

Zweite Prämisse: Die Aufnahme von CCS in den CDM führt zum Preisverfall von CERs.

Schlussfolgerung: Die Aufnahme von CCS in den CDM unterminiert Investitionen in kleinere dezentrale CDM-Projekte, in erneuerbare Energien, Energieeffizienz und kohlenstoffarme Formen des Wirtschaftens.

\section{Enthymem BRA 3-11 (Seite 6f)}

Erste Prämisse: Die Risiken, die neuen Technologien immanente sind, können minimiert werden, indem nur bereits reife Varianten kommerziell umgesetzt werden.

Zweite Prämisse: Die einzige reife Variante zur geologischen Speicherung von $\mathrm{CO}_{2}$ ist EOR. Schlussfolgerung: DIE RISIKEN, DIE DER GEOLOGISCHEN SPEICHERUNG VON CO2 IMMANENT SIND, KÖNNEN MINIMIERT WERDEN, INDEM NUR EOR KOMMERZIELL UMGESETZT WIRD.

\section{Enthymem BRA 3-12 (Seite 7)}

Erste Prämisse: In den CDM sollten keine Technologien aufgenommen werden, die Anreize schaffen für die Steigerung der Produktion fossiler Brennstoffe. 
Zweite Prämisse: EOR- und ECBM-Projekte schaffen Anreize für die Steigerung der Produktion fossiler Brennstoffe.

Schlussfolgerung: EOR- und ECBM-Projekte sollten nicht in den CDM aufgenommen werden.

\section{Enthymem BRA 3-13 (Seite 7)}

Erste Prämisse: FÜR INDUSTRIELÄNDER KANN ES IN DER PHASE DES ÜBERGANGS IN EINE KOHLENSTOFFARME WIRTSCHAFT SINNVOLL SEIN, AUF BRÜCKENTECHNOLOGIEN ZURÜCK ZU GREIFEN.

Zweite Prämisse: CCS ist eine Brückentechnologie.

Schlussfolgerung: In der Phase des Übergangs in eine kohlenstoffarme Wirtschaft kann es für Industrieländer sinnvoll sein, auf CCS zurück zu greifen.

\section{Enthymem BRA 3-14 (Seite 8)}

Erste Prämisse: DIE FÜHRUNG IN DER BEKÄMPFUNG DES KLIMAWANDELS ZU ÜBERNEHMEN BEDEUTET, FÜR DIE ENTWICKLUNG DES PORTFOLIOS TECHNOLOGISCHER OPTIONEN VERANTWORTLICH ZU SEIN.

Zweite Prämisse: Die Industrieländer sollten die Führung in der Bekämpfung des Klimawandels übernehmen.

Schlussfolgerung: DIE INDUSTRIELÄNDER SIND FÜR DIE ENTWICKLUNG DES PORTFOLIOS TECHNOLOGISCHER OPTIONEN VERANTWORTLICH.

\section{Enthymem BRA 3-15 (Seite 8)}

Erste Prämisse: NOCH UNREIFE TECHNOLOGIEN DES PORTFOLIOS SOLLTEN ZUNÄCHST NUR IN DEN INDUSTRIELÄNDERN SELBER ZUM EINSATZ KOMMEN, BEVOR SIE IN ENTWICKLUNGSLÄNDER EXPORTIERT WERDEN.

Zweite Prämisse: CCS ist noch eine unreife Technologie.

Schlussfolgerung: CCS sollte zunächst nur in den den Industrieländern selber zum Einsatz kommen, bevor es in Entwicklungsländer exportiert wird.

\section{Enthymem BRA 3-16 (Seite 8)}

Erste Prämisse: Die Lösung der Atomkraft hinsichtlich der Problematik der langfristigen Bürde lässt sich auf CCS-Projekte übertragen.

Zweite Prämisse: Die Problematik der langfristigen Bürde der Atomkraft wurde durch elaborierte Versicherungssysteme und staatliche Überwachung gelöst. 
Schlussfolgerung: Die Problematik der langfristigen Bürde der CCS-Projekte kann durch elaborierte Versicherungssysteme und staatliche Überwachung gelöst werden.

\section{Enthymem BRA 3-17 (Seite 8)}

Erste Prämisse: Elaborierte Versicherungssysteme und staatliche Überwachung der CCS-Projekte können nur von Ländern gewährleistet werden, die stabile politische, ökonomische und institutionelle Strukturen haben.

Zweite Prämisse: Viele Entwicklungsländer haben keine stabilen politischen, ökonomischen und Institutionen.

Schlussfolgerung: VIELE ENTWICKLUNGSLÄNDER KÖNNEN ELABORIERTE VERSICHERUNGSSYSTEME UND STAATLICHE ÜBERWACHUNG DER CCS-PROJEKTE NICHT GEWÄHRLEISTEN.

\section{Enthymem BRA 3-18 (Seite 8)}

Erste Prämisse: DIE VERSICHERUNGEN DER CCS-PROJEKTE WÜRDEN NUR CERAUSFÄLLE IN DER ANRECHNUNGSPHASE KOMPENSIEREN.

Zweite Prämisse: Der mittel- oder langfristige Austritt von $\mathrm{CO}_{2}$ wäre außerhalb der Anrechnungsphase und würde somit keinen Einfluss auf die bereits abgeschlossene Ausgabe von CERs an die Industrieländer haben.

Schlussfolgerung: Der mittel- und langfristige Austritt von $\mathrm{CO}_{2}$ würde von den Versicherungen der CCS-Projekte nicht kompensiert werden.

\section{Enthymem BRA 3-19 (Seite 8)}

Erste Prämisse: Die zentrale Idee des CDM ist die langfristige Unterstützung in der Entwicklung zu einer kohlenstoffarmen Wirtschaft.

Zweite Prämisse: Die Aufnahme von CCS in den CDM steht der Entwicklung zu einer kohlenstoffarmen Wirtschaft entgegen.

Schlussfolgerung: Die Aufnahme von CCS in den CDM steht der zentralen Idee des CDM entgegen.

\section{A.2.4 Enthymeme in den Stellungnahmen der EU}

\section{EU 1-1 (Seite 10)}

Erste Prämisse: DAS ZIEL DER KLIMAPOLITIK IST DIE STABILISIERUNG DER TREIBHAUSGASKONZENTRATION IN DER ATMOSPHÄRE. 
Zweite Prämisse: Die Stabilisierung der Treibhausgaskonzentration in der Atmosphäre wird durch ein Portfolio technologischer Optionen erreicht.

Schlussfolgerung: DAS ZIEL DER KLIMAPOLITIK WIRD DURCH EIN PORTFOLIO TECHNOLOGISCHER OPTIONEN ERREICHT.

\section{EU 1-2 (Seite 10)}

Erste Prämisse: DAS ZIEL DER KLIMAPOLITIK IST DIE STABILISIERUNG DER TREIBHAUSGASKONZENTRATION IN DER ATMOSPHÄRE.

Zweite Prämisse: CCS kann dazu beitragen, die Treibhausgaskonzentration in der Atmosphäre zu stabilisieren.

Schlussfolgerung: CCS KANN DAZU BEITRAGEN, DAS ZIEL DER KLIMAPOLITIK ZU ERREICHEN.

\section{EU 2-1 (Seite 18)}

Erste Prämisse: Das Ziel der Klimapolitik ist die Stabilisierung der Treibhausgaskonzentration in der Atmosphäre.

Zweite Prämisse: Die Stabilisierung der Treibhausgaskonzentration in der Atmosphäre wird durch ein Portfolio technologischer Optionen erreicht.

Schlussfolgerung: Das Ziel der Klimapolitik wird durch ein Portfolio technologischer Optionen erreicht.

\section{EU 2-2 (Seite 18)}

Erste Prämisse: DAS KLIMASCHUTZ-POTENZIAL VON CCS ERGIBT SICH AUS DEM PROGNOSTIZIERTEN ANTEIL FOSSILER BRENNSTOFFE AN DER DECKUNG DES PRIMÄRENERGIEBEDARFS.

Zweite Prämisse: Die Prognosen gehen davon aus, dass der Anteil fossiler Brennstoffe an der Deckung des Primärenergiebedarfs mindestens bis zur Mitte des Jahrhunderts dominant bleiben wird.

Schlussfolgerung: Das Klimaschutz-Potenzial von CCS ist, entsprechend des prognostizierten dominanten Anteils fossiler Brennstoffe an der Deckung des Primärenergiebedarfs, hoch.

\section{EU 2-3 (Seite 18)}

Erste Prämisse: VIELE VOLKSWIRTSCHAFTEN KÖNNTEN WEITERHIN FOSSILE BRENNSTOFFE ZUR SICHEREN UND ZUVERLÄSSIGEN ENERGIEVERSORGUNG NUTZEN, WENN IHRE STEIGENDEN CO2-EMISSIONEN VERRINGERT WERDEN WÜRDEN. 
Zweite Prämisse: Mit Hilfe von CCS könnten die steigenden $\mathrm{CO}_{2}$-Emissionen der fossilen Brennstoffe verringert werden.

Schlussfolgerung: Mit Hilfe von CCS könnten viele Volkswirtschaften weiterhin fossile Brennstoffe zur sicheren und zuverlässigen Energieversorgung nutzen.

\section{EU 2-4 (Seite 18)}

Erste Prämisse: Das Ziel der Klimapolitik ist die Stabilisierung der Treibhausgaskonzentration in der Atmosphäre.

Zweite Prämisse: CCS kann dazu beitragen, die Treibhausgaskonzentration in der Atmosphäre zu stabilisieren.

Schlussfolgerung: CCS kann dazu beitragen, das Ziel der Klimapolitik zu erreichen.

\section{EU 2-5 (Seite 19, 21)}

Erste Prämisse: DIE BISHER GESAMMELTEN ERFAHRUNGEN MIT EOR UND MIT DER UNTERIRDISCHEN LAGERUNG VON SAUERGAS LASSEN SICH AUF CO2 ÜBERTRAGEN, DAS MIT CCS-TECHNOLOGIEN IN ADÄQUAT AUSGEWÄHLTEN GEOLOGISCHEN FORMATIONEN VERPRESST WIRD.

Zweite Prämisse: Die bisher gesammelten Erfahrungen mit EOR und mit der unterirdischen Lagerung von Sauergas zeigen, dass Gase sicher in ihren Speichern verbleiben.

Schlussfolgerung: Mit CCS-Technologien verpresstes $\mathrm{CO}_{2}$ verbleibt sicher in adäquat ausgewählten geologischen Formationen.

\section{EU 2-6 (Seite 19, 21)}

Erste Prämisse: MIT DEN BISHER GESAMMELTEN ERFAHRUNGEN AUS DEN DEMONSTRATIONSPROJEKTEN LASSEN SICH ZUKÜNFTIGE CCS-PROJEKTE BEURTEILEN.

Zweite Prämisse: Die bisher gesammelten Erfahrungen aus den Demonstrationsprojekten zeigen, dass die Speicherung von $\mathrm{CO}_{2}$ in geologischen Formationen sicher ist.

Schlussfolgerung: Die Speicherung von $\mathrm{CO}_{2}$ in geologischen Formationen ist bei zukünftigen CCS-Projekten sicher.

\section{EU 2-7 (Seite 20)}

Erste Prämisse: ES IST WICHTIG, DASS CCS DORT ANGEWENDET WIRD, WO FOSSILE KRAFTWERKE ENTSTEHEN.

Zweite Prämisse: In den Entwicklungsländern entstehen fossile Kraftwerke.

Schlussfolgerung: Es ist wichtig, dass CCS in den Entwicklungsländern angewendet wird. 


\section{EU 3-1 (Seite 22)}

Erste Prämisse: Das Ziel der Klimapolitik ist die Stabilisierung der Treibhausgaskonzentration in der Atmosphäre.

Zweite Prämisse: CCS kann dazu beitragen, die Treibhausgaskonzentration in der Atmosphäre zu stabilisieren.

Schlussfolgerung: CCS KANN DAZU BEITRAGEN, DAS ZIEL DER KLIMAPOLITIK ZU ERREICHEN.

\section{EU 3-2 (Seite 22)}

Erste Prämisse: Für die Stabilisierung der Treibhausgaskonzentration in der Atmosphäre bedarf es unter anderem massiver Emissionsreduktionen bei Kohlekraftwerken in Industrieund Entwicklungsländern.

Zweite Prämisse: Massive Emissionsreduktionen bei Kohlekraftwerken in Industrie- und Entwicklungsländern können durch CCS erreicht werden.

Schlussfolgerung: FÜR DIE STABILISIERUNG DER TREIBHAUSGASKONZENTRATION IN DER ATMOSPHÄRE BEDARF ES UNTER ANDEREM CCS.

\section{EU 3-3 (Seite 22)}

Erste Prämisse: CCS SOLLTE DORT ENTWICKELT WERDEN, WO MASSIVE EMISSIONSREDUKTIONEN BEI KOHLEKRAFTWERKEN NÖTIG SIND.

Zweite Prämisse: Sowohl in den industrialisierten als auch in Entwicklungsländern sind massive Emissionsreduktionen bei Kohlekraftwerken nötig.

Schlussfolgerung: CCS sollte sowohl in den industrialisierten als auch in Entwicklungsländern entwickelt werden.

\section{EU 3-4 (Seite 23)}

Erste Prämisse: EINE GEEIGNETE ANSCHUBFINANZIERUNG UND EINE UNTERSTÜTZUNG DES TECHNOLOGIETRANSFERS KÖNNTE EINE UNTER VERSCHIEDENEN UNTERSTÜTZUNGSMECHANISMEN FÜR DIE DEMONSTRATION, VERBREITUNG UND ANWENDUNG VON CCS SEIN.

Zweite Prämisse: Die Aufnahme in den CDM bietet eine geeignete Anschubfinanzierung und unterstützt den Technologietransfer.

Schlussfolgerung: Die Aufnahme in den CDM könnte eine unter verschiedenen Unterstützungsmechanismen für die Demonstration, Verbreitung und Anwendung von CCS sein. 


\section{EU 3-5 (Seite 23)}

Erste Prämisse: POTENZIELL WICHTIGE KLIMASCHUTZTECHNOLOGIEN SOLLTEN WELTWEIT DEMONSTRIERT UND VERBREITET WERDEN.

Zweite Prämisse: CCS ist eine potenziell wichtige Klimaschutztechnologie.

Schlussfolgerung: CCS SOLLTE WELTWEIT DEMONSTRIERT UND VERBREITET WERDEN.

\section{EU 3-6 (Seite 23, 25)}

Erste Prämisse: DURCH EINE PILOTPHASE KÖNNTEN POTENZIELL WICHTIGE KLIMASCHUTZTECHNOLOGIEN WELTWEIT DEMONSTRIERT UND VERBREITET WERDEN.

Zweite Prämisse: CCS ist eine potenziell wichtige Klimaschutztechnologie.

Schlussfolgerung: Durch eine Pilotphase könnte CCS weltweit demonstriert und verbreitet werden.

\section{EU 3-7 (Seite 23, 25f)}

Erste Prämisse: DIE BEFÜRCHTUNGEN DER LÄNDER, DIE EINER AUFNAHME VON CCS IN DEN CDM SKEPTISCH GEGENÜBER STEHEN, KÖNNEN DURCH EINEN ERWEITERTEN WISSENSSTAND AUSGERÄUMT WERDEN.

Zweite Prämisse: Durch eine Pilotphase kann der Wissensstand erweitert werden.

Schlussfolgerung: DIE BEFÜRCHTUNGEN DER LÄNDER, DIE EINER AUFNAHME VON CCS IN DEN CDM SKEPTISCH GEGENÜBER STEHEN, KÖNNEN DURCH EINE PILOTPHASE AUSGERÄUMT WERDEN.

\section{EU 3-8 (Seite 25)}

Erste Prämisse: UM DAS KLIMASCHUTZ-POTENZIAL VON CCS PRÄZISE EINSCHÄTZEN ZU KÖNNEN, IST ES NOTWENDIG, DASS ES WELTWEIT DEMONSTRATIONSPROJEKTE GIBT.

Zweite Prämisse: Durch eine Pilotphase könnten weltweit Demonstrationsprojekte entstehen. Schlussfolgerung: Durch eine Pilotphase könnte das Klimaschutz-Potenzial von CCS präzise eingeschätzt werden.

\section{EU 4-1 (Seite 32)}

Erste Prämisse: DAS ZIEL DER KLIMAPOLITIK IST DIE STABILISIERUNG DER TREIBHAUSGASKONZENTRATION IN DER ATMOSPHÄRE. 
Zweite Prämisse: CCS kann dazu beitragen, die Treibhausgaskonzentration in der Atmosphäre zu stabilisieren.

Schlussfolgerung: CCS KANN DAZU BEITRAGEN, DAS ZIEL DER KLIMAPOLITIK ZU ERREICHEN.

\section{EU 4-2 (Seite 32, 40)}

Erste Prämisse: ES IST WICHTIG, DASS CCS DORT ANGEWENDET WIRD, WO FOSSILE KRAFTWERKE ENTSTEHEN.

Zweite Prämisse: In den Entwicklungsländern entstehen fossile Kraftwerke.

Schlussfolgerung: Es ist wichtig, dass CCS in den Entwicklungsländern angewendet wird.

\section{EU 4-3 (Seite 32)}

Erste Prämisse: FINANZIELLE ANREIZE KÖNNTEN EINEN EINSATZ VON CCS IN ENTWICKLUNGSLÄNDERN UNTERSTÜTZEN.

Zweite Prämisse: Die Aufnahme in den CDM bietet finanzielle Anreize.

Schlussfolgerung: Die Aufnahme in den CDM könnte einen Einsatz von CCS in Entwicklungsländern unterstützen.

\section{EU 4-4 (Seite 37)}

Erste Prämisse: ES SOLLTEN NUR DIE CCS-TECHNOLOGIEN IN DEN CDM AUFGENOMMEN WERDEN, DIE DAS KRITERIUM DER ZUSÄTZLICHKEIT ERFÜLLEN.

Zweite Prämisse: EOR und EGR erfüllen möglicherweise nicht das Kriterium der Zusätzlichkeit.

Schlussfolgerung: EOR UND EGR SOLLTEN MÖGLICHERWEISE NICHT IN DEN CDM AUFGENOMMEN WERDEN.

\section{EU 4-5 (Seite 40)}

Erste Prämisse: DER ÜBERGANG ZU EINER KOHLENSTOFFARMEN WIRTSCHAFT KANN ÜBER BRÜCKENTECHNOLOGIEN ERFOLGEN.

Zweite Prämisse: CCS ist eine Brückentechnologie.

Schlussfolgerung: Der Übergang zu einer kohlenstoffarmen Wirtschaft kann über CCS erfolgen.

\section{EU 4-6 (Seite 40)}

Erste Prämisse: CCS-DEMONSTRATIONSPROJEKTE SOLLTEN DORT ENTSTEHEN, WO ES VIELE FOSSILE KRAFTWERKE GEBEN WIRD. 
Zweite Prämisse: Auch in den Entwicklungsländern wird es viele fossile Kraftwerke geben.

Schlussfolgerung: CCS-Demonstrationsprojekte sollten auch in den Entwicklungsländern entstehen.

\section{A.2.5 Enthymeme in IETAs Stellungnahmen}

\section{Enthymem IETA 1-1 (Seite 2ff)}

Erste Prämisse: VERSCHIEDENE AKTEUR_INNEN ARBEITEN AN DER ENTWICKLUNG EINER KLIMASCHUTZTECHNOLOGIE, WENN DIESE FÜR BESONDERS RELEVANT ANGESEHEN WIRD.

Zweite Prämisse: Verschiedene Akteur_innen arbeiten an der Entwicklung von CCS.

Schlussfolgerung: CCS wird als besonders relevante Klimaschutztechnologie angesehen.

\section{Enthymem IETA 1-2 (Seite 2ff)}

Erste Prämisse: VERSCHIEDENE AKTEUR_INNEN ARBEITEN AN DER ENTWICKLUNG EINER KLIMASCHUTZTECHNOLOGIE, WENN DAVON AUSGEGANGEN WIRD, DASS BEFRIEDIGENDE ANTWORTEN FÜR FRAGEN, DIE UNSICHERHEITEN UND RISIKEN BETREFFEN, GEFUNDEN WERDEN.

Zweite Prämisse: Verschiedene Akteur_innen arbeiten an der Entwicklung von CCS.

Schlussfolgerung: Es wird davon ausgegangen, dass für Fragen, die Unsicherheiten und Risiken von CCS betreffen, befriedigende Antworten gefunden werden.

\section{Enthymem IETA 1-3 (Seite 3)}

Erste Prämisse: SEHR EHRGEIZIGE EMISSIONSREDUKTIONSZIELE KÖNNEN NUR MIT HILFE EINES GROßFLÄCHIGEN EINSATZES VON CCS ERREICHT WERDEN.

Zweite Prämisse: Die EU und bestimmte einzelne Länder haben sich sehr ehrgeizige Emissionsreduktionsziele gesetzt.

Schlussfolgerung: Die EU und bestimmte einzelne Länder können ihre Emissionsreduktionsziele nur mit Hilfe eines großflächigen Einsatzes von CCS erreichen.

\section{Enthymem IETA 1-4 (Seite 5f)}

Erste Prämisse: DER EINSATZ VON BRÜCKENTECHNOLOGIEN IST NOTWENDIG, BIS DIE ERNEUERBAREN ENERGIEN DIE NÖTIGE REIFE UND DAS NÖTIGE QUANTUM ERREICHT HABEN, UM DEN GLOBALEN ENERGIEBEDARF DECKEN ZU KÖNNEN.

Zweite Prämisse: CCS ist eine Brückentechnologie. 
Schlussfolgerung: Der Einsatz von CCS ist notwendig, bis die erneuerbaren Energien die nötige Reife und das nötige Quantum erreicht haben, um den globalen Energiebedarf decken zu können.

\section{Enthymem IETA 1-5 (Seite 6)}

Erste Prämisse: BEI EHRGEIZIGEN EMISSIONSREDUKTIONSZIELEN KONKURRIEREN CCS UND ERNEUERBARE ENERGIEN NICHT UM INVESTITIONEN UND ANREIZE.

Zweite Prämisse: Die EU hat sich sehr ehrgeizige Emissionsreduktionsziele gesetzt.

Schlussfolgerung: In der EU konkurrieren CCS und erneuerbare Energien nicht um Investitionen und Anreize.

\section{Enthymem IETA 1-6 (Seite 6f)}

Erste Prämisse: EMISSIONSREDUKTIONSZIELE KÖNNEN ENTWEDER DURCH INVESTITIONEN IM EIGENEN LAND ODER DURCH CDM- UND JI-PROJEKTE ERFÜLLT WERDEN.

Zweite Prämisse: Es gibt Länder, die ihre Emissionsreduktionsziele nicht allein durch Investitionen im eigenen Land erfüllen können.

Schlussfolgerung: Es gibt Länder, die ihre Emissionsreduktionsziele nur durch CDM- und JIProjekte erfüllen können.

\section{Enthymem IETA 1-7 (Seite 7)}

Erste Prämisse: In einem marktbasierten Regime können kosteneffiziente Klimaschutztechnologien schneller und zu Lasten von anderen wachsen.

Zweite Prämisse: Das internationale Klimaregime ist marktbasiert.

Schlussfolgerung: Im internationalen Klimaregime können kosteneffiziente Klimaschutztechnologien schneller und zu Lasten von anderen wachsen.

\section{Enthymem IETA 1-8 (Seite 7)}

Erste Prämisse: Es ist unproblematisch, dass manche Klimaschutztechnologien schneller und zu Lasten von anderen wachsen.

Zweite Prämisse: CCS könnte im internationalen Klimaschutzregime schneller und zu Lasten von erneuerbaren Technologien wachsen.

Schlussfolgerung: Es ist unproblematisch, dass CCS im internationalen Klimaschutzregime schneller und zu Lasten von erneuerbaren Technologien wachsen könnte. 


\section{Enthymem IETA 1-9 (Seite 7)}

Erste Prämisse: Das Ziel der Klimarahmenkonvention ist eine kosteneffiziente Reduktion von Treibhausgasemissionen, die Technologietransfer und eine nachhaltige Entwicklung ermöglicht.

Zweite Prämisse: Die Aufnahme von CCS in den CDM trägt dazu bei, kosteneffizient Treibhausgasemissionen zu reduzieren und Technologietransfer sowie eine nachhaltige Entwicklung zu ermöglichen.

Schlussfolgerung: Die Aufnahme von CCS in den CDM trägt zur Erreichung des Ziels der Klimarahmenkonvention bei.

\section{Enthymem IETA 1-10 (Seite 7)}

Erste Prämisse: WENN ES EINES WACHSTUMS VON ENERGIEQUELLEN BEDARF, KÖNNEN SOWOHL CCS ALS AUCH ERNEUERBARE ENERGIEN WACHSEN.

Zweite Prämisse: Da der globale Energiebedarf steigt, bedarf es eines Wachstums von Energiequellen.

Schlussfolgerung: Da der globale Energiebedarf steigt, können sowohl CCS als auch erneuerbare Energien wachsen.

\section{Enthymem IETA 1-11 (Seite 8)}

Erste Prämisse: ES WERDEN DIE TECHNOLOGIEN ALS MÖGLICHE OPTIONEN DES PORTFOLIOS IN BETRACHT GEZOGEN, DIE POTENZIAL ZUR SENKUNG DER BETRIEBSWIRTSCHAFTLICHEN KOSTEN DES KLIMASCHUTZES HABEN.

Zweite Prämisse: CCS hat Potenzial zur Senkung der betriebswirtschaftlichen Kosten des Klimaschutzes.

Schlussfolgerung: CCS wird als mögliche Option des Portfolios in Betracht gezogen.

\section{Enthymem IETA 1-12 (Seite 8)}

Erste Prämisse: EINE ÄNDERUNG DER ENERGIEINFRASTRUKTUR IST NICHT NOTWENDIG, INSOWEIT DIE FLEXIBILITÄT INNERHALB DES STATUS QUO DER ENERGIEINFRASTRUKTUR HOCH GENUG IST, UM DIE NOTWENDIGE REDUZIERUNG DER TREIBHAUSGASEMISSIONEN ZU ERREICHEN.

Zweite Prämisse: Die Entwicklung von CCS erhöht die Flexibilität, innerhalb des Status quo der Energieinfrastruktur die notwendige Reduktion der Treibhausgasemissionen zu erreichen. Schlussfolgerung: DIE ENTWICKLUNG VON CCS VERRINGERT DIE NOTWENDIGKEIT DER ÄNDERUNG DER ENERGIEINFRASTRUKTUR. 


\section{Enthymem IETA 1-13 (Seite 8)}

Erste Prämisse: KLIMASCHUTZTECHNOLOGIEN, DIE AUF DER ZENTRALISIERTEN ENERGIEPRODUKTION BASIEREN, HABEN DAS POTENZIAL, GROßE MENGEN VON TREIBHAUSGASEMISSIONEN EINZUSPAREN.

Zweite Prämisse: CCS BASIERT AUF DER ZENTRALISIERTEN ENERGIEPRODUKTION.

Schlussfolgerung: CCS hat das Potenzial, große Mengen von Treibhausgasemissionen einzusparen.

\section{Enthymem IETA 1-14 (Seite 8)}

Erste Prämisse: DIE BISHER GESAMMELTEN ERFAHRUNGEN MIT IN DER NATUR VORKOMMENDEN CO2-SPEICHERN, MIT EOR UND MIT DER UNTERIRDISCHEN LAGERUNG VON SAUERGAS LASSEN SICH AUF CO2 ÜBERTRAGEN, DAS MIT CCS-TECHNOLOGIEN IN ADÄQUAT AUSGEWÄHLTEN GEOLOGISCHEN FORMATIONEN VERPRESST WIRD.

Zweite Prämisse: Die bisher gesammelten Erfahrungen mit in der Natur vorkommenden $\mathrm{CO}_{2}$ Speichern, mit EOR und mit der unterirdischen Lagerung von Sauergas zeigen, dass $\mathrm{CO}_{2}$ sicher innerhalb geologischer Formationen verbleibt.

Schlussfolgerung: Mit CCS-Technologien verpresstes $\mathrm{CO}_{2}$ verbleibt sicher in adäquat ausgewählten geologischen Formationen.

\section{Enthymem IETA 1-15 (Seite 8ff)}

Erste Prämisse: DIE BESONDERHEITEN UND IMPLIKATIONEN EINER TECHNOLOGIE STEHEN EINER AUFNAHME IN DEN CDM NICHT ENTGEGEN WENN ES LÖSUNGSVORSCHLÄGE GIBT, DIE SOWOHL FÜR DIE PROJEKTTEILNEHMERIN_NEN ALS AUCH FÜR DEN KOHLENSTOFFMARKT PLANUNGSSICHERHEIT GEWÄHRLEISTEN.

Zweite Prämisse: Für die Besonderheiten und Implikationen von CCS (inklusive der Eventualität von Leckagen) gibt es Lösungsvorschläge, die sowohl für die Projektteilnehmer_innen als auch für den Kohlenstoffmarkt Planungssicherheit gewährleisten.

Schlussfolgerung: Die Besonderheiten und Implikationen von CCS (inklusive der Eventualität von Leckagen) stehen einer Aufnahme in den CDM nicht entgegen.

\section{Enthymem IETA 1-16 (Seite 10)}

Erste Prämisse: Geringe Mengen an zusätzlich gefördertem Erdöl führen nicht zu einer höheren Nachfrage an Erdöl und Erdölprodukten. 
Zweite Prämisse: Durch EOR-Projekte werden nur geringe Mengen Erdöl zusätzlich gefördert.

Schlussfolgerung: EOR-Projekte führen nicht zu einer höheren Nachfrage an Erdöl und Erdölprodukten.

\section{Enthymem IETA 1-17 (Seite 12f)}

Erste Prämisse: IM KAMPF GEGEN DEN KLIMAWANDEL IST ES UNERLÄSSLICH, ALLE TECHNOLOGISCHEN OPTIONEN MIT VIELVERSPRECHENDEN POTENZIALEN ZUR REDUZIERUNG VON TREIBHAUSGASEMISSIONEN WELTWEIT EINZUSETZEN.

Zweite Prämisse: CCS ist eine technologische Option mit vielversprechenden Potenzialen zur Reduzierung von Treibhausgasemissionen.

Schlussfolgerung: Im Kampf gegen den Klimawandel ist der weltweite Einsatz von CCS unerlässlich.

\section{Enthymem IETA 1-18 (Seite 12f)}

Erste Prämisse: DIE AUFNAHME EINER KLIMASCHUTZTECHNOLOGIE IN DEN CDM TRÄGT ZU IHREM SCHNELLEN EINSATZ BEI.

Zweite Prämisse: Angesichts der vielversprechenden Potenziale zur Reduzierung von Treibhausgasemissionen ist ein schneller Einsatz von CCS wichtig.

Schlussfolgerung: Angesichts der vielversprechenden Potenziale zur Reduzierung von Treibhausgasemissionen ist die Aufnahme von CCS in den CDM wichtig.

\section{Enthymem IETA 1-19 (Seite 12)}

Erste Prämisse: EINE NACHHALTIGE ENTWICKLUNG WIRD DURCH TECHNOLOGIEN ERMÖGLICHT, DIE ENERGIE BEREITSTELLEN OHNE DAS KLIMA ZU BEEINTRÄCHTIGEN.

Zweite Prämisse: CCS stellt Energie bereit ohne das Klima zu beeinträchtigen.

Schlussfolgerung: CCS ermöglicht eine nachhaltige Entwicklung.

\section{Enthymem IETA 2-1 (Seite 1, 3, 5)}

Erste Prämisse: Das Ziel der Klimapolitik ist die Stabilisierung der Treibhausgaskonzentration in der Atmosphäre.

Zweite Prämisse: Die Stabilisierung der Treibhausgaskonzentration in der Atmosphäre wird durch ein Portfolio technologischer Optionen erreicht. 
Schlussfolgerung: DAS ZIEL DER KLIMAPOLITIK WIRD DURCH EIN PORTFOLIO TECHNOLOGISCHER OPTIONEN ERREICHT.

\section{Enthymem IETA 2-2 (Seite 1f, 13)}

Erste Prämisse: UM DIE STABILISIERUNG DER TREIBHAUSGASKONZENTRATION IN DER ATMOSPHÄRE ZU ERREICHEN IST ES UNERLÄSSLICH, DAS VOLLE POTENZIAL ALLER TECHNOLOGISCHEN OPTIONEN DES PORTFOLIOS AUSZUSCHÖPFEN.

Zweite Prämisse: CCS ist eine wichtige technologische Optionen des Portfolios.

Schlussfolgerung: Um die Stabilisierung der Treibhausgaskonzentration in der Atmosphäre zu erreichen ist es unerlässlich, das volle Potenzial von CCS auszuschöpfen.

\section{Enthymem IETA 2-3 (Seite 1)}

Erste Prämisse: EINE NACHHALTIGE ENTWICKLUNG WIRD DURCH TECHNOLOGIEN ERMÖGLICHT, DIE WIRTSCHAFTSWACHSTUM UND LÄNDLICHE ELEKTRIFIZIERUNG MIT DER NOTWENDIGKEIT ZUR REDUKTION VON TREIBHAUSGASEMISSIONEN IN EINKLANG BRINGEN.

Zweite Prämisse: CCS bringt Wirtschaftswachstum und ländliche Elektrifizierung mit der Notwendigkeit zur Reduktion von Treibhausgasemissionen in Einklang.

Schlussfolgerung: CCS ermöglicht eine nachhaltige Entwicklung.

\section{Enthymem IETA 2-4 (Seite 1, 4ff)}

Erste Prämisse: Für einen Einsatz von CCS ist eine Anschubfinanzierung nötig. Zweite Prämisse: Die Aufnahme von CCS in den CDM bietet eine Anschubfinanzierung. Schlussfolgerung: Für einen Einsatz von CCS ist die Aufnahme von CCS in den CDM nötig.

\section{Enthymem IETA 2-5 (Seite 1, 4f)}

Erste Prämisse: Für einen Einsatz von CCS in Entwicklungsländern sind finanzielle Anreize nötig.

Zweite Prämisse: Die Aufnahme von CCS in den CDM bietet finanzielle Anreize.

Schlussfolgerung: Für einen Einsatz von CCS in Entwicklungsländern ist die Aufnahme von CCS in den CDM nötig.

\section{Enthymem IETA 2-6 (Seite 1, 6f)}

Erste Prämisse: NUR EIN GROßFLÄCHIGER EINSATZ VON CCS KÖNNTE ANDERE CDM-PROJEKTE VERDRÄNGEN. 
Zweite Prämisse: Die Aufnahme von CCS in den CDM führt in der ersten Verpflichtungsperiode nicht zu einem großflächigen Einsatz.

Schlussfolgerung: Die Aufnahme von CCS in den CDM führt in der ersten Verpflichtungsperiode nicht zur Verdrängung anderer CDM-Projekte.

\section{Enthymem IETA 2-7 (Seite 1, 5)}

Erste Prämisse: Für einen weltweiten Einsatz von CCS ist es entscheidend, die Kosten von CCS-Projekten zu senken.

Zweite Prämisse: Die Kosten von CCS-Projekten werden durch eine frühe Anwendung von CCS gesenkt.

Schlussfolgerung: Für einen weltweiten Einsatz von CCS ist eine frühe Anwendung von CCS entscheidend.

\section{Enthymem IETA 2-8 (Seite 2f)}

Erste Prämisse: DAS KLIMASCHUTZ-POTENZIAL VON CCS ERGIBT SICH AUS DEM PROGNOSTIZIERTEN ANTEIL FOSSILER BRENNSTOFFE AN DER DECKUNG DES PRIMÄRENERGIEBEDARFS.

Zweite Prämisse: Die Prognosen gehen davon aus, dass der Anteil fossiler Brennstoffe an der Deckung des Primärenergiebedarfs dominant bleiben wird.

Schlussfolgerung: DAS KLIMASCHUTZ-POTENZIAL VON CCS IST, ENTSPRECHEND DES PROGOSTIZIERTEN DOMINANTEN ANTEILS FOSSILER BRENNSTOFFE AN DER DECKUNG DES PRIMÄRENERGIEBEDARFS, HOCH.

\section{Enthymem IETA 2-9 (Seite 2f)}

Erste Prämisse: UM EINEN GEFÄHRLICHEN KLIMAWANDEL ZU VERHINDERN IST ES UNERLÄSSLICH, DIE TECHNOLOGISCHEN OPTIONEN MIT DEN GRÖßTEN POTENZIALEN ZUR REDUZIERUNG VON TREIBHAUSGASEN WELTWEIT EINZUSETZEN.

Zweite Prämisse: CCS ist eines der technologischen Optionen mit den größten Potenzialen zur Reduzierung von Treibhausgasen.

Schlussfolgerung: UM EINEN GEFÄHRLICHEN KLIMAWANDEL ZU VERHINDERN IST DER WELTWEITE EINSATZ VON CCS UNERLÄSSLICH. 


\section{Enthymem IETA 2-10 (Seite 3, 13)}

Erste Prämisse: ES WERDEN DIE TECHNOLOGIEN ALS MÖGLICHE OPTIONEN DES PORTFOLIOS IN BETRACHT GEZOGEN, DIE POTENZIAL ZUR SENKUNG DER BETRIEBSWIRTSCHAFTLICHEN KOSTEN DES KLIMASCHUTZES HABEN.

Zweite Prämisse: CCS hat das Potenzial, die betriebswirtschaftlichen Kosten des Klimaschutzes zu senken.

Schlussfolgerung: CCS wird als mögliche Option des Portfolios in Betracht gezogen.

\section{Enthymem IETA 2-11 (Seite 3)}

Erste Prämisse: EINE ÄNDERUNG DER ENERGIEINFRASTRUKTUR IST NICHT NOTWENDIG, INSOWEIT DIE FLEXIBILITÄT INNERHALB DES STATUS QUO DER ENERGIEINFRASTRUKTUR HOCH GENUG IST, UM DIE NOTWENDIGE REDUZIERUNG DER TREIBHAUSGASEMISSIONEN ZU ERREICHEN.

Zweite Prämisse: Die Entwicklung von CCS erhöht die Flexibilität, innerhalb des Status quo der Energieinfrastruktur die notwendige Reduktion der Treibhausgasemissionen zu erreichen. Schlussfolgerung: DIE ENTWICKLUNG VON CCS VERRINGERT DIE NOTWENDIGKEIT DER ÄNDERUNG DER ENERGIEINFRASTRUKTUR.

\section{Enthymem IETA 2-12 (Seite 4f)}

Erste Prämisse: Eine große Zahl der kosteneffizientesten Möglichkeiten für frühzeitige CCSProjekte befinden sich in Entwicklungsländern.

Zweite Prämisse: Ohne finanzielle Anreize werden in Entwicklungsländern keine CCS-Projekte durchgeführt werden.

Schlussfolgerung: Ohne finanzielle Anreize werden eine große Zahl der kosteneffizientesten Möglichkeiten für frühzeitige CCS-Projekte nicht genutzt.

\section{Enthymem IETA 2-13 (Seite 5)}

Erste Prämisse: Das Hauptziel der Klimarahmenkonvention ist die Stabilisierung der Treibhausgaskonzentration in der Atmosphäre.

Zweite Prämisse: CCS UNTERSTÜTZT DIE ENTWICKLUNGSLÄNDER IN IHREN MÖGLICHKEITEN, ZUR STABILISIERUNG DER TREIBHAUSGASKONZENTRATION IN DER ATMOSPHÄRE BEIZUTRAGEN.

Schlussfolgerung: CCS unterstützt die Entwicklungsländer in ihren Möglichkeiten, zum Hauptziel der Klimarahmenkonvention beizutragen. 


\section{Enthymem IETA 2-14 (Seite 5)}

Erste Prämisse: ANREIZE FÜR KOSTENEFFIZIENTE CCS-PROJEKTE SIND ENTSCHEIDEND, UM DIE EMISSIONEN BEI INDUSTRIELLEN PROZESSEN REDUZIEREN ZU KÖNNEN.

Zweite Prämisse: Die Aufnahme von CCS in den CDM schafft Anreize für kosteneffiziente CCS-Projekte.

Schlussfolgerung: Die Aufnahme von CCS in den CDM ist entscheidend, um die Emissionen bei industriellen Prozessen reduzieren zu können.

\section{Enthymem IETA 2-15 (Seite 7)}

Erste Prämisse: KLIMASCHUTZTECHNOLOGIEN DIE SICH NICHT ERSETZEN, SONDERN GEGENSEITIG ERGÄNZEN, KONKURRIEREN NICHT UM GELDER UND ANREIZE.

Zweite Prämisse: CCS und erneuerbare Energien ersetzen sich nicht, sondern ergänzen sich gegenseitig.

Schlussfolgerung: CCS und erneuerbare Energien konkurrieren nicht um Gelder und Anreize.

\section{Enthymem IETA 2-16 (Seite 8)}

Erste Prämisse: DIE ENERGIEGEWINNUNG DURCH FOSSILE BRENNSTOFFE WIRD ZWANGSLÄUFIG FORTGESETZT.

Zweite Prämisse: Die Energiegewinnung durch fossile Brennstoffe führt bei einem Verzicht auf CCS zu hohen Treibhausgasemissionen.

Schlussfolgerung: Bei einem Verzicht auf CCS werden die hohen Treibhausgasemissionen zwangsläufig fortgesetzt.

\section{Enthymem IETA 2-17 (Seite 8)}

Erste Prämisse: SEHR EHRGEIZIGE EMISSIONSREDUKTIONSZIELE KÖNNEN NUR MIT HILFE EINES GROßFLÄCHIGEN EINSATZES VON CCS ERREICHT WERDEN.

Zweite Prämisse: Die EU und bestimmte einzelne Länder haben sich sehr ehrgeizige Emissionsreduktionsziele gesetzt.

Schlussfolgerung: Die EU und bestimmte einzelne Länder können ihre Emissionsreduktionsziele nur mit Hilfe eines großflächigen Einsatzes von CCS erreichen.

\section{Enthymem IETA 2-18 (Seite 9)}

Erste Prämisse: EINE ERFÜLLUNG DER FESTGELEGTEN CDM-MODALITÄTEN UND -VERFAHREN IST IM PRINZIP AKZEPTABEL, WENN SICH DIE BETROFFENEN 
LÄNDER UND DIE PROJEKTTEILNEHMER_INNEN AUF DIE KONKRETEN UMSETZUNGSKRITERIEN EINIGEN.

Zweite Prämisse: Die betroffenen Länder und die Projektteilnehmer_innen können sich auf die konkreten Umsetzungskriterien der langfristigen Haftung der Zielländer für CCS-Projekte können.

Schlussfolgerung: DIE ERFÜLLUNG DER FESTGELEGTEN CDM-MODALITÄTEN UND -VERFAHREN DURCH EINE LANGFRISTIGE HAFTUNG DER ZIELLÄNDER FÜR CCS-PROJEKTE IST IM PRINZIP AKZEPTABEL.

\section{Enthymem IETA 2-19 (Seite 11f)}

Erste Prämisse: DIE BISHER GESAMMELTEN ERFAHRUNGEN MIT EOR UND DER UNTERIRDISCHEN LAGERUNG VON SAUERGAS LASSEN SICH AUF CO2 ÜBERTRAGEN, DAS MIT CCS-TECHNOLOGIEN IN ADÄQUAT AUSGEWÄHLTEN GEOLOGISCHEN FORMATIONEN VERPRESST WIRD.

Zweite Prämisse: Die bisher gesammelten Erfahrungen mit EOR und mit der unterirdischen Lagerung von Sauergas zeigen, dass Gase sicher in ihren Speichern verbleiben.

Schlussfolgerung: Mit CCS-Technologien verpresstes $\mathrm{CO}_{2}$ verbleibt sicher in adäquat ausgewählten geologischen Formationen.

\section{Enthymem IETA 2-20 (Seite 13f)}

Erste Prämisse: DIE NÖTIGE DRASTISCHE REDUKTION VON TREIBHAUSGASEMISSIONEN KANN NUR ERREICHT WERDEN, WENN DIE EINZELNEN LÄNDER AUF JEWEILS DIE KLIMASCHUTZTECHNOLOGIEN ZURÜCKGREIFEN KÖNNEN, MIT DENEN SIE DEN GRÖßTEN BEITRAG LEISTEN KÖNNEN.

Zweite Prämisse: Für alle Klimaschutztechnologien müssen förderliche Rahmenbedingungen geschaffen werden, damit die einzelnen Länder auf jeweils die Klimaschutztechnologien zurückgreifen können, mit denen sie den größten Beitrag leisten können.

Schlussfolgerung: Für alle Klimaschutztechnologien müssen förderliche Rahmenbedingungen geschaffen werden, damit die nötige drastische Reduktion von Treibhausgasemissionen erreicht werden kann.

\section{Enthymem IETA 2-21 (Seite 14)}

Erste Prämisse: EINE NACHHALTIGE ENTWICKLUNG WIRD DURCH TECHNOLOGIEN ERMÖGLICHT, DIE ENERGIE BEREITSTELLEN OHNE DAS KLIMA ZU BEEINTRÄCHTIGEN.

Zweite Prämisse: CCS stellt Energie bereit ohne das Klima zu beeinträchtigen.

Schlussfolgerung: CCS ermöglicht eine nachhaltige Entwicklung. 


\section{Enthymem IETA 2-22 (Seite 14f)}

Erste Prämisse: Das Ziel der Klimarahmenkonvention ist eine kosteneffiziente Reduktion von Treibhausgasemissionen, die Technologietransfer und eine nachhaltige Entwicklung ermöglicht.

Zweite Prämisse: Die Aufnahme von CCS in den CDM trägt dazu bei, kosteneffizient Treibhausgasemissionen zu reduzieren und Technologietransfer sowie eine nachhaltige Entwicklung zu ermöglichen.

Schlussfolgerung: Die Aufnahme von CCS in den CDM trägt zur Erreichung des Ziels der Klimarahmenkonvention bei.

\section{Enthymem IETA 2-23 (Seite 15)}

Erste Prämisse: $\mathrm{CO}_{2}$, das mit CCS in adäquat ausgewählten geologischen Formationen verpresst wird, lässt sich mit in der Natur vorkommenden $\mathrm{CO}_{2}$-Speichern vergleichen.

Zweite Prämisse: STUDIEN ÜBER IN DER NATUR VORKOMMENDE C02-SPEICHER ZEIGEN, DASS CO2 SICHER INNERHALB GEOLOGISCHER FORMATIONEN VERBLEIBT.

Schlussfolgerung: $\mathrm{CO}_{2}$, das mit CCS in adäquat ausgewählten geologischen Formationen verpresst wird, verbleibt dort sicher.

\section{A.2.6 Enthymeme in Greenpeace' Stellungnahmen}

\section{Enthymem GRE 1-1 (Blatt a, Seite 1)}

Erste Prämisse: Das Ziel der Klimapolitik ist die Stabilisierung der Treibhausgaskonzentration in der Atmosphäre.

Zweite Prämisse: CCS KÖNNTE DAZU BEITRAGEN, DIE TREIBHAUSGASKONZENTRATION IN DER ATMOSPHÄRE ZU STABILISIEREN.

Schlussfolgerung: CCS könnte dazu beitragen, das Ziel der Klimapolitik zu erreichen.

\section{Enthymem GRE 1-2 (Blatt a, Seite 1)}

Erste Prämisse: NICHT EINKALKULIERTE (UNERWARTETE) TREIBHAUSGASEMISSIONEN WÜRDEN EINE DRASTISCHE REDUKTION DER ZUKÜNFTIGEN EMISSIONEN DES GLOBALEN ENERGIE- UND LANDWIRTSCHAFTSSYSTEMS ERFORDERLICH MACHEN.

Zweite Prämisse: CCS birgt das Risiko nicht einkalkulierter (unerwarteter) Treibhausgasemissionen. 
Schlussfolgerung: CCS birgt das Risiko, eine drastische Reduktion der zukünftigen Emissionen des globalen Energie- und Landwirtschaftssystems erforderlich zu machen.

\section{Enthymem GRE 1-3 (Blatt a, Seite 1)}

Erste Prämisse: NICHT EINKALKULIERTE (UNERWARTETE) TREIBHAUSGASEMISSIONEN WÜRDEN EINE NOCH ZU ENTWICKELNDE ENERGIETECHNOLOGIE MIT NEGATIVEN EMISSIONEN ERFORDERLICH MACHEN, UM ERNSTHAFTE PROBLEME VERMEIDEN ZU KÖNNEN.

Zweite Prämisse: CCS birgt das Risiko nicht einkalkulierter (unerwarteter) Treibhausgasemissionen.

Schlussfolgerung: CCS birgt das Risiko, eine noch zu entwickelnde Energietechnologie mit negativen Emissionen erforderlich zu machen, um ernsthafte Probleme vermeiden zu können.

\section{Enthymem GRE 1-4 (Blatt a, Seite 1f)}

Erste Prämisse: EINE RISIKOABSCHÄTZUNG UND DIE BERECHNUNG DER EINGESPARTEN EMISSIONEN SIND WICHTIGE VORAUSSETZUNGEN FÜR DIE GENEHMIGUNG VON CDM-PROJEKTEN.

Zweite Prämisse: Bei CCS-Projekten ist eine Risikoabschätzung und die Berechnung der eingesparten Emissionen kompliziert.

Schlussfolgerung: BEI CCS-PROJEKTEN IST DIE ERFÜLLUNG WICHTIGER VORAUSSETZUNGEN FÜR DIE GENEHMIGUNG ALS CDM-PROJEKT KOMPLIZIERT.

\section{Enthymem GRE 1-5 (Blatt c, Seite 2)}

Erste Prämisse: BEI CCS-PROJEKTEN SOLLTEN SICHERHEITSRELEVANTE ENTSCHEIDUNGEN VON EINER INSTANZ GETROFFEN WERDEN, DIE KEINE EIGENEN INTERESSEN (BEISPIELSWEISE NACH KOSTENEFFIZIENZ) HAT.

Zweite Prämisse: Eine unabhängige internationale Instanz hat keine eigenen Interessen (beispielsweise nach Kosteneffizienz).

Schlussfolgerung: Bei CCS-Projekten sollten sicherheitsrelevante Entscheidungen von einer unabhängigen internationalen Instanz getroffen werden.

\section{Enthymem GRE 1-6 (Blatt d, Seite 1f)}

Erste Prämisse: DIE KLÄRUNG DER KURZ- UND LANGFRISTIGEN HAFTUNG FÜR PROJEKTE IST EINE WICHTIGE VORAUSSETZUNG FÜR DIE AUFNAHME IN DEN CDM. 
Zweite Prämisse: Die kurz- und langfristige Haftung von CCS-Projekten ist noch nicht geklärt.

Schlussfolgerung: Bei CCS-Projekten ist eine wichtige Voraussetzung für die Aufnahme in den CDM noch nicht geklärt.

\section{Enthymem GRE 1-7 (Blatt d, Seite 2)}

Erste Prämisse: ES SOLLTEN NUR TECHNOLOGIEN IN DEN CDM AUFGENOMMEN WERDEN, DIE DER ZIELSTELLUNG DES CDM (NACHHALTIGE ENTWICKLUNG) ENTSPRECHEN.

Zweite Prämisse: CCS entspricht möglicherweise nicht der Zielstellung des CDM (nachhaltige Entwicklung).

Schlussfolgerung: CCS sollte möglicherweise nicht in den CDM aufgenommen werden.

\section{Enthymem GRE 2-1 (Seite 1)}

Erste Prämisse: Das Ziel der Klimapolitik ist die Stabilisierung der Treibhausgaskonzentration in der Atmosphäre.

Zweite Prämisse: ES BEDARF WEITERER FORSCHUNG UM ENTSCHEIDEN ZU KÖNNEN, OB CCS DAZU BEITRAGEN KANN, DIE TREIBHAUSGASKONZENTRATION IN DER ATMOSPHÄRE ZU STABILISIEREN.

Schlussfolgerung: Es bedarf weiterer Forschung um entscheiden zu können, ob CCS dazu beitragen kann, das Ziel der Klimapolitik zu erreichen.

\section{Enthymem GRE 2-2 (Seite 1)}

Erste Prämisse: Eine Voraussetzung für die Aufnahme einer Technologie in den CDM ist, dass sie nachweislich umweltfreundlich und sicher ist.

Zweite Prämisse: Bei CCS-Projekten wurde bislang nicht nachgewiesen, dass sie umweltfreundlich und sicher sind.

Schlussfolgerung: CCS-PROJEKTE ERFÜLLEN BISLANG EINE VORAUSSETZUNG FÜR DIE AUFNAHME IN DEN CDM NICHT.

\section{Enthymem GRE 2-3 (Seite 1f)}

Erste Prämisse: NOCH UNREIFE TECHNOLOGIEN DES PORTFOLIOS SOLLTEN ZUNÄCHST NUR IN DEN INDUSTRIELÄNDERN SELBER ZUM EINSATZ KOMMEN, BEVOR SIE IN ENTWICKLUNGSLÄNDER EXPORTIERT WERDEN.

Zweite Prämisse: CCS ist noch eine unreife Technologie. 
Schlussfolgerung: CCS sollte zunächst nur in den den Industrieländern selber zum Einsatz kommen, bevor es in Entwicklungsländer exportiert wird.

\section{Enthymem GRE 2-4 (Seite 2f)}

Erste Prämisse: Es sollten nur Technologien in den CDM aufgenommen werden, die prinzipiell der Zielstellung des CDM (nachhaltige Entwicklung) entsprechen.

Zweite Prämisse: CCS entspricht prinzipiell nicht der Zielstellung des CDM (nachhaltige Entwicklung).

Schlussfolgerung: CCS sollte nicht in den CDM aufgenommen werden.

\section{Enthymem GRE 2-5 (Seite 3)}

Erste Prämisse: DIE SUBVENTIONIERUNG VON FOSSILEN ENERGIEN KANN ZUR REDUKTION DER FÖRDERMITTEL FÜR ERNEUERBARE ENERGIEN FÜHREN.

Zweite Prämisse: Die Finanzierung von CCS-Projekten im Rahmen des CDM ist eine Subventionierung fossiler Energie.

Schlussfolgerung: Die Finanzierung von CCS-Projekten im Rahmen des CDM kann zur Reduktion der Fördermittel für erneuerbare Energien führen.

\section{Enthymem GRE 2-6 (Seite 3)}

Erste Prämisse: Die Generierung großer Mengen an CERs ermöglicht den Annex-B-Staaten die Fortführung des business-as-usual, den Betrieb konventioneller Kohlekraftwerke.

Zweite Prämisse: CCS-CDM-Projekte werden große Mengen CERs generieren.

Schlussfolgerung: CCS-CDM-Projekte werden den Annex-B-Staaten die Fortführung des business-as-usual, den Betrieb konventioneller Kohlekraftwerke, ermöglichen.

\section{Enthymem GRE 2-7 (Seite 3)}

Erste Prämisse: DER GROSSFLÄCHIGE EINSATZ VON CCS HÄNGT VON DER WIRKUNG DER FLEXIBLEN MECHANISMEN DES KYOTO-PROTOKOLLS AB.

Zweite Prämisse: DIE FLEXIBLEN MECHANISMEN DES KYOTO-PROTOKOLLS ENTFALTEN IHRE WIRKUNG ÜBER DEN MARKTPREIS DER EMISSIONSZERTIFIKATE.

Schlussfolgerung: Der großflächige Einsatz von CCS hängt vom Marktpreis der Emissionszertifikate ab. 


\section{Edition Politik}
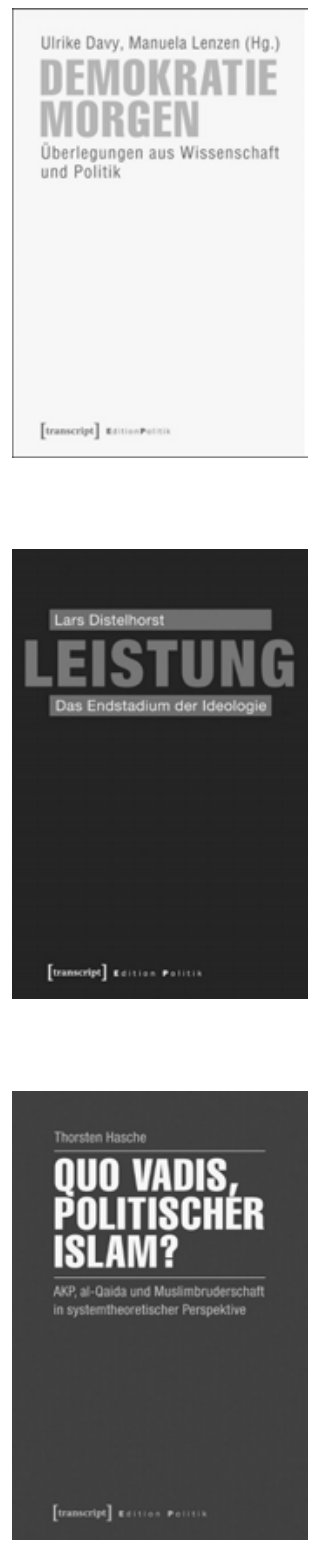

Ulrike Davy, Manuela Lenzen (Hg.)

Demokratie morgen

Überlegungen aus Wissenschaft und Politik

20I3, I20 Seiten, kart., I6,80 €,

ISBN 978-3-8376-2387-I

Lars Distelhorst

Leistung

Das Endstadium der Ideologie

20I4, I92 Seiten, kart., 22,99€,

ISBN 978-3-8376-2597-4

Thorsten Hasche

Quo vadis, politischer Islam?

AKP, al-Qaida und Muslimbruderschaft in systemtheoretischer Perspektive

April 2015, 390 Seiten, kart., 39,99€,

ISBN 978-3-8376-3120-3 


\section{Edition Politik}

Marcus Koch

Das

utopische

Europa

Die Verträge der politischen

Integration Europas und

ihre utopischen Elemente

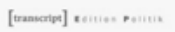
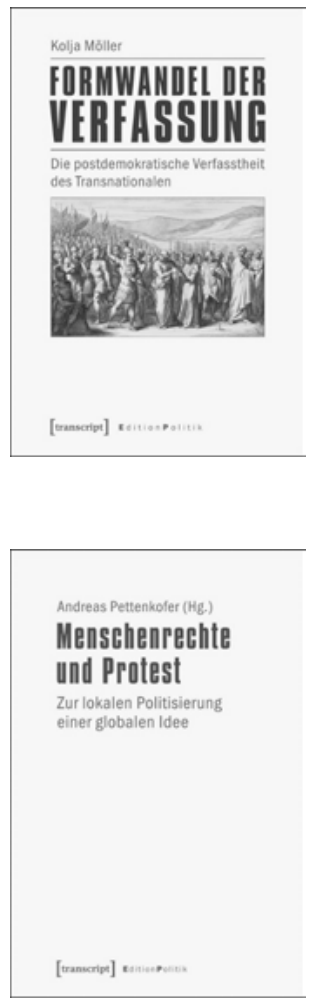

\section{Marcus Koch}

Das utopische Europa

Die Verträge der politischen Integration Europas und ihre utopischen Elemente

Januar 2015, I62 Seiten, kart., 24,99€, ISBN 978-3-8376-2958-3

\section{Kolja Möller}

\section{Formwandel der Verfassung}

Die postdemokratische Verfasstheit

des Transnationalen

August 2015, ca. 250 Seiten, kart., ca. 29,99€, ISBN 978-3-8376-3093-0

\section{Andreas Pettenkofer (Hg.)}

Menschenrechte und Protest

Zur lokalen Politisierung einer globalen Idee

Dezember 20I5, ca. 250 Seiten, kart., ca. $28,80 €$, ISBN 978-3-8376-21I2-9 


\section{Edition Politik}

Karin Bischof

Global Player EU?

Eine ideologiekritische

Metaphernanalyse

Mai 2015, 242 Seiten, kart., 34,99€,

ISBN 978-3-8376-3II5-9

\section{Ahmet Cavuldak}

Gemeinwohl und Seelenheil

Die Legitimität der Trennung

von Religion und Politik in

der Demokratie

Januar 20I5, 632 Seiten, kart., 49,99€,

ISBN 978-3-8376-2965-I

\section{Lucyna Darowska}

Widerstand und Biografie

Die widerständige Praxis der Prager

Journalistin Milena Jesenská gegen

den Nationalsozialismus

20I2, 528 Seiten, kart., 39,80€,

ISBN 978-3-8376-I783-2

Michael Daxner,

Hannah Neumann (Hg.)

\section{Heimatdiskurs}

Wie die Auslandseinsätze

der Bundeswehr Deutschland verändern

20I2, 340 Seiten, kart., zahlr. Abb., 32,80 €,

ISBN 978-3-8376-2219-5

Stefan Luft, Peter Schimany (Hg.)

20 Jahre Asylkompromiss

Bilanz und Perspektiven

20I4, 332 Seiten, kart., zahlr. Abb., 29,99 €, ISBN $978-3-8376-2487-8$

\section{Hendrik Meyer}

Was kann der Staat?

Eine Analyse der rot-grünen

Reformen in der Sozialpolitik

20I3, 282 Seiten, kart., 32,80 €,

ISBN 978-3-8376-23I2-3
Werner J. Patzelt (Hg.)

Die Machbarkeit politischer Ordnung

Transzendenz und Konstruktion

20I3, 472 Seiten, kart., $38,80 €$,

ISBN 978-3-8376-2247-8

Shamim Rafat

Ethik und Qualität

in der Politikberatung

Zur Entwicklung von professionellen

Standards und Grundsätzen

20I2, 272 Seiten, kart., zahlr. Abb., 32,80 €, ISBN 978-3-8376-2085-6

Jana Trumann

Lernen in Bewegung(en)

Politische Partizipation und Bildung in Bürgerinitiativen

20I3, 298 Seiten, kart., 29,80€,

ISBN 978-3-8376-2267-6

Bärbel Heide Uhl

Die Sicherheit der Menschenrechte

Bekämpfung des Menschenhandels zwischen Sicherheitspolitik

und Menschenrechtsschutz

20I4, 238 Seiten, kart., 34,99 €,

ISBN 978-3-8376-2640-7

Hans Vorländer (Hg.)

Demokratie und Transzendenz

Die Begründung politischer

Ordnungen

20I3, 534 Seiten, kart., 39,80 €,

ISBN $978-3-8376-2278-2$

Zentrum für Ethik und Nachhaltigkeit (ZEN-FHS) (Hg.)

Herausforderungen für die Politik

und die Ethik

Moral - Terror -

Globalisierung - Demokratie

20I4, 94 Seiten, kart., I6,99€,

ISBN 978-3-8376-26I2-4 